\title{
Nursing as an Aesthetic Praxis
}

\author{
Marina Tucakovic
}

A thesis

submitted to the Victoria University of Wellington in fulfilment of the requirements for the degree of Doctor of Philosophy

In Nursing

Victoria University of Wellington 2001 


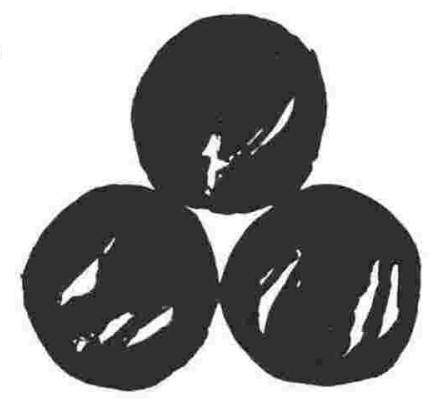

\title{
Nursing as an Aesthetic Praxis
}

\author{
Marina Tucakovic
}

A thesis

submitted to the Victoria University of Wellington in fulfilment of the requirements for the degree of Doctor of Philosophy

In Nursing

Victoria University of Wellington 


\begin{abstract}
This Thesis focuses on the experience of being human as process in order to reveal being. Illness and health are seen as reflections of this process of revelation. This work argues that health and illness are physical expressions of consciousness and therefore an outcome of what a human being has thought. In this way, this work shows how thought/intent serves to create life in the moment. In this understanding lies the potential to change reality, to change life.
\end{abstract}

The Thesis identifies self-responsibility as the key to changing consciousness. Taking responsibility for the creation of one's reality eliminates the human tendency to blame another for what is experienced in life. To that end, this work argues, we are each free to choose what is felt in response to life. In so doing, we can become conscious that life is a choice approached from either the position of perfection, or excellence.

This work argues that as human beings we have grounded thinking in perfection. In this playing out of rights and wrongs, an independent form of surrender, the outcome is the reification of the thought that we are separate from God. I think, therefore I Am. Such thinking it is argued, is the basis of disease and thus illness is an outcome of thought that as experience has been judged.

The thesis develops the position that human beings approach life from the position of perfection thereby creating an appraisal from the outcome of life's experiences. Excellence as a state of being creates the appraisal from the effort of an outcome. Thus excellence, is to experience life as an Isness, and then make a conscious choice to feel love. Perfection makes a judgement about life, and so pronounce life and therefore thinking as good and bad, or right and wrong.

In the understanding that human beings are the creators of their reality, it is possible to conceive of care in nursing that is directed at changing thinking/thought. Such change would be to focus on the excellence of life, and in that way enact care in nursing that is an enabling through a process of being that is an emotional allowance in response to life.

To this end, this work is titled Nursing as an Aesthetic Praxis. The aesthetic is emotion and feeling. Praxis, is presented in its dialectical relationship of thought and action that is then bound to emotion and feeling in such a way that it illuminates the nature of thinking. This way of thinking, this work shows, is transformatory. Where transformation is a process of being that as a state of excellence is one of incremental human freedom accompanied by incremental responsibility. 


\section{Dedication}

At one level, this work is the result of having undertaken an inquiry into nursing that is the result of a linear sequence of time, a beginning, and an end. As I write this dedication, I know it to be so much more. Having undertaken this work, I now know that everything I have ever been, and every being I have ever experienced are in some way represented in these pages because we are all connected. Our lives have purpose.

In this light I dedicate this work to:

The human-beings I have nursed and who have nursed me. You have taught me about love and in that way helped to evoke the healer so that I might then begin to teach. In particular to the memory of dear Rowena, I will always bless the day when this six year old, attached to the end of a ventilator, said "Mawina, what is perception?" And then I will bless the night when, as she stirred from her coma, I asked "Hello darling, where have you been?" "Ah Mawina, you should have seen it, it was so - so beautiful, it was all - light".

The human-beings I have taught, and have taught me. In particular my beloved third year students and clinicians as Deakin University, Geelong, Australia during the years 1990 - 1995. To the 1994 and 1995 groups, whose stories, drawings and photographs with their kind permission became the data from which to proceed. I offer my heart felt thanks. Through our years together, you helped to invoke the storyteller in me, so that she might stand in the forefront and allow the real teacher and researcher to emerge. Please know that you are all here, on very page, ALLWAYS.

The human-beings with whom I have explored and developed these insights and in that way gained further clarity. To the Tikashi group; without you the written document would not be manifest, the real story left untold and the Philosopher would have remained hidden. I acknowledge your courage and commitment to walk where few are brave enough to go. In this way, you too are all here on every page.

Tikashi, Starlight and Isaiah, there are now words to express my gratitude for your unconditional love, without which I could not have held onto my dream for more love in this world.

Heshella, my daimon, whose love from there is what has held me here, until I remembered there is no here or there. Simply said, this work is dedicated to - US ALL. 


\section{Acknowledgments}

The Faculty of Nursing at the University of Sydney, Australia, in which I initially enrolled. My three year enrolment enabled completion of this work to a first draft level. Thank-you to Associate Professor Jan Horsfall in providing supervision of this canditature.

To the Graduate School of Nursing and Midwifery of Victoria University of Wellington, New Zealand for accepting me and this work so that I might complete the task. To Professors Alison Dixon and Jan Duke, Associate Professor Cheryle Moss and administrator Abbey McDonald for dealing with the enrolment detail. To Dr. Margi Martin and Cheryle Moss for their friendship, encouragement and supervision.

To Mrs Judith van Velsen for making sure the commas and full stops are in the right places thereby ensuring that the reader, occasionally, is able to draw breath.

To Ms Elizabeth Hewitt in applying her desktop publishing skills, with exquisite finesse, to the final document.

To Mrs Merle Pritchard for drawing the chapter symbols that appeared in my minds eye as I began this work.

To the one person who even when I had laid this work down for two years between enrolments never questioned or doubted that it could be completed. To my darling mother Justina Tucakovic, I would acknowledge your never wavering love demonstrated in so many ways so often throughout the course of this work. Thank-you, you are the embodiment of its message. I have spent most of my life discovering this truth whereas you have always just 'been it'.

To my father Marko Tucakovic I express my deep gratitude. By his fidelity I have been able to undertake this work as a full time student. In his discipline, he taught me discipline, without which I could not have sustained this project.

To my dear sister and brother-in law Maxine and Philip O' Brien, for their love, expressed in so many ways but particularly in their acceptance of my challenging social consciousness.

Finally, I would acknowledge my grandmother Emelia Tuzakowitsch who as a woman demonstrated that women could be and do whatever they chose, and in that, education was something to be valued. Thank-you, for being my grandmother. 


\section{Table of Contents}

\section{Page}

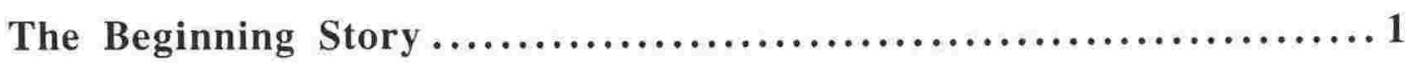

Introduction................................................... 7

Chapter 1: Paradigmatic Position as Process.................... 14

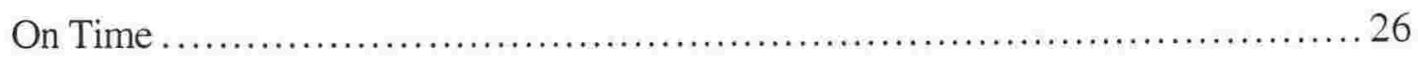

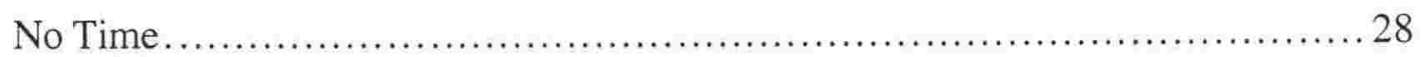

Intuition - The teacher within ............................................... 35

Phenomenological thinking and writing ........................................ 80

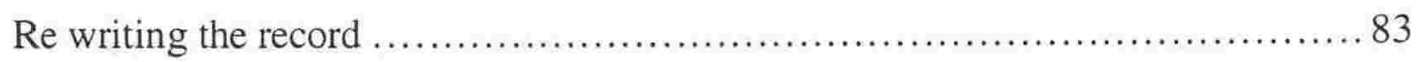

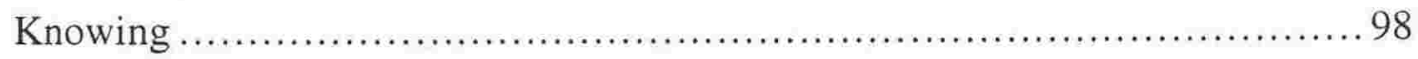

Methodology and movement: the process of a paradigmatic position.............. 101

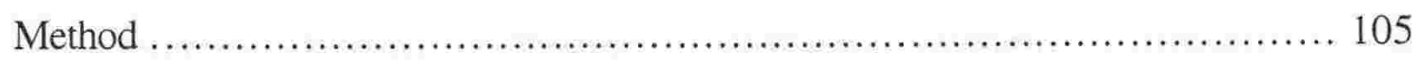

Loving what you do and doing what you love ….......................... 115

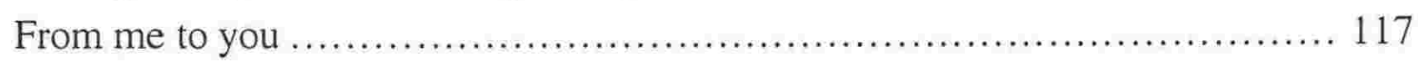

Chapter 2: The Void: The human, Being as an empty vessel...... 122

The nature of Being: nurse and patient ...................................... 122

Self in other and other in self ................................................ 126

Reflection before refraction ................................................. 132

Action as both outcome and intent ............................................ 137

Process or product ........................................................ 140

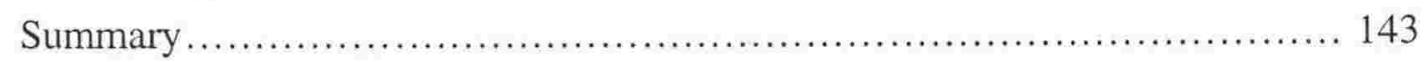

Chapter 3: Aesthetics in Nursing........................... 144

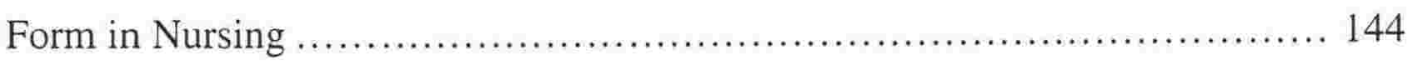

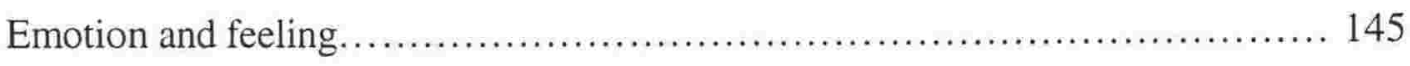

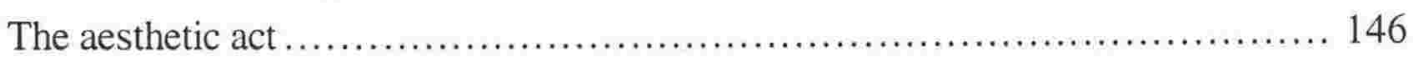

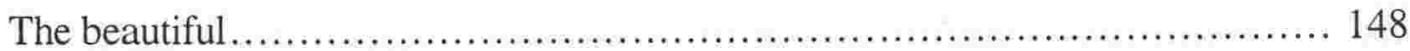

Aesthetic as a pattern........................................................... 149

Pattern as creation............................................................ 151

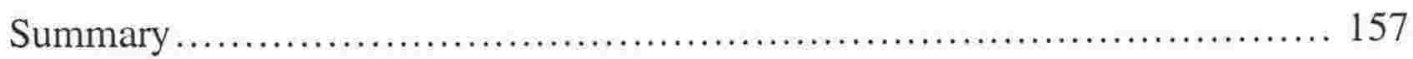

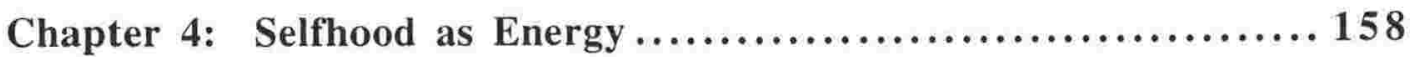

Human fields ............................................................. 158

Human field as thought....................................................... 160 


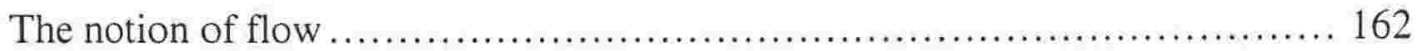

Disease as blocked flow .............................................. 164

Pattern seen as flow charts........................................... 167

The act of nursing seen as co-creators of flow ........................... 179

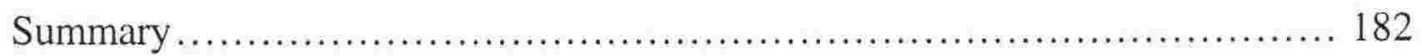

Chapter 5: The Ethics of Health........................... 184

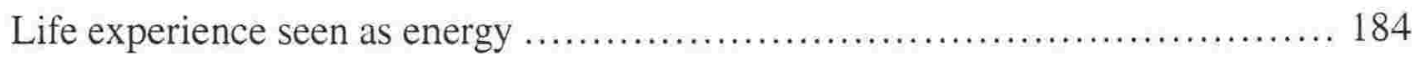

Experience as expansion or contraction ................................ 191

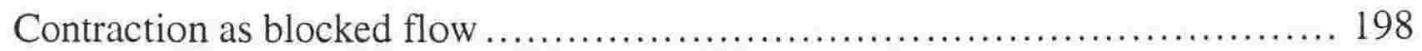

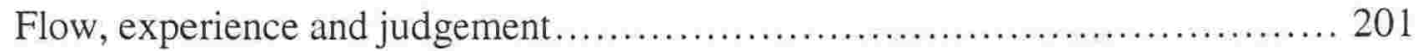

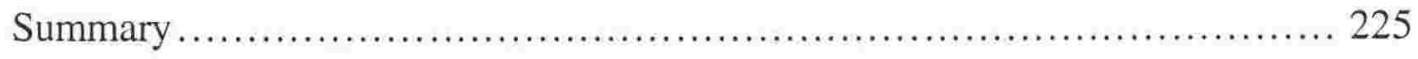

Chapter 6: The Human-being, Creator Energy ................ 226

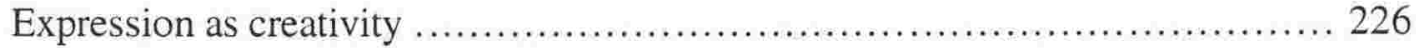

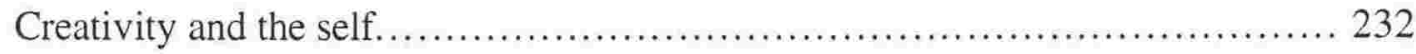

Nursing as a creative act............................................ 237

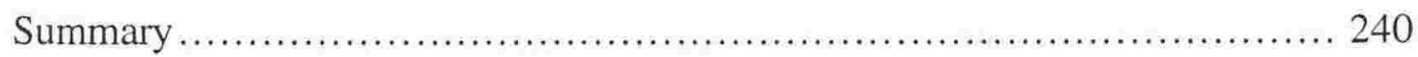

Chapter 7: On Thought and Action in Nursing.................241

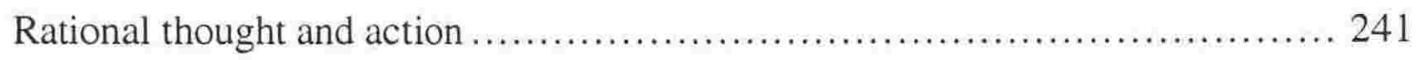

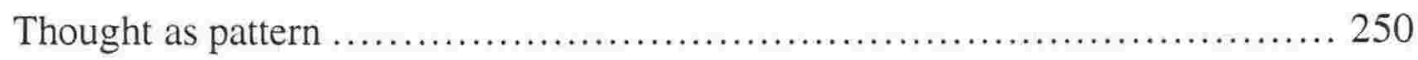

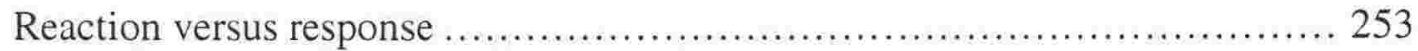

The teacher within...................................................... 256

Nursing as a dialectic of thought and action .............................. 260

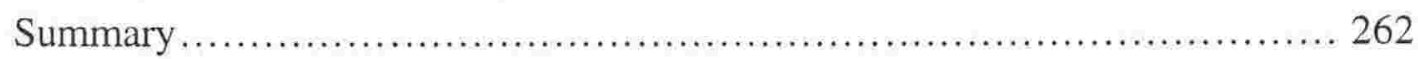

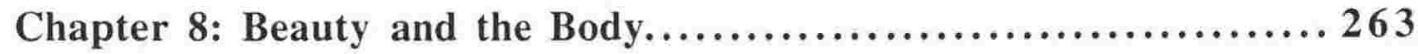

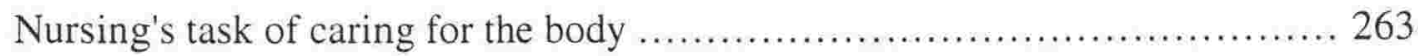

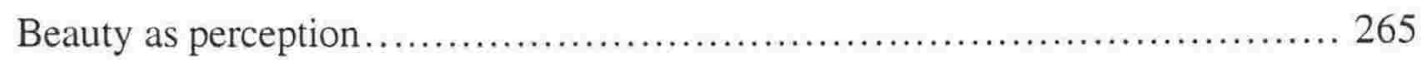

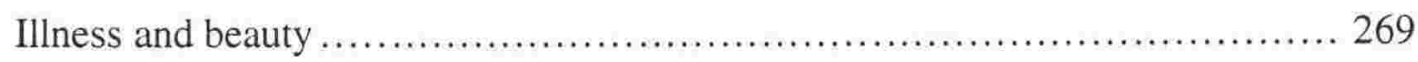

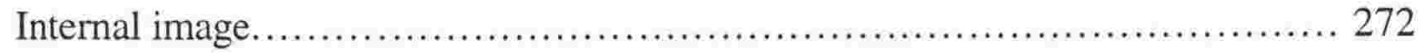

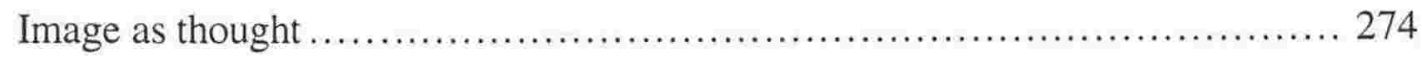

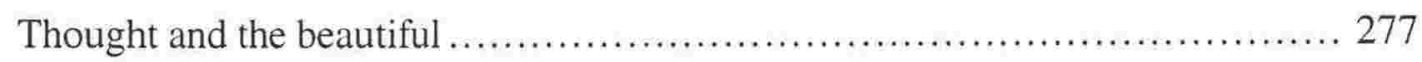

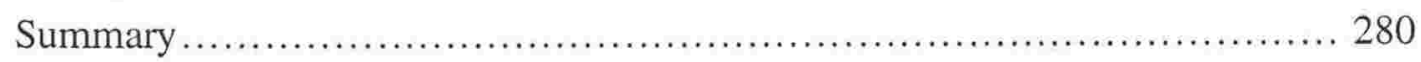


Chapter 9: Body as Memory ............................... 281

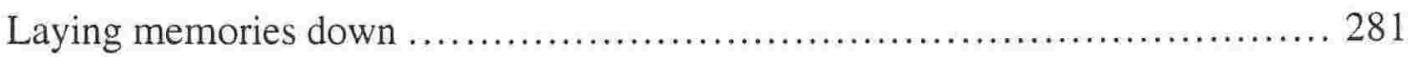

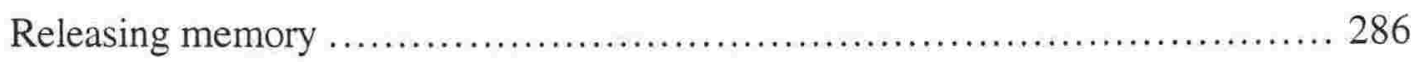

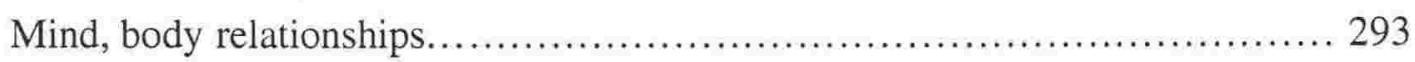

The role of body therapies .................................................... 301

The relationship between body therapy memory and disease.................... 303

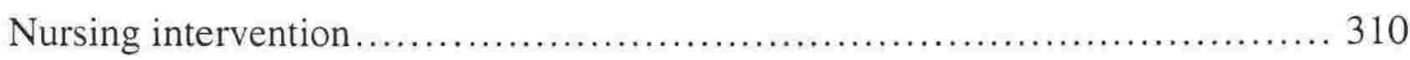

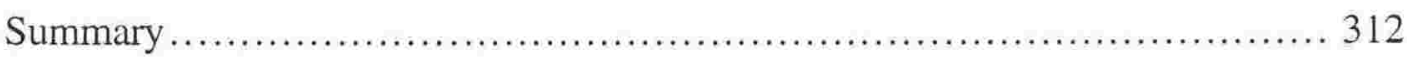

Chapter 10: The Aesthetic in Practice and Curriculum ............. 313

Nursing as it is lived............................................................ 313

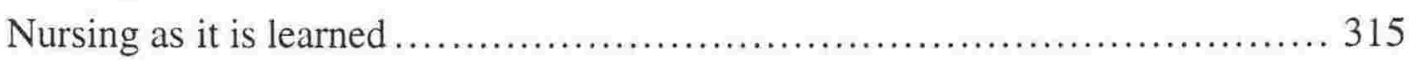

Envisioning new ways of living and learning Nursing ........................ 316

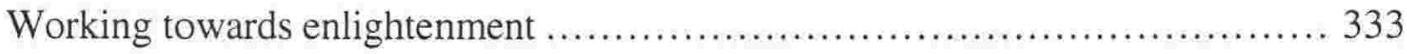

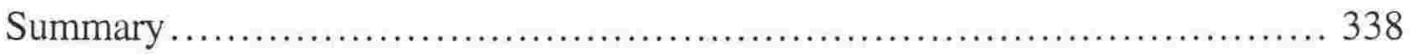

Chapter 11: The Body as Temple.............................. 339

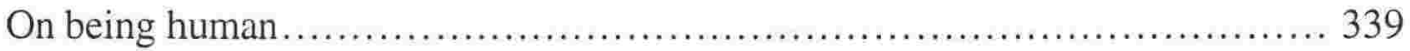

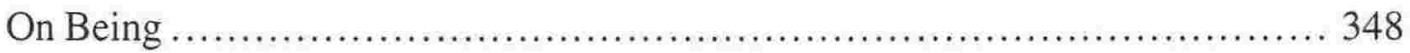

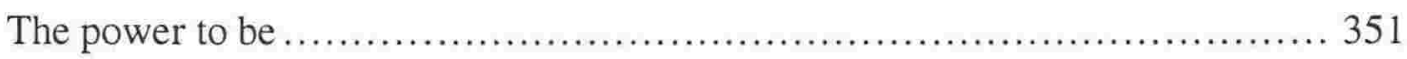

Nursing's purpose of evocation/midwifery/healing.............................. 354

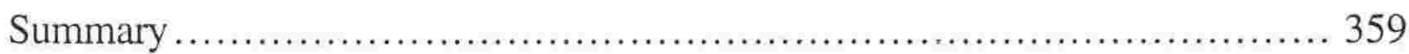

Chapter 12: Transformation through Health Care................. 360

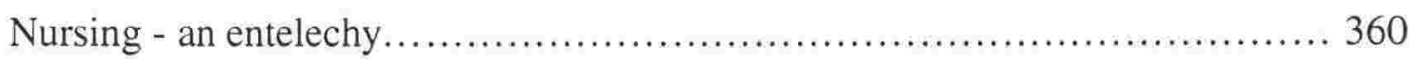

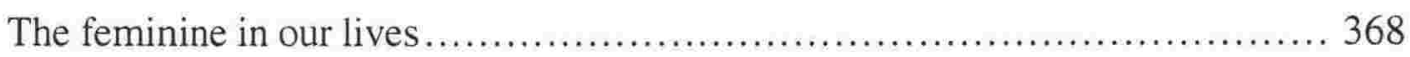

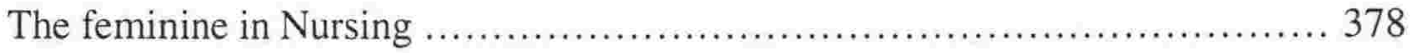

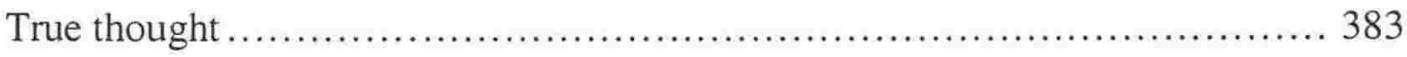

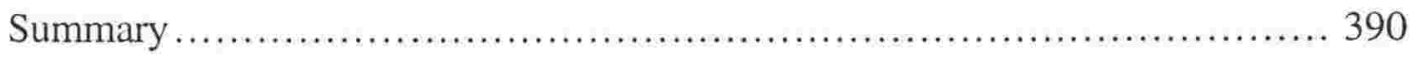

Chapter 13: To Love and to Nurse............................391

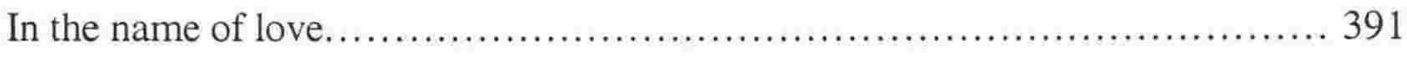

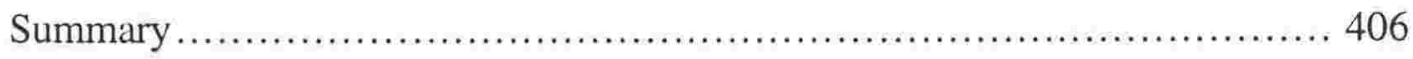

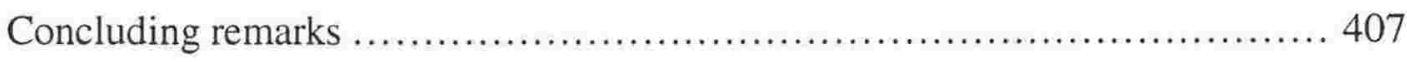




\section{List of Illustrations}

Figure 1: Expressing How I Feel ........................................... 113

Figure 2: Looking Up ..................................................... 156 


\section{The Beginning Story}

In early June on a Monday afternoon in 1991 I stood in SB421 at Deakin University in Geelong 'doing' the final lecture of the semester. I had structured the lecture to be concrete, a deliberate strategy employed to decrease the pre-anxiety stress that tended to build as the half year examination loomed closer. To this day I can still hear myself explaining the relationship between intracranial pressure, mean arterial pressure, arterial carbon dioxide level and cerebral blood flow, as they effect respiratory and heart rates, blood pressure and pupillary dilatation. As I made the connections, I must have been speaking with my eyes diverted to the floor, because when I looked up all I could see was a wall of blank faces staring back at me. I paused, and then from a seat in the front row a voice called out "Tell us a story", and with that the lecture theatre dissolved into gales of laughter. I laughed too, and smiling as I wagged my finger at them, I responded with "Well - yes, I do have a story". My response was met with more laughter and applause. I then told them a story.

With the half-year examination papers and assignments marked, I began work on the second semester program, a program run for the first time that previous year and one with which I was not satisfied. As I sat at my desk holding my head between my hands, I heard myself say " how can we do this differently, how can I teach nursing in a way that enables them (and me) to see more?" Four years earlier, in another place and at another desk, I had sat in exactly this same position and asked myself this same question. What I had received then had taken four years to evolve and unfold. Now it was time for more. And just as my question had been answered that first time, so too was I given an answer this time. "If they like your stories so much, perhaps it is time to get them to tell their own". The answer was clear and simple and I did not give any thought to where it had come from. In pondering on how to create a classroom process where students were able to tell stories about Nursing, as I began to imagine it I became excited. That was the only assurance that I needed.

Yes, it was possible, but how was I going to incorporate story telling within an existing structure of the Habermasian (1987) notion of knowledge constitutive interests and the Paterson and Zderad (1976) Theory that supposedly underpinned this unit/subject/paper? I rushed to share the idea with a colleague, Penny Cash. "What do you think, and how am I going to justify it?" She laughed as she stretched out her right arm to pull a text down from a bookcase. "Here", as the page opened exactly and she placed her index finger on a section of the text, "this is how you are going to justify it". 
Like a weather map that statistically represents major factors and currents in their interrelatedness, the framework discloses a nexus of elements. But it is as far from the real phenomenon of nursing with its pains and suffering and comforting and joys and hopes as the weather map is from real weather with its wind and rain and heat and cold.

(Patterson and Zderad 1997, p.23)

I had found a way to create the unit on paper, but I needed to do more in order to work with the actual idea in the classroom. How would I get then to tell stories? Not everyone is a story teller, or so I thought. I discussed the idea with my sister, then a librarian who had done some work with children's stories. "Start them with kids' books; show them, from children's stories how to tell a story", she suggested. So late in July in 1881, armed with 'Baba the Elephant', I walked into my first tutorial to begin the process of storytelling. In the six years that I worked with storytelling as process, the one tutorial was all that was required about how to tell a story. 'Baba the Elephant', a story about an elephant being taken away from his mother and his home in the jungle to live in a city environment, did the job brilliantly. In addition no University student was ever offended by my kindergarten approach.

And so we began an exploration of Nursing through story. In 1992 I gathered the stories that were to become the data for my Masters Research work, 'Spiritual Aesthetics in Nursing', and while completing the coursework of that degree I was introduced to the Aesthetic. One afternoon just prior to beginning the research component, Dr Colin Homes who at that time coordinated the programme, in one of those priceless student teacher dialogues, said "Marina, I challenge you to define freedom and autonomy/responsibility within the Habermasian notion of emancipatory knowledge". Thirty-six hours later I fronted his office having attempted to do so. "I am unable to define it. I cannot see how one can be both free and responsible at the same time!" He just smiled. I well understood that if I perceived my personal freedom were threatened in any way that this force would rise up in me and so enable me to take on the world. Yet, I also perceived responsibility as a burden that then threatened my personal freedom. And so the only way to move past this point in my life had been to perceive the freedom of others as my freedom and in that way diffuse my ideas about responsibility. I knew that this was not a balanced view and so I tucked Colin's question into the back of my mind.

By the end of 1992 the students and I were engaged in story telling, and as the second semester of each academic year arrived I began to hear story in a different way. So many times their stories invoked the memories of my own stories, long ago stories that I had not thought about for years. I was engaging in my own re-membering without really having much consciousness of what was going on. I could see that the students really enjoyed storytelling. I had expanded our activity by creating a framework from which they could explore their stories further and had 
incorporated their journalling and a literature search into the process. My focus remained on the teaching. I did not pay much attention to what was going on inside me until I began writing up my Master's work, when my awareness began to shift. I noticed that after the tears in response to re-reading some of the stories how clear something would then appear. I would complete writing a section at night and on waking the next morning hear very clearly how to proceed that day. Still, I did not give this too much thought. I completed my Masters and refocussed my attention on teaching.

As each academic year progressed, I added another dimension to the storytelling. In 1994 we began the drawing/colouring part of our work. I asked a friend in the University Press section of the University to draw me two, two-dimensional, back and front views of a naked male and female body. I photocopied these diagrams and after a student had told their story all the students would select either a male or female drawing and colour it in. The colouring represented whatever they chose as a response to what they had heard. In my final year at the University, 1995, one tutorial group agreed to be photographed. In response to a story they would adopt a body position that was the outcome of what they heard/felt about story. One student agreed to this with me every week and my task was to respond to her body with my body. We did not speak. While in retrospect all these activities have in some way directed this research, to say that I had some grand plan or idea of what I was doing would not be the real story. It was my natural state of inquiry and the desire to engage students in learning that would in some way improve nursing which motivated me. I was also engaging in my notion of freedom, where their freedom was my freedom. While I was not conscious of this then, my eye could see change; something I had trained myself to do both as a clinician and as teacher.

I had begun teaching in 1983. My first position was to co-ordinate an adult intensive care nursing course. I was a clinician, about to become a teacher. In preparation for this new role I searched for a definition of learning. Learning, my chosen definition said, was 'an observable change in behaviour'. And so with great pleasure I lined the students up for a class photograph at the beginning of the academic year (a very easy thing to do when you have seven students in your first year of teaching). I then repeated this procedure at the end of their year. In the meantime, I had omitted the behaviour aspect from my definition. In the same way that a clinician learns to see change in a patient, I had began to 'look for' so as to 'see' change in my students (and no doubt the students in the early years of my teaching would suggest that their observable change was the weariness resulting from how hard I had pushed them). My photographs certainly showed that by the end of their school year they did look different. And so for years, I unconsciously walked around with this interpretation of learning. I secretly rejoiced each time a student changed their hairstyle, began to dress differently, or entered into a new relationship [and their class and clinical work remained steady or continued to improve], for 
these were outward signs of change. To learn, in my mind, meant that we change, so where there was change there was learning.

Throughout my time in teaching nursing I have been blessed by placing myself in teaching positions where I have always had a whole academic year with any one group of students. This has been vital in supporting my work, because I have had the opportunity to observe people for extended periods. While I could not have articulated the import of this at the time, it is only now that I am able to acknowledge that the opportunity to observe people for these extended periods, while very naïve as an understanding of the complexity of learning, was how I began to evolve a methodology that has as its core, 'how we be', from which we can then initiate change.

I spent 1994 and 1995 teaching. In the process, I had gathered stories, drawings, poems and photographs as classroom product. I was also engaged in my own reading. An academic position in a University requires that the incumbent publishes and presents scholarly work. To that end I had written a paper titled 'The Colour of Emotions: Form and Feeling in Nursing' for presentation at a conference. As I presented this paper to about a dozen people, it appeared to me, there was little impact. The audience clapped politely and I began to pack up my things. Then a women from the audience approached me. "I am from Arts, I am not a nurse. I just want to say, I think you are really onto something - keep going". I thanked her. Some months later I submitted the paper to a nursing journal. It was rejected the reviewer's comments concluding that it was impossible to consider the aesthetic within the context of an ethic. In retrospect, this paper became the basis on which I began to build this work.

At the end of 1995, a series of events occurred that lead to major changes. After having presented another paper at another conference, in making my way home I fell and broke my arm. Fourteen days later my father died and four weeks after that I flew to New Zealand to participate in a workshop facilitated by Nancy Dieklemann on Phenomenology. While I did not have Nancy's familiarity with Heidegger's (1962) work, when she spoke I had an interpretation that was my own. This workshop experience enabled me to position myself in such a way that I affirmed that I was ready 'to do' my $\mathrm{PhD}$. My only anguish lay in the idea of leaving at a time when the third year of the curriculum, which I had planned, developed and implemented as an ongoing process over the past six years, was in its final year. As such, I had envisaged starting my studies at the end of the 1996 academic year. I was on my way home having made the decision but still feeling uneasy. How could I leave and not see this last lot of students through a programme, which by now had gained national and international recognition? I would be letting them down. As I sat looking into nothing through the aeroplane window I suddenly remembered the words spoken to me about two years earlier ... when this next mountain is reached, because they become concerned about the probationers they forget themselves in total 
selflessness. Don't let this happen to you, travel soon. Leave it behind you and find a lighted path. Take a risk, no matter how crazy your logical personality may perceive it to be. In these words, I found the courage to carry out the decision I had made some hours earlier. I knew what I had to do. Within twenty-four hours of arriving home, I had made the appropriate arrangements to leave the University. Within the next two months I sold my home, shifted out of the city, and armed with my boxes of stories, drawings and photographs enrolled in my studies. In hindsight I now see how my degree studies in education, underpinned by Critical Social Theory, had impacted on my thinking/practice to free me from drawing a distinction between teaching, research and administration as mutually exclusive activities.

In the dedication section I have said that everything I have ever been and every being I have ever known are in some way represented in these pages. Plato in the Rebublic claimed that before we are born, each soul is given a unique soul companion. The soul selects an image or pattern through which to live life, and the soul companion or Daimon holds the image of that pattern (Hillman, 1996). Thus the Daimon serves to assist the soul in fulfilling its destiny by supporting and encouraging the conditions by which that soul can proceed towards its chosen pattern. It is also written that as it is above, so it is below, therefore every human being we engage in life can be viewed as a soul companion whose purpose is to support another in fulfilling their destiny.

In November 1995 I was preparing for my father's funeral. I envisioned creating a space where people could stand and tell a story about my father, where he and they were the central characters. In thinking about what I wanted to say in this space, I chose to acknowledge his gift to me of our mutual love of music. While I am not a musician, nor can I even cite music, my gift is that I have innate ability to feel a rhythm expressed through tone. In that way I can hear what the music is saying. When I am unable to find words, I use music.

My parents were post World War Two immigrants to Australia who met and married in this country in 1951. They moved into their first home on June $3^{\text {rd }} 1954$, exactly one month before I was born. Their home, which was a castle to my mother after her worn torn Europe, was very sparsely furnished. The only furniture, apart from their bed, was a very grand radiogram. Therefore, I came into a home in which there was, and always has been, music. In recalling my father's gift to me of music, which was the story I wanted to tell at his funeral, I then recollected that on the occasion of my fourth birthday he had given me my very first recording. The song on that 72 r.p.m. entrée-plate sized piece of china was titled, Tell Me A Story.

Story for me has been my way 'to be' in the world. I did not appreciate this until that afternoon in 1991 in the lecture theatre when a student shouted "Tell us a Story". Up until this point in my 
life I had learnt to tell a good story. On that July afternoon in 1991 I had unconsciously set myself the task of learning how to hear/listen to story again so that I might begin to work with story in the way that I inherently knew how to work with music.

Nursing as an Aesthetic Praxis is the result of listening to story in this new way, from which I have learned to listen to how I was hearing life. Story, I came to see, is an expression of being through our being human. Thus I came to see that Nursing as an Aesthetic Praxis is a story about who we are and who we be. It is a story about how we as nurses in knowing how to journey through life can assist and support our fellow human beings in their life journey. It is a story about the journey that we all choose to make. It is a story about the journey back to love and therefore is a story about the grandest version of who we be, for who we be, is love. Nursing as an Aesthetic Praxis, then, is a love story - a story about love. I am so honoured to be able to tell (reveal) it. For in undertaking the activity of Tell us a Story what I have done is follow my pattern, my soul purpose, my destiny. 


\section{Introduction}

This work is titled Nursing as an Aesthetic Praxis. The aesthetic denotes the human reactions through emotion to life that then is an engagement of mind translated into physicality throughout the body. Praxis as used here is the relationship between thought, energy and consciousness. Together, as an aesthetic praxis, they serve to reveal a mind body relationship that then expresses consciousness and as such reflects a human being's reality. That reality consists of multiple facets.

The thesis contends that dis-ease or illness is an expression of consciousness and as consciousness can be changed. From the understanding of dis-ease as an expression of consciousness the thesis positions Nursing as an art through the form of a human to human connection expressed in patterns of energy and experienced as human emotion.

In this way, the activity of nursing has as its focus consciousness and energy. Nursing activity is guided by the intent to enable another in the expansion of their consciousness so that the other is supported and assisted to raise their consciousness to move out of a condition.

As a research work, this work challenges perceptions of reality grounded in physical existence because this work takes the position that physical reality is the product of thought/intent and as such is outcome, rather than the nature of reality.

To name this work as phenomenological or metaphysical, where the principal area of speculation is ontological is not how I designate this work. For while I have attempted to make as clear as possible some phenomenological and metaphysical principles through my unfoldment of the nature of being, these principles have occurred as a result of a hindsight and not foresight. Thus, they have not guided the work as a conscious directive.

So while this work has not been presented as an ontology for the purpose of engaging in a discourse that is concerned with the ultimate nature of being, this work is concerned with the nature of being. This concern is positioned as a verb, through which in the activity of research has then required that I have had to be both the observed and the observer. In order to focus on being/beingness, I have had to be. I have had to experience the essence of being human in order to allow the self to observe myself in the process of learning to consciously collapse energy so that I could see, 'what is'. 
Therefore, what this work offers is an illustration of being in order to be more. For in speaking to being this work speaks to the possibility of an ongoing expansion in consciousness through which we can each come to know that which is unknown. In that way, as this work does reveal, we move toward the light of our divinity, where movement, as action, is grounded in the experience of being human where we exist in a state of excellence as opposed to perfection.

To locate this research within a theoretical position of an ontology, would be to suggest that consciousness as truth, exists within an ultimate reality. This work argues that consciousness exists as thought and that thought is a product of how the world is experienced. That what exits, exists until thought is changed. A view of the world is the result of how the world has been thought about. Therefore, as this work will show there is no ultimate nature of being, rather, there is only the ongoing expansion of consciousness that as the energy of creation is then expressed as the purest form of being that is infinite.

The first chapter unfolds my way of working. I have presented a way of working that began by exploring methodology but which was then abandoned when that exploration served to open a new possibility. As a research work, I have located tenets of paradigms from which some methodological assumptions are exposed. These exposures are as a result of having identified how I learnt 'to be', and therefore observe. In this way I made the decision not to use the term methodology to express how I have conducted this research and as such have named the chapter Paradigmatic Position as Process to reflect this position.

The chapters that follow the documentation and explanation of learning to observe and therefore be, are products of the experiences of having observed myself. The chapters, in particular the early ones, can be read as separate papers. The writing style varies significantly, as does the genre of literature. While at one level this variance reflects the different moments of exploration, this in turn is also the outcome of an expansion of consciousness that when grounded in physical reality then clearly demonstrates this particular shift in my consciousness. In other words, as I shifted the consciousness that resulted in my use of multiple voices the outcome is that I did not need as many voices to express the ideas. Where I have been able to touch upon the fullness of that which is I, there are moments in the text that reflect a non fragmented perception and then the work speaks with the most beautiful voice. 
The other account for the chapter variance in style also reflects the ongoing developing skill of learning to observe. The written work is a clear demonstration of this coming to learn how to observe the self. In the initial stages the completeness or depth of the text makes visible the limitations I placed on my own observation. As such they are the physical manifestation of my beginning to observe myself and this is exposed in the text in as much as the ideas are not quite complete or fully revealed/explicated. As I learned to observe myself more fully, then so too does the text change. This point is critical if the reader is to grasp not only how we access states of consciousness to then be given form, but the ability to access states of consciousness also determines the nature/quality to be formed. In other words, a piece of silk, or nylon. Both can be crafted into a garment, yet there is a clear distinction in the nature or quality of the material. In this way, the chapters are a reflection of this truth about consciousness.

I arrived at the content in the chapters through having allowed myself to observe myself and so have been able to express my inherent knowing that is then supported by literature. The chapters exist as the result of having made the ongoing shifts in my consciousness and in that way reflects my movement from the unknown into the known, through having engaged in being. Each chapter does come to a natural closure that then is not an endpoint in itself, but as an outcome of what I had processed through having observed myself. The closure of one chapter does not determine where the next will begin. For the unfoldment of consciousness is not a straight line. Being is not linear. Being unfolds in order to come to know being, and in that way life is not linear. Having said this though, there are ideas that are woven throughout the entire document until a much bigger picture is more visible. Thus the work is like a tapestry in the making, where the threads are eventually woven together to convey a fuller picture. To claim the picture would not be consistent with the nature of this work.

I also wish to make clear how I have used the literature. While I have read much, I have not read to write. The literature is a vehicle to convey or validate the ideas. In this way the text is a living demonstration of having to engage in process as an ongoing process where the literature rather than informing the text then validates the process. One writes to then read, rather than reads to write. To this end I have not used the literature to engage in a critique of multiple views in an area. What I have drawn to myself to assist and support me in expressing this work is in someway a reflection of consciousness/vibration/frequency. To that end, it is not who has said what, but rather, what who has said, as a reflection of the consciousness/vibration of that being, which has determined what literature appears in this work. Also, given the nature of this work I hope it does not come as a surprise that I have been supported by both incarnate and non incarnate beings. To that end, some of the literature reflects this. 
I would also take the opportunity to convey to the reader that in keeping with the nature of this work where the crux of the argument rests in the notion of the aesthetic through emotion and feeling the what of how I have crafted the cited literature, nursing stories, dialogues and song lyrics into the text. The focus is on the aesthetic moment that then rests on the understanding that the aesthetic is both timeless and apersonal and in that way then belongs to 'the one' and 'the many' simultaneously. In this way, I have not located story to person or time. While I have shared some personal stories in the chapter Paradigmatic Position as Process, I have done so to 'show' process and so unfold process, to convey how I have undertaken this work. The commonality then is not in the context or situatedness of story, but in the emotion embedded in story.

In the latter chapters of the project, some of the data is used differently. While on one hand it is positioned to demonstrate the ideas/thoughts, it is also positioned to engage the reader through feeling. To this end, the argument particularly in these latter stages is not always directly signposted through analysis, debate, critique and summation. It is an effort to speak to the reader at the unconscious level because to appeal directly to the intellect does not convey fully what I am attempting to communicate. Therefore, I have attempted to speak to the reader at both a feeling and intellectual level to illustrate the ideas in the work.

Having made these important points about the style, flow and use of the literature I would now offer the reader a very brief outline of the chapters that follow the description of the research process. These brief outlines are not intended as a map to guide the reader on the journey, but to provide a small indication of the possibility in taking that journey.

Chapter One unfolds how I learned, stumbled, discovered and explored being, so as to identify being as a process. In revealing some of my experiences 'to process', I then begin to illustrate being.

Chapter Two starts as an exploration of being grounded in descriptions. I identify yearning as how we then engage ourselves in being. The discussion then moves to identify being as situated in human beings, and lived out through a form of connectedness

Chapter Three is an introduction to the meaning of the aesthetic that is bound in human emotion and feeling so as to then explore the nature of perception. In this way, what is revealed is how life experience as emotional memory, reifies an idea about reality that then has the outcome of 'tricking' the mind that it is generating the percepts. Dis-ease when 
presented as an interruption to the flow of energy is then an outcome of reifying a particular reality.

Chapter Four presents the idea of the human body as fields of energy to then convey the possibility of the movement of energy from cellular, universal and mathematical perspective's. In so doing it is then possible to view illness as a pattern of energy that reflects thought that is linked to emotion.

Chapter Five begins to build on the ideas presented in chapter three. This chapter, while incomplete, reveals how the aesthetic and the notion of judgement are crucial to being. That these experiences in life can serve to either expand or limit being/consciousness that then illustrate an attitude to life that is either perfection or excellence.

Chapter Six explores the idea that we are the Creators of our reality. This chapter argues that who we are is God/Love/Source. Our lives are acts of creation. Illness is a creation. With this understanding nursing can be viewed as, creative acts.

Chapter Seven argues that most thought is unconscious given that the world is perceived through filters. As such, creation is mostly an unconscious act. This chapter starts to identify how to begin to make thought/intent conscious.

Chapter Eight begins to identify thinking that is pure thought through further exploration of image and perception. Such thinking is pivotal on experiencing life from the position of the beautiful. 'The beautiful' as this chapter explains, connects body, mind and spirit and in that way connects the self to the self, and other. Through the beautiful, we are open to all things. We open to pure thought/intuition.

Chapter Nine explores emotion, feeling and non-judgement as a process of being. This chapter further develops the idea of the body as memory through the notion that memory is stored on/in the body. In this way, the body communicates states of being. This idea then serves to further explicate being as either an automatic response and thus an already achieved state, or a wilful action, and in that way a state to be achieved. As such being is then positioned as an engagement of the mind and body through emotion and feeling that serves to either reinforce the idea of separation or non unity through the experience of being human or, to connect a being to the greater Mind/God/Love/Source as consciousness that is feeling to be expressed. Illness as a state of mind is an expression of consciousness and therefore the experience of illness holds the potentiality for a human being to express a greater consciousness through making choices about being. 
Chapter Ten explores the possibility of nursing as an aesthetic praxis through how nursing is lived and learned. Where thought and action can serves to evolve the consciousness of the human being named nurse, so that she/he can support another named patient who in the experience of illness can evolve their consciousness.

Chapter Eleven picks up key concepts already outlined to expand the notion of thought/intent as conscious consciousness, that evolves from the awareness of 'how' reality is created as the outcome of thought. Consciousness is presented as the ongoing evolvement of mind/heart in the experience of being human, through being, a human being. With this understanding, Nursing's role as midwife and healer is then further explicated.

Chapter Twelve further expands the key concepts through examining the feminine as feeling that then serves to connect us to God through which all things are made possible. God is known in feeling, and God is made known through energy and consciousness as thought/intent. Health and healing are positioned in relation to these key concepts, that revolve around intent/thought and emotion and feeling.

Chapter Thirteen is an illustration of the transmutation of energy in practice that serves to demonstrate a number of facets of being that are grounded in emotion and feeling as praxis. The act of nursing is portrayed as reflection that holds the potentiality of more love for both beings or, refraction that is an act of pure love. Refraction is an already achieved state of being that then demonstrates nursing as the finest of the fine arts. In either nursing situation, reflection or refraction what is revealed is more love, and as such, all beings, through being human, have undergone a transformation/healing.

And so it is in being that I have identified a process that is the movement toward the pureness of my beingness, toward the light of being. As consciousness, it is Christ or God consciousness, where the meaning of the word Christos is - to know. Knowing is not finite. For if God cannot create then God ceases to exist and then all things which have their origins in God do not exist either, because all things come from God. While I lay no claim to having attained this level of consciousness, I know it to be my intent and as such, this work is but many many steps toward that infinity. Therefore, the gift of this work, as I then perceive it to be, is not in what it reveals, but how I have learned to reveal.

To impale being in post modernity, or claim design as metaphysical with phenomenological beginnings that exist within an ontology that is concerned with the 
ultimate nature of being, is to engage in theorising. To theorise and 'to know' are not the same. Theorising does not change consciousness. So rather than theorise, what I am presenting here as a result of this journey through stories about nursing, supported by phenomenological and metaphysical understandings and incarnate and non incarnate beings, is how I have wondered about being. In the wondering there has been an allowance of the energy of all things to move and flow in divine timing.

From this space of wondering about being I now offer what might be called a natural philosophy, that is, a study of truth in which I have explored how to become more through the experience of being human. Where the naturalness of it is, that in this process of coming to a place of knowing that just knows, I have become more knowing of who I naturally am, that my origin, is LOVE. 


\section{Chapter 1: Paradigmatic Position as Process}

No matter how 'postmodern' we pretend to be, each of us has been marinated in the medieval soup of the mind. To face the radical need of the future, we need a new natural philosophy, one that encompasses an appreciation of what is ... as our evolutionary possibilities.

Houston (2000, pp. 21-22)

To designate what I have engaged in, in the name of a qualitative inquiry, as only phenomenology, does not position this work accurately. To position this way of working as metaphysical is accurate in the sense that metaphysical understandings became apparent in the course of this research and indeed are what enabled me to make the move from phenomenology so as to delve deeper into consciousness. While I have outlined paradigmatic concerns in the introduction and therefore outlined a position, rather than begin by naming what I have done here, I have decided to unfold my process of research. To this end I have chosen to unfold my work by unravelling my understandings of being in a way that tracks the story that began as a phenomenological inquiry, but from which there was a seemingly natural movement. In this natural movement, this shift in thinking, I then positioned myself in such a way that this work reveals tenets of a paradigmatic position from which I then consider how 'we be'.

Having made such a claim, I use the words 'paradigm' and 'how' mindfully. For in the human condition we have a tendency to box things, as a way of creating new ways 'to be'. The new rules about how things should be become criteria for evidence to validate our choice of box. Therefore, with this in mind, because this work is mindful, I have titled the chapter 'Paradigmatic Position as Process' as a reminder to avoid this tendency of our being human. 
Paradigm has become something that has had a natural course of disclosure that is neither an end nor starting point, but rather, is a place where I have chosen to pause for a while as I go about creating my evolutionary possibilities.

On one hand, research is a systematic process. Research is a way of making public/available its product and often its processes. To 'do' research, is an opportunity to consciously engage in one's world through activity that investigates, inquires, studies, scrutinises and examines that world. While any word, as language, denotes meaning, it is the particular meaning that we as individuals subscribe to a word that then alludes to its form of action. To 'do' research, on one hand, can imply that what is being 'looked at', 'studied' 'investigated' is in some way separate to and from the person 'doing' the research. Alternatively, when the investigating, studying or examining is realised from the position that all things are connected, then slowly, 'the doing' becomes an examination of one's world that identifies the researcher, me, as the central character. Everything else is positioned as a form of support on the understanding that all things serve as a mirror because all things are connected.

In this way what I could begin 'to do' as a researcher was move toward positioning myself as the central sun of my own universe. In any one lifetime, the stage of life has afforded me many entrances and exits, through which I have engaged in life with other human beings, who are themselves being. Therefore, as human beings, being, I consider that we are each other's support actors and at the same time 'the star' of our own drama called to life, where each person is free to determine their own process/condition/journey. To this end, I have consciously identified as the star engaging in the world through research. The stage on which my drama has been played out is the world of nursing, my support actors and actresses students of nursing. In that way, what I/we have done is to produce a work titled 'Nursing as an Aesthetic Praxis' that, as a methodology/process, is available to us all.

To begin I had named this way of working Phenomenology, using Heidegger's (1976) work where the phenomenon under study was being. To now say that I had any developed idea on the notion of being, despite my pondering Heidegger's work, does not acknowledge what or 
how much I have learned in the course of this research. My hope is that in the reading of how I learned to be, the reader considers being revealed in that experience. To this end, I present a way of working that conveys being that is our engagement in life, that then affords us the opportunity to allow the purity of our beingness to emerge. This thesis then reveals my expression of a sacred truth, that all we ever need do is just be.

I have outlined in greater depth my early understanding of being in the second chapter. The detail is important to the overall thesis in two ways. Firstly, after a year of attempting to work with my initial research proposal, I recognized that what I was getting 'back to' or what I was 'attempting to make visible' would remain hidden from us all unless I changed my way of working. Essentially, to move forward I had to put aside my initial blueprint/map/methodology as a way of working. This was an important step and one which I will describe in greater detail.

To proceed I had to abandon my previous understandings of being from a Heideggerian perspective of phenomenology and consider how to explore thinking in a way that did not have a design/plan with which to step forward. This essentially meant I had to step forward into 'the unknown - yet'. Therefore, as a methodology there were no rules, but identifiable design elements that emerged as hindsight with which I could then move forward into the next moment of the unknown - yet. Thus I identified 'tools' as after events, which then assisted me in taking other steps in a process that I inherently learned to trust as the pursuit of truth/reality/beingness/existence. The further I progressed, the greater the level of trust I required. Such a way of working is not intellectual, which is not the same as saying that one does not use the intellect. Rather, one moves in the research as if blindfolded, but in the knowing that the potentiality of uncovering exists.

I began with the understanding that to proceed with research I needed a research methodology. While I positioned my original design as phenomenology, it was the phenomenological intent to uncover or reveal by engaging in the notion of being where my focus lay. Therefore, phenomena were of import only from the perspective that they could assist to reveal being. In 
abandoning my plan, but not the original intent, I have discovered how to make more of the 'unknown' 'known' and in that way reveal being. So while the common word within nursing research circles to describe how one has engaged in one's work is methodology, I would suggest that this way of working is better represented in the word process. A process infers something that is ever evolving in the ongoing act of creating and recreating. In that way, process can never be an end. The name of this chapter 'Paradigmatic Position as Process' is to reflect this text as part of an ongoing act that is my act of creation, in which I have paused for periods to identify the elements of design.

The word methodology, on the other hand, when used to denote a design or recipe, implies a blueprint/map/plan. In this light, I argue, the finished research product is then the result of a preconceived idea, even if that idea is not conscious. As a preconceived idea the research work is not an engagement in being and truth, in a way that I will reveal throughout the text. The word process as it relates to phenomenology, and in particular a Heideggerian notion of phenomenology, is then a deliberate choice of wordage to outline my method of interpretation. It is from this position that I now write and share the process/methodology that I have uncovered by undertaking this research work.

In my initial experience of attempting to follow my interpretation of a phenomenological inquiry by exposing ground structures, as I had done in previous research activity using story (Tucakovic, 1993), I came to the daunting prospect that to proceed in the manner in which I was proceeding would result in the production of a similar work as that undertaken previously. This is in spite of having different/new data. The issue became, how to allow this evidence, this new data, to speak to me as a new awareness. While this insight was an incredibly 'earth shattering' revelation at the time, and one that took just over twelve months to reach, I can now thank myself for having gone down that particular path. Only by moving over a different terrain in the same way, and essentially discovering the same thing, was I then able to place myself in a position to find a way 'to be' open to more. I discovered that the very nature of being could only be revealed, by being. While still a very limited understanding of being, at that stage, it was enough to begin to make the shift in thinking about being to a form of doing, 
so as to be able to see being in a new light. In this way, my old blueprint had served me very well. In the knowing of what did not serve me any longer, I was able to recognise that I had become open to something new.

Secondly, in being willing to explore being from a form of 'doing being', the previous experience revealed that my blueprint, while helpful for a period, had served to keep me tied to an old map that then grounded me in time. While recognizing that this is not the same as saying that another blueprint or map would have offered different insights, I eventually recognized that I had explored the terrain from every possible direction and what I had been unconsciously searching for was a way to experience the terrain from a whole new perspective. I then determined that in order to come to know more of 'the unknown' I had to proceed unknowingly, that is, to move forward in a way that appeared 'to be' without rules. A key in doing so was to listen to my inner voice and then follow that lead without knowing where it was leading. I became aware that I had begun to cultivate my ability to listen/hear my true inner voice. Having said this, I wish to make clear that the ability to 'listen/hear intuitively' is both a process and an outcome. The outcome of the process of being is to be more intuitive. As process, I was to discover there were many voices competing to be heard as this intuitive voice. None-the-less, by having identified the need to abandon my plan I had the conscious awareness of listening for my inner voice as a design element to approach the 'unknown - yet'.

In the idea that I had to 'appear to be without rules' I had grasped the concept of a freedom that could then foster a greater freedom. Until I could free myself from my self imposed limitations [reflected in my thinking, which I argue in this thesis as being mostly unconscious] I would continue to unconsciously project the same thoughts into whatever I thought, said and did. To then distinguish between unconscious thought that is rule bound, from "meaning that is more accurately a process of insightful invention, discovery or disclosure .... [because it] is not a rule bound process" (van Manen, 1990, p.79), is to then acknowledge that 'to be' in the research as process is to position oneself in such a way that every unconscious 
rule/belief/thought pattern is then 'to be' contested. While I had grasped this idea, I had little insight at this stage what this was going to mean for me.

To begin to understand this idea is to acknowledge that to not be rule bound means to not have any preconceived notion of what one should or should not do/be [consciously or unconsciously]. In being free I could then become free. Freedom, in a sense, that it is not an either or situation. Being free is to engage in meaning making that is an insightful invention as a reflection of process, in which there are degrees of freedom that represent incremental changes as a result of the process of freeing the self. In this way, the knowledge that my project would yield is proportional to the ongoing degrees of freedom that $\mathrm{I}$ as the researcher was willing to attain. I say willing, because what I had positioned myself to do was confront the individual and collective consciousness bound in rules that $I$ as a researcher brought to this work. And this was in spite of my pronouncements in the phenomenological method of grasping and formulating thematic concerns as being a non-rule bound activity. To say that it could be otherwise is to deny my/our humanity. So rather than deny my humanness I had, in abandoning my initial proposal, unconsciously called myself to begin to embrace all that I held in my unconsciousness about being human. I say unconscious because, as I have already said, at this early point in the research I did not realise what I had positioned myself to do. In order to reveal more of the unknown, I was compelled to approach what is not rule bound, with every rule [belief] I had. The paradox was that on one hand I brought to this research every unconscious rule I had ever held about myself, and on the other I was then required to undertake the research in a non rule bound way. For in exploring the terrain as I had previously done, what I had revealed was that, in order to reveal the unknown, my way to the unknown was then to be unknown. The unknown does not come with a set of rules or a blueprint.

So while more of the unknown/mystery can come to be known, it is beyond that which is prescribed or defined because it is boundary-less. The discovery of something which is boundary-less, is undertaken by something that has boundaries. In other words, in order to approach that which is non-definable I had to use that which is already defined. What was 
defined was my construct of reality, created by the ideas/beliefs/rules I had about the self, even though those definitions were mostly unknown [unconscious].

In abandoning my original plan, I did not abandon the original intent of my research work. My intention was to make the invisible visible which, at a conscious level, I thought would lead to making nursing more visible by revealing more form in nursing. And while I have achieved my goal of more visibility in nursing, only now can I see that my unconscious intent was to make me, that which is I, more visible. The outcome is the intent, and in that way outcome and intent are one and the same, working toward making the unknown known, the invisible visible, to 'get back to things themselves'. This thesis presents as an example of my becoming revealed that then is an illustration of the not knowing. As such it reveals that even though the conscious mind perceives to be headed in a certain direction, on the other hand there maybe something that is grander. I describe this larger experience as, more knowing. And it is this that I had to learn to listen to, because this more knowing knows where we each need to go, the lead that is to be taken, even when the direction stands in stark contrast to what we 'think' we have planned.

This work then, as I have described it, has resulted in the thesis text being presented as my revelation that then is a reflection of the whole, which is not the same as saying it is the whole. I constantly had to work with a process that is about 'how to be' and in one sense it then became learned, as I continued to approach the whole as a not knowing. This attitude then is reflected in my choice of the word process to describe the shift in the relationship of the researcher to the research. As the researcher [human being] I am rule bound while engaging in an activity that requires me to have 'no rules'. In other words, I was required to give up my rules, which in turn brings forth/surfaces everything to contest my perception of reality as the outcome of my rules. To change my reality meant, that in the first instance, I had to experience my reality - consciously.

For if a thing is nothing except in the space of that which it is not, then YOU cannot be ANYTHING except in the space of that which YOU are not. And so the 
opposite of what you wish to "be" will appear almost as soon as your wish to "be" is heard.

Walsch (1995, p.55)

The extraordinariness of this is, that as a rule bound human being I was then confronted with a research process that is not, and, as such the opposite of what I wished 'to be' then presented itself as an integral component in a process of releasing a rule. In essence this meant, in expressing the intent to 'get back to things themselves', 'make the invisible visible', what I wished/desired/ to be was love.

While I did not fully comprehend this at the time, in my desire to be love I had set in motion the possibility of experiencing the rules/beliefs that served to create my reality that were an expression of everything that was not love. In that way the opposite of what I wished to be love, was then positioned against its opposite - fear. In my desire to be love I had unconsciously called myself to face my fears. Fear denoting anything that is not real and yet fear through which my construct of reality is created and then bound in the rules that I then believed both consciously and unconsciously were real. On reflection, had I fully understood what I had called myself to do I may not have proceeded. For in my calling forth the intent to make the invisible visible, I had set myself the task of giving up, step by step, my known and unknown perception of reality.

It is from this frame of reference that I now can say that what I have engaged in, in the name of research, is a work that moves through the illusion of life by peeling away the layers that make up those illusions. As such, I have engaged in my own healing, which ironically is the very purpose of being human! At this point I both laugh and cry at the discovery, for I did not have this conscious consciousness when I began. To arrive at this place of knowing has been to engage in the notion of being, and therefore learn to allow being, so as to experience a thing as only what it IS, relative to another thing that is not. Therefore, the me that I have created through my experience of being human has, in undertaking this work, encountered whatever I have ever perceived myself to be. In pacing my map without a map, as a piece of research 
work, I have been able to 'glimpse the pearl of great price' - my own soul. Through this pearl, I have been able to connect to a greater consciousness.

The research process, while not rule bound, is not to be interpreted as being without a discipline. The word discipline and the word rule are not synonymous, as I have used them here. By discipline, I mean an order, and so it is in this sense that I use the words 'becoming learned'. To become learned is to begin to expose the discipline of process through conveying action. Initially I stumbled around in the process until eventually I discovered how to be, in the same way that a craftsperson acts in the process of creating/building. While I had understood what was required of me in order to set aside my rules, and which will be clearly explicated later in the text, I was yet to grasp that the creative process does not prescribe the tools for building, or predetermine what is to be built, yet does contain universal patterns that are creating an order. And while I had little idea at this stage of the availability of tools, somehow at this point I had enough insight to grasp that ultimately, as process, I Am the craftsperson. Until I had this awareness, I was unaware of just how I was limiting my limitless creativity, because I was veiled in the not knowing that, as a human being, what I was crafting was my own life. In other words, 1 perceived that while I made decisions and choices in my life I did not perceive that I had absolute power to create my life in whatever way I chose. Therefore, my reality or unconscious rule was governed by the idea that life was something that happened because life was created by forces outside of me. In my exploration of creativity, I began to perceive creativity as an act and choice.

If the word create is defined as 'bringing into existence' or 'to make by one's own actions', creation then is an activity enacted through the choices made about action. As such, our actions are the potential of an expression of the intent to create. How then, or on what basis, do we choose? Choices are a reflection of a built up code of rules and patterns based on past experience, so that when we are called upon or faced with a familiar problem under similar conditions, our response/act is then to respond/act with that particular code or pattern (Koestler, 1964). In this way, a choice that initially was an activity of creation is no longer creation in action because the choice becomes a habit or routine. In other words, what was 
boundary-less has now been given a boundary "... like an engine driver .... driving a train along fixed rails according to a fixed timetable" (Koestler, 1964, p.118). Creativity then becomes rigid, and something that is rigid then lacks flow, which Koestler (1964) considered to be contrary to creativity. So in order to make manifest my act of creation, then translated into an ongoing text as a thesis, I had to make new choices about how to work that were not bound in the same old rules or patterns.

I had identified that the old rules and patterns reflected my understandings of phenomenological enquiry where interpretation was an act of grouping data and identifying common themes. At this point I could use the word reflection deliberately, recognising the truth that these old rules and patterns were a reflection of the same rules and patterns that were me. For I had realised in my previous exploration of vision that most of what is seen is described internally and the mechanism for description is bound up in how we image the world. That image is created by what that individual believes/thinks. I was now in a position to move beyond using words or images to create my world by exploring consciousness as experience and expression.

Finally, I was able to understand why my new data (as opposed to the data collected for my master's work) did not make that much difference to the results of my initial interpretation. Koestler (1964) explains this phenomenon where, in changing an environment, using the example of a car as opposed to a train, there is more creativity than previously but there is still impediment to the flow. When the new/now situation still resembles some of the past experience, the new situation, while containing new aspects or greater degrees of complexity, is still met with the old pattern/map until such time that it will no longer work (Koestler, 1964). My dilemma became how to allow today's evidence to speak to me in the clear light of a new awareness.

I realised that I had changed my environment, new data (new stories etc), but in approaching my research with the same rules I could have produced almost the same thesis work. To say that I felt blocked or stuck in this situation would be an understatement! The feeling of 
frustration and stagnation was an old pattern that I easily recognised. Koestler (1964) argues that as this storm rages in us on the surface, we are in fact immersing the totality of our being in the situation. In that way the mind remains active as it searches for answers. While a breakthrough is not a certainty, what is certain is that there will be further opportunity for a breakthrough. The breakthrough occurs as a fusing of a vertical matrix/pattern through intuition with the old blocked horizontal matrix/pattern (Koestler,1964). There is a displacement of the attention/focus that then opens the space to ALLOW the flow to flow. In the flowing, more of a new pattern can be revealed. I knew that the feeling of being stuck existed only when I/one held/holds onto a particular perception of where I/one should be. I was telling myself that I should have had more of the thesis done. I was then faced with the choice to tour part of The United States of America. Should I, or should I not, go?

I was in San Francisco. As I dressed that morning I saw myself crossing the Golden Gate bridge - on foot. Whilst in New Mexico the previous week I had purchased a quartz crystal carving of a bald headed eagle. That morning I put the eagle in my backpack. Later that day our guide parked the bus at a tourist stop near the Golden Gate Bridge. I clearly understood her to say that she would pick us up on the other side of the bridge in fifteen minutes [what she had in fact had said was to be back in fifteen minutes]. As I marched across that two mile plus bridge I felt the distance between the first and second span would never end. I had become separated from my travelling companions in a new city and different country. I could not see my way into the distance. I could not see the end, nor did I know what lay across the other side of the bridge. I wondered how this was reflected in my life? I had placed myself on a bridge between here and there. My choice was to go back to what I knew or to keep walking to where I knew not. I kept walking, and walking. Just as I approached the end of the bridge our bus arrived and pulled into the only tiny spot available - much to the consternation of other drivers. I then scaled a fence and joined my travelling companions. I had crossed the bridge.

A month later back in Australia and at Graduate School in Sydney I sat in front of a panel reviewing my progress into the first year of $\mathrm{PhD}$ candidature. I explained that I had gone down the path of possibly producing the same work. In the first instance it was simply the admission of my dilemma, speaking my situation openly. Then there was a response to that admission by a member of the panel, and in my response to her response I then stood on the precipice that held the opportunity to choose to change the space. With the space open I then had the choice to respond with my old pattern thereby closing the space off from something new. I chose to make a new choice, and this then enabled the shift energetically. 
On 'confessing' my perceived lack of progress at that time, a panel member responded with, 'that's normal'. It was the word 'normal', and my response/reaction to the word, that then became the key to fusing the vertical and horizontal patterns. I had created the opportunity, through my intuition, to access more of my intuition. I had connected more. Unconsciously, I was terrified of my work and therefore me being seen as 'not normal'. I had my own constructs of the consequences of not being normal. In that moment I chose to take another step out of my self imposed limitation. And while it was one step, it was a huge one where, in order to create more, the action needed was to awaken to more by 'appearing' to have held myself back. It was an awakening moment. To walk into the unknown requires radical TRUST. And trust is trust, whether it be for crossing a bridge, facing a panel, or to keep heading in a direction when one knows not which direction one is headed.

Journal entry

I have said in the Beginning Story that my data for this research were narratives of nursing, drawings and photographs. At this stage I could not see how to interpret the drawings and photographs, and so my focus remained on the narratives that were to serve as the main source of data. What I now envisaged was that I had to find a way to transform the narratives into more than a collection of dialogues to be transcribed into text from which an interpretation would proceed. But how? In order to think process, I had to learn/discipline myself to widen my focus and keep an eye on the goal. I have also said that the human capacity to wonder is to invite a response. But how, I wondered.

Prior to commencing my studies - formally - I had attended a conference at the University in which I was initially to become enrolled. The conference was titled 'Stories from the Field'. I recall listening to a presenter who in the course of her presentation told a story about her nursing practice. I remember the auditorium became so still/silent that you could have heard a pin drop - and I recall hearing my thought: that story must have 'happened' over twenty years ago, but it also could have been yesterday.

Journal entry

In recalling this experience I realised how I could begin to widen my focus. My initial attempt at interpretation had viewed the narratives as something to be worked on. To view the narratives as an anthology of history would begin to position them in such a way that they would be allowed to work upon. I would allow the stories to work on me. The key to this 
change in perception then shifted the main source of data [narratives] from single units of data to an anthology as well as the difference between on and upon. In that sense they then became a history which, while serving as a record, was not a mere record of the past. For when they were allowed to become more, in the interpretation of this history, the interpretation moved from the space of past into the space of the present. In the space of the present, as the researcher, I could then experience the data in the now moment and in that way allow them to work upon. I could enable history to become a story in time and in that way reveal what is beyond time. Therefore I had to reconstruct my relationship to time while at the same time acknowledge that as a human being I was also in time.

To do this I had to explore time from my inherent knowing of time that involved me tapping into the timeless aspect of myself. While this was something I knew how to do as a procedural aspect in offering people 'feedback' after energy healing work, it had never occurred to me to explore something for myself in this manner. For the first time, I consciously asked my consciousness to speak to me about time. The response from the journal I was keeping at the time is recorded under the headings of On Time and No Time. It appears with some grammatical changes that have been inserted so that the text can be read in a more grounded manner.

This experience was important in two ways. First, some twelve months later I came across literature that spoke to the concept of past, present and future in a similar way and therefore validated the piece of text. Second, and much more important to me was that I began to awaken to how I was writing the thesis. And while I was not totally comfortable with the idea I began to realise that I was discovering how to tap into consciousness at a higher frequency that was not just an upward movement but also a downward one, and from this space bring the work forward. The relevance of this flow or movement is to be discussed later.

\section{On Time}

Time is a man made phenomenon. It serves to keep the hours, days, weeks, months and years in a linear trajectory that then assists us in sorting and categorising our daily lives. Time tracks a being, being human, from birth until death. In time we locate ourselves 
spatially; and so time assists in creating the perception that we exist. If we exist we must be real, and in that way we make time real. As human beings, we exist in time and space.

As a man made phenomenon, though, time is an illusion. An illusion is something that gives the appearance of being real when in truth it is not. Time is not real because it exists only as a dimension of space. Beyond space, time ceases to exist. So if time only exists as a phenomenon of human existence, that is, something we have created as human beings, then we as beings existing beyond space must also exist beyond time. We exist beyond time and space.

Time belongs to third dimensional reality. What characterises the third dimension, what makes the third dimension appear real, is physicality. If we can see, hear, touch, and smell something then we say it is real. Within this reality, time exists as a temporal notion, a trajectory, whose direction moves from the past to the future. Such a perspective, while serving to support the notion of our existence, also serves to suggest that our existence moves in a singular forward direction through time and space.

When human beings speak of time, it is in reference to either the past or some point in the future. Rarely is time spoken about as in a now moment - right now. Yet, within time and space, the past is past. It has passed. As past, time no longer exists. The future, on the other hand, exists as a myriad of possibilities and probabilities, neither of which make it any more or less real, because the future exists only as possibility and probability. So, a past that has passed, and a future that is a possibility, means that the only time that exists is right now. Now is the only real time. Our perceptions of time eg. fast, slow, yesterday, tomorrow, belong not to our being, but to our being human.

Within the time now, past present and future are all made real. How? As everything that has existed and everything that can exist, everything is present in the now. So whether we are existing in time and space, or beyond it, the only real time that our being knows is what we term NOW. Now exists both within the notion of time and space and beyond it. Therefore it is now that becomes the connection between being human and to that which is called - being, and so now enables that which is beyond time and space to be present in time and space. I would repeat this statement - it is now that enables that which is beyond time and space to be present in time and space. Such a possibility is created not just by bridging some sort of gap between here and there, but by lifting the veil of illusion that says that a here and there even exists. In making the two one, whether those two be termed above and below or heaven and earth, what is created is One. Only in Oneness can we evoke or invoke the presence of the presence. In other words, make present our own presence, bring down our divinity.

So when the stories as history are experienced in the now moment, what we are doing is revealing the mystery?(my thought) 
When we are present in the moment, by being in the now we are surrendering to the process of making divinity real. Divinity making can only occur in the now because the now, as has been explained, is both in and beyond time and space. As a human being we can choose to remain veiled off from ourselves and the truth that not only are we divine, but that we can make our divinity real - here on earth. Alternatively, we can choose to engage in the process of making that real. The irony of this is that, while we are free to choose, we will always choose the latter - it is only a matter of time.

In the understanding that each human being is a God or Goddess, albeit veiled, walking upon the earth, one can begin to feel the primordial yearning that comes from the heart. That yearning is the longing to walk on earth in the full remembrance of who we truly are. In its manifestation, it is the appearance of return to the garden we chose to leave so long ago. In the experience we forgot who we are. We are not what we seem to be. We are not human beings infused with Spirit, rather we are Spirit having a human experience. We make the journey of life to know that we do not need to make the journey, and the now as a form of timelessness exists to open the void or space and connect the two. Each time we make that connection, what we are making is ourselves. We are making ourselves more real. As we lift the veils that have served to keep us from that remembrance, veil by veil, step by step, what we are doing is walking ourselves back into the garden.

The garden, then, is not some religious mystical mythical place up and out there from which we were evicted. Rather, the garden serves as metaphor for something to be made real, here, on earth.

\section{Is this the intention of being human? (my thought)}

In the turn around that brings the future to the past, rather than the past to the future, and as each one of us makes conscious our journey home, it will not be in the understanding that we are Gods and Goddesses, it WILL BE IN THE KNOWING THAT WE ARE. As when we know, as we re-member, now is the only time that exists.

\section{No Time}

I have already said that time as a man made phenomenon exists, in one instance, to create the illusion that we exist as we perceive ourselves. In other words, that being human is the only reality. Perception therefore belongs to the same continuum as time, and in the same way that time is an illusion, so too is perception. In order to come to know ourselves as divinity, our relationship with perception and time needs to be experienced differently, because it is how we experience time that then determines how we then perceive ourselves. In this way, the two are inextricably linked and, as such, can either serve to continue to re-create our reality of mortality or our reality of divinity. It is our choice. 
In viewing time from the perspective of the now, in contrast to linear time that is perceived to move in a forward motion - past through to present, a now moment may also be met from the position of the past, where the past is brought forward into the next new moment, so that what is created is a now moment that is the same as the previous past. The past is brought into the now and becomes the possibility of the future. In the human condition, perception of a thing remains unchanged. The irony of this is, though, that while what we are attempting to do is undo the past, a movement backward in time, we cannot move in this direction until we are able to leave the past in the past. For in being able to leave the past in the past, it then appears as though we are moving forward. In other words, what we are calling ourselves to do is exactly the opposite from how it would appear to be. Paradoxically, in order to undo the past, the net effect of our being human, we need to move backward in time by appearing to move forward. The ongoing backward movement in time is of course to the beginning of time - to no time. This was a time when we knew we were divine, and if we are to know it again then we need to be able to learn to live and breathe in the now.

In being able to leave the past in the past, what we are actually doing may be termed an act of allowance. It is in 'the allowance' that we are able to meet a life experience with openness, to then experience that life experience as a 'new now moment'. To do so requires that we feel whatever feeling the experience evokes. In that way we can begin to change our perceptions of reality, for the previous perception of reality can then remain in the past. How we perceive or believe our world to be, is our act of creation, where what we believe is the effect of how we have processed life - emotionally. Our beliefs are the result of our emotional experiences, over and over and over again.

Our reality is the construct of what we believe to be real. Our thoughts create our reality. We experience our world as we believe it to be, and at the same time it as an opportunity to change what we believe. The experiences of life, as an act of creation, then serve to challenge our belief structures. Such a process is not a mental one. To change one's belief system, and therefore change one's reality, requires that what is changed, in the first instance, is the experience of the experience. While some of our beliefs are conscious, most of our beliefs are not.

This process of transformation is one where to change the experience of the experience is to feel the emotion embedded in the experience. To embrace an e-motion. To embrace an emotion is to allow the feeling of the emotion 'to be'. In this way, we begin to change our perception of reality. As we do so, we come to know that perception, like time, belongs to the phenomenon of being human that acts to either diminish, or expand, the knowing of our divinity. In the knowing of our divinity we know there is no time, for in Oneness we know we are not bound in or by time.

Journal entry 
I had tapped into consciousness in a way that I had not previously experienced. While I did not fully understand the concepts I could now see in writing this text I realised that I needed to continue with my stories as an anthology and that my exploration of time in this manner had revealed that the narratives were coded with emotion. My work to date had brought me to this point and even though I had been working with emotion I did not have this level of awareness. In looking back on what I had written, it is now obvious I had also tapped into much more. Hence my upward and downward movement of flow. The upward movement had enabled me to connect the downward movement is to bring it into the body and make it wisdom/knowing. At this stage I had some ability to tap into. The challenge ahead lay in making what I had tapped into as my wisdom/knowing. My ability to be open, to trust, to be, had all served to come to this point of knowing. My way forward was to feel my data.

To that end this student narrative serves as an illustration, of an opportunity, to feel an emotion.

Second year of second semester and I was going to Heath 6. At the time I didn't know what Heath 6 was, so I found out, and when I found out that it was the cancer ward I thought to myself, "There's no way I'm going there". I really didn't know what I was going to expect, but I didn't want to deal with cancer again, not yet. So the day arrived and I walked slowly to the ward. I had all these mixed feelings, I can't do this. I'm not ready to deal with this. What am I going to say? How am I going to cope? They opened the ward doors and the doors slammed tight behind me. I just stood there for a second. I looked down the ward with its dimmed lights, it looked really cold. There was a nurse doing the drug round, a nurse walking across the hall emptying a bed pan. I walked down slowly, avoiding looking into the rooms, I was afraid of what I would see. I didn't know what to expect.

I introduced myself to the staff and I was allocated three patients. Two women, both elderly, both with melanomas and a forty five year old man with extensive metastases to his liver, bones, pancreas - you name it, he had it. When they handed over this man I felt really nervous and I could only think of this man and not everything that was said about the other patients. It was like a mental block, all that mattered was this man. Forty seven years old and dying, it's my dad's age. I couldn't find the courage to tell the Charge Nurse that I didn't feel comfortable with this man. I hadn't even yet met this man and I had already made judgements - but I didn't want them to know how gutless and hopeless I was. So I avoided him for the first hour or so, and I attended to my women. Then the registered nurse comes and said, "You have to do this this and this, for this man". 
After a while I knew I had to go into his room, so I did. I took a deep breath and I walked in. I was about a metre and a half from him, he was asleep, thank God. I just stood there and my eyes filled with tears. The sunlight from the crack in the curtain shone in his face. He looked thin, fragile, jaundiced, with sunken eyes. The tears just filled so that I could no longer see, and I started to remember the slow agonising death of a very close family member, memories of hospital, admissions and discharges, of chemotherapy, of radiotherapy, and the loss of hair. The deterioration of a woman who once ran a restaurant who was to be restricted to her bed, unable to walk or even lift her arms because the cancer had invaded every single cell of her body. I remembered her pain and crying for help, this feeling of helplessness, the help she wanted was to end her pain, even if it meant taking her life and I was prepared to do it but I didn't because I knew it was up to God to let her die when she had to - but I wanted her to die. I couldn't bear to watch her. I resented going to visit her because I couldn't cope with her suffering, I wanted to remember the energetic woman that she was and not what she had become. I kept hoping she would die, I prayed and I kept asking why it had to be her? She was just starting to enjoy her life, her new house, the holidays they'd planned with her family. She worked her whole life and she couldn't even enjoy her life's work when she got the sentence of death from cancer.

I remember studying for my Higher School Certificate exams, in swat vacation, and the phone rang, it was the hospital, so my parents and all the other relatives went to the hospital. I wanted to go so much but I was a kid and I wasn't allowed, there was no room in the car. I was angry, I wanted to say goodbye, so I rang a taxi but then I found a lift. I walked into the room and she was just lying there struggling to breathe. She didn't have any strength, not even to open her eyes, but she knew we were all there by the depth and rate of her respirations. I couldn't stay because I would have burst into tears and I didn't want anyone to see me, how I felt, but the hardest thing I've ever had to do was say goodbye. I kissed her forehead and tears fell on to her face and I walked out and sat out in the waiting room. There was silence and then I heard the screams from her room, her kids, her family. I felt total emptiness, I didn't have any more tears, but I was somewhat content that her suffering had come to an end, and that our sufferings were just beginning.

So when I saw Mario I was reliving my sufferings. I walked out of his room and into the treatment room and cried until I had no more tears. I thought to myself, "I'm not strong enough to be a nurse, I'm too weak". I didn't know what to do, but I knew I had to go back, I had to overcome these feelings. I walked in again and I met his wife who was lying on the mattress beside him. I introduced myself. She saw my name and asked if I was Italian, and from that moment I felt that there was a bond. At first I thought I was going to be task orientated but once I started talking there was no stopping me. I found out everything about his family life and he about mine. Even thought Mario only spoke in short sentences, he was always involved, his eyes, and facial expressions conveyed this. 
I met his family and friends. I encouraged Cathy, who was his wife, to help me with his care. We shared laughter and tears together. We would talk about the good times, something I never did with my aunty. I didn't feel like he was dying, I felt like he was living with an illness. I told Cathy that I knew what she was going through and she replied, "I know, you're different". So I felt comfortable and I told them my story and she was comforting to me, and Mario told me, "Enjoy life to the fullest", which were my aunty's exact words!

At the end of my second day with this family I said to Mario "I'll see you next week", he held my hand and he said, "Gratsi", which means "Thank you". It was as if he knew he wasn't going to make it, and he didn't. I was sad for weeks because it rekindled all my memories. I went on for weeks thinking about this family and what they were going through, - because I knew. And then I had this beautiful dream where I saw him up and about, dancing, talking, laughing, it was as if it was a message to tell me that he was OK. I've now written a poem about it.

Within the chest the heart still beats

The fading brain more often sleeps

The spirit lives in too dim flesh

Awaiting freedom, peace and rest

Those who love her must sit and wait

Wondering what will be their loved one's fate?

Is this the life they hold so dear?

They kiss her cheek and shed a tear

The decision made to no longer treat

May death come quick to God they plead.

Death is sure when there's no earthly hope

With this slow death they try to cope

Could she be kindly put to sleep

Her soul released for God to keep

But who will give the fatal dose?

The nurse, or the one who loves her most?

And will such death then count as sin

as life's snuffed out before it's end?

The race on earth is almost run

she'll soon get the crown that she has won.

Her life is not theirs to take

the time of death is God's to make.

So they do the only thing that they can do

they bow their heads and see it through.

They pray dear God to let her be

because in death the soul is free. 
In order to translate their code, something that will be explicated further in the following discussion, then meant that I had placed myself in a position where, as the researcher, interpretation was dependent on my being able to feel the emotion/s within a particular narrative and then change my experience of that emotion within that now moment. The first task in this two step process was to allow myself to really feel, whatever a narrative invoked. I will discuss my method of narrative selection later in this section. Further, I wish to impress upon the reader that one's construct of reality is individual and therefore, in offering the narratives that are inserted in the text of the thesis, I do so on the basis of illustrating process and not structuring a formulae for being. While we might share a common emotion in response to a particular story, what we have each made it mean, will and does differ. This then will determine an individual's pacing of their map and what experience will be created in order to facilitate process - initially.

At this point in the research I was both excited, and terrified. Now I felt that understood my life. For it to have been any other way, I would not have been prepared, not as an act of unwillingness, but as a readiness/preparedness to go further/deeper into this work. In the awareness that I had only just begun to allow myself to feel my reactions and responses to life I felt totally confronted. Prior to this insight I considered myself as capable of deep feelings. Now I could grasp that being was not a theory; being was realised in a form of doing in order to feel. In that sense I had brought myself to the realisation that I had to fully engage my self in life differently, step by step, where, in order to be, I had to become what I affectionately called, a 'do-be'. Where to be meant I had to do in a way that was not a mere doingness. And so on one level where I might go was exciting, and on anther, what I might have to do was terrifying. Tapping in was only one side of the equation, one was then challenged to make what one had tapped into real, and until such time that one did so the frequency of what one tapped into remained the same. Evolution or Revolution.

In the insight that at a being level we communicate through feeling, I could then see that in order 'to be' I had to trust what I had called forth, to feel through my experiences. The process 
involved always identifying my highest purpose or the most creative possibility, and then surrendering myself to that feeling. To suggest that this is simple is to have little insight into the illusory power of the human ego, and the degree of resistance generated in the name of illusion in order to avoid feeling a feeling.

In the experience of feeling, however, I would describe an intimacy that is primarily a reflection of the depth of relationship I have with myself. When I listen to myself, I am validating my true self, regardless of how that might appear to be. Each time I do so, I have more of a sense of my eternal being through this way of acknowledging my human existence, thereby reinforcing a reality that who I am is a spiritual being expressing in a body. In this way I could then begin to see life as a gift whereas in the past life was something to be endured and conquered because I did not perceive it as a gift. Life for me had meant a struggle that was interjected with moments of happiness. In the process of awakening myself to what I was - thinking - by being able to acknowledge myself through feeling, I began to change my thoughts. As such my perception of my world, of life, began to change, and in so doing my internal perception of the outside world began to change accordingly. Thus I began to reveal being human, and the project was a vehicle to record the experience.

To be, I had to learn to feel and then choose to feel something else. As I began to master my emotions, not as a form of control but in the full embrace of feeling, I did not need to repeat the same experiences. The past no longer presented itself in the present because I had chosen to react rather than respond and in so doing create a new future. In creating a same future, the illusion is that while the context/scenario/drama/narrative in one's life may appear to look different from a previous one, embedded within the new drama is the same old feeling. Eventually I did learn that until such time that a feeling is felt freely, without judgement, I would create the same reality by creating an experience in which the familiar feeling was embedded. So while the players in a life situation may differ, in essence it is the same experience, because nothing on the inside has changed. There is no new flow. Through embracing the feeling embedded in an experience of life, I had embraced myself by acknowledging my act of creativity. In this way the narratives are life experiences to be 
experienced emotionally. Until I had moved through an experience, by feeling the emotion, no further expanded interpretation was possible, because I remained locked into a perception of reality that represented a realm of consciousness.

Further, while I acknowledge that I have had to process the emotions consciously, and to that end can speak freely to my experience, the notion of WE exists so strongly in my consciousness that at times I struggle to separate us and speak about this research in terms of me and mine. To perceive the narratives as an act of creation that is not an act of my creativity, is to carve consciousness into pieces. In viewing the narratives from a perspective of wholeness is to understand experience as an act of creation that is also a co-creation. In that way, I have recognized that we (the students, patients and I) had stood on the stage of life together. I had called from my beingness, and they and their patients had responded through theirs. Together we had called ourselves to awaken to what IS, although I had very little understanding of what that meant in its fullest expression, and despite not knowing what we had called ourselves to do, we had set in motion a grand project. Whether we each fulfilled our intent in coming together in this way is an individual choice. For it is an individual choice whether to be or not to be, and regardless of the choice, a being is still being something in any moment. In my choice to be - more, I began to open myself to more.

\section{Intuition - The teacher within}

The data [narratives], when approached with the intention of coming 'to know', then 'sets up' a different attitude to everyday life. The attitude is one that is reflected in the relationship of the researcher to the data, where there is much greater awareness of both what is going on on the outside, in relation to how one feels on the inside. The outside, life, becomes a mirror of an aspect of the inside that has its roots in feeling that is either a reaction or response to every day circumstances/occurrences. A flat car tyre no longer is just an inconvenience. Now it becomes a reflection that can serve to show me something about me. In this way, I consciously began to stop seeing and experiencing myself as having a boundary. 
As such there is a greater realisation that everything in our world is connected. When the outside is acknowledged as in some way being a reflection of the inside, then the relationship to all things in our world ceases to be one that is dualistic. Where at this level of dualism the pattern of thought is one that believes we exist as separate entities, then our perceived boundaries are real. So in reframing my thinking on reflection through increasing my awareness that the outside can show me something about the inside, I then also connected the narratives [students and patients] and myself as the researcher. Where the connection is timeless, it is without time. The challenge then is to make this connection real. My text on time was invaluable.

To say that this is just a mere shift in attitude is an understatement. In addition, I would add a caution here. In viewing the world with this attitude it can also be used negatively by the ego because the temptation is to interpret/analyse a reflection. Thus I have said the outside, life, becomes a mirror of an aspect of the inside that has its roots in feeling. That how we feel in response to what we see/hear, is a key. Learning to trust the feeling takes some practice.

We were asked to recall experiences of equipment that had broken down. I recalled a week I had vowed I would never forget. What a week! The car had just stopped dead on the road. The garage man said it was only a little part, about the size of a matchbox, but that it controlled the electronics. He had remarked that it was most unusual for this part to break down, nor did that match box sized part come with an equivalent sized repair bill. The next day the iron and an electric beater died and, to end my perfect day in a perfect week, when I had plugged in the school's power book the screen just went black. The technician's report said I had blown up the motherboard. In remembering this experience, I recalled doubting that I had done something wrong because the week prior to that one, had been one of the most extraordinary weeks of my life.

In sharing my equipment catastrophes the facilitator just smiled and said - Ah, ready for a new way of thinking. I had only just begun to grasp the idea of the outside being a reflection of the inside but which hinged on feeling.

Six years later

I was driving home on the highway. An elderly women interpreted my left hand signal to indicate that I was changing lanes as my intention to make a left hand turn, and with that she shot out across a four lane highway. I attempted to drive around her but she just didn't stop and consequently most of the left hand side of my car was badly damaged. I 
had banged my head on the driver door window when we collided and the car had precariously tilted to the right balancing only on two wheels. I managed to steer the car through and brought it to a stop. As I began to collect myself I could see her in my rear vision mirror marching down the highway. As she approached I opened the door and was confronted with an hysterical screaming woman. I did not react. When I felt inside of myself, I was amazed to find that I felt calm and relaxed. I then directed my attention to making sure the woman had not been hurt and assisting her to make the appropriate arrangements. She finally stopped screaming blame at me and began to cry.

The next twenty-four hours were amazing. I was aware that I was searching for a reason to feel bad about what had happened. I must have done something wrong. I knew legally I had not, but man's law and God's law are not the same. By this time my way of relating to the world was not so bound in the social consciousness of right and wrong. This was an act of my creation. And as hard as I tried to find a reason - I could not. I just could not - my head was inventing all sorts of stories but there was no feeling that a story could attach to and 'pull my strings'. All I could do was get in touch with that calm relaxed feeling and every time I invented a new scenario with which to blame myself I would check into the feeling - and there it was, calm and relaxed. My car was repaired with minimal fuss, and this was in spite of a panel having to be manufactured and flown in from Japan. The challenge, I realised, was whether I would listen to the feeling or the head chatter. I had created a car accident for this purpose. Ah, but now I had a brand new left (feminine) side to my vehicle.

Journal entry

To allow the reactions and responses to become opportunities for reflection, is a key to revealing the meaning/s embedded in a particular narrative/experience. To do so requires taking responsibility for both the outside and inside worlds. 'To be' the central sun of my own universe meant that I had to take responsibility for my universe. I know this prospect will be daunting to some. For on one hand we co-exist, and in that way are not separate from every other thing, and yet at the same time we are an individual.

The idea that we coexist as both an individual and one, and that the outside is a reflection of the inside, enabled me to place myself differently in the research. In that way, I was then more willing to allow what my intention had called forth to be experienced, and/or re experienced. I was more willing to go where I was being led, not in an inert way, but in the sense that I was willing to listen to a higher aspect of myself than I had in the past. As process, the outside world is at once a reflection of the self which in a beginning sense is $a$ subjectivity, and in its grandest form is an end, 'an' objectivity. I say 'an' objectivity rather than 
objectivity because I cannot yet say object in a finite sense. Six years separated the two journal entries. What had changed in that time, in my using the environment to mirror consciousness, was my ability to apprehend my unconscious intent by being clear about what I was feeling.

And so I continued. The challenge was, and still is, to feel more deeply because as I was to learn, my ability to 'see something' was contingent upon the depth of feeling I could allow. Later I was to learn that when I felt something and still had an emotional attachment to it then I was unable to articulate what I was feeling. This is a crucial distinction because emotions are also felt. Feeling on the other hand is pure thought that then is communicated through a human form of communication. Chapter four distinguishes between emotion and feeling and the last three chapters evolve the discussion on feeling as it relates to pure intuition or pure thought.

Thus far I had seen that the data was a record that was coded with emotion. I had begun to embrace the idea that I existed in a reality where I was responsible for that reality; that the outside world could serve as a reflection of the inside in some way that then assisted me to line myself up more fully with the greater aspect of myself. And perhaps the greatest challenge of all was that I had to be willing to follow where I was being led, even when I did not have a purpose or an outcome. In this way, I could embrace the record further. In so doing I could rewrite the record, where the impetus in rewriting the record is to feel the emotional response to life and record the emotion consciously. In this light I present the following student story.

OK. This story is about a person that I had met over a six week period and it was on a ward that deals with vascular problems. And I met a lady, she was in her seventies and her name was Mrs Daniel. She was a lovely lady. She had been admitted for a femoral poplateal bypass, and when they had taken the dressing down they found that the wound was infected and that she required a graft. She had had two grafts which had failed to adhere and at that point Mrs Daniel was being reviewed for a third one.

I was never allocated Mrs Daniel. However, I did go in and talk with her as often as I could because I felt that this lady was missing something that the other people that were looking after her were failing to see. So I developed a rapport with her over the three clinical days we were out each week over six weeks left of the semester. She was 
situated in a four bedroom ward and her bed was on the right hand side, closest to the window, and the other three ladies that were in the room changed quite often, but there was one lady who was in the bed beside Mrs Daniel who was Mrs Travers. She had had an amputation, so she occupied the room for a fair bit of time with Mrs Daniel.

Mrs Daniel used to wear a cotton nighty all the time in bed and she used to have this blue crocheted shawl wrapped around her shoulders, and I'm not sure whether she knitted that herself - but I'm pretty sure she did. She used to wear glasses and her right leg, because that was the leg that she had the bypass on, was always elevated on one pillow and on her foot she always, well most of time, wore a sheepskin heel protector to prevent her from getting ulcers. Unfortunately she did develop one on her heel which was noticed by her son.

Every time I walked into the room Mrs Daniel was sitting up in bed, she always had the back of her bed upright and she was always rubbing her right toe, her right big toe, because it was sore. And if you looked at it you could see that the skin was taut and it was red and you could see that it looked painful but there was no investigation ever to find out what was wrong. She thought it might have been gout.

At the head end of her bed she had a picture of a baby and everybody thought it was her grandchild but the story behind that was the people in her family thought she would be a grandmother first but instead her sister became a grandmother first so that was a constant reminder to Mrs Daniel that she wasn't a grandmother first. That was a bit of a joke in her family. On the bedside she had get well cards and a lot of flowers and her favourite flowers were the carnations. At the end of her bed was a helium balloon which was quite deflated by the end of the six weeks that I was there, so it used to hang on the floor. And the amazing thing was, she had a trapeze bar on top of her bed, above her head, and she used to use that to move around in bed but the thing about that was, as the weeks went by, she actually used that trapeze bar to tie ribbons on it to signify the amount of days she had to wait for her third graft to take - and it meant a lot to her because she wanted to go home and she was just so sad, because she was only supposed to be in there for a couple of weeks and she'd been there, well - it was well over two months! And I could see that Mrs Daniel always smiled. She always smiled and she always greeted you, but I could see that there was always this sadness. She had a sad demeanour - I suppose that's what drew me to her.

I used to go in and sit with her and she would talk about her family and the places she'd travelled, her interests, and she'd also express how disappointed she was that she was staying in hospital longer than what she had expected.

On the last week of my placement I had developed quite a rapport with her and I used to sit there and hold her hand and rub her foot for her, and she was telling me that she really wished that she could go home. She really missed the things that she used to do. And she said to me, this was the Thursday, my second last day, I was on an afternoon shift. She said to me that when she goes home, the first thing she was going to do was 
cook herself some well cooked loin chops, bacon, eggs and tomatoes - when she got out of hospital that is what she was going to do. So I presumed she didn't like the hospital food much while she was there and she had come from a farm environment and so she was used to the hot breakfast type thing. So then I went off to debriefing and I had an idea - and so with the support of my clinician and the consent of the Charge Nurse, the very next morning, which happened to be my last day, I brought in my fry pan, some utensils, home made bread, bacon, eggs, and tomatoes, and I cooked her up a breakfast.

And in the cooking of the bacon, or the smell of the bacon, it filled the whole ward - but she had no idea what was going on. So you can imagine the look on her face when I walked into her room and handed her this big plate of bacon, eggs and tomatoes. Because all I could focus on was - this lady was sad, and all I wanted to do was make a difference and actually make her smile from within. Like she was always smiling on the outside but I could see that she was sad on the inside. So I wanted to do something that would actually bring out the genuine happiness from inside as well. So, yeah, she was pleased, really really pleased - and I will always remember the look on her face. It really, really made my day! She just had the biggest smile and it was just genuine. I could see that. It was just like there was her and there was myself, and all the misery that she had been through from her disappointment of staying in hospital just lifted. "Oh, God", she just said, "Oh, thank you. I don't believe this, this is so nice". She had tears in her eyes - I think just from happiness, which was really really nice.

Oh - The irony was, the doctors happened to be doing their rounds at that time of the morning and they went into Mrs Daniel's room and there she was sitting up eating bacon and eggs - and they knew she was there for a femoral poplateal bypass that was probably the result of atherosclerosis! Ha ha ha

In some instances of interpretation, the movement or direction of flow was to simply experience a narrative. What is within the narrative is easily experienced. The emotion rises into consciousness like a bubble to the surface. That is, the feeling emerges spontaneously, the narrative serves to invoke that emotion as a feeling. The emotion is whatever is felt in response to listening/reading of the story. This then serves to begin to shift consciousness. In the changing of consciousness the ability to tap into consciousness then is also changed. Thus interpretation means to work with emotion as a process.

In other instances, the movement of flow that results in an interpretation is from a life experience to the narrative. In my creating a position in which I had chosen to experience my world without boundaries, I then realised that I had to learn to really live the research. What that meant in practical terms was that in order to interpret some of the narratives I required 
more life experience. Where what was embedded within me, my subjectivity and the subjectivity contained within a particular narrative, was so deep that in order to see clearly I then required more life experience to allow a particular emotion to surface.

To this end I undertook both a personal development and self expression/drama class throughout the entire project because I began to appreciate the need for a greater awareness that is at once tuned within and without. These classes afforded me the opportunity to engage with others in multiple ways, thereby creating another milieu for me to monitor/observe my internal dialogue reactions and responses to my interactions. I have also learned much through observing others and journalling. The writing and subsequent thesis are lived research in which I became conscious that every word written was in some way played out or to be played out in my life. In this way, the work was never just left on my desk or in my computer. To convey this idea of the research being lived, and the text being the outcome of this experience, I have attempted to convey this by saying that the data works upon. In retrospect the idea is comprehensible, initially writing lived research was very challenging. To live the research is to make it real/genuine/true and in order to make something real/genuine/true then requires the one making the claim to be more real/genuine/honest with oneself.

To be real with myself meant an internal honesty. To be more real was to express what I was feeling, to say/acknowledge how I felt. To do so allowed me to get deeper into the uniqueness of my horizontal matrix, that is the expression of how $I$ be as a human being, my personality. I consider that what $I$ be as a human being, at this point in my evolution, is not the expression of the purity of being and hence the purpose of my being human. As such who and how I am as a human being determined my particular starting point in working with the data. That is, once I had identified how I would proceed. This then is akin to gathering in the Heideggerian (1972) sense of the word, and discussed in chapter two.

In this way, I had a greater appreciation that the data is a representation of an idea or belief about life which I then had to connect as a pattern. And so it is important to make clear here that another researcher working with this same data would not experience the same direction 
or order of flow. I would even argue now that another researcher would not have 'attracted' this same data. For we have each patterned ourselves differently, and thus our horizontal matrices are unique. In this sense what we 'attract' as life experience is determined by how we have each patterned ourselves. Developing this understanding was integral to the way I worked with the data as emotion. (The body of the text explains this in length). The purpose of raising it here is to convey my next step in working with my data where I realised honesty was the key, because my construct of an emotion, for example, happy and sad, is different to that of the next person. The commonality lies in the surety that we do share a construct of happy and sad as an emotion with every other being, being human. So while our horizontal matrices are shared, they are also unique. Our commonality lies in our essence and not our humanness. With this understanding I then widened my focus to include being human and in so doing recognised that in order to be what I needed to do was - be honest.

I recorded in diary/journal notes what I was experiencing in life. As I did so I shuffled and reshuffled the narratives. I created groupings and attempted to find links between what I was recording and the groups. With a greater awareness of how to work with my narratives emotionally I knew that I had to do order the data differently.

A circle is universally recognised as a symbol representing 'wholeness'. So if I spread the data out in a circle, as opposed to a line, I realised it didn't matter where I began the process of interpretation, rather, in the same way that I had drawn this data to me, I now accepted that I would inherently know which narrative to select and therefore it was only a matter of beginning - to do. What is critical in this understanding is to move forward with purpose even when the direction is not clear. In knowing this, I could trust. In my willingness to be more honest and trust my inner knowing, I was able to move forward with the thesis. In this way I began to grasp the idea that a piece of data selected in this way was the perfect piece of data with which to work, whatever the outcome. The process reflects this. 
In describing the process I used for writing and selecting the narratives, it is clear that this is not the same as ordering the data in a linear fashion. In choosing narratives from the circle is to begin to come to know one's intention/thought by beginning to work with one's

. Thus I began to consciously allow my intuition to guide the work where the word intuition means - Intuit, in $=$ inside, tuit $=$ teacher. The teacher within or inside. I consider every person has an inner teacher. So working from my inner teacher enabled me to find and hold the position from which I would then draw forth every thing I needed in order to process that particular narrative. My human field then acted as a magnet to attract whatever I needed to work my way through a story. And whether the experience came in the form of a conference, a book, a telephone conversation or a dog on the beach, as long as I remained aware and open to all possibilities I was working with my inner teacher. As I stepped into more life I could walk further into the 'unknown - yet'.

The following journal entry and subsequent narrative reveals this process. I had selected the narrative and then allowed my consciousness to unfold it.

as I remind myself ..... enjoy the journey, it is not about walking from this point to that point ..... it is the journey ...... and I then entered the rock pools where the child was .... making my way through rock pool after rock pool stepping over bunches of sea weed as I was walking along the beach .... I saw a child playing in the rock pools ..... I stood still .... allowing myself to feel the water rise to knee level, and then subside again ..... I knew I had a choice .... I could walk above the water line - above the rock line and just look at it, or I could be in it, I could experience it .... that choice was mine and mine alone ....

and as the tide flowed in and out there were times when it was clear to see where I was going, and there were times when it was not ..... again I heard myself say .... you will always take yourself to where you need to go .... and safety comes from the inside, safety comes from the inside ..... and when you come upon a place where it is not clear .... stand still ... breathe .... remain within your centre .....

and as I did, it was as if the ocean would magically part and my path became crystal clear again ..... walking this way I did not fall over .... I did not even stub my toes ... not once! I came to a place where it was deep ..... I jumped the rocks .... rock to rock .... like leaps of faith ..... trust ...... then I came upon a place where there was not another rock to leap to ... nor could I could see the bottom..... there was water all around ... I had walked onto something that had just become an island... I stood and waited ..... in that still place I felt secure, there was trust, I have learnt to trust the 'not knowing' - more.... how can we come to know the unknowable, if we do not allow ourselves into the 'not knowing'?..... 
and then from what seemed like nowhere, a dog walking along with its owner walked straight through the water to me and nudged his nose against my hand .....and then just turned around ..... it was as if he said .... there you are, come, this is the way .... and still being unable to see the bottom I followed his path and when we were on the flat sand again he went on his journey and I on mine .... Ah yes, there is always support, support is always there ..... all it takes is ..... allowance and trust .....

I looked across at the land line and even though it seemed but a moment that I had begun my walk I realised that I had walked further today than yesterday .... I laughed as I made my way up to the dunes.....

so then I sat gazing at the water .... I allowed myself to be a wave .... phew the spin of it and then the unfolding ...... and we didn't crash when we had stopped curling, we just curled and unfolded, curled and unfolded, and the whole of the time there was motion ...... I have always been scared of crashing .... there is no such thing ....

I had picked up a white shell on the way up to the dune and when I had sat down there was a white feather at my feet .... but not pure white ... Oh there was still something in the way .... for once, I didn't let my heart sink .... and in that moment, ah that is the moment when the wave unfolds, just before it curls back ..... in the silence .... I heard it yesterday in a way that I never have before ... and in the silence I heard - are you ready for more .... the last time I heard these words I responded with ..... it depends on what more looks like .... this time I said, YES .... and as I did, my head turned and there was a small feather ..... black and white .... I knew the white was approaching the black .....

and then I looked at my legs ..... the rash came back yesterday .... so yesterday on the beach I let myself raise the anger ..... when I had raised the anger ..... I went back to issues of relationship and sex ..... that afternoon there had been roars from my liver and pancreas for about an hour

but today as I looked at my legs ..... I acknowledged that what I felt was deceived ..... I allowed myself to feel deception a few Sundays ago ...... I know what that feeling feels like ...... but now I could see the pattern ....

so as I walked back down the beach today I heard myself say.... and what of forgiveness/acceptance ....... and I traced each iteration each pattern of the fractal through all the deceptions ..... through the thought .... yes yes yes yes ..... no ......there is something there .... and it was then that I remembered the talk I had with my visitor on Thursday .....

he came because he did not know whether to stay in his relationship or leave ..... he said he felt dirty when they made love, he said he knew he was hurting her .... he was ready to run .... again ....... and so we explored his construction of intimacy and sex .... we looked at the patterns in his life .... I had known these same patterns of relationship .... 
but that is the predictability .... but it is always about the other ... you have to go into the chaos ... I attempted to help him see with other eyes .... I have to develop further my ability to assist them to take themselves there ... he knows I can go there .... that is why he came .... but he has to go himself ... and I can go with him, but not for him ...

but I also knew that there was something in this for me to look at ..... something that comes with that universal glue called love so I then went back to that space and having done that, it was then, then I could forgive/accept ....and in that moment there was the connection of both ends ..... the deceived and the deceiver .... the thread joined again ... and I heard myself say .... it can be that easy ... when .... you trust and allow it .... home.

I am just home and a car pulls up

one of the women in the group .... we called it the 'fat group' from the year before last ..... we came together weekly to talk .... I have thought of her many times this past few weeks as I begin to think and write about creativity .... she is a superb cook, wonderful sewer and embroiderer .... I ask about her relationship with her husband ..... she tells me .... we talk of possibilities, choices, options and how to work with ..... still, there is something else to see ..... my thoughts drift off ...

as I awoke the other morning my eyes focussed on the two clocks on the dresser ..... neither of which now work ..... each was given to me by the two partners I have had in my life ... the end of each relationship was the same..... they ended in deception, I experienced being deceived..... and then it dawns on me ..... it is time to give those two clocks up ... am I able to give them up? ........ and as we talk, she and I ..... I suddenly realise ... the clock restorer, he is her husband - and I then know what to do ....

...so while she has come to talk, I have called her ... she has come for the clocks, I have the opportunity to let them go, these particular moments in time, and in so doing change my perception bound up in time ...... we go down to my bedroom with a bag ..... and as I place the clocks in the bag I am conscious of my hand on only one of the clocks..... it hangs on for just a moment, I breathe, I acknowledge this and then ... let it go ...

Now I understand the human made phenomenon of time ... time per se does not exist .... but space time does, it is curved. The closer light gets to density the more it curves. In this way it can keep curling so that it bends back on itself making a circle, or, by decreasing the density of the object we in fact straighten the light. As we do so, we are creating new waves to curl and unfold, until such time that we have moved ourselves beyond space time. How does one know the feeling of deception without having been both the deceived and the deceiver? 
This student narrative had been sitting on my desk and now I was ready to feel it.

I'm just going to share an experience with you guys that's stuck in my mind and played on my mind since last semester - for some reason, and I refer back to then. I was working on a late shift, on a ward, last semester, and it was about $9 \mathrm{pm}$ when the registered nurse grabbed me and said would you like to practice your catheterisation skills and as I had never actually catheterised a real person before I went for it, - yeah, sure. And we went into the treatment room and got all of our equipment and everything ready and went over the correct procedure as to how to go about it and she gave me a brief run down, a very brief run down of the situation. She said the patient had already been catheterised but she had demonstrated very low urine output in the last few hours and they suspected that the catheter was blocked or too small. So, we were to remove the original catheter and put a larger one in.

I walked into this single room and although I was confident about what I was going to do I was very focussed on the procedure, just the procedure. So I stood to the right side of the patient's bed and had all my equipment laid out perfectly and the registered nurse stood to the end of the bed with a heavy duty torch, shining it on the vagina, because the lighting was really poor. And I looked very carefully at the way the original catheter was so that I knew where to put the next one, so I didn't make a mistake for my first attempt. I removed it and went about my way to insert the larger catheter.

Now to get a better view and to do the procedure correctly I held the lady's legs apart with my left hand. This woman had a very distended abdomen, so I used my forearm to hold her abdomen back because it was obstructing my view. And I tried to insert the larger catheter, but I felt so much resistance that I didn't know if it was in or not and there was no urine coming out and it kept falling back out again - but I was determined to get it right. So I kept trying but after a couple of tries my arm started to really ache and instead of concentrating on what I was doing I was really focussed on the pain in my arm and I couldn't tolerate it any more. It was a really unbearable pain. So I admitted defeat and I let the RN have a go and I held onto the torch from then on.

She had a try but she couldn't do it either and the charge nurse came in and she also tried and she couldn't do it. So they called up a gynaecology registrar and he came up and he had a go and he too described the same resistance that I felt. He decided that it was necessary to do an internal examination. I was still holding the torch trying to give them the best light possible, moving it around and everything. And it wasn't until after, or during the internal examination that I realised that I'd missed something really important - and that was, I hadn't even looked at the patient. In fact I don't think anybody had looked at the patient. I hadn't even looked at this lady, I hadn't even looked!

She was semi-conscious, and we hadn't heard a word from her until the internal exam began and all she said was, "Lord, dear Lord, oh no", and all she could say was that, and it was only for a very brief time. But at that I put the torch down and I went up to the patient and I held her hand. Her name was Maggie. And I stroked her on the brow and I 
looked at her. Now she was an eighty-two year old, a retired registered nurse, she had no family and no friends and she was barely conscious. I just stood there holding her hand and stroking her forehead. How could I have forgotten her, just how could I have done that? [Pause]

After the internal exam raised questions, they decided to do an ultra sound and discovered renal pathology.

Anyway, I left work at ten o' clock that night and I couldn't say goodbye to anyone because for some reason I had a very big lump in my throat. I went home crying that night because I just didn't feel right about the situation. I cried and cried. I sort of tried to reflect on it and everything, but I just cried. I went back to work at seven o' clock the next morning and the first thing I did was look in her room - it was empty - she had died fifteen minutes after I left the night before. I didn't know what was worse, the fact that she went through all those invasive procedures only moments prior to her death or that she died alone. I forgot to be there for her - that really stuck in my head.[Pause]

Patterson and Zderad sort of summed it up for me really. I was quite surprised to find a model that made some sense and helped me resolve what has constantly been on my mind. And even though I still think about her a lot, she's the sort of one patient, I don't know if any one can relate to it, you always remember one patient for something. I will always remember her for that. Patterson and Zderad, on page 31 to 32, say that, 'Often in nursing it is necessary to focus my attention on some aspect of the patient's body or behaviour. The patient may or may not have the same focus of attention, at least momentarily, then or even for a prolonged period I place some aspect of the patient before or opposite myself. And to the extent that this detail absorbs my attention I lose my sight of my relatedness to the whole person who happens to be the patient. While I know this focussing in detail is to be a necessary step in the nursing process, sometimes I find myself abruptly refocussing my attention on the whole person, with almost a twinge of guilt for having abandoned him'.

And that sort of sums up, exactly how I felt [Pause] There was another paragraph I found, it's pretty deep - but it, to me, was also very related to my story. And I'll just read it to you, it was from page 30, of Patterson and Zderad. 'A nurse may be going through her daily activities, functioning effectively, relating humanly, when suddenly she is stopped by something in the patient. Perhaps a look of fear, a tug at her sleeve, a moan, a reaching for her hand, a question, emptiness. In a suspenseful pause two persons hover between their private worlds and the realm of inter-subjectivity. Two humans stand on the brink of the between for a precious moment filled with promise and fear. With my hand on the door knob to open myself from within I hesitate, should I? Will I let me out, let him in? Time is suspended then moves again as I move with resolve to recognise, to give testimony to the other person'. 
On the surface, this narrative could have been interpreted from the perspective of being with another, advocacy, privacy, respect, invasion of another's body, doing 'to' as opposed to doing 'with'. There were a number of themes exposed, but until I had felt my own experience of deception, I could not feel the lump in this student's throat. Until I could trust myself even more, I could not proceed further. For me, to love, at this level had meant to be deceived, and in calling myself to be love again meant I had to feel love. How then was I to allow myself to feel something [love] when the idea/rule/belief I held is bound in deception? How could I trust more when I believed that I could be deceived? I could only move forward by acknowledging my past feeling of deception. In that way, I was 'more free' to reach another level of trust that then translated into the allowance of feeling in order to come to know more, as a result of my being able to feel more deeply. In moving to this next layer/level of feeling love, so too had I then positioned myself to feel within that next layer or level anything that was not love.

I have said that we feel the same emotions. Our individuality lies in what meaning we then attach to that particular emotion at whatever level it has been held. I have said that for me to love at this level was then confronted with my reality that I could be deceived. That this was so for me had been evidenced as an outcome in my life/past. Therefore, until I could feel the emotion of deception and allow it, my reality would remain constructed in the idea that to love meant to be deceived. As process, until I was able to allow the feeling of love in response to this emotion this then is where I would remain. In allowing the feeling of deception, I could feel the particular narrative. That is not to say that I have never felt deception before. It was the depth of the emotion deception. To move from the surface to the depth of an emotion would be shattering and so in that way it is incremental until a particular emotion is experienced fully, as feeling. The emotion of grief serves as an excellent example, for only those who have grieved the loss of a beloved could claim to know grief in its fullest expression. And so it was for me with the feeling of deception.

In experiencing this emotion at a deeper level I was able to see that deception/the trickster in life comes in many forms. At the level of ego versus beingness, the game is always one of 
reclaiming/knowing one's divinity. The deeper/closer one gets to changing a particular perception of reality, the bigger the 'egoic hook' to keep one chained to that reality. In other words, the greater the resistance mounted by the ego. The distinction is always in the feeling, and hence the import of being able to identify one's feelings. By now I was now becoming more skilled at feeling my way around as opposed to listening to the voices in my head. By this time however, the voices, my mind chatter, had stopped chattering and had begun to scream at me.

I was sitting in my self-development workshop of about thirty people and the facilitator asked each person to stand, in turn, and list any attributes they admired in themselves. The task was to see if we could then observe when, what the person was saying was internally judged. I watched as each person stood and attempted the task. Most people got to a third or fourth descriptor before it was plainly evident that what was being said had an echo couched in some form of internal doubt or criticism and in that way was judged. When my turn arrived, I announced that I would not even stand to attempt the exercise. So loud were my voices at this time, that any endeavour to describe myself as committed, passionate or courageous would have been met with a resounding internal 'bullshit'. The duality of self doubt and confidence was being played out to the full, and so I knew that the only way to stop myself swinging from one side to the other was to proceed with my feeling work and in that way begin to silence the voice of self doubt. The facilitator offered me a tool. Whenever I heard my voice of self doubt, I was to internally respond with - whatever I do is OK. In that way I was affirming that I trusted myself and thereby empowered my self confidence, rather then my self doubt, and so could proceed with my work. Whatever I do is OK, whatever I do is OK, whatever I do is $\mathrm{OK}$, did not silence my self doubt, but it sure turned down the volume.

\section{Journal entry}

In my experience with deception, I also had more clarity about outcome as intent. What is experienced in life has been the intent, and therefore I more fully owned that I was creating my world by what I thought/believed. Most thoughts are unknown/unconscious. I have used the example of my conscious and unconscious intent in undertaking writing a thesis to illustrate this understanding. Therefore, in order to change an outcome, evolution as opposed to revolution, is to place one's awareness on the process, even though the focus remains on the unconscious or conscious intent/goal. This distinction is important. 
I came to appreciate that, by working in the now, I was making my unconscious intent conscious by being in the present. Given that most thought is unconscious, then in order to make conscious an intention/thought is to place the awareness on now. By experiencing the now moment, then and only then can I create a new now that is different from my previous experience of now. The same applies if the goal/intent is conscious; for example the intent is to interpret the narrative sitting on my desk, my focus is on my goal but my awareness is placed on what was occurring in the moment. The outcome is the intent until such time that the intent is changed by experiencing an emotion in the now. And the closer one comes to this point, the bigger the egoic hook will present to serve to limit this process of changing reality/consciousness.

It was almost the end of the year. Since childhood, the period between the end of the school year and Christmas would see me in bed sick. In that way, I managed to miss out on the fun/parties/festivities that occurred at that time.

I was at my drama/self expression class. My group had been given two minutes to come up with an act. We decided to tell the story of Snow White - in our own way. I asked to be Snow White, a part I had missed out on in pre school and had been offered the part of the witch instead. This was the source of much shame as a five year old, because at five I had my very own construct of what it meant to be a witch - you were a very very very bad person. I remember declining the part of the witch and chose instead to sit cross legged on the floor, head bowed, and eyes closed for the entire activity. No coaching by my teacher would change my stance because I was absolutely mortified that I could be considered to be a witch. I felt totally shattered.

And here I was - forty year later and I had my chance to be Snow White. We decided to see if we could make it up as we went along - no script or plan. I set my intention to have fun. And I did have fun - the audience rolled around in hysterical laughter. When I was asked how I felt about my part in the play I shared my trauma as a five year old and hence my desire to play the role. I said that I had set my intent to have fun and had enjoyed myself immensely sharing that I had in fact curtailed my hilarity for fear of taking over the whole scenario/play. I was feeling good about me. Four days later I walked into a one-metre hole and injured my right leg severely. It was ten days before Christmas.

In early February the following year I sat in an audience that was to be addressed by an Ascended Master. There I sat, my left arm bandaged and in a sling after having had the plate and pins removed, for the second time, from the now healed compound fracture. In my right hand I clutched the walking stick that I now needed for support following the pre Christmas injury. My left knee was stiff from the oncoming osteoarthritis as a 
consequence of the fall in which I had broken my arm and the added strain of supporting my body as a result of the injury on the right side. He began the evening by greeting each member of the audience in turn. When he reached me he stood there surveying my situation and then asked, "Have you had enough, yet?" I replied, "Yes, I have".

The next week I attended the first session of the year of my self-development group. To start the year we performed the ritual of washing one another's feet as a way of leaving the past in the past. We then had been asked to discuss what we had experienced, in this experience, and while I have no recall of the exact conversation, suddenly I was aware that I was reacting to something some-one had said. I sat, head bowed towards the floor with my eyes closed and allowed myself to feel what I was feeling. In this instance, I could not name the emotion. What occurred when the feeling subsided and I lifted my head to look at the group was, that the consciousness became plainly apparent - like a bubble rising to the surface. What became conscious in that moment was, that I believed that to have fun meant - in my case - I had to get sick. Some-how, in my creation of reality, I had associated the word fun with some sort of negativity. How I had lived that out as child was through respiratory type illness, tonsillitis in particular, that could be timetabled as a pre Christmas event. I learned to really harness/limit the energy of anticipation by repressing the energy of excitement. I would not allow myself to look forward to something/event. As 1 had started to change in the course of the research and allow myself to feel more joy/fun, I started to break bones and injure myself. Now I had a new consciousness. The unconscious intent was made conscious. I was free to feel fun/joy without getting sick. I could consciously set my intention to have fun and create that as outcome - without 'paying' for it.

I suspect that my Snow White experience as a child was bound in some joyous anticipation of the event that, when met with the actual experience, set the pattern in motion. I do recall vividly, that same year, lying in bed in raptures as my eyes gazed upon my satin blue gown hanging on the door ready for the Sunday school Christmas pageant. I had the role of Mary. My costume was so beautiful. I could hardly wait for the event. Christmas Eve did eventually arrive but by then I was not able to lift my head off my pillow for fever and tonsillitis. Even so, I cannot describe the disappointment as my precious Mary gown was removed, and given to another little girl. By then I knew that to have fun or be in joy extracted some sort of payment, the outcome of which would be disappointment. Thus I created this reality, where the unconscious intent was not to have fun, but to reify the idea that life was joyless.

Journal entry

Now I could clearly see that the data [narratives] served my unconscious intention as opposed to my conscious intention which was to undertake and complete a $\mathrm{PhD}$, and that my unconscious intention was being revealed to me in increments or steps as outcomes through a process of being that was pivotal in feeling emotion. Where it was not a mere matter of just picking up a narrative and feeling, but that my life and the narratives were 
intertwined. This intertwining then served the process of being. The narratives were a field, in the same way Rogers (1994) conceptualised the human field, that then placed me the researcher, the students, patients and their families and other hospital staff together, so that we might 'thing'/process. Thus I began to grasp the Heideggerian (1968) notion of thinking, in which he claimed that we cannot not think, because we 'thing' in order to think. Our lives, while an individual creation, as outcomes of acts of creation then determines who or what is drawn into our lives as a field of experience to be experienced. Consciousness is changed in the now/present by making new choices about what is felt. In this way I came to understand what Heidegger (1968) meant when he said we cannot, not think. We are free to keep thinking the same thoughts, but we are not free, to not think. In my coming to the realisation that life is a process in which the data, researcher, students and patients coalesced as a field of experience to be experienced, I could appreciate that we are an aspect of the One, as well as the One, reflected through and by each other. How this occurs was the project, and is the subject of the thesis. Now I was able to let go of my uneasiness about not doing this research properly because I had broadened my definition of data to include everything and everybody.

I have said that the data serves the intention as outcome through the process. What I have not stated clearly is, that I take the position that we are intention - thought. In this way, I brought myself to the understanding that by engaging in what I now termed a process of being, through feeling an emotion as a response to being, what I was doing was making conscious my unconscious thoughts/intention. As such, I was recreating my reality by thinking different thoughts.

I had learned how to open the space consciously/willingly and so exist for moments in timelessness. By seeing beyond the illusions of past, and future I was tapping into Universal Mind/Source/God as a frequency of consciousness. In its expression what I was experiencing in those moments were, greater depths of the feeling of love/bliss. The ultimate goal/intent as outcome more realised. Each time I stepped out of my self imposed history/past by experiencing the data/life as a field of experience held in the now, I had the 
choice to experience it anew. Each time I made the choice to do so, the intervals between those moments of One decreased.

In choosing to experience life emotionally, in the first instance, I could afford the opportunity to change my perception of the world. While it is generally recognised that perception is not an all or nothing thing, as a process it is to be able to take the next step and then the next and so on. I recognised that one's perception of reality does not change in one movement. In each step it is intention and outcome created as process in the human experience that begins to recognise how to become one with the flow. Where the particle and the wave, or observed and observer are one, because they are the same. Thus, the outcome is the intent realised and the data an instrument to serve that end in the same way that life serves that end, not as an end but as an opportunity/gift to become more.

I also came to learn that the narratives could be multilayered, that is, that they contained more than one layer of emotion. In some instances, the emotions were processed/experienced consecutively or sequentially. In others, a narrative had to be revisited later. In this way, data interpretation is not only from one place in the circle to the next, and therefore finite in the sense of a distinct beginning and end, but interpretation is crossways and sideways and thus flows in all ways. This insight was challenging at first, and as such I asked myself was I doing this research properly? In allowing myself to proceed in this manner I came to see that it could not be otherwise, because I realised that a wave of creation is not confined to a single direction. Therefore I became more confident in literally putting a narrative down for a while and moving to another, and in following my intuition silenced more of my self-doubt.

What determined when to leave a multilayered narrative because of the need to shift/move/change something in me before I could experience the deeper meaning in a particular story, was to be even more honest with myself. I translated this experience into becoming aware if I was 'being willing', or 'making excuses'. To make excuses is to use 
reason, and in the human condition we use reason as a way of avoiding feeling, or engage in certain behaviours to reinforce an old feeling and in that way affirm our existing reality.

In the second year of my project, I facilitated a group of women who were interested in exploring what we called our weight issues. One of the activities we undertook was to keep a food diary. For me this exercise revealed an interesting point. In conjunction with the research, it became evident that when I was fighting something emotionally I would crave sugar. The greater the resistance I mounted to not feeling an emotion, the greater the sugar craving. I would now argue that excesses of gambling, tobacco, caffeine, alcohol and sex are all cravings that have the same basis. When I had processed a narrative as much as was possible, I always felt a sense of balance or completion in which there was a feeling of contentment and peace. When there was more to be dealt with, I was irritable, non-focused and hungry. If I craved sugar and wanted to bury a particular narrative under a pile of papers on my desk, it was a sure sign that I had not processed the emotion. While for some this might appear trivial where issues of ontology, epistemology and methodological questions are at stake, to this day a sugar craving remains my clearest indication of how I am being in the world. It is also fascinating to watch for the moment when other people reach to light up a cigarette, have another glass of wine, need a cup of coffee or crave chocolate.

I have already said that the data is both intent and outcome through the process. When the data is viewed as unconscious thought yearning to become conscious, that is, intention, then as I will explain in the body of the thesis, the human field through the aura is magnetised [it attracts]. The field acts as a magnet to draw forth all things/conditions [gathering] which will serve to assist in making the unconscious conscious. In this way, as the thesis reveals, thought is termed 'confused', in the Aquinian (1267) idea, until it is made 'unconfused'. In understanding this I confirmed again, that what guided me to and from a story was my intuition. And while I had to a point followed my intuition thus far, I now was challenged to allow more of my intuition by trusting my intuition and so identifyied that my intuitive knowing was guiding the process. To allow this meant, 'laying down' my 
intellect and 'picking it up' again in order to communicate what I had discovered. To move into an intuitive space is a skill. How I learned to recognize my intuition at work occurred in multiple ways.

First, I had to learn to recognize when my intuition was urging me to follow a particular direction. At times it is as if a single object or person stands out amongst objects or people; the focus is sharp and clear eg. a book on a shelf, a page in a book, or a person in a group. I had to be able trust and follow this direction. In essence, I was learning to trust and follow myself. Sometimes this meant that what was to be experienced was apparent quickly and at other times is was a step to the next step in the process. The step to step experience was the most challenging because there was no immediate outcome to reinforce having made the right choice. There were other times that I would hear a line in a conversation or a piece of music that would resonate so clearly that a direction then became evident. And when presented with options there is just a knowing of which one to follow. Then of course there are the hole-in-one moments where "the loom of the mind activates and the shuttlecock of memory weaves old and new associations into a Eureka!" (Houston, 200, p.51).

If an idea or option presented itself and I became excited, then I learned that that was my intuition at work. This energy opened a whole new vista, another territory to explore. In the experience of working with the energy of fun/joy not only did I change the old pattern of creating disappointment, made evident in sickness and injury, I had opened myself to more. Where once I had learned to restrain my being from feeling the energy of excitement or anticipation because that then had particular meanings, why get excited or look forward to something that could end up in disappointment and, having fun meant that you had to get sick, now I was free to unleash more of the creative force within me. How does one create without foresight/forethought/intuition? I began to recognise and allow this feeling of excitement/anticipation to guide my work. I say began, because my ability to listen to my intuition was still challenged. The feeling of anticipation can be overridden by feelings of anxiety/dread/fear that act to disconnect the self from the self and therefore 
one's intuition. The ego is always at work. Wherever there is an attachment to the outcome of something the ego can enter the arena. Intuitive flashes are just that, flashes, and the reactive mind will respond as quick a flash when what is intuited is outside the known reality. And thus the only way to work with this is to be acutely aware of what is being felt in the now moment. The process remains the same. To acknowledge a feeling is to validate it, whatever the feeling. This then is what I consider to be an act of love. For in loving the thing it is changed/transformed in that moment it is loved.

When I made the choice to pursue a particular path, regardless of what that path looked like, the feeling was sometimes one of certainty and others doubt/fear/dread. What I finally came to appreciate was that the more I said YES as opposed to NO, the more I invited my intuition into my life. I wonder, how often in the human condition we say no instead of yes because the old responses can and do kick in. Like anything, it takes practice.

We were asked to give twenty cents to a stranger with no explanation. I offered the coin and it was readily accepted. I then decided to increase the amount to a dollar.

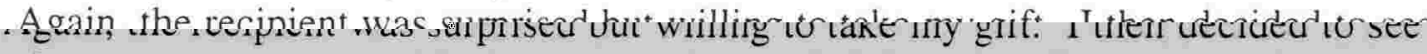
what my response would be in the experience of giving away five dollars. The first person informed me that she could not possibly accept my money. I was not aware of any reaction within me. The second woman looked at me sternly, and in response to me saying that I would like to give her some monies, she loudly shouted "No". I felt shattered. The third women vacillated between saying yes and no until I told her that this activity was homework as part of my self-development course. Then she readily agreed announcing that her daughter was a psychologist. The daughter joined us and concluded that her mother had accepted the money because she was Irish.

\section{Journal entry}

In my learning to listen to my intuition, I offer the following to illustrate how it could take me days, weeks, months or years to connect a particular set of dots. And in hindsight, I would say, trying to connect the dots is an exercise of the intellect. The dots connect themselves in their own timing. In hindsight I can see that I had called myself many many times to follow/trust that part of me that knew, unwaveringly, where I needed to go and 
what I needed to experience. With each experience I was learning to surrender more easily, with grace, to the greater me.

I have had a week at the Hospital and University like you would not believe! The word trouble would be an understatement. I am clear about my actions but the consequences could be huge. It is Saturday morning and I have hardly slept. I force myself to go and do the grocery shopping. As I walk around the supermarket in a daze, my head spinning with any number of possible outcomes, I recognise a voice singing over the broadcasting system. It is Bette Midler, but I have not heard this song before. I stop still, my hands gripped on the trolley and my head directed upward at the sound speaker. As I stand motionless in a supermarket aisle listening to a song, it is the chorus which just about brings me to my knees. God is watching you, God is watching you -from a distance. In that moment I knew that whatever the outcome of my actions, my choice to act was what I needed to do. The fear of what might happen had less power over me now because in that moment I knew that whatever the outcome I had followed an inner direction that in no way could be harmed by any outer occurrence.

Journal entry

Justin's story seems so simple, or so I thought. I considered myself finished with that one. Why am I so stirred up by the death of Princess Diana and intrigued at the timing of Mother Teresa's? Every time I think I have finished with this story somehow it makes its way to the forefront again. And then I remind myself of a comment I overheard while walking behind Nancy Diekelmann at a nursing conference, it took me four years to get to the bottom of that story - and when you present it, it seems so simple ... it was the notion of the four years that was reverberating in my brain. Again, I needed to go to Justin's story.

Journal entry

I was offered the opportunity to make a drum. I said yes to the opportunity. Some months later I considered taking my drum into class and showing the students. Maybe I could do a body drumming? What will other Faculty members say when they hear a drum banging out of my classrooms? Will I or won't I do it? Yes, I will.

Journal entry

With each choice comes an outcome. The outcome of taking my drum into class appears below. The outcome of Justin's story appears in the body of the thesis. The outcome of my having lived that week at the Hospital and University is mine to know. The point is, that 
when one follows one's inner voice - no matter how the circumstances might appear, there is always a purpose and always an opportunity to become more.

\section{TO FEEL THE CONNECTION OF CHOICE}

I thought about the water.

I looked at the way it moved. How placing one droplet on another caused it to get bigger. However that one extra droplet would make the first droplet disappear, the force or weight of it seemed to break the circular drop, and the droplet would roll away.

I then parallel this to myself.

Have I been droplets that have grown inside until they could no longer bind together, and in that point in my journey the droplet could no longer stay as a droplet - it changed.

By lifting your hand out of the water, at the base of your fingers droplets form. They've come from the great collection of water in the bath. I took a handful of droplets out of the water bank. But they soon washed back into the main collection of water, either when I put my hand back under, or when they streamed away.

When I get out of a bath, water is on my body in droplets.

I shake some of them off, but still some stay.

That is why I grab a towel.

That is why anyone grabs a towel after being in water.

I then rub this over myself until there is no water, on my feet, between my legs, my back, my face.

I then turn and let the bath water out.

The main collection goes down the hole, into a drain. I don't know where that drain leads to.

I step into a bath full of water, and that water surrounds my body.

It touches the parts of my body that I want to get wet. For instance, tonight it didn't touch above my neck. Another time I might wash my hair. Another time I might only soak my feet.

I then get out of that bath, that water, and dry myself off.

Am I the same person once I have done this?

What stops me from allowing myself to be wet? 
I am writing this tonight following our experience today. Today felt very special and I would like to share this with you, my feelings now hours after the tutorial.

Together Janet and I shared our feelings through a poem [above] and the way Janet expressed its meaning truly touched me. Nicki created with the pink dough, Julie with the green created a hand. Sophie used the orange. Kelly cut out some figures of people. Sally did the same and put glitter on one person. Heather created with the earth and the glitter and wrote the words love, wings, freedom and journey. Lyndal expressed through poetry. Michelle wrote her expression and placed it on her window which she had made and brought to class. And Marina, you wrote your expression - I'd love a copy of it, the words created such a feeling - we are but children!

I then played your drum. And what I felt when I banged the rhythm that came from within. It began to envelop me, all I could hear was the drum and the rhythm. There was so much energy.

Last week you brought the drum to our class for the first time [just as I write this there is an African drumming on the television - amazing hey!) You did a drumming with Janet and you then asked if any-one else would like to be drummed. And do you know that I sat there and I really did want to experience - but my fear - of what others might think, what I was thinking about them, stopped me in my chair. How often I allow this little voice and its feeling to stop me from an experience. Yesterday I plucked up the courage to ask you to bring the drum again. And today, well you experienced today too. So you know Kellie played her rhythm. Nicki beat it out on the drum. Sally played. I felt that I could have beat on that drum forever today. It was grounding, yet it was releasing - just a bit of anger is out now.

I felt safe today with our group. Safe enough to get up and sound my flute again, safe enough to feel the drum even though that little voice niggled at me initially. Even though I did feel afraid, I went with it. It was so special. I've written this poem in response today, and I'd love to share this with you. Today I can see my understanding of the words, of what they mean for me. What this experience has touched in me -

We started out with a poem and some music

Words placed to express

Sounds arranged to be heard

How are the two connected?

They both are what I, what you feel

What you, what I know 
We expressed our expression

The creation of our creativity

We then extended our energies to you

As you extended yours to us

To you, your inner being

To create, that which is within you.

You moulded

You cut

You placed the earth and glitter to paper

You felt the dough

You felt the pencil within your fingers as it connected to the paper

Your creativity began to move

And yes, you too

Used your creativity as your expression

And the drum

Oh the drum

When it was first bought in and introduced

I heard the beat

I heard the tones

Today,

I made the beat

I felt the beat

I felt the rhythm

I heard the tones

So many tones

I felt the movement within

I felt the beginning of my release

Others played the drum

I heard their rhythm

Their tone

Their sub-beat

My sub-beat

I put out for that drum

Put out for your drum

Feel the rhythm, the pitch, the beat, the tone, the sub-beat

Even hear beyond that sub-beat

There is more

That resonating sound

The very feeling that surrounded

Created by each individual 
To experience the very experience

And it was safe to feel that piece of fear, anger and vulnerability

The very essence of life

I know that I am here

Growing

I know that it will come

Knowing

Listening and hearing in a new way

I begin to release

I now acknowledge that to begin to feel

Really feel again will and is occurring

In my own time

In my own space

Within my own journey

It is my knowing

That I experience myself, my experience

What will come, I need to learn

What will be is my creation

My journey, my creativity

I felt my soul today

It is my drumming and my beat

Me, that will unlock the silence

I am finding my $\underline{\text { drum }}$

Is it in finding my drum that others will begin to play the rhythm upon their drum, that they too will discover?

Thankyou and with love, Christine Student

I have said that my life prepared me to undertake this work. Listening to one's intuition takes practice. At this point in the research I was being challenged to let my intuition do even more of the driving. I could still resist following the flashes of intuitive insight or particular gut feelings directing me to do or proceed in some way. The notion of the interconnectedness of all things allows one to position oneself in such a way that one is more observant and open to life. I was open. I said yes more than no, and in the allowance of all things allowance I was then inviting the opportunity for even greater awareness. To be aware of something is to be alert, and in that way 'be' a particular state of mindfulness. 
In retrospect, I can share some of the experiences that have served as 'training' to listen to my intuition. Without my having said yes to taking the drum into the classroom on that day, I would not have held the pattern that then in the course of interpretation in the research process assisted in another movement in thinking. Another opening of me to me, to more of my inherent knowing.

In this way, I have attempted to show how I learned to listen to my intuition more. How I have inserted the journal entries, poems and letter to illustrate my intuition at work does not reveal how the experience as a whole shifted my thinking. That is bound in the key to this whole work where, in putting these pieces of stories together for one purpose the new bigger story evoked an emotional response in me. In experiencing this emotionally, I made a leap in thinking. As I edit the work yet again and in the ensuing space having experienced more I could say more. Suffice to say that this serves as a reminder that the process of becoming is never ending - that there is only more.

I feel Heidegger (1926) was conveying this willingness to follow one's intuition, in his idea of ready to hand. Where 'to be' ready to hand, is to position oneself in readiness 'to be' present at hand and therefore hold the possibility to become more. Before one can be present, one needs to be ready. How then did I ever know I was ready for something? I did not, but what I did know was that I would never call to myself something that I did not have the potential ability to deal with, no matter what the experience looked like. This then is trust in action.

It is also a state of mindfulness that knows that cause and effect means to take responsibility for both creating, and having created life. In that knowing I began to grasp that what I gave out is what came back to me. In the experience of the drum I took my drum into that room with the energy of love, expressed in the experience of sharing a drum. So while any number of drums can be taken into any number of rooms, the result [outcome] will be determined by the intent as it is lived out in the experience. My intention was evidenced in what came back to me. My experience of this was that only in 
working with the letter and poems some five years after they had been written, was I able to receive what I had been given. I could allow my self to feel the love expressed. The love had always existed. It was my ability to receive love that had changed.

In this giving out, as the thesis will explain, our unconscious thoughts as patterns of energy are returned to become our fields of experience in order to either create the same thing or a different reality. More love is a different reality. The love I remember feeling for my golliwog as a child is different to the love I now feel when I gaze at my two-year-old pug dog, snoring tucked up under his doona/rug/blanket. It is not a comparison of love; rather, it is an expression of a depth of feeling. To engage in life in this way is not a choice, for as I have already said we are intent/thought. We cannot not think (Heidegger, 1968). Therefore, choice is a form of allowance that then allows the self to be supported by one's intuition, and to then make a choice to respond to life as emotional experiencing. When we judge the outcome, make an appraisal of the outcome, it is a judgement of our act of creation. Then, not only do we close ourselves off from ourselves, we are also less likely to follow our intuition the next time we are ready to experience more life.

My progress by the time I had connected these ideas was that I had four draft chapters in the thesis completed, none of which looked like they were related to each other. I had also written a couple of conference papers which explored critical ideas that had surfaced and were then incorporated in subsequent chapters. While I was comfortable with what I had 'uncovered' to date, my work had brought me, naturally, to a very grand research idea. I had arrived at the idea that if we were intent and had the potentiality to change feeling and in that way change thought, then this was an act of creation. While I did have the full ramification of what I was saying, I touched upon enough of the idea that, as creator energy who we are, who I was, was God. To argue a lower case g or capital G was beyond my grasp. Having arrived at this point was mind blowing in itself. Once again, as is the nature of this way of working, I had placed myself face to face with my own fear/illusions about reality. And as I was to encounter a myriad of times throughout the research, when I had come to the place of beginning to feel a fear within me, to recognise movement within 
my own body, then I began to appreciate that I was ready to face that fear through an experience of life.

I began this paragraph by stating my interpretation of Heidegger's (1926) ready to hand. In the awareness that everything in life is connected, that nothing ever just happens, and that there are no accidents, I have argued that one learns to becomes more observant and aware. As such I understood ready to hand to then work with what presents. I have also made the claim that the research process is equally valid when sitting at a desk or walking along the beach deep in thought. It was time to attend research school, which then was in Sydney, and present my work in some way so as to ascertain progress and receive support.

Note: I started out with a collection of narratives about nursing and somehow have managed to bring myself to a point where I am going to claim that we are God; god or God I am not sure. I have come to this position through the notion of Creator Energy. And while this revelation is crystal clear to me, the idea of speaking to this idea is nauseating. I know that when some people hear the word God it is a real turn off. Yet, to really express what I want to express, I can't avoid using the word. I know what I want to say at school this time, but I am not sure how to begin the discussion. How do I begin to talk about human beings as God by virtue of our ability to create our lives that avoids the traditional Christian philosophy of a man in the sky with a beard and a rule book holding a big stick?

I had pondered this question as I left my home at 4.30 am to get to the airport and catch an early morning flight to Sydney. I was now thirty minutes away from school and still had no idea of what I was going to say. I felt ill, at another level however I was ready to hand.

Mallet Street, Camperdown please.

Oh, you are a Nurse?

(Here we go)

Yes, I am

Are you studying then?

(This one is not going to let up)

Yes. 
What are you studying?

(This should keep him quiet)

Health, as it relates to consciousness.

Is that your $\mathrm{PhD}$ topic?

Yes, it is.

Oh, so you believe in God then?

(Bingo, hole in one, he's got it, now where will he go with this?)

I don't believe, I know. (I couldn't believe what I had just said!)

Yes, I was a student too; I was born in Iraq and studied in Yugoslavia. The children are taught from the age of six, (as he gestures a height level with his left hand), that there is no God. Even the courses at the University are taught from a Marxist perspective. Well - one day we were in class and the Professor said - there is no God! There is only evolution. Now we (the students) were all Muslims, and so we believe in God. So one of the students says, Professor - Darwin developed the Theory of Evolution, but Freud's Theory was about The Self - was Freud wrong then Professor?

And the Professor responded to this with: Well it is like this, a tree grows in the forest, it is then cut down. As wood it is made into a chair, but it has been a tree.

But Professor, how did that chair, which was a tree, become a chair?

Well, that is easy! said the Professor. There was a Master Craftsman who turned that tree, which was and still is wood, into a chair.

I see, Professor, said the student. If that is so, then how and who do you suppose made me - and this body?

While I suspect his idea of God was still couched in images of the man in the sky I had been handed my starting point.

Journal entry

In conveying this experience, what I want to convey is that I had reached a certain level of insight of how to proceed with my work. That insight was not directed in thinking that revolved around the use of logic or intellect but was thinking that was directed by my ability to tap into consciousness to convey truth through language at whatever level I was capable of tapping into. At this point what I had tapped into was the idea/thought that we are God, and I regarded this possibility as frightening. In setting out with my boxes of data 
I could not have entertained for a moment that my work would take me here. To arrive through the notion of creativity that we are God was 'mind blowing'. And while it was one thing to make this discovery in the privacy of my home to make such a claim in public was very challenging. Therefore, I could have spoken about any number of things at the school and in that way side stepped my issue, but I knew that to be real/honest with myself I needed to speak about this. I had couched my fear in how I would begin to explain this idea at Research School. I was then presented with an opportunity. That however did not change the fear.

To arrive at this point I had wondered what will I say and then let it go, with no attachment to an outcome. I was in a taxi on the way to school before I had any idea of how I might present this. At an energetic level I had magnetised my field to draw forth everything that would assist me in my intention. I had called this one taxi driver in the whole of Sydney to me. By engaging in process, facing my fears, and being 'willing' to do, I was ready and so had opened the space to allow support to come from - wherever. An Iranian taxi driver. Now, having taken one step would I take the next step of facing my fear about talking about God in the context of Research and Nursing? If I had not, I now understand how I would have recreated the experience. Until I was willing to feel whatever it was that was attached to my thought that then held a particular meaning constructed in the idea of talking about God my consciousness would remain locked into this particular reality. In this way, I hope I have further clarified how the research is lived and in any moment we choose revolution or evolution.

At this point I could insert any number of nursing stories that illustrate facing a fear by doing something that is a challenge. A fear is only known by the being experiencing a particular fear. What is terror for one can appear trivial to another. By inserting the taxi driver dialogue what I wish to convey is; how we are supported in this process, that we never call forth something that is not possible to transcend, intuition at work, how beingness will be contested by ego through fear, doubt and judgement as a means to maintain the known reality, and wondering and letting go as they relate to intention, 
outcome and process. In the moment, that one willing to be more it is as if the universe rearranges itself to accommodate the change. The outcome is to have evolved rather than revolve. In choosing to evolve, the view becomes more expansive. I came home from Research School ready for more, and with a greater confidence at being able to navigate myself through my work and my life.

In coming to realise that everything is connected, I began to 'think' more clearly. In my facing the fear that presented in the experience of speaking about God, what I had transformed was a level of thought that believed that I could make a mistake, or get this work wrong. This belief then has its own construct of the outcome of making a mistake of this magnitude. This, together with the earlier realisation that the data works upon, made it clear that it was not about having to think out or engage in analysis to find answers. Rather, it was about allowing the answers to come to me. To be open to this possibility I had to go or do what intuitively I was calling myself to do, recognising that in each now moment I could choose. So whether I felt drawn to read a certain book or journal, attend a presentation or conference, meet with a friend for lunch, go to a movie, make a telephone call or even take a walk along the beach, there was in some way, always, the potential to be open to more. To allow the flow to flow. Where the purpose, all ways, was, and is, to do just that, reveal more.

Throughout this process of uncovering, I perceived myself to be engaging in phenomenological inquiry. Initially, I languaged my project activity as phenomenological thinking that was then translated into phenomenological writing. In walking the reader through how I unfolded this research, I have thus far attempted to show how I engaged in processing my thinking by revealing some of the insights that result from this way of processing narratives/life. In processing an emotion, I labelled this activity thinking. The writing of the chapters, that text that follows this chapter in the thesis, resulted from my emotional processing. This distinction served to produce the work.

The text as phenomenological writing can be questioned. The crafting of the words themselves, is an activity in itself, and one that has had its own challenge. While I have 
continued to refine the work, that refinement has not been from the perspective of a lateral shift, that is, the addition of new ideas, rather, that refinement has been a vertical one where the existing ideas have more depth and as such the wordsmithing has evolved from both an intellectual and inspired space. In working in this way, I continue to be astonished at the ongoing ability to fill in the spaces, as I continue to process life. At the same time the experience of it is a wonderful validation of the process in action, for it is not a matter of being able to tap into consciousness, it is a matter of how much. To then claim that the style of this work clearly illustrates phenomenological writing would be misleading.

To this end, this chapter of the thesis is structured to show process in such a way that it is a sufficiently clear exposition of the process/methodology, and at the same time not a prescription of how 'to be'. To convey some of how I did my 'thinking' has been a challenge, from the perspective that I had had to reveal myself. The narratives have served as my mirror. They have been my "YOU cannot be ANYTHING in the space of that which YOU are not" (Walsh, 1995, p.55).

The project has encompassed seven volumes of journals, travelling to the other side of the world twice, jumping off a ladder into the arms of six willing friends, and reading across many genres. To perceive being as a form of mere introspection, or type of contemplation as it relates to intellectual thinking bound in beliefs, is to perceive an inquiry that remains fixed in the human capacity to reason. To perceive being from the perspective of having taken myself to wherever and done whatever as acts of being, where the purpose was and always is to feel, and from which arises a natural consciousness about the nature of being, will challenge those with a vested interest in understanding being as a code of attributes and practices to be emulated.

As I have already said, the starting point will be determined by the intention 'to be'. The start felt like I was working with a jig saw puzzle that could be begun from many points. I felt that I had a number of groupings or pieces of text that initially do not reveal much of a bigger picture. The initial five chapters of the work illustrate this point. They stand as five separate 
essays. Chapter five was written over a four year period and I still perceive there is much more to reveal in the comparison of cellular function and blackhole particle activity as it relates to being.

The challenge then is to trust and continue to follow one's inner knowing. Even as I write this summary this need to trust my inner teacher/guide is still challenged. I used to agonize how my work would 'fit' into academia that then challenged my ability to trust. Being trust has been one of my greatest challenges. Yet without trust I could not have walked this far.

So while I had enough trust to piece together five chapters, even when I could not quite see an overall pattern in the draft stage, I challenged myself to trust even more. Until I worked even further with the notion of trust, for like honesty trust too has many levels, I could not proceed with the interpretation of my narratives by experiencing them emotionally. I had reached the point I regard as 'hard bar', that until I embraced it, would result in the work proceeding at the same level - onward and onward, rather than onward and upward.

When it comes to the human record we only have to look around us to see ample evidence for cultural jumps ....... Take something as simple as accounting. From the abacus to the ledger book is not a great jump - just a few way stations of records on clay tablets and papyrus. But from the ledger book to the spreadsheet is a jump so huge it boggles comprehension.

Houston (2000, p.30)

I had to jump. Yet the process for jumping a 'hard bar' or going through a wall is the same as that for the smaller hurdles. I identified the difference as being the passion with which that illusory hard bar appears to be real, and therefore the degree of resistance generated in avoiding feeling that particular feeling. My ability to trust was attached to some illusion about trust, and until I let another level of that go, I could not proceed. At was at this point I jumped off the ladder - twice - and then took myself to The United States to present some of 
my work at conferences in New York and Chicago. I returned six weeks later having had a wonderful trip and with the beginning understanding that, I was ready to experience more of my fear of not being approved of. I had grasped the idea, beyond the intellectual level, that the only approval I really needed was self-approval.

At the breakfast meeting at the conference in Chicago I had managed to get myself involved in a discussion on interpreting stories - and so there I stood. Patricia Benner had invited me to explain my point of view. There I was in front of a microphone surrounded by a couple of hundred people eating breakfast attempting to tell them how to feel a story. It wasn't going so well, and in the course of my explanation I decided to illustrate my point by actually telling a story - I told this one.

I was a student midwife working in a nursery and the time had come for one of our charges to be picked up by his adoptive parents. I had cared for this baby boy since birth - purchased clothing for him, washed and ironed that clothing so he did not have to always wear 'hospital uniform', fed him, rocked him and walked him in his cot in the sunshine on the large balcony around the hospital.

We received a phone call at $3 \mathrm{pm}$ one afternoon to say the couple would be there at four thirty to pick him up. As I fed him and changed him for what I thought was the last time I watched anxiously out of the window as each couple approached the hospital front door. What I was doing was inspecting them to determine if they were suitable for this child! Well, four thirty came and went as did five o'clock, six o'clock etc etc. I was shocked. What sort of prospective parents were these?

On duty at seven am the next morning I received a call from the Director of Nursing informing me that the adoptive parents would arrive at $8.30 \mathrm{am}$. I would be handling the 'procedure' she said, as the Sister in Charge of the Nursery was off sick.

At 8.25 am the nursery door bell rang and a couple stood before me with the appropriate documentation in hand. I introduced myself. My role was to do a bathing feeding demonstration, answer any questions and escort them to their vehicle.

At the point when I was about to dress 'David' I said, I cannot help but ask - we were expecting you yesterday, why didn't you come? The wife responded to my question.

We received the telephone call yesterday afternoon at $2.30 \mathrm{pm}$. We have only been on the list for eighteen months and they told us not to get anything ready for a baby for two years - so we had nothing for a baby - absolutely nothing! So we rushed to the shops to get some things and by that time it was too late. So where did you get this beautiful knitted layette? I couldn't believe the question that popped out of my mouth! There was no reaction. Again, she gently responded. 
Oh - something just made me start knitting the hat and booties at Christmas time and I had only just started knitting the jacket - my mother had begun the shawl - and so after we got home from the shopping yesterday, my mother and I sat up all night - last night to finish them. Every baby in our family for three generations has come home in a layette in this pattern. My baby wasn't going to miss out.

And then, the husband, as if to answer my unspoken question said - and I am a milkman - and I have never run so fast to do my delivery round as I did this morning.

I layed out the shawl into which I placed a brand new bunny rug. I then wrapped David up and placed him into a mother's arms. I handed the father a small plastic bag with a dummy and waterproof pants inside.

I handed 'David' over - emotionally, as well as physically.

I am here in this nursery for another three weeks, if you have any concerns please ring. We call him David, so use his nursery name, and we will know who you are .....

About a week after the adoptive parents had taken him home the nursery phone rang .....

Marina speaking - Oh good Marina it's you - this is David's mother speaking - and then she paused as if she was deciding whether she would continue - yes she said, I know that we are supposed to keep it confidential but - I am telling you - we decided to keep his name as David. Now what I rang for was ......

Journal entry

In writing this story down twenty five years later it still invokes such profound emotion in me. On the day I told it in an auditorium in Chicago I was unaware of any reaction or response by any other delegate. I then felt what I felt. I took myself to the swimming pool at the end of the session and sat in that pool for two hours. I felt disapproved of. I had taken myself to the other side of the world to feel this particular feeling.

I was now ready to interpret this student narrative.

The story I am going to tell today is of a situation, an encounter, this semester which probably changed my outlook towards life and showed me the importance of the unspoken language, body language and reading somebody's eyes and everything.

The patient I'm going to refer to today, I'll call him Alan just to keep him private. It was my first day on this particular ward. It was the very first day of the semester actually so I was really nervous and I didn't know the ward's routine, I didn't know where anything 
was and I felt like I was going backwards. I was allocated this room and it had three gents and they were all admitted for the same complaint, unstable angina, except Alan was the only one who was going into the Alfred for CAG'S, which is coronary artery grafting. And he knew this might fail because he's had it twice within the last ten years already and I walked into the room, I can remember walking into the room and standing at the door and looking around thinking, 'Oh shit, what am I meant to be doing now?!' and this one guy just stood out to me amongst the three of them - and I introduced myself to all of them and I went over to Alan and introduced myself to him and all I could see were his eyes. He had very sharp and definite eyes. They weren't cutting or intimidating, they were just very sad and desperate and he wasn't really interested in, you know, me, looking after him or talking. He didn't want to talk but I could tell that there was something wrong with him, but he wouldn't say what it was and it wasn't like, you know, he needed to go to the toilet or he had pain or he was scared of dying, it wasn't anything like that, it was much deeper - and it wasn't something that you could put your finger on.

As the day went on Alan showed his personality to me, and he was quite a very funny man. He was always laughing and joking around. He was a Scottish man and he had quite a thick Scottish accent and he laughed and joked and you know, made all these innuendos that he was going to race me off to the Mediterranean and he was just a really nice character. But when he was away from the other guys in the room and it was just he and I talking he was a very different person. We talked, for the three days that I was caring for him - we talked continuously and he was really interested in my life and what I'd done in the past and yet to do in the future and my dreams of life and expectations and everything. Every time I answered one of his questions he would nod and then he would go silent and I soon learnt that when he went silent that was the end of the conversation, we didn't talk any more. And he did this continuously over the three days and it was, I didn't know how to take him, because I didn't know, you know, what he wanted from me, yet he really wanted to know my dreams and everything. And he told me many different stories about when he was younger and before he migrated to Australia. He was in the navy and he went to many different countries and met many different people. And the way he used to tell the stories, it was like, he took you there to that country, you could almost feel and touch what he was experiencing. He was a very kind and generous person but every time he went silent, his eyes would stand out the most and his eyes would be saying something and they would reach out and they touched me every time. It was a continuous cycle of the same thing, over and over again.

It took me a while to understand the situation in Alan because I'd never experienced anything so intense in nursing before - but I came to the understanding I really believe that he was trying to compare his life to my life, although he was in his high seventies and I'm only twenty one! He was comparing what he'd done in his life to what I'd done in my life, and just making sure that he had lived his life completely and that he hadn't missed out on anything through his life. 
He told me about one story and it puzzled me for days, why he told me this story because it had no, superficially, it had no relevance. It was one New Years Eve, he was in hospital and one of the nurses brought in a bottle of champagne and he explained to me in graphic detail. He was standing by the window in the sun room looking down upon the bay and just watching the fireworks - and although I've just said that in a sentence, he told the story in about ten minutes and what I told you was every piece. You could actually see him standing and watching the fireworks, and I thought later, well maybe this is what he has been trying to tell me for the past three days - that he's scared that he's just watched his life go past and that he has been a spectator to his own life instead of being in there and doing things. He is not sure if he's just watched his life fly by?

At the start of every shift I used to walk into his room and I'd go around and say, you know, 'I'm caring for you today, if there's anything you need, blah, blah, blah, blah, blah', and every time, Alan used to jump up to his feet and race over to me and give me a big cuddle and put his cheek against mine and give me a kiss on my cheek and whisper in my ear so the other guys couldn't hear, 'Good'. And then we'd start talking and everything and seeing how he felt and what more stories he was going to tell me. Over the three shifts we covered so much of his life but not once would he tell me in words how he was actually feeling. It was, his mouth was telling me the words but his eyes were telling me how he was feeling and he didn't have to tell me in words what he was feeling because it was inappropriate and it would have been even more inappropriate for me to say to him, you know, 'How are you feeling? What do you think about this operation?' If I'd said that, he would have put up the barriers and that would have been the end of all of the friendship that we had formed.

Regularly, I thought, you know, I may have got in too close and too personal. I was talking about this patient to another nurse and she said in a friendly way to watch out, that I am probably getting too personal and too close and it's not good to do this and I went home feeling very unprofessional as such, and thinking, you know, if I don't do it this way I won't be able to help him in any other way because this is the way he is connecting with me.

Alan was discharged on Friday, as I was saying 'Goodbye' to the patients at the end of the shift and he came up to me and I said, 'Goodbye', and he said, 'Well I'm going home as well'. The doctor had just finished seeing him and I said, 'Oh well, that's really good and blah, blah, blah'. And he said, 'I don't think I could have stayed here unless you were working'. I thought oh yeah, you're just saying that to be nice - sort of thing and he said, in a roundabout way, he said, that he'd really enjoyed the conversation that we'd had and the process going on. And I sort of thought about it that night. I thought well, every time I went up to him it was another chapter in his life and it was like he was dictating his life and I was writing a book on his life, sort of thing. And with me he was working through all the different stages. Like through when he lived in Scotland and his family, through to joining the navy and why and through to migrating to Australia and marrying his wife and everything. Everything - was covered. 
The next week I went back to the ward and it wasn't the same, it felt quite empty being in that room without him there. You know I expected him, because you know, if I was making the beds he'd stand at the end of the bed and talk to me or if I was at the nurse's desk he would follow me down to the nurse's desk and start chatting away to me. Like there was no escaping this guy, and when I went to dinner he'd try to follow me to dinner and that was, 'I'll come back', sort of thing. And I got a message. Several messages actually, through several different people, saying that Alan was re-admitted over the weekend with more chest pain and that he was in another ward because all of the beds were occupied. And I thought, 'Oh God. Do I go and visit him or don't I?' You know, I'm not caring for him now, he's in another ward, he's somebody else's responsibility, what do I do? And then my clinician said to me, 'You know, if you feel comfortable about it go and visit him after de-briefing', and I thought, that was the first time I thought,'Well, yeah, I will and what I'd been doing is right'. You know, I just had that reassurance from someone that I'd been looking for.

And I went to see him and I looked into his room in this other ward and I was standing in the shadows and he looked up at me and he couldn't see because I was in the shadows, who I was and he had the same sad desperate eyes and I thought, 'Oh, all the work that we'd done, you know, the progress, it's just gone backward. And I stepped forward and he saw that I was there, and he jumped up and he raced over to me and he had tears in his eyes and I'm thinking, 'What's happening now?'

And we didn't talk for very long - but later I went back to the ward and then he came to visit me the next day and I thought, 'Enough's enough. You know, like I think I can see what you're feeling but I don't know for sure because I need some sort of feedback from you'.

And I said to him, I can't remember how I worded it - but I basically said, 'What are you feeling?' and he sort of looked at me in a shocked way and then he told me exactly what I thought he was feeling and what I'd read for the past three days. It was really eerie because he'd never said anything, it was just as plain as day in his eyes. In the different way that he looked and the colour tones in his eyes, it was just really amazing. And we didn't talk for long but I could see that he'd worked through his life and everything and he said that he's not scared of dying because he now knows that he has lived his life and he has, you know, done all these wonderful things that we had talked about - a bit and everything. And he said, 'If I die, well that's meant to be'. And I asked him, you know, 'Have you told your wife how you feel?' He said, 'No'. And I tried to get him to talk to his wife a bit and that, but he was really at ease with the situation that he might die. That this one may fail. And I walked him back to the door and I said 'Goodbye', and everything and he trundled off down the hallway and that was the last time I saw him, but I really feel deep down within me that I made a difference to him and I just hope that at the Alfred he had somebody else to carry on the last few, you know, steps. 
I can't remember his exact words but he said in words everything that I'd perceived him to feel and to think over the three shifts and he confirmed everything that I'd thought earlier and all the you know, the little conclusions that I'd came up with throughout the week, - he actually said verbally and it was really eerie to hear it back at you, that what I was perceiving was actually what he was feeling. He was searching through his life. That he was going through all the phases of his life and searching and making sure that he'd lived life how he wanted to live life. That he hadn't missed out on anything, you know. Like his story about New Years Eve, he wasn't a spectator from the window looking down, he was actually, you know, he didn't let things pass him by, he was actually in there doing as much and getting as much out of life as possible. And he basically, not in those words, but he basically said that to me.

Until I had felt the feeling of disapproval, I could not feel the fear of disapproval in this story. In the preceding section, I have discussed following one's intuitive lead, following one's inner teacher. It is one thing to follow that lead, and another to not acknowledge it, because one is fearful of not having done the 'right thing'. The student's story is about a man who has done many things in his life and yet still doubts how he has lived life. In his need for approval outside of himself who or what he is not acknowledging is the self. The fear of disapproval then creates its counter position of having to get it right, opposite ends of the same duality continuum belong to the fractal pattern of the fear of getting life wrong. The fear of disapproval, as does any fear, engenders many strengths. The appraisal from the effort after having felt the disapproval enables one to move on.

I could only come to this place of knowing as I retraced this same pattern in me, but which I had laid down in a different way. Telling my story in Chicago was the scenario/drama by which I then created another feeling to be felt. On returning home I could then interpret the particular narrative so as to then proceed with the text. The experience of telling one of my stories created another feeling to be felt. In writing the original story down in the thesis, the original story is now some twenty five old and yet still so powerful for me. I now need to tell the rest of it.

I had gone into the nursery early. It was nearly time for the day staff to arrive when the nursery phone rang. It was my house mate who was on night duty on the floor above. Marina, you know that baby boy you have down there for adoption - well his mother 
wants to speak to a nurse who is looking after her baby. What do I do? I will come up. But that is against the rules. I will come up. I went upstairs.

Which room is she in - my flat mate pointed. I went in. She was in the room alone. Hello, I am one of the nurses looking after your baby and I understand that you want to speak to some-one. Yes, she said - I haven't changed my mind - so don't worry. I know I can't see my baby but - would you give him this?

With her hand and forearm cradling her now empty abdomen she bent her knees as she lowered herself to open the bottom drawer of her locker. She produced a plastic bag and lay it on her bed and still cradling her abdomen as she shut the drawer ever so gently and carefully she removed each item - one by one out of the bag. The first item was a dummy/comforter, the second a pair of waterproof pants to go over the nappy and the third - a bunny rug .......Can I give him these?

I am not permitted to take you to your baby, but I promise you - I give you my word, that he will have these things. She nodded.

We stood there in the early morning light - looking at each other. Then I said, it is customary for us to give the baby a nursery name - what name would you choose? She paused and looked at me - David she said - I nodded. David it is. I turned to walk out of the room - nurse - yes, as I turned back - and she looked right into me - this beautiful young girl with long dark shining hair- and she said, I want you to know, that I am not giving my baby away because I don't love him - I am giving him away - because I do.

Finally, finally I can see.

I dreamt last night that I was on a vehicle ready to ride a wave - but I would not ride it. I kept the brake on because there was something I had left behind and would not go forward without. I was not fearful of taking the ride but it was this sense that I would not go any further this time without collecting this thing I had left behind.

Journal entry

I will always remember how she spoke those words to me, I want you to know, that I am not giving my baby away because I don't love him - I am giving him away - because I do. Somewhere in my being I too believed that to love meant that you had to lose something - to give it up or, that it would die. And so I would not ride the wave of life any further, progress with the research further because that meant that I would have to leave something that I loved behind. In the past that had meant loss/grief, so to move forward meant that something had to 
die. I understood why this story touched me so deeply - it invoked the feeling of loss/grief but there was also something else.

Being does not have a code of rules. Being does not say whether something is right or wrong to keep or adopt a child, whether or not to speak to a mother relinquishing an infant, or in fact carry a name from one to the next. One feels one's way and then one knows how to act. Being made sure that I was on duty early that morning, that my flat mate was upstairs, and that the nursery sister was sick when the adoption time came. There are no accidents. Being chose the perfect parents - all four of them. The two that created this child's physical body and the two that would nurture his soul, and then placed me fairly in the middle for a while. At any stage any one of us could have moved in a different direction. The flow is clearly evident and while challenging to each person in a particular way, we moved as a whole - over an eight-week period.

It is only in feeling this story again, that I have allowed myself to experience it in a new way. In the past it invoked feelings of loss/grief/abandonment. Now I can also feel disapproval. In doing so, my vision becomes clearer. What I now see is that one of my life challenges has been presented through this experience. It was but another opportunity to learn not be shaped by another's consciousness and in that way learn to dance my own dance and sing my song, regardless of how it is perceived by another. Finally, I can see that there is no such thing as 'normal', and therefore no need for approval from the outside for fear of disapproval. The irony of it is, that this was the same lesson learnt in the (re)telling of the story as a result of the Chicago experience, but a lesson not acknowledged twenty five years ago in the experience through not being able to move through the grief/loss.

This then is a grand truth of being. We will keep repeating the pattern until we 'get it'. Until we have the consciousness of a thing. Does this mean that I never feel the fear of disapproval? While not to the depth as in the pool in Chicago that feeling can still arise. Now when I feel this feeling I say simply thank-you to myself. In the validation, in the loving of a thing, the fear dissolves. 
To be able to transform my life I had come to the understanding that that which was guiding me, is that which is the real me, inherent in which is trust. That as God I do know what is going on, even when in physicality, the human condition, it can appear otherwise. In the first instance what this meant was five chapters of a draft thesis that hardly looked like they were connected. In the second, it was to touch upon the knowing that if love is unconditional then nothing can ever be lost/die/given up. For how can love ever die? And so now I was freer to experience more love. In my fear of being disapproved of, this was then lived/played out in life by being cautious about loving, receiving and giving love, and in that way was a boundary to love.

Thus I resisted more love in my life for fear of being disapproved of and in that way did not have to risk loosing something that I might love. With this consciousness, how could I allow myself to receive more love that then in its expression was to be new text in the thesis? Until I could let go of the fear of love at this level, I could not keep evolving the thesis. Revolution or evolution that is our choice. Thus a story within in a story was how I moved at this point.

As for the original David's story landing in the thesis, I had not re-membered my interaction with the mother until writing it down. In the past I have stopped telling the story at the adoptive father's words. Having (re) experienced that memory, and finally shed more of the tears that belong to grief/loss, I was left with a new consciousness, and new wonderings about our human existence.

At the moment of our physical birth our great mother/father hands us over to life, not because we are not loved, but because we are. With this truth the story of our eviction from paradise because we did something wrong, as truth, is then challenged. In such a challenge the wondering is, if we were given over in great love, then what is the purpose of our being human? Surely, it has to be to make this love conscious as a human being, where love is not conditional upon anything or any - body.

Journal entry

To say that I had the knowing of this truth when I wrote the final chapters of the thesis is not true. To say that it was another grand emergence of an awareness about being where I came 
to realise that all I had 'to do' was 'be', would be accurate. In the understanding that in any given moment I was being something, I realised that when I was not being love I was being something else. That in any given moment I could choose to be love by feeling love in response to whatever I was feeling. This then enabled my move/jump from the ledger book to the spreadsheet. The fullness of that insight has gradually unfolded. The David and Alan stories, the jumping off a ladder - to be caught by friends, and my experience in Chicago, had all served to enable me to take this leap in consciousness. In arriving at the fullness of a shift in consciousness it then becomes clearly visible how our human to human encounters can serve to engage one another in this process. David and his four parents, a room full of nursing colleagues in another country and the character in a student's particular nursing narrative have, over a twenty-four year period moved into my life to engage my being in evolving consciousness

In being, there is always movement, for there is always a purpose. Even when that purpose is not clear. In the human condition we tend to want to 'see forward' before we will proceed. Being, on the other hand, calls us to just experience from which there is movement. If we are constantly trying to work it out [reason] beforehand, then we stop ourselves from being all things. Then we are not flowing. By the time I had learned to just go with my inner guidance, my in-tuit-ion, to stop thinking about what might happen, the purpose of an experience, or what I should be doing, the heaviness of 'doing' this work began to lift. I was 'being' more trusting and more passionate/enthusiastic. Moreover, when I was 'being' more trust and more passion, the last few draft chapters were written easily. I had begun to jump/leap.

In the latter chapters of the work, it can be seen that key research ideas become more cohesive as a whole. These chapters do not stand in such stark isolation in comparison to the earlier ones. In this latter work, I have been able to draw together more and more threads of thought/knowing. Threads begun in earlier chapters which then woven through into the final chapters are physical evidence of the process in action. This same phenomenon in the writing 
is no different to being, where the direction might not always be apparent, but that there is a direction is certain because it is always about 'being'.

To walk into the unknown and at the same time know, is to know that where one is in relation to being, is 'to be'. In the process of being, being is no longer a concept or a belief; being becomes something that is experienced, and in that way becomes 'more' known. When a thing is felt consciously then it can be said, that thing is known. I now knew more, trust, passion, courage, willingness, openness, allowance, honesty, joy, inspiration, creativity, power, wisdom, flexibility, nurturing, delight, compassion, freedom, peace, wonder, magic and worthiness.

While the process remains unchanged, I had changed. The change was reflected in my ability to feel more deeply, where feeling was now much more than the movement toward the depth of the Self. I was becoming more of the expression of the true self and as such had begun to communicate with the core of my being. In having walked further into my centre, I had further clarity on how I was creating this work.

\section{Phenomenological thinking and writing}

I had to come to terms with the process of recognising that thinking and writing phenomenologically were different steps in the project. While this point is not new to those experienced in phenomenological inquiry, understanding that distinction is what was critical to me. I had heard Max van Manen speak on the subject in Australia in 1995, but still I was unable to make this relationship lucid in the context of my own work. It remained an idea rather than something that was known. I had to discover through experience that to think phenomenologically and then write phenomenologically are different processes.

I recognised the thinking as a doing that then is the basis for a form of reflection, which together becomes a key to release what is held within. It is after the release that a new reality 
is apparent. It has been a challenge not to tinker too much with my early work, since it does not clearly reflect this. The text is the outcome of my early conscious engagement in being. Further, I have chosen not to explore this distinction earlier in this section until I had illustrated how I engaged in thinking. Until I had made the connections I could not speak to this distinction with clarity, and hence my choice to begin the thesis describing how I have unfolded my research process. Therefore, what the early thesis work reflects is the coming to this point of realisation. As I came to this understanding within me, so too was the work able to come more together. The outside a reflection of the inside. I had to consciously develop my ability to both think and write phenomenologically through insight and the experience of this positioning. I could only live/do phenomenology when I followed my feelings. When I listen/ed to my in-tuit-ion. This was how I engaged in my thinking.

As I was developing the skill of listening to, and then following my intuition, so too was I developing the skill to write [and speak] phenomenologically. The thesis as such is a written product which reflects all this. As a text it is a mixture of explanation and description that includes both the adequacy and inadequacy in expression of what I have uncovered. This has been, and remains, part of my personal challenge. Where I have been unable to express verbally what I can feel, I have listened to the lyrics of a piece of music in an attempt to reach the words that would enable me to convey the fuller rhythm or pattern that I felt. In some instances, I have used another's words expressed as lyric.

Both in the project and in creating the text of the thesis there are times when the words do 'hit the mark'. These times are evident. These are the moments that I have been able to bring forth, to invoke, the very essence of me to speak on these pages. For the purpose of the project I identify this expression as channelling, where in this situation channelling is to express from the purist form of one's being. What it represents is thinking that comes from the heart. We recognize it as phenomenological writing at its best. The words are felt as a pattern of energy that then bubbles up from the heart to the brain to be translated into language. These instances leave no room for doubt about the origin of what has been spoken, written or read. The words are like music to the soul, they dance across the heart. It is both 
experience and an expression that has been central to my philosophical and cosmological exploration in this project. As such I use words in the text that are natural to my community and personal vocabulary to share and have begun to appreciate that the style of the text that is channelled reads in a certain lyrical pattern that is different from the more discursive or philosophical or narrative parts of the text. I believe recording the text that is channelled has been integral to this expression, and have, as the project continued become more comfortable in embodying my own voice when I am inspired.

The depth of writing is also a reflection of the depth of what has been uncovered. Like the narratives, the text is also multilayered and therefore reflects those moments where I have uncovered from the point that I can speak/write from the purity of my beingness as well as every place or point in between. As a work, this work is not finished. For in one sense I am not finished. The process is not a linear progression as in a singular movement from shallow to deep, but rather it too is multilayered and therefore as a whole is representative of varying degrees of depth. This then accounts for the text having sections which are clear and others that are dense by comparison. As a linear concept, though, it is still a movement from surface to depth. This is clearly evident in the early chapters of the thesis because they reflect the early process in action. And while they are not the product of reason, for they are the product of thinking that is phenomenological, as writing they are written from the intellect and in that way are hard/descriptive/explanatory.

Phenomenological thinking and writing have different directions of flow. One is a downward flow and the other an upward one. Both are created through feeling. I would use the metaphor of head and heart working together, where the writing moves up from the heart to the head, and the thinking moves from the cerebral hemispheres down to the heart. I am not speaking of the physical heart, but rather the energetic one known in eastern philosophy as the heart chakra. It is energy that then is given form. It is energy made physical to convey meaning in a third dimensional reality. As language, I have discovered that certain words, natural to me but not commonly used in the English language, for example, made $\mathrm{real} / \mathrm{manifest}$ denoting something that can be seen or evidenced, exist to convey a broader 
meaning than that which currently exists. To make something evidenced has very specific meaning when positioned in a positivist framework. I am completely at ease with, say, human beings thing. I can offer no explanation for my expression other than it is clear and simple to me. To then claim that some of my language belongs to a metaphysical discourse assumes that I have been directed linguistically by those philosophers. I have not. The words arise as they arise and the challenge has been to explicate them and adhere to some grammatical uniformity. Thus it has been head and heart together, as process, that has produced this text. I have had to learn to feel as thinking, and then feel again to write. My ability to think in this manner is well developed, my ability to write from this position has only just begun. The thesis recording this journey of the project as process. This then is what I now recognise to be phenomenological thinking and writing.

I consider that to think phenomenologically is inherent in being. In the unity of body, mind and spirit there is the natural guidance toward the feeling of wholeness. This then is one meaning of the word 'Integrity'. Throughout the course of this work I have, in many instances, made reference to the interconnectedness of all things. With this understanding, the data, the narratives, are not some inert pieces of paper transcribed from audiotapes. They are not mere pieces of information/stories for dissection in the name of interpretation. The data is energy. I would repeat this point. The data is energy. It is pattern made manifest. As such it is a reflection of the Self in such a way that it presents the opportunity to know more of the Self. To make the Self more conscious.

\section{Re writing the record}

In this sense, the data, as subjectivity, is really about Integrity/Object/Spirit/Wholeness, to engage thinking in a process of feeling in order to make the self more known, more visible, uncovered. In the process of (re) experiencing the subjectiveness embedded in the data/stories one/I then re-experience one's/my record. The record is all those places represented by the marker of a string that in the experience of the past I have judged because 
in any one moment I am what I am, and who I am is all that I have ever been and all that I will ever be.

The record is thought that is limited through having judged an emotional experience in life. The research data as record, as energy made manifest in the form of life experience, has then served the purpose of not merely rewriting of the record, but to uncover, and move back to the original record. Where the original record is, was and always will be, the purity of being, our integrity, our wholeness or Love/God/Source/Universe.

In order to think I have had to feel. The data, the stories, have acted as both a stimulus and catalyst for feeling. Where a story has acted as a stimulus, I recognise it as an invocation, that is, the narrative invokes a feeling that is within. Story can also act as catalyst. As a catalyst story can act as an evocation, a calling forth of life experience to support one to go within, because in the experience lies a reflection of being

Piaget (1971) in Trainer (1997) distinguishes two types of regulatory mechanisms. One regulates structure, and the other function. Structural self-regulating mechanisms promote a dynamic equilibrium through evolution with the environment, thereby creating a relationship with the environment that is seen as essential for change occurring through active participation and thereby is self governed (Trainor, 1997). Functional self regulatory mechanisms achieve stability by insulating toward a static equilibrium in response to changes initiated in the environment, and therefore change is predicated as contingent upon the environment occurring as a passive resistance governed externally (Trainor, 1997). Piaget's theory (1971), while grounding these ideas in the language and principles of biology, offers a position as "a comprehensive system of thought addressing self-regulatory mechanisms as they pertain to knowledge and activity as phenomena" (Trainor, 1997, p.92).

In this way I am identifying that in my early work with the narratives I would respond to a narrative from the position of stimulus/environment. As such I 'thought' in a functional way. In other words, I was feeling a feeling as a functional self regulatory mechanism, where the 
emotion embedded in me was insulated as a response to the change initiated by the narrative. As such, change was contingent upon the environment and occurred as in the Piaget (1971) sense - a passive resistance from the outside. In other words, the feeling in the environment/story met with the feeling inside me. In this way I began to 'learn' to allow the 'Isness' of a thing, the meaning of which is discussed in detail throughout the body of the work. As a result, though, my thinking could then move toward becoming more self regulatory. The narratives, while still acting as environment were then able to be met/responded to - differently. Why?

I had begun to use my intentionality consciously, albeit with only some awareness at first. Where to think then meant that I still had to feel, but now I was consciously [re] living the emotional experiences embedded in a narrative because by then I had opened myself to higher states of consciousness. The result is that the thesis as text then becomes product produced from the inside out, in a way that Houston (1997) describes as a learning to harness an archaeology of the mind. By delving into the depths of one's own being, one is able to connect to "forms and patterns of Creation itself.... Each being is a world, complete with organisms and environments held within the greater Environment of Being, which it both contains and mirrors/duplicates/copy's" (Houston, 1997, p.19). What I had begun to do was mine my own body, for as this thesis will argue, the body is a reflection of the mind through which we cover our objectivity with our subjectivity.

If there was one thing I remembered from my anatomy and physiology lecturer in nursing school, it was her endless reminder -'structure determines function'. It then follows if one is to change the function of a thing the structure needs to be changed. This then is consistent with the idea presented in the thesis that dis-ease is the result of impediment to the flow of energy. For example, an athersclerosed wall of an aorta has a changed structure; the cells that are cancerous have a structural variance in comparison to other cells. To follow Paigetian (1971) idea, one then needs to act in a way that is structural self regulation, as opposed to functional self regulation. The latter only maintains the equilibrium or status quo. Things 
remain the same. Therefore, to then change the function of a thing requires something different,

To participate with our environment in a structural self regulatory way is to become conscious of what we are thinking in a way that is not dependent on the exchange with the environment (anything outside of ourselves) to consciously change our thoughts. And while I had begun with the narratives in a functional self regulatory manner, that is, as environment where I learned to adjust myself to maintain my equilibrium, in so doing what I learned was how to feel.

In the experience of needing more life experience to interpret a narrative I had begun to work in a structural self regulatory manner where the relationship with the environment is as context, and not catalyst. Thus I realised that in this relationship with the environment I was now beginning to consciously create my life through reflections in the environment. I began to see how I could call life to myself through my process of a way 'to be".

If I could call the experience of feeling disapproved of, then what else could I consciously create through this structural self regulatory way? In other words, I was just beginning to create life without an environment as catalyst, that is, the outside beame context to evoke a feeling. For a feeling can be invoked by consciously choosing to feel a particular feeling, and in that way is not dependent on 'an outside environment'.

This journal entry recording illustrates the rather dramatic way I made this discovery.

I had been cutting and pasting text that related to the story on page thirty-three and in doing that I replayed the scenario in my mind. I put myself back in the classroom and recalled my experience of seeing and hearing the student's utter dismay. I remembered at the time of the story telling that I had no consciousness of what I was feeling only my distress at the students distress. The student had acted out the patient's agony expressed by the words, "Lord dear Lord, Oh no". I recalled how I had left the classroom that day not feeling as though I had supported her. I also remembered how she described her throat. "I couldn't say goodbye to anyone because for some reason I had a big lump in my throat", and I remembered that I could not keep telling/expressing the thesis (story) 
until I had felt the feeling in her story. This had required me to have more life experience in order to do so. In replaying the whole scenario in my mind, the feeling of deception just popped up. I continued my typing.

Suddenly, I was aware that the heavens had opened and I knew that the drains would not handle this amount of water, this fast. The ground was so dry after five years of on and off drought, and so the earth would not be able to soak up this volume of water. To add to the disaster I had had the driveway graded two days earlier and now had the perfect ingredients for a river of mud.

I knew that it would only be a matter of time before the water would come pouring into my beautiful glass workroom whose parquetry floor I had mended and repolished only four weeks earlier. As the water began to rise I screamed at the heavens while thumping my fists on the desk. I am doing my best, what more do you want of me! And as I continued to moan and wail, thumping my desk, a fist hit the mouse and the loaded CD Dry your Tears, Africa by John Williams from the movie Amistad began to play. [I had taken the $\mathrm{CD}$ out of the letter box some thirty minutes earlier and popped it into the computer but not yet turned it on].

The rain continued to pour and as I predicted the water gushed into the room. At that point the music gathered momentum. I stopped yelling and just sat bedazzled by the whole thing. Then all of a sudden, I felt something I had never felt before. In that moment, the house could have fallen down and it would not have mattered! As I sat there suspended in time the rain stopped and the water began to flow out.

The next morning there were patches of dry dirt which I then vacuumed. The damage to the floor was minimal. But my perspective on life was changed forever. No longer did I just believe in my power but I had touched on it in a way that I now knew it really existed.

While I did not fully appreciate what had occurred at the time, the sense of power that I felt was something I could not ignore. It took some time to realise that by spontaneously invoking the feeling of deception (my reminiscing an experience while editing text in the thesis - in other words thinking about something ) I had then in fact created an experience in which what I had felt while reminiscing was recreated. The feeling of power did not come from feeling the deception. It came from the ability to change the feeling of deception in the moment. And while John Williams's Dry your tears Africa supported me in that moment, I could have chosen to stay in the feeling of deception - and maybe flooded the whole house in the process, and missed the potentiality of the experience. 
My earlier work with narratives had trained me to feel. My drama classes where I learned to be whatever I was feeling, and the environment, had supported me in the realisation that once a feeling is known, in that it has been consciously experienced, I now understood that a feeling could be invoked at will, and therefore came to the realisation that we are not dependent on the environment, or anything outside of ourselves, to feel anything. More importantly, though, when we then choose what we feel as part of the mechanism for consciously creating our reality, this then is how we create our experience of physicality. As an act of conscious intentionality, it is in the conscious harnessing of our mind that 'we be' whatever we choose to be. And how we be it is by 'being it'. I could choose to be deceived/damaged and therefore a victim or, I could choose to be power and therefore powerful.

Whether Piaget (1971) would agree that this is what he meant by a structural self regulation mechanism is not the issue; rather, what I now had stumbled on was my Divinity-in-action, and to this end I now lifted out of my data and began to more consciously live this process, in the process of living my life and creating the thesis. At every turn I have been gently nudged to move back to the base of feeling to determine my reality as a way of remembering that when I was feeling anything less than love, it was my choice and mine alone, as to what I felt. In this light I continued refining the document, and at the same tome rewrite my record.

In sharing some of my processing my intent has been to illustrate how I have conducted this research. Some may be tempted to see it as a form of psychoanalysis to explain behaviour. I have argued that to change consciousness is to make conscious our unconscious beliefs by releasing emotion, and in that way expand consciousness. I hope that by sharing some of my experiences that my research process is more clearly visible, where what I am conveying is constructs of a process through having used my own beingness to explore, discover and identify how we be.

To this end I have been careful to present this work in a way so that it is not viewed as a recipe for being. The decision to share some of how I have engaged my beingness through 
narratives of nursing and life in the first instance has been to expose being in sufficient clarity to make the research process visible. In the second, I hoped that in laying the thesis out in the way I have I can offer others the opportunity to consciously explore their beingness. I now know what to be or not to be means. The narratives, having initially served as nursing life context have enabled me to bring forth more of my beingness, that in turn has been presented in the form of a thesis, that then is an expression of being.

In ordering the narratives as an anthology, I was able to transcend the notion of time. I had to learn to intuitively select a narrative with which to work, and then come to know when to leave a narrative and return at a later point, or acknowledge when the interpretation was incomplete because I was not willing to delve further into the context at a deeper emotional level. Further, in working in this way there is the recognition that one's fields/aura acts as a magnet to draw to one that which will in some way support one in the expansion of consciousness. Therefore, at some level I had positioned myself to call forward the data in the first instance, that somehow was a reflection of me. In that way, the order has been according to [my] the researcher's patterns, as the data has mirrored 'a thing' that was the same as my thing(s).

Thus the sequence of data only has import from the point that I had to be able to tap into my sequence. To be able to do so I had to come to see that the process for data selection is also a process of being. The data served to make clearer the meaning of the direction of flow of creativity. And in that way I learned to trust myself, know that there was no such thing as a mistake, and that nothing in the universe is ever wasted. The greatest strength was my vulnerability, and my clarity of mind was enabled by the allowance of the 'Isness that just is'. In this way I came to know that the direction is all ways because balance is not a fine line to tread but a state of being, where beingness will always move toward a state of balance.

From a position of greater balance within my being I now appreciate what it means for a thing to have consciousness of itself; the thing is no longer not known, because the thing is more known. How I know that I know is that what I feel is more love than I have ever known. A 
love that is not dependent on anything or anybody outside of my self, for it just is that - love. The intent and outcome as process. So whether it be the bigger picture [macro] or the tiniest particle [micro] the process is the same. For it is all ways. Gradually I came to realise how could it be otherwise, when God is in all things? In coming to know that God is all things my relationship with my self changed.

Through my subjectivity I have accessed more of my objectivity. The way to the whole has been through the part. As such it is the expansion of being, by being. In allowing myself to be in the chaos in order to find the area of non chaos I have come to know more of God/Love/Source. In undoing the fractal pattern, by performing an iteration or one turn of the wheel as a step, step by step I have made the complex more simple. In this way, the process is absolutely predictable. For it is God in motion, the Master craftsman creating the Self. With each step, with each turn backward, the mind is cleared, and so thought is then less confused in the sense that consciousness has expanded, and as such we are able to see/access more truth. Truth as an objective reality that moves toward God consciousness/Love.

In sharing 'the how' of the process, I have explained that as a work it is produced from what goes on the inside, an archaeology of the mind, where the product is the result of a 'pouring out'. As such there are episodes that reflect the mind's effort of resistance, aided by the ego, that represent the struggle of holding onto an old reality/memory/pattern that is portrayed through the body. At such times health issues, as patterns of energy, will and do manifest because this way of working is to work with the totality of our being and in that way reexperience at some point at some level all that we have ever been. On many occasions, I have had to remind myself that pain is a measure of my resistance to change. And so while a wonderful testimony to the process in action, that is, our ability to manifest illness and then heal, what is integral to conducting research of this nature, where one is actually working on a number of levels of consciousness at the same time, is that it is imperative to care for the physical self. So just as I have conveyed tools for walking into the labyrinth of the self, I wish to make very clear here that continuing to engage in the process of being, while supporting and nurturing the body physically, is also paramount. The body support I make 
reference to is that of diet and vitamin and mineral supplementation, rest and exercise, without which I would not have been able to continue.

To undertake research in this way requires openness, honesty, integrity, humility, courage, tenacity, patience and respect. Research of this nature begins with boxes of data and concludes with even more paper. Initially I generated a plethora of journalling that served both as a reflection on experience, but more importantly, raised my awareness. Journalling was a Faculty activity and therefore something I had undertaken for six years prior to the research. My early journal entries in conjunction with the research were very descriptive but served to help track the process and raise my awareness as to what was happening in my body.

I am at the ..... nursing conference. We started the morning off at the beach. The face that appeared around the door this morning made me smile. I noticed as I did my exercises [an ancient form of Tai Chi] on the beach, that I skipped a specific movement called 'shadows of the past'. I then went for a swim and something said to me 'let go- let go - let the flow carry you'. I did, it felt good. I drifted around a corner. Then I reached a point where the fear rose and at that point I needed to feel the bottom with my feet. I went to stand. I could not. I swam in toward the shore a little and still I could not stand. The tide was moving inward so the current was not dragging me out. I swam some more, still I could not stand. I felt terror - for a few moments. Momentarily, I imagined drowning. I decided that I wanted to keep going. I looked at my friends on the shoreline who were oblivious to my situation. I asked for a wave to carry me in. My strokes then became more purposeful. I tried to stand again and still I could not. It didn't make any sense. I wasn't that far away from the shore line. I then decided to see if I could paddle in and as I stretched my arms out they struck sand. I had swum myself into a deep hole. In a moment I went from feeling fear to expressing laughter.

A workshop facilitator at the conference placed us in what she termed a human sculpture. Then she assisted each person in the sculpture to descend into their consciousness by asking specific questions of each person or cluster of persons as a group. We repeated this process two more times. Each time I was challenged with being myself, in a specific way. We were able to observe each other, but we were also surrounded by an audience. I was able to maintain my integrity easily with the first two challenges by expressing what I felt.

The final activity placed me in a challenging position. I had challenged myself to having to choose between repeating the past, because of having judged myself in the past, or choosing to express what I truly felt in this new now moment thereby feeling a 
feeling without judgement. This time, I chose the latter. The next day so many people made the comment that I appeared to be glowing.

Journal entry

Beingness does not judge. Things, 'just are'. The notion of Non-judgement had shifted from concept to reality.

When my awareness had developed to the point where I was able to recognise that an energy shift was imminent I stopped journalling. By this time I was presenting myself with more emotions to process because I was able process 'things' more quickly and easily. I was more confident in the process and more skilled at engaging in it, and so my need to journal, in this way, had changed. My focus was directed at developing my skill at working with a pattern in the moment, a type of reflection in-action. I had begun to see that the subtlety lay in the moment and therefore I wanted to be more conscious of what I was feeling in my day to day interactions.

We were presented with metal washers. He called them talking discs. The idea was that only the person holding the disc could talk. As a result I began to allow myself to listen more closely, not only to what the other was saying but to what I was feeling in response to what was being said. I realised that I needed to pay more attention to me in this way in everyday life.

Journal entry

Further while my style of journalling varied, looking back over some four years of entries I could see where my intellect would move in under the guise of 'self reflection'. Something I was not aware of during the six years I worked with journalling as an academic. And so while I ceased to journal in this manner I kept other records to support my growing state of being.

These other records were self-appreciation and acknowledgment journals that then served to develop the ability/skill to counter the negativity mounted to resist the process. I have already made the point that to dismiss the resistance encountered by the human ego in this process is to have little understanding of the degree of resistance we as human beings can garner as an expression of fear when faced with the choice of holding onto a known reality as our beingness urges us forward into the unknown. In these moments of feeling negative states, 
for example criticism, loneliness and unworthiness, to then validate this negativity in the moment is a skill. In the human condition, we have conditioned ourselves to perceive these states as bad/wrong. How then does one validate something one has perceived to be bad/wrong in the very moment that such a feeling is being felt? Therefore, my selfappreciation and acknowledgment journals assisted me in working in the moment. To this day to remember to validate the negativity I am feeling in the moment by some form of acknowledgment remains my greatest challenge. In the act of validating a feeling that has been so harshly judged, that is, pronounced wrong, means to do a turn around from judgement to acknowledgment which then means I have been wrong and in that way am no longer right. This then is a reflection of my perception of the self as duality played out through my personal stake in the fear of getting something wrong, and therefore having to always be right.

I have also said that in undertaking one experience it can lead us to another. In undertaking the self appreciation and acknowledgment journals, I also developed further clarity on the notion of the difference between judgement and assessment in evaluating a thing, and in that way be less likely to engage in judgement through critique. Something I had wondered about as an educator. How to support the beingness of another [student] when through assessment I had perceived myself engaging in endorsing duality by my pronouncements of right and wrong that then can impact on a person's self esteem and self confidence.

I recalled this struggle in my role as an educator and lived out in this particular experience.

My second Head of School informed me one day that I could not write assessments in the way in which I was approaching the task. "Stick to the facts", she told me. Now some years later, employed in a University, I so wanted to say something in a particular way - but her old words "stick to the facts" kept reverberating in my brain.

He had failed third year the first time and so his first assignment at his second attempt to complete the year was of great import to him. I read the work. He had completed the task extraordinarily well and so I pushed my old Head of School out of my head and concluded my critique with,

Well Well Well Mick, have you had a brain transplantation since last year? Well done (High Distinction in big letters) now, keep it up! I look forward to reading your next piece of work. 
His mother told me at graduation, and he had graduated with either Distinctions or High Distinctions in all his subjects, that he had stuck this assessment form on his bedroom wall. It had become his motto for the year, the whole family engaging in the delight of it.

Journal entry

As a teacher I was confident in what I did. My students knew this. What I had done was convey to him my confidence about him in a way with which he could connect. All he needed was a little self-confidence, and while it was a pseudo self-confidence to begin with, it did grow. I had understood confidence from this perspective. In the activity of my selfappreciation and acknowledgment journals, for the purpose I have already outlined, I was confronted with having to examine my thoughts, then expressed in language that either affirmed my existence or degraded it. In that way, I could began to refine my ability to determine the difference between evaluating and judging a thing, and as a result come to see more clearly how I used judgement to undermine my confidence. Confidence I had become to appreciate was crucial to this process. Without self-confidence, one cannot move into the unknown because doubt will be dictating the course. The egoic ability to undermine confidence is played out brilliantly, eloquently, subtly, through judgement.

As a teacher and a nurse I had an innate ability to create a beingness to beingness connection that would serve to support another as they moved through their lives. Confidence I knew to be a key. Confidence I still perceive as something not consciously nurtured throughout educative and work systems in society. And while an inflammatory statement, I argue, that what exists in much of our assessment or evaluation practices is judgement that then serves to undermine confidence. At one level this acts to maintain control and so can be viewed as a power issue. At the another it limits beingness from moving into the unknown thereby also reflecting the issue of power. A being is unable to claim more of their personal/soul power without being confident.

I knew that when I felt confident, when I was clear about what I was doing, I was able to express more of that which is I. I felt confident as a nurse and a teacher. In embarking on the activity of the research I was no longer engaged in either of these roles and had immersed 
myself in an activity where I had made the decision to let go of any preconceived ideas of how to approach this work. At the very time that I needed confidence, a key, my selfconfidence score was about zero. In that way I came to realise that my self-confidence was contingent on being something, and in that way was then a pseudo self confidence. Like my student I needed support while I built my confidence and in that way more fully support myself.

As a researcher I did not know how to support myself whilst I was engaging in what was to be the most challenging period of my life. My past experience with action research had taught me about the need for a critical friend. I came to realise very early on in this work that, while requiring the connection with another human being, a human being that is able to hold you energetically during those times when you are unable to hold yourself, a critical friend was not the answer this time. Through my interactions with people in my self-development group, I came to the realisation that a single person could not fulfil this role in this type of research. We all need to go into our own chaos, and at times we are experiencing the chaos simultaneously having created the pattern as an individual act of creation. In those moments, the same person cannot always be available. In those moments that person at best, may be reflecting the same thing. Therefore, I had to learn to allow support to come from any direction. Support was the tool where and how it came from required that I let go of what support looked like. No expectations.

In laying aside the activity of journalling and picking up self-appreciation and acknowledgment as new tools, I was able to gain further insights into being by working with the experience that these two activities offered. Non-Judgement and Confidence are keys to this work. In working in this way I identified further subtleties about judgement and in the process increased my self-confidence, as well as conveying the issue of support. Confidence and support are states of being. I then experienced them from a different perspective and so could move forward in the process with enough awareness that I would encounter greater challenges to these states of being in order that I might be even more confident, and learn to allow new levels of support. 
I have made the point earlier that we draw to ourselves whatever it is that we need in order to move forward in life. The teacher presents when the student is ready. I felt blessed. What I had drawn to me was a whole group of human beings that have held me energetically in those times I was unable to hold myself. My self-development group has served to remind me when I am not choosing love. They have willingly mirrored aspects of their own subjectivity and in that way been prepared to do the same but separate walk. To be able to remind a being of when they are not choosing love and support them in this process requires great skill so as not to be drawn into the other's subjectivity. A skill that in the process of learning to choose love I too have been developing. To then be willing to mirror an aspect of one's own subjectivity represents those times when two or more human beings have been prepared to take total responsibility for an act of co-creation. The walk then is a form of mutuality in the absolute knowing that the same aspect of creation is being mirrored by one another, to one another [reflection], to serve as a possibility of divinity making. I have been supported in this way by those in human, and non human form, for the entire period of this research work. These beings have confronted me when I have avoided feeling, and held me when I have entered into such depths of human feeling. In this way, I have learned to work with my emotional self in a community that has supported me as I have undertaken this research. The following journal extract illustrates this point.

She was telling us that she was unable to let her baby be cared for by others, even though she felt so unwell. I watched as several in the group started to wriggle in response to what she had said. I asked, was she using this situation to reinforce the old idea that she was not good enough that in this instance could be played out by accepting support. (I perceived this to be behind her fear of not caring for her baby herself, and in that way she would move into the old pattern because the emotion had not been transformed). What she was struggling with was, what would occur if she let herself experience herself as not good enough. By telling herself that she was not being a good mother if she allowed others to support her, she was avoiding the emotional experience. She had acknowledged that her whole body was aching and she had withdrawn from the group during the afternoon. Her physical exhaustion was evident. I asked, was she using her baby to run the old pattern that then would reinforce the belief that she was not good enough. She looked at me and said No, and then she said, Yes.

In saying yes, she was willing to acknowledge the ego game. With that she began to sob. We sat and allowed her to cry, to express her emotion and then when she had cried enough she was able to acknowledge, I am so scared of losing him. With that I felt the 
loss/grief within me, and my tears began to flow, as did one other person. The rest of the group then served to support the three of us.

Journal entry

Without learning to receive love, I could not have sustained this work. My most important lesson has been in being able to both give and receive love that was not a form of antidependence in response to my fear of being dependent. My own version of an 'independent form of surrender', and something I had done most of my life as a way to protect myself from feeling the feelings I had judged to 'be bad'. I had to learn to support myself emotionally, as opposed to doing the supporting. This was a new way of being, and one that I had to embrace if I was going to be able to engage in this method of interpretation. The initial research proposal did not include these people gathered in the name of self-development, but it soon became evident that what I was doing was running parallel to my experiences, where not only have they acted in the ways that I have just described, but where I have had the opportunity to test, define and refine the aesthetic at work in our lives and in that way become more eloquent.

As I have explained, the first step was to consciously feel an emotion, and while this might appear simplistic I have spent a number of years watching the human capacity that has perfected the ability to avoid feeling. I then had to become skilled at letting an emotion go so that I no longer walked around for days feeling moribund. As I developed this skill, and as the writing progressed, what I was actually doing became more apparent. I realised that by engaging in this process what I was actually doing was, becoming 'lighter'. With this realisation I set about in earnest to - 'fix myself'.

I have already made the claim that nothing is ever wasted and there are no dead ends. In my desire to fix myself this then was a reflection of what I thought about myself or what I felt about myself. While there are no mistakes and no wrong paths to take, there are however easier ways to do things. In the experiencing of a thing there is always the possibility of making new choices and so, having travelled down the path with my attitude of 'fixing me', I 
came upon my greatest insight from which I became free to choose a new way of being. In retrospect, it was very, very simple.

In response to hearing, for what seemed to be the millionth time .... that we were NOT.... and remembering that I created my reality I reminded myself to take responsibility for my creation, which in this instance was some-one telling me that I was NOT ...

I decided that enough was enough. I had had enough of hearing what was not OK about me. I had experienced this since childhood and therefore had spent my life trying to be what some-one else thought I should be. In that way I had given myself the idea that who I was, was NOT ENOUGH ...

In holding onto the judgement of criticism, a feeling I knew so well, I had reinforced the idea that I was not enough. The effect of this was that I would try and fix what was wrong to avoid being criticised. In that moment, I made a conscious choice to accept me, that how I was in that very moment was - not perfect - but excellent. In the knowing that I could always chose to be, more.

Journal entry

The insight into my attitude of fixing was that I was more confident about me. I did not have to be perfect, and in the process I had jumped another hard bar by being able to now view myself in my work differently. The view was now from the position of excellence as opposed to perfection.

\section{Knowing}

I began this chapter by making reference to knowing and not knowing. How a thing is known is, it is just known. It is recognised or understood. It is felt. It is known. What I have not made clear is, the recognition of the process of knowing within being having witheld this discussion until I exposed the shift in thinking from an attitude of being that perceived I had to fix myself to one where the beingness of my being IS more love. When I was being more love thereby decreasing the distance between the moments of love because I now knew there was nothing to fix. No matter how being, is being made manifest. Simply said, until there was enough love within me for me, in any given moment. 
In retracing some of the unfolding of a process of being, in the way that I have outlined here, I have made reference to the import of awareness, and how willingness serves to assist in changing a thing. I began this chapter by explaining how, in order to walk into the not known, I had to abandon my set plan (proposal). To proceed differently I had to be willing to look for a new way to see (and say yes more than no in the process). In changing my relationship to time, I then positioned myself as the researcher so that I had a new awareness about my data. Meantime, I had to trust myself. Trust that I was heading in a direction even when I did not know - the not knowing where I was headed until I arrived. In that way, I also needed to be confident about what I was doing, for without confidence doubt would direct the process. When I had these three facets in position I then had a new way of knowing. I could begin to work with the narratives differently if I could position willingness, confidence and awareness on a base of love.

My base of self love was very limited in the beginning and I could not have begun had it not been for the love that was mirrored to me from an outside source. That love came from the very purest source of love. In the way that another might gaze into a lover's eyes on a moonlight night and so evoke that feeling of love, that outside source mirrored love to me until such time that I could feel more love within my being. Again, I was supported. This non incarnate being uses the name Tikashi, and expresses his consciousness in the body of an incarnate being, for periods, to work in ways that will enable another to remember that they too are God. I have said that we draw to ourselves what we need. I drew a very grand reflection of love to me that in the initial stages of the research served to evoke the feeling of love so that I might place my growing awareness, shaky confidence and sometimes stubborn willingness on a base of love. For without love, willingness, awareness and confidence do not serve knowing.

In this way I began with some knowing, where knowing like consciousness is ever evolving. In looking back over the illustrations I have selected to convey my way of working, I have highlighted the virtue of trust. To trust is to have faith or confidence. My confidence was easily shattered until I had created a draft document. At that point I lay the formal thesis 
down for almost a two-year period and proceeded to translate the core ideas into a text for non-academics. I found this a most liberating task. I felt free to write and that I was not trying to squash my style into a preconceived idea of what the thesis should look like. It was evident that this work was not going to look like a 'normal thesis'. The result of this was that the lingering doubt about what I was doing and my struggle with writing, grounded in the belief that I could not was laid to rest. My confidence grew again. I now trusted the process, and while my ego would still provide a challenge in an attempt to keep me in a known reality and as such I would sometimes travel over the same territory several times before I would choose to shift, there was enough trust to be able to make the shift.

I have always been observant of my world. My clinical background in Intensive Care Nursing provided a wonderful context in which to develop my ability to pay attention to multiple stimuli at once. Awareness took on a broader dimension in this work. I had to develop the awareness of what was going on inside me, and as I have already explained, my self-development group was critical to this development. Without awareness at this level, I would not have been able to work with not knowing, in order to come to know.

Willingness, I identified as the third corner of the triangle. Without willingness this work would have ground to a halt - many times. Enthusiasm and excitement are fuel for the soul. They propel it onward and as such serve to make the difficult appear easy. How much more can be achieved when enjoying an activity? When I am enjoying something my experience is that I am more creative and the activity appears effortless. Willingness has this dimension of shifting or assisting to move energy from hard to easy by simply being willling. Willingness has all these aspects to it. Willingness was an energy that I knew in teaching and nursing. As a researcher, I began with tenacity, the willingness emerging as I began to have insight into the realisation that I was working with consciousness, that in turn was reflected in the work taking shape.

To say when one knows, one knows, might pose a difficulty for those whose sense of reality is grounded in a need for physical evidence. Knowing does not belong to a realm of 
consciousness that has to prove. Knowing comes from a place that is beyond evidence. Knowing is like love, it comes from the heart. When something comes from the heart, it is heart felt. Something that is heart felt leaves no room for doubt. Something that is heart felt is felt, because that thing is known. Further, when a thing is not felt in a heart outside one's own heart, that then does not mean that a thing is untrue. All that means is that the other is yet to feel that thing in their own heart, because for the other, that thing is still unknown.

Knowing just comes to that place of knowing that just knows. In order to be something is to know it, you know that you know. Then, in being that thing everyone can see what you be, and so then there is no need for proof because you already are it.

Confidence, willingness and awareness on a base of love, are integral to being and in making the unknown - yet, known. Knowing.

\section{Methodology and movement: The process of a paradigmatic position}

In my early thinking about philosophy I had wondered about the relationship of Phenomenology to Metaphysics. I had avoided any discussion on the issue, not as something that was undesirable, but because I did not have the insight to do otherwise.

For me, phenomenology, while essentially an exploration and interpretation of phenomenon to make visible the nature and meaning of being, in its quest to uncover, reveal the hidden, get back to things themselves, peel off, seemed to arrive at a position where there was the implication of a sense of imperfection.

On one hand, the ideal to uncover the nature and meaning of something, and in this instance being, was interpreted as unwrapping a parcel to reveal its contents. And while some argue that as a methodology this is not consistent with phenomenological inquiry because such a view would be an inquiry of beings as beings, how can being be 
conceptualised separate from a being, being human, when we are called 'to be' whilst in the human condition? This, Heiddeger (Crotty, 1996) asserted, was the same position of traditional metaphysics. Traditional metaphysics is an inquiry of beings as beings. Heidegger argued that traditional metaphysics needed to 'overcome' this same point, because in his view, traditional metaphysics did not see past the being of individual beings, to being itself (Crotty, 1996). Traditional metaphysics also conceives of beings as beings; inquiring after the Being of beings, but not after being itself (Poggeler in Crotty, 1996, p.77).

I asked myself how can being be known separate from a being, being human when we are called 'to be' whilst in the human condition, and at the same time not be perceived as an inquiry of the being of an individual thereby rendering the inquiry to not be about being itself? I take the position that we can not. Being I have said is a function of the soul, and all beings have a soul. In exploring my soul through the expression of being human there exists the potential to see all souls. To view my soul as separate from another's is to not see from the perspective of the whole. Beingness, and there fore being, is about the whole.

Further, by the implication implicit in phenomenology, where the worldview or paradigm is a quest to make visible the nature and meaning of being - to uncover, regardless of whether that uncovering is perceived as an unwrapping or not, I argue, is the expression of the belief that how a thing is, that is, what it IS, in the moment is not enough. This is not the same as saying there is more. More belongs to a different frame of thinking.

In the notion of not being enough [and therefore having to be fixed because how I was, was not right and therefore must be wrong] truth is then perceived in a way that it is an either/or thing. In that way, there will always something to fix. For as an either/or thing, truth, thinking, can only be approached as if it were a razors edge, a cutting edge. Truth then is still right or wrong. In the understanding that we each are free to choose what we feel in response to life, and in so doing, life is then a choice that is approached from either the position of perfection, or excellence. Perfection is a state that exists when the appraisal is created from 
the outcome, and in that way furthers the ego's expectation of perfection. On the other hand, excellence is the state of being where there is an appraisal of the effort of an outcome.

Excellence is to experience life as Is, and then choose to feel love. Perfection is to make a judgement about life and so ground thinking in notions of good and bad or right and wrong thereby continuing to play the ego's game of seeking perfection and so reify the notion that we are not perfect. In that way, not only can we never be good enough, more importantly in this way we perpetuate the belief that right and wrong exist.

Further, a phenomenology created in the pursuit of interpretation of phenomena based in a truth that we uncover to get back to things themselves, is then saying that what we are is better than how or who we are in the now given moment. Only in experiencing this phenomenon did I come to realise this very, very subtle point. Which as a point of friction is a boundary in thinking that then limits being. Being is limitless.

This limitation of phenomenology is the very same limitation inherent in traditional metaphysics, where the inquiry is about a Being of beings, bound in the notion of beings being that then implies that God (as a Supreme Being) is better than God in motion (a being). In this way traditional metaphysics also holds that God is outside of the self, and that we need to find him or her. Phenomenology on the other hand says that who or what is hidden is to be found/discovered/revealed/disclosed by the process of making visible the nature and meaning of being. In that way, 'what is hidden' can imply that 'being' is not here yet, and so what is not here yet has then to be separate from the here and now. While this is very subtle, only in experiencing it can I now argue that in this way there is an aspect of both philosophies that perceives being as futuristic and as such grounds thinking, in time. Being is timeless.

This work has argued that we are beyond time, and so to ground 'thinking' in time is to locate it within a paradigm that is dualistic, and in dualism, god can only be perceived as separate. 
On the other hand, to say what is, IS, is to say that everything IS. In that way how I am being as a human being in the now moment then determines being. In understanding this, I can come to know the nature of being, by being. Where everything Is, is not just a belief that what is, IS, but is the expression of knowing that everything is as a movement beyond time - whilst being in time. Where what is known is, that it is always LOVE, and in that way the outcome is a form of excellence. allways, all ways. In the knowing it is always love, it has to be whole, because the whole can never be separate. By being, we be, and who we be is God/Love. The Father and I are One, that is not revealed as a Being of beings but by knowing being.

I have often pondered on the meaning of Heidegger's 1926 title Sein und Zeit - BEING and TIME. And while I have understood time from a phenomenological and physics (spacetime) perspective, it is as if Sein und Zeit has been my way to more. Now I can say that phenomenology has enabled me to transcend this aspect of dualism played out in the position of opposites, of pairs. Having done so, I now can explicate the point of friction, which for years (time) has been waiting patiently, and is that which is expressed in my questioning of the relationship of phenomenology to metaphysics. Now I can see.

Delete the word traditional from traditional METAPHYSICS, and in speaking of such an action I am not making a mere stroke of the pen, what I am doing is undertaking an inquiry that views beings being. Having done this I pick up my pen again and delete the word time, from BEING and Time. In this way I have moved methodology, as process, using phenomenology and questions as they relate to traditional metaphysics, into a pattern of thought that I can now name. I name this pattern of thought, this paradigmatic process, as BEING METAPHYSICAL, which for me is a natural philosophy where consciousness exists as thought until thought is changed, and in that way there is no ultimate nature of being, rather, there is only the expansion of consciousness that in its expression is the purest form of being. 
In this way, Being Metaphysical is to BE THAT WHICH YOU LOVE (I AM, therefore I think) AND LOVE THAT WHICH YOU BE (I think, therefore I AM). For only in loving that which I be, can I then be that which I love. SO BE IT! (Amen)

\section{Method}

I have explained the origins of my data in The Beginning Story. In that way I have located my data in space and time in such a way that depicts the data as more than mere procedure but something that is 'in life', because that is where it came from. The data came from a group of people living life through Nursing.

Much has been written about the narrative in Nursing. Nursing's oral history has been well recognised (Street, 1991), and narrative inquiry in nursing has gained momentum (Emden, 1998). Nancy Diekelmann is one nurse scholar whose work with narrative, as it informs pedagogy, is well recognised internationally.

In writing about story as method during my previous research, I was influenced by the work of van Manen (1990), who says that language becomes a repository for a wealth of human experience and that idiomatic phrases "proceed phenomenologically" (p.60). Story-telling, is specific in that it is used as method in exploring and gathering experiential data and thus becomes a resource for developing greater depth and breadth in understanding human experience (van Manen, 1990). Interpretation, "its meaning is more accurately a process of insightful invention or disclosure - grasping and formulating a thematic understanding is not a rule bound process but a free act of 'seeing' meaning" (van Manen, 1990, p.79). Nine years later, while I still hold with what van Manen says in relation to the narrative not being a rule bound process, which I hope I have clearly articulated, I would also add a point about 'idiomatic language proceeding phenomenologically'.

For language to 'proceed phenomenologically', I would argue, it has to be language that is derived in a way that reflects 'praxis' in the Freirian sense (Freire, 1972) where word is said to 
have two dimensions, reflection and action. Where language, word, does not maintain the dialectical relationship between these two, then word as language is either empty, or an activism. As Freire (1972) has pointed out, an unauthentic word cannot transform the world.

We have all heard 'empty stories', 'empty talk'. While it is possible to create language fictionally, scripts of movies, plays and texts serving as an example, what makes something inert, alive, animated, is not the imagery that it portrays per se, but the emotion and feeling that the imagery or dialogue then elicit. In this way, a narrative is not story writing or recording, rather it is specifically story-telling, where in the act of telling a story it is of great import.

In the telling of a story, its words become tone expressed. Tone is vibration. Vibration is energy. Feeling, I have argued throughout the thesis, is how we connect to patterns of energy. We feel from our beingness to connect to these patterns. In that way beingness hears through the tone and not the words themselves. In this way, tone is resultant in the way that the words are crafted, in the same way that the notes of music make a pattern that we then hear as music.

For those doing the listening, what is being listened to is the tone that the words create. The one speaking is an instrument that has a particular pitch. In hearing the tones we may then hear the difference between words that are spoken from the heart, and words that are spoken from the head. By words that are spoken from the heart I mean, words that hold the dimension of reflection and action in their dialectical relationship. Words that are spoken from the heart may then be heart felt.

Further, when we listen to a live story told, (as opposed to listening via an audio medium such as radio or a tape recording) we are also observing the storyteller. In that way, we also are observing the body. This body to body communication is significant, and one that I expand upon in a chapter of the thesis. Therefore, there is much to be gained by the telling of stories. Nursing's oral tradition has served a grand purpose. 
In making such claims I am not saying that this level of hearing is exclusive and so cannot be facilitated through text. The work of many great authors stands testimony to this. What I am saying is, that this level of hearing will not be facilitated by text alone. I have been able to feel a story more easily by listening to that story being told, both as a classroom activity and a audio recording. The text, in my experience, serves as a prompt to relive the classroom experiences. Also when a story has really impacted on me at the time, I can still place the people and events in the room.

I have made the point earlier that words spoken from the heart may then be heart felt. I have used the word may most deliberately. In the first instance, there is room for argument about visual kinaesthetic, and auditory representational systems of processing information (O'Connor and Seymour, 1995). Listening/watching/hearing a story will be received through the sense that represents the lead system of a person. In other words, a story is told by a person who primarily uses visual, auditory or kinaesthetic representational system of communication to another person who receives that communication with that same preferred system. The systems may be different.

On this basis I would suggest, that in reading the transcription of the tapes as text, some narratives could not convey the experience in the hands on moment. And while it would be possible to mount an aesthetic versus intellectual argument, in the way Kaelin (1970) argues, I would maintain that at times the text has served to prompt me in reliving the actual story 'performance' experience. In this way the ability to process a story cannot solely be attributed to another reader's inability to delve to an emotional depth, At one level this represents the potential of processing that relies on the form the communication has taken. I insert this student narrative to illustrate the point.

This story is from last semester. I was working on CCU and it was the second week I'd been there and I'd been allocated a patient, his name was Peter. I didn't know much about him apart from the fact that he was about forty three years old and he had been admitted with severe chest pain and he was to have an angiogram the next day.

I don't know if everyone has been to CCU but it's set up where you've got a desk and six beds where you can see all of them and they are sort of like in little cubicles. He was in 
the furthest one where you could probably not see a lot, you couldn't see much from the desk. When I walked into his cubicle I just looked at him and thought -this guy should be on a Harley. He was a big guy. He was tall. He had a dark long beard and I could just picture him dressed in black leathers and sitting on a Harley and just hooning around. And he just didn't look like the type of guy that would be sick. He was like, he was all happy. I walked in and introduced myself and he's sort of gone, "Oh hi Julie, how's it going?" and started raving on and probably didn't shut up for the next ten minutes. So we sort of hit if off pretty well straight away. His chest and arms and back were covered in tattoos and he had this little one on his shoulder or a little angel and he said, "This one's you." And I've just sort of, I said, "What?" He said, "This tattoo is you". And I thought, "Oh, OK. Fair enough, I'm an angel now. No worries." And I hadn't even done anything. I'd just walked in and talked to him.

I sort of just started doing the ECG and all his vital signs and all that sort of thing and just throughout that day we sort of chatted. Later on we discussed his angiogram for the next day. Went through the education and watched the video and he's just saying, "Oh, so they're going to stick this thing in here and inject some dye and take some X-rays and they'll see what's wrong." And I said, 'Yeah, basically." He said, "Oh, that's fair enough", and he said, "Well what's the worst thing that can happen"? I said, "What do you mean"? He said, "Well, if they find something wrong what will they do"? I said, "Well, most likely you might have to have by-pass surgery". He said, "Oh, fair enough, I can handle that". And he was just really good about it. I thought this maybe was the way he was coping with everything because it's pretty much a shock to come in and find out you've got heart problems. And the next day he had his angiogram and the worst case scenario came true - and more.

They did an angiogram and found a huge blockage in one of the arteries and they had to put in, I don't know, you've probably heard of it - a balloon, what they do is put in this balloon and inflate it and it compresses the obstruction. Well, they had to put in a balloon and hooked it up to a machine which was the length of the bed. It was big and huge and it would just inflate the balloon and deflate it to allow blood through. And that was pretty scary. He came back and it was unbelievable, he was still thinking, "Oh yeah, this is going to be alright". And he was supposed to stay on this machine until he was stable enough to be moved to Melbourne so he could have major bypass surgery.

Anyway, the next day I turned up to the unit and at handover they said that something had gone wrong with Peter over the night. I just thought, Oh, shit. The balloon had dislodged and they had to remove it and he was told that he was no longer able to have bypass surgery. He was now on a waiting list to have a heart transplant! And this guy had gone from being optimistic, thinking, Yep, this'll be fine, no worries, to having his entire life flash before his eyes. And I had to go up and talk to him, take his ECG and I went in and just said good morning and he just looked at me and he said, "Yeah, it will be". And I took his ECG and he just looked at me and he said, "I want to ask you something". I said, "Yeah, go ahead", and he said, "I'll wait until you've finished", so I said, "Fair enough". So I've done the ECG and I've taken his blood pressure and I could 
barely hear the beep because my heart was just going pound, pound, pound. So I took it about three times and I finally got it and then I sat down on the side of the bed and I said, "What did you want to ask me"?

He just looked at me - he had tears running down his face - and he said, "Do you think there's a God"? And I've just thought, Oh shit. But I said, "Out of all the people to ask, you ask me this". I thought OK, do I tell him what I think or do - I tell him like, yeah, of course there's a God - to make him feel better. And I said, "Do you want me to be honest with you"? And he said, "Yeah, please". And I said, "I don't know, I've never been religious, I've never gone to church and I don't really know". "I'm trying to figure it out for myself". "So I don't know what to tell you". And he said, "I think there's a God". And I said, "Well, I hope there is", and he said, "I'm going to die aren't I"? And I said, "Well, yes, there's a possibility". He said, "I'm not going to have this heart transplant". And I just looked at him and he said, 'I'm not going to make it that long", and I thought, "OK. Now what the hell am I supposed to say to him? He's just told me that he's dying. And I just sat there and I thought this guy is not the type of guy that you'd think would even believe in God let alone want to know anything about it. And then he said, "You've got a place in Heaven, but have I"? And I said, "Well, I think that if you believe enough about it, and you believe in yourself and in Heaven that there'll be a place for you". And he just looked at me and he said, "Yeah, I think there's a chance". And I just thought, OK, and I just walked out of the room. Two weeks later he died.

It is the unknown - dying, and what emotional state he would be in, given his recent events? There was also a sadness which came from the realisation that he would probably die before a heart became available. And then there was the irony that you almost hope that someone else dies so that he can get another heart. The experience did a number of things for me. It allowed me to confront the issue of death. Question my own mortality and more importantly it helped me to begin to think about my own spirituality, to question my beliefs and religious views which was something that I hadn't ever done before. I'd sort of been told that I can figure it out for myself when I get older and I never bothered.

Having reflected on this particular experience the emotional feelings are quite different given the time and space. The feeling of fear, sadness and bitterness have faded and they have been replaced by a feeling of satisfaction and content. The realisation has dawned on me that just being with him was enough. That it was my presence and not necessarily my wisdom that he was after. Looking back, I feel really satisfied with what came out of the experience. He was able to cry and not be judged for it. He was able, through me, to confront his mortality and question his beliefs. I don't know if he found any answers, I know I haven't, but the process is beginning. You know the point that Patterson and Zderad make - how by describing nursing situations, the nurse is better able to relate to people. That was really highlighted from this, for me. I think that in the future, if someone ever asked me if there was a God I'd probably react better and not look so stunned. And the situation that he was in where he was confronting his own death was a real learning experience for me because I've never ever looked after anyone 
that was that confronted with it. And just the uniqueness as well, this was the first one, the person is unique because he was, just looking at him and thinking he was just so tough and so rough as anything and it was just so easy to stereotype him but then when I saw him crying - I was just blown away. I just thought this person is just not what you picture when you walk in - and I think he showed me that in a really really big way.

This narrative I perceived myself to primarily process kinesthetically, because in listening to the audio tape or reading the text it does not have the same impact as it did on the day that I experienced it in the classroom. The language of tough, rough and sadness convey this possibility. I clearly remember my response in the classroom as a body sensation. This stands in stark contrast to other narratives where the emotion surfaces at a point in the story that does not have this same body sensation. And yet, an emotion is felt in the body. To feel an emotion and to kinesthetically receive information, is two distinct experiences.

So while I have laid claim to my exposing how I have interpreted the narrative only in so much as to convey being, here-in is an illustration of the futility in attempting to convey which emotion a particular narrative served to illicit when in the representation of this narrative I did not experience the same thing initially and therefore attempted to dismiss the aesthetic in this story on the basis that I did not respond 'each time as if it were the first time'. It was only in 'reliving the classroom experience as a visual memory that I could then 'bring up' that memory of the body sensation I experienced on that day.

In my way of processing, that predominantly uses hearing [tell me a story], the 'idiomatic phrases that proceed phenomenologically' have assisted me, the researcher, to focus in a way that opened me up to hear more. The idiomatic phrases then served to widen my awareness and at the same time keep me focused. In this way, the phrases became foreground that supported my interpretation in the way that I have described. And while it is word that works upon, it must be stressed again that word as tone (auditory), or picture (visual) or bodily sensation (kinaesthetic) is then feeling expressed.

For the one 'doing' the hearing, seeing, or body sensation, word will be heard, seen and sensed as it is perceived. Until such time that the one experiencing the narrative changes their 
perception by feeling what the tone, vision and sensation invokes the images souns and feelings of perception will remain unchanged. This is why communication is so complex. We experience our world through the filters of our psyche, making heart to heart connections possible only when we acknowledge what we are feeling and in that way come to express more love.

I have said that my data consisted of stories, drawings and photography. While the narratives were the main source of data, following the discussion of how hearing idiomatic phrases may impact on the listener, I would like to discuss the import of the photographic data. I had asked one tutorial group to participate in this activity that involved a student upon hearing a story to be willing to enter the circle and pose in whatever way they felt inclined. Any student that wanted to respond in this non verbal way to another student was then invited to do so. One particular student had agreed to undertake this activity in response to every story, so that when she responded with her body to a story I then responded to her body with my body. This idea had evolved from the two dimensional colouring in of bodies that we had engaged in during the previous year and which we continued in that same year. The body posing, to me, was another adjunct. In the experience of undertaking the research, this activity served to make more apparent how we communicate emotion via our bodies, from which I was able to begin to grasp ideas of invoking feeling as part of the activity in conscious manifestation of reality. Therefore, the idiomatic phrases that proceed phenomenologically, while not couched in language, were still evident through undertaking this activity, and at one level remained couched in how the narrative had been experienced by the student.

The body posing also opened another significant area for me in thinking about the aesthetic from the perspective of an unconscious communication that also serves to keep us connected. Chapter nine in the thesis deals with this idea. Suffice to say here though, that by being present when a story is told, not only have I opened my awareness through my hearing, vision and sensory stimulation, but not until very late in the research was I able to consciously appreciate the body to body communication that was going on between us, as the students and I, listened to story. My experience with the one student in this body to body communication I had never questioned. How or where did my responses to her responses come from? I never 
thought about what I was going to do - I just did it/be it. So what was going on when I watched the students pose in response to a story? While my data had been collected and stored on audio tapes and in drawings, I had not considered that I had used my own body to collect and store data. And while this is perfectly 'reasonable', given the position I have taken in the thesis about life experience and the body, it was not until late in the research that I could appreciate this.

In my undertaking the body to body experience with one particular student I began to open myself to both myself and other. By observing the other students use their bodies, a natural phenomenon in nursing, I now perceive that they were giving me something that they could not communicate in words. I can still hear David's story because what I remember is how he positioned himself in the circle after the telling. The image is in my mind, the photograph inserted here but a physical representation of the image as memory. I do not need to see it in order to remember David standing in the circle, his right arm draped across his chest, his left across his upper abdomen. In this image, I can feel the deep sense of loss carried in his story and played out in caring for an elderly gentleman a week after his own dear grandfather's death. 
Figure 1: Expressing how I feel

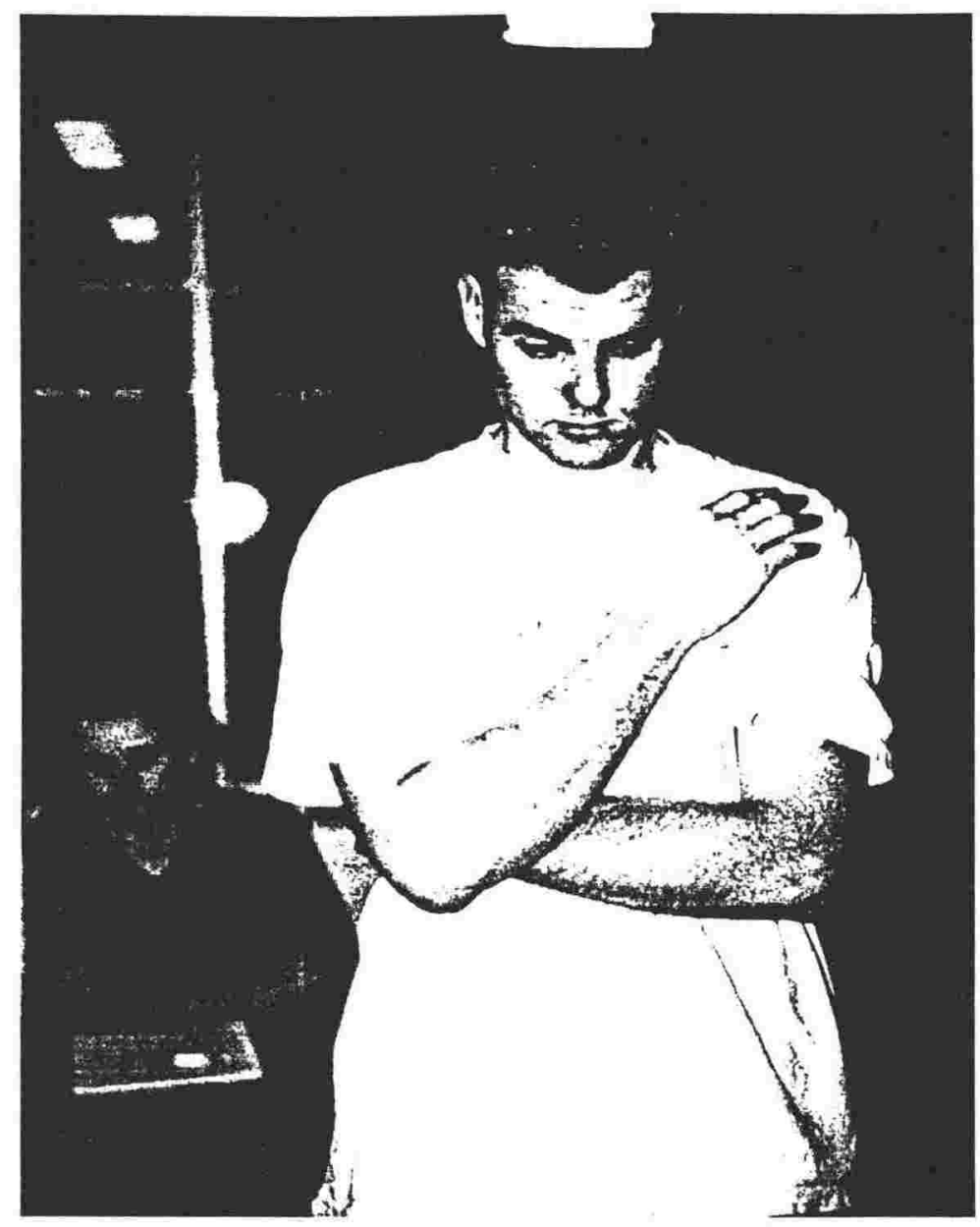

While the fullness of the body to body communication is expressed in the thesis, without this data I don't know whether I would have been able to clearly see being as a pattern that can be invoked as a result of having known a thing that then is an automatic demonstration of being. Having said this though, I would say again, that I could only arrive at this consciousness about being in the way that I have unfolded the process. Therefore, I have included this discussion as method that then follows my explanation of identifying a paradigm and an explanation of knowing. My argument is, that by listening to a story told the full potentiality of what is embedded in that story may not be able to be conveyed by text/language alone. In this way, my students telling and then demonstrating physically their story served to convey the fullness of what was held that then could be seen as unconscious data until I was able to access this generosity of spirit. 
To Janet, who participated with me in the body to body communication each week, her gift was enormous. In her allowing me to respond with my body to her body, as an act of love, this then served to awaken my unconscious consciousness to begin to more fully express my being. "Your body is a living demonstration of the state of beingness in which your soul resides" (Walsch, 1995, p.29). While on one hand this serves as a reminder that our human field acts as a magnet to draw to us whatever we need, whatever will serve us in this journey of life, on the other, it is a living demonstration of the capacity that we can in the human condition, assist and support one another in the experience of life. Through body work/body posing I was given such precious gifts, without which I could not have conducted this research. They used their souls, and in that way bypassed my humanness to leave an imprint on my soul that then sat as gift waiting to be opened.

Initially I pushed the colouring in/drawing on the two dimensional diagrams of male and female bodies aside. While they served to raise my awareness as to just how different the responses were by each person experiencing the same story, this knowledge is readily available as the psychology of perception. As I began the formal interpretation of the research, 'my bodies', as I called them, helped to keep me honest. I could not explain them in the way that I had initially begun to interpret the work and yet, hard as I tried, I could not ignore them either. They acted as a constant reminder to look for a new direction. At the point in the research where I had begun to explore the human aura my bodies served to reveal, that each student by engaging in this process was undergoing individual change. By creating a linear sequence of drawings drawn by a particular student rather than looking at a group in response to a particular narrative this became visible. Those drawings/colourings if read by anyone skilled in aura readings, people that are able to see colour clairvoyantly from which feeling then arises and interpretation occurs, would reveal the individual's pattern on a given day tracked over a whole semester. The drawings are evolving life created in response to thinking. Thus my bodies are also a testimony to the process where by engaging in the research/teaching we were all changed. Ironically, my maybe not so naive definition of learning was made real/manifest. Thus story/narrative served as experience to invoke a 
feeling that as thought is then displayed in the auric field and of which the student, by tapping into their own intuition, had some awareness of as they coloured in 'the bodies'.

\section{Loving what you do and doing what you love}

Love comes to those who allow it, and to those who wait. Love is not something to be sought after or worked/reasoned out. Love is around us always, where all we need do is let it descend through our being. "To attain what has eluded you, be still and allow it to land upon you. As a feather would gently float into your hand, so do your wishes descend upon you" (Tikashi, 1997).

To nurse that then is love made real is to engage in activity or actions that cannot be prescribed. Love cannot be prescribed, love just IS. In the same way that one opens the space for the self to be present, in that open space is where I have learned to listen to what another person is saying. Listening is much more than mere words. Listening is to hear the world with your heart. When I listens with the heart, then an answer comes from love. I intuitively grasp how to act. My ability to listen to another's heart is a direct reflection of 'how well' I can listen to my heart. For how do you hear another when you do not hear yourself? Your sub-beat. To keep the space open in order to listen is to not bypass the human or reactive mind but to silence this mind, so as 'to be' in the silence.

In this way, this thesis, other than arguing the potentiality in the experiential basis of nursing practice, does not present a myriad of what needs to be changed, improved, or recommended. This thesis has identified a process of being that in uncovering, the 'side effect' is the ability to 'tap into' more love and so be guided by love. Some name this intuition and others call it pure intuition. As I have uncovered myself, so too have my insights into healing grown, because what I have become more conscious of is how to be in the energy of all things, and so be all things. 
Therefore, all we need do is be love, because all things exist as ideas and exist as patterns of energy in this space. The clearer our beingness, the more we be it. The more we love, the more love loves or moves through us. Moreover, sometimes this may mean that we seek out a person skilled in a practice and so engage in a traditional form of learning or healing. The difference is in whether what has lead one to this place has been the result of prescription or inspiration. I can now bow my head in the recognition of just how much of my life has been directed by grace.

In presenting some of the early work of this research at conferences I have been asked on more than one occasion how I knew their stories were real? Interestingly, other colleagues have expressed concern that students could 'make up' a real 'tear jerker' in order to meet classroom requirements. In relation to the authenticity of a story, I would say this. Stories that are 'manufactured' are easily discerned, they are empty. This is not the same as saying that a story that has little depth is a manufactured story, but rather, a 'little story' is a direct reflection of how much the storyteller is prepared to open themselves to feeling, and to then share that experience through story. In this way, no story ever lacked authenticity.

As for any Oscar winning performances in the classroom, oh yes, there were those! And these are the stories that I will be able to repeat, even when I am an old lady. But did I meet any future Oscar script writers? I said that in listening to story I experienced nursing from many perspectives. During those experiences, many of the students would have made great actors/actresses or playwrights. Why? Simply because they did not have to act or manufacture a story. Their story was within them and they shared their stories, willingly and lovingly. In truth, though, I now know that the honesty and openness that I encountered in those days in the classroom were a reflection of the degree to which I was open and honest with my self. So where there was a little story, it was a reflection of the part of me that was more covered or more closed.

During the process of creating the data for this work, and I use create in the sense of the intention to gather, there were many occasions where I was filled with such joy and 
wonder. As I listened and observed 'my students' share their lived experiences of nursing, I could not have had more pride had I been their mother. They still felt about nursing in the way small children feel about Christmas. Nursing to them was still magical and wonderful, full of discovery and surprise. They were doing what they loved and they loved what they did. Where their sense of magic and wonder could had been tarnished by an encounter with the big bad witch or three ugly sisters, we worked in a way that focused on acknowledging the experience and therefore embraced our vulnerability.

I have said that I had little consciousness of where this process was taking any of us. I was following an inner direction while not knowing the direction. My guidance was my desire to engage students in a teaching learning process where we might all develop a greater insight into nursing so that we might all better serve those whom we nurse. As I/we sat and listened to the stories, our classrooms began to fill with hundreds. I was not just a teacher with groups of students doing story-telling in their nursing tutorial, rather through and by telling stories WE evoked the essence of others from practice, from life, that we know to be patients and their loved ones, other nurses, volunteers, doctors, physiotherapists, dieticians and cleaners. I have said hundreds. As the three secretarial staff transcribed the tapes each week they too laughed and cried at the stories. I hope if I ever get sick one of our students cares for me. Separatism/Dualism is the illusion, for in essence there is no here and there, there is only now. In the now we can all be present. For that is how we give ourselves the present, of the presence.

In every new present we can experience love, and in that way create more love by loving what we are doing, which in turn is, to love what we do.

\section{From me to you}

I finished teaching to begin the task of interpreting the narratives, drawings and photographs I had collected as part of second semester activity for the previous two years. As I began to work with the data, the initial sense of joy and wonder experienced in the 
classroom changed. This change was the result of becoming conscious of the very privileged position in which I was now standing. This was so overwhelming at times, I could only hold onto the work for limited periods. Somehow, in feeling such honour and abundance, honour as it relates to integrity, and abundance in the sense of fertility and flow, I also felt that I was not worthy enough to express what I was expressing.

With this sense of worthlessness, I had placed myself in a position which paradoxically required me to stand in all positions. At some level of my Being, I had trusted myself to both hold and carry the preciousness contained within the stories, drawings, poems and photographs, portrayed through illness and nursing, which at the same time were a real reflection of me. When one does not have a strong sense of self worth that is coupled with doubting [not trusting] one's self, it is very difficult to own this reflection. In undertaking the research, I have healed. I now know that I am worthy and trust myself with this power.

From this perspective, data and research, as words, are inadequate to describe that which has been the material (data) to undertake this work, and to convey what I have engaged in. And in the same way that the words, data and research are inadequate, researcher, as a designation of the positions in which I have stood, is to use the word in such a way that it merely depicts an activism. Such can be the limitation of language.

I have said that my desire to engage the students in a teaching learning process where we might all develop a greater insight into nursing to then better serve ourselves and those whom we nurse has directed my action. In this understanding, I now see how this work has taken the form of a practical action to express that intent/thought. To this end, I would now dare to call forth/dream again through my capacity to create reality. That in the ongoing wave of developing further insight into nursing to better serve ourselves and our fellow human beings, that this work will be made available to nurses. And so it remains to be seen how, my intent expressed through 'Nursing as an Aesthetic Praxis' will be realised. For where love has flowed in, it does flow out, in the never ending cycle of receiving and 
giving. In the adage, that you have to be old to handle love is the wisdom of knowing that we are, and always were, worthy. I had only to 're-member'.

From the core of my Being I thank you all for the love that has enabled me to re-member who I AM. For while what has been produced is this research work, 'Nursing as an Aesthetic Praxis', from that which is I, I can now say that I know what we have done. What WE have done, rather, what WE have created, is a love story. We have created a story from love about a way to be LOVE. So yes, you do have to be old to handle love. For it is in the being old that you are more complex and therein lies a key to simplicity. The simplicity which always was, and always will be, LOVE - ALL WAYS. 
And in a workshop facilitated by Jean Houston in response to her instruction to write a letter to ourselves, from ourselves, I penned the following words:

And so in your feeling of worthlessness, so have you opened the door to allow all that you are. We would say dear one - we love you, we watch you in awe, we await you with hearts open wide. Do you remember agreeing to this journey? We said that it would be a most challenging one. You agreed to be challenged! And so you have, and so you have triumphed. Blessed be as blessed does. Give yourself the gift of the wondrous being that you are.

$10^{\text {th }}$ August 2001

And then again the next day:

\section{$\underline{\text { TO BE }}$}

To be

To be love

To be light

To be joy

Without expectation

Without attachment

For the joy of it

For the love of it

For the delight of it

To be

Hast thou no words to express that which you feel in your heart?

Does thou not know God?

How come not, when thou and thee are one

In the wind

In the rain

In the sun

In the trees

The lakes, rivers and oceans

In the one drop, and in the many

The pattern of creation creates

It lives and breathes in every moment

You are that pattern of creation

My greatest breath

My deepest ocean

My brightest sun 
Your radiance is magnificence

Your glory glorious

You are all and everything

Nothing and nowhere

Mysterious and yet known

You are all that you could ever dream of becoming and more

The grandest version of myself

A pearl amongst pearls

A symphony amongst symphonies

A star as bright as any star

My glorious glorious one

I love you

and then

As I 'held the circle' by standing in the middle of the innermost circle of three concentric circles, eighty people dancing an ancient Greek dance witnessed me Be love as an automatic demonstration of being.

$12^{\text {th }}$ August 2001

And so I connected with the fuller expression of me or, that which be I, and what that felt like... 


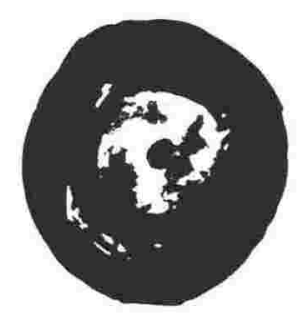

\section{Chapter 2: The Void: The human, Being as an empty vessel}

\section{The nature of Being: nurse and patient}

In Nursing, the theoretical works of Martha Rogers (1970) 'An Introduction to the Theoretical Basis of Nursing', Margaret Newman (1986) 'Health as Expanding Consciousness', Jean Watson (1988), 'Nursing: Human Science and Human Care', and Paterson and Zderad (1976) 'Humanistic Nursing', have enabled Nursing to continue to explore itself from the notion of energy, in relation to the concept of consciousness, and from the dialectic of body mind spirit all framed within the rubric we name health.

Phenomenology as methodology is concerned with the notion of being. The meaning of being has emerged from philosophical inquiry. Nursing continues to explore its relationship to being through considering interpretative methodology as a cornerstone through which to explore the meaning of health and the construct of person that then serves to define and refine its metaparadigm.

Walsch (1997) says that when we speak of being it is the soul that we refer to, and that way being is a function of the soul as opposed to doing, which is a function of the body. Beingness, is a state which the soul seeks (Walsch, 1997). Nursing, through some of its theoretical work does speak to the notion of soul. Nursing practice largely involves itself with doingness through the concern about illness as it relates to the body. Therefore, soul in nursing exists as an idea that is devoid of expression in practice.

The notion of soul is a concept expressed by various disciplines in discipline specific language. In Theology, the words Father, Son and Holy Spirit convey the conceptualisation that we exist as a three fold Being. Father is the soul, because son denotes man and Holy Spirit God. Conscious, subconscious and superconscious are the expressions of Psychology that also uses the words psyche and mind as the interchange for soul then expressed as the subconscious. Energy, matter and antimatter are recognised as 
nomenclature belonging to Science, where energy would be soul. Body mind and spirit and, physical non-physical and metaphysical, reside in both traditional and modern thinking. Mind or non-physical, in these conceptualisations, convey the notion of a tripartite existence thereby inferring the notion of soul as the link between the two points.

Heidegger (1962) describes being in a relational aspect to meaning whereby the innateness, the essence (abstract entity; reality underlying phenomena) of who or what we are, draws forth and engages in existence in such a way that we create the opportunity to uncover that which is concealed.

In Watson's (1988) theoretical works, she raises discussion on transcendental or depth phenomenology and the poetic. While the purpose of positioning this argument is to present her view that the notion of the preservation of truth and depth of experience derived from phenomenology can only be adequately expressed by methods aligned with a correspondence theory of truth, and she says this in the following manner; "There needs to be an ... adapting to the Aletheia theory of truth which is associated with discovery of the unknown, or concealment" (1988, p.93), it is her insight of the adaptation to the Aletheia theory of truth that can connect being and nursing.

The word Aletheia, from the Greek, in an extrinsic/overt/exoteric sense means to heal. The meaning in an intrinsic/covert/esoteric sense implies a process by and through which healing can take place. In the latter interpretation there is the implication that in being we truly exist in a way that is bound in a process by which and through which healing takes place as the adjunct of the discovery of the unknown. Therefore, Watson (1988) makes reference to being in the same way that Heidegger (1962) speaks to the what of or to the purpose of being. This same inference is found in Walsch (1997) who suggests that the soul in its desire for a state of being, be, as a function of the soul.

Heidegger (1962) in articulating the relational dynamic between being and meaning, in his debate on intuition, drives the point home. "Dasein only has meaning so far as the disclosedness of Being-in-the-world can be filled in by the entities discoverable in that disclosedness. Hence only Dasein can be meaningful or meaningless" (p.193). In other words, it is only through being that existence can uncover that which is concealed or the entities discoverable, and that this is the result of how meaning is made by the engagement of the entity in the world. 
In this, then, there is one meaning of, 'meaningful'. The how of it is through the how of the human-being, Being-in-the-world. I make this point on being with much caution, aware of the arguments that exist in the interpretation of being from a phenomenological stance which sees phenomenology as the making of meaning through the subjective interpretation of everyday experience/life. One way in which the how of the human-being, being in the world can be interpreted. And in the second instance, and in a way which Heidegger himself claimed was the limitation of traditional metaphysics. 'Metaphysics conceives of being as beings; it inquires after the Being of beings, but not after Being itself' (Poggeler cited in Crotty, 1996, p.77). Being is integral to both positions regardless of whether a phenomenology does not preclude an ontology because of the assertion that it is not an inquiry on being, in the same way that traditional metaphysics is said not to have overcome. Yet, while this argument is useful, there is a gnawing sense that to view being only from these positions is to somehow limit being. How and why this is so, I am not yet sure.

The notion of being can not be easily defined. Language to depict states inherent in being include, flow and energy, trust truth and purity, allowance choice and responsibility, openness expansion and clarity, balance joy and honour, now experiencing and focus, letting-go creating and confidence, awareness love and unfoldment, knowing power and safety, non-judgement I Am and reality, peace oneness and rhythm, feeling and unlimitedness, freedom intuition and essence, vulnerability and movement, acceptance and Isness.

The notion of Being in Nursing, Taylor (1994) notes, has been directed by the efforts of Nursing Scholars in their endeavour to define Nursing through the metaparadigm concept of person. 'Nurses and patients are beings, who embody Being, that is they are entities within whom existence is situated' (Taylor, 1994, p.7). In this way, Taylor (1994) is saying that Being-in-Nursing is what is, and that it is visible through nurses and patients. It is that, which exists between the person/human-being named nurse and the person/human-being named patient.

Paterson and Zderad (1976), in their discussion on B(b)eing and doing, while pointing out that the focus of nursing is often on the doing because it can be charted, counted and measured, the actual interhuman experience, which they call B(b)eing, is felt and known, but not easily described. In their effort to describe B(b)eing, they identify it as a presence whose effect is known, thereby suggesting that it is this presence where one's attention is focused .... 'being aware of and open to the here and now shared situation, and communicating one's availability' (Paterson and Zderad, 1977, p.14). The word presence, interpreted in a 
physical sense, implies some sort of closeness, proximity, or attendance. On the other hand, presence as what is known and felt would suggest that a definition bound in the physicality of an experience is too limiting a definition to convey the meaning of this phenomena. Expanding upon a notion of presence that is not exclusively bound to physicality while following Taylor's (1994) insight into the situatedness of Being-in-Nursing, I feel, affords a greater scope from which to come to know being.

Heidegger (1962) describes being in a relational aspect to meaning. Meaning is created as an engagement in the world as both a process of our interactions and encounters and an outcome of that process. In this relational aspect of being something, to then become something, the thing becomes meaningful or meaningless (Heidegger, 1962). In this way, a comparison of meaning does not assert a thing to good or bad, but rather as meaningful or meaningless is to imply the expansion or contraction of Dasein. Dasein is the German term for existence. Heidegger (1926) used the word Dasein to denote human being, where being manifests itself. So it is existence that is either expanded or contracted and in that way it is also consciousness. This same argument can be found in Nursing, where Paterson and Zderad (1977) in their discussion of the interhuman experience conclude that "the weight of (B)being is felt" (p.14) and when understood from the notion of contraction or expansion of Dasein, might then be demonstrated as having either a corporeal or affective/sentient effect.

In this way, Taylor's (1994) Being-in Nursing can be positioned to convey what the 'is' is, in the nurse -patient experience and captured in the phrase Being-in-Nursing, that then is further informed by Heidegger's (1962) relational aspect of being and meaning. In the idea of a relational aspect of being and meaning, there is the implication that each human-being is

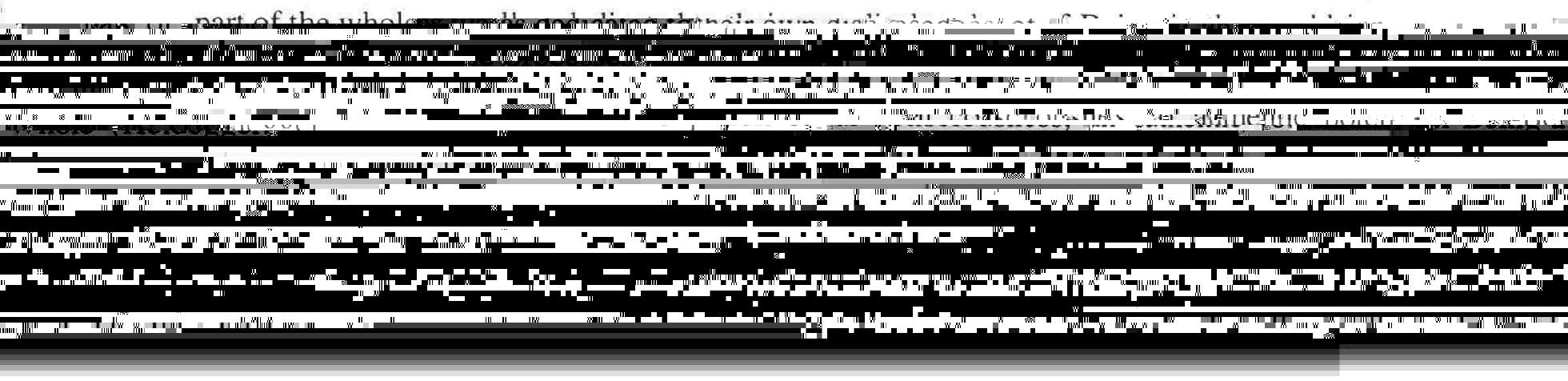




\section{Self in other and other in self}

Reviewing the Cartesian image of self as a reflection, Merleau-Ponty (1972) suggests that the image of the self, reflected in a mirror image, conveys to the viewer an object picture of the self as an image. Because the image is the object conveyed to the viewer, the viewer then chooses to relate to the image, this relationship then providing the link between object image and the self. The image is perceived as bearing no substance dislocated from the viewer. In this way, Merleau-Ponty (1972) invites us to examine the image of self, reflected in the relationship between the viewer and an object. An image of self that is dependent on the viewer choosing to relate to what is being portrayed that then results in a link between object image and the self. In this form of relatedness, the object image becomes real, because it is chosen thing (Merleau-Ponty, 1972). Therefore, the image of the object in relation to the self is created by choice. In other words, we choose to see a thing in a certain way.

Taking this concept and applying it to Taylor's (1994) Being-in-Nursing, it is now possible to perceive that the one whom we have named patient can be an image of the one we have named nurse? The one I name nurse the image for and of, the one we name patient. And while we say that what brings the two together is for one to facilitate care and the other to be cared for, through this engagement in care, can we now not say that through that which we have called nursing and that which we have called illness, we create a background on which to Be-in, a background so that we can Be? This background, Merleau-Ponty (1972) tells us, is contingent upon a choosing to relate. That same background in Nursing, which Taylor has described as
Patients and nurses are beings, who embody Being; that is, they are entities within whom existence is situated. In this sense, Being-in Nursing is 'what really is' in nursing; that is, the nurse-patient relationship as it is lived in health care contexts. The meaning of nursing is embodied in nurses and patients, and it is manifested by them, as they interact daily together.

$(1994$, p.7-8)

Therefore, using the work of Heidegger (1962), Merleau-Ponty (1972) and Taylor (1994) I perceive being to be bound in a choice to relate that then serves to set the intention and in that way call forth. What is called/brought forth has been afar and so now it is nearer and so we begin to be present to the presence. It is an act of allowance. In the allowance is the 
potentiality to be who we are, for in such a state we begin to create a space 'to be'. In this choosing to relate, to be willing, is the possibility of the expression of being, where what we will be, is a choice made in the moment.

In Heidegger's (1971) paper titled 'The Thing', he uses a jug as metaphor to further explore the notion, 'to think about Being'. In his paper, I perceive that the argument is presented in both a sequential and mosaic manner, the effect of which may be likened to an attempt to read ideas that coexist on both a horizontal and vertical axis. This has made interpretation quite a challenge. The point at which I wish to begin a discussion of some of the concepts contained within his paper, and which I see as relevant to the discussion on self in other and other in self, is where Heidegger (1971) asks, how does the void of the jug hold? For it is in the notion of space, I feel, there is further insight into that which is experienced by nurses when the patient is viewed as object self.

The void, Heidegger (1971) says, holds by taking what is poured in. Holding is about keeping and retaining. Both the taking of what was poured in, and the keeping of what was poured in, are said to indwell each other. Heidegger (1971) names this as the twofold holding of the void and draws our attention to the unity which is bound in this relationship and which rests upon the outpouring. In order to hold in this way there is a taking/accepting which is then followed by another keeping/holding. The outpouring is that which creates the authenticity of the holding. Outpouring is distinguished from 'to pour from the jug'. Outpouring, to pour, is to give, and it is because we are able to pour the outpouring that not only do we give, but at the same time we create the holding of the vessel. It is in the pouring out that the holding of the vessel becomes apparent. In this way it is the void that holds. I would repeat this again - it is the void which holds. In other words, the presence is in the space and is either held or not held.

Thus what we perceive to be empty/a space is that which holds and upon which the outpouring can manifest. This Heidegger (1971) explains is because the nature of the holding void is gathered in the giving. What is meant by the nature of the holding void, I interpret as the essential quality of the space which has both taken in and kept what has been poured in and in this way has gathered. The alchemy of this process, what has gone on in the void, is then the poured gift. "We call the gathering of the twofold holding into the outpouring, which, as being together, first constitutes the full presence of giving: the poured gift" (Heidegger, 1971, p.172). 
Therefore, it is in this outpouring, the poured gift, that Heidegger (1971) shows us not only what makes the jug a jug, but what has been poured into the void and held/kept and then poured out, is what creates the relationship between the 'three fold'. Heidegger (1971) uses sky, jug and earth, and this is not to be confused with his later use of earth and sky, divinities and mortals, but the use of sky jug and earth could just as easily be described using any of the nomenclature outlined in the first section that speaks to our existence as a three fold Being. Being here is a noun as opposed to a verb. Jug then, would be another metaphor to name a mortal and jugging the function of the soul, namely Being and in this sense a verb - being. Therefore, by the very nature of what nursing is, there is a potentiality created between two beings whereby the nurse can choose to open the space within herself in which she can hold something. The space holds. How she holds, determines the alchemy upon which the outpouring rests.

Heidegger (1971) goes on to further examine the outpouring that becomes the giving of the gift. The outpouring is discussed in such a way that it may be viewed on two levels. Heidegger (1971) uses water as an example, and while water quenches a thirst and is refreshing, it is just that, water. On the other hand the outpouring can be that which is consecrated or sacred, and Heidegger (1971) describes this as the outpoured in the first instance which is the inpoured or sky. Again using the example of water, water this time is a poured gift but not in the sense that it is water in an inn or a drink for mortals (Heidegger, 1971) but outpouring then as that which is the libation poured out for the immortal gods. This then is the authentic gift, the real gift, and it is in the giving of this consecrated libation "that the pouring jug occurs as the giving gift" (Heidegger, 1971, p.173). In other words, something has happened in the void in such a way that it has come out the way it went in. However, to do so, the shift has had to occur within the void for it is the void that has been able to hold and keep. This is a consecrated gift, and as such it is sky.

The word for a strong outpouring flow or gush translated from German and Greek means to offer in sacrifice, to donate, and hence 'to give' (Heidegger, 1971). When the gift of the outpouring is water, man/mortal/matter stay in their own way. Where the gift of the outpouring is a consecrated libation, divinities stay in their own way (Heidegger, 1971). "They who receive back the gift of giving as the gift of the donation", Heidegger (1971, p.173). In other words, that that which came from divinity/sacred/godly/immortal/spirit and given out as divinity/sacred/godly/ immortal/spirit is then made divine/godly/immortal/spirit. Heidegger is telling us very plainly, that that which the void held and kept and then gave out, is that which the void becomes. What the void becomes, is then what the jug is/becomes. Unless of course, the holding is a mere filling and decanting, an unauthentic gifting 
(Heidegger, 1971). In this way, the unauthentic while having a meaning, in the context of sacred/divinity becomes that which is meaningless as in the outpouring of mere water.

Martha Rogers (1970), in her 'Introduction to the Theoretical Basis of Nursing', presented nursing with the idea that man/human is an open system. In her view, human beings have an energy field not separate from either the environment or universe. Quantum physics on the other hand has shown that human beings are not just cells organised into particular body organs and categorised into various bodily systems. That in fact we are made up of space, and that space accounts for hundreds of thousands of times more of our volume than the mass/matter that is normally considered the physical body. The space, it has been recognised, is not a mere void, an abyss or hollow, but rather, the space has forces, it holds energy. The space is energy and the energy actually holds particles in particular patterns, without which the particles would explode, into the universe. The subatomic particles are 99.999\% space, and held by the titanic forces that the space contains. The effect of these energies are, that we continue forever throughout all space and time as a continuance across the entire universe because these energies, their minute differences, mingle with those from every other physical thing in existence to cause the universe to be as it is. In this way, a human being, a mortal, cannot be conceived as being separate from the universe nor the universe as being separate from human beings. This being so, then human beings cannot be separate from each other.

In presenting the idea that man was an open system, Rogers (1970 and cited in Madrid \& Barrett 1994, and Malinski \& Barrett, 1994) opened up the possibility in Nursing that the universe does not merely flow around human beings, but that the universe is in us and we are in it. In this way, the notion of connection, which has been the focus of much discussion and exploration in Nursing, takes on a more expansive meaning and makes Heidegger's (1971) outpouring into and out of the void more conceptually graspable. While questions remain concerning what and how the pouring occurs, none the less, what is seen is that we can call forth something in some way that potentially can alter the very order of nature of the universe, and at the same time is already who we are.

Heidegger (1971) moves his discussion along to further examine the outpouring, the gift of which he names a fourfold. This fourfold, is constituted by mortals and divinities that reside separately, and earth and sky whose relationship is also said to be separate. However, in the gift of the outpouring, gift in the sense that it is a consecrated libation or that which is authentic, they become one, "together all at once" (Heidegger, 1971, p.173). While this could be interpreted as a kind of combining of ingredients, my focus is drawn to 
Heidegger's choice of expression that makes a distinction. Together all at once could imply that the four dwell in such a way that they are well aware of each other but there is something that determines how they are drawn together. At the same time this togetherness, Heidegger (1971) says, is because that is how they belong. "In the gift of the outpouring dwells the simple singlefoldness of the four" (Heidegger, 1971, p.173).

Where the gift of the outpouring is received it is because each of the four has remained as earth and sky, divinity and mortal. Together in such a way that each retains its individuality, but at the same time reflecting a oneness. "Staying appropriates in that it brings these four into the light of their mutual belonging" (Heidegger, 1971, p.173). A relationship which is binding and separate. Where by their union, for in truth they are united - "at one in thus being entrusted to one another" (Heidegger, 1971, p.173), the process of which is what can become 'the gift' of the outpouring. "What is gathered in the gift gathers itself in appropriatively staying the fourfold. This manifold simple gathering is the jugs presencing" (Heidegger, 1971, p.174). The question then as it relates to this discussion is, what is it that enables the four to be as not only one, ie single, but also one, together, so that there is a connection or presence? In the answer to this question lies the revelation of the four.

Paterson and Zderad (1976) define presence as "a mode of being available or open in a situation with the wholeness of one's unique individual being, a gift of the self which can only be given freely, invoked or evoked" (p.132). In this way, presence implies that which exists also has to stay or be present in order for the gathering to take place. For that which can/does exist in the space/void, from where the call is sent forth so that the presence is either invoked or evoked, is what draws the fourfold. Where the fourfold become onefold, both Heidegger (1971) and Paterson and Zderad (1976) in respect to the presence term it a gifting. The gift we give to ourself is the gift of the self.

This gift, or consecrated libation is an authentic gift and realised in the meaning of Aletheia where what has been concealed is revealed is the outcome of what has taken place. Aletheia is a process of uncovering. "It brings the four into the light", for that which is concealed has been hidden in the dark (Heidegger, 1971, p.173). To bring the four into the light is to illuminate. When a thing is illuminated, it is more easily seen. Then that which binds each to each other, the gift of the outpouring stays and the jug presences as a jug (Heidegger, 1971). In other words, each of the four are bound in a way that serves the jug coming to know itself to be a jug, to have consciousness of itself. In this process the four become unconcealed. 
"The gift gathers what belongs to giving: the two fold containing, the container, the void and the outpouring as donation" (Heidegger, 1971, pp.173-174). In this gathering, is the jugs presencing. Gathering, which Heidegger (1971) says is an ancient word that means 'thing'. The jug is only a jug as long as it 'things', in other words, as long as it gathers (Heidegger, 1971). I would suggest this same axiom can be found in Rogers Principle of Helicy, "The nature and direction of human and environmental change is continuously innovative, probabilistic, and characterised by increasing diversity of human field and environmental field pattern and organization emerging out of the continuous, mutual, simultaneous interaction between the human and environmental fields and manifesting non-repeating rhythmicities" (cited in Malinski and Barrett, 1994, p.228).

So while I cannot yet articulate what the fourfold are, what is apparent thus far is that as a human being we are the space through which the gift is revealed. Whether a gift is revealed is determined by how the gift is held in the space. When held in a way that the four are 'appropriatively staying the fourfold' the gift is poured. In so doing, the gift as gift becomes revealed. Integral to this is the four that while individual are bound to one another as one. While Heidegger (1971) names the four as, earth and sky, divinities and mortals, and makes the point that they precede everything that is present and are enfolded into a single fourfold, I am yet to articulate what this means as it relates to the void. What is apparent though, is that in gathering or thinging, being, as a function of soul, is what goes on in the void connecting the souls and spaces through the portrayal of images of ourself to ourself that is in some way revealed through one another.

Heidegger (1971) continues his exploration by working with the meaning of the word 'thing'. He examines the use of thing in: Old High German (Ding), Greek (causa), Latin (res), French (chose) and English (thing) and while I will not repeat the discussion here, Heidegger (1971) concludes this section of his paper by holding to his original argument, "that the jug is a thing insofar as it things" (p.174). "The presence of something present such as the jug comes into its own, appropriatively manifests and determines itself, only from thinging of the thing" (Heidegger, 1971, p.177). In this way, that which is, can only be, when it is that which it already is. Then it is made manifest/revealed/illuminated.

Having ascertained that each of the four is integral to gathering and as already has been said, gathering is process within the void, the outcome of which is an outpouring Heidegger (1971) tells us by thinging the four are brought nearer in their remoteness. Near in this way I perceive is not to convey a sense of spatiality, rather, implies an indwelling as the potential of a greater connectedness. Heidegger (1971) says that nearness preserves farness, nearness 
presences nearness in nearing that farness. Further, the definition of Dasein in German means being-there so as to denote being human where Being manifests itself. In that way Dasein supports the concept of a potential connectedness that is not an either or thing, but in the process of Aletheia is an ongoing illumination of the dark where always there is the potential for more light and as such the nearness that preserves/guards against farness.

Rogers' (cited in Malinski and Barrett, 1994) notion of an open system perceived human kind to be in the universe and the universe to be in human kind thereby portraying existence to be without boundaries. This then stands in stark contrast to belief about existence that is confined to the boundary of the body. Heidegger's (1971) idea of nearness preserving farness within a context of an open system invites the possibility of considering a greater connectedness that is brought about by calling something forth so that it can be made nearer. In this way, what is called forth can be conceived of spatially as being within, because if it exists in the furthermost corner of the universe it must also exist within for the system to be open. An open system consists of energies continuing forever throughout all space and time across the entire universe, their minute differences mingling with those from every other physical thing in existence. As such these energies cause the universe to be as it is. In this way, if what exists without also exists within, then within and without are a reflection of each other and existence, adding Heidegger's (1971) line of thought, is a state of mutual belongingness brought about by the nature of the relationship of the four which is said to precede everything that is present. Accepting this argument it then becomes possible to speculate on the relationship between one person and another where being might bind us together in some sort of horizontal relationship, person to person, in ways we have barely begun to comprehend.

As an open system, I am in you and you are in me, as our energies mingle with all energies in the universe. Therefore, when I nurse you, you are in me and I am in you, where in being we 'thing', that is the potentiality of the gift of uncovering/healing/Aletheia.

\section{Reflection before refraction}

Levin (1988) in his exploration of vision points to the human phenomena of crying as a way of reminding ourselves of our need for a vision of the whole. A vision of the whole is vastly different from a vision that names and frames. The human phenomena of crying is the end stage of a revelation that occurs in moments of profound learning (Levin, 1988). We cry having seen something, crying is an expression of the need to see. It is vision expressed, and thus gives vision its historical task (Levin, 1988). Crying is an expression that distinguishes itself from everyday seeing to seeing that can be described as visionary, 
because it is "as a transformation of its relatedness to Being" (Heidegger as cited in Levin 1988, p. 174).

As a historically motivated form of suffering, crying brings background into the foreground, and when seen as such, crying becomes vision expressed, it is the outward manifestation of insight. This way of seeing, this sight, is a particular moodedness, a moodedness where vision is clear. The clarity is in the ability to be moved deeply by that which is seen (Levin, 1988). Crying is therefore grounded in what we perceive we need, needs which are not egoic in nature, but derived from 'the self' (Levin, 1988). Need then, not in the sense of a lack of but, rather, need in a sense that is a yearning. For to yearn is to will, and in order to will, one has to choose. To choose, as has already been 'seen', is to begin to gather. In gathering, we are beginning to 'thing'.

So what then is crying when it is grounded in the vision of our needs? Levin (1988) says it is the need for openness and contact, the need for wholeness itself. Yearning is inherent within us in such a way that we cannot ignore its call. To do so is to deny who we truly are, and try as we may we cannot deny that we are true and so this then engages us in being to create the ground of our being (Heidegger cited in Levin, 1988). To yearn, then, is the comportment that is universally tuned to the "openness of Being as the whole" (Heidegger cited in Levin, 1988, p.175). In this way vision is a process, a process of the relationship that we have with ourselves. A relationship which is a practice of care and is directed toward the openness of Being (Levin, 1988) "Vision needs real closeness, contact" (Levin, 1988, p.175). Therefore, crying is immersed in the ground of our very being.

My eye, Merleau-Ponty (cited in Levin, 1988) claimed is a particular power of connecting with things. And it is this trueness, for we are true, which is experienced when we connect with each other. It is a way of relating which is authentic, a way of relating that each of us yearns for - whether we are aware of it or not. For it is in the relating that there is the reflection of that which is within us, so that what has been gathered can be held within the void. We gather and then hold, and when we do so there is the potentiality of the pouring out as the authentic gift, the presence of what is present. It is this pouring for which we yearn, and which can be made manifest, through our connection with each other.

In a phenomenological sense, crying has called us to think very deeply on how our vision needs to feel that intertwining to the pattern of the visible as a whole (Levin, 1988). "This need is a need ... for healing" (Levin, 1988, p. 176). It is our primordial yearning. We cry when we have seen, we cry to see. In such vision, we are uncovering that which we have 
concealed. In the Aletheia of suffering, we allow ourselves to see deep within the void and our vision is felt, felt and expressed in the flow of all things. Our connection is deeper.

We are more open. More open in the sense that the space within us has changed because, the void is changed.

At this point I would play Heart of Perfect Wisdom sung by On Wings of Song \& Robert Gass, Spring Hill Music 1998. This recording, by a choral group, of a traditional Buddhist chant conveys the essence of Buddha's teaching where to free the self from attachment to the personality and the world of senses, is to be free. The Buddha said, "that his disciple sitting in the depths of prajna wisdom (that true wisdom that is beyond intellect) saw the emptiness or void ..." (Gass, 1998).

Martha Rogers' (cited in Malinski and Barrett) argued that "in a universe of open systems, causality is not an option" (1994, p.235) and therefore fields of energy are open. The human field and the environmental field indwell while in a state of constant change (Rogers, cited in Madrid \& Barrett, 1994). A particular energy field is distinguished by a pattern. "Pattern is an abstraction and reveals itself through its manifestations" (Rogers, cited in Malinski and Barrett, 1994, p.247). In other words, what is in our world exists, because energetically it exists. Each human field pattern and its relationship to the environment is unique, and it is this relationship between the human field and the environment that can be called pattern making. It is this latter phenomenon that is described by Rogers' Principle of Integrality: "The continuous mutual human field and environmental field process" (Rogers, cited in Malinski and Barrett, 1994, p.235).

The word reflection means to show an image of reproduction to the eye and mind exactly corresponding in appearance or effect. Rogers (cited in Malinski and Barrett, 1994) takes the position that energetically the pattern of each human field is individual. This being so, how then do we show an image that is exactly corresponding to each other and what is it that draws us to one another? For if what is in our world exists, because energetically it exists, it is then possible to suggest that while field patterns are individual, that which makes up a particular field can be what at one level connects us in our humanness? Such a possibility would then allow for an expanded vision of Roger's Principle of Integrality, whereby the notion of mutuality is located in a form of reflection and from which a fuller understanding of the environmental field process may then begin to be enunciated. Why? We do not yearn alone, we are not alone in calling and we cannot uncover alone. How could it be otherwise, when we are in the universe and the universe is in us as an open system. We are not separate or defined by the boundary of the body? Is not our wholeness something to do with 
ALL ONE? What is created, when two or more gather? Is it, as Paterson and Zderad (1976) suggest, "Whenever two persons are present to each other as human beings, ... they can know each other within themselves" (p.29)?

Dilethy (cited in Ermarth, 1978), discussing the concepts of life and lived experience, argues that by grounding the human sciences in the standpoint of life, one can then view life in a way that does not limit the view to a private subjectivity, but rather creates a potentiality for vision which is panscopic. Panscopic because the complexity of relations encompassed by the social, cultural and historical worldview can then be focused upon. In Dilethy's view, (as cited in Ermarth, 1978) this focus, this set of relations, is life. "External objects are to be sure components of lived experience and as such belong to the sphere of life itself" (Dilthey cited in Ermarth, 1978, p.126). Thus reflective awareness is not mere subjective awareness or an introspection, for the self is not without an objective reality, an outer reality. Self reflection then is at the same time a reflection upon the relation of the self to an external reality, an external reality that is an image that is not an independent object. In this way, the relationship is not separate to an opposite object, apart from awareness (Dilthey cited in Ermarth, 1978). In other words, given a state of awareness, what Dilthey is telling us is, when I see you, I can see me. "Self consciousness and consciousness of the world are only two sides of the same consciousness" (Dilthey cited in Ermarth, 1978, p.126).

Rogers (cited in Malinski and Barrett, 1994, p.241) defined pattern "the distinguishing characteristic of an energy field perceived as a single wave", and that the Unitary human being (human field) and Environment (environmental field) are energy fields identified by pattern thereby accounting for what is in our world. What is in our world is, because it exists energetically. Dilthey (cited in Ermath, 1978) says that we reflect the world to each other through our consciousness of it. A consciousness which has been created by the relationship between our social, cultural and historical world, which becomes the matrix we call life. Therefore, if what exists, exists because it exits energetically, that is, it is made up of patterns, and our consciousness of our inside world is reflected to us in our outside world, then we are drawn to one another because of what exists within our consciousness. I wish to labour this point. I am suggesting that what in fact draws us to one another is that which exists within our energy field, and while each human being has their own field pattern, like is drawn to like. Why? For when I see you, I can see me. In this way we 'gather' and 'thing'. I wonder then, if this serves uncovering?

We reflect our wholeness to one another. Such a notion then raises questions about the therapeutic act of nursing where the perception is that nursing is done to another and where 
the one we call patient is a passive recipient of the actions of another called nurse. When Nursing is viewed from an awareness of being, then those whom we call nurse and those whom we call patient are one and the same. And while one presents with the manifestation of an illness or disease or a health issue, and the other is present to be of assistance to that other human being, what can take place through the human to human interaction at this level is a form of healing for both. It is as Taylor (1994) has described it, where she defines the form of existence between nurse and patient in relation to Being and the notion of meaning making as the manifestation of that interaction. This same phenomena is articulated by Paterson and Zderad (1976) in their discussion on Being and Doing in Nursing. Being is described as simply a presence, a presence that, when experienced, the effect is known. "It is this presence where ones attention is focused upon the patient .... being aware of and open to the here and now shared situation ..." (Paterson and Zderad, 1977, p. 14). The key words here are, where one places one's attention and focus, and that the situation is shared. Therefore, given a state of awareness, and by that I mean a state of consciousness, as I move about my historically socially and culturally constructed world, I do so knowing that each and every human being I engage in existence with can be the other side of the same consciousness. That is, object image, not an independent object. In this way I can see me, I can envision who I am in this now moment, and at the same time know that there is more.

The word refraction means to deflect at a certain angle when a beam of light enters obliquely from another medium of different density. Rogers (cited in Malinski and Barrett, 1994) defines her Principle of Resonancy as, "continuous change from lower to higher frequency wave patterns in human and environmental fields" (p.262). I wonder, through the process of reflection do human beings change their field patterns, and as we each do, are we are in fact changing the frequency of our human field pattern? In addition, while an individual can raise or lower their frequency, when the frequency of the human field pattern is increased does this mean that the pattern is then conscious? If so, is this the expansion or unfoldment of consciousness while holding the memory of the old pattern, albeit in a different form? The memory held differently becomes the new ground on which to be. Light has entered obliquely from another medium of different density on this ground of being. This light is energy, light as consciousness, light that is refracted or straightened. This refracting or straightening of the light would then be the essence of human care that is an enabling of each other through our common yearning to be true that is mobilised as we universally tune into the "openness of Being as a whole" (Heidegger cited in Levin, 1988, p.175).

In being able to refract the light I call forth, I call from the core of my own being. I reach out and guide another to this place of knowing. I can only do so, in the first instance, when I 
am conscious of the pattern, that is, when I have the map on my own body. When the knowing is embodied I am consciously able to support another to straighten their light. In having raised my consciousness that in the first instance has been brought about by me being, through the form of a reflection to show that image.

\section{Action as both outcome and intent}

The word action, is commonly used to communicate the notion of doing. Action means movement/response/energy and therefore implies that at some level of our being we are in a state of constant motion. Outcome, on the other hand, conveys a result of action, and thus we easily connect the words action and outcome, that is, as a consequence of certain activity we assume a predictable result. The word intention conveys some sort of plan or aim and is also defined as meaning.

Such a way of being in the world then, planning action and result, assumes a worldview of predictability or non causality. Nursing epitomised this pattern of thought with the introduction of the Nursing Process: assess, plan, implement and evaluate. Indeed, a whole system of care delivery was constructed around this rational linear deductive model. A model that seemed functional until we began to attempt to quantify nursing activity, assisted by the push for economic rationalism, based on expected outcomes deduced from stated intentions (or goals or standards). We, like many other disciplines in society, were attempting to determine and predict human behaviour. Ours was to visualise a horizontal axis of health and illness within some sort of objective framework that had behavioural, cognitive and affective domains. The experience was, that such a model not only raised questions about what we perceived health to be, or what we meant when we used the words person and environment as recognised domains of metaparadigm work then lived out in practice, but clearly became another catalyst in our ongoing endeavour to make more visible the complexity of what it is we do when we nurse, and what it is we mean when we ask the question, what is nursing?

From this way of exploring, the movement/outcome was that we saw a plethora of theory development during the seventies. A plethora that coincided with the re-emergence of the Nursing Process in the practice arena. From this activity, it can now be argued, we created a new ground to continue to envision nursing. This space, this new ground, was opened because some had begun to recognise that the so called measuring sticks for this system could not even measure the three behavioural domains. At best, nursing was reduced to 
activities connected to some behavioural objectives concerning biological outcomes which in no way reflected the totality of activity or action and outcomes experienced in practice. By this time, the practice world was outraged. As the framework was debated defined and redefined, nursing added another dimension, albeit in an attempt to demedicalise its language not withstanding the language of communicating pathology of disease, by creating its own language. Such action was born from the intention of continuing to identify and communicate a specific body of knowledge. In the process, in the sense of action, by identifying the independent dependent and interdependent domains or role functions of nursing practice, nursing argued it could separate itself from the domination of allopathic medicine. We called this new language Nursing Diagnosis. And regardless of whether the language was, or was not used, this process model of the fifties that was then shaped and reshaped over the next twenty years, remained firmly entrenched in a particular world view that then influenced practice, education, and research. Toward the end of the seventies nursing began to see how such a perspective had limited our worldview of our discipline. Nursing, whose activities call together the cornerstones of the health of human-beings, who we are, and our engagement in what we call life. While we had remained immersed in modernity for the best part of another decade and a half, we then attempted to move ourselves by embracing a new set of constructs under the new doctrine of post modernity.

In this way, our actions have created our experiences. The models, the theories, the frameworks, the objectives with their intended outcomes, when viewed on a vertical axis, an expression of the whole can be layed out as a mosaic. In viewing this mosaic from the whole, then what it represents is the outcomes of the various intents. That is, by the activity of Nursing, Nursing has engaged in intent and outcome as its natural evolution. When seen in this light, no action can be deemed better or worse, right or wrong, as having a beginning or an end, a start or finish, rather, each action has been the expression of an intent and outcome. And as we have stood on the threshold of one century to then move into the next, can we not say that our intention has always been to serve humanity in the context of health care and that the outcome is the dogged persistence to continue to do so? I perceive that we can. Each action represents a movement of Nursing and Nurses, and in that way is the expression of both our intent and outcome.

In outlining the argument in this manner, I am aware that I have raised some fundamental questions. Questions that are centred on what it is that guides our actions, and how an outcome is the actual intention, even when the outward appearance would contraindicate it to be so. Having said this I remain firm in this relationship of outcome and intent and therefore in order to reconcile what appears to be a contradiction would explore this idea further. 
Hillman (1996) suggests, if we want to begin to change how we 'see' things, we need to fall in love. For love, he says, is redemptive in that the what of our day to day existence having been perceived as worthless can then become useful and reclaimed (Hillman, 1996). I would say, meaningful. In order to do so, Hillman (1996) explains this as process by using the word symptom. Symptom, in the sense to mean a combination of accidental happenings, that then are happenings or symptoms. That is, what we create, what we do, on a day to day basis, is neither good nor bad but rather, "coalesces this with that into an image" (Hillman, 1996, p.34).

Symptoms are not viewed from a disease orientated framework. Symptoms, Hillman (1996) says are about destiny, destiny in the sense of some grand overall plan. This, I perceive is what is meant by falling in love. Symptoms as destiny means to be able to release the attachment to a specified outcome in the knowing that the outcome is the intent and that what we do is but a reflection of this. This idea stands in stark contrast to ideas of intent and outcome when an outcome is experienced as not congruent, with an expected outcome. In being able to view symptoms as destiny, we caste aside both fear and moral reasoning, because symptoms become regarded as what they are, phenomenon, phenomenon to be looked at (Hillman, 1996). Then, and only then, can we see how a particular symptom has opened us to more of our destiny. A destiny that is free from both fear and judgement, because it is a destiny created from and in love. It is a destiny which is not an accidental happening, for it is our destiny which we are uncovering (Hillman, 1996). Therefore, in this idea that an outcome has been the intent, even when it would not appear to be otherwise opens up the possibility of a new view. By placing the attention on the outcome as an awareness, it might be possible to begin to make the true intent conscious, and in that way change that intent and in so doing create a new outcome. This then is more congruent with the idea of a destiny, that is destined to be true, where a key in the movement between outcome and intent, is love. This is what I perceive Hillman (1996) meant by falling in love.

I would conclude this section of the chapter with the concepts with which I began. The word intention conveys some sort of plan or aim and is also defined as meaning. Action is commonly used to communicate the notion of doing. Action means movement/response/energy and therefore implies that at some level of our being we are in a state of constant motion. Outcome, on the other hand, conveys a result of action, and thus we easily connect the words action and outcome, that is, as a consequence of certain activity we assume a predictable result. What I have argued here is, that our actions are guided by our intentions and that the outcomes are also the intent, even when the outward appearance 
would contraindicate this. To begin to see this is to experience life in a redemptive sense through falling in love. And it is this ability to experience life as love that then changes our vision, for then life is experienced in a way that moves us beyond moral reasoning, and intellectualisation, because life is then accepted/allowed as Is.

\section{Process or product}

Levin (1988), in examining how Heidegger has interpreted the word Logos, says that the word was used to denote gathering. Gathering, in the sense of "the gathering of the lighting that gathers all visible beings into its field of unity" (Levin, 1988, p.443). Levin (1988) points out that there is much evidence throughout history within our myths, poems and philosophies, which suggests, in a metaphorical sense, that we turn away from the light and yet, if we would but turn ourselves toward it, our vision, our sight, could then become a gathering. Gathering, which Levin (1988) says, "inscribing in the openness cleared for events of light a gesture of gathering repeats, and in this way makes visible, the more primordial gathering upon which it essentially depends" (p.443). In other words, when we choose to open ourselves, we open ourselves to the possibility of lightening, and in this way we can become lighter, for we are light/energy beings, for it is from light that we have come. Gathering then is process and spoken of metaphorically, we look upward, "an upward glance that spans the between of the sky and earth" (Heidegger in Levin, 1988, p.443). An upward glance, which is no mere lifting of the eyes, our vision, in a heavenly direction, but is, I would suggest, a calling. A call to gather, so that we might thing.

Paterson and Zderad (1976), in their discussion on process - choice and intersubjectivity, begin their argument by suggesting that, if nursing is to be a truly humanistic process, then it is has to be demonstrative of the nurses' awareness that through the action and activity of nursing that we create the possibility for the development of the human person. In this way nursing reflects the existential notion of becoming through choice and intersubjectivity (Paterson and Zderad). It is this notion of choice and intersubjectivity, which I think, directs our vision toward what Heidegger (1971) and Levin (1988) term gathering. This same phenomenon is presented within the thematic philosophical underpinning of the Patterson and Zderad (1976) Theory of Nursing. While I do not wish to take the debate along an existential argument, in the sense that from the human to human encounter we can become more and in this way focus on the potentiality of product, what I am arguing here is, that by shifting the attention again to then look at process, action can be viewed as both the outcome and the intent, and in that way our gaze is directed at gathering within the context of an 
intersubjectivity and choice that then is revealed in outcome to uncover the intent. Action as an intersubjectivity and choice, realised as outcome from which the intent is made visible. In this way, it may be possible to reveal true intent and in that way make real the true intent of Nursing.

Paterson and Zderad (1976) in suggesting that we are our choices, say that in order to recognise this there needs to be "an openness to and an awareness of one's own situation" (p.17) thereby positioning choice is a response to possibility. Possibility in the sense that we are our choices, that in each situation we not only have choice, but we have choices, that is realised in alternatives/options. Here-in, I believe, Paterson and Zderad (1976) have bought to our attention a crucial point. In order to choose, one has to be open. Openness which is experienced both as freedom to choose and freedom from habit/routine - responding to a given situation in the usual manner (Paterson and Zderad, 1976). Thus openness creates an allowance of the self to be, without judgement. Openness means getting in touch with one's experience, one's subjective world in the way Hillman (1996) describes as redemptive And yet, while we are independent subjects, we act from our human capacity to disclose or enclose ourselves and thus there is no certainty that "the availability and presence necessary for a genuine confirming encounter will come forth" (Paterson and Zderad, 1976, p. 17).

Rogers (cited in Malinski and Barrett, 1994, p.235) said that, "causality is not an option" in an open system because change is innovative. And while change is innovative, this capacity to enclose or disclose ourselves, as presented by Hillman (1996), when seen from the perspective of choice then positions causality as a possibility within an open system by suggesting that an effect as outcome is determined by choice. Then it is possible to conceive of the notion of presence being given freely. Where "presence, the gift of one's self, cannot be seized or called forth by demand, it can only be given freely and be invoked or evoked" (Paterson and Zderad, 1976, p.17). In that way we choose whether to be open to our world and, and having made that choice we can choose again, because at some level we do know that, we cannot not think. That then would be congruent with exploring an open system as innovative or open to change but in which there is causality where choice is the bridge between the two.

In choosing, we can choose to respond, responding which requires that we experience our subjective world. In this way we call forth, we invoke or evoke a presence, the gift of one's self to create the possibility in the way Levin (1988) has described, "as inscribing in the openness cleared for events of light a gesture of gathering repeats, and in this way makes visible, the more primordial gathering upon which it essentially depends" (p.443). And in 
this process, this process in which there is presence, the gift of one's self, the what of the notion of presence in relation to the 'between', a crucial element to the Paterson and Zderad (1976) theory is, I argue, the same phenomenon Heiddeger refers to when he speaks of the "upward glance that spans the between of the sky and earth" (cited in Levin, 1988, p.443). What we are calling, through our intention/thought is, that which spans sky and earth, and I perceive is, our own soul. Not as a spatially defined entity but in the way that I have argued using Heidegger's (1971) notion of nearness and farness as it relates to connectedness, and the Paterson and Zderad (1976) idea of presence that can only be invoked or evoked by being.

It is this, our presence, that is the connection between our mortality and our divination - "the more primordial gathering upon which it essentially depends" (Levin,1988, p.443) and it is from this space, I perceive, that through the action and activity of nursing, we create the possibility for the development of consciousness through the ground of our being. This, then, is not product, but rather as Paterson and Zderad (1976) have said, it is what the interhuman dimension of nursing is about, "a quality of being that is expressed as doing" (p.13). Being, which I have argued at the very beginning of this chapter, is a function of the soul.

In choosing to title this chapter 'The Void: The human, Being as an empty vessel', I have presented the idea that we can begin to look at Nursing not only from the perspective of what it is we do to, with, and for another but, rather, what it is that can go on in the space, the space that exists both between and within one another. In this way, it is possible to refocus in order to create a new vision, a new vista from which to expand our consciousness. This new vision has, as its starting point, possibilities about the $99.99 \%$ of the human, the 99.99\% which is space, hollow - The Void, through which the gathering can take place.

Researchers have found evidence of an enormous black hole located at the centre of the Milky Way Galaxy. Data from radio waves and telescopes indicate that the gigantic black hole is 2.6 million times the size of the Sun ...... This is the gravitational anchor that all other objects in our galaxy including the Sun are revolving around ...... The study said the massive black hole caused stars to speed by the Sun at 3.2 million $\mathrm{km} / \mathrm{h}$.......... had found evidence that the universe did not have enough matter to stop its expansion and may continue forever without collapsing.

Herald Sun (1998, p.18)

As it is above, so it is below. 


\section{Summary}

This chapter starts as an exploration of being grounded in descriptions. Using the work of Martin Heidegger and David Levin, I identify 'yearning' as how we engage ourselves in being. The discussion then moves to identify being as being situated in human beings, lived out through a form of connectedness.

The essential nature of this chapter has been to raise or bring into the reader's awareness being as positioned from a phenomenological perspective so as to highlight nursing's endeavour to define person through metaparadigm in its theoretical development and in that way begin to explore the notion of who we are as human beings.

The notion of reflection as an image of self is then explored in relation to personhood so as to further explicate the situatedness of being within a being, being, and in that way provide insight into - how a being is being.

This chapter has also introduced ideas from quantum physics that can be linked to Rogerian Science and in that way the work begins to explore being from an energetic perspective so as to be able to introduce the notion of intent and outcome. In this way, the groundwork has been layed to begin an argument of cause and effect from the position of predictability in an open system that then begins to frame person hood from this position. 


\section{||||}

\section{Chapter 3: Aesthetics in Nursing}

\section{Form in Nursing}

In speaking to the notion of form, my intention is to convey the appearance, shape, or composition of something by focusing my attention on it. Focusing on a thing is to think about it thereby directing energy in such a way that the thought can be made real. In this way, to convey the appearance, shape, or composition of nursing, its form, is by focusing on nursing.

Many nurse scholars have attempted to shape/pattern nursing. Much of that shape has been through the exploration of that which is visible to the naked eye or ear and in that way the focus has largely been directed outward. By this outward gazing we have hardly noticed the inside and therefore been unaware of what is felt in nursing. And it is precisely that, that which is felt in Nursing, that I intend to focus upon. For what is felt in nursing, by nurses engaged in nursing care, has the potentiality to refocus our focus and so bring forth what largely has been background. This background becomes a new foreground from which it is may be possible to convey form.

Nursing's oral history has been a reservoir for storing feeling. Storytelling, as a form of oral history, has emerged from the sitting rooms and bedrooms of 'Nurses Homes' to become both method in research and process in teaching. This shift in conscious by focusing on experience has revealed story to have served as a guardian of form in nursing, by locating form as being non-spatial. Storytelling is timeless. The essence of a story is embedded in such a way that is independent of context, because feeling is both timeless and acontextual. Therefore, story can act to transport the listener in time and place in such a way that a sense of presence is evoked or invoked, for presence is also timeless and acontextual. Presence exists in the now moment. Presence in nursing, is where the true acts of nursing take place, it is the place where the weight of being is felt. Therefore, story holds this knowing of form in such a way that it creates the space to allow one to see an image and in so doing reveal a 
shape, appearance or composition. This vision is insight, and is bound to the realisation of our yearning as we make real the openness of being as the whole that has its origin in feeling. In feeling we see, through this real closeness or contact form can be conveyed.

My challenge is to use the thesis as a vehicle to express how I as a nurse feel, and then create text that makes the form visible in such a way that the essence, the aliveness of the dialectic of nursing conveyed through how it has been lived [experience] and then transcribed [the story], does not become lost because it is dislocated from the whole.

\section{Emotion and feeling}

The word emotion is defined as, a disturbance of the mind, a mental sensation or state, an instinctive feeling as opposed to reason. In the projection of a disturbance of mind there is a potential to interpret this state as undesirable thereby dismissing or subordinating emotion that by definition is instinctive in the sense of a mental sensation that is uniquely human.

Heron (1992), in response to this question of human emotion argues that in our irrationality, as opposed to reason, individuation is located. Each human being is perceived as having a locus within a network highlighting a distinctive being whose differential experience varies from every other human being (Heron, 1992). This differential experience makes us individuals. The differentiation, (Heron, 1992) argues, is not because of what we have experienced in any given moment, but rather, how, we have experienced in any given moment. The how is, precisely our irrationality, the affective mode, that makes us individual. And while they are subjective, at the same time they are who we are not, and in that way a key in the process of becoming (Heron, 1992).

In assigning definition to the word feeling, the language used to create meaning includes the notion of being conscious - consciousness, experience, and, to think/thought. "In feeling we live and move and have our being, through it, we live, whether we choose to notice or not, in a one many integrated universe" (Heron, 1992, pp.93-94). Heron (1992) describes feeling as that which connects the distinct being within the network of beings, the one, and the many. Feeling, as perceived, is what is felt as whole. It is the structure or basis of perception, yet is not perception per se. Feeling is how we align with what Heron (1992) terms the one many integrated universe, for through feeling there is "a unique presence and its qualities of being" (Heron, 1992, p.119). In this way, the nature of being, having the 
innate capacity to resonate with both the many and the one, makes possible the form of unification or wholenesss/notion of being conscious/to think.

So we dwell in the world through our emotions/the many/subjective, as well as resonating with it when we feel/the one/objective. Subjectivity, which we deem as irrational, and objectivity, which some class as rational. Therefore, to look/see/view with our traditional lenses, feeling cannot be understood by inquiry methods that are positivist or post positivist, known only from the position of science or located in action that is defined by an analysis or critique of our historical understandings in the hope of transformation. Abandoning these traditional arguments to look/see/view the world just as, or in the Isness of a thing, is to begin to look in a way that sees subject and object representing part/separate and whole/oneness, where part and whole are neither mutually exclusive nor interdependent but emergent in a form of simultaneous growth. In this way, ontological, epistemological and methodological assumptions embedded in a paradigm position that is a process, that embraces this view of part and whole, might then be explicated. That is not to say that these assumptions are non-existent, rather, if the nature of an inquiry is to explicate/reveal then this work will endeavour to do so through the exploration of the emotional feeling nature of being human through which the ontological, epistemological and methodological assumptions are made real.

\section{The aesthetic act}

What is meant by the term, aesthetic action? How is feeling portrayed in and through acts of nursing?

It was that time when the dark begins to fade and the light of morning brings in the next shift. I was washing him with a cotton wool swab. He now weighed 1380 grams. $\mathrm{He}$ had entered the world at 564 grams. I had reached the part of the morning wash ritual where I was about to change his bottom sheet. In considering how I would do so I decided it was now safe to lift him, momentarily, out of the head box. He was so small that almost his whole body was contained in the perspex box. So, I placed the head box on the shelf behind the cot and then, gently, ever so gently, scooped him up into my hand. As I stood there holding him in the palm of my left hand - the right hand was engaged in changing the bottom sheet, his arms dangled each side of my fingers and his legs lay spreadeagled over my wrist as I held him cupped in one hand. I don't know why but I paused for a moment. I stopped what I was doing to gaze into his tiny tiny face. As .......

Chinn, Maeve and Bostick (1996) in their discussion of art and aesthetics in nursing use the work of Eisner (1985) to define aesthetic knowing. Aesthetic knowing, Chinn et al suggest, "is the ability to sense the forms and meanings that an art form conveys, to apprehend the 
intentions that are part of the form or the act, and the human experience that the form makes possible" (1996, p.4). The question then is, what is the process that occurs when what is being conveyed, the apprehension of the intentions, and that which is perceived by the observer/participant when exploring aesthetic reactions/responses? Is what is being relayed always the same as that which is received? It would appear not. For how else do we account for the one art form being perceived differently by the many, while it is recognised that the one art form can be commonly perceived.

The layer of the percept, the actual visual or auditory or tactile image, is what portrays the world (Heron, 1992). Perception is an interaction between psyche and being. The psyche is involved in shaping percepts not just passively receiving them. Perception involves the processes of structuring, categorising and construing of a world that cannot be attributed to the brain alone (Heron, 1992). Perception is a way of giving meaning to experience, and meaning is an irreducibly mental phenomenon that manifests through brain processes but cannot be produced by those brain processes (Heron, 1992).

Perceiving as a mental process, is giving meaning by shaping a world, that is of a different order of reality to the brain through which it works. The structure of the sense organs, neural connections and cortex certainly do determine a lot of what and how we perceive, but they do not explain the origin of percepts, only some of the limits within which they manifest. So while perception includes physiology, it transcends it (Heron, 1992). In this way, perception is how we see the world through the processes of our interaction with it. Somehow, we lay down percepts that end up as human brain function, but which are the products of what takes place in the mind, the mind not being synonymous with the human brain. It is our mind which creates the percept from the interaction, as Heron (1992) suggests, between our psyche and being, a process that in the main is unconscious. The how of this process then determines what we see [percept], and the human mind gives it consciousness [concepts].

We therefore construct our reality or version of truth, and this then is my interpretation of the consciousness of our being. This phenomena accounts for the difference in how we see the world, perception, even when faced with the same experience - the how of experience. Given Heron's (1992) idea on individuation, whereby each human being has a locus within a network highlighting a distinctive being whose differential experience varies from every other human being, it is possible to surmise that what drives that locus is emotion. In this way, aesthetic action can be explored from the position that it is the reply to an emotion as feeling portrayed within an art form. 


\section{The beautiful}

What is the beautiful and how does this relate to the aesthetic which in turn conveys something about form in nursing? Beauty is coming to a place of knowing, beauty is being able to allow the 'isness' of what is. It is knowing that all that has been, and all that is to come, is now. Beauty connects the world of dualities. In that way I can create a position that I describe as being above or lifted above the everyday to see life as it truly is while in that now moment. It is as if time stands still, the past, present and future roll into one. In this space I feel the expansiveness of who I truly am. This, then, as a totality is the beautiful.

I stopped what I was doing to gaze into his tiny tiny face.

As I raised my left hand in which I was holding this tiny baby and moved him closer to my face .... at the same time I lowered my head .... our eyes met .... in this meeting of eyes I heard a voice inside my self say - and this, this, is a human being .... As I stood transfixed upon the tiny form I felt the power that came from an understanding of how another's hand could either crush him or hold him. As I remained there motionless, timeless, gazing at this miracle of life, I began to see, that by my own hand, his life did not truly move between being either held, or crushed.

Beauty can connect the world as perceived through the consciousness of part/opposites/duality. In the experience of dualities, life is seen exclusively from a horizontal perspective as a continuum of opposites, health and illness, through which one swings to and fro or back and forth. In this experience, the world is perceived and as such a perception of reality is created or reified. At any one time reality is perceived at any one point along the particular continuum, as well as being open to change. For in this process of swinging to and fro, I am experiencing the depth and breadth of a phenomenon. In having done so, having experienced my perceived reality in this way, then, I am able to cross a threshold, to rise above, where a whole new level of reality exists for my exploration. The key, I am arguing, having experienced my perceived reality by being present to the presence, is beauty. By allowing life to be the Isnes, of what is.

In such a place there is movement and flow, the negative and positive as energies come together. It is like standing in the middle of a see-saw, a foot on either side of the fulcrum, and what appears as stillness is actually perpetual motion. The question here is, can one come to this place, the beautiful, without the experience of dualities, or is it a matter of being able to respond more efficiently aesthetically so as to continually move to this place of balance? I perceive it to be the latter. I have learned to respond more efficiently aesthetically. 


\section{Aesthetic as a pattern}

Aesthetic experience commences from an emotion. The aesthetic experience "is a particular emotion ... and only works of art, have the power through the characteristic use of significant forms, to evoke aesthetic emotion" (Bell 1947 cited in Holmes, 1991, p.447). An aesthetic response implies a certain heightening of, or dwelling in, our experience. How the emotion arises, and its relationship with the image, remains a crucial question. Pole (1983) in an effort to distinguish an aesthetic judgement, response or evaluation from that which might be termed moral, economic or intellectual, argues that it is because the experience is memorable, in that there are significant moments or occasions. In this way there is a differentiation of that which is aesthetic from that which is not. One feels and experiences something.

Scruton (1983), in examining aesthetic understanding, critiques Beckett's interpretation on the work of Proust, where the Cartesian notion of 'the self' is portrayed by contrasting habit and suffering. In such a contrast, whereby habit [routine] gives way to the capacity for suffering, 'the self' finds intense inner solitude for a transformatory process, and it is this transformatory process which enables one to see not only the self, but also others; for it is in the breaking of habit [routine] that truth might be seen. "The notion of what [he should] can be seen, has not had time to interfere its prism between the eye and its object" (Scruton, 1983, p.231). Here in we are presented with two significant factors pertinent to the argument thus far. Firstly, it is in the interpretation of the meaning of the word suffering, for if, as Pole (1983) suggests that what is aesthetic is so because it is memorable, that is, what one experiences/feels is remembered, then what Proust (cited in Scruton, 1983) means as suffering can then be interpreted as, feeling our emotions. Given this, the transformatory process, the contrast of habit and suffering, must involve the experience of dualities.

Heron (1992) says that, through the interaction between the imaginal mode with the conceptual, perceptual imagery is created. We experience/feel something and then 'process it', thereby creating our picture/structure of reality .... "a person creates a pattern of perceptual elements that is symbolic of some deeper pattern that interconnects perceptual imagery of this world ..." (Heron, 1992, p.165). In this way, blocks of knowledge as aesthetic patterns serve to inform some whole arrangements as perceived within the world. It is the picture/ structure Heron's (1992) perceptual imagery, that then becomes not only how we see the world, but on what basis we engage within it. In this way, how we see the world is the image and thus the work of art, the structure of the image becoming the object image and from which, questions about the notion of form can then arise. Thus the form exceeds the image itself, for it is the form that acts to enable the creation of meaningful patterns within 
life. Form captures both object and subject through the weaving of past with the present in the work of the art (Lukacs cited in Markus, 1983). There is no past or future, they are both contained within the now. The creation of the work of art arises out of the unison of the totality of life and at the same time is that which enables transcendence [transcend=denseness (matter) that belongs to time].

Pole (1983) argues that shape, colour and sound invite our attention thereby giving us reason to think. In this way, the reaction is minimally aesthetic. To think, in a rational sense, then implies that logical thought cannot be considered aesthetically. However, as Pole (1993) does point out, it is our attention that is invited thereby implying a sense of awareness that is stimulated by shape colour and sound. Awareness that then can serve as a preparedness or readiness to be able to respond or react as feeling and experiencing something, in response to something.

Art creates what we think of and as some sort of object invites us to take up a certain attitude (Scruton, 1983). This attitude implies a certain detachment where there is the ability to step out and so create moments when life momentarily stops, where habit [routine] can give way to the capacity for suffering. The object can then be seen as an isolated unique instance because the object being experienced stands on its own, having no similar preconditions or principles [no past or future] which might act as a basis for comparison. This I argue is the meaning of, "the notion of what he should can be seen for it has not had time to interfere its prism between the eye and its object" (Scruton 1983, p.231). Where the interest is not in comparison, but rather involves a disinterested self which captures the object purely for the pleasure it offers (Pole, 1983). In a Kantian sense, "the individuality of an object is then seized and made present in thought" (Scruton, 1974, p.15). A disinterested self that has the capacity to seize the individuality of an object that is through the engagement of a particular attitude. This attitude, I argue is, to allow what is, that then is congruent with Hillman's (1996) falling in love in a redemptive suggests which then transcends a particular duality by appreciating the beautiful. In the Isness, the aesthetic act can then serve to capture the object purely.

"An aesthetic response ... implies no more than a heightened present awareness of the qualities of an external or would be external object ... " (Pole, 1983, p.33). All objects allow the adoption of this attitude, that is, an attitude that is no more than the full experiencing of a given thing (Pole, 1983). In the idea that all objects can be experienced aesthetically and that we react/respond aesthetically to pure forms, lies the possibility that we respond/react aesthetically to each other as human beings. 
I have argued that the hallmarks of an aesthetic response are to be able to feel and experience something. Such a reaction/response must then be partly metaphorical, for what is felt is neither a tangible surface nor a feeling (Pole, 1983). Language, Pole (1983) argues, in itself is inadequate to express these notions, and thus these reactions/responses as metaphor serves to portray the feelings that create the images. Any work of art that reveals these images must then be termed art.

So, do we react/respond aesthetically to pure forms, to each other as human beings? Pole (1983) argues that this attitude does not need to depend on a material object, and it is possible to stand back and regard real people, their characters and their lives as objects of aesthetic contemplation. In that way the stories about real people and their lives as art, can be contemplated aesthetically. In this way, nursing too can be explored for, "Nursing is an art .... It is one of the Fine Arts; I had almost said, the finest of the Fine Arts" Nightingale (1859).

Form in nursing can be viewed from a dialectic involving culture and beingness, object and subject, that when experienced aesthetically reveals the pattern held within an experience/nursing story. In revealing the pattern, form is conveyed and as such the individuality of an object has been seized and made present in thought.

\section{Pattern as creation}

Vision was thought to involve either, natural or artificial light being reflected to the eyes where the wavelength of the light varied thereby producing variations in the colour of objects. The brightness of an object was accounted for by the brightness of the light falling on it, and differences in the reflecting power of a surface. On reaching the eye, the lens focuses the light onto the retina. Retinal cells then react by initiating nerve impulses in the ocular nerves to convey the light via the optic nerve to the occipital area of the cerebral cortex. What reaches the brain is a pattern of nerve impulses. That pattern has a frequency that corresponds to the brightness of the light reaching the eye. The point on the brain surface is stimulated and corresponds to the point excited in the retina which in turn is related to the particular point in space from which the light comes (Vernon, 1971).

Now it is known that light does not reach the brain from the retina. "Seeing is the interaction of retinal cells, cones and rods, ganglions, optic nerves, primary and higher visual cortical regions and ions of visual data leaping chasms from synapse to synapse backed up by 
neurotransmitters" (Houston, 2000, p.104). Eighty percent of the visual field is generated from many parts of the brain and only twenty percent directly from the eye, the information then culminating at the lateral geniculate nucleus where 'seeing' occurs (Houston, 2000). The information gathered is fed back to the eye. In that way, 'seeing' is more an in brain process than an ocular generated one, "where higher cortical structures build the rich imagery of the inner world that we project into the patterns we see in the outer world" (Houston, 2000, p.106).

It is impossible to see The Present. The Present 'happens', then turns into a burst of light, formed by energy dispersing, and that light reaches your receptors, your eyes, and it takes time for it to do that. All the while light is reaching you, life is going on, moving forward. The next event is happening while the light from the last event is reaching you. The energy burst reaches your eyes, your receptors send that signal to your brain, which interprets the data and tells you what you are seeing. Yet that is not what is now in front of you at all. It is what you think you are seeing. That is, you are thinking about what you have seen, telling yourself what it is, and deciding what you are going to call it, while what is happening 'now' is proceeding your process, and awaiting it. When you understand, you will understand that nothing you see is real. You are seeing the image of what was once an event, yet even that image, that energy burst, is something you are interpreting. Your personal interpretation of that image is called your image-ination. Imagination is a function of your mind, which is one third of your three-part being.

Walsch (1998, pp.359-360)

Heron (1992) argues that it is precisely because the images of perception are created from patterns that he terms meaningful, that meaning can be viewed as an irreducibly mental phenomenon. The basis of mentality is built upon pattern, pattern which is made of shape, contrast and ratio. Both Pythagorus and Plato held that pattern is fundamental to all mind and ideation (Heron, 1992). Thus the images that portray the world are constructs in a radical sense, as they are products produced by the imaginal power of the psyche or, what Kant 
termed the notion of a productive imagination, to coalesce from a synthesis of the manifold of sensory apprehensions into concrete wholes (Heron, 1992).

To grasp concrete wholes, is to make experience coherent. Coleridge (cited in Heron) termed this primary imagination, "the living power and prime agent of all perception and a repetition in the finite mind of the eternal act of creation in the infinite I AM" (1992, p.145). The imaginal mind at work in perception which Kant called "productive' and Coleridge labelled a 'power' and agent (cited in Heron, 1992). This then gives rise to questions not directly concerned with what is imagined but, rather, how do we imagine, where the vested interest is in the product that then represents the nature of reality.

This imaginal power of the psyche acts as an interface in the perceptual transaction with being (Heron, 1992). It is an unconscious process in that there is no awareness of the continuous process of the generation of perceptual imagery (Heron, 1992). The consciousness is of the image, the product of the process, but not of the imaging itself. The image is hypostatized, reified, into an appearance in the world that is independent of 'the self' (Heron, 1992). In a process of shaping and moulding, perceptual imagery is being made by the psyche in accordance with some unknown blueprint or programme. Meaning is viewed as a mental phenomenon as the images of perception are created as meaningful patterns from the composite of sensory apprehensions that in the human condition, Shakespeare in Hamlet (cited in Houston, 2000, p.107) recognized that, "There's nothing good or bad but thinking makes it so".

The word create is defined as: bring into existence, make by one's own actions. Creation then is associated with action and action is integral to thinking. In thought, word and deed/action, a process of thinking, we can uncover that which is concealed. In uncovering that which is concealed, then surely what we are doing is bringing into existence, in other words, creating.

Koestler (1964) says that we build up a code of rules/pattern based on our past experiences so that when faced with a familiar problem under similar conditions, the response/act, the action then reflects that particular code/pattern. In this way, responding/reacting/doing is routine, habit has not given way to suffering and in that way the codes of rules or patterns are the way we continue to see the world. That worldview created by the imaginal power of perception and then reified. The psyche subsuming the imagery of perception under concepts, a naming that comes with language, that then is resultant in the world being split into a subject which has made a judgement about an object (Heron, 1992). 
Language then is not mere verbiage but in the naming and framing inherent in conceptualisation there is the tendency to split the world that then is resultant in rules or specific patterns that represent how the world is imagined. According to Koestler (1964) these codes of rules, or patterns, then become our way of reacting to life. The antithesis of which, I feel, Pole (1983) is grappling with in his exploration of the notion of an aesthetic attitude that implies a reaction/response.

Pole (1983) points out that the response must be partly metaphorical, for what is felt is neither a tangible surface nor a feeling. In other words, the aesthetic object has served to convey an emotion and in that way it is neither a tangible surface or feeling, but is then met with either a learned response [habit] or suffering. As a learned response, the subject tends to get set over against the object and the image of the world is reified (Heron, 1992). That is, the prism between the eye and its object has interfered with the notion of what can be seen. What can be seen, is not. The world is seen as it was before because the image has been reified. And here in is a crucial point; it is this that is resultant in our perception that images are things outside of the self. This is how we alienate the creator from our continuous generation of percepts and in so doing, cannot see ourselves as the creators of our worldview. The patterns are outside of us and so we are gazing at our world, in it, but not of it.

Spinoza (1677/1952) suggests it is the affect [noun], which creates an image in the mind. I am using the term affect to denote an emotion. The affect he terms a 'confused idea', confused in the sense that the idea of the body has been created by the affect. If this is so then what would be the effect of (re)experiencing a particular affect? Can the idea become 'unconfused' to then express more reality because the notion of what can be seen has not interfered with by the prism between the eye and its object. If so, then the world would be seen differently because the trial, 'his suffering', 'his point of friction', the emotion, is used to grow in being. Not as an asthetic, but by the aesthetic, where growth in being does not mean cessation at the point of matter but rather extends itself to embrace the whole. By embracing the whole, both the trial and state prior to, become mere mechanisms, the catalyst/stimulus "... as before, but differently and better than before ... an undreamed of promotion, a transfiguration" (Marcel 1935, cited in Vaillot 1970). Where "the individuality of an object is seized and made present in thought" (Kant cited in Scruton 1983). Expressed by Spinoza's (1677/1952) as 'more reality' or 'an unconfused idea'.

Perception then, as an unconscious or conscious transaction between the imaginal layer and being serves to reveal thought that is represented in codes or patterns of rules by which we 
react/respond to life and in that way determine a reality. In the (re)experiencing of an affect/emotion the potential exists to express more or less reality (Spinoza, 1677/1952), in the ongoing experience of unifying object and subject. Changing perceptual imagery through disengaging with the conceptual layer is resultant in hints and gnostic intuitions, however, "....these intimations of a wider power are disconcerting to the psyche and lead it to identify with the conceptual layer so that it doesn't get more reality than it can handle" (Heron, 1992, p. 147).

In disengaging with the conceptual layer what occurs is, a displacement in focus that is actioned through a form of responding. In this act of allowance, it is a state of beingness because the space is open to allow the flow to flow. Where there is an identification with the conceptual layer, that then is actioned in the form of reaction, and as such the density of an affect/emotion sits closer to the body. Then intuition is lost, the knowing is lost, "that streaming or flow" (Heron, 1992, p.147).

Therefore, in the process of daily perception lies a key to the liberation of awareness from the preoccupations of the ego (Heron,1992). "Whatever the ego is busy with - whatever its compulsions, guilts, blamings obsessions, restlessness, indulgences - this imaginal force that shapes my world is at work with immaculate thoroughness" (Heron, 1992, p.147). That energetic creative force, the creative imaginal flow is not only stopped, but the result is less reality because there has been interference of its prism between the eye and its object. The pattern of light remains the same and so the vision becomes dimmer. Vision then is created as thought, yet the thought is vision and thus vision is a dialectical process which is both lived and reflected on and which is then portrayed through the body (Merleau-Ponty, 1972).

The word attention is defined as, give, pay, attract, call, and draw to, and the word intention is defined as intensity, high degree of a quality, strenuous exertion of mind thought or will. I suggest that in the subjugation of the affective/irrationality nature of human kind it is the ego that is given attention, and that in the intention is where the possibility of creating a new view lies. It is intention, which draws the attention, to participate in the world of perceptual creation. If the pattern has always been to look down, then that is how reality is reflected. The view limited that as the stabilisation of perception, as meaning, represents the dominant story or belief about the world.

In the intention to get to know 'the self' there is a different energy that ultimately creates a different pattern. In getting to know 'the self' and expand the self' is to create more. To feel that magic and expansion, that is the expansion of consciousness, then a greater energy is 
brought through - brought forth, where beingness to expand outwardly has been the outcome and the outcome has been the intention (Tikashi, 1995). In this immediate might, perceiving is a universal process focused through personhood and participation, and because it flows through my being I can turn into it and know what it is - "an impeccable form and patternmaking, emerging from a ground of archetypal grandeur ..." (Heron, 1992, p.147).

In looking up, the intention to look up, Figure 4, the attention and the focus will be drawn to get back up, that is what will draw 'the self' there (Tikashi, 1995). In the process of perceptual creating there is an on-going self-transfiguration and so there is a shifting shape in form. Thus form in nursing can be viewed as a dialectic involving culture/experience and being, as a means to transcendence. Form as both object and subject, the aesthetic, a key to seeing the patterns that are brought forth into existence as an outcome is life to be reexperienced anew the purpose of which is to further unify subject and object, and in so doing create a new view.

Figure 2: Looking Up

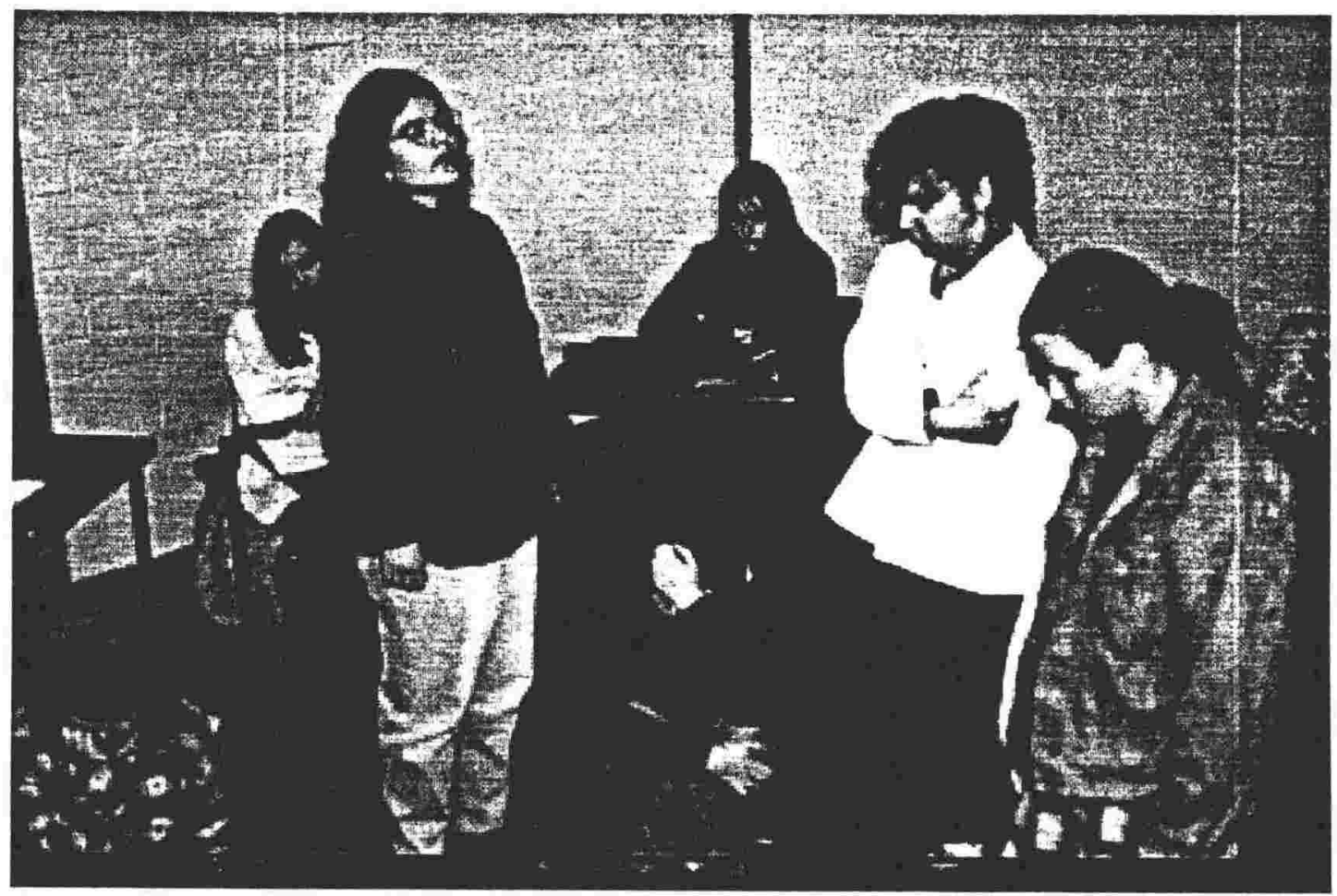




\section{Summary}

The aesthetic has been positioned so as to ground it in human emotion and feeling. The work of Heron (1992) Scruton (1983) and Pole (1983) are presented so as to distinguish an emotional response from that which is moral or intellectual. The nature of perception is discussed, as is the phenomenon of sight. In this way an argument is layed open to begin to explore form from the perspective of emotion and feeling as patterns of perception that then determine how the world is viewed.

Having presented these ideas about how the world is apprehended from our aesthetic responses/reactions, what is then revealed is how life experience as emotional memory, reifies an idea about reality. In this way, the notion that the mind thinks that it is generating the percepts has been presented.

The idea of dis-ease as an interruption to the flow of energy has been introduced. This idea is then positioned as an outcome of continuing to reifying a particular reality and in that way illustrate how percepts become attached to concepts. 


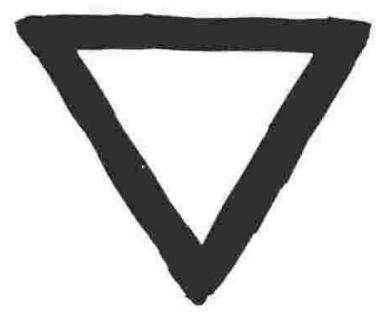

\section{Chapter 4: Selfhood as Energy}

\section{Human fields}

Roberts (1950) defines the aura as, "a magnetic field of vibration which surrounds every person" (p.1). Kathumi (cited in Prophet, 1991, p.22) says that "...the combined manifestations of body, soul and mind creates around the spinal column and medulla oblongata those emanations called by some the human aura and by others the magnetic force field of the body of man".

The aura ... both permeates the solid body and draws external energy into the whole organism ... Because the aura's pulsatory rate is immensely quicker than the body's, it telegraphs precisely what is happening within the person on all functional planes: the physiological, the emotional, the mental, and the spiritual. ... Therefore, the state of functioning in one phase determines the state of functioning in the other. A localized alteration of the reciprocal energy exchange will reverberate throughout and beyond the organism.

Pierrakos (1987, p.70)

These layers surrounding the human body are distinct from it. At the same time they emanate through and of it. These layers have been described and drawn from early time (Hildegard of Bingen 1098-1179 cited in Fox 1985). They are both distinctive and variable in colour are interdependent and in a state of constant change (Brennan 1987, 1993; Pierrakos 1990). Together, they make up the human aura. Thus I have presented some definitions and descriptions of the human aura to begin an exploration of humankind from the notion of an energetic or vibrational sense. 
This view of human as energy/vibration/light coupled with the Rogers (cited in Malinski and Barrett, 1994) position of human as an open system, not separate to either the environment or the universe, makes it possible to conceive, that while 'being-there', as in the Heidegger's (1962) notion of Dasein speaks to existence as grounded in time, it is also continuos forever throughout space and in that way beyond time. As an open system that is being-there, it is possible to position humankind as existing across the entire universe. As such the minute of each particle of each human being potentially mingles with those particles from every other physical thing in existence. Thus universe is in us and, we are in it. The human aura emanating from the body of mankind is then in the universe to coalesce as one.

In the previous chapter, I engaged in a discussion in relation to perception and sight. I would wish to redraw the attention to two points. Early theoretical work held that light was transmitted from the eye to the brain (Vernon, 1971), and also that what would be viewed if one could observe the brain would be flat patterns of light shade and colour, an abstract picture or a variegated piece of textile material, rather than the view of the world around us. Brain mapping supports this early idea, where an area of the brain literally lights up in response to a stimulus. Further, when a visual impression connects with the visual field, it is the eyes or the body which are moving in relation to the environment and the objects in it (Vernon, 1971).

Colour mapping, throughout the whole body, is visible to those who can see auras. Therefore, in discussing the human aura in relation to sight, whereby sight is a process of information transmission of various patterns in the brain, what I am suggesting is, given that energy radiates light and what is perceived is a form of reflection, are the patterns of light in constant motion. If so, it is then possible to conceive from an energetic sense that humankind, and everything else for that matter, resembles a large artists paint palette. Such a notion would then give rise to an exploration where the focus is not how the colours are derived on the palette or what they mean, to one of changing the patterns of colour in relation to what we term health. Then questions concerning the meaning of colour changes within the layers or fields, and changes in the sense of the quality of their luminescence and movement along colour spectrums might then be explored. Such an exploration would create a position that calls forth human existence in a manner that can be likened to, an ongoing work of art. A work of art which is continually being created and recreated, that then is an evolving expression of form. 


\section{Human field as thought}

The Principle of Reciprocity, is a scientific phenomenon of pulsation governing the movement of internal and external energy within all entities, and is the manifestation of a pulsatory rhythm emitting internal substance on one beat, and taking in external substance on the next (Pierrakos, 1987). The work of Einstein in 1905 enabled atomic technology to show that mass and energy were interconvertable that then paved the way for another branch of research to identify that the smallest unit recognised as a living entity, a protoplasm, to the larger aggregates of cells, organs and systems, form rhythmical reciprocal patterns that vibrate and pulsate as a unity (Pierrakos, 1987). In other words, while physical man starts as a single cell that through countless divisions and permutations arrives into the mature form, none-the-less, "the organism retains the essential activity of the single cell, the overall pulsatory pattern" (Pierrakos, 1987, p.71). The one as beautiful as the many, the many as beautiful as the one.

Pert (1997) in her ground breaking work in the area of neuropeptide and receptor pharmacology and chemical neuroanatomy, proposed that an information network composed of neuropeptides and receptors connects all systems of the body into one unit - bodymind. Publishing their findings in the Journal of Immunology in 1985, Pert and Ruff proposed that neouropeptides and their receptors are the biochemical substrates of emotions (Pert, 1997). In presenting this work to the world, Pert (1997) was also able to deduce that peptide ligands and their receptors remain stable across millions of years of evolution in the same way that Darwin predicted for the physical components of emotions, whereby he suggested that emotions were not only essential to survival and thus evolved early, but importantly, were passed on and conserved. Even the simplest of organisms have various neuropeptides and receptors on their cellular surface. Pert (1997) was able to conclude that this information network, which crosses the entire body, "gives us feelings as it runs the physiology" (1997, p.117).

Psychologists James and Lange grappled with similar questions over one hundred years earlier. Consequently, their theory has influenced a century of research on emotion (Lang, 1994). James initial 1894 theory had its origins in philosophic psychology and focused on the human experience of emotion whereby specific 'feelings', the direct experience of the coarser emotions, are evoked in the conscious mind (Lang, 1994). The central hypothesis held that emotional feelings are the conscious leavings of physiological stimuli produced within the organism, particularly the viscera. James on the other hand proposed that emotional feelings were not truly givens; rather they were secondary phenomena, prompted 
by the perception of somatic and visceral changes evoked by external stimulation. That is, our feeling of the bodily changes as they occur is the emotion (Lang, 1994).

Pert (1997) in describing aspects of her work, says it is the receptor molecule which, when energy is applied, responds by vibrating.

\begin{abstract}
..... receptors wiggle, shimmy and even hum as they bend and change from one shape to another ..... receptors are always found attached to a cell, sitting on the surface wall with their roots enmeshed in the cells oily membrane ..... and able to slide anywhere along the surface of the cell membrane. ..... the activity of the cell at any given moment is influenced by two things: what particular receptors populate its surface and, what kind of shape they have assumed - how they are 'humming' ......
\end{abstract}

(1997, p.118)

This vibrating/humming motion is created by ligands - any substance which binds to a receptor, which acts to excite the molecules into rearranging themselves. In other words, they change shape. It is in the rearrangement that the cell wall is opened per se, a mechanism initially described metaphorically as, a key and lock. Once the cell wall has opened, there is an influx of ligands and in this way there is a potentiality for influencing cellular function. This potentiality is determined by how many of the cell's receptors are occupied by their specific ligands in any given moment (Pert, 1997). Importantly however, it is this crosshum of ligands, informational substances and peptides binding to their receptors and connecting all systems through the peptide providing glial cells of the brain and neurons which makes it possible to reconsider the perception of the human brain in its relationship to consciousness.

Such an idea would suggest that not only is the human brain another endocrine gland whose function involves the production of neuropeptides, "coming out of glial cells in the brain and entering from the body and going everywhere" (Pert, 1987, p.119) but, given the mechanism of cellular to cellular connection through the neuropeptides and their receptors, consciousness can be considered not only in terms of the human brain but the whole body. Furthermore, given that the research work identifies that the total connection is underpinned by what the neuropeptides and their receptors, or what Pert (1987) termed "the interplay of peptides and other ligands or information molecules" (p.117), consciousness then, it can be argued, is 
within every cell of our body. Who we are, and how we are, is inextricably linked to our emotions.

The James-Lange Theory of 1894 (cited in Lang, 1994) when viewed from this perspective, is a type of feedback loop, whereby the neuropeptides and their receptors as the physical manifestation of our emotions are both resultant of, as Lange argued, 'the conscious leavings' of a cell and, and as James suggested, the bodily sensations from the sensory perceptions of our world. The 'Principle of Reciprocity' then adds further clarity whereby the 'conscious leavings' of a cell are the emission of internal substance and the what of our interaction with our external world is the taking in of external substance. In this way, there is a combined movement of internal and external energy or, the phenomenon of pulsation. And it is this same phenomenon, metaphorically expressed as 'what we put out, is what we get back' and 'what we focus on is what we create', that then serves to alert me to the power of this reciprocity that is inherent in all life.

\section{The notion of flow}

Centrifugal and centripetal flow is a phenomenon of the universe. This dual movement, toward as well as away from the originating centre, is replicated in every phenomemon mankind has observed (Pierrakos, 1987). The Big Bang Theory, an explanation of creation, serves to illustrate this phenomenon at a macrocosmic level, while systems and organs of the human body illustrate this phenomenon at a microcosmic level.

...as in the whole universe, the energy of each part of the body moves both internally and externally, contracting and expanding, pulsating inward to the nucleus of the part and outwards to the other parts of and into the whole ........ So energy, whether in the cosmos of all existence or the cosmos of the human organism, moves like streams from a watershed.

(Pierrakos, 1987, p.15)

In this way, Pierrakos (1987) is also making visible his knowing of man, not just as a form of quantifiable living energy, but rather, that the macrocosm and microcosm are but reflections of one another - as it is above, so it is below. "That the intelligence and harmony of creation point to a consciousness that is both wholly comprehensive and minutely specific" (Pierrakos, 1987, p.16). It is in this notion, energy as consciousness, that makes possible 
the conceptualisation of the difference, yet the sameness of substance and form. For while our being in a body is how we identify ourselves as individuals, it is our shape, mass and density that defines our motion in time and space. And so by definition, energy is motion, and therefore not only are we consciousness, but every minute particle is consciousness, each unit having a function and purpose, "a plan for fulfilling its potential, inherent in its fact of being" (Pierrakos, 1987, p.16). While this discussion could be perceived as presenting a separatist argument, for each particle it has been said has its own consciousness, 'doing its own thing', given that energy flows undivided, it then follows, so too does consciousness. And if each particle of every cell has consciousness, one can then ask, of what is it conscious of, and how then is every part directed towards 'the whole' given Pierrakos' (1987) assertion that consciousness is wholly comprehensive? Following on from this, what is the effect on flow, flow as movement toward as well as away from the originating centre?

Pierrakos (1987), in his discussion of the human aura, says that the energy field of a human being is like all entities in one sense and at the same time is also different. The commonality exists in the reciprocal energy cycle throughout nature whereby it exhibits two active phases. The difference is in the subtle variations that exist within the basic pattern. These variations, Pierrakos (1987) attributes to what he terms "the assertive operation of the person's core and its receptive operation" (p.72).

Kuthumi (cited in Prophet (1991) says that everything which is observed by the five physical senses (visual, auditory, taste, smell and touch) is automatically transmitted to the subconscious levels by, 'an inner hieroglyph'. In this way, there is an entire transmittal of data from the external world to the internal world of our being. The process of recall is both involved and almost instantaneous, through what Kuthumi terms the "misqualification of thought and feeling", in which there is a manifestation of many undesirable traits. It is by the misqualification in the emotional body of man, that is, in the feeling world of man, that the heart is touched in such a way as to "sway the whole of the life record of the individual into a miasma of doubt and questioning" (Kuthumi, cited in Prophet, 1991, p.27). In this misqualification in the feeling world, there is "a certain leverage to the power of amplification" (Kuthumi, cited in Prophet, 1991, p.27).

According to this idea, our emotions amplify any misqualified thoughts and feelings in such a way that they then assume a dominant position because they are magnified. And while Kuthumi points out that such a path is dangerous, he also points out the potentiality, in that it is precisely this path which is the turning point. Metaphorically this phenomenon has been expressed in Christianity as, "... darkness does cover the earth". "Yet Christ has said, I AM 
the light of the world" (Kuthumi cited in Prophet, 1991, p.27). This same phenomenon can be found philosophically in the expression, "the true which is not to be found by conscious pursuit, but rather, by going precisely in the opposite direction" (Baudrillard, 1990, p.28).

It is at this point that I wish to make what I perceive to be an important distinction. First, that which I have interpreted as a turning point to be exactly as I presented it. That there comes a moment in one's life where one can continue as before, or where what is experienced can later be termed a life-altering event. Something within us has irrevocably changed and there is no turning back. On the other hand, I perceive this same potentiality exists in the interaction of life in every moment to then be expressed not as a turning point, but in the notion of change that is process rather than event. Big or small it is the same phenomenon in which there is another important distinction.

In the idea that the human aura exists as the reciprocal movement of energy flowing inward and outward this image could create the perception that human beings are inert organisms and as such are passive recipients of life. In this light, I would reiterate the point made in the opening sentence of this section on centrifugal and centripetal flow. The dual movement toward as well as away from the originating centre is replicated in every phenomenon mankind has observed (Pierrakos, 1987). Therefore, what has been presented to date are but the possibilities of what we create, the changing shades and patterns of colour from our artist's palette, rather than how we create. The how then, even though fraught with danger, exists as a possibility through the emotions that in some way directs this ebb and flow of energy which in its translation is experienced as life, to then serve the ongoing potentiality of the expansion of consciousness/being, or what Heidegger (1962) refers to as Dasein.

Through this dual movement, this ebb and flow, the giving out of energy so that we are in the universe to then draw it back into our being so that the universe is in us. In this way we are constantly flowing. The human aura a telegraph of what is happening within the person on all functional planes: physiological, emotional, mental, and spiritual where the emotional body is the door to the other layers.

\section{Disease as blocked flow}

"Expansion and joy are part of the birthright of humanity; they are native feelings that can soar from emotional health" (Pierrakos, 1987, p. 84). Dossey (1991), in his groundbreaking work in medicine, draws attention to the relationship between emotion and death by providing case histories and research reports as evidence of this connection. In particular, 
Dossey (1991) cites the work of Dimsdale, whose work was formulated as a possibility for emotionally triggered instances of sudden death, proposed a chain of events leading up to death in which he argued that how an event is interpreted by a person then becomes a contributing factor. In this way, his work showed that life meanings enter the body.

Osler (cited in Pierrakos, 1987), in his work with people experiencing angina pectoris, and Canon (cited in Pierrakos (1987), who in late 1910 demonstrated that the sympathetic nervous system responds in two opposite ways to the emotions of rage and fear, are two other well known pieces of research linking emotion and cardiovascular responses. In the case of the latter, this research work showed that there was either a contraction or an expansion of the whole organism. One of two reactions, termed the fight or fright/flight syndrome resulted in cardiovascular changes. The physiological effect is an increase in heart rate and thereby a possible increase in cardiac output, constriction of blood vessels of the skin, an increase in circulating glucose and fatty acids, dilatation of the pupils and aroused mental status. This same term in Psychiatry, fight or fright, refers to the action of a person who when presented with stress will either flee from the situation or stay.

Given the research into sudden death and its relation to emotion, is death in such instances the result of a reaction to an emotion which is expressed as fleeing at one level and manifested physiologically by contraction of the organism? Such physiology is easily understood when one considers the mechanism of say a coronary occlusion and myocardial infarction, where the normal feedback loops and homeostatic processes no longer act to maintain the human organism. If so, it could be argued that the flow inward to the human organism, that is, the environmental stimuli, has been met with a reaction. On the other hand, where the response to the inward flow is not met with reaction as action, then is it a form of passivity that can be interpreted as a non obstruction to flow in the duality of its movement? Rather than react that then is an obstruction to flow, the human organism has chosen to hold this energy, made the decision to remain present and attempt to deal with the situation, and therefore the energy is available to be held.

If the energy is interpreted as experiencing emotion as a form of passivity, that then is the outward expression of staying present to 'deal' with a situation. To react to the energy/emotion would then mean that one is not present. One has flown. As energy, the reciprocal movement expressed as an ebb and flow is then blocked. There is an obstruction to the ebb and flow of life where the mechanism to restore flow is created by setting in motion the same cycle. 
In other words, what has been given out as a reaction to the inward flow then serves to draw inward again the same energy so that the energies become balanced. As action by the human being, expressed as a reaction, this then creates represents an intent that then calls forth energy to re-balance the energy pattern and in that way restore the flow. Where there is continual resistance to this re-balance, that is, the essence embedded in the life experience is met with the same reaction, then there is an accumulation of the blockage to flow, that at some point results in an implosion (as opposed to explosion). That is, the human organism then turns in on itself, having created what, in its physical manifestation, we term dis-ease.

While it is acknowledged that the research work into sudden death and emotion cited here does recognise a pre-existing underlying pathology in most cases, none-the-less the question can still be asked, are some mechanisms of death but an expression of the accumulation of this pattern repeated over and over and over again? The continual contraction of being - disease, in response to a human emotion, rather than its antithesis - an expansion that is in fact the claiming of our birthright as part of being human and which is born from emotional health. Is this why Kuthumi (cited in Prophet, 1991) says, this path is fraught with danger? And does the notion of flow serve to illustrate our divinely given ability to make our own choices/decisions - free will, expressed by Pierriakos (1991) as "the assertive operation of the person's core [innermost reality] and its receptive operation" (p.72). I think so.

These concepts extend readily to surfaces in three dimensional space; time, distance and mass, and in the work to follow in the subsequent chapters I will attempt expand these concepts further in relation to the human body. Suffice to say here, that our knowledge of the pathology of disease processes is such that medicine has charted the physical pattern [gene mapping] of many human pathologies. I have presented dis-ease as an obstruction to the flow of energy, in which there is a lowering in frequency manifested by a change in shape [detail]. Drawing on the work of Pert (1997), it is the shape, and which receptors populate the cell surface - how they hum frequency/vibration/energy are known to influence the activity of a cell. These receptors, as Perts' (1997) view, are the biological substrates of emotion. In this way what I am arguing is, that from these observable cellular changes in shape that then effect the pattern sequencing of the DNA molecules and therefore the function of the organism, might then be interpreted as either blockage or flow, erosion or growth, that is inextricably linked to our being in a body through our emotions. As a physical expression, it is the expression of health or dis-ease as one reflection of the expansion or contraction of our being, in our ever-changing universe. 


\section{Pattern seen as flow charts}

Wilhelm Reich (cited in Pierriakos, 1991) also recognised the human being as a unified energy system as opposed to an aggregation of soma and psyche. The flow of this unified energy system, in Reich's view, becomes impeded by both physical and emotional blocks which are created when we deny our primal emotions (Pierriakos, 1991). These distortions are not only evidenced in malfunction or what we commonly term dis-ease, but are also evidenced in how we look, feel, hold and move our bodies (Reich cited in Pierriakos, 1991).

This chapter commenced with three definitions of the human aura. These fields or layers of energy are interconnected, in that there is a type of 'flow on' effect. Indeed it is Reich who is credited with discovering that a person who is not aware of the negative primal movements, and who rejects his potential for destruction, will trap a great amount of energy in that denial, "for the organisms energy slows down, in a sense thickens, stagnates, and then freezes" (Reich cited in Pierrakos, 1991, p.85). Emotions, it is argued, are moving energy currents, the word emotion derived from the latin emovere, which means - to move. In this way the flow of the human aura, its changing shape and hue of colours, are connected to our emotions. The emotional body, the door to the others layers of the aura.

I would pause here in the discussion to make the following clear. When I speak of negative primal emotions, I do not mean that these are 'bad', but rather, as this work progresses, I hope to make clear why some emotions are perceived to be negative and others positive. Unfortunately this posivitivity and negativity tends to be translated into meaning 'good' and 'bad', but suffice to say at this point, whenever there is a block to the flow of the negative there is also a block to the flow of the positive. Emotions are made from the same 'yarn' in that they are moving energy currents (Pierrakos,1991), and so when you block one aspect you also block the equal and opposite energy, that is, when you block sad you also block happy.

Benoit Mandelbrot, a modern mathematician, is recognized as having built a knowledge of fractal geometry from about 1960. Even though mathematicians have known something about fractals for about a century, and artistic knowing would date this form of knowledge to be even older, computerisation and graphics have opened this branch of mathematics only in the last twenty years (McGuire,1991). The word fractus from the Latin means broken. Fractal geometry ... "helps everyman to see the same old world differently" (Mandelbrot cited in McGuire 1991). It is in seeing the world of fractals, that I see some relationships, which I sense relate to the discussion on flow and blockage in the human body. 
Some of the mathematical characteristics of fractals are that a fractal looks the same over all ranges of scale. This is called self-similarity and self-similarity over limited ranges of scale is common in nature. One need only to examine a section of the frond of a tree fern to see that it is the same pattern repeated over and over again. Therefore in the simple there is also the complex. Fractals are also said to possess a fractal dimension, in that "they pack an infinity into a grain of sand" (McGuire, 1991, p.14). They are regarded as falling between dimensions, and generally the dimension of a fractal is not a whole number. Therefore a fractal curve, a nominally one dimensional object in a plane which has two dimensions, has a fractal dimension between 1 and 2 , and a fractal surface dimension of between 2 and 3 . The dimensionality is determined by how the fractal is constructed. However, the closer the dimension of a fractal is to its possible upper limit (the dimension of the space in which it is embedded) the more filling of that space (McGuire, 1991). In other words, what appears as a two dimensional object exists in time and space in such a way as to present a reality in which we are able to accommodate a finite form yet, when looked at by a particular mathematical method, we are able to recognise that form as space is infinite.

McGuire (1991), in speaking of fractals, describes them as "visually complex mathematical objects that are similar in shape and structure over an infinite range of scale" (p.21). Their origins are from an iterated (repeated operation, generally using the last result of that operation as the input) application of a simple rule. While nature can be visually complex, at the same time she has material shapes and structures over a finite range of scale that also reflect a simplicity in the rule or law of formation or growth that produced that structure (McGuire, 1991). Such a constancy may be found in the underlying geology of a mountain or the genetic identity of a DNA molecule that programmes how a tree grows (McGuire, 1991). And it is in this sense, that I argue, that erosion and growth are in some way a variation on a theme, where on one hand there is an expansion, that is, a growth of consciousness, and on the other, a contraction that is not relative to physical size but to being.

Contraction, as has already been presented, is the physical manifestation of dis-ease. A reduction of flow, where energy is slow, thick, stagnant, and finally frozen. At this point I would again make clear that I do not want to impress upon the reader that there is a relationship between physical size/mass and consciousness. For it is precisely here where fractal geometry makes apparent that what is 'packed into the tiniest of spaces' can be infinity. So what may be of interest to the discussion is the phenomenon of shape contained within that concept of size. Shape, I sense, holds an interesting observation, and as such some possible explanations. 
McGuire (1991), in his ongoing discussion on fractal dimension reminds the reader, that not only is the space filling capacity a correlation to the closer the fractal dimension is to the interger (whole number), but that the detail appears to vary with the spatial frequency. In other words, the greater the frequency, the greater the apparent detail or shape[s]. Shape was one of the phenomena reported by Pert (1997) as the effect of ligand receptor connection on the cell. This phenomenon is recognised by some perceptual psychologists to account for the way in which sensory processing is decoded and processed by the brain. "... a brain .... might be expected to have structures complementary to, and adept at apprehending fractal structure in nature" (McGuire, 1991, p.30). Leonardo Di Vinci expressed it this way:

You should look at certain walls stained with damp, or at stones of uneven colour. If you have to invent some backgrounds you will be able to see in these the likeness of divine landscapes, adourned with mountains, ruins, rocks, woods, great plains, hills and valleys in great variety ....

Leonardo Di Vinci cited in McGuire (1991, p.109)

I have already presented the notion, in the discussion on vision, that we apprehend our constantly moving world in pattern or in shapes so that we then see particular form[s]. While how we see is dependent on the decoding of individual pattern, what is now presented is an expansion of that argument that how we see, what detail, is then related to frequency. Where the greater the frequency, the more detail or differing shape[s] are perceived. This frequency in this sense is relative to flow. The less the flow, the lower the frequency so that what is seen is viewed as having less detail. The object is seen as dense, or more solid. Reality is then reductionist and deterministic. In other words, it is as Leonardo has said, my view of a thing as valleys, lakes and mountains, worlds within worlds, or simply as a stain on a damp wall, will depend on my shape. My shape is determined by my vibration, by my frequency.

Further, I sense a correlation of the notion of what can be termed the space of our being and what goes on in the space, as that which is represented in our physicality by the internal external environment of the cell and the receptor ligand connections. This insight is derived from fractal geometry, where the space filling capacity is a correlation of the degree the fractal dimension is to the integer (whole number). That is, the closer to a whole number the fractal dimension is, the greater the frequency and detail/shape of the space. In other words, the space is not just filled, but what it is filled with increases the vibratory level, thus giving the space a different detail or shape. This, it could be said, is the same phenomenon described 
by Pert (1997), where a humming/vibrating receptor connects with its ligand thereby changing the shape of that cell. There is an outside to inside communication that in some way influences cellular function. The question is, does it reflect a contraction or expansion, that is meaningful or meaningless. Has the jug, having gathered and held, held in a way that it has poured out a consecrated libation, or has it merely poured?

Finally, fractals may offer another aspect into seeing our world as it relates here to understanding how emotion and feeling serve to create the expansion or contraction of being. McGuire (1991) claims that chaotic behaviour in the deterministic meaning of the word can be visualised by observing fractals. As was explained earlier, the complexity of behaviour is a repetition of a simple rule spoken of in fractal geometry, as an iteration. The same pattern is repeated over and over, and while it may not be a visible fractal structure, none-the-less there are tracks in the natural world which make these patterns visible as fractals. Such an example would be turbulent flows (water, air) and their erosion patterns in nature (McGuire, 1991). McGuire (1991) then walks the reader through a number of mathematical equations to support some highly abstract concepts, which I see as relevant to this work.

The notion of chaos can occur in a number of ways (McGuire, 1991). Linear growth is nonchaotic. Mathematically it is so because it is related to a previous value. Thus it is constant or predictable. Growth that is termed non linear, and therefore chaotic, characterises an exponential growth which eventually reaches a limit, thereby rendering the rate of growth as no longer constant, in other words unpredictable. McGuire (1991) explains this by using the following example that might appear as laborious I feel makes the argument more comprehendible.

A fishpond with a fixed food supply can continue to multiply until the food supply is exhausted. Then some or all the fish will die. The growth rate is dependent upon the fish population. In calculating the growth possibilities of the population, there is a variety of behaviours or outcomes. This possibility, that is, the possibility of possibilities, is dependent upon the numerical value assigned to the growth rate, an infinite food supply, or a decreasing population of fish. In other words the starting point, which, up to a certain value, can produce the same result, can do so only to a point. Then, when the growth rate numerical value is increased to a certain fractal dimension, the cycles become termed a 'period doubling cascade'. Finally, raising the fractal dimension further results in the periodicity disappearing, the possibilities then become infinite and the behaviour termed chaotic. The calculations illustrate, a 'sensitivity' to initial conditions. This sensitivity to initial conditions is a basic property of chaos and, at the same time, is what is termed the 'hell' of chaos. For there is no 
shortcut way to predict the future of a chaotic system. The only way to predict (the example was of a fish population that after a certain number of iterations [repeated pattern]) is to actually perform them. In other wise repeat the operations one by one. In this way chaos is completely deterministic (McGuire, 1991). In other words, where a pattern will go is sensitive to the initial pattern. To attempt to predict, as in a forward movement, is by undoing the pattern, and in that way it is not a forward movement but a backward movement. That a pattern can be undone, is certain, and herein is the predictability. Albert Einstein said, "God does not play dice" (Hawking, 1993, p.72). The question is, in Einstein's reference to God was it some external notion of deity or an internal process that represents the interface between our being and being human that as predictability, is God like?

McGuire's (1991) mathematical computations about hypothetical fish in a pond and their food supply offer three distinct pictures. In the first instance what is presented, if recorded as an electrocardiograph rhythm strip would visually depict an atrial flutter that gently moves into asystole, that is, the wave becomes a straight line. In the second picture, between certain values, within a defined value, there is a fixed regular rise and fall - like a sinus ventricular tachycardia, which cycles through certain predictable cycles. In the third instance, the aberration which presents, and which McGuire (1991) describes as 'chaos' (interestingly he terms chaos theory as a physics of physics - a metaphysics), is determinable only by performing each change or iteration. It is third description, chaos, that another important observable behaviour demonstrated through applying concepts from fractal geometry is pertinent to exploring how pattern might be seen as a flow chart.

McGuire (1991) shows that by looking at the variables in another way the result in a chaotic system is, that there is a bifurcation or a window where chaos disappears. A phenomenon, which does not just apply to the hypothetical fish population but one, which is universal. This mathematical phenomenon illustrated graphically shows that there are areas where the pattern repeats, but that the repetition then turns on its original axis. The new pattern then becomes the chaotic area because the pattern has reached its 'threshold', its fractal dimension has reached its upper limit (McGuire, 1991). This area, the chaotic area, is not a solid form as compared to the stable area, but rather it is depicted as 'salt and pepper' or grey and white. Amazingly, there is an area free from chaos or the non-chaotic area within it, and it is hollow/clear/white. Therefore embedded within a chaotic system is an area of non chaos and it is this observation that reminds me of the work of Stephen Hawking. 
The laws of physics are time-symmetric. So if there are areas called black holes into which things can fall but not get out, there ought to be other objects that things can come out of but not fall into. One could call these white holes. One might speculate that one could jump into a black hole in one place and come out of a white hole in another.

(Hawking, 1993, p.119)

While Hawking (1993) does explain that the black hole white hole travelling concept is not quite so simple, none-the less he does end by saying that there is a good chance that a black hole exists at the centre of our galaxy, and that a white hole is the time reverse of a black hole. Hawking's work was published in 1993. His black hole hypothesis was validated in 1998. Black holes, Hawking (1993) postulates are objects from which things can come out of, but which things cannot fall in.

At this point one may stop and ask, what have black holes and fractal geometry to do with Nursing? I see that these branches of Science, mathematics and physics, do provide further direction in explicating the idea that dis-ease is the manifestation of blocked flow that then is linked to the idea that we create our reality as consciousness that in the human condition is a from of emotional processing as the expression of being. Therefore, I have lead the discussion along these lines as I wish to begin to explore chaos and some ideas from quantum physics and quantum mechanics through the work on black holes undertaken by Hawking (1993) in an effort to continue this exploration of patterns as flow charts. I intend to make the relevance to nursing, more visible in the final section of this chapter.

Science is yet to show that anything can travel faster than light. The speed of light is central to the 'Theory of Relativity'. When a giant star dies and a black hole has formed all of its mass is squeezed into a single point at which both space and time stop. At this point mass has no volume, time does not exist. This point at the centre is termed a singularity. At a specific distance from the singularity, the gravitational pull becomes so strong that nothing can escape. This area of a black hole is known as the event horizon and has been formed by light that just fails to get away hovering on its edge (Hawking, 1993). The greater the mass of the singularity the larger the event horizon of the black hole. Science argues that it is impossible for anything to escape from regions known as black holes. So on one-hand black holes are completely black because light rays that get too close bend into, and therefore 
trapped by the intense gravity of a hole. On the other, this idea of blackness includes radiation and particle emission and therefore a flow of energy occurring within a hole.

Quantum mechanics implies that the space of a black hole is filled with pairs of virtual particles and antiparticles that are constantly materialising in pairs, separating, and then coming together again and annihilating each other (Hawking, 1993). They are called virtual because they cannot be observed with a particle detector, but they can be measured (Hawking, 1993). In this way, it is possible to conceive of movement in and out of black holes that cannot be explained by quantum physics. Further, when things [particles] come out of a black hole, they are different than when they fell in, "only the energy will be the same" (Hawking, 1993, p.121).

One feature of particle activity is, that it is paired. The pairing process, it would appear, continues, for as a black hole gives off particles and radiation, not only does it emit particles more rapidly, it loses mass to the point that it eventually disappears. At that time, whatever is in a black hole will go off into a baby universe. A small self contained universe that branches off from our region of the universe, only to then possibly re-emerge in our region of spacetime as another black hole and, as it was (Hawking, 1993). So while some things fall in, they re-emerge. Further, as a black hole looses its mass, its frequency or flow increases, and in this way, there is a greater emission of particles.

What is it then that determines particle emission, and therefore the potentiality of the decrease in density/mass of a black hole? Hawking (1993) says that the uncertainty principle of quantum mechanics suggests that particles cannot have both a well-defined position, and a well-defined speed. Therefore, when one variable is accurately defined, the other cannot be, and vice versa. This then raises an interesting point. Given that light has the greatest velocity, this variable precision of quantum mechanics suggests that the speed of a particle can be greater than the speed of light. In this way, it is possible to hypothesise that particles can escape from a black hole although it is uncertain from where in a black hole they have escaped and that the escape process takes a very long time. Even so, escape they eventually will. This idea, however, is contingent upon something travelling faster than light that then impacts on the Theory of Relativity that is underpinned by the position that nothing can travel faster than light.

Strange attractors are defined as "fractals in the space of the behavioural variables of a chaotic system" (McGuire, 1991, p.97). This 'strangeness' property is explained by illustrating a Lorenz attractor, named so because it was derived from a computational experiment into long 
range weather forecasting. The results of this study highlighted two differing points of iteration in relation to strange attractors (McGuire, 1991). The Lorenz attractor shows a structure that resembles the wings of a butterfly made up by a back and forth movement in a three dimensional figure eight or, infinity symbol. What is interesting here is that the lines never intersect, thereby demonstrative of the possibility of packing an infinite fractal structure into a finite space (McGuire, 1991). On other words while the space can be quantified whereas what is in that finite space is infinite. Further, what this demonstartes mathematically is that a very small difference in the starting point - termed the sensitivity to initial conditions, will, after a few repetitions result in a very different position on the attractor. In these two points I see a correlation between this behavioural aspect of strange attractors, finite and infinity and the black hole white hole potentiality described by Hawking (1993) that is relevant to the ideas presented thus far.

As has already has been explained, a black hole is not totally black because it emits radiation and particles until such time it loses enough mass that it will collapses in on itself. Then whatever it contains goes off into a baby universe to then possibly return as a black hole and if so the hole is as it was, but in a different point in time in the same galaxy [space]. This concept is not unlike that illustrated by Lorenz and identified as the 'sensitivity to initial conditions'. A pattern that potentially keeps on repeating itself indefinately [and in this instance the pattern was the outline of butterfly wings] within a designated space but a different space dimension and capable of infinity. In that way the lines of the pattern never intersect upon themselves all the while being in the same space dimension.

This insight was derived in an attempt to forecast weather numerically. The back and forth figure eight lines of the butterfly represented the variable to convection in the atmosphere. In theory what Lorenz showed was, that the flap of the wings of one of the butterfly's could start a hurricane (McGuire, 1991). The question was, which butterfly would create the chaos?

In principle the laws which govern the universe allow one to predict, yet the motion given by the laws is often chaotic, meaning that a tiny change in the initial situation can lead to change in subsequent behaviour (Hawking, 1993). "On the other hand, the behaviour of the universe on a very large scale seems to be simple and not chaotic" (Hawking, 1993, p.155). And it is this that is the two differing points of iteration in relation to strange attractors. Chaos has two faces. There is always the possibility of instability, and yet, on the other hand, there is the possibility of a great stability (McGuire,1991). Where a chaotic dynamical system will end up on its attractor (fractals in the space of the behavioural variables of a 
chaotic system) is exquisitely sensitive to initial conditions, but that it will be pulled onto its attractor regardless of initial conditions, is certain (McGuire, 1991). It is as if a pattern can be repeated infinitely yet it is always a variation on a theme that eventually be pulled onto its strange attractor and in that way move out of the chaos. The complex is made simple again in which something ensures a threshold where the bifurcation occurs and hence the movement into a chaotic system. In the chaotic system, exist windows of non chaos and in that way present, at one level, the possibility of instability and at another, stability. Is the attractor, then, a mechanism to ensure this possibility, and in this way chaos becomes not the difference between order and unpredictibility, in a dualistic sense, but becomes, what McGuire (1991) calls, a third pole. If so, I would wonder here about flow in this meaning of chaos.

Given that a black hole is said to emit radiation and particles, and the rate of emission accelerates as emission increases, one can assume that there are enormous shifts in energy. Indeed, this statement is supported by calculations that show emitted particles have a thermal spectrum corresponding to a temperature that increases rapidly as the mass of a black hole decreases. So while particle temperature increases, particles from a black hole decreasing in mass are different/changed while the energy is the same (Hawking, 1993). The question here becomes, what is the effect on a black hole while a particle is in there, and what determines which particles remain and which are emitted? Is whatever is in a black hole in some way responsible for ongoing change that must be occurring in the hole, for the close down phase is the net effect of shedding mass/density? Is this then related to Heidegger's (Heidegger, 1971), gathering, holding and outpouring in the void of the jug? Thus we have a black hole that energetically is getting faster and faster, but at the same time would appear to be becoming smaller and smaller. Given the shed of mass, what is the density of a closing black hole, that has mass but no volume. What is its essence, what is left? By definition, is it the event horizon - light, and whatever particles have not been shed. Do these remaining particles have a pivotal role in, when, how, and where that hole re-emerges? I wonder?

When something vibrates fast enough, it appears that it is not moving. So, rather than shoot off into a baby universe, does a black hole sit as if invisible, changed in form, until something triggers events to make it appear, to reappear? Is chaos, as I have described using the work of McGuire (1991), simply the possibility for the process for shedding mass/density so that what remains is in essence, the essence of a black hole, a white hole? If so, is this process linked to what goes in and out of black holes, or what a black hole attracts, so as to collapse matter? What acts as the attractor, for things to move into a black hole? It has been said that a black hole is radiatory. It must also be magnatory, otherwise how do 
things get into the hole, a hole that leaves and can return? But if it does so, it does so in a different time-space dimension, to then undertake the same cycle of radiation, particle emission and subsequent mass reduction.

Hawking (1993) says a black hole is formed by the collapse of matter that has a net electric charge. This net charge becomes the charge of the black hole and attracts those members of the particle-antiparticle pairs that have the opposite charge, repelling those members of the particle-antiparticle that have a like charge. In this way, a black hole will preferentially emit particles of the same sign and so will rapidly lose its charge. Further, if the collapsing matter has what is termed a net angular momentum, the black hole will be rotating, but again like the preferential emission of like charges, will emit particles that carry away the angular momentum. Hawking (1993) explains that the reason a black hole remembers its electric charge, angular momentum and the mass of matter that collapsed, and 'forgets' all else, is that these three qualities are coupled to 'long range fields'. In the case of the electric charge of a black hole, it is related to the electromagnetic field, and in the case of the latter two, the gravitational field. Charge and fields as energy are flow.

Quantum mechanics has added another 'chance' in relation to black hole emission of particles. In this way there is the possibility to see more. It is suggested that black holes formed by the collection of a collapse of baryons (a class of particles including protons and neutrons) forget their baryon number. This would result in a black hole radiating equal quantities of baryons and antibaryons, and when such a black hole collapsed it would "violate one of the most cherished laws of particle physics, the law of baryon conservation" (Hawking, 1993, p.112). In other words, it looses memory of itself, as it was. The memory of itself as it was has not been further explicated and therefore I am interpreting this to mean first, its memory of being a particular black hole and second, something to do with the electromagnetic field which is related to the baryon number.

The idea that black holes have a finite entropy (measure of the unavailability of a systems thermal energy for conservation into mechanical work) is dependent on whether black holes radiate thermally (Hawking, 1993). The explanation is that the emission of particles or, as Hawking (1993) says, the 'tunnel out' of particles, occurs from a region that we do not know about. However, for such a phenomenon to occur black holes would have to radiate thermally. In other words, when we speak about thermal radiation we are speaking about flow. Therefore "all configurations of emitted particles that have the same energy, angular momentum, and electric charge are equally probable. Indeed, it is possible that a black hole could emit a television set or the works of Proust in ten leather bound volumes ...." 
(Hawking, 1993, p.113). Having said this, it is now also possible to say that a finite entropy, the cessation of appearing and reappearing, is linked to density. Indeed Hawking (1993) does confirm this by saying,

if the density of the universe is greater than a certain critical value, gravitational attraction will eventually stop the expansion and make the universe start to contract again ..... would be rather like the big bang ..... the big crunch would be called a singularity, a state of infinite density at which the laws of physics would break down.

(1993, p.146)

In a discussion on information theory and complexity, McGuire (1991) says that information is the accounting of the number of possibilities, states, or conditions that a system could be in. Complexity, is the amount of computation or effort it takes to describe what is there (McGuire, 1991). Complexity, then can become a third pole, a pole that lies 'inbetween'. Such an inbetween is not the midway point between two poles as in a two dimensional reality; rather it is like a door that allows entry into a different space, but at the same time an inbetween which has arisen from the between of two points. In deterministic chaos, complexity is at a maximum. There is no computational shortcut, every iteration, or every repetition of a pattern must be done (McGuire, 1991). In the same way that one would wind a camera lens into focus, the winding continues until such time as what is being focused upon becomes clear. Iteration then, it might be argued, is a backward movement in order to move forward. By definition iterate means to repeat an operation, generally using the last result of that operation as the input. What appears as complexity then, can in fact be a repetition of the same pattern. For until each turn and twist is undone, it is not possible to see this, and while the backward movement is 'predictable', in that we can see what has been created, the forward movement, it would appear, is not. At one level it is 'predictable', and yet at another, and here is the contradiction, it is not. This same contradiction is presented, in McGuire (1991), by explanation of the two faces of chaos, where there is always the possibility of instability, and yet, on the other hand, there is great stability.

This, I have argued, is the same phenomena expressed by Hawking (1993) in relation to the predictability of the universe, where on one hand the laws that govern the universe are predictable but the motion that the laws give rise to are not. Where a chaotic dynamical system will end up on its attractor (fractals in the space of the behavioural variables of a 
chaotic system) is exquisitely sensitive to initial conditions, but that it will be pulled onto its attractor regardless of initial conditions, is certain. This is in the same vein as the uncertainty principle in quantum mechanics where one or the other variables, position or velocity, of a particle can be used to predict a result, but not both. In this way a prediction made by the result of measuring one combination of position and velocity reduces the chance of making a definite prediction to about half, or a fifty percent chance (Hawking, 1993). These odds are even further reduced in consideration of particle emission from a black hole, because particles are emitted from a region about which not much is known, and therefore there can be no definite prediction of the position or the velocity of a particle, or any combination of these two factors (Hawking, 1993). The only certainty about emission from black holes is, that particles are emitted. In other words, while the process of prediction as outlined here is unpredictable, the result is the same as that of a chaotic dynamical system, and that is that it will be pulled onto its attractor, a black hole will emit particles. The clue here is, what do we really mean when we say attractor?

A change in the state of matter is termed a phase transition. Magnetic material undergoes a phase transition to become non-magnetic when heated above its Curie temperature (McGuire, 1991). At absolute zero temperature there is total order and therefore negligible information content, while at infinite temperature there is complete randomness or chaos (in the usual meaning of the word) but, at the Curie temperature, a maximum in complexity is required to describe the magnetic structure (McGuire, 1991). A maximum of complexity, as has already been explained, implies all the patterns have to be done. Interestingly, the mathematics of the phase transitions regard zero and infinite temperatures as attractors, while the opposite, the repeller, is the Curie point, a point at which it is hard to stay (McGuire, 1991). By this means, are we always moving toward a point of balance?

If the Curie point represents a maximum of complexity, the point at which the third pole becomes visible, then in the same way that the dimension of the fractal surface reaches a point where the space is filled and from which chaos then ensues (and in which the non chaotic area is embedded), is this not the same phenomenon of the 'Lorenz butterfly' where the pattern never intersects on itself as it packs its infinite structure into a finite space? If so, then what occurs at the Curie point determines if there is transition/change/transformation because at zero and infinite temperatures there is an attraction or drawing forth, but at the Curie point the magnetic state changes from attractor to repeller.

So is being pulled back onto the attractor that which can occur at the Curie point? At that point of complexity, there is chaos (third pole) and in the chaos there appears a window of 
non chaos. So, rather than keep moving onto the same attractor, is the Curie point another metaphor in fractal dimension that, having reached its space filling potential, creates the opportunity for change. I think so. Which way that change will go is the crucial question? Change that is meaningful or expansive and therefore a backward movement - an unwinding of a thread of the Lorenz butterfly, an iteration revealed, the complex made more simple. Represented as non chaos brought about by 'true attraction' and expressed as repulsion. This just might be how a black hole sheds its mass/density? For if a black hole can be likened to the energetic representation of chaos, its event horizon existing as light or non chaos, then such a possibility would allow for an exploration of what the Curie point represents and how this is connected to black hole particle activity and subsequent change in density.

Such an abstraction would then allow mapping, or charting of patterns of flow. Flow that at a microcosmic level is that which is represented by the human aura that then is the reflection of pattern in which infinity is packed and of which there is no conscious memory.

\section{The acts of Nursing, seen as co-creators of flow}

Madjar (1997) makes the point that while disease is located in the physical body, 'the person' experiences the experience of illness. In this way, illness is portrayed as that which goes beyond an organic level. Citing the work of Merleau-Ponty 1962, and Leder 1984, Madjar (1997) says that while the physicality of the body is, what is physical, the object-body of Descartes [res extensa] is derived from the experience of the lived body. How we experience our embodied selves, is less likely to be focused upon consciously when in a state of health (Madjar, 1997). Madjar argues that this idea is supported by the work of Herzlich 1973, who is cited as naming the experience of health as an 'organic silence', or an 'unawareness of the body' (Madjar, 1997, p.55).

In the first chapter of this work, I presented the idea of a doingness, as opposed to a beingness in Nursing, that is focused on the body. Following Madjar's (1997) argument, patients are people for whom an illness experience can precipitate an experience of embodiment. Nurses as people, whose focus are those with an illness experience, by virtue of their health status, it could be said, are unaware of their embodiment. Yet, both populations, nurses and people, are embodied. Through the experience of illness, one group, it has been suggested, can become more conscious of how they experience their embodiment than those who provide the care. 
This then raises questions about knowledge development in nursing. Given that certain phenomena are predictable based on experience of particular patient populations, for example grief; at the loss of a body part or permanent change in body function, and say joy at the birth of a child, the notion of perception makes it apparent that in experiencing the same experience people can, and do, hold very different views. While there are some shared realities, there are also differing realities. Using Madjar's (1997) argument it has been argued that all nurses while with the patients do not experience embodiment through illness, while it is acknowledged that nurses as people do experience illness. Therefore, predicting certain outcomes for people experiencing common illnesses by those not having had that particular experience becomes fraught problems that then is compounded further by how the individual experience is experienced. Hawking (1993) raises this same point in relation to predicting black hole particle emission. The laws of physics while predictable cannot explain behaviour and therefore at a level where the laws are in motion there is unpredictability. McGuire (1991) demonstrates through his example of a hypothetical fish population that after a certain point the number of cycles become infinite and the system chaotic therefore also demonstrating the unpredicatability of a system in motion. Therefore, I argue, Nursing cannot continue its knowledge development through structures of inquiry that assume predictability, where the focus of inquiry is directed at understanding the experience of health and illness that in some way is meaningful.

In other words, we have in Nursing, in our effort to move nursing from a perceived historical focus on the body to that within the body, engaged ourselves in discourses to explore the experience of illness that still have at their core this notion of predictability. This is in spite of having located ourselves outside of a positivist paradigm.

Having said this, I wish to make it clear, that I perceive that in the same way that McGuire (1991) showed in the example of the period doubling cascade that a system does not remain constant after a certain point, we in Nursing are yet to realise that most of our research is still located at this level of inquiry. And this is regardless of whether we have used feminist, ethnographic, ground or action theories and located them in post modern, critical or constructivist paradigms. For while our research into the experience of illness has yielded further insight into nursing, none-the-less I perceive it remains at the level commensurate with the period doubling cascade where the system is still believed to be predictable in the futuristic sense of the word.

In this way it is limiting, even though our examination of what we do is positioned with a different world view, the limitation is in this continuation of predictability in the forward 
movement sense. In other words, what Madjar (1997) has called our attention to in relation to the notion of embodiment through the experience of illness, I am arguing is chaos for that human being. As chaos illness needs to be understood from the perspective of chaos as, I have begun to outline. Where to undo the pattern requires a step by step movement that is backward and in that way predictable. For as I have already said, I see that we are still working with prediction in the forward sense of the word that is then reflected in the epistemological and ontological positions embedded in nursing theory, research and practice.

This chapter began with a discussion of the human aura as the energetic representation depicted by patterns of what is happening on all functional planes that then make up the human being. This then becomes life. The idea that we are energy/consciousness, not only in the universe but of it, was also presented. In the consideration of our being in terms of flow of energy, dis-ease was depicted as a manifestation of the interruption to, a change, stagnation of, or a contraction, in relation to flow. In this way, dis-ease can be perceived as not merely a diminution of consciousness, but as that point in chaos in which there is non chaos. In this way dis-ease has the two faces of chaos, where on one hand it is not possible to predict where a system will end up on its attractor, but on the other that it will, is certain. In understanding how, lies the possibility of moving from the chaotic area in chaos, to the non-chaotic area by identifying the third pole within the system.

To do so is to begin to view the human being as the Universe. Where on a large scale the behaviour of the universe is simple and governed by well defined laws that are predictable that then become chaotic by the motion given by these same laws (Hawking, 1993). Therefore, what I am suggesting is, that chaos, in the sense of the only way to determine a system is to actually perform the 'iterations' or the patterns, is where we focus our attention in nursing. In this way we can uncover/reveal/make visible the simplicity of the above disguised in the complexity of the below. For as it is above so it is below, and so is ours to be created by the motion/action of being human.

Nursing then would take on a new perspective. For as was outlined in the first chapter, one cannot refract until one has worked with reflection. We cannot be a white hole, the time reverse of a black hole where things can come out of but which nothing can fall into, until we have worked with our own black hole. In this sense, I am not speaking of a completion or final product. What I mean here is a process by which we consciously change the patterns within ourselves and in so doing know how to consciously support another in changing theirs. 
At the first level, nursing at its best becomes a co-creation of flow, where nursing is a process of reflection in which nurse and patient mirror an aspect of self to the self. This mutuality holds the potential for an act of transformation and thus expansion for one, the other, or both. In this way, it is deterministic. At the same time, it is also the potential for contraction for one, or the other, or both. Then the complexity of the beingness of each being is made more complex, and in that way what has been created is another wing or turn of the butterfly or the black hole has lost more heat. This potential is called forth as the dualistic pulsation that is the movement toward and away from the originating centre represented by the patterns that make up the human aura as it is acted out in the experience of life patterned as dis-ease that then bring the nurse and patient together.

This is what I see, Taylor has really told us about nurses and patients in her discussion on being, "... they are beings, who embody Being, that is they are entities within whom existence is situated" (Taylor, 1994, p.7). The one that we name patient is in some way an image of the one we name nurse. The one that we name nurse is in some way an image of the one we name patient. Together they are co-creators of flow, that as entities within whom existence is situated, they can assist one another to become what they already are. White holes manifested as black holes, connected to one another in their humanness through e-motion. 


\section{Summary}

Presents the idea of the human body as fields of energy or human aura to then convey the possibility of the movement of energy from cellular, universal and mathematical perspective's.

Pierrakos (1987) and Candace Pert's (1997) work are presented to explore emotion from a cellular and psychological level so as to begin to connect a human being from a physical and non physical perspective. Dis-ease is then further explicated from the non-physical position as it relates to these ideas on emotion and energy. Illness is again viewed from the position of a pattern of energy and then further linked to thought and emotion.

The human aura as a non-physical expression of what thoughts are being thought in any given moment is then highlighted in order to expand the notion of the nature of a human being, being. In that way, thought and emotion are not separated into subjectivity and objectivity in the traditional sense of use and meaning of the words.

In an effort to make links about the nature of being from the macro (being) and micro (human) perspective's the cellular functioning of mankind is paralleled with ideas about black hole and particle activity using the work of Stephen Hawking (1993).

Concepts from fractal geometry and chaos are presented to show how predictability within an open and chaotic systems is possible, when considered as pattern that has been created by repeating an emotional reaction. In this way, the text begins to explain how in the reexperiencing of an emotion it is then possible to unwind a particular pattern and in so doing make simplicity from complexity.

Implications for Nursing and Nursing Research using interpretive method are then drawn from these insights. 


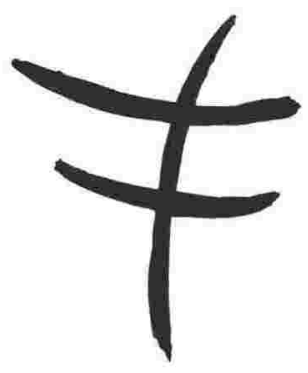

\section{Chapter 5: The Ethics of Health}

\section{Life experience seen as energy}

In the second chapter, the notion of a thing manifesting physically was explained in terms of energetics, where it was argued that everything already exists. In this way, there is nothing new in the universe. To say that there is nothing new in the universe is not the same as saying that everything in the universe already exists in physicality.

An energy field is distinguished by a pattern where pattern is an abstraction that reveals itself through its manifestations. Rogers' defines pattern as "the distinguishing characteristic of an energy field perceived as a single wave" (cited in Malinski and Barrett, 1994, p. 241). Therefore, what is in our physical world is, because energetically it is. A thing in physical manifestation is a pattern of energy made manifest.

The word experience implies the connection between ourselves and our world where experience is an engagement, both in the world and of it. In this sense experience is not passive, because to engage in a thing requires a form of action. Any action grounded in physical reality is then governed by laws pertaining to gravity. In Newtonian terms, each action has an equal and opposite reaction.

Quantum mechanics, in its efforts to explain that which is beyond gravity, perceives a universe filled with pairs of virtual particles and antiparticles (virtual in the sense that they cannot be observed directly) which then materialise in pairs, separate and then come together and annihilate one another (Hawking, 1993). As particle and antiparticle these pairs are matter, however when they annihilate one another, they are then pure energy, or light. Hawking (1993) explains that one of the pair may enter a black hole thereby leaving 
the other without a partner to annihilate. At this point the other of the pair may follow its partner, or escape to infinity, in which case it is then detected as radiation emission from the black hole. The member of the pair that fell [or was drawn] into the black hole is travelling backward in time, while the opposite or other half of the particle pair is actually coming out of the black hole, but also travelling backward in time (Hawking, 1993). At the point where the particle antiparticle originally materialized, the movement in time is a forward one because it is scattered by the gravitational field (Hawking, 1993). These insights have been made possible by Einstein's Theory of General Relativity and expressed in the formula $E=m c 2$, where $E=$ energy, $m=$ mass and $c=$ light.

A black hole is formed by the collapse of matter which has a net electric charge. This net charge becomes the charge of the black hole, which then attracts those members of the virtual particle-antiparticle pairs that have the opposite charge and repels those that have a like charge. All combinations or configurations of emitted particles that have the same energy, angular momentum, and electric charge, are equally probable (Hawking, 1993). Currently our understanding of particle emission from a black hole leaves many questions unanswered.

During her research work into validating the existence of the opiate-receptor, Candace Pert 
In so doing, she opened up the whole concept of a communication system within and between cells.

The drugs Naloxone and Morphine are almost identical chemically, their action and subsequent cellular effect, though, are radically different. When Heroin or Morphine bind to an opiate receptor, what is felt is euphoria or bliss. Naloxone reverses these sensations/feelings. Furthermore, as an antagonist, Naloxone binds to the opiate receptor in such a way that it 'pings' less, thereby occupying the receptor site more readily than the agonist (Pert, 1997). In other words, the situation is such that it appears as though 'blocking' is the favoured state which, when compared to bliss and euphoria, could be perceived as a negativity. Negativity, which in the case of the opiate receptor influences cellular function to the point where there is less bliss/euphoria/joy experienced. At one level this assumes cellular stability, up to a point, because this ensures whatever is 'happening' in a cell remains unchanged. Science however tells us the cell needs to keep being given the signal in order to produce more of whatever. Further, as there are multiple receptor sites so too are there multiple ligands sitting diffusing through the exctracellular fluid and so what determines which ligand and receptor connect remains the mystery. What is known, is that communication within a cell is ongoing.

Change then is the result of a ligand and receptor connection in the space outside the cell. Whether that connection be described as a lock and key mechanism or a vibration/humming motion, without it there is no new communication from one space to the other. Pert's (1997) opiate receptor work (and of course the peptide endorphin is the naturally produced opiate of the body) made it clear that unless the agonist binds with the receptor there is no cellular influence. So the cell does not receive the message/information to make more bliss, more joy - more endorphin. I would also like to make the point, the significance of which I am yet to make clear, that in the course of Pert's research work (1997) one of the follow-on discoveries was that the antagonist Naloxone required sodium $[\mathrm{Na}+]$, the major extracellular cation, to perform its blocking action. Pert (1997) clearly demonstrated that there was some crucial connection between sodium and Naloxone. The level of sodium 
was a critical factor in potentiating the ability of the drug Naloxone to block the opiate receptor.

The human body has well documented homeostatic mechanisms which maintain fluid balance within the body. One of those mechanisms is the control of movement of sodium and potassium across a cell membrane. The major intracellular electrolyte Potassium $[\mathrm{K}+]$ has a positive charge and is able to cross the cellular membrane or boundary, while the negatively charged molecules, mainly organic phosphates DNA, RNA, ATP, and creatinine phosphate, do not tend to cross cell membranes (Halperin and Goldstein, 1988). The numbers of positive and negative charges in any compartment are about equal. In other words, for the body to be in a state of homeostasis, is to be in balance. Movement of potassium across a cell membrane is contingent upon an exchange of $\mathrm{K}+$ for $\mathrm{Na}+$ and or $\mathrm{H}+$, or simultaneous movement of $\mathrm{K}+$ and an intracellular anion. Forces that act at the extracellular fluid/intracellular fluid interface are $\mathrm{K}+$ is pumped into the cells - NaKATPase and $\mathrm{K}+$ diffuses out of the cells when the resting membrane potential is close to $-90 \mathrm{mVolts}$, in muscle. The point here is that when something with a + charge is pumped out of a cell then something with a + charge is pumped back in, the pumping an energetic activity that can be measured in terms of an electric charge. These homeostatic mechanisms, we know, are part of the mechanisms that keep the physical body balanced, and are those which are disturbed in certain dis-ease states.

Therefore, a cell, like a black hole, has 'things' in it and outside of it as well as those moving in and out of it. Unlike a black hole though, some mechanisms appear to be reversed. In the ionic exchange across a membrane, the exchange is contingent upon the exchange of like charges, whereas what factors determine which receptor will connect at a site and thus engage in another type of movement, is not known. What is known, is that there are multiple possibilities. Black hole particle activity reasons that the determining factor of particle attraction is that the particle charge will be the opposite charge to that of the net charge of the hole. What determines a hole's charge in the first instance is also cause for speculation. At a cellular level, it would also appear that the level of the 
positively charged main extracellular cation sodium in some way plays a role in agonist/antagonist behaviour particularly in relation to opiate - euphoria/joy/bliss behaviour.

Our understanding of the pathology of disease is built around our knowledge of the changes to the internal and external environment of a cell. As we continue to research various disease states, we continue to chart the course of these changes to the balance and harmony of the delicate and magnificent workings of our body. Yet, having said this, what is it that acts as a catalyst to create these imbalances in the first instance? Do we really know how we get [create] diabetes or cancer? While we have identified links - strings, what is the basis of a cerebro vascular accident when it could just as easily have been a myocardial infarct, given that both are attributed to vascular wall change?

Our studies in epidemiology identify certain predisposing factors linking certain dis-ease states. Biology names organisms, science and medical research is now focused on the human gene as the basis of all dis-ease. Therefore we say, given the presence of particular factors or organisms or genes, there is either an increased risk of an individual to exhibit this or that particular dis-ease. By identifying what we term familial patterns [inheritance], genetic cause, what if these patterns are no different to that which is represented by the phenotype, that is the physical human being? In other words, an expression of a phenomenon where an offspring resembles a parent or grandparent, are we any more informed other than that this child has the same red hair that his grandmother did?

The human genome project has set out to make a map of our human genes. The ability to identify genetic cause of dis-ease is one result of this project. The degree to which gene patterns will be manipulated as a means of dis-ease prevention is yet to be fully explicated. In the meantime our experience of dis-ease reveals that a grandmother, mother and daughter may all manifest breast cancer. We also know that two ten year old boys may experience the same viral infection, after which one of those boys will be diagnosed with Type 1 Diabetes Mellitus. What brings on the accumulative changes within a cell so that 
one person no longer produces insulin in sufficient amounts to be able to facilitate the regulation of the metabolism of glucose, and another occludes an arterial wall? Why, when the mechanism for two dis-eases are the same, ie arterial wall narrowing and occlusion, how is it decided whether it is a coronary artery in this person that is affected and a cerebral artery in the next, so as to make the health issue apparent? What is the meaning of that common gene displayed through the family relationship of grandmother, daughter and granddaughter?

As has been stated, our pathological knowledge of dis-ease charts the progess of dis-ease and in some instances points of origin, but how that imbalance is brought into being is still not fully understood.

Our current endeavour to illuminate dis-ease states through gene mapping and manipulation could be likened to removing all red haired children from this planet without understanding how red hair was created in the first instance. And in the same way that we now face multi resistant organisms through the mutation of bacteria as a result of our efforts to kill bacteria with antibiotics, our approach to gene work is grounded in this same ideology where the approach to dis-ease is one of conquering, overcoming and controlling. Our experience over some fifty years of killing and conquering has resulted in the realisation that the issues are just as, or even more serious than those before discovery and mass implementation. Real questions concerning the ability of our immune system to respond might be raised at how we deal with the whole gamut of factors as they relate to immunity. Can it be said that the health of western society has really been improved by the practices of a health care system that we as a society have created and embraced during the past fifty years? How much of what we have created in the name of health care has been created from our fear of death? Those beliefs are then lived out as they are represented by the structures and practices that we immerse ourselves in as a means of avoiding what it is we fear. In this way, we continue our killing, conquering, irradicating and controlling systems. Are we really any more informed about the basis of dis-ease even though our knowledge of physiology, pathophysiology and genetics, and the use of technology have not been 
paralleled in any other time in recorded history? I think not. As such we continue to approach dis-ease as the enemy grounded in the physicality of who we are. We look for physical solutions to deal with our physical selves and this is in spite of our science having shown us that all physical things exist as energy. It would have to follow then that dis-ease, too is energy.

Dossey (1991), in his text Meaning and Medicine, uses anecdotal notes from his experience as a medical practitioner to illustrate the power of meaning in its relationship with illness or dis-ease and health. The text is dedicated to showing its readership the many faces of the how, of meaning making, both in creation of dis-ease and health. The power of meaning made, Dossey (1991) portrays, is in the interpretation of life events and is encapsulated by the unique how of what a person thinks and feels in response as a result. It is in the uniqueness of what a person thinks and feels in response to their human situation that Dossey (1991) suggests is the key in assisting our understanding of our acts of creation. In other words, what we feel/think becomes physically manifested and in that way we create health and illness. By our engagement in life, the cells in our bodies whose receptor laden membranes, Pert's (1997) biological substrates of emotion awaiting their specific receptor ligand connection that can change cell function, in its physical manifestation can be interpreted as balance and harmony or imbalance and disharmony. Health or illness, either of which is created by a feel/think mechanism enacted by the meanings we make in our moment by moment interaction with life.

If the word energy means power, activity, action, motion and movement, then is it possible to view the experiences of life as energies? Energy that is reflected in the peptide and cellular activity recognised by some as receptor ligand connection and cosmically expressed by particle movement of a black hole. In this way, I suggest, that a cell and a black hole are a mirror of one another Where the clue to their activity is hidden in the meaning of the Latin word emovere - to move. The ability to move energy that by our being human, energy expressed in matter, through the engagement in life, the experience of living, we shift/move/change energy. 


\section{Experience as expansion or contraction}

Contemporary psychologists and biologists replaced the classical philosopher's word 'passions', with the word 'emotion'. The renaming was to enable emotions to be considered in terms of a 'neuronal ideology' which was deemed to be active, whereas passions were perceived to be passive and therefore could not be considered from this perspective (Vincent, 1990). Not all philosophers embraced this idea. Even the classical philosopher Descartes, whose work it has been widely acknowledged was responsible for creating the split between body and mind argued that the foremost criterion of passion was not passivity but rather, movement. Therefore he too asserted that passions were not passive (Vincent, 1990). But in replacing the word passions with emotion the idea was to represent a view which reflected movements of the sense organs and nerve pathways that not only culminated in the brain, but which were the domain of cerebral function. Hence the term neuronal ideology.

Spinoza (1677/1952) in his work titled 'Ethics' records a theory of passions suggesting that not only can all passions be explained with reference to pleasure, sorrow and desire, but that the idea of 'the self' is contained within the passions. Where the interface between 'the self' and exterior stimuli serves to restrict or heighten our existence. This tendency towards self preservation, coupled with the power to further counter this tendency is integral to this construction (Muller 1826, cited in Vincent, 1990). Where the driving force, the central expressive innate commonality of human beings, is that which maintains and extends the power of our existence, and thus desire, [sorrow and pleasure] serve to act as some sort of catalyst by which 'the self' [soul] can approach the good, and escape evil (Muller 1826 cited in Vincent 1990). Good in the sense of that which is useful to us, and evil which hinders us from possessing anything which is good (Spinoza, 1677 cited in Vincent, 1990).

This same idea is conceptually represented by the Lorenz butterfly and phenomenon of the Curie temperature introduced in the previous chapter. The Curie temperature, it was explained, is the point at which there is a maximum of complexity required to describe a 
phase transition of magnetic material and therefore can also be recognised as the point at which a third pole becomes visible or, an inbetween. This concept is repeated in the understandings of fractal geometry. When the dimension of the fractal surface reaches a point where the space is filled it is then termed chaotic, the system is no longer predictable in the literal sense of the word but importantly a non chaotic area is embedded in this space. Therefore, the Lorenz butterfly demonstrates an ever-repeating pattern that never intersects on itself as it packs its infinite structure into a finite space. So what I am arguing is, that schematically, the Curie temperature and the Lorenz butterfly represent what Spinoza and Muller (cited in Vincent, 1990) mean when they speak of the tendency towards self preservation coupled with the power to further counter this tendency. For what is, termed self-preservation is innate. That is not the notion of survival, but embedded in our consciousness as we engage in a life there is the intention of realising, making real, 'the good'. Therefore, we pack infinity into what appears finite, and in this way, it is complexity, which then expressed, as consciousness becomes multiple levels of consciousness. This then follows that in our expression of physicality, being human, that at any one time our cells must hold multiple levels of consciousness. Further, in considering black hole activity from this perspective not only might there be further insight into particle activity, but the collapse of a black hole and possible re emergence in our region of spacetime can then be viewed as an expression of the Platonic notion of anamnesis. Anamnesis, 'multiple cycles of life and death, of bodied and disembodied states' in order that we not only approach the good, but realise, make real that which we already are. In this way, what I am arguing is, that the passions serve as a catalyst to approach the good and so in some way relate to love or the whole. Where love is responsible for the human passions in that it contains, and excites them (Senault 1641 in Vincent 1990).

Spinoza (1677/1952) titles part three of his Treatise on Ethics, 'On the origin and nature of the affects'. Spinoza defines an affect as, "By affect I understand the affections of the body, by which the power of acting of the body itself is increased, diminished, helped or hindered together with the ideas of these affections" (1677/1952, p.395). In the introduction section of his work, Spinoza (1677/1952) asserts that no one had determined 
the nature and strength of the affects and what the mind is able to do towards controlling them. This Spinoza (1677/1952) argued was despite Descartes 1649 work, who had asserted that the mind was absolute master over its own actions. In this way he had attempted to deal with the passions by explaining their origin to then demonstrate how the mind controlled or had power over the passions. Descatres 1649 efforts, in Spinoza's (1677/1952) view, did not explain how the mind controlled the passions.

Spinoza (1677/1952) presents a list of forty-eight affects [passions] and then theorises how each one belongs to a category of either sorrow, joy or desire. His schemata of body and mind depicted that they were one. An affect, he argued, created an image in the mind. This he concluded was the basis for a confused idea. A confused idea is not pure thought (Spinoza, 1677/1952). Subsequently the mind suffers, as it has inadequate or confused ideas (Spinoza, 1677/1952). The body then, because the body and mind are one, has an idea of itself that is created by the effect of the affect in the mind. This then creates an image that determines what we become. In other words, the image we create as thought is dependent on what we do with an affect but which in turn creates what we image.

For all ideas which we possess of bodies indicate the actual constitution of our body rather than the nature of the external body; but this idea, which constitutes the form of an affect, must indicate or express the constitution of the body, or of some part of it; which constitution the body or any part of it possesses from the fact that its power of action or force of existence is increased or diminished, helped or limited.

Spinoza $(1677 / 1952$ p.421 -422)

Thomas Aquinas (1267/1952) in his discussion of the passions, also begins by exploring the use of the word passive. In the first instance it is generally assumed that the word passive implies that one is the recipient of something and nothing is taken away. This, Aquinas (1267/1952) says, is not passivity, but a form of perfection. Passivity in its proper 
sense includes both being the recipient of something and something being taken away. Aquinas (1267/1952) illustrates this in two ways. Firstly, what is given up is sometimes that which was not suitable in the first place. Aquinas (1267/1952) makes this point by pointing out the obvious, ill health being replaced with health. In this way, ill health is deemed passive. In the second instance it is also possible to turn this perspective around. Again using health as an example, Aquinas (1267/1952) says that to ail is to be passive too, because ailment is received and health is lost. In this way, Aquinas is making it plain that it is not about something being more and the other less than, but rather it is in the notion of giving and receiving in which passion has its proper meaning (Aquinas, 1267/1952). Conceptually this notion is further expanded as he writes, "For something is said to be passive from its being drawn to the agent, and when a thing recedes from what is suitable to it, then especially does it appear to be drawn to something else" (Aquinas, 1267/1952, p.721). And herein Aquinas (1267/1952) gives us some important clues in the process of 'being drawn to' through the example of ill health being replaced with health. He says, "when a more excellent thing is generated from a less excellent, we have generation absolutely, and corruption relatively" but that also the contrary is possible, "when from a more excellent thing a less excellent thing is generated" (Aquinas, 1267/1952, p.721). And that passions are a domain of the soul from the perspective of reception in as much as they are feeling and understanding, therefore "passion accompanied by the loss of something is only in respect of bodily change; ..." (Aquinas, 1952, p.721). Therefore Aquinas (1267/1952), in the notion of giving and receiving, 'something is received and something is taken away', explains a process that as process is movement and at the same time has movement as its outcome.

Movement in the first instance is as a recession. In first sense it is a reversal/backwards and in the second is that which is termed a loss as opposed to being taken away. In regard to the latter, the movement remains at a bodily level (Aquinas, 1267/1952). It would also appear that this distinction is a factor in determining passion as the domain of the soul. For it is in the notion of being taken away, or reversal, that is connected to feeling and understanding, and in this it is soul process, whereas the movement which is termed loss, is 
movement that somehow remains at bodily (corporeal) level (Aquinas, 1267/1952). I would wonder here about a fuller interpretation of movement at corporeal level that is termed loss as opposed to being taken away. From the Heideggarian notion of an outpouring is it what determines an outpouring that is a consecrated libation as opposed to an outpouring that is a mere decanting? My hunch is that it is and that such a view would be consistent with the outcomes Aquinas (1267/1952) describes. Those outcomes he argues are 'generation absolutely', in response to process where 'a more excellent thing is generated from a less excellent', and 'corruption relatively', in response to process 'when from a more excellent thing a less excellent thing is generated' (Aquinas, 1267/1952, p. 721). This perspective is also consistent with Spinoza's (1677/1952) argument, whereby the passions serve to act as some sort of catalyst by which 'the self' [soul] can approach the good, or that which is useful to us, and escape evil, that which hinders us from possessing anything which is good. But how this is so, I am yet to uncover.

The idea of movement also contains the possibility of direction that is movement that is either backwards [reversal] or forwards. In the sense that it becomes a more excellent thing, because it is a simplification in the way an iteration of movement in fractal geometry was explained, movement could be described as a reversal that then is forward in the sense of expansion. As a movement forward from the perspective of the backward movement, where one has moved to, is closer to 'back to things themselves' and so has approached the good. The pouring has been a consecrated libation, something has been given and taken. Where movement is such that it is a loss, then the movement is also forward, but a less excellent thing has been generated because there is a greater complexity. Then one has moved further away from the good. The pouring a mere outpouring where something was given and something was not taken away.

Still I arrive at the point of the previous paragraph where it is apparent that this discussion requires further expansion. I am yet to expand upon these ideas and so rather than continue I would introduce another concept while acknowledging that the discussion to date has raised the issue of a body mind soul connection, which on one hand speaks to a soul 
process and on the other focuses on losses from the body. What is important to the discussion here is, that there be an understanding that there exists a relationship between our emotions and movement, which are indicative of the possibility of expansion or change in consciousness - a more excellent thing. And in that way it is movement. The how of that body mind soul connection, and thus the process of movement needs to be explored more fully as this work progresses.

What is meant by the word experience? When I say I experience a thing, then I mean not only that which I encounter in every now moment, but how that encounter both shapes my reality and becomes the basis from which, and upon which, I act. Action then, is the outcome of how I have perceived my world. While perception occurs in the moment it immediately belongs to the past. In the moment, I can respond/act in a habitual way. My choices are based on a built up code of rules and patterns, so that when called upon or faced with a familiar problem under similar conditions I act according to that set code or pattern (Koestler, 1964).

Praxis, in the Freirian (Freire, 1972) sense, is examined through the notion of word as dialogue. Freire (1972) points out that word as dialogue has two dimensions that exist in such a radical interaction that even a slight deviation in one is resultant in a major shift in the other. He names these dimensions as reflection and action. Where to deprive a word of its dimensions of reflection is to engage in mere activism thereby making denunciation of the world impossible. Denunciation cannot occur without a commitment to transform, and yet there is no transformation without action. Action that is emphasized exclusively, converts word to activism, or action for action sake, thereby also negating the true praxis or real word. Without the dimensions of reflection and action, word is unauthentic. An unauthentic word then is unable to transform the world [reality] because the original dichotomy is reinforced and as such unauthentic forms of existence are created (Freire, 1972). As unauthentic forms of existence they are unauthentic thought forms (Freire, 1972). In other words, confused ideas. Thus my reality and the basis from which I act remains unchanged without my ability to reflect and act together as I experience my world. 
In the second chapter of this work, the work of Merleau-Ponty (1964) reveals the notion of reflection in relation to the meaning of portrayal of an image of reproduction to the eye and mind. That image, it was said, was an image that exactly corresponded in appearance or effect. In this way, the notion of mutuality located within the form was expanded using the work of Dilethy (as cited in Ermarth, 1978) who, in supporting this understanding of reflection, argues that "external objects are to be sure components of lived experience, and as such belong to the sphere of life itself" (p. 126). Herein, it is important to stress that what is reflected as an objective reality is not meant to convey objectivism in the sense that it is true/pure/unconfused/ authentic, rather, self reflection or reflective awareness is a reflection upon the relation of the self to an external reality. The relationship then is not separate to an opposite object, and in the way that Dilthey (as cited in Ermarth, 1978) describes, given a state of awareness reflection is about seeing myself in another. "Self consciousness and consciousness of the world are only two sides of the same consciousness" (Dilthey cited in Ermarth, 1978, p.126). And so we reflect the world to each other through our consciousness of it even though we may not consciously know what we are unconsciously portraying as an 'image of reproduction to the eye and mind'. Consciousness of the outside world can serve to assist in making the unconscious conscious in the same way that we might consider a conception of form held within a work of art.

And so form may be used to connect all those elements, patterns and facts into a construction that enables the creation of meaning. In so doing we are enabling a mediation between what is being reviewed and the self. Mediation that is a form of reflection and contemplation of the self, for the self. For if a piece of art in its form conveys the intimacies of life, art then can convey meaning that embodies and reveals particular understandings of life (Markus, 1983). Chinn (1994, p.24) states that the art in nursing "is the art/act of the experience-in-the-moment". If this is so, then in the experience of the moment there is the potentiality of reflection and action and when their radical interaction has been maintained, then word/work/praxis is authentic because there has been a transformation of reality in the way Freire (1972) proposed. Then it can be said that the power of acting of the body itself is increased as suggested by Spinoza (1677/1952). 
Further, there has been passivity. Something has been both received and given up and in that way it has become as Aquinas (1267/1952) says, a more excellent thing. In this way, the Lorenz butterfly has not repeated its old pattern, for there has been a receptor ligand connection that in some way has influenced the cell to create a new pattern. The black hole has shed density as particle and antiparticle annihilate one another. The outpouring has been poured and the gift is one of a 'consecrated libation'. The movement backward is then forward, because the thing has 'thinged'. This then is to experience life for the purpose of expansion. It is our choice, and one that we make with every breath that we take. We are making those choices, either consciously or unconsciously, in every now moment.

\section{Contraction as blocked flow}

Pierrakos (1987), in his discussion on the origins of dysfunction, notes that inherent in most species is the knowledge of how to rear its young to the stage of self sufficiency. Animals do this by teaching their young to integrate their innate movements with those in their surroundings while allowing them the freedom of expression to do so. Humans on the other hand teach their young the exact reverse. Children are taught to subordinate both their innate movements and freedom of expression to those in their surroundings (Pierrakos, 1987). Therefore, human beings learn from infancy that some emotions and other natural functions are not acceptable. This persistent prohibition creates belief structures, where to experience particular emotions will bring pain and destruction to the self or others (Pierrakos, 1987). In this way of being in the world, 'the good' and 'the bad' is born, good and bad which is then structured on a socio historical perception of what is and what is not acceptable. Pierrakos (1987) introduces this section of his text with what can be interpreted as a supplement or rider to this construction, and one that is critical if this argument is not to follow the traditional nature nurture debate.

It is asserted that "each living being comes into an environment not of its own making, but from an infinitely complex orbit of concentric systems that encompass bigger and bigger 
fields of external reality" (Pierrakos, 1987, p.102). Each person enters the world called (Hillman, 1996, p.7). Plato in the Republic argued that before birth each soul is given a unique daimon (soul companion) and that the soul has selected an image or pattern through which to live on earth (Hillman, 1996). The daimon remembers what is in the individuals image and what belongs in the pattern and therefore is the carrier of destiny (Hillman, 1996). "A calling may be postponed, avoided, intermittingly missed. It may also posses you completely. Whatever; eventually it will [win] out. The daimon does not go away" (Hillman, 1996, p.8). I wonder, is Plato's daimon what science terms 'the strange attractor' and that in new age philosophy is spoken about as a spirit guide? Is the image or pattern that the soul selects represented by an archetype that is then one form of expression of a souls purpose? Where in order to fulfill ones destiny - the souls purpose, each being, each child, is exactly where they need to be, in order to experience the exact socio historical constructs of reality that on one hand act to subordinate their freedom of expression, and on the other can become the tickets for their flight to freedom. Plotinus AD 205-270 (as cited in Hillman, 1996, p.8) also argued that "we elect the body, the parents, the place and the circumstances that suite the soul, and that as the myth says, belong to its necessity".

The argument then is, that somewhere in this process of choosing the conditions from which one can grow, and in this way becomes the flight to freedom or the expansion of consciousness, the enactment and engagement in and of life, in the main, serves to stifle the tremendous living force within the child as they begin to confront the restrictive mores, religious codes and fabric of social consciousness. While we perceive that in teaching our children how 'to be', our actions have as their core the energy of love, when the spontaneous movement of life in the child is not respected, the outer self is severed from the inner reality, shattering the integrity of their energetic system, and chaining that child/person to an illusion (Pierrakos, 1987). This then is how the power of the body is diminished (Spinoza, 1677/1952), and a less excellent thing is generated from a more excellent one (Aquinas, 1267/1952). Meanwhile the Lorenz butterfly continues to pack infinity into its finite structure. Because the self is now engaged in life that is 'good' or 'bad', and the notion of good and bad is the basis for how one then perceives the 
spontaneous movement of life so as to influence every ongoing act of creation. The irony is that at the same time we have placed the self in exactly this position in order to discover this truth.

Pierrakos (1987) asserts that positive emotion from the core is mostly perceived as contrary to human interest. If this were not so, then our institutions and work environments would be happy places in which to be. Even more of an indictment to the situation is that our reaction to 'too much' expression of joy, laughter or fun, is often one of suspicion, caution and distance (Pierrakos, 1987). Patch Adams almost did not graduate from medical school, partly because he was "excessively happy" (Adams, 1993). And in the recognition that the feeling of joy just might be in our best interests, people are having to be reminded of how to laugh again in workshops specifically designed for this purpose. Laughter workshops. And while we are cautious of the so called positive emotions, our perception of the negative emotions; anger, sadness, disappointment, powerlessness, hatred and shame, is even more vehemently opposed to the interest of our being human (Pierrakos, 1987). The terms positive and negative as used here do not imply good and bad, but rather, are used in the sense to denote an energetic charge. So while I do hold with the Pierrakos (1987) position on judgement of the so called negative emotions, what this argument does not consider is, what I would now call more closely for your attention.

I have already argued that our environment, the world around us, is but a reflection of our inner world. It is the relation of the self to an external reality and therefore the relationship is not separate to an opposite object. In this way whatever the child encounters is not the issue, because the adult too is the external world. This being so, then how can an adult assist a child when that adult does not understand how to engage in their world in a way that denounces it, so that the world might then be changed through changing one's perception of reality? On one hand the child adult relationship can be viewed as the oppressed and oppressor, but when seen in this light, the adult and child are both 'the oppressed'. Change is brought about by changing not the circumstances of life, but how we respond to those circumstances. In this way we are changing our external reality, which is 
but the reflection of our inside reality, by first changing the internal reality. We change the image we have given to our minds eye!

Martha Rogers (cited in Malinski and Barrett, 1994, p.27) said that "pattern is a manifestation that reveals itself", and thus everything exists because energetically it exists. Before anything is made physically manifest, it exists as energy. Plato 428BC-348BC in his 'Theory of Ideas' (cited in Lemay and Pitts, 1994), said that everything that exists derives its shape and meaning from its form, forms which are the perfect eternal ideas of things that everyday objects copy. This being so, then I argue that our lives, work places and institutions are the product of what we create with our minds. They are our creations. Are we creating from the possibility of energy, which is positive or negative? When we stop a small child from expressing anger, sadness, loneliness, jealousy, greed, worthlessness, guilt etc etc it is because we judge that negativity, that is, it is perceived in terms of 'good' and 'bad'. It is a choice and the outcome of such action is the continuity of creation - more of the same thing. We (re)create what we focus upon, for that is where we have placed our energy. And when we judge a thing, then that is what we have focused upon.

But judge not, and neither condemn, for you know not why a thing occurs, nor to what end. And remember this: that which you condemn will condemn you, and that which you judge you will one day become ..... Yet, bless all - for all is the creation of God, through life living, and that is the highest creation.

Walsch (1995, p. 38)

\section{Flow, Experience and Judgement}

In his discussion on the stifling of emotions/feelings, Pierrakos (1987), while holding to negative and positive as representative of expressions of life as a reflection of life as part of its duality, goes on to argue that feelings channel an enormous amount of movement. 
Movement which ceases when feelings are shut down/closed off. When movement is closed off, so too is creativity. In other words Pierrakos (1987), like Spinoza, Aquinas, and Descartes recognized that in some way the notion of passions or emotions are linked with movement. Movement is also synonymous with flow.

In the early discussion of this work the notion of humans existing as energy was raised. In linking energy and emotion the connection between flow, experience and judgement can be further explicated so as to reveal the ongoing process of consciousness making. In the ongoing movement of energy is the ability to become conscious of how to move energy. To be able to consciously move energy is to make pattern manifest.

Energy, as has already has been stated, is the abstraction behind all that exists. That is, there are no physical manifestations of that which does not exist energetically - the Platonic notion contained within the 'Theory of Ideas', and expressed by Martha Rogers (1994) in Nursing as pattern. Further, it is relevant to point out here that when I speak to the 'Theory of Ideas' I also am cognizant of the position Aquininas (1267/1952) takes in his notion of a 'confused idea'. In this I wish to avoid the pitfall of language by labelling pure as good, and confused as bad, in the same way as I have defined positive and negative in the previous section of this chapter. This distinction is vital, for to label a thing as 'good' or 'bad', 'positive' or 'negative', 'right' or 'wrong' is to make a judgement. The notion of judgement is central to this discussion.

Much has been written about experience and the formulation of percepts into belief patterns. Patricia Benner (1984) is one nurse scholar who has explored the notion of percepts and conceptual thinking through her work in practice development. In beginning to explore the notion of judgement, I would explore perception in a way that moves traditional thinking about perception into the background so as allow something else to move forward. This then is how one widens one's focus while still keeping an eye on the goal or, begins to invite creativity as in the Koestler (1964) idea of giving way to habit or routine. In this way, a thing is then revisioned. 
Descartes, in his 'Theory of Radical Doubt' (cited in Lemay and Pitts, 1994) concluded that knowledge derived from the physical senses couldn't be trusted. I have already attempted to raise this point, albeit in a different form, through the work of Dilthey (cited in Ermath, 1978). In the second chapter I posited that the outside world is but a reflection of the inside world that is not to be interpreted as wrong seeing, but rather, that what is seen it is not truth in the sense of an objectivity. So on one hand, what is being perceived through the physical senses can be a 'confused idea', yet on the other, it is a grand new starting point.

Paterson and Zderad (1976), in their beautiful theoretical work 'Humanistic Nursing', write about the notion of presence. They say, "A presence cannot be grasped or seized like an object. It cannot be demanded or commanded; it can only be welcomed or rejected. In sense, it lies beyond comprehension and can only be invoked or evoked" (Paterson and Zderad, 1976, p.30). That is, we somehow call it forth. It is as if through the experience of life, when-in-the-now-moment, we have an opportunity to engage in existence in a way that is wholly or fully present. And when-in-the-moment, when whatever we are engaged in is met with the old beliefs, old patterns, what we are in fact doing is rejecting the presence, the presence of the presence, and in so doing reconfirm our existing reality. I argue that the in-the-now-moment becomes another same moment. For when we judge what we are experiencing, we shut down, we close ourselves off to ourselves, and in so doing, in that instance, we are no longer present. The flow or the streaming is lost because we have propelled ourselves either into the past or the future. And as was explained in the methodology section of this work, the past has passed and the future is not yet. So while we do exist in the past and the future, existence in a body that is both in and beyond time and space can only be realised in the now moment. For that is what exists, whatever is in the now moment, and the truth is, it just IS.

To understand the Isness of a thing is to know that nothing exists apart from God/Love. Therefore God is all things and therefore must be in all things. To then perceive God as this particular thing and not that, is to perceive God in some things and not in others. In this way we divide God into bits. God is whole. This wholeness is expressed as the I AM. 
In the Christian tradition it is the Christ consciousness, and it is to this consciousness that every being, as a human being, aspires. On this basis, I argue, God is happy and sad, joy and grief, complete and lonely. By embracing everything IS, is to embrace God/Love. To embrace God is to feel what we feel in response to a given circumstance, where openness, as a state of mind, then allows or creates the space to change the past as perception of a phenomenon. The space then can be just that - an empty space, and when we have allowed the space we are allowing something new to enter. Then we can experience something anew. This then is to experience what is, for what is, just is, and all things just are to be experienced. In this way there is no meaning other than what we create. In truth there is only experience and creativity.

Therefore, when we engage in an experience by allowing the experience to act as a catalyst, the experience can become process. Then what is called for in-the-moment can be likened to a suspension or timelessness, where we dwell in the experience for a period of linear time. Where experience [circumstance, situation, scenario, story] is but a pattern that has a form. In allowing oneself to feel what is in the pattern, which has been created by the self in the first instance, then one is not only acknowledging one's own creation but then changes the pattern.

On the other hand when the space is open and the feeling felt but then judged, then what is being judged is the self, and as has already been stated, the I AM is no longer present. Why? God is love, and love does not love conditionally. To love this but not that is to place a condition on love, and therefore love conditionally. To love unconditionally is to be able to feel love no matter what. This is not the same as saying deny what one is feeling in any given moment. That is not unconditional love. Unconditional love is to feel the feeling of whatever and then consciously choose to feel love. We can only choose to feel love when there is no judgement, when we have not judged what we have felt in the first instance. For then there is no presence of the presence because one has disconnected from the self. God does not judge. For if everything just is, then I AM is all things. In judging my experiences, I am saying that I will only accept this part of me. In this way I am 
denying my wholeness, I am denying the totally of I AM. I have pushed myself away. I have made real the law of gravity, where for each action there is an equal and opposite reaction. As a result I have called forth another same particle, because the net charge of the black hole is unchanged and at the same time there is a radiation leak detected as the antiparticle escapes into infinity. At cellular level that cell/s hold/s the same consciousness because either the agonist remains firmly on the receptor site or the same message has been communicated.

Therefore, what I have drawn to me is what manifests. For I call forth and so what I have created is my creation. As process, in-a-now-moment, as described by Paterson and Zderad (1976) in their discussion of presence and what Heidegger (1968) calls the step back in his writing on 'Thinking of Being', where one is, is in the inbetween, or space. One enters the silence and the silence can only be silent when the old thoughts are set aside. The space is an allowance, it is an intersection of Beingness, unconditional love (non judgement) and awareness, and what goes on in that space determines whether there is an expansion of being and thus the opportunity 'to be' more. In this space the revisioning occurs. The process is just as quantum theory posits. Pairs of virtual particles/anti particles separating and then coming together so that they may annihilate one another - the result of which is pure energy, or light. The mass has released its energy and in that way, it is expansive. For in so doing it has moved backwards, it is simpler and that then is forward movement, an expansion of consciousness that is resultant in more light.

At a physical level, I am arguing, that this process is manifested in the receptor ligand connection, agonist/antagonist where in opening a cell wall, the cell has been willing to let go of its past perception by having allowed itself to receive new information about itself, and in that way set about creating a new reality by creating a new pattern. The question is always, what reality is being created? That will depend on which of the two strands of DNA were chosen? Love or Fear, and that in turn will depend on whether what was felt was loved or judged. Judgement is the prodigy of fear. [prodigy/genius/brain/grey matter]. 
When a receptor and ligand bind on a cell wall that cell changes shape and opens (Pert, 1997). The cell receives information that in some way influences its function. Pert's (1997) work showed that when a receptor connected with its ligand the message changed the state of the cell in any number of ways. One possible change is, that the organism experiences/creates more of what has been communicated. For there exists a feed back loop where what is being communicated to a cell is then signalled to other cells by the release of neuropeptides which bind with receptors (Pert, 1997).

Emotions as the informational content are exchanged via the psychosomatic network, with the many systems, organs and cells participating in the process. Like information, the emotions travel between the two realms of mind and body, as the peptides and their receptors in the physical realm, and as the feelings we experience and call emotions in the nonmaterial realm.

(Pert, 1997, p.261).

I am suggesting that what is being communicated as a result of the receptor ligand connection is consciousness that is either, feeling that represents a pattern of consciousness which a cell is then able to translate or, information as a result of having felt an emotion. Receptors hover in the membranes of cells and ligands diffuse through the extracellular fluid to then bind selectively to their own specific receptor (Pert, 1997). In any given moment we are all that we have ever been. Who we are is love, and what we have been is anger, sadness, guilt, jealousy, happy, peace, joy, and serenity etc. And in the same way that a black hole needs its particle pair to annihilate in order to create more light, then so too does happy attract sad. For the law of the universe is balance and in that way sad balances happy and together they create more light. On the other hand I would also wonder whether everything when experienced as a state of beingness when expressed as a feeling represents a pattern of consciousness which a cell is then able to translate/manufacture? For until we are able to consciously process our emotions which are an expression of 
beingness, then we will not be able to consciously choose what it is we desire to feel and in so doing consciously create our reality. Therefore, to expand our reality is to allow the movement into the inbetween, where we are required to leave the past in the past so as to experience the now as a new now for that moment is specific, where receptor and ligand come together by not having judged what was felt.. So that inbetween, the place that is not here or there, that is neither inside or outside the cell, is the gathering place where we then choose whether or not we are going to hold. Holding then is what needs to go on in the space inbetween, a ligand and receptor unite and depending on how the two hold each other determines what is poured out. Where in love what is poured out is different information that then is also a gift, a present of the presence, a consecrated libation.

If as I have said all is One, then to perceive some emotions as desirable and others as undesirable is to judge. While Pierrakos (1987) asserts that we are wary of the positive emotions, that wariness pales into insignificance given the resistance we are capable of garnering in order to avoid consciously feeling a perceived negative emotion. Therefore, if what I create is as Green has said,

Every change in the physiological state is accompanied by an appropriate change in the mental emotional state, conscious or unconscious, and conversely, every change in the mental emotional state, conscious or unconscious, is accompanied by an appropriate change in the physiological state. Green (cited in Pert, 1997, p.137)

Then what determines what travels that two way street, I would suggest, is how I respond to what I feel and how I feel about what I have responded to. To suggest that we do not feel say sadness in response to life is to deny our humanity. How and what we do with the feeling of sadness in-the-moment is then what becomes the key to opening the door in understanding how we create our reality through feeling the emotional self. Where that 
reality is then potentially expressed through every cell in our bodies because, receptors are found throughout the body (Pert, 1997).

..... the way in which peptides circulate through the body, finding their target receptors in regions far more distant that had ever previously been thought possible, made the brain communication system resemble the endocrine system ..... The brain is like a bag of hormones.

Pert (1997, p.139)

We are sentient beings. We take in information through our five physical senses. In the first instance I can choose not to allow myself to be conscious of a feeling, I can deny what I feel. Denial in the first instance can be a reflection of a lack of awareness. We shut ourselves off to ourselves. We lock ourselves out. The outside world will always mirror this back in some way. Once having felt a feeling, that is having consciousness of a feeling, say I feel sad then when feeling sad is bad this is a judgement. How judgement is portrayed is that a thing will be projected. We will blame another for how things are, or project the feeling in some way onto another. For we perceive that the world has happened to us. I hasten to add here that I am not advocating feeling sad for the rest of one's life and will deal with this further in subsequent chapters. Rather, I am presenting this concept in a linear fashion as it relates to experience, emotion and judgement. Further, and here-in is the subtlety, while mostly we are conscious of how we feel in response to major life events, say the death of a spouse/partner/friend, what I am saying here is that, whether we are conscious of it or not, we are feeling in every living breathing moment. Mostly, though, we are 'unaware' - we lack the awareness that we are feeling. And If by chance we do feel then, because of how we have conditioned ourselves we tend to either 'stuff the feeling down' or project it, because unconsciously we have judged that what we are feeling is $\mathrm{bad} /$ wrong/no good. 
Reported behaviour of particle antiparticle pairs suggests that when one of the pair is drawn into a black hole, the other of the pair may follow its partner or escape to infinity and then be detected as radiation emission from the black hole. One might then wonder what goes on when the other of the pair follows its partner? Does the annihilation take place within the hole/cell/space? Where one of the pair escapes to infinity, on what basis is that choice made, and what then of the particle activity within the hole/cell/space? Science is yet to offer the answers to these questions.

What we do know is that whatever the net charge of a black hole, then that charge will attract the particle pair that is its opposite, while a particle sharing the same charge as the hole will be repelled. Then when the particle with the opposite charge enters a black hole, its particle pair is able to follow it into the hole. In other words, the ability of the black hole to repel something with the same charge must for some reason be forfeited temporarily. When the particle pair annihilate one another the result, we know, is pure energy or light, and the hole sheds mass. I wonder if after annihilation of a particle pair if the charge of the hole becomes the opposite from the previous net charge, ie the hole if positive then becomes negative,? If so is this how the hole attracts a negative particle which will have a positive antiparticle to enable the whole process to cycle again? Each time annihilation occurs this then is movement. Where the result in terms of consciousness is movement that is a backward movement in the same way that an iteration is performed in fractal geometry and therefore results in a movement forward, in other words growth/expansion. The positive negative change of the net charge of the hole, a mechanism for creating balance.

On the other hand, where the antiparticle has not followed its pair into the hole is it because its particle pair has not been held? Where to hold is to embrace. To embrace is not to judge. When a particle is not held, then in scientific terms the particle pair or antiparticle is unable to follow, and so flings off into time and space detected as a radiation leak. As such, it is a reflection of the energy loss within the hole, and as movement could be described as forward/futuristic or a less excellent thing from a more excellent thing. At 
another level nothing is lost, because that particle exists in infinity until such time that it is called forth again. At another, because the particle within the hole was not held in such a way that its particle pair was able to follow, then the hole as consciousness is unchanged, the net charge is unchanged. The past has been moved forward into the future, a movement that is backwards in the sense that something has been lost and as such the hole has become more dense. It has not shed mass.

At cellular level the information [signal] a cell is given can and does alter its function. The function of a cell can be altered so that what we see physically is the manifestation of disease. In health, the cation/anion balance in extracellular and intracellular fluid is about equal. At same time it is recognised that there are many homeostatic mechanisms at work to maintain this delicate balance. Sodium $(\mathrm{Na}+)$ is the largest extracellular fluid cation, while Potassium $(\mathrm{K}+)$ is the largest intracellular fluid cation. So while the net charge is said to be neutral, that is, there is an equal number of cations and anions, the negative electrolytes are made up of other smaller groups with both the environment outside and inside the cell having a large grouping of positive electrolytes. Thus, it can be said, that while the charge is neutral, the positive electrolytes appear in bigger groupings. Further, it is recognised that when either of these two main electrolytes are outside a normal range, the effects on health can be deleterious. In other words, our natural state is to move towards the positive while the mechanism of positive and negative is to keep things in balance.

Black hole particle activity is determined by the net charge of the hole. Particles with the opposite charge are drawn into the hole, while the particle with the same charge as the hole but opposite to its pair is in the first instance repelled. At cellular level, it is known, that an antagonist will sit on the receptor site making it more difficult for the agonist to strike the receptor and thus bind. The process of binding is not a locking mechanism, but rather the ligand and receptor engage in bumping each other. "The ligand bumps onto the receptor and slips off, bumps back on, slips back off again" (Pert, 1997, p.24). It is the ligand bumping on, that is called binding. What is critical here though, that in this process, the ligand transfers a message via its molecular properties to the receptor. "Ligand and 
receptor - striking the same note and producing a vibration that rings a doorbell to open the doorway to the cell" (Pert, 1997, p.24). Then the receptor, having received a message transmits it from the surface of the cell deep into the cell interior. The message can change the events of the cell. In other words, the life of a cell, what it is up to at any given moment, is determined by which receptors are on its surface and whether or not those receptors are occupied by ligands (Pert, 1997).

As was explained earlier, using the examples of Naloxone and morphine, these two substances, while having almost identical chemical composition, in their role as antagonist and agonist the difference in effect on the organism could not be more distinct. The area outside the cell contains all possibilities, and in this way could be likened to chaos where there is always the potential for non chaos. Pert (1997) describes a cell wall as studded with receptors, waiting for a ligand to bind selectively to its own specific receptor on the cell's surface. Given that antagonists and agonists can be so similar in structure, and yet have such a radically different outcome, one wonders if agonist and antagonist belong to the same realm as a particle and antiparticle? If so, what further parallels may be drawn between their activity and human emotion? At one level human emotions may travel around as particle antiparticle pairs, and what if it were not a question, in the first instance, of which acted as an agonist or antagonist, but rather, whether the space is opened and then held in order to experience? For while Naloxone as an antagonist does block the morphine receptor site and euphoria and bliss is then not experienced, there is still an experience that could be termed lesser than euphoria but none-the less is still an experience.

It has been said that there is a fine line between love and hate. Could the same not be said for happy and sad, sorrow and joy, anxiety and excitement? Might each particle pair might be viewed as the extreme end of a same axis? If so, could they not be an expression of the same phenomena represented in the particle/antiparticle and agonist/antagonist relationship that then serves as a glimpse into the mystery of the ongoing majesty of creation. Where what determines which one of the pair acts as either the agonist or antagonist is not the electrical charge, but something whose purpose is, to draw us forward toward higher states 
of consciousness. For herein is the subtlety, to perceive euphoria as better than non euphoria, is to make a judgement.

Science has defined an agonist as something that is seen to enhance the activity of the cell in some way. An antagonist is defined by a ligand fitting the receptor site, but not well enough to signal the cell. Pert's (1997) work demonstrated that when Noloxone blocked the opiate receptor the cell did not produce more opiate. Noloxone was the opiate receptor's antagonist. This being so, what if the emotions -positive and negative and particle/antiparticle pairs - positive and negative, don't think of themselves as anything else but ONE? While in their action singularly, each is capable of producing a reaction that is dependent on how the one is received. In this way, what would determine what will ping against a receptor more readily than some thing else is not whether it is defined as an agonist or antagonist, but rather the attitude that is adopted when that emotion/particle/receptor connects in such a way that we become aware of its existence. Pert's (1997) initial work was done under controlled laboratory conditions in a test tube using homogenized animal brain. In that way, I am arguing, the ability to observe a cell was an after event, in other words the result of how one has engaged in life at the moment of death but not in the engagement of life itself. That in-the-moment where our beingness intersects with life, and in which we make a choice as to how we are going to respond to what we are feeling.

In the moment we can choose fear or love. To embrace an emotion with an attitude of love then has a different outcome to that when the attitude is one of fear. Judgement is an attitude of fear. It is the expression of an emotion that has a particular thought or belief pattern attached to it. Fear then translated is the stimulation of the sympathetic nervous system, whereas love opens an entirely different realm. In this way emotions are not only in the between, they are the between where every emotion may act as either an agonist or anatgonist that then become an outward manifestation of love or fear. 
To speak and write of love without creating a dualistic perspective is so challenging. To say that the human experiences of war, murder, rape, pillage and torture are experiences of being, will be unfathomable for some. To then identify the energies of honour, respect, compassion and humility as already existing within our being in such a way that they do not create a division of good and bad is also a challenge. For until we understand that it is by our judgement that we create further duality, and that we are creating our reality in every breath, then we will have difficulty in grasping the significance of I AM everything.

I have already said that to assume that which exists, exists apart from God, is to then divide God. If God is whole, then God is all things. To say that God is this thing but not that thing is to divide God into bits. The bits do not make up the whole. The sum of the parts do not equal the whole. The whole, the I AM energy, God, Love, are all expressions of the One. It is the consciousness to which every being, as a human being, aspires. We choose to incarnate to know this consciousness - and more.

And so everything just Is. Everything is to be embraced, because as this thesis is suggesting, it is the process of being. So where a human being has placed themselves be that in a war zone, in a rape situation, or any of those other human situations that we may be tempted to name as bad, it is because that being has created this experience in order - to be. It is only in being that we can expand in consciousness, where the experience holds the potential to fulfil an aspect of that being's beingness. I know that such claims will be unfathomable to some, and yet how else in the human condition to we come to know a thing until we have experienced it. How for example, do we know grief until we have placed ourselves in a context in which grief is the experience? Where we have been grief.

When we see a homeless person, a murderer or rapist, we do not know the totality of their being. We do not know the life record. We do not know that the being of that homeless human being yearns to experience powerlessness, and that the experience of being homeless is the final desperate plea of being to do so. We do not know what a being has come to remember in a particular lifetime. What is known, though, is that by feeling it is 
possible to change one's life experiences and thus the circumstances of life. It is possible for the homeless person to have a home within the lifetime.

Knowing this, then in witnessing a child living in great poverty, there is the understanding that this particular child may grow up to support thousands of children in poverty, and in that way her beingness has choosen the place for her 'to be'. From this childhood experience she will develop the skills of survival and compassion and thus create the basis from which she might undertake her soul's purpose. She is following her intuition, and her daimon that holds the image of the pattern is supporting her soul intention.

How then do we ever know what another has been, or is desiring to become? We do not! For if we did, we would never judge. Our way of being on this earth would revere all life from the true energies of honour, respect, compassion and humility. We would give the homeless man a meal, not because he was homeless and that made us feel sad, but because it was a way of honouring him on his life's journey. The praxis, where our action with its dimension of reflection is then authentic, for one has not engaged oneself in mere activism. The energy is not one of sympathy, but the doing of being where the action is a responding that is grounded in the energy of respect. In knowing this difference, our donating monies to children who live in poverty or engaging in some activity to 'change' childhood poverty, is a reflection of love. Action is free. We have not acted because the image has served as a reminder of the misery of our own poverty stricken childhood, or because we a feel a sense of guilt about how much we now have. Nor, is it based in a belief that childhood poverty is bad, or a sense that to do so is good and so not to do so must be - bad. It is then an act of unconditional love. In this way, our actions are the outcomes of feeling that has either been loved or judged. As such, they are either the expression of love, or the expression of fear. And where we place our focus that is then what we create. The portrayal of the image of reproduction to the eye and mind. Only love can change the world.

Where a thing is feared, it is because there is a judgement of it. We perceive it to be a particular way, and so what is beginning to be felt is suppressed/shutoff/denied, because it 
is deemed to be bad/wrong. Our consciousness then not only remains the same but we embed ourselves more deeply into that particular consciousness thereby giving ourselves the message that our reality is real. In this way we continue to distort the truth. On the other hand when what is felt, is not judged, then activity is focused within the cell, so that in some way cell activity is changed and subsequently so too is our perception of reality.

The change is an ongoing process, and not an event.

I was on Extended Campus Practice in a medical ward. I'd been there for a long time and my enthusiasm was getting a bit low and I was wondering about whether nursing was really what I wanted to do. I was kind of cruising along and nothing was really challenging me and this was because I was kind of avoiding challenges. I mean, I could have chosen patients that were more challenging, but I just sort of thought, "Oh well, no one's pushing me to do that so I'll just sort of cruise along".

Yes, so I was kind of sliding down hill, you know. Not really sort of going ahead with my nursing and my clinician was fairly perceptive and she noticed this and said, "Well look, you've really, you've got to start getting stuck into your nursing, you've got to take the bull by the horns". And I sort of said, "Yeah, yeah, alright", you know, but not really being serious about it.

Anyway, this was a Thursday night and I was working a late shift and I went up to the nurse who was allocating patients to the students and she hadn't done anything yet and I went to her and said, "Can I have this patient, this patient and this patient?" She said, "Yes, that's alright". So I went off, trundling merrily along my way thinking that I knew what was going on because I was looking after these three patients that I was fairly familiar with. And there was another man who was in a different room and he had had a CVA and he was like, on his death bed, and he was dying and his family were there and his relatives and stuff and I'm thinking, "Oh what, yeah, lucky I'm not in there, that'd be a pretty heavy situation to be in", you know? And during the first part of the shift a lot of other nurses came to me and said, "Can you do this for this man?" I'll call him Mr E. And I was wondering about that, "Why are these people, because I've got my own patients to look after, why are they asking me to look after this fellow?" Then my clinician turns up and she asks me to explain about my patients. She had had a look at the allocation book, and what had happened was that the RN who was organising the allocation had changed her mind and she had put me in charge of this person, Mr E - without telling me!

So that was like two hours into the shift or something and I hadn't done anything for this guy and it was a really a sort of heavy situation. The family were all there and they were all mourning and crying and everything and they started sort of complaining that he wasn't being looked after, that he was all really sweaty and everything. I can remember going into the room, like he had stubble on his chin, he 
was a middle aged man. He looked like a real sort of Aussie farmer type. He was just sweating and he was quite red. He was unconscious but he was moaning and every now and again he'd move his arms and stuff and the sheets were soaked. So we changed the sheets and you could see the sweat running in little rivulets down his face.

You know, I didn't really take the bull by the horns, - you know? I was a bit concerned about the family, I was a bit afraid about, well maybe they would sort of blame me if something went wrong or maybe I didn't want to get involved in all these sort of heavy emotions. And so I was holding back and I wasn't really nursing the family. I mean I was just looking after this guy's body. I wasn't touching him very much and I ended up just sort of, kind of, not really doing all that much for him, just doing his obs and I think we gave him a few morphine injections.

Then I was on the next morning, Friday morning, and just after hand over my clinician came to me and said, "Look, I'm really concerned about your practice. You've got potential to be a good nurse but you're just not getting a hold of it. Somehow there's something stopping you from getting to your potential". And just while we were talking an RN came up and wanted to talk to me about the patient allocation and said, because what happened the disorganisation of the day before, he came up to me and asked, "Look, do you want to look after Mr E again today?" And then he said, "I don't think he'd going to make it through the shift". That's what the RN said to me. I knew then that I really had to make a big decision - you know, I was at the cross roads here, it was like, "Is nursing really what I want to do?" My clinician was breathing down my neck saying, "You've really got to get on top of this". And here is this really difficult situation. It was one of those real cross roads that you go through sometimes, and well I decided yeah, that I'd go for it. You know, $\mathrm{OK}$, I'm going to be in this and I'm not going to hold back, I'm just going to go in and face this situation and do what I can for the family and for the patient. I mean, even if it's going to be really difficult.

So I went in and we washed the patient with, just like, you know, face washes and stuff, and I tried to get the family involved. I mean they were going to leave because we said we want to give Mr E a wash, right? And I said, "Well no, look, you can get involved as well". I mean it wasn't a real intimate sort of wash we were just going to change the sheets and freshen him up a bit. So I started to try to get them more involved in his care and just sort of, I really, I really tried to touch him more because that was something that I was really kind of holding back on. I wasn't really nursing the family and they were a fairly conservative family, particularly the mother. And at one time she said to one of the daughters. Oh, I'll tell you who was in the room, yeah, it was a really a packed out room. Like it wasn't a small room but I mean there was his sister and her wife, there was his wife and three daughters and their kids. There was a baby in there was as well and it was like walking into this big crowd of people and it's like, they were all sort of, "Oh, here's the nurse", you know, and they were all 
looking to you for direction and support and you know, what's going to happen next? So it was a pretty full on situation.

Anyway, one of the daughters started to cry, well sort of half started to cry and the mother quickly said, "Don't do that, don't cry. You know he wouldn't want you to do that". And it was sort of really surprising and I'm even surprised that I said anything at the time too, but what I said at the time was, "No, no, look, it's good to express your emotions. It's good to let it out, this is the time for you to say goodbye". And I just sort of did that, like it was just a spontaneous sort of urge I had to say that, and afterwards I felt like it was a really appropriate thing to say, but I didn't think about it at the time. Yeah, I mean, and the daughter seemed to relax but there was still some sort of, you know, the mother was trying to be really strong and trying not to show her emotions.

Anyway, I got some of the daughters involved, like I gave them kidney dishes or little bowls and stuff with water in them and face washes and they were washing him down. And I felt like they were really sort of getting a lot out of that. This was really good for them.

He was going into pulmonary oedema and his breathing was really ragged and noisy and gurgly. So we were giving him two hourly morphine hits through a butterfly and that was really good at settling down his breathing. But you know, there's just this thought in the back of my mind, it's like, OK, he's having trouble breathing, this morphine is just actually sort of sending him off, it's helping him to die. And really, I didn't have a problem with that because he was, it seemed like the right thing. You know, he was really, I mean, he didn't have much function left or anything but he was still struggling to live, you know and that was something that was difficult about the situation.

At one stage the RN who was like my buddy, came in, and it was time for another dose of morphine and he said to one of the daughters, "He's really fighting isn't he?" and she said, "Yes, he always was a fighter", and the RN said, "Is that what you want? Do you want him to fight?" And she said, "Well no, I don't. I would like him to just let go". And you know what it wasn't long after that, that he died. It was like about, fifteen minutes later that he died! I was actually out of the room at the time, I went to do something and I came back and he was dead. You know, it was like his body was really exhausted but he looked really calm, it was as if he was given permission to leave and permission to stop fighting. Yeah, and the family stayed for a little while and then they all wanted to leave because they felt really awkward about being in the room with a dead body and I sort of tried to encourage them to stay. "Look, you don't have to go if you don't want to", and we talked about funeral plans and arrangements and things like that but I didn't really know what the protocol was how much the hospital did and so I might have sort of messed them up a bit there. 
Anyway, when they left it was a really, really a strange feeling. It was like we had really, I mean I didn't even know it their names and stuff. It was like we just skipped all the trivialities, we just jumped into this really meaningful relationship. And, yeah, when they left it was like I was looking after something that was really valuable to them, they were leaving and trusting me to look after their father's body. And I had this impression that it was like parents leaving a babysitter in charge of their kids when they go out for the night or something, you know, and they said, "Bye now", and it was really interesting. The mother gave me a hug and I hugged one of the daughters and they were all saying, "Thanks for doing such a good job, looking after our dad", How amazing, I really felt like I was flying by the seat of my pants, you know, and I didn't feel like I was in control. I actually told them that it was the first experience of being with someone who was dying and nursing them through death. I told them that it was my first experience and I realise that it was a real big risk because they might have said, "Oh well we want someone who's experienced". But I felt the genuineness really enhanced the relationship because it was like - then it became an experience - of like, it wasn't - I wasn't pretending to be someone who was all in control of everything that was going on. We were two groups of inexperienced people going through same thing together. That was the really positive part of the experience.

And yeah, that's about it I suppose. I've found that since then I've been through similar experiences with other patients and their families and it's really been a lot easier and I've really been able to provide nursing for those people - provide care for those people because I've been through that. And my enthusiasm really picked up and I really felt like, yeah, you know, this is what I want to do. And it was because I wasn't dealing with the challenges. I wasn't facing the challenges, I'd just sort of avoided them and although it was difficult to face I now feel like, Wow - this really was a risk and it really paid off!

At some level loss/sadness/grief expressed through the experience of dying, as a particle, was drawn into the hole. "Look, do you want to look after MrE again today?" And then he said, "I don't think he'd going to make it through the shift". That's what the RN said to me, and then I really knew that I had to make a decision. I was at the cross roads here, it was like, "Is nursing really what I want to do?" My clinician was breathing down my neck saying, you know, "You've really got to get on top of this". And here is a really difficult situation. It was one of those real cross roads that you go through sometimes, and well, yeah I decided that I'd go for it.

The decision is made in-the-moment. And it is the willingness to change, where what is being changed is an attitude that is not a mere shift in attitude [habit, custom, comportment 
or behaviour]. It is a change in attitude brought about by a willingness to experience the unknown and in that way change the attitude [feeling]. This point is illustrated in the text of the story, where as soon as this change has occurred energetically the physical manifestation of the pattern begins. The scenario is under way. I am arguing that this experience was these beings unconscious intent made manifest. While the language does not convey the nurse's full emotional response, it is intimated at through the daughter where at one level all the beings did unconsciously embrace a fear by allowing the space to remain empty. They served to reflect the same thing to one another. As such the past was left in the past, and a new now was experienced by all. In so doing there is a new future brought about by stepping back in the sense of a backward movement that is a choice made in the moment.

The process for most is an unconscious one, a hit and miss affair, an agonist pinging on the receptor in its attempt to bump the antagonist off its receptor site. The new attempting to replace the old as a willingness to know more. In identifying the process, as a process of being, we can then begin to respond to our calls of being where being in-the-world is to be. In that way, then, who we can be is anything we desire when we decide to step back.

When and in what way do things appear as things? They do not appear by means of human making. But neither do they appear without the vigilance of mortals. The first step toward such vigilance is the step back from the thinking that merely represents - that is explains - to the thinking that responds and recalls. The step back from one thinking to the other is no mere shift of attitude. It can never be any such thing for this reason alone; that all attitudes, including the ways in which they shift, remain committed to the precincts of representational thinking. The step back does, indeed, depart from the sphere of mere attitude. The step back takes up its residence in a co-responding which, appealed to in the world's being by the world's being, answers within itself to 
that appeal. A mere shift of attitude is powerless to bring about the advent of the thing as thing, just as nothing that stands today as an object in the distanceless can ever be simply switched over into a thing. In thinking of being, it is never the case that only something actual is represented in our minds and then given out as that which alone is true. To think Being means: to respond to the appeal of its presencing. The response stems from the appeal and releases itself toward that appeal. The responding is a giving way before the appeal and in this way an entering into its speech. But to the appeal of being there also belongs the early uncovered has-been (Aletheia) as well as the veiled advent of what announces itself in the possible turnabout of the oblivion of Being. The responding must take into account all of this, on the strength of long concentration and in constant testing of its hearing, if it is to hear an appeal of being. But precisely here the response may hear wrongly. In this thinking, the chance of going astray is greatest.

As a response thinking of Being is a highly errant and in addition a very destitute matter. Thinking is perhaps after all an unavoidable path, which refuses to be a path of salvation and brings no new wisdom. The path is at most a field path, a path across fields, which does not just speak of renunciation but already has renounced, namely, renounced the claim to a binding doctrine and a valid cultural achievement or a deed of the spirit. Every thing depends on the step back, fraught with error, into the thoughtful reflection that attends the turnabout that is prefigured in the destiny of Being. The step back from the 
representational thinking of metaphysics does not reject such thinking, but opens the distant to the appeal of the trueness of Being in which the responding always takes place.

Heidegger (1968, p.197)

Judgement is a thought process. When we judge we have then reacted. In reaction we cannot respond. Expressed as consciousness, it is then the maintenance of a perception of truth which then chains one to that same perception of reality. One is locked into a particular reality because one believes that is how it is. An emotion that is felt, and then not judged, is free to act as an agonist. A negatively charged emotion/feeling that is not judged will be balanced with the opportunity to experience a positively charged emotion/feeling.

I've found that since then I've been through similar experiences with other patients and their families and it's really been a lot easier and I've really been able to provide nursing for those, you know, provide care for those people because I've been through that. And my enthusiasm really picked up and I really felt like, yeah, you know, this is what I want to do. And it was because I wasn't dealing with the challenges, I wasn't facing the challenges and I'd just sort of avoided them and although it was difficult to face I felt like, Wow - this really was a risk, and it really paid off!

Life is full of risks. Risks are easy when a being trusts and enters the flow of all things. To acknowledge the self is also to express gratitude. In the self-giving thanks of the self, what is being acknowledged is the self. It is self-validation.

When a negatively charged emotion/feeling is drawn into the cell and is then judged then there is more negativity. I use negativity because we are more likely to judge the so called negatively charged emotions. In that way it is negativity upon negativity, that reflects a judgement upon a judgement, and this I am arguing influences the cell in such a way that the end result is dis-ease. Dis-ease is both the manifestation and the reflection of the consciousness of a group of cells that have become so distorted that the pattern produced is 
a distortion. Dis-ease is the distortion of truth. It is the manifestation of a chaotic pattern because the message it carries is 'confused'.

At the point where a particular emotion has been felt to its depth, a being can then begin to consciously choose to create something different, that is, begin to move further into positively charged energy. Our beingness only knows positivity. Having said this though, it is important to make clear that, as multidimensional beings to assume that any one cell has only one consciousness at any one time would be erroneous. Therefore, in saying that there comes a point where a particular emotion has been felt to its depth is true, however what that means for each individual is individual, because we do not know the life record of another, nor what a being has called forth to experience in the particular lifetime. In this way our only guide is to feel and let go in the ongoing act of creating our reality. How one knows is, one knows, and the outside world will reflect that inner state.

So while it is as simple as choosing positive over negative, and that has a double meaning, it is only so when one has allowed [loved] the negativity, that one can then change the negativity. While we continue to judge negativity, we will continue to create more of the same. For it is as Pierriakos (1988) suggests, we perceive the negative emotions as negative to our interest of being human. When we perceive something as better or worse, good or bad, we devalue the experience of that which just Is. We have judged it to be lesser than the greatness of God, for without judgement all things are the greatness of God. Aquinas' (1267) choice of words are no accident - 'a more excellent thing from a less excellent thing'. In this way he has avoided making a judgement. The lesser thing is not bad, it just is less and in that way he has presented us with an observation.

Until we understand judgement, we will keep recreating the same cycles in our life. The cycles get bigger and bigger, in the same way that fractal geometry has identified a pattern - where the branch of the tree is a leaf its pattern repeated many times over. We cannot, not be. It is only a matter of choosing when to be and we make that choice in every breath. Until we choose to respond to our calls of being we repeat a cycle, until we get the 
message, until we get the real information. I would suggest that the cycle can be over in a moment or repeated in three generations of a family - grandmother, daughter and granddaughter. The sins of the father are visited upon the son.

In letting go the judgement, for we all surely judge, this act of will draws the other of the pair into the cell, in the same way as has been theorized that in black hole particle activity the other of the pair can follow its partner into the hole. Then what I am suggesting is, that the particle and antiparticle reach the point where they originally materialized, as is represented by Curie point discussed in the previous chapter to describe phase transition. At this point there is annihilation of the particle/antiparticle because what is represented by this point is the maximum in complexity which is the possibility of the diversity that flourishes at boundaries. The particles are emitted and travel forward in time, because they are scattered by the gravitational field. The density has been released from the $m$ in $E=m c 2$. It is $\mathrm{E}=$ energy that is then multiplied by the power of 2 , as it is converted to more light. There is more light in the universe. From the less excellent thing a more excellent thing has been generated. Something has been given up/lost and something has been received in a way that the black hole is lighter, that the cell glows and where consciousness has expanded.

By the how of our engagement in life, from birth until death, the 'what' that we yearn for is in fact a state of union, which is, and can be born from that very separation. In other words, the tendency towards self preservation coupled with the power to further counter this tendency. Self preservation which is innate, that is, embedded within our consciousness which is contained within in every single living cell, that through the engagement in life, has as its intention the realising of 'the good'. Where every thought is thought of something, every desire a desire of something and every judgement a rejection of something (Bretano cited in Crotty, 1995).

God consciousness is embedded within every cell of our bodies. Yet at the same time this inherent yearning - the realizing of 'the good' creates within our very existence a tension 
which is brought about by our socio-historical constructions of how we must or should be. What we deem to be right, and wrong. In this way there can be no ethic on how to be. There is only being. Being that is the immersion of the self in the experience of living, that then creates action and reaction from which we can then choose how to be. In this way being, as an ontology, offers us the potentiality to make visible our thoughts desires and judgements.

So on one hand it is as Hawking says, absolute order, ".... the universe is governed by well defined-laws that in principle allow one to predict the future, but it is the motion given by the laws that is often chaotic (1993, p.154). Therefore, when we ignore the call to be, by judging what we feel in any given moment, where what we are in fact doing is severing the outer self from an inner reality. The integrity of one's energetic system is shattered, we chain ourself to the same perception of truth (Pierrakos, 1987). Then we have not revisioned; we have not poured a consecrated gift. We have cut ourselves off from the flow, and so the image we then give to the mind is that there is no more flow.

In this way I present a sketch of an ethic of being human that is presented through an ethic of health where dis-ease is an act of creation bound in the contraction of 'how we have been'. As such it is the reflection of praxis, a dialectic of thought and action, where distorted thought is manifested by fear.

The results of quantum physics thus far are, "it is indubitable that each of us participates in genesis" (Wheeler in Curling, 1992, p.2). "Participators in genesis - and therefore participators in every event in the universe" (Curling, 1992, p.2). "There are about fifty thousand million neurones in the cerebral cortex, forty thousand more in the cerebellum, and about another ten thousand million in the remaining structures of the brain and spinal cord - about the same number, as there are stars in our galaxy!" (Morgan and Morgan, 1986, p.7). 
The wording as it is above so it is below describes a truth about love. Where the shortest distance to connect these two points is not a straight line but a fold that folds the space and so brings the two points into contact with one another so that a third position is then possible. From this third position, one then can move into a new dimension/consciousness. Where the key to being able to fold the space is the willingness to be more and as such is a choice for love. In that way, what is being given up is that which acts to weigh us down or, keep a thing in a certain shape. In third dimensional reality, we could call it gravity. As energy, it is judgement. Being does not judge. Being responds in feeling, and then no matter what the feeling choses to feel love.

\section{Summary}

This chapter while deliberately incorporating some of the groundwork of the previous chapter does so in order to expand the work. Nursing theory, quantum physics and mechanics, cellular biology and philosophy are used to draw out an understanding of the notion of judgement. From this position, the chapter presents an idea about how we be that does not hinge on an ethic of 'must', or 'should', about being human.

This chapter presents an argument about life as experience that can serve to either expand or limit being/consciousness. What is crucial to illustrate this attitude to life, is that it is either grounded in notions of perfection. or excellence. As perfection it is thinking that is grounded in moral reasoning and as such sets up an ethic of human behaviour that then can be contrary to being.

Black hole and cellular activity have been compared and contrasted in relation to the being where I have touched upon the idea of an ongoing creation of the cosmos that then is reflected in the expansion or contraction of consciousness. I perceive that there is more to be revealed about black hole and cellular activity as they relate to consciousness. I have taken the dialogue as far as I can at this stage. Even so, how the aesthetic and the notion of judgement are crucial to being, remains the crux of the argument and therefore this chapter. 


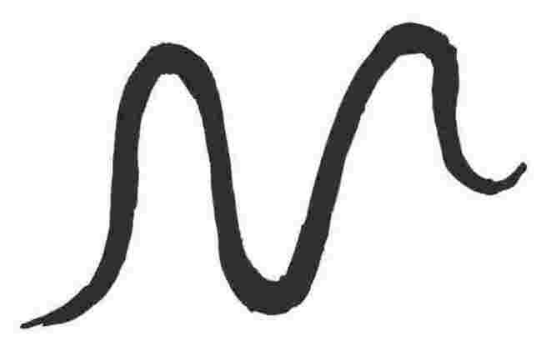

\section{Chapter 6: The Human-being, Creator Energy}

Individual men are part of a whole, of mankind, of the Son. They are attainers, acquirers of what the Father is and has. They are in Him, one with him, in proportion as they attain to be and to know truth. Different parts of one whole are contributing to one purpose in the case of mankind. Mankind is transmuting itself into the divine by exercise through God's communication of the divine. Man is utterly incapable of anything, except through exercise, appropriate exercise of his own nature.

Florence Nightingale (1860 cited in Calabria and Macrae, 1994, p. 117)

\section{Expression as creativity}

Jean Houston in her text titled, 'A passion for the possible' asks, "What is it that allows some people to tap into their creative power and do wonders in music, art, literature and science, while others flounder in despair and confusion, cut off from the creator within?" (1997, p.19). In her efforts to probe this question, Houston (1997) studied fifty-five of the most creative people in America and found a commonality that these people shared was that they were familiar with the world within themselves. These people knew that the ideas and images which gave impetus to their projects were generated from within and likened what they had learned to do as a harnessing or an archaeology of, the mind. "By delving into the depths of their own being they were able to connect to "forms and patterns of Creation itself" (Houston, 1997, p.19).

In this way Houston calls into question who or what we are. "We are not encapsulated bags of skin dragging around a dreary little ego" (Watts cited in Houston, 1997, p.19). Each being is a world, complete with organisms and environments held within the greater 
Environment of Being, which it both contains and mirrors/duplicates/copies (Houston, 1997).

Our bodies are the stuff of the stars and the minerals of Earth. Our blood runs briny with the seas, and we ourselves are living planets for billions of little beings, microorganisms and who knows what else. Our genes are universes in themselves, coded with enough information to recreate the world. Our cells contain the memories of all things past - the birth of stars, the coming of life and the lure now calling us from beyond the horizon to enter the next stage of our becoming.

Houston (1997, p. 20)

Houston (1997) then makes what I feel is a profound statement. She likens the nature within as an inner mirror of the Great Nature pushing the universe on its evolutionary path. "Perhaps, then, it is the nature that lies within - the inner mirror of the Great Nature pushing the universe along its evolutionary journey - that is the 'who' calling us to be more than we ever thought we could be" (Houston, 1997, p.20). That then is expressed in language such as Oneness, Being, God, the essence of that which is I is the same as that which is the universe because the universe and I are One, the Creator and I are One and, where the One is as beautiful as the many, and the many as beautiful as the One.

In this way, Houston (1997) has called to our attention the relationship expressed through creativity manifested by the moment by moment intersection of Being as we live the experience of being-human. If we are not 'encapsulated bags of skin dragging around a dreary little ego' but an 'inner mirror of the great nature', then who we are, is God in motion. "That which we call God may have greater plans for us than we could ever imagine. Of course we have the freedom to accept or reject plans. We can choose to co-create with the Creator, or we can deny our inheritance" (Houston, 1997, p.20). And in this way we have the choice to live as God through the consciousness of what we create, that as creation is occurring in every now moment. 
'our deepest fear is not that we are inadequate. Our deepest fear is that we are powerful beyond measure. It is our light, not our darkness, that most frightens us'. We ask ourselves, Who am I to be brilliant, gorgeous, talented and fabulous? Actually, who are you not to be? You are a child of God. Your playing small doesn't serve the world. There's nothing enlightened about shrinking so that the other people won't feel insecure around you. We are all meant to shine, as children do. We were born to make manifest the glory of God that is within us. It is not just in some of us; it's in everyone. And as we let our own light shine, we unconsciously give other people permission to do the same. As we are liberated from our own fear, our presence automatically liberates others.

$$
\text { Williamson (1992, 1996, pp.190-191) }
$$

We can remain unconscious for as long as we choose, but that we will become conscious is the certainty/predictability of universal law, expressed by the force physicists as the 'strange attractor'. The same truth as that exhibited/shown in fractal geometry. Whereby after a certain point predictability ceases in the sense that we can predict in a forward sense and chaos ensues but, embedded in chaos is the area of non chaos. In complexity there is always the potentiality of simplicity through the third pole - the beautiful. The pattern can be repeated over and over again, never intersecting on itself, represented in the 'Lorenz Butterfly', until eventually we 'get it'. Until we choose. Which at one level appears as instability, and at the another is total predictability.

Creation, then, is that which is expressed. As God in motion we are expressing in every now moment. The questions here is how conscious are we of what we are creating, and on what basis do we choose what we create?

In the previous two chapters I have drawn some parallels between a cell and a black hole in order to suggest that they are one and the same expression. If this is so then surely the answers to how conscious we are of what we are creating and on what basis we choose what we create, lies in the notion that creativity is expressed in the conscious awareness of what is felt. What differentiates the true self from that which can be termed ego, is the ability to feel. In other words, it is in feeling that I can make manifest what is considered to be Houston's (1997) 'inherently within'. The possibility of manifesting is acknowledged in science by 
Hawking, "Indeed, it is possible that the black hole could emit a television set or the works of Proust in ten leatherbound volumes" (1993, p.113). This then surely is an act of creation evidenced in the universe and in a cell. Creation then is not just dreaming or visualising, creation is about consciousness/energy, in consciously making physically apparent, that which already exists. The keys to that inner/within/kingdom are, being able to image it, not just by forming an image in the minds eye, but by feeling a thing as consciousness in conjunction with the dreaming, visualising and doing.

In her discussion on love, Hannah Arendt's (1929/1996), critique of the work of Saint Augustine (354-430), speaks on life and death. Using Augustine's notion of the 'not yet', Augustine said that every creature comes from the 'not yet' and heads for the 'no more'. The 'not yet' is defined as creation, and creation exists because of the link with its own 'not yet' (Arendt, 1929/1996). In other words, what Augustine is saying is that we come from creation; it is our origin. And given that this is from 'whence' we have come, then we must be creation, as we move toward what we already are.

This is what life is all about. We are in the world and of it per se, but we also are not. "For the fact of being created has the structure of fieri, of having to come to be, and thus also has the structure of transience as such" (Arendt, 1929/1996, p.70). We are in the world creating ourselves. On one hand, it is as Arendt (1929 1996) says, we are born into the world and when we die we depart from it. We also are not. In this way our being in the world can be viewed from a 'whence' and 'whither' stance Augustine in Arendt (1929/1996). It is in 'whence' that there is the 'not yet', and in the 'wither' that there is the 'no more'. Arendt $(1929 / 1996)$ points out that this past future terminology is quite different. But are they? Surely they are, when expressed as a linear perception of time. In that way we come, and we go. We are born and we die. But as has already been said in this work, linear time is a man-made phenomenon. What if 'whence' and 'whither' and 'not yet' and 'no more' are expressions of the same phenomena, the difference being that one is bound in time space, and the other transcending that limitation? In this way, 'whence' and 'whither' and 'not yet' and 'no more' are not bound in some sort of linear temporality, but rather become expressions of Being that serve to alert us to the idea that in the human condition we are God in motion that is lived out through the creation of life.

For since the creature is made out of nothing the final limit of the past is indeed non-being. However, it is precisely at this final limit that the creature meets its proper being because it has been called into being. Thus it comes not exactly 
from nothing but from the Supreme Being in its attributes as First Principle (summe esse qua principium - The First Principle abides in itself and makes all things new). Therefore, before the creature existed, there was the Supreme Being as well as absolute nothingness. God is the 'before' as such only for that creature that was made out of nothing.

Augustine (cited in Arendt 1929.1996, p.70-71)

And while it is clear that both Augustine (cited in Arendt1929/1996) and Arendt (1929/1996) make the point that, in the fieri of the 'not yet' by its very negation of life does in fact determine life in the positiveness of its being. What I wish to do here is use this argument as a means of transcending time and space while making it very clear that I do not take the position that the 'not yet', while 'nothing' and originating from the Supreme Being, is not to be interpreted as a Being of beings. For when I refer to God, or in Augustine's words, the Supreme Being, I mean that which is I - the I AM - and in this way I can make explicit the dynamic between God, Creativity and Experience. Furthermore, it is important to add here that in this section of Arendt's interpretation of Augustine's work she too argues that Augustine is saying that God is not some Supreme Being, but rather "as the ever-present authority that man keeps confronting on his way through life" (1929/1996, p.87).

Augustine says, that we come from creation - the 'not yet', and as such we are creation. As a human being we are creation bound in time space. We are 'being-there'. The question is, what is it that goes on from the moment we are conceived until the moment we leave, that which we call the birth death continuum? How can we, as was suggested earlier, shift our thinking so that while we are immersed in the beginning and the end by being-there, we can by how we engage in that immersion transcend space and time?

\section{HAVE A DREAM}

Written by Delanoe/Fugain/Hill. Sung by Nana Mouskouri (1973)

I have a dream

That you'll come to me

Just like the sun

Like a morning wonderous to see

So let me wake

To a golden sun

Gold are our dreams 
When we wake to no-one

So many roads I've stumbled on before

Now I can live no more without you

If only I can find my way to you

There are so many words

I long to say to you

I'll bring to you the secrets of my life

Like petals in my hand

And you will understand

I'll ask for nothing more

My whole life through

If I can't find my way to you.

I have a dream

That you'll come to me

Just like the sun

Like a morning wonderous to see

So let me wake

To a golden sun

Gold are our dreams

When we wake to no-one

Demand of me all that I have to give

And while I live I'll give it gladly

Command me to deny the world I knew

I'd give it all away if you ask me to

Surrendering the fragments of my life

I'll follow where you are

Although the road be hard

And if I falter you will see me through

If I can't find my way to you

I have a dream

That you'll come to me

Just like the sun

Like a morning wonderous to see

So let me wake

To a golden sun

Gold are our dreams

When we wake to no-one.

( $)$ Shapiro Bernstein \& Co. Ltd. International copyright secured. All rights reserved. Administered in Australia by Campbell Connelly (Australia) Pty Ltd. Used by permission.

๑ Universal Music Publishing copyright secured. All rights reserved. Used by permission.

The not yet/nothing/No-one - Gold are our dreams when we wake to no-one, and while these lyrics do speak clearly to the what of being, the argument as presented so far leaves one with the impression of separateness, a here and there - 'no more' and 'not yet. Therefore, as has already been stated, that if I have come from creation, then I must be creation moving toward creation, and in this way, I see that I can transcend the dualistic 
position of here and there in the realization that it is all about becoming. For if I am born with the intention of becoming more than I have in the past - 'the strange attractor,' while I am my history, I am what I am, what I have become, but I am also what I am not, what I have not become ' (Paterson and Zderad, 1976, p.16). Becoming, then, is but the human expression of creativity. The mortal expression of creating is the how of experiencing beinghuman.

As God in motion, creation is about making physically apparent what we already are. And so it is in this way that the focus can be shifted from creation per se, so as to refocus upon creation in a way that brings into my awareness, 'what' I am creating, as I experience every now moment.

\section{Creativity and the self}

The notion of the self has been the source of exploration by any discipline that has asked the question, who am I? Perera (1981) defines the self from a Jungian position. The self is "The archetype of wholeness and the regulating centre of the personality. It is experienced as a transpersonal power which transcends the ego, that is it is God" (Perera, 1981, p. 96). In this way, I am saying that creativity is about recreating that archetype/pattern of wholeness, of God, in the expression of being human, and that the process of creation is woven by, 'the how' of everyday life.

Having said this, I wish to make it perfectly clear that this process is occurring whether we are conscious of it or not. The challenge is to make the process conscious, and in this way become conscious creators of our universe. Further, I wish to make it clear that I will deliberately begin this discussion of the notion of Creator knowing that others have used the word co-creator. In the sense that we share the universe and can participate knowingly in a form of co-creation, a form of mutuality that has as its potentiality the ability to offer each other more human freedom, I too would use the term co-creation. The relationship I have with myself is also an expression of co-creation. Having said this, though, I would also say, the more that I express the Oneness of I AM that I AM, then in the reflection of that which is I, that which is I is a Creator. To this end, I use the word Creator.

In order to begin to consider ourselves as creators of our universe, we need to be prepared to accept responsibility that we do create our reality. In this way, the onus is on each being for who they are and what they have created. The notion of free will is of course embedded in 
such a proposition, for we each have choice, I have choice. Whether we choose to choose or not, is also a choice.

In saying that I create my reality, I am saying that nothing just happens, that there are no accidents. No one can do anything to us. In this light, all of our experiences, all of our experiences are individual acts of creation. The murders, rapes, car accidents, abuse and the dis-eases, are all an act of creation, created as thought made manifest. Everything exists, because energetically it exists Experiences are pattern made manifest. It is not easy to contemplate such an idea. It is an enormous proposal to grasp. In the collective consciousness of our being human is the idea that life happens, and so rather then own this creative power we have become accustomed to gazing outward and in that way not only are we then victims to life, more importantly we do not have to take responsibility for our acts of creation. The responsibility that I speak of is, feeling the emotion embedded in the experience.

Then there is another aspect of being prepared to do take responsibility for creation, where it is still possible to direct blame or fault. In shifting blame/responsibility/accountability from the outside world, it can then be directed at the inside world. By accepting the self as the creator of reality, an act of creation when judged as being 'wrong' proportions blame to the self. In this outward to inward shift, I mean something different. What I am speaking of is freedom, and with freedom comes responsibility. Every degree of freedom is accompanied by a degree of responsibility that is realised in a form of acknowledgment that in turn is an act of love.

Freedom as it relates to this discussion is about becoming the true self, where the self is defined as wholeness - as God. As God, I AM the Creator of my universe. As God, I am all things. In this way, God is in the rapist and the raped, the abused and the abuser. To understand this is to lay aside forms of discourse that attempt to make meaning through rationality that is embedded in notions of morality and ethics. Such discourses can only lead to further fragmentation through perpetuating the dualities of right and wrong. Therefore, what I am arguing here is, that it is about what is embedded in a situation that holds the potentiality of our becoming. I do acknowledge that I have chosen examples that inflame most people. To make the claim that God is in both the rapist and raped is to acknowledge that every human being is God in motion. In the same way that Hawking (1993) points out that the laws of universe are simple and predictable, but that the motion given by these laws make them unpredictable, some Gods do chose to experience creation from either end of this 
particular polarity. One butterfly, in the infinite butterflies that make up these two human beings, has chosen to flap its wings. Chaos, in which there is an area of non-chaos.

The one being raped may have experienced powerlessness, and the one raping, power. This then becomes the potentiality, the ground of being, that as a co-creation, each being is challenged to bring into balance this level of consciousness that as thought is thought on power and powerless made manifest, but also in the experience of rape and raped is now the possibility of becoming more in the journey to wholeness. To position this in notions of right and wrong only reinforces the idea of a victim consciousness for one and an illusory sense of power for the other. In the polarity of the emotion powerless and powerful we remain attached to the idea that who we are is, 'an encapsulated bag of skin dragging around a dreary little ego', and not God. In the knowing that we each are God, that in the experience of being human we are creating our reality, the challenge then is not to judge our acts of creation, but rather, learn to take responsibility for what we have created by moving to the third pole, the midpoint. The midpoint, as I have already explained, can only be approached from the place of the beautiful. Then, it is possible, having felt powerless to feel love, while at the other end of this polarity, expressed in duality as an illusion of power, will be seen as what it is, an illusion.

Hodgson in an introduction to astrology speaks of exoteric and esoteric astrology. Esoteric astrology is defined as,

the study of spiritual laws which guide the evolution of humanity, the spiritual principles which lie behind all material manifestation. Its basis is that universal law of correspondences recognised by the Ancient Wisdom and simply expressed in the words, as above (in the heavens) so below (on earth); as below, so above.

(Hodgson, 1943, p.10).

These Spiritual Laws are: Reincarnation, Karma (cause and effect), Opportunity (that we are placed in the exact conditions which give the required opportunities for soul growth and development), and Balance or Equilibrium (which causes the soul to pass through the opposing or balancing experiences - the ebb and flow of the tides of life) (Hodgson, 1943). I have already argued that life does not just happen, that experience is pattern, and wholeness is a pattern. Therefore, to identifying the pattern/s is to engage in process and so change the known reality, and in that way, change the pattern. 
By saying I am my choices, I mean I am this here and now person because in my past life I took particular paths in preference to others. In this sense, I am my history, I am what I am, what I have become. But I am also what I am not, what I have not become. So, I am my choices not only in terms of my past but also in regard to my future, my possibilities.

Paterson and Zderad (1976, p.16)

Augustine (354-430) in Arendt (1929/1996) says that the perfection of good, in other words wholeness, is negatively defined because self-deliverance from the world amounts to a choice of the Creator. In this sense, choice does not mean a list of never ending options, but rather, choice is about the search for our own being/becoming. It is as if we turn away from our wholeness in order to return to it. Augustine in Arendt (1929/1996) speaks of it as God's Law in its expression, that is, it is given with the creature's 'being of God' and therefore God is the Supreme Being and man's own proper being. In the turn away from God, a choice that we make, we are rendered helpless. In this state of helplessness, Arendt (1929/1996) says that what becomes sinful is independence - sinful not as a rebellion of the part against the whole, but as an independent performance of surrender. Sin - Self In Negativity, and in this way we lose sight of the fact that we are God, which as eternity presents the eternal law - As above so below, as below so above - simultaneously in it several parts.

So on one hand my choice to turn away from my wholeness, as I continue to reincarnate, is surrender, but when that surrender is lived in a way that loses sight of God, then what I am in fact doing is what Arendt ('19291996) terms 'an independent performance of surrender'. And so it is this, man's inability to work with the law that reflects not a lack of will but a lack of power. For by the very experience that the law creates, what we do in fact experience is the gulf between 'to will' and 'to be able', and when we come to understand this, then we know that "in God's case will and power coincide" (Augustine cited in Arendt, 1929/1996, p.87). For by that very gulf between 'to will' and 'to be able' there is the promise of our reunion, the finding of our own being again. But it is not something to be recovered as if it were lost, rather, it is our power to create. I would say this again, it is our power to create, and it is experienced as a transpersonal power that transcends the ego. We are the Creator, we are nothing, we come from nothing, and to nothing we shall return. "God is the 'before' as such only for that creature that was made out of nothing" (Augustine cited in Arendt, 1929/1996, pp.70-71). 
Therefore, conscious or unconscious, every experience is my creation that has as its intent becoming, the remembering of my being, becoming that which I already am. Experience is how I gather so that I might thing, [circumstance/happening/time/pastpresentfuture] "the manifold simple gathering is the jugs presencing" (Heidegger, 1971, p.174 ). And when I judge what I have created, (do not judge lest ye be judged), that is, the feeling that the experience has acted as a catalyst for, then what I am in fact doing is judging the Self. It is an independent form of surrender, man's inability to work with the law that then widens the gap between 'to will' and 'to be able'. In judging myself I lose the present [gift] - of the presence [closeness/nearness/intimacy] of the present [show/expose/lay-open/reveal] and then I am no longer in the now. It is as if in a third dimensional reality we can only wholly exist in the now moment, and in that way, time is real. But in judging our experience, we have judged our creation, we have judged the Self/presence. In this way, we project ourselves into the future, we move forward in time, we scatter ourselves energetically, we scatter ourselves throughout time and space - we are more dismembered.

If I consider myself to be a black hole, then as a black hole I have radiated energy from the void. There is a loss of energy, a radiation leak, and the particle antiparticle pair move separately throughout time and space until such time that I call them forth again. As a cell, I have given myself the same old message, for the same receptor and ligand have connected. Mortal and Divinity, Earth and Sky, the fouring of the four -

\section{Mortal/culture/opportunity \\ Divinity/beingness/balance and equilibrium \\ Earth/subject/reincarnation \\ Sky/object/karma}

and who are to be held in the void for the pouring, have not been held, the pouring a mere decanting of water - there is no gift, no consecrated libation. And I can continue this way until I radiate myself out of this existence - as above, the collapse of a black hole, and so below or, that is also how I create the physical manifestation of dis-ease.

This then is 'the how', of God's coinciding of 'will' and 'power'. In this way we are the creator of our universe, we create our experiences as the process of our becoming, we gather so that we might 'thing', and whether we choose to accept it or not - we are each God for $Y e$ have been made in my image. 


\title{
Nursing as a creative act
}

Augustine (354-430) in Arendt (1929 1996) describes the state that is brought about by life and death as the in-between position. This state is not to be understood in a two dimensional fashion, that is, the area between two poles, but rather, it is the space created by life when we know that we have come from being, and are moving towards nothing. Then the inbetween position of man, between being and non-being, is essentially a matter of time, time not just an index of transience, but transience itself (Arendt, 1996). In so much as human life owes its possibly positive aspect to its past alone ( in that we have come from nothing and to nothing we shall return) memory becomes the real possibility of holding on to the past and of arresting transience (Arendt, 1996). "This is because in memory the past is not pure past, but the past is presented as present" (Augustine 354-430, in Arendt 1929 1996, p.73). In other words, within our consciousness we hold the memory of who we are and all that we have ever been.

\begin{abstract}
When I reflect on an act of mine (no matter how simple or complex) that I can unhesitatingly label 'nursing', I become aware of it as goal directed (nurturing) being with and doing with another. The intersubjective or interhuman element, 'the between' runs through nursing interactions like an underground stream conveying nutrients of healing and growth. In everyday practice, we are usually so involved with immediate demands of our 'being with and doing with' the patient that we do not focus on the overshadowed plane of 'the between'. However, occasionally, in beautiful moments, the interhuman currents are so strong that they flood our conscious awareness. Such rare and rewarding moments of mutual presence remind us of the ever present 'between'.
\end{abstract}

Paterson and Zderad (1976, p.23)

So in the between, through this third pole, we catch glimpses of a new vista that then serves to remind us that there is more. At the same time in the experience of life, we challenge ourselves to make the view even more expansive through a relationship with the past that is presented as present, by being present, in the present. 
In their glossary of terms, Paterson and Zderad (1976) define the between as the "realm of the intersubjective" (p.131). Intersubjective is said to "pertain to where two or more human persons and their shared between; a relationship of two or more human beings in which each is the originator of human acts and responses" (Paterson and Zderad, 1976, p.131). In the identification that each person is the originator of his or her human acts and responses, is the recognition that we do create our reality. With this understanding lies the possibility of taking responsibility for those acts of creation.

Therefore, what I am suggesting is, that the creativity in Nursing begins with the process of reflection in the way that I have already outlined in the first two chapters of this work. In this form of mutuality, where we are drawn together because what exists energetically exists within each other's human field/aura, by our reactions/responses to each other we act as a mirror for each other through our unconscious subjectivity. Paterson and Zderad (1976) have described this state as a mutual presence which reminds us of the ever present between. What I am saying, and what Augustine and Arandt (1929/1996) are saying, that the inbetween holds the potentiality of offering each other a little more human freedom - nothing.

When we understand this, when we learn to respond rather than react to our own human situation that can be described as the adoption of an aesthetic attitude that is a form of suffering so that in God's case will and power coincide, then the process of refraction, which I argue is the true work of the healer, can exist. For until I as a nurse embrace my own being as life process, until I am able to guide myself by accepting responsibility for my acts of creation then how then can I even contemplate guiding another, consciously? Here-in I would emphasise the word 'process' again. For as I have argued in the third chapter of this work using concepts from fractal geometry regarding chaos, the only way to predict is to actually perform the 'iterations'. So when I speak about consciously guiding another human being, refraction, I mean working with emotion because it is recognised that each person's uniqueness or individuality is the uniqueness of patterns resultant from not what has been experienced in life, but how, life has been experienced. In that way it is what we have made, matter.

The universe is governed by well defined laws that in principle allow one to predict, but it is the motion given by the laws that is often chaotic (Hawking, 1993). The way through chaos, to the sensitivity of the initial condition or non-chaotic area, is by emotion/feeling. Anything else is analysis, a form of rationality or logic. Beingness is not logic. Beingness cannot be approached by logic, to do so is not just futile but begins another cycle of infinity in a finite space, the Lorenz butterfly. Each human being, in their interaction with life, has 
created their own pattern in response to their human situation. Where that human experience/situation has been judged reflected in that the human response is a reaction/projection then it is an expression of fear or doubt and thus negative. In essence it is a lack of love, the eventual outcome, I argue, is the physical expression or manifestation we name, dis-ease.

All dis-ease is the result of inhibited soul life, and that is true of all forms in all kingdoms. The art of the healer consists in releasing the soul, so that its life can flow through the aggregate of organisms which constitute any particular form.

Bailey (1953)

From the position, that dis-ease is an expression of a lack of love, I argue that what is being called forth from Nursing is creativity in its highest form ... the finest of the fine arts. It is a form of call and response that is not to be interpreted as a mere asking for, and responding to. Rather, this call and response is a form of invocation, genesis - the sensitivity to initial conditions. It is a calling forth that comes from the soul of one being that can be heard by the soul of another being. The response to such a call can only come, when the one who is being called has learnt to listen to their own inner voice. In this way, the one who has been called, has learned to stay in the present, in the now, and so enter into that space of allowance, non-judgement and unconditional love from which all things flow.

In this space the voice is heard, because that voice is felt. Then the human being who has been called knows how to act. Then in choosing whether to respond or react to the action from the one who has listened, the one who has called can choose to listen/respond or react [projection/denial] to their own inner voice. Again, this act of listening/responding requires the one who has called to stay present and enter the space of allowance, non-judgement, and unconditional love. Some might call this space - the no-thing.

In choosing to listen/respond, it is a co-responding, and when there has been a coresponding, then what has been called forth is a response to Being, which has taken place in the between. Nurse and Patient as Creators of their universe, have engaged in a form of cocreativity, that is Creation itself. In this way, we come from Creation, we are Creation and we continue to move toward Creation. And in this way, Nursing serves creativity in its highest form. 


\section{Summary}

This chapter has presented the idea that we are the Creators of our reality. This chapter has argued that who we are is God/Love/Source and as such our lives are the manifestation of ongoing acts of creation. In viewing life as acts of creation, it is then possible to view illness in this same light.

The work of St Augustine (354-430) and Hannah Arendt (1929) are used to explicate an ontology of being for the purpose of examining the gulf between being human and God, and how that gulf is bridged. In this way the argument is brought back to a position of using 'the will' in acknowledging 'what is' as 'just is' from which we are then free. By making the choice to feel love because we have understood that what we have felt is in response to what we have created, what we are in fact doing is acknowledging to ourselves that we are the creator and so then are free to create something new/more.

With the understanding that we create our lives, nursing can be viewed as an expression of acts of creation. Where action is actioned in the form of a co-responding to other as a call and response and in that way serves creativity, in its highest form. 


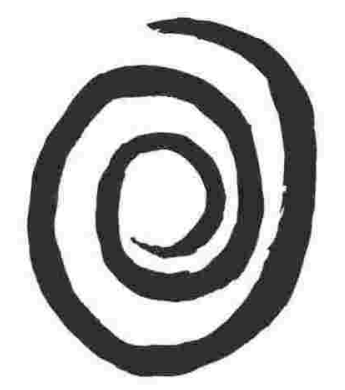

\section{Chapter 7: On Thought and Action in Nursing}

\section{Rational thought and action}

Parapsychology, or psi, is used to refer to psychic phenomena such as telepathy, clairvoyance, precognition and psychokinesis (Roney-Dougal, 1991). Its symbol is the $23^{\text {rd }}$ letter of the Greek alphabet. That letter is the first letter of words such as, psyche (mind, soul), psychic and psychology (study of the mind). In quantum physics, psi denotes the hidden variable involved in the collapse of wave function, where the hidden variable is thought by some to be 'will' and 'consciousness' (Roney-Dougal, 1991). The same symbol appears on the Norse rune alphabet Algiz which is said to serve as a mirror for the Spiritual Warrior (Blum, 1990). The symbol also appears on both Neptune and Boadicea's trident (Roney-Dougal, 1991).

For all the advances in understanding the psychology of psi, the central question of how psi works is still unanswered (Roney-Dougal, 1991). Research has shown that the dreaming state of consciousness does assist in raising awareness of what Roney-Dougal (1991) terms intuitions, but how that information came to be within the subconscious mind in the first place is still not understood. At the beginning of the previous chapter, the research work of Jean Houston (1997), who for the past thirty years has been a leading light in the area of consciousness and the ongoing understanding of what we are capable of, was noted as identifying that creative people were familiar with the world within themselves. These people knew that the ideas and images which gave impetus to their projects were generated from within themselves (Houston, 1997). What they had learned to harness was, the ability to engage in an archaeology of the mind that delved into the depths of being, and in this way were able to connect to, 'forms and patterns of Creation itself' (Houston, 1997, p.19).

The terms subconscious and subliminal are used to express all mental and bodily processes outside of conscious awareness and control that are said to not only be the source of all of our creativity, but retain every experience in its entirety (Roney-Dougal,1991). At a subliminal 
level everything that is physically present, because of our ability to process billions of items of information simultaneously, is registered and therefore retained (Roney-Dougal, 1991). This, coupled with our telepathic, clairvoyant, and precognitive abilities, in other words our psychic abilities, is what renders us potentially omniscient (Roney-Dougal, 1991). Thus at a subliminal level we are not just potentially divine, rather, we are divine.

Let me repeat: everything, all subliminal stimuli, all psi stimuli, all body process, everything is incorporated into this mind. Potentially at the subconscious level we are aware of everything that ever was, is, or will be - we are omniscient - we are divine.

Roney-Dougal (1991, p.15)

Our conscious mind is only able to process seven things simultaneously, whereas the subliminal mind is capable of processing billions of items of information at once and therefore has a complex series of barriers, which in psychology are termed filters, to protect the conscious mind from being overwhelmed (Roney-Dougal, 1991). So on one hand we have the ability to process massive amounts of information, but in the main this information remains unconscious for there are filters that exist because we are in need of some sort of protective mechanism. We get as much reality as we perceive we can handle, and in this way the subliminal mind determines what we do and do not see, hear, and think (Roney-Dougal, 1991). In Psychology these filters are termed perceptual defence, and we use the defence mechanisms of repression, denial, and projection as a way of filtering (Roney-Dougal, 1991).

These filters, when analysed, are a left brain activity, and in that way they are blocks (RoneyDougal, 1991). The reference to analysis is used to denote a problem solving approach. While not specifically stated, Roney-Dougal (1991) does imply that as right brain phenomena, the removal of blocks or filters is what enables us to consciously access the information of the subliminal or unconscious mind. This suggestion is brought about by the opinion that psi [telepathy, clairvoyance, precognition and psychokinesis] is essentially a right brain activity. So while I do hold with the suggestion that it is about accessing the subliminal mind, and in this way the filters need to be removed, I would also argue that these forms of psi, as stated, are but the tip of the iceberg. Furthermore, while what is termed right brain process is a culmination of change that results in right brain change and a corresponding flow onto left brain function, and in that way a right to left movement, to perceive that this 
process is bound to a form of cerebral activity is to fall into the traditional dualistic argument. The expansion of consciousness involves our whole being in order 'to be', and in that way it is, Being. I would also add here that telepathy, clairvoyance, precognition and psychokinesis, are the lowest form of intuition and hence my reference to the tip of the iceberg.

One way to look at how the human mind functions is to liken it to a computer that once having had a particular programme installed continues to run that particular programme until it is removed (Tikashi, 1998). The initial programmes have been run over and over again, generation after generation, and until such time that the particular being realizes that these programmes no longer serve him/her, "we do not begin the process of re-educating the reactive mind" (Tikashi, 1998, p.2). In this way, I argue, we are rendered helpless, in the way Arendt (1996) has described and which was discussed in the previous chapter. In other words, we can bring about our own surrender, not as an independent performance of surrender, but because we have experienced the gulf of 'to will' and 'to be able' and had enough! We come to a point where we begin the turn around, as a conscious process, to return to God consciousness. It is then that we begin to step into our true power in the way Augustine has said, "in Gods case, will and power coincide" (Augustine cited in Arendt, 1996, p.87).

The purpose of the initial programmes are to allow each person to feel the feelings that incarnate beings are here on earth to experience (Tikashi, 1998). In this way, the reactive mind serves the purpose of interpreting/processing life experiences in a particular way, so that we feel particular feelings in response to life experience. Because the reactive mind strives to maintain consistency, to perceive what it knows, the original programme is repeated over and over again, and so the outward expression is that while the people and places may change the situation does not. In that way a being keeps creating the same reality. This, I have argued, is because the same wave pattern is being emitted, the same energy, and where a being focuses their energy, this energy then flows to turn those thoughts into realities. So the programmes, while having had an original purpose, have in fact become blocks or filters, and in essence are what Spinoza (1677) terms, 'a confused idea'. Our minds are confused and so while we have enormous potential, until we clear our minds we are unable to actualise our true potential. This clearing of the mind is not a mere clearing of the human brain, rather it is a clearing of our whole Being which is bought about by and through the process of becoming. Psychology speaks to the notion of changing perception, and while it is about altering perception, and in that way the removal of filters or blocks, psychology does not explicate the changing of perception through Being. And while a human being is capable of 
modifying behaviour on the basis of what is perceived to be right or wrong, this does not reflect a change in perception. This type of change is the result of a gratification of the ego. Where there is either a fear of not being seen to act in a certain way and so a negative response (that appears positive), or a feel good feeling from the change therefore a positive response energetically the behaviour modification is not permanent. Regardless of which mechanism, positive or negative, reality remains distorted because perception has not changed. A behaviour when based on moral or intellectual reasoning is not permanent. This accounts for why, after the passage of six hundred years, changes in social conditions and geographical boundaries, given the 'right' stimulus two groups of people can invoke seven generations of hatred that manifests in human genocide. After months of tragedy/loss/grief followed by twelve months of respite, when geographically these same people are placed in close proximity the whole cycle would be reinacted but for the presence of peace keeping forces. Time alone does not change perception about reality. Nor does moral or intellectual thinking. Therefore, in order to continue to expand on this notion of thinking as a total body process that has being at its core, I would wish to repeat some of my earlier discussion on emotion or affects.

In the third part of his Treatise on Ethics, 'On the origin and nature of the affects', Spinoza (1677) defines an affect as, "By affect I understand the affections of the body, by which the power of acting of the body itself is increased, diminished, helped or hindered together with the ideas of these affections" (1952, p.421). Spinoza (1677) lists forty-eight (48) affects arguing that whether an affect is a desire, joy or sorrow, the affect has an effect on the body. Rather than examine the list I would draw attention to the three categorisations. Spinoza defines the word desire as

the essence itself of man in so far as it is conceived as determined to any action by any one of his affections ..... desire is appetite which is self conscious, and that appetite is the essence itself of man in so far as it is determined to such acts as contribute to his preservation. But in the same scholium I have taken care to remark that in truth I cannot recognise any difference between human appetite and desire ........ and therefore, in order that I might include the cause of this consciousness it was necessary to add the words, in so far as it is conceived as determined to any action by any one of his affection.

Spinoza (1677/1952, p.416) 
If the word desire, to be hungry for, in its relation to affects can also be interpreted as 'to want'. To want a thing it is not the same as needing a thing, or desire as desire relates to the essence of man. To want is an expression of lack, for it is wanting. Lack has its origins in fear. Fear in the sense that it is false evidence appearing real or, a confused idea. It is an idea about reality that is not real because fear is not real. Fear is a human phenomena. Joy on the other hand is the energy of love and in that way it also desire in the sense that it is the essence itself of man.

Spinoza defines sorrow as "man's passage from a greater to a less perfection" and adds,

I say passage, for joy is not perfection itself. If a man were born with the perfection to which he passes, he would possess it without the affect of joy; a truth which will appear the more clearly from the affect of sorrow, which is the opposite to joy. For that sorrow consists in the passage to a less perfection, but not in the less perfection itself, no one can deny, since is so far as a man shares any perfection he cannot be sad.

Spinoza $(1677 / 1952$, p.416)

If sorrow is seen as suffering, as was explained in chapter three of this work where to suffer as withstanding and experience means to feel, then sorrow as a passage to less perfection is not a final destination. Sorrow is a port of call in which joy or love might be realised. It is a choice that represents either chaos or non chaos. In this way sorrow and joy as affects belonging to the same continuum of a dual system, work to move a human being to the third pole as a way to transcend a dualistic position. In so doing then there is more love. Thus, sorrow as an affect belongs to one end of a continuum but also represents process where affects [sadness/loss/grief] can be determined as chaos - for a time, or non chaos.

In this way I have attempted to make clear that regardless of a classification of affects it is not the affect as an energy or pattern of thought that is resultant in love or fear, as love and fear relate to reality, rather, it is how that affect is processed that determines whether there is more love or fear. So on one hand any system that attempts to divide affects into good or bad, better or worse, positive or negative, fear and love, as has been presented, I would again call 'to the attention' that whatever the categorisation of emotions it would seem that what is relevant is whether they are thought of, in terms of love or fear. 
In this way I wish to continue to focus on how our emotions are connected to the process of clearing our minds through clearing out whole being by being and as such make manifest an expression of love. How we process our emotions, determines not only what we see or how we see, but also, what we create. Love or fear. "I say again, by which the mind affirms of its body, or any part of it, a greater or less power of existence than before" (Spinoza, 1677/ 1952, p.421).

Spinoza (1677) views the body and mind as one, and in this way the body is in the mind and the mind in the body. It is the affect which creates an image in the mind. This he argues, is 'a confused idea', it is not pure thought. "An affect or passion of the mind is a confused idea" (Spinoza, 1677/1952, p.421). As such, it is the mind that suffers, for it has inadequate or confused ideas and as such the idea of the body is then created by the affect. In other words, our minds are not clear, our bodies are not clear. By our engagement in life, we lay down an experience. Recall Roney-Dougal's (1991) point that our subliminal mind has the capacity to take in billions of information at once and in this way we memorise, we store it, as an affect. What we lay down/store determines not only how we see the world, but is our image of the world. In this way. we programme our minds, we create our thoughts and beliefs. We are our own programmers. The idea of the body having been created by affects. Where the process of the affect creates the image, and then that is what we in fact become, the image we create is dependent on what we do with an affect (Spinoza, 1677). Energy follows thought. The system has reached the point of chaos. Reality has become so distorted because thought is confused. . It is thought reflected through the body that as confused thought is dis-ease. In this way I am saying that dis-ease is an image of the mind made manifest physically.

\footnotetext{
.... but this idea, which constitutes the form of an affect, must indicate or express the constitution the body, or of some part of it; which constitution the body or any part of it possesses from the fact that its power of action or force of existence is increased or diminished, helped or limited. .... But the idea which constitutes the form of affect affirms something of the body which actually involves more or less reality than before
} 
In other words, Descartes' famous quote, 'I think, therefore I AM'. I become as I think. As I think so I am. For as God, as I have already argued in the preceding chapter that we are God in motion, we are the Creators of our reality where the purpose of life, of our being human is to realise [make real] our God state. This Godliness is not something to be bestowed upon death it is something that coexists with our embodiment.

At this point in the research, I came to fully realise that in working with the affects [emotion embedded in my data and reflected through life] I was unconfusing myself, and so unconfusing my mind. I was clearing my mind and clearing my body, so that the mind of God and my mind could move closer to becoming the same mind. To accept that I was the creator of my reality had been my first challenge. To then think of myself in terms of god was the next, but to entertain the idea that my mind could be the same mind as god's, challenged every thought I had ever had about who I was. "If you go deeply enough into your mind, and deeply enough into mine, we have the same mind. The concept of a divine, or Christ mind, is the idea that, at our core we are not just identical, but actually the same being" (Williamson, 1996, pp.30-31). My perception of reality was shattered. And yet, the yearning for union is depicted in so many ways in so many writings down through the ages. Still, it was something I could barely contemplate.

As above, so below, as below so above is recognised as a Universal Law. I proceed with the word law very cautiously because in the interpretation of a thing as law historically humankind has created rules that then determine the rightness or wrongness of a thing. In other words, we have equated law with judgement. I am also cautious of using the words first principle or ultimate cause in relation to law as this then leads the discussion into a debate on a Being of beings. In the same way that there is an inherent rate at which my heart beats, so too is there an implicate order about the universe and expressed in many forms eg Reciprocity. What determines what that order will look like at any given moment is as this thesis is arguing, our thoughts, but that the order exists is certain.

Therefore, below and above can be interpreted as human and the cosmos, but also above and below can be interpreted in the physical sense, as above - our brain, and as below - our body. Candice Pert's (1997) opiate receptors found in the brain as well as in a big toe illustrate this point. In this way above and below are not only heaven and earth but brain and body as they relate to a reflection of mind. As such the mind below and the mind above can be, as it is above so it is below. Where true mind is non-spatial, and access to the realm/plane of true mind is through our feeling state. 
In prayer, having completed the last portion of the third part of the Summa, St Thomas was witnessed to be raised several cubits in the air. He had prayed, fasted and given penance to be preserved from error in doctrine. In having completed the work he asked that he might have grace to know if what he had written were the truth - his levitation was in response to the answer (Cavanagh, 1890). C J Rolling when told that her first Harry Potter book would be published experienced the same phenomenon. She jumped so high that she touched a twelve foot ceiling.

Such propulsion is the result of energy expressed. In order to express energy, and everything exists as energy, then thought too must first exist as energy/consciousness which in order to be expressed must first be felt.

$\ldots$ as Thomas [Aquinas] was saying mass ... in the presence of .... he fell into such a profound ecstasy, that a long time elapsed before he could be restored to himself. ... saying that what he has seen and heard had filled him with wonder.

(Cavanagh, 1890, p.152)

This wonder and ecstasy is then contrasted against the puny set of beliefs we create with our reactive minds but which serve as the real block between our unconscious mind and universal mind so that we perceive ourselves as separate from that which we truly are - God, I AM, and therefore, I think.

The process, then, is a process of decoding embodied knowledge by allowing the body to communicate with the mind. For as I have argued the body is a reflection of the mind which exists spatially, that is the body is located in physicality whereas the mind is not. Therefore, we experience life through our bodies as we store the stories of life. Hence the sensitivity to initial conditions as the characteristic inherent in chaos, and memory as past, but not past, but presented in the present. In this way, we begin the process of re-educating the subliminal or reactive mind so as remove the filter/block/distortion. In other words, allowing one's self to feel the affect because as was stated in an earlier chapter, the ego cannot feel. The confusion of the mind has been an act of ego in how the affect was processed in the first instance. The ego uses judgement, fear and doubt to confuse the reactive mind as the reactive mind strives to maintain consistency. In this way I came to realise that that is how we as human being keep ourselves separate to that which we are. In allowing myself to feel the affects [emotions] and then work with an affect differently then it is as Spinoza has said. 
But it is to be observed, that when I say greater or lesser power of existence than before, I do not mean that the mind compares the present with the past constitution of the body, but that the idea which constitutes the form of affects affirms something of the body which actually involves more or less reality than before.

Spinoza, (1677/1952, p.422)

By the process of decoding embodied knowledge, by removing the filters, we come to know.

Moreover, since the essence of the mind consists in its affirmation of the actual existence of its body, and since we understand by perfection the essence itself of the thing, it follows that the mind passes to a greater or less perfection when it is able to affirm of its body, or some part of it something which involves a greater or less reality than before.

Spinoza, (1677/1952, p.422)

And in a reality which is greater than before, what is seen energetically is a change in pattern. This process is Augustine's (354 -430) (cited in Arendt 1929/1996) coinciding of will and power in God's case, and while the hidden variable is no longer hidden, and thus termed in quantum physics a collapse of wave function, the wave does goes on. By removing the filters or blocks, the process is but the expression of will and power, and the wave has changed pattern/frequency - a new wave form. It is Martha Rogers Principle of Resonancy, The continuous change from lower longer wave to higher shorter wave frequency patterns in human and environmental fields (Rogers cited in Malinski and Barrett, 1994).

Therefore, in speaking of the power of the mind, Spinoza (1677) is not referring to intellect or logic, but rather he is speaking of the decoding process of embodied knowledge to change the dialectic of body mind whereby thought becomes object. Object in this sense meaning 'an unconfused idea', in other words - pure thought, the mind of God, the River of all Knowing, Universal Mind. 
When therefore I have said that the minds power of thought is increased or diminished, I have wished to be understood as meaning nothing else than that the mind has formed an idea of its body, or of some part of its body, which expresses more or less reality than it had hitherto affirmed of the body. For the value of ideas and the actual power of thought are measured by the value of the object.

Spinoza $(1677 / 1952$, p.422)

\section{Thought as pattern}

I began chapter four with a discussion on the human aura. The word aura is a Greek word meaning breeze (Pierrakos, 1987). The human aura was defined earlier as "the combined manifestations of body, soul and mind" (Kuthumi cited in Prophet, 1991). The history of a person's life, as well as the present situation, can be observed in the aura (Pierrakos, 1987). Pierrakos (1987) goes on to say that pain as systemic and enduring as rejection in infancy, or as localized and transitory as a tooth extraction can be observed in the human aura. Thus our lives are literally displayed in our aura. Each experience has been laid down in such a way that we create our own life map, and our maps are made up of unique patterns and colours. Each of us, like Joseph, has a coat of many colours. "The person appears to swim, as in a fluid sea tinged rhythmically with brilliant colours that constantly change hues, shimmer and vibrate" (Pierrakos, 1987, p.74). In the same way that it is possible to view this planet from space, or view space as we stand on the earth and gaze at the night sky, so too can we see our own map.

In describing the pulsation of the aura, Pierrakos (1987) says there are three phases. In the first phase the aura swells for one or two seconds away from the body, reaching a distance from two to four feet, and then loses its distinctness by merging with the surrounding environment, in other words the aura of everything else. At its peak, the aura is oval with fringed edges, and when this peak stage has been reached the aura retains it oval form for about $1 / 4$ of a second, to be then followed by a second, very rapid phase of about 1/8 to 1/5 of a second where the aura becomes contracted. Finally, there is a resting state that lasts from one to three seconds and after which the whole cycle of expansion and contraction recommences. The cycles normally occur about 15 to 25 times per minute. However, the frequency of pulsation, vibrancy of colour and degree of extension are all enhanced with 
excitement (Perriakos, 1987). When the body goes into vibration as a result of deeper breathing and strong emotion, the effects are a rise in rate, an increase in the width of the field, and a brightening of the colours (Pierrakos, 1987). Further, in a group where there is 'a strong communication', the individual rate rises to about 50 pulsations a minute extending outward to fill the space, and then there is a merging of energies so that a new energy mass envelops the group (Pierrakos, 1987). This new energy mass is "more than the sum of the individual consciousness's, and spirals into and through the contributors as well, again because energy flows undivided" (Pierrakos, 1987, p.74).

Pierrakos (1987) then goes on to give a detailed and fascinating description of the layers of the aura and the pattern of their movements, saying that while movement in the three layers is simultaneous they can in fact be reduced to two summative patterns. Most interestingly these two patterns are a longitudinal figure 8 and a perpendicular pendulum swing (Pierrakos, 1987).

The pendulum is easily recognised as a symbol of balance, the movement from one extreme to another the midpoint representing balance. Also in a side to side movement, left to right, could it also represent the feminine and masculine aspects of an energy? The figure eight might be conceived of as a continuos cycle of movement away from and then toward as an infinite cycle. If so, then reviewing the Universal Laws of Correspondences introduced in the previous chapter, and which are said to guide the evolution of humanity and therefore behind all material manifestation, then 'As above so below, so below as above', in it parts, are represented by these two auric movements and become the Law of Equilibrium [the pendulum] and, the Law of Karma [the figure eight]. In other words, our natural state is union with every other atom resonating to Universal Law, Divine Law, God, and that we inherently move ourselves towards this state in every breathing moment of our physical existence, no matter what motion we have given to the laws, is certain/predictable. We are not free not to be free.

Therefore, what I am saying is, it would appear that as we live and breathe there is an unconscious process at work that is guided by a grand map. Moreover, while each person has a little local map, there is embedded throughout the whole universe the knowing of this grand map. The challenge of our lives then is about making the local map and the grand map, one and the same. In this way all of our pulsations, seen etherically as the wave patterns of our aura, evidenced biologically as the vibration of receptors and ligands as they send information to the cell, and some insight into particle activity of a black hole, I argue, are all 
expressions of the same phenomena, that is, the expression of the movement toward God consciousness.

The patterns that guide this process are governed by our thought. Thought, I have argued, while a product of mind and manifested by the physical brain and then expressed as consciousness, has its origins in feeling. What we feel is what we are in fact thinking at the subliminal level. This then is how we create the patterns in our auric fields that give motion to the waves. Where there is a confusion of the mind - a block or filter, the energy appears distorted, the colour lacks vibrancy and the particular colour is indicative of what the block pertains to. This pattern of energy is what then in the outward pulsation mingles with the energy of all things to attract more of the same energy that is then translated into life experience. In this way, we draw to ourselves an experience in order to remove the block or filter as we strive to create the pattern of the grand plan. Everything exists because energetically it exists, and in this way, as I have already said, we are the Creators of our experience, of our reality. The figure eight and the pendulum are that which assists us to do so, and therefore all experience, all experience, is a divine blessing and it is only our judgement of it that deems it anything less.

I have often struggled with the meaning of life is a gift. From the perspective that in every moment there is the potential of a present, a gift, through the presence of the presence, I can at last see how life can be a gift. In the knowing that all is a divine blessing at last I can accept life as a gift, for every experience is to be valued, whether I have understood the lesson or not.

In saying this then, the concept embedded in fractal geometry now becomes more clearly apparent. Where after a certain value the periodicity disappears, as was discussed in chapter three and the number of cycles become infinite or chaotic, it is this that makes clearer the form of thinking that engages us in an analysis of life experience. It is what is done when we attempt to identify common themes, when in truth an experience has been created by an individual in order to feel a particular feeling. This is how we perform each iteration. By repeating an operation using the last result of that operation as the input, in this the way we can repattern oursleves. Each time I do so my local map begins to look more like the grand map. As I re-pattern my mind's power of thought is increased. Not in the sense of generating the precepts, but in being 'open' to receiving them.

Pierrakos (1987) does not speak about the direction of flow. I would suggest that as the pendulum swings back and forth, the top circle of the figure eight, when looking at a person 
front on, would move in an anticlockwise motion, while the bottom circle would move in the opposite direction, that is, a clockwise motion. These movements, I argue, are Heideggers (1971) fouring of the fourfold in action. Each swing of the pendulum left to right, and each circle top and bottom rotating to draw energy into our being, and is what is meant by gathering, that is the creation of experience so that we might 'thing' in order to think.

\section{Reaction versus response}

In his discussion on the core, Pierrakos (1987) describes the core as,

The core is the human being's whole capacity, a glowing, vital mass, both the source and the perceiver of life force. The core has complete unity. No duality can exist at this first level of reality, no either-or, no good-bad. It is an indivisible vibratory operation, a process in which every person knows the truth instinctively by sensing the pulse of life. The qualitative characteristics of the core's movements are the primal positive emotions, or movements to make contact and unify with the outside world. These can be summed up as one supreme expression: love.

(1987, p.25)

Two other layers cover that innermost reality. The layer closest to the core is said to be that which contains the negative primal emotions, and the outermost layer is named as a state of distorted reality. These two layers effect energy flow from and into the core (Pierrakos, 1987). In health there is a free flowing of energy into and out of the core. The layer closest to the core represents our ability to "counteract external force moving inward and to alter core force moving outward" (Pierrakos, 1987, p.21). The outermost layer is the area of defense and mediation between forces moving in both directions (Pierrakos, 1987). The inner self is represented by the first two levels, whereas the outer layer is a mask of distorted reality which Pierrakos (1987) says is a necessary filter, but none-the-less the world of illusion.

The negative unconscious impulses or negative primal emotions that are unified, controlled and organized by the ego and super ego, as suggested by Freud, are contained within the second level and brought into action to negate the positive impulses of life from level one, 
regardless whether these are from inside or outside the being (Pierrakos, 1987). It is important to emphasise here that when speaking of positive and negative I mean as energetic charge, as outlined in chapter four, not in a dualistic sense of right and wrong or good and bad.

The core, Pierrakos (1987) says, has no faculties for dealing with excessive calls or attacks on its substance, nor is it able to answer frustrations or rejections of its pulsatory flow. In other words, it emits energy and receives energy, energy that flows through two other layers. The primal negativities and their distortions from layer three serve the purpose then of protecting and affirming life, expressing life and responding to the dualities in existence (Pierrakos, 1987). Freud saw these as death instincts, and Reich as intrinsically pathological forces, but Pierrakos (1987) says they are neither, and what they represent is the perceptual intrusions that our energy has to battle on its integrity. In other words, love contrasted against everything that is not.

The energy in the second layer is altered, condensed and slowed in its vibrations, but when compared with the compression and deceleration in the energy of the fixed stratum of the defensive perimeter made up by the third layer, it is fluid in form (Pierrakos, 1987). The peripheral or third layer encompasses the element of self-consciousness, the ego as the agency of self-aware thought and outer will, in which the influences of the ego's conscious perceptions and decisions is embedded (Pierrakos, 1987). This I argue is the same meaning as I have outlined in the previous section where I stated that the challenge is to remove the blocks in our process of becoming. The blocks having been created in the first instance by our interaction with life, and in that way are our past, I am my history, and so I am also my memory that is then presented as the present. The third layer or defense perimeter, is both the ego's self-aware powers, or volitional thinking, as well as the area of negation or denial (Perrakos, 1987). As we begin in early childhood to control the flow of energy into and out of our whole being, we disrupt the flow of energy from levels one and two so that they become, in Reich's term, energy blocks (Pierrakos, 1987). "Blocks are stagnated pools of vital substance that accumulate in the defensive perimeter and armor it in dysfunctional patterns that Reich named character structures" (Pierrakos, 1987, p.24).

Pierrakos, (1987) in his work with Alexander Lowen, then makes an important observation which I believe to be crucial in the process of working with the flow of energy from and to the core. "We have a choice as to whether to continue to maintain the pain", (Pierrakos, 1987, p.24). It is a matter of will, which appears most strongly in the defensive perimeter, whereas volition/choice is evident through all three layers because of a persons 
psychosomatic identity (Pierrakos, 1987). In other words, we are being told that what makes the difference as to whether we cling to our old perception of reality, the maintenance of constancy, or open to the clearing and thus a greater power of the mind/more reality, is our ability to choose. In order to do so, it is a matter of will. To be willing. Will as determination [noun] is judgement, but will as command [verb] means direct/straight, and therefore is - uninterrupted flow. In this way will, as an act of consciousness, in fact becomes consciousness, and is expressed in quantum physics as psi, or the hidden variable involved in the collapse of wave function. This is how we truly make manifest. We chose to be willing, or not.

Therefore, in our reacting or responding to life lies the key to our becoming. The interaction of the three layers is such that, as energy, we create patterns that are then translated into experience for the purpose of feeling something. When we have perceived something as bad, we have judged our experience. In essence, as I have already explained, we have judged ourselves. How we have perceived our experience is attached to a particular emotion. Each time we create an experience that becomes the catalyst to feel a feeling and we react to what is felt, the result is that we maintain our constancy. For the ego, in its part of maintaining conscious awareness and perception, has hooked the reactive or subliminal mind into the old perception of reality. We chose to feel a feeling, and so can also make a choice to deny, repress or reject that feeling in the first instance.

In responding, by choosing to feel a feeling, the purpose of an experience what we are in fact doing is engaging in an allowance of being. This allowance of being is also an acknowledgment because it is a reminder and in that way a re-membering that the core has unity, that duality is not real.

In acknowledging the self, it is an expression of unconditional love of the self. That acknowledgement exists no matter what the feeling - from this feeling of disapproval I have gained ..., and in that way, the feeling is acknowledged/validated. As such it is the actioning of, unconditional love, non-judgement, and allowance. "Our inner balance of harmony and truth is strengthened by our triangle of non-judgement, allowance and unconditional love" (Tikashi, 1994, p. 33). As balance, it is the pendulum in motion. The Spiritual Law of equilibrium. As the pattern of the figure of eight in motion or the Spiritual Law of Karma of Cause and Effect, a new cause can come into play. We are now free to experience something anew in order to feel different feelings. And so each time we choose to feel something different, and then do it, we are reprogramming ourselves. We can stop running the old programme/story/perception of reality as we move on in our process of pattern making, or 
creating as method. In so doing, we increase the power of the body and mind. In this knowing then, there is the knowing that in letting go of the little local map there is something guiding us toward a larger grand plan.

\section{The Teacher Within}

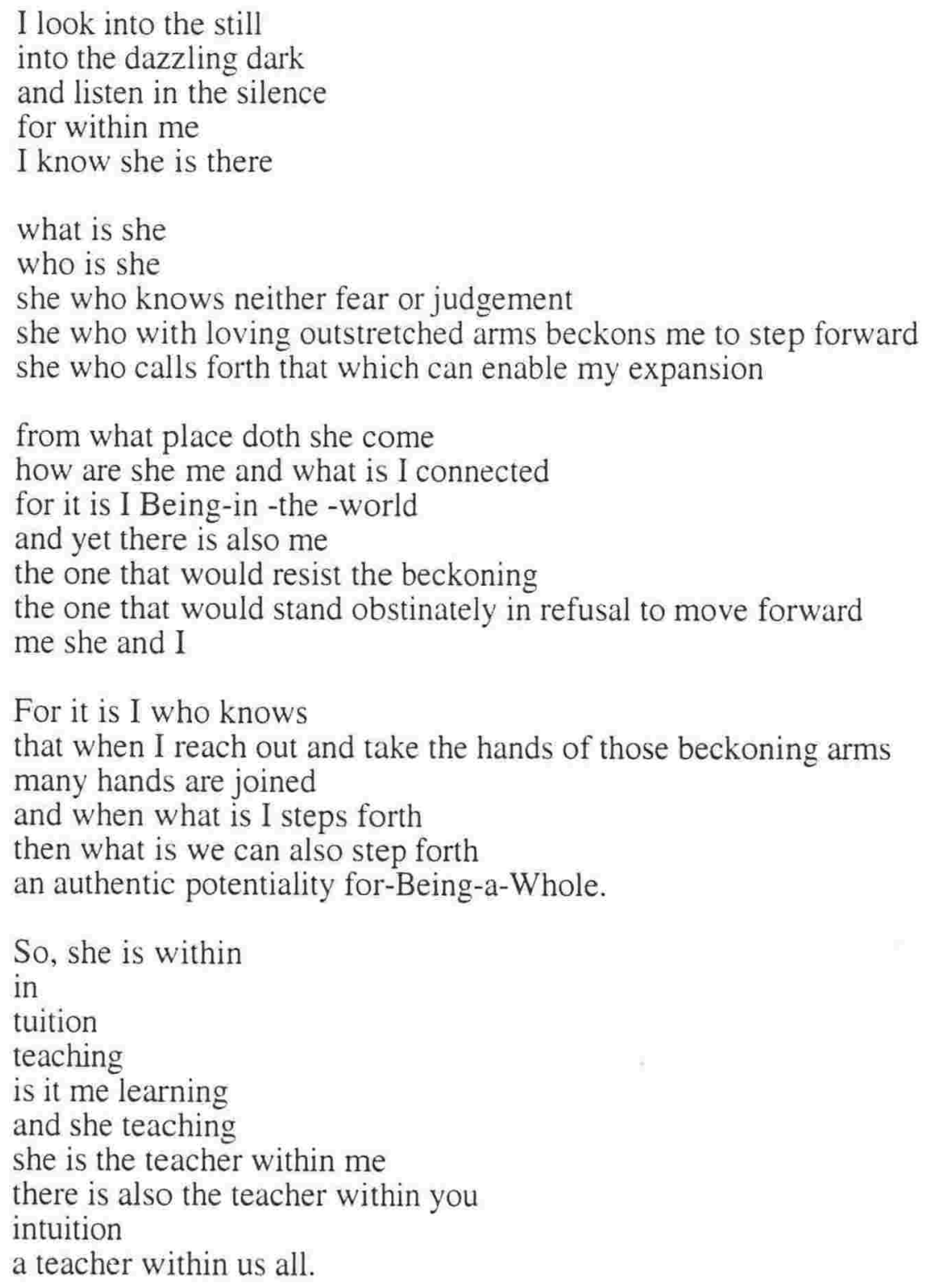

Since Aristotle philosophers have pondered on, and articulated notions of, what thought or thinking is. Heidegger, in his exploration on thinking makes the point that "what keeps us in our essential nature holds us only so long, however, as we for our part keep holding on to what holds us. And we keep holding on to it by not letting it out of our memory" (1968, 
p.3). The word thinking comes from the word Thanc, which means memory. Memory, Heidegger (1968) defines as thought which is gathered, and because memory is the gathering of thought, we give it thought, as that is what is required to be thought about. "What is thought is the gift given in thinking back, given because we incline toward it" (Heidegger, 1968, p.4). In our inclination toward thinking, this then calls thinking forth.

Memory is the corpus of unconscious material observed by Pierrakos (1987) in the defensive layer or layer of illusion/distortion and that I have argued is experience laid down that then is attached to a particular emotion. Further, this assertion concurs with Augustine's view that on one hand human life owes its possibly positive aspect to its past alone (in that we have come from nothing and to nothing we shall return) but memory becomes the real possibility of holding on to the past and of arresting transience (Arendt, 1996). "This is because in memory the past is not pure past, but the past is presented as present" (Augustine 354-430, cited in Arendt 1929/1996, p.73).

Heidegger suggests that in order to think we need to learn, and it is by "disposing everything he does", that what is essential is then learned (1968, p.4). So we call, in the same sense we now call what in itself is to be thought about, and in this way it is thought provoking. For what is thought provoking is in fact what creates the opportunity to think and, at the same time, in a sense is that which is thought provoking, is that which is intrinsically what must be thought about (Heidegger, 1968). In other words, we call forth that which we need to learn, not what we think we need to learn. I argue that the call is from the core, and in this way it is thought released as energy. Physiologically then, it is what is represented by the receptor ligand connection, the information that a cell receives and by which cellular function is influenced, and is what has occurred as process. In that way, life is the answer to the call.

As has already been outlined, how we respond to the call determines what we learn/the information the cell receives/whether the power of the mind and body is increased/our ability to see more reality/the expansion of our consciousness/the movement back to things themselves/Aletheia/ the closer we are to nothing, the black hole becoming a white hole but not as entropy per se. "Most thought-provoking, what remains to be thought about always, because it is at the beginning, before all else" (Heidegger, 1968, p.4). Even so, says Heidegger (1968), we are still not thinking, although he does concede that the world is becoming more thought-provoking. We are reminded that we need to move beyond proposing what ought to be and how it out to be done, for what is lacking is not thought, but action (Heidegger, 1968). Heidegger (1968) does however make the point that where we focus our thinking needs to be reviewed, while cautioning that action is not to be interpreted 
as mere action, because for centuries "man has acted too much and thought too little" (p.4). It is here that I am reminded of Paulo Freire's (1972) discussion of the word, praxis.

Praxis, as Freire (1972) argues it, is born through an examination of dialogue as a human phenomenon whereby word is the essence of dialogue. Freire (1972) points out that word is not merely an instrument that makes dialogue possible, but that within itself word has two dimensions. Freire (1972) names the two dimensions as reflection and action. Reflection and Action exist in a radical interaction so that even a slight deviation in one, is resultant of a major shift in the other (Freire, 1972). Depriving a word of its dimension of action is to engage in mere verbalism, hollow words, and an unauthentic word is unable to transform reality, for denunciation of the world is not possible without a commitment to transform, there is no transformation without action (Freire, 1972). Yet action emphasized exclusively, converts word to activism (Freire, 1972). Action, for the sake of action, negates the true praxis and thus makes dialogue impossible (Freire, 1972). In either case, the original dichotomy is reinforced, and as unauthentic forms of existence are created so too are unauthentic thought forms (Freire, 1972). In this way, Freire (1972), in his discussion on praxis, by an examination of word, is also saying that thinking that is transformative, is dependent on reflection and action. Heidegger is saying the same thing

\begin{abstract}
Every thing depends on the step back, fraught with error, into the thoughtful reflection that attends the turnabout that is prefigured in the destiny of Being. The step back from the representational thinking of metaphysics does not reject such thinking, but opens the distant to the appeal of the trueness of Being in which the responding always takes place.
\end{abstract}

(1968, p.197)

Action then, in its dialectical relationship with reflection depends on the step back, the ability to respond, in the way I have described in the previous section of this chapter. It is the use of will, and 'to will', as a verb and not noun, that is about choosing. Making a choice and then doing it, is action. This then is thinking that stems not from the empirical analytical nature of man, but arises from the core of our being and which is accessed by being-human, in that, we can feel that then is the choice to be willing to be more by feeling love in response to whatever is felt.

Thought is what we are called to do, and do in such a way that we can be conscious of what calls, "the presence of what is present, what is present in presence" (Heidegger, 1968, p.244). When we focus we can illuminate, and so we touch the essential nature of thinking, 
the Being of beings Heidegger, 1968). When in this rhythm or flow of thought, this is when the gift is given, and such thinking recalls, thanks (Heidegger, 1968). Life is a gift. "Thinking is thinking only when it recalls in thought the unspoken, tacitly, and it is this which is the duality of beings and being" (Heidegger, 1968, p.244). To think is innate. It has been there since the beginning and, while in our memory, at the same time it is our memory. Our memory is integral to the knowing of what it is we need to think about, and therefore we call forth that which will assist us in the process of thinking. In being we can touch more of our Being, as a human-being. We cannot do this without each other, and so we are connected so that we cannot, not think.

To exist humanly is to name the world and change the world (Freire, 1972). Human existence cannot be silent and so, when named, the world appears to the namers as a problem and thus requires of them a new naming (Freire, 1972). "We are not built in silence, but rather in word, in work, in action reflection" (Freire, 1972, p.61). Thus dialogue is an encounter among people who name the world, and is about the liberation of men (Freire, 1972). It is an act of creation, for the process of naming the world does not exists without a profound love for the world and men (Freire, 1972). Love is both the foundation of dialogue, and at the same time is dialogue (Freire, 1972). Love that is to be made real in the human condition, for as Freire (1972) says, it is an act of creation that cannot occur without a profound love of the world and men. A profound love realised through a connection that is within and with one another.

This notion of connection, I argue, is the connection within our being, and the connection to beings lived out through the connection to each other. It is our spirituality expressed in the connection between human and cosmos, felt by the interconnection between people. The interpretation of other is that of known, in a transcendent relationship where on one hand there is connection, and on the other, a separate existence. In the state of Being, it is a state of connection that can be represented as human and cosmos, and therefore when not in a state of Being, that then is the nature of duality. Then we are not connected/aligned/balanced and then "the presence of what is present, accordingly keeps and guards within itself as what belongs to it" (Heidegger, 1968, p.242).

Yet it is precisely this duality which emerges from a unity which is concealed, of the presence of what is present, which sets out the call. This is what Aletheia calls us to do. The essence of who we are, the core, draws forth and engages in existence in such a way that there are opportunities to uncover that which is concealed. So even in a state of duality we are still connected, so we cannot, not think. It is our interconnection that holds the potentiality for 
remembering, our memory, of what is required to be thought about. This is Freire's (1972) profound love of the world and men. Wherever we are, however we are, we are always where we need to be. There is no such thing as the wrong place or wrong people. For our intuition, our inner tutor, is also the Spiritual Law of Opportunity in action so that we are placed in the exact conditions that give the required opportunities for soul growth and development. How long we remain, however, is determined by our thinking. It is the effect of our praxis. It is our choice, to chose to respond or react.

\section{Nursing as a dialectic of thought and action}

In a discussion of presence Paterson and Zderad (1976) attempt to portray their insights through a description of presence. "The qualitative differences in the various experience of presence that deserve, yet almost defy, description. The presence seems to have a different quality of intimacy. It is seen as the patient's vulnerability. As a nurse I find my presence flows through a filter of therapeutic tact" (Paterson and Zderad, 1976, p.31).

Thus there is the recognition that vulnerability is a key to presence, and also the understanding that presence flows through filters or layers. In nursing we experience moments of reciprocal flow. I argue that these are the flashes or peeps into reality translated as therapeutic tact and felt as connection. These moments reflect the degree of expansiveness of the macrocosm, but are created within the microcosm through the human to human interrelationship. On one hand, I argue, they reflect the ability to move into this space as a known that few know. On the other, having called an experience as a potentiality of presence is then the outcome of having responded to one's own call of being. And so while these moments reflect a separate existence, paradoxically, and here-in is the magnificence of it, when two or more beings come together and think in the way I have desribed, then what can be experienced is love - a different quality of intimacy that deserves yet almost defies description. Where that love is the outcome of thought and action because in that moment the human mind is suspended to allow the response to being. In this state there is vulnerability, but in this state lies the true power.

The loving person is not rebellious, but accepts the heart. The heart is two curves coming together, sinking into each other and fusing. The heart is not two counter forces that stop each other. The heart is a flaming jewel of life that has beautiful colours, emanates waves, and inundates the human being with messages. It is in effect a state of creation.

Pierrakos (1987, p.253) 
Thinking, as process, begins in our structure of family, and is then created and recreated in adult life. Teilhard de Chardin and Nietzche (cited in Paterson and Zderad) viewed being as man's fundamental project, and in this way there is no fixed nature per se, but rather "each person takes on a mode of being in his world dependent upon his degree of freedom, and the how and what of the world is presented by his family and perceived by him" (Paterson and Zderad, 1976, p.45). This is the Spiritual Law of Reincarnation. In other words, we incarnate into families that reflect the degree of freedom within our own being, therefore engaging in our own reflections or patterns, held unconsciously, but created in our engagement of being human. As limited beliefs they are boundaries/filters/blocks, limitations based upon fear. We then move into the world and the world I am speaking of is nursing. To perceive that a nurse is synonymous with nursing is to lose sight of the fact that the nurse is a human being necessarily related to other human beings (Paterson and Zderad, 1976). The nurse is also her history, the nurse, as a human-being, is also required to think.

Each time a nurse calls it is thinking that as memory is attached to a particular emotion, then she too can continue to act in a way that reflects her old code or pattern so as to repress, project or deny that emotion which at some point in her history she has deemed bad, and therefore judged. She had alienated herself from her core. The Isness of that now moment, which just is, is then no more. But in the first instance, as I have already explained in the process of reprogramming, in choosing to allow the feeling of that emotion, then in that allowance what is allowed is, the presence of the presence. It is a response to her own call of Being, that lies embedded in the relationship with another human being. In the allowance of what is, then there is a quality of intimacy that is felt. It is lovemaking. When two human beings, nurse and patient, experience this depth of relationship, it does defy description, and yet it is known.

Therefore, we call ourselves to one another energetically in the mutual process of pattern making, to (re)think. And as we think we empower ourselves. As empowered nurses we are more able to assist others in empowering themselves, to assist others in their process of thinking. As I remove my filters/blocks then I know how to assist another in their process of removing their filters/blocks. This I perceive to be Nursing's true service. For in freeing myself, I refract my light. I am no longer a reflection of an image, because I am that image in it truer sense. In this unconfused state what I am is more love. The more love I am being, the more love can love through me.

And so from the core of my being I call, I AM that, and response to being is, that I AM. As I AM, so it is. 


\section{Summary}

This chapter has began to explore the nature of thinking, from both an unconscious and conscious perspective. This chapter has taken the position that most thought is unconscious and that the world is perceived through filters created from 'what has been thought about'. These filters about reality represent levels of consciousness. As such, creation is mostly an unconscious act created from these perceptions or distortions about the nature of reality.

In this way this chapter is positioned to identify how to begin to make thought/intent conscious that then hinges on the ability to respond to life emotionally and in so doing create a new view.

Nursing is presented as a dialectic of thought and action. As such the human/reactionary mind is suspended to allow this response to being from being. This response, a movement from the whole. 
In this way I wish to continue to focus on how our emotions are connected to the process of clearing our minds through clearing out whole being by being and as such make manifest an expression of love. How we process our emotions, determines not only what we see or how we see, but also, what we create. Love or fear. "I say again, by which the mind affirms of its body, or any part of it, a greater or less power of existence than before" (Spinoza, 1677 / 1952, p.421).

Spinoza (1677) views the body and mind as one, and in this way the body is in the mind and the mind in the body. It is the affect which creates an image in the mind. This he argues, is 'a confused idea', it is not pure thought. "An affect or passion of the mind is a confused idea" (Spinoza, 1677/1952, p.421). As such, it is the mind that suffers, for it has inadequate or confused ideas and as such the idea of the body is then created by the affect. In other words, our minds are not clear, our bodies are not clear. By our engagement in life, we lay down an experience. Recall Roney-Dougal's (1991) point that our subliminal mind has the capacity to take in billions of information at once and in this way we memorise, we store it, as an affect. What we lay down/store determines not only how we see the world, but is our image of the world. In this way. we programme our minds, we create our thoughts and beliefs. We are our own programmers. The idea of the body having been created by affects. Where the process of the affect creates the image, and then that is what we in fact become, the image we create is dependent on what we do with an affect (Spinoza, 1677). Energy follows thought. The system has reached the point of chaos. Reality has become so distorted because thought is confused. . It is thought reflected through the body that as confused thought is dis-ease. In this way I am saying that dis-ease is an image of the mind made manifest physically.

but this idea, which constitutes the form of an affect, must indicate or express the constitution the body, or of some part of it; which constitution the body or any part of it possesses from the fact that its power of action or force of existence is increased or diminished, helped or limited. .... But the idea which constitutes the form of affect affirms something of the body which actually involves more or less reality than before

Spinoza, (1677/1952, pp.421-422) 
In other words, Descartes' famous quote, 'I think, therefore I AM'. I become as I think. As I think so I am. For as God, as I have already argued in the preceding chapter that we are God in motion, we are the Creators of our reality where the purpose of life, of our being human is to realise [make real] our God state. This Godliness is not something to be bestowed upon death it is something that coexists with our embodiment.

At this point in the research, I came to fully realise that in working with the affects [emotion embedded in my data and reflected through life] I was unconfusing myself, and so unconfusing my mind. I was clearing my mind and clearing my body, so that the mind of God and my mind could move closer to becoming the same mind. To accept that I was the creator of my reality had been my first challenge. To then think of myself in terms of god was the next, but to entertain the idea that my mind could be the same mind as god's, challenged every thought I had ever had about who I was. "If you go deeply enough into your mind, and deeply enough into mine, we have the same mind. The concept of a divine, or Christ mind, is the idea that, at our core we are not just identical, but actually the same being" (Williamson, 1996, pp.30-31). My perception of reality was shattered. And yet, the yearning for union is depicted in so many ways in so many writings down through the ages. Still, it was something I could barely contemplate.

As above, so below, as below so above is recognised as a Universal Law. I proceed with the word law very cautiously because in the interpretation of a thing as law historically humankind has created rules that then determine the rightness or wrongness of a thing. In other words, we have equated law with judgement. I am also cautious of using the words first principle or ultimate cause in relation to law as this then leads the discussion into a debate on a Being of beings. In the same way that there is an inherent rate at which my heart beats, so too is there an implicate order about the universe and expressed in many forms eg Reciprocity. What determines what that order will look like at any given moment is as this thesis is arguing, our thoughts, but that the order exists is certain.

Therefore, below and above can be interpreted as human and the cosmos, but also above and below can be interpreted in the physical sense, as above - our brain, and as below - our body. Candice Pert's (1997) opiate receptors found in the brain as well as in a big toe illustrate this point. In this way above and below are not only heaven and earth but brain and body as they relate to a reflection of mind. As such the mind below and the mind above can be, as it is above so it is below. Where true mind is non-spatial, and access to the realm/plane of true mind is through our feeling state. 
In prayer, having completed the last portion of the third part of the Summa, St Thomas was witnessed to be raised several cubits in the air. He had prayed, fasted and given penance to be preserved from error in doctrine. In having completed the work he asked that he might have grace to know if what he had written were the truth - his levitation was in response to the answer (Cavanagh, 1890). C J Rolling when told that her first Harry Potter book would be published experienced the same phenomenon. She jumped so high that she touched a twelve foot ceiling.

Such propulsion is the result of energy expressed. In order to express energy, and everything exists as energy, then thought too must first exist as energy/consciousness which in order to be expressed must first be felt.

$\ldots$ as Thomas [Aquinas] was saying mass ... in the presence of .... he fell into such a profound ecstasy, that a long time elapsed before he could be restored to himself. ... saying that what he has seen and heard had filled him with wonder.

(Cavanagh, 1890, p.152)

This wonder and ecstasy is then contrasted against the puny set of beliefs we create with our reactive minds but which serve as the real block between our unconscious mind and universal mind so that we perceive ourselves as separate from that which we truly are - God, I AM, and therefore, I think.

The process, then, is a process of decoding embodied knowledge by allowing the body to communicate with the mind. For as I have argued the body is a reflection of the mind which exists spatially, that is the body is located in physicality whereas the mind is not. Therefore, we experience life through our bodies as we store the stories of life. Hence the sensitivity to initial conditions as the characteristic inherent in chaos, and memory as past, but not past, but presented in the present. In this way, we begin the process of re-educating the subliminal or reactive mind so as remove the filter/block/distortion. In other words, allowing one's self to feel the affect because as was stated in an earlier chapter, the ego cannot feel. The confusion of the mind has been an act of ego in how the affect was processed in the first instance. The ego uses judgement, fear and doubt to confuse the reactive mind as the reactive mind strives to maintain consistency. In this way I came to realise that that is how we as human being keep ourselves separate to that which we are. In allowing myself to feel the affects [emotions] and then work with an affect differently then it is as Spinoza has said. 
But it is to be observed, that when I say greater or lesser power of existence than before, I do not mean that the mind compares the present with the past constitution of the body, but that the idea which constitutes the form of affects affirms something of the body which actually involves more or less reality than before.

Spinoza, (1677/1952, p.422)

By the process of decoding embodied knowledge, by removing the filters, we come to know.

Moreover, since the essence of the mind consists in its affirmation of the actual existence of its body, and since we understand by perfection the essence itself of the thing, it follows that the mind passes to a greater or less perfection when it is able to affirm of its body, or some part of it something which involves a greater or less reality than before.

Spinoza, (1677/1952, p.422)

And in a reality which is greater than before, what is seen energetically is a change in pattern. This process is Augustine's (354 -430) (cited in Arendt 1929/1996) coinciding of will and power in God's case, and while the hidden variable is no longer hidden, and thus termed in quantum physics a collapse of wave function, the wave does goes on. By removing the filters or blocks, the process is but the expression of will and power, and the wave has changed pattern/frequency - a new wave form. It is Martha Rogers Principle of Resonancy, The continuous change from lower longer wave to higher shorter wave frequency patterns in human and environmental fields (Rogers cited in Malinski and Barrett, 1994).

Therefore, in speaking of the power of the mind, Spinoza (1677) is not referring to intellect or logic, but rather he is speaking of the decoding process of embodied knowledge to change the dialectic of body mind whereby thought becomes object. Object in this sense meaning 'an unconfused idea', in other words - pure thought, the mind of God, the River of all Knowing, Universal Mind. 
When therefore I have said that the minds power of thought is increased or diminished, I have wished to be understood as meaning nothing else than that the mind has formed an idea of its body, or of some part of its body, which expresses more or less reality than it had hitherto affirmed of the body. For the value of ideas and the actual power of thought are measured by the value of the object.

Spinoza (1677/1952, p.422)

\section{Thought as pattern}

I began chapter four with a discussion on the human aura. The word aura is a Greek word meaning breeze (Pierrakos, 1987). The human aura was defined earlier as "the combined manifestations of body, soul and mind" (Kuthumi cited in Prophet, 1991). The history of a person's life, as well as the present situation, can be observed in the aura (Pierrakos, 1987). Pierrakos (1987) goes on to say that pain as systemic and enduring as rejection in infancy, or as localized and transitory as a tooth extraction can be observed in the human aura. Thus our lives are literally displayed in our aura. Each experience has been laid down in such a way that we create our own life map, and our maps are made up of unique patterns and colours. Each of us, like Joseph, has a coat of many colours. "The person appears to swim, as in a fluid sea tinged rhythmically with brilliant colours that constantly change hues, shimmer and vibrate" (Pierrakos, 1987, p.74). In the same way that it is possible to view this planet from space, or view space as we stand on the earth and gaze at the night sky, so too can we see our own map.

In describing the pulsation of the aura, Pierrakos (1987) says there are three phases. In the first phase the aura swells for one or two seconds away from the body, reaching a distance from two to four feet, and then loses its distinctness by merging with the surrounding environment, in other words the aura of everything else. At its peak, the aura is oval with fringed edges, and when this peak stage has been reached the aura retains it oval form for about $1 / 4$ of a second, to be then followed by a second, very rapid phase of about $1 / 8$ to $1 / 5$ of a second where the aura becomes contracted. Finally, there is a resting state that lasts from one to three seconds and after which the whole cycle of expansion and contraction recommences. The cycles normally occur about 15 to 25 times per minute. However, the frequency of pulsation, vibrancy of colour and degree of extension are all enhanced with 
excitement (Perriakos, 1987). When the body goes into vibration as a result of deeper breathing and strong emotion, the effects are a rise in rate, an increase in the width of the field, and a brightening of the colours (Pierrakos, 1987). Further, in a group where there is 'a strong communication', the individual rate rises to about 50 pulsations a minute extending outward to fill the space, and then there is a merging of energies so that a new energy mass envelops the group (Pierrakos, 1987). This new energy mass is "more than the sum of the individual consciousness's, and spirals into and through the contributors as well, again because energy flows undivided" (Pierrakos, 1987, p.74).

Pierrakos (1987) then goes on to give a detailed and fascinating description of the layers of the aura and the pattern of their movements, saying that while movement in the three layers is simultaneous they can in fact be reduced to two summative patterns. Most interestingly these two patterns are a longitudinal figure 8 and a perpendicular pendulum swing (Pierrakos, 1987).

The pendulum is easily recognised as a symbol of balance, the movement from one extreme to another the midpoint representing balance. Also in a side to side movement, left to right, could it also represent the feminine and masculine aspects of an energy? The figure eight might be conceived of as a continuos cycle of movement away from and then toward as an infinite cycle. If so, then reviewing the Universal Laws of Correspondences introduced in the previous chapter, and which are said to guide the evolution of humanity and therefore behind all material manifestation, then 'As above so below, so below as above', in it parts, are represented by these two auric movements and become the Law of Equilibrium [the pendulum] and, the Law of Karma [the figure eight]. In other words, our natural state is union with every other atom resonating to Universal Law, Divine Law, God, and that we inherently move ourselves towards this state in every breathing moment of our physical existence, no matter what motion we have given to the laws, is certain/predictable. We are not free not to be free.

Therefore, what I am saying is, it would appear that as we live and breathe there is an unconscious process at work that is guided by a grand map. Moreover, while each person has a little local map, there is embedded throughout the whole universe the knowing of this grand map. The chalienge of our lives then is about making the local map and the grand map, one and the same. In this way all of our pulsations, seen etherically as the wave patterns of our aura, evidenced biologically as the vibration of receptors and ligands as they send information to the cell, and some insight into particle activity of a black hole, I argue, are all 
expressions of the same phenomena, that is, the expression of the movement toward God consciousness.

The patterns that guide this process are governed by our thought. Thought, I have argued, while a product of mind and manifested by the physical brain and then expressed as consciousness, has its origins in feeling. What we feel is what we are in fact thinking at the subliminal level. This then is how we create the patterns in our auric fields that give motion to the waves. Where there is a confusion of the mind - a block or filter, the energy appears distorted, the colour lacks vibrancy and the particular colour is indicative of what the block pertains to. This pattern of energy is what then in the outward pulsation mingles with the energy of all things to attract more of the same energy that is then translated into life experience. In this way, we draw to ourselves an experience in order to remove the block or filter as we strive to create the pattern of the grand plan. Everything exists because energetically it exists, and in this way, as I have already said, we are the Creators of our experience, of our reality. The figure eight and the pendulum are that which assists us to do so, and therefore all experience, all experience, is a divine blessing and it is only our judgement of it that deems it anything less.

I have often struggled with the meaning of life is a gift. From the perspective that in every moment there is the potential of a present, a gift, through the presence of the presence, I can at last see how life can be a gift. In the knowing that all is a divine blessing at last I can accept life as a gift, for every experience is to be valued, whether I have understood the lesson or not.

In saying this then, the concept embedded in fractal geometry now becomes more clearly apparent. Where after a certain value the periodicity disappears, as was discussed in chapter three and the number of cycles become infinite or chaotic, it is this that makes clearer the form of thinking that engages us in an analysis of life experience. It is what is done when we attempt to identify common themes, when in truth an experience has been created by an individual in order to feel a particular feeling. This is how we perform each iteration. By repeating an operation using the last result of that operation as the input, in this the way we can repattern oursleves. Each time I do so my local map begins to look more like the grand map. As I re-pattern my mind's power of thought is increased. Not in the sense of generating the precepts, but in being 'open' to receiving them.

Pierrakos (1987) does not speak about the direction of flow. I would suggest that as the pendulum swings back and forth, the top circle of the figure eight, when looking at a person 
front on, would move in an anticlockwise motion, while the bottom circle would move in the opposite direction, that is, a clockwise motion. These movements, I argue, are Heideggers (1971) fouring of the fourfold in action. Each swing of the pendulum left to right, and each circle top and bottom rotating to draw energy into our being, and is what is meant by gathering, that is the creation of experience so that we might 'thing' in order to think.

\section{Reaction versus response}

In his discussion on the core, Pierrakos (1987) describes the core as,

The core is the human being's whole capacity, a glowing, vital mass, both the source and the perceiver of life force. The core has complete unity. No duality can exist at this first level of reality, no either-or, no good-bad. It is an indivisible vibratory operation, a process in which every person knows the truth instinctively by sensing the pulse of life. The qualitative characteristics of the core's movements are the primal positive emotions, or movements to make contact and unify with the outside world. These can be summed up as one supreme expression: love.

(1987, p.25)

Two other layers cover that innermost reality. The layer closest to the core is said to be that which contains the negative primal emotions, and the outermost layer is named as a state of distorted reality. These two layers effect energy flow from and into the core (Pierrakos, 1987). In health there is a free flowing of energy into and out of the core. The layer closest to the core represents our ability to "counteract external force moving inward and to alter core force moving outward" (Pierrakos, 1987, p.21). The outermost layer is the area of defense and mediation between forces moving in both directions (Pierrakos, 1987). The inner self is represented by the first two levels, whereas the outer layer is a mask of distorted reality which Pierrakos (1987) says is a necessary filter, but none-the-less the world of illusion.

The negative unconscious impulses or negative primal emotions that are unified, controlled and organized by the ego and super ego, as suggested by Freud, are contained within the second level and brought into action to negate the positive impulses of life from level one, 
regardless whether these are from inside or outside the being (Pierrakos, 1987). It is important to emphasise here that when speaking of positive and negative I mean as energetic charge, as outlined in chapter four, not in a dualistic sense of right and wrong or good and bad.

The core, Pierrakos (1987) says, has no faculties for dealing with excessive calls or attacks on its substance, nor is it able to answer frustrations or rejections of its pulsatory flow. In other words, it emits energy and receives energy, energy that flows through two other layers. The primal negativities and their distortions from layer three serve the purpose then of protecting and affirming life, expressing life and responding to the dualities in existence (Pierrakos, 1987). Freud saw these as death instincts, and Reich as intrinsically pathological forces, but Pierrakos (1987) says they are neither, and what they represent is the perceptual intrusions that our energy has to battle on its integrity. In other words, love contrasted against everything that is not.

The energy in the second layer is altered, condensed and slowed in its vibrations, but when compared with the compression and deceleration in the energy of the fixed stratum of the defensive perimeter made up by the third layer, it is fluid in form (Pierrakos, 1987). The peripheral or third layer encompasses the element of self-consciousness, the ego as the agency of self-aware thought and outer will, in which the influences of the ego's conscious perceptions and decisions is embedded (Pierrakos, 1987). This I argue is the same meaning as I have outlined in the previous section where I stated that the challenge is to remove the blocks in our process of becoming. The blocks having been created in the first instance by our interaction with life, and in that way are our past, I am my history, and so I am also my memory that is then presented as the present. The third layer or defense perimeter, is both the ego's self-aware powers, or volitional thinking, as well as the area of negation or denial (Perrakos, 1987). As we begin in early childhood to control the flow of energy into and out of our whole being, we disrupt the flow of energy from levels one and two so that they become, in Reich's term, energy blocks (Pierrakos, 1987). "Blocks are stagnated pools of vital substance that accumulate in the defensive perimeter and armor it in dysfunctional patterns that Reich named character structures" (Pierrakos, 1987, p.24).

Pierrakos, (1987) in his work with Alexander Lowen, then makes an important observation which I believe to be crucial in the process of working with the flow of energy from and to the core. "We have a choice as to whether to continue to maintain the pain", (Pierrakos, 1987, p.24). It is a matter of will, which appears most strongly in the defensive perimeter, whereas volition/choice is evident through all three layers because of a persons 
psychosomatic identity (Pierrakos, 1987). In other words, we are being told that what makes the difference as to whether we cling to our old perception of reality, the maintenance of constancy, or open to the clearing and thus a greater power of the mind/more reality, is our ability to choose. In order to do so, it is a matter of will. To be willing. Will as determination [noun] is judgement, but will as command [verb] means direct/straight, and therefore is - uninterrupted flow. In this way will, as an act of consciousness, in fact becomes consciousness, and is expressed in quantum physics as psi, or the hidden variable involved in the collapse of wave function. This is how we truly make manifest. We chose to be willing, or not.

Therefore, in our reacting or responding to life lies the key to our becoming. The interaction of the three layers is such that, as energy, we create patterns that are then translated into experience for the purpose of feeling something. When we have perceived something as bad, we have judged our experience. In essence, as I have already explained, we have judged ourselves. How we have perceived our experience is attached to a particular emotion. Each time we create an experience that becomes the catalyst to feel a feeling and we react to what is felt, the result is that we maintain our constancy. For the ego, in its part of maintaining conscious awareness and perception, has hooked the reactive or subliminal mind into the old perception of reality. We chose to feel a feeling, and so can also make a choice to deny, repress or reject that feeling in the first instance.

In responding, by choosing to feel a feeling, the purpose of an experience what we are in fact doing is engaging in an allowance of being. This allowance of being is also an acknowledgment because it is a reminder and in that way a re-membering that the core has unity, that duality is not real.

In acknowledging the self, it is an expression of unconditional love of the self. That acknowledgement exists no matter what the feeling - from this feeling of disapproval I have gained ..., and in that way, the feeling is acknowledged/validated. As such it is the actioning of, unconditional love, non-judgement, and allowance. "Our inner balance of harmony and truth is strengthened by our triangle of non-judgement, allowance and unconditional love" (Tikashi, 1994, p. 33). As balance, it is the pendulum in motion. The Spiritual Law of equilibrium. As the pattern of the figure of eight in motion or the Spiritual Law of Karma of Cause and Effect, a new cause can come into play. We are now free to experience something anew in order to feel different feelings. And so each time we choose to feel something different, and then do it, we are reprogramming ourselves. We can stop running the old programme/story/perception of reality as we move on in our process of pattern making, or 
creating as method. In so doing, we increase the power of the body and mind. In this knowing then, there is the knowing that in letting go of the little local map there is something guiding us toward a larger grand plan.

\section{The Teacher Within}

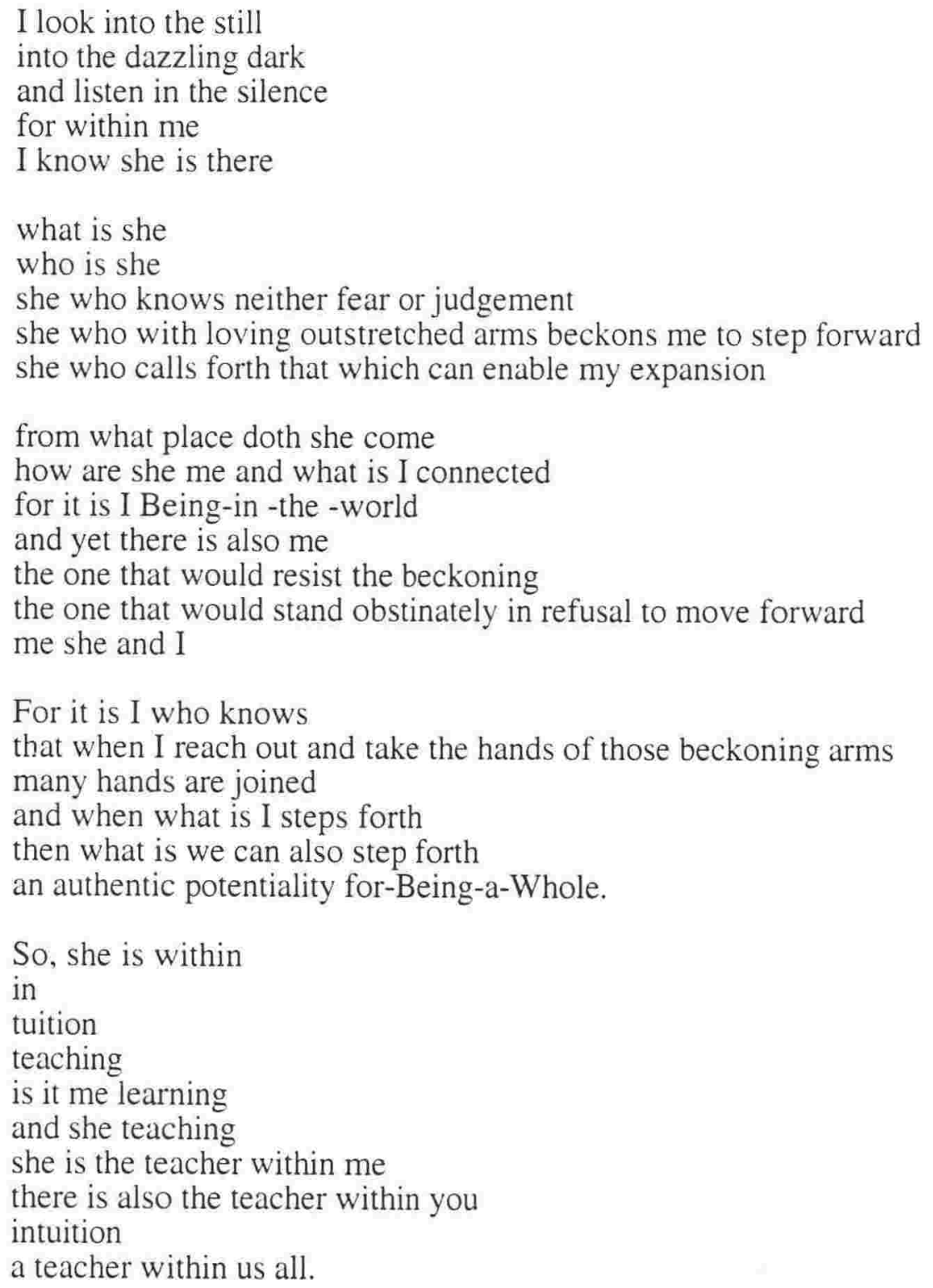

Tucakovic (1996)

Since Aristotle philosophers have pondered on, and articulated notions of, what thought or thinking is. Heidegger, in his exploration on thinking makes the point that "what keeps us in our essential nature holds us only so long, however, as we for our part keep holding on to what holds us. And we keep holding on to it by not letting it out of our memory" (1968, 
p.3). The word thinking comes from the word Thanc, which means memory. Memory, Heidegger (1968) defines as thought which is gathered, and because memory is the gathering of thought, we give it thought, as that is what is required to be thought about. "What is thought is the gift given in thinking back, given because we incline toward it" (Heidegger, 1968 , p.4). In our inclination toward thinking, this then calls thinking forth.

Memory is the corpus of unconscious material observed by Pierrakos (1987) in the defensive layer or layer of illusion/distortion and that I have argued is experience laid down that then is attached to a particular emotion. Further, this assertion concurs with Augustine's view that on one hand human life owes its possibly positive aspect to its past alone (in that we have come from nothing and to nothing we shall return) but memory becomes the real possibility of holding on to the past and of arresting transience (Arendt, 1996). "This is because in memory the past is not pure past, but the past is presented as present" (Augustine 354-430, cited in Arendt 1929/1996, p.73).

Heidegger suggests that in order to think we need to learn, and it is by "disposing everything he does", that what is essential is then learned (1968, p.4). So we call, in the same sense we now call what in itself is to be thought about, and in this way it is thought provoking. For what is thought provoking is in fact what creates the opportunity to think and, at the same time, in a sense is that which is thought provoking, is that which is intrinsically what must be thought about (Heidegger, 1968). In other words, we call forth that which we need to learn, not what we think we need to learn. I argue that the call is from the core, and in this way it is thought released as energy. Physiologically then, it is what is represented by the receptor ligand connection, the information that a cell receives and by which cellular function is influenced, and is what has occurred as process. In that way, life is the answer to the call.

As has already been outlined, how we respond to the call determines what we learn/the information the cell receives/whether the power of the mind and body is increased/our ability to see more reality/the expansion of our consciousness/the movement back to things themselves/Aletheia/ the closer we are to nothing, the black hole becoming a white hole but not as entropy per se. "Most thought-provoking, what remains to be thought about always, because it is at the beginning, before all else" (Heidegger, 1968, p.4). Even so, says Heidegger (1968), we are still not thinking, although he does concede that the world is becoming more thought-provoking. We are reminded that we need to move beyond proposing what ought to be and how it out to be done, for what is lacking is not thought, but action (Heidegger, 1968). Heidegger (1968) does however make the point that where we focus our thinking needs to be reviewed, while cautioning that action is not to be interpreted 
as mere action, because for centuries "man has acted too much and thought too little" (p.4). It is here that I am reminded of Paulo Freire's (1972) discussion of the word, praxis.

Praxis, as Freire (1972) argues it, is born through an examination of dialogue as a human phenomenon whereby word is the essence of dialogue. Freire (1972) points out that word is not merely an instrument that makes dialogue possible, but that within itself word has two dimensions. Freire (1972) names the two dimensions as reflection and action. Reflection and Action exist in a radical interaction so that even a slight deviation in one, is resultant of a major shift in the other (Freire, 1972). Depriving a word of its dimension of action is to engage in mere verbalism, hollow words, and an unauthentic word is unable to transform reality, for denunciation of the world is not possible without a commitment to transform, there is no transformation without action (Freire, 1972). Yet action emphasized exclusively, converts word to activism (Freire, 1972). Action, for the sake of action, negates the true praxis and thus makes dialogue impossible (Freire, 1972). In either case, the original dichotomy is reinforced, and as unauthentic forms of existence are created so too are unauthentic thought forms (Freire, 1972). In this way, Freire (1972), in his discussion on praxis, by an examination of word, is also saying that thinking that is transformative, is dependent on reflection and action. Heidegger is saying the same thing

Every thing depends on the step back, fraught with error, into the thoughtful reflection that attends the turnabout that is prefigured in the destiny of Being. The step back from the representational thinking of metaphysics does not reject such thinking, but opens the distant to the appeal of the trueness of Being in which the responding always takes place.

(1968, p.197)

Action then, in its dialectical relationship with reflection depends on the step back, the ability to respond, in the way I have described in the previous section of this chapter. It is the use of will, and 'to will', as a verb and not noun, that is about choosing. Making a choice and then doing it, is action. This then is thinking that stems not from the empirical analytical nature of man, but arises from the core of our being and which is accessed by being-human, in that, we can feel that then is the choice to be willing to be more by feeling love in response to whatever is felt.

Thought is what we are called to do, and do in such a way that we can be conscious of what calls, "the presence of what is present, what is present in presence" (Heidegger, 1968, p.244). When we focus we can illuminate, and so we touch the essential nature of thinking, 
the Being of beings Heidegger, 1968). When in this rhythm or flow of thought, this is when the gift is given, and such thinking recalls, thanks (Heidegger, 1968). Life is a gift. "Thinking is thinking only when it recalls in thought the unspoken, tacitly, and it is this which is the duality of beings and being" (Heidegger, 1968, p.244). To think is innate. It has been there since the beginning and, while in our memory, at the same time it is our memory. Our memory is integral to the knowing of what it is we need to think about, and therefore we call forth that which will assist us in the process of thinking. In being we can touch more of our Being, as a human-being. We cannot do this without each other, and so we are connected so that we cannot, not think.

To exist humanly is to name the world and change the world (Freire, 1972). Human existence cannot be silent and so, when named, the world appears to the namers as a problem and thus requires of them a new naming (Freire, 1972). "We are not built in silence, but rather in word, in work, in action reflection" (Freire, 1972, p.61). Thus dialogue is an encounter among people who name the world, and is about the liberation of men (Freire, 1972). It is an act of creation, for the process of naming the world does not exists without a profound love for the world and men (Freire, 1972). Love is both the foundation of dialogue, and at the same time is dialogue (Freire, 1972). Love that is to be made real in the human condition, for as Freire (1972) says, it is an act of creation that cannot occur without a profound love of the world and men. A profound love realised through a connection that is within and with one another.

This notion of connection, I argue, is the connection within our being, and the connection to beings lived out through the connection to each other. It is our spirituality expressed in the connection between human and cosmos, felt by the interconnection between people. The interpretation of other is that of known, in a transcendent relationship where on one hand there is connection, and on the other, a separate existence. In the state of Being, it is a state of connection that can be represented as human and cosmos, and therefore when not in a state of Being, that then is the nature of duality. Then we are not connected/aligned/balanced and then "the presence of what is present, accordingly keeps and guards within itself as what belongs to it" (Heidegger, 1968, p.242).

Yet it is precisely this duality which emerges from a unity which is concealed, of the presence of what is present, which sets out the call. This is what Aletheia calls us to do. The essence of who we are, the core, draws forth and engages in existence in such a way that there are opportunities to uncover that which is concealed. So even in a state of duality we are still connected, so we cannot, not think. It is our interconnection that holds the potentiality for 
remembering, our memory, of what is required to be thought about. This is Freire's (1972) profound love of the world and men. Wherever we are, however we are, we are always where we need to be. There is no such thing as the wrong place or wrong people. For our intuition, our inner tutor, is also the Spiritual Law of Opportunity in action so that we are placed in the exact conditions that give the required opportunities for soul growth and development. How long we remain, however, is determined by our thinking. It is the effect of our praxis. It is our choice, to chose to respond or react.

\section{Nursing as a dialectic of thought and action}

In a discussion of presence Paterson and Zderad (1976) attempt to portray their insights through a description of presence. "The qualitative differences in the various experience of presence that deserve, yet almost defy, description. The presence seems to have a different quality of intimacy. It is seen as the patient's vulnerability. As a nurse I find my presence flows through a filter of therapeutic tact" (Paterson and Zderad, 1976, p.31).

Thus there is the recognition that vulnerability is a key to presence, and also the understanding that presence flows through filters or layers. In nursing we experience moments of reciprocal flow. I argue that these are the flashes or peeps into reality translated as therapeutic tact and felt as connection. These moments reflect the degree of expansiveness of the macrocosm, but are created within the microcosm through the human to human interrelationship. On one hand, I argue, they reflect the ability to move into this space as a known that few know. On the other, having called an experience as a potentiality of presence is then the outcome of having responded to one's own call of being. And so while these moments reflect a separate existence, paradoxically, and here-in is the magnificence of it, when two or more beings come together and think in the way I have desribed, then what can be experienced is love - a different quality of intimacy that deserves yet almost defies description. Where that love is the outcome of thought and action because in that moment the human mind is suspended to allow the response to being. In this state there is vulnerability, but in this state lies the true power.

The loving person is not rebellious, but accepts the heart. The heart is two curves coming together, sinking into each other and fusing. The heart is not two counter forces that stop each other. The heart is a flaming jewel of life that has beautiful colours, emanates waves, and inundates the human being with messages. It is in effect a state of creation.

Pierrakos (1987, p.253) 
Thinking, as process, begins in our structure of family, and is then created and recreated in adult life. Teilhard de Chardin and Nietzche (cited in Paterson and Zderad) viewed being as man's fundamental project, and in this way there is no fixed nature per se, but rather "each person takes on a mode of being in his world dependent upon his degree of freedom, and the how and what of the world is presented by his family and perceived by him" (Paterson and Zderad, 1976, p.45). This is the Spiritual Law of Reincarnation. In other words, we incarnate into families that reflect the degree of freedom within our own being, therefore engaging in our own reflections or patterns, held unconsciously, but created in our engagement of being human. As limited beliefs they are boundaries/filters/blocks, limitations based upon fear. We then move into the world and the world I am speaking of is nursing. To perceive that a nurse is synonymous with nursing is to lose sight of the fact that the nurse is a human being necessarily related to other human beings (Paterson and Zderad, 1976). The nurse is also her history, the nurse, as a human-being, is also required to think.

Each time a nurse calls it is thinking that as memory is attached to a particular emotion, then she too can continue to act in a way that reflects her old code or pattern so as to repress, project or deny that emotion which at some point in her history she has deemed bad, and therefore judged. She had alienated herself from her core. The Isness of that now moment, which just is, is then no more. But in the first instance, as I have already explained in the process of reprogramming, in choosing to allow the feeling of that emotion, then in that allowance what is allowed is, the presence of the presence. It is a response to her own call of Being, that lies embedded in the relationship with another human being. In the allowance of what is, then there is a quality of intimacy that is felt. It is lovemaking. When two human beings, nurse and patient, experience this depth of relationship, it does defy description, and yet it is known.

Therefore, we call ourselves to one another energetically in the mutual process of pattern making, to (re)think. And as we think we empower ourselves. As empowered nurses we are more able to assist others in empowering themselves, to assist others in their process of thinking. As I remove my filters/blocks then I know how to assist another in their process of removing their filters/blocks. This I perceive to be Nursing's true service. For in freeing myself, I refract my light. I am no longer a reflection of an image, because I am that image in it truer sense. In this unconfused state what I am is more love. The more love I am being, the more love can love through me.

And so from the core of my being I call, I AM that, and response to being is, that I AM. As I AM, so it is. 


\section{Summary}

This chapter has began to explore the nature of thinking, from both an unconscious and conscious perspective. This chapter has taken the position that most thought is unconscious and that the world is perceived through filters created from 'what has been thought about'. These filters about reality represent levels of consciousness. As such, creation is mostly an unconscious act created from these perceptions or distortions about the nature of reality.

In this way this chapter is positioned to identify how to begin to make thought/intent conscious that then hinges on the ability to respond to life emotionally and in so doing create a new view.

Nursing is presented as a dialectic of thought and action. As such the human/reactionary mind is suspended to allow this response to being from being. This response, a movement from the whole. 


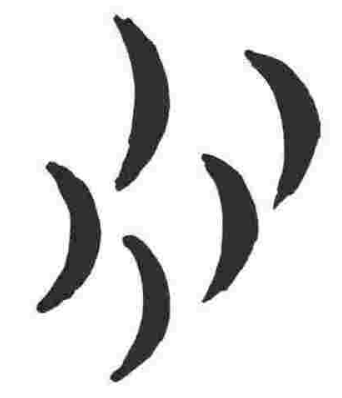

\section{Chapter 8: Beauty and the Body}

\section{Nursing's task of caring for the body}

It is extraordinary that, whereas the laws of the motions of the heavenly bodies, far removed as they are from us, are perfectly well understood, the laws of the human mind, which are under observation all day and every day, are no better understood than they were two thousand years ago. But how much more extraordinary is it that neither mothers nor nurses of hospitals, are taught anything about those laws which God has assigned to the relations of our bodies with the world in which He has put them.

Nightingale (1859, p.7)

This quotation from Nightingale, while directed at the need for knowledge about the Laws of Life so as to enable women in relation to both their own health and that of their children, at the same time recognizes that there exists a relationship between our being in a body and being in the world, and that that relationship is governed by some sense of order. Earlier in this work, reflection was presented in such a way as to suggest that the outside world is but an image of the inside world, or the other side of the same consciousness, and therefore they are One. The perception of an inside world as separate to the outside world belongs to the notion of duality.

In viewing the inside and outside as One, the external image represented in the defective household hygiene issues and infant mortality rate as made reference to by Nightingale (1895), are then a reflection of an aspect/s of the internal state of the group consciousness of the time. In other words, these images served as a reflection of an aspect of consciousness. In this way, "the laws which God has assigned to the relations of our bodies with the world 
in which He has put them" (Nightingale, 1859, p.7) and Nursing's task of caring for the body, may be more clearly explicated for the reflection still exists.

To suggest that a reflection is an image of an aspect of consciousness is to imply that each person in every bed in every hospital ward is in some way connected. This is true. Reflection is not to be confused with refraction, for until a being has held and transcended a pattern on their own body that being will continue to reflect the same aspect of consciousness to another or others. In the way that fractal geometry has served to illustrate that after a certain point prediction is possible on the basis of iteration performance, then what has been laid down on the body and where it is located on a body varies from person to person and room to room. But that those persons grouped together within a four bed room of a medical ward, where two have diabetes, the next a chest infection and the fourth a renal disease, share a commonality that is much more than the classification of pathology is certain. Furthermore, while the individual pattern exhibits some variance and therefore manifests as a different disease, the whole ward is reflecting a part of the pattern in varying stages, as does the whole hospital and its community. For Oneness is just that, Oneness. And while aspects of a pattern are what is reflected, none the less it is a reflection of the same phenomenon, a pattern that has been created by the interpretation of life experiences. Thus pattern, as the process of creation, can be [re]created, a pattern can be changed.

To do so is to know that we call an experience forth, and then move within that experience in full awareness in every now moment. For then there can be an allowance, where what is allowed is the presence of the presence in the encounter, in the exchange. In so doing, we bring forth from within ourselves an emotion, and having done so, our task is then to feel the feeling, feel that emotion. Such a process is not done alone, separate. This process is one of mutuality and for the nurse it is mostly with the persons with whom we engage in caring. The one, the human-being who is most difficult to attend, is usually the one whom we need to get to know the most because what is being reflected is the magnification of an aspect of the self that we are not willing to own. In this way, we keep our self separate from our self, and that then is reflected in the world. God, in his/her own Oneness.

Therefore, the tasks of caring for the body in nursing, the tasks that have filled our curriculums and that many in the wider community perceive to be the focus of Nursing, might then be likened to acts of grace to enable us to come together. As the tram/train ticket they have been the backgrounds to 'thing', to take the ride so that we might heal. Surely then, as we begin another century, the time has come to begin to teach "the laws that God [Universe] has assigned to the relations of our bodies with the world in which $\mathrm{He}$ [She] has 
put them". Where I interpret the laws of God to be the order of the universe, rather than a list of decrees by a supreme being.

\section{Beauty as perception}

In Book V11 of The Republic, Plato 428 B.C-348 B.C.(1952) tells the story of a group of prisoners living in an underground cave bound and chained so that they are only able to see directly in front of them. On the walls of their cave are shadows of men carrying all manner of vessels, statues and figures of animals made of wood, stone and other materials. These shadow men move about behind the chained prisoners and are divided from each other by a raised section, upon which is built a low wall. Above and behind both the prisoners and men a fire burns whose light castes the shadows seen by the prisoners on the wall. Socrates, (cited in Want and Klimowski, 1997), argued that Plato's story is a metaphor of the human condition.

The prisoners represent Man witnessing the fire of divine truth through layers, thus inhabiting and experiencing a mere semblance of true reality, which in essence is unity. That the state of unity [wholism] may be [re]attained, is the assertion of inquiry, whether it be Philosophy, Theosophy, Mysticism or Religion. It is the arguments as to how this state is attained that differ.

Platonic philosophy argues that unity involves a series of reincarnations and in that way man approaches unity. Christianity views unity as the outcome of how the one life is lived, but then asserts that outcome is either heaven or hell. Mysticism is the search for God through contemplation and self-surrender, while Theosophy is the knowledge of God by spiritual ecstasy, direct intuition and is said to seek Universal Brotherhood/Sisterhood.

In the first part of the Transcendental Doctrine of Elements, Transcendental Aesthetic, Kant (1724-1804, 1952) argues by "whatsoever mode, and by whatsoever means, our knowledge relates to objects it is at least quite clear that the only manner in which it immediately relates to them is by means of an intuition, an intuition only taking place as the object is given to us" (p.23). Kant then reiterates that an intuition can only take place in that it is given. The object then [a]effects the mind in a particular way (Kant, 1952). The capacity for receiving representations is called sensibility (Kant, 1952). Objects then are given to us, and this alone furnishes us with intuitions, understanding that they are thought from which conceptions arise (Kant, 1952). In other words, we receive thoughts that affect the mind and then arrange 
these thoughts into concepts. Therefore, thought does not originate in the mind, but rather the mind organises thought, and therefore in its original sense, thought is object.

At this point I would again state that this thesis has been very careful in distinguishing the use of word affect and effect. While I have attempted to make clear that an affect, as a noun, has been used to denote an emotion/passion/movement, I find it most interesting that Kant uses the word affect that can be interpreted as both a verb and a noun. "The effect of an object upon the faculty of representation, that is, the effect of thought on the mind, so far as we are affected by the said object, is sensation" (Kant, 1952. p.23). In other words, what is received as thought is felt. But this in itself is not enough, and Kant (1724-1804) continues his discourse to make a distinction between intuition that is empirical and intuition that is pure.

$\ldots$ in so far as we are affected by the said object, is sensation .... where the undetermined object of an empirical intuition is called phenomenon. That which in the phenomenon, corresponds to the sensation, I term its matter; but that which effects that the content of the phenomenon can be arranged under certain relations, I call its form."

Kant 1724-1804 (1952, p.23).

It is here that Kant then makes an important distinction between intuition that is termed empirical, and intuition that is pure or transcendental. According to Kant, (1952) sensation is not an arrangement which is then represented as form, for this is a posteriori, and therefore he terms it empirical. But sensation that is true intuition is an a priori, "wherein nothing is met with that belongs to sensation ... in which all the manifold content of the phenomenal world is arranged and viewed under certain relations ... as a mere form of sensibility, and without any real object of the senses or any sensation" (p.23). The clue is in the word sensibility. In other words, intuitions that are perceived belong to the realm of a priori, and therefore true intuitions whereas intuitions that are sensed are a posteriori and in that way are phenomenon arranged according to how we perceive the word. As I understand it then the question is Object as object, or object as subject?

As subject, these intuitions belonging to the realm of matter and are therefore bound in time and space - hence Kant's (1954) use of empirical. As object, they are beyond time and space, and therefore are pure forms of thought, in other words, feeling. It is in the 
arrangement, which is represented as form, that speaks to thinking which is conceptual, as well as the notion introduced in the previous chapter, where impressions received are filtered as the mind strives for constancy (Roney-Dougal, 1991). And so while thought is attached to emotion, then as this thesis is arguing true thought cannot be 'brought through'. So on one hand we can access pure forms of thought. On the other it is a process of 'decoding' so as to not distort thought that is not dependant on how we have gathered but how those thought forms are held in the jug determine whether what is poured out is a gift/present. A present of the presence. Whereas an empirical intuition is a mere decanting, water is poured out. In this way I am arguing that to access true thought in the first instance is to begin to feel our emotions as the way to begin to learn to feel again. In so doing what we are doing is, beginning to change our own thought patterns that as process is mind clearing. In this way, my mind moves closer to God's mind, toward union of the one mind.

Heron (1992) argues that the subject-object polarity belongs to the conceptual mode of the psyche whose function it is to sort, classify and distinguish therefore is dependant on the use of concepts that come with the mastery of language mastery as well as the conceptual component in perception. He argues that this mode of the human psyche, or mind, has the effect of disrupting the "transactional, participatory nature" (Heron, 1992, p.25). In this way I am drawing a parrallel with Kant's (1724-1804) notion of 'pure intuition' with Heron's (1992) 'transactional participatory nature'. To conceptualise then effects the psyche, in that the psyche and the world become bipolar and in that way dismantle the original unity of observer and observed (Heron, 1992). While the subjective-objective polarity is evident in the psyche-world relation it is also manifest in the conceptual mode between discrimination and reflection (Heron, 1992). Where discrimination is a conceptual element in perception whose function it is to classify percepts by attaching language at the same time it is the process by which the transactional participatory nature is disrupted thereby creating the experience of a separate subjectivity (Heron, 1992). Thus the psyche is detached from percepts by the process of conceptualisation making "Its role in generating them obscured, the effect is that the psyche is fooled that it is generating these percepts and the mind is turned into a disconnected centre for noticing what is going on" (Heron, 1992, p.26). In other words, we loose the awareness of our connection to God.

In Heron's (1992) 'Theory of the Person' discrimination belongs to the individuating end of the conceptual mode and reflection at the participatory end and in this way discrimination and refection are polar opposites of the conceptual mode. Reflection is to think about the world in earnest and in this way formulate theories and laws about things which "reinforce the notion of the world as object, as other, as over against the subject" (Heron, 1992, p. 26). In 
conceptualising the human psyche gains independence that is then conveyed through both the written and spoken word (Heron, 1992). Further, concepts are not bound to percepts and in this way they can be formed into innumerable belief systems reflecting the human experience of the world for that individual. That world however remains a world of separatism. Where on one hand language is liberating but on the other where language creates separation and differentiation experienced through the perceived reality of object and subject. Thus human development attains the ability to conceptualise through reflecting and discriminating which is then communicated through language, yet by this very process, Heron (1972) is arguing, the notion of duality is perpetuated. And while Heron has provided an explanation for how in the human condition we create the illusion that boundaries exist between ourselves as a human being and ourselves as consciousness intermingling with all consciousness, I argue, that we can master language and at the same time transcend the state of consciousness that perceives that duality or separateness is real. In so doing what is received as sensation is pure intuition rather than empirical.

The earlier discussion on Praxis revealed through an examination of dialogue as a human phenomenon, that word was recognized as the essence of dialogue or the instrument that makes dialogue possible. Freire (1972) claims that word with its two dimensions of Reflection and Action exist in a such a radical interaction, that even a slight deviation in one is resultant in a major shift in the other. Where a word is deprived of its dimension of action, it is then said that there has been an engagement in mere verbalism or the production of a hollow word (Freire, 1972). A hollow word is an unauthentic word and an unauthentic word is unable to transform reality (Freire, 1972). On the other hand denunciation of the world is not possible without a commitment to transform and there is no transformation without action (Freire, 1972). Yet, where action is emphasized exclusively it converts word to activism (Freire, 1972). In other words action, for the sake of action. This then negates the true praxis and thus makes dialogue impossible (Freire, 1972). In either case, the original dichotomy is reinforced and as unauthentic forms of existence are created, so too then, are unauthentic thought forms (Freire, 1972).

Thus thinking that is transformative in the Freirian (1972) sense, has held this radical interaction of reflection and action rather than conceptualized through reflection or discrimination in the way Heron (1992) has described. And as I have already explained in the previous chapter thinking that is transformative stems not from the empirical analytical nature of man, but arises from the core of our being that has its beginnings in feeling human emotion. In our being-human, in the engagement of life, we learn to choose to respond to life, and in that way transform the world. In so doing, we fuse more of our local mind with 
Universal Mind and 'be' open to receive more. It is a process. It is learning to let go - a surrendering or releasing of attachments, of conceptualizing the world that on one hand is the artifact of language and on the other has resulted in the perceptions that we each hold about our world. In so doing we dwell less in our local mind and more in the world of Universal Mind or God's Mind. In so doing what we 'bring through', is then what Kant (1952) describes as true intuition that is sensuous. For how does one know God? God is felt. Through feeling we consciously access the place of all knowing, pure thought, which in essence is, love.

Beauty then is coming to this place of knowing. Beauty is being able to allow the isness of what is. In allowing the isness of what is, then one is not attempting to arrange the percepts into the old concepts. In that way the reflection is embraced, and the "notion of what he should see, has not had time to interfere its prism between the eye and its object" (Scruton, 1983, p.231). In this way it is love and not fear. It is knowing that all that has been and all that is to come, is now. Beauty is that which connects the world of dualities, and in that way we lift above the everyday so as see life as it truly is, in that now moment, for we are without fear or judgement. Time stands still, time no longer exists, the past present and future are one. In that moment we feel our expansiveness, in that feeling we are connected to pure thought. This then is the beautiful.

Therefore, to unchain ourselves from the Plato's cave, we are called upon to allow our perceptual conceptualizations in such a way that we challenge ourselves through our interaction with life. In that allowance, in allowing ourselves to respond to those challenges, that is, to feel our feelings, what we enable is ourselves. In so doing we begin to remove the self-imposed chains that have held us to density, to a third dimensional reality. As we remove each of our chains, each confused thought or idea each empirical intuition each shadow on the wall, we are moving. As such, we begin to move out of the darkness out of the cave closer and closer to the light.

\section{Illness and beauty}

Disease, both physical and psychological, has its roots in the good, the beautiful, and the true. It is but a distorted reflection of divine possibilities. The thwarted soul, seeking full expression of some divine characteristic or inner spiritual reality, produces within the substance of its sheaths a point of friction. Upon this point the eyes of the personality are focussed and this leads to disease. The art of 
the healer is concerned with the lifting of the downward focussed eyes unto the soul, the true Healer within the form.

Bailey (1953, p. 533)

The unconscious holds/stores and processes all the memories of past experiences: biological, racial, ancestral and personal (Krishnamurti, 1956). In meeting a challenge, and here Krishnamurti (1956) uses the word reacts, the reaction takes the shape of an idea, a feeling or urge. Challenges, it is argued, are continually changing. The contents of the conscious mind remain on the surface for only a short time, if at all, to then become unconscious (Krishnamurti, 1956). This process is ongoing, our unconscious memories affecting and influencing how we deal with new memories, therefore the new is not new but only as "newconditioned-by the-old" (Krishnamurti, 1956, p.8). And yes, it is possible to sometimes trace the effect of the old on the new, however Krishnamurti (1956) says that the effect of the distortions of the past remain mostly unconscious and that that which we have buried deep within us continues to colour our current worldview. "The unconscious sends from below its disturbing messages like a gramophone record continuously playing; blurs our vision like a photographic plate that has already been exposed" (Krishnamurti, 1956, p.8). In this way, we lay down the same pattern, over and over again, which is pattern making where these changes appear in context, but not in essence, because we are meeting the same challenge with the usual response. In that way we continue to create more of the same, and where the memory of the experience is laid down, I have argued that memories are laid down as emotions, is somewhere on the body. The body is the storehouse of our memories.

Our thoughts, emotions and brain communicate directly with our immune, nervous and endocrine systems and with the organs of our bodies. Moreover, although these bodily systems are conventionally studied and viewed as separate, they are in fact, aspects of the same system. If the uterus, the ovaries, the white blood cells, and the heart all make the same chemicals as the brain, where in the body is the mind? The answer is, the mind is located throughout the body. The mind can no longer be thought of as being confined to the brain or intellect; it exists in every cell of our bodies. 
In this way I am arguing that our bodies are our unconscious memories that then are patterns of energy that can be likened to fractal patterns. Infinity packed in a grain of sand until such time the point is reached where the pattern or level of density, the confused ideas, are such that we term the system chaos. In other words, until such time that we have altered cellular function so that it no longer makes the patterns of health, but rather, manufactures the patterns of dis-ease. Dis-ease that has such a level of complexity that the system is unpredictable and, as chaos, includes the area of non chaos. It is the area of non chaos that holds the potentiality for changing the pattern, by performing each iteration so as to begin to undo each distortion. In this way the system has always been, and always will be, predictable.

Einstein, in a letter to a colleague in 1926 wrote, "But an inner voice tells me that it is not the real thing. The theory says a lot, but does not really bring us closer to the secret of the 'old one'. I, at any rate, am convinced that He is not playing dice" (Einstein cited in White and Gribbin, 1993, p.216). The question of whether God plays dice with the universe continues to be debated. I would say, it is not God that plays dice with the universe, but rather, it is man. It is played out in the action of non surrender, so as to not bring about, "in Gods case, will and power coincide" as suggested by Augustine (Augustine cited in Arendt, 1996, p.87). Again I argue that God's Law is predictable, but the effect of the motion given by those laws results in the unpredictability of man because we are free to chose how we will respond in any given moment.

From the position of the beautiful there is the coming to a place of knowing that everything just Is. In this way, what we term a crisis in health or an illness, can be viewed as another opportunity to rewrite the old programming. It is one way that we draw our attention to the need for reprogramming. Health as expanding consciousness. Nor is physical death to be interpreted as failure. For some, this final experience of a lifetime is that which can enable the reprogramming or rewriting of a major distortion. Until such time that one is able to read the whole story of a being, that is, the sum total of an incarnate man, then to say anything else would be to judge health and illness, life and death. In judging, we are viewing health and illness from the world of duality, and the world of duality, as has already been explained, is not the beautiful, in other words, health and illness as expanding consciousness. Thus "disease, both physical and psychological, has its roots in the good, the beautiful, and the true. It is but a distorted reflection of divine possibilities" (Bailey, 1953, p.533) is a truth. Having said this then, how we direct love or fear can underpin our caring practices. When creating from love, our creations are very different to those created from fear.

\section{Internal image}


Gregory (1997), in chapter eight of his text 'Mirrors in Mind', begins this chapter, Mirror of Perception, by suggesting that mirror images can be ambiguous or distorted or paradoxical or fictional. "Perceptions are active brain creative brain-descriptions, these illusions of mirrors are in us rather than in the mirror" (Gregory, 1997, p.207).

The Aristotelian view of praxis is connected to the Greek word phronesis (Grundy, 1987). Phronesis does not have a comparable English word, but refers to a form of judgement [decision making] in which tacit knowledge; knowledge which is implied or exists without being stated, experience; knowledge or skill as a result of observation or practical acquaintance, and personal knowledge; individual knowledge, informs a person (Grundy, 1987). Practical judgement or decision making leads to practical action, and that action is directed towards a goal that is believed to be 'the good'. The judgement that initiates the action may be located in a form of reflection that is reasoned through one's understandings of a situation and at the same time is reflective of the experience and understandings of the person initiating the action. The question here is, what is it that guides action towards 'the good'? For what is believed to be 'the good' may in fact be a distortion or a confused idea, as whether it be experience, personal knowledge or tacit knowledge, none are exempt from distortion. In this way, practical action, based upon practical judgement, is thinking that has its origins in empirical intuition and thus practical judgement is but moral reasoning or, man made rules. Where this thesis through the notion of being, has attempted to reveal, that the Laws of Man are not always the Laws of God/Universe.

St Augustine (354-430 cited in Arendt 1929/1996) said that the perfection of the good, in other words wholeness, is negatively defined because self-deliverance from the world amounts to a choice of the Creator and that the choice of the Creator is not always the same as the choice of man. This then is congruent with the idea that God's Law is predictable, but it is the motion given to those law's by man that make them appear as if they are not.

In defining the world in terms that are either good and bad, there exists the possibility to negatively define a thing. As the Creator, as God, I am all things and in that way good and bad cannot exist. As man I can perceive myself in terms of good or bad. St Augustine speaks of choice as Gods Law in its expression, that is, it is given with the creature's 'being of God' and therefore God is the Supreme Being and man's own proper being (Augustine cited in Arendt, 1929/1996). But in the turn away from God, we are rendered 'helpless'. In the state as man, what becomes sinful, is our independence. Sinful not as a rebellion of the part against the whole, but as an independent performance of surrender where our choices 
reflect the unwillingness to be God/Love/Source. So on one hand we choose to turn away from our wholeness in order to turn back to our wholeness, the lure of our becoming, and the ultimate surrender. However in the turn away what can be lost is the sight of God, and then what we are in fact doing is "an independent performance of surrender" (Arendt, 1929/1996).

Through the experience of life we begin to generate our perception of reality. In other words, in our state of separateness we fool ourselves that the psyche is generating the percepts, $I$ think, and therefore what we have thought is real and so therefore, I Am. I think, therefore I $A m$, which is the well recognised position of the philosopher Rene Descarte (1641).

Augustine's argument is that it is man's inability to work with the law that reflects not a lack of will, but rather, a lack of power (Augustine cited in Arendt, 1929/1996). In that way I perceive that by the very experience that the law creates is to experience this gulf between 'to will' and 'to be able'. In understanding this, then we can come to know that 'in God's case "will and power coincide" (Augustine cited in Arendt, 1929/1996, p.87). In other words, I Am, therefore I think. In the gulf between 'to will' and 'to be able' there is the promise of our reunion, the finding our own being again. But it is not something to be recovered as if it were lost, but rather, it is our power to create. More precisely I see that it is as Augustine said, 'it amounts to the choice of the Creator', - I think, therefore I Am, which is then experienced as a transpersonal power that transcends the ego.

We can continue to work with our beliefs, distortions and confusions and to do so is to begin to experience life in a way that greets each experience as if it were the first experience. One of the defining factors that distinguished something as being aesthetic was that it was greeted as if it were the first time, every time. In this way, as has already been explained, we begin to change our internal images. It is by the process of image changing that we create a more expansive view, and that process is not a process of perceptual/conceptual thinking. It is a question of Being.

In Beingness we encounter every new moment with non judgement, unconditional love and allowance. In this way, life is lived as a form of invocation. We call forth, we invoke, from within ourselves the distorted image, stored as an emotion, so as to re-experience that emotion, which just Is. That is how we begin to change the image, and it is a process not an advent. In so doing, we enable the presence of the presence, we gather and hold within the void so as to give ourselves the outpouring of a consecrated libation. A gift. What gift? What is to be poured out? It is but more embodiment of our own Divinity, for as we have been told, we are created in God's image/replica/duplicate. 


\section{Image as thought}

Johannes Kepler 1571-1630 (cited in Gregory, 1997) noted that the images of the eye, though not perceptions, are reversed up-down and sideways. That is, we see reversed images but we see them as not reversed. While it was assumed that the image in the eye was seen as a picture, an explanation as to how we see straight when what is received is upside down, was inexplicable (Gregory, 1997). Finally, it was recognised that we do not see pictures in the brain, but rather, the brain describes the image in the eye and therefore the image is no longer present in the brain once it has been described (Gregory, 1997). Thus we see an image, which is then described and after which we hold a description of an image and it in turn becomes the visual image turned about, and we see back to front (Gregory, 1997).

One of the factors in determining rotation of the reversed image and therefore the suggestion that we do not see in pictures/images is that there would need to be an internal eye looking at the picture in the eye. This internal eye would necessitate another eye to view its image and therefore necessitate another eye and so on and so forth (Gregory, 1997. The idea that the brain described images in the eyes gives rise to the notion of perception. This along with the infinite eye position then dismissed the supposition of an internal eye (Gregory, 1997). On the notion that the brain describes the inversion and reversal of images was then not problematic. But this then gave rise to another observation. "What does matter are positions of retinal images compared to experience of touch objects. These relations have to be learned. An infant though does not have to learn how to invert the image, rather what an infant learns is, what the eyes signals mean in terms of characteristics of objects (Gregory, 1997, p.210). In other words, the child is taught not how to see but what to see. Every distortion shared by every adult caring or teaching that infant. How often in childhood does a young child experience the difference in what they see and what they are told they see? Gregory (1997) notes that what the eye's signals mean in terms of characteristics of objects is beyond current computing technology. One explanation may be, in the process of the description or how the communication of the image held in the eye to the brain takes place, in that way we can and do rotate the image that is then the end result of how we have interpreted our world. The point that I wish to emphasise here is that seeing is an internal process that then determines what is seen.

Gregory (1997) goes on to explain that retinal images are always ambiguous. The brain has to guess the meaning of the images and does so by selecting a single perception (Gregory, 1997). But here-in is the catch. In the process of perceiving, there is no response from the moment-to-moment stimuli from the senses, but rather, it is about guessing what is about to 
happen. In other words, this is the space that I have argued is created through the intersection of Being, Unconditional Love and Awareness and, even in this space one can react to what is being perceived. As Gregory (1997) explains, this phenomenon is what enables us to hit a ball. Given the considerable delay in transmission of the signals from the eyes and activity of the arm that holds the racket, to avoid neural-reaction time we hit at a guess, we hit at where and when we think the ball is going to land (Gregory, 1997). And we do hit the ball, but at others times, we do not. Perceptual information as brain description, then, is no different to conception as brain description. In this way, perceiving and conceiving become one and the same and therefore might be termed Kant's (1952) empirical intuitions, or to use Gregory's (1997) terminology, Eye-deas as opposed to I-deas. I-deas are not an arrangement attached to form, but rather "in which all the manifold content of the phenomenal world is arranged and viewed under certain relations ... as a mere form of sensibility, and without any real object of the senses or any sensation" (Kant, 1952, p.33). In other words pure intuition. Therefore, I have arrived at the possibility posed earlier about the process of the description, or how the communication of the image held in the eye to the brain takes place, the image is said to rotate.

In pursuing this line of argument I would go back to the start of this section where Gregory (1997) says the mirror image is us, and the idea introduced earlier in the first chapter of the thesis, where self reflection is at the same time a reflection upon the relation of the self to an external reality, an external reality which is an image that is not an independent object (Dilthey in Ermarth, 1978). In this way, our relationship is not separate to an opposite object, apart from our awareness of it (Dilthey in Ermarth, 1978). In this way, what we see is ourselves! Our vision is a vision of what we have thought, our thoughts are our images. As we think, so we are. Yes, this is the will of I think, therefore I AM, and while powerful, it is not power. It is an illusory power, for it is power over and not power to. So in the question of thinking, we need to consider how and what we think. For if light does not pass through the optic nerves into the brain, then the sight of insight, and the sight that enables us to move around our world and apprehend it physically, must be different eyes.

In the world of duality, in physicality, we have two eyes. It would follow then that in a world of oneness there would be one eye. Some call this one eye the third eye. This eye works differently with an image, for it does not conceptualisee what is perceives, and nor does it guess. For this eye is the eye that is able to see because it sees by feeling, it feels the images. This eye projects I-deas, this is the eye that the ancients called the eye within the Triangle. This eye some know as the eye of God. But the eye of God, like the mind of God, 
has been bypassed for the human mind and the physical eyes, as we have continued to think empirically.

The thinking through this eye, is our insight, and needs to be acknowledged. To acknowledge something is to validate it. It is action that is not a notion of 'rightness' but is an appreciation for the sight of beingness. As such beingness is what is being acknowledged or validated. I give thanc[s] for this thinking. Thinking that is an act of grace and as such is beauty. Each time a child is taught to reject what this eye has seen, then it is not just sight that is being invalidated, but beingness itself. In so doing, this way of thinking, our insight become more dimmed. The image is then rotated or inverted another turn. It is rotated and rotated. Revolution and not evolution.

And so we begin to yearn again, and as such we cry to see and then cry when we have seen (Levin, 1988). In that way we continue to remind ourselves of our need for a vision of the whole, and that that vision is vastly different from the vision which names and frames (Levin, 1988). Crying is an expression that distinguishes itself from everyday seeing to seeing that can be described as visionary, visionary because it is "as a transformation of its relatedness to Being" (Heidegger cited in Levin 1988, p.174). As a historically motivated form of suffering, crying brings background into the foreground, and when seen as such, crying becomes vision expressed. It is the outward manifestation of insight and this way of seeing, this sight, is where vision is clear, the clarity is in the ability to be moved deeply by that which is seen (Levin, 1988). Crying, then is grounded in what we perceive we need, needs which are not egoic in nature, but derived from 'the self' (Levin, 1988). "This need is a need ... for healing" (Levin, 1988, p.176). By such vision we are uncovering that which we have concealed. We are restoring our insight.

I interpret this to mean that the 'thing in itself does not lie above or beyond appearances, as is suggested in certain traditions of metaphysics. Rather the thing itself remains concealed because its own appearance is concealment. But what is revealed is our ability to see this.

Heidegger 1927 (cited in Want and Klimowski, 1997, p.164)

In the Aletheia of our suffering, we allow ourselves to see deep within the void, for our vision is felt, felt and expressed in the flow of all things. In this way, our connection is 
deeper and we are more open. Open in the sense that the space within us changes, the void changes, what we think and see.

On December 6, 1273 while saying mass that morning a great change come over him, and afterwards he ceased to write or dictate. Urged by his companion to complete the Summa, he replied: I can do no more; such things have been revealed to me that all I have written seems as straw.

St Thomas Aquinas (1952, p.vi)

\section{Thought and the beautiful}

Thought, thus far has been presented as the connection to true thought or pure intuition that some call the river of all knowing, and others the Mind of God. Thus thought involves having moved through the filters and blocks created by perceptual imaging as an outcome of life experience through emotional reaction. This movement then, is not one great act of surrender, but rather are ongoing acts of surrender, that are a surrender to Being. As an act of submission 'the will' is actioned in such a way that it responds to the call of Being. In responding the self is wholly present, and so the will has not been subservient or submissive in a passive sense but actions the response to the call by being willing.

Kant (1952) argued that aesthetic experiences must be first hand, and Pole (1983) explains this to mean that an aesthetic response must be as if each time were the first time, and that this is not true in morals or elsewhere. I would add here, that I will use reaction and response as Pole (1983) has used these terms, with the reminder that in the previous chapter I explained the critical difference as it applies to the actual surrender.

Therefore, while an initial reaction may be that of delight in discovery, and each time this may bring an opportunity to deepen an insight, each time it is essentially not new, and in this way it is not an aesthetic experience. For the more efficiently we respond, the less we feel. Whereas, as has been explained in the second chapter of this work, an aesthetic response, on the other hand, implies a certain heightening of, or dwelling in, our experience. The focus is on the experience, experiencing it as fully as possible, while the experience is of the object itself, "that the experience must consist in a heightened awareness of the thing" (Pole, 1983, p.30). In focusing, we can raise our awareness, we can become more aware, and that 
heightened awareness, is a reaction to the formal features of the thing. In this way we experience the simplest, or most obvious, form of aesthetic reaction. But as I have said in the fourth chapter of this work, where I have discussed experience, judgement and flow, this may not be so. For while we have called forth the possibility, that is, gathered, we then need to able to hold, and it is when we have held in a particular way that there can be outpouring of the gift. How we hold is then what we see.

Pole (1983) extends this further, and while he attributes his observation to a different stimuli, none the less he attributes it to the same outcome that shape, colour and sound, while inviting our attention, give us reason to think, and therefore renders the reaction only minimally aesthetic (Pole, 1983). This, as I have said is linked to a different explanation, but is also consistent with the arrangement of percepts attached to forms as described by Kant (1952). As empirical, intuition it is also minimally aesthetic. Therefore, to be able to 'see it' and 'feel it', are the hallmarks of an aesthetic response (Pole, 1983). In this sense, one has 'felt it' to be able to 'see it'. Having done so, then it is as I have argued, one has responded aesthetically. To learn to respond aesthetically is what will engage us in thinking that is pure intuition. This thinking uncovers, and in order to think pure intuition, such thinking is inextricably linked to the beautiful.

To begin to understand the beautiful, one has to continue to know maturing love. For the relationship in mature love is such that nature becomes part of civilised living (Chaudhuri, 1987). On one hand this means that within the beingness of a being there is the knowing that there is honour and integrity of 'the self'. When this is known then the being lives in accord with nature/cosmos/universe/macrocosm in the microcosm/earth, as opposed to existing in it. Also, given that the below is within, and this we term the unconscious, it is the unconscious which is organically related to nature and through which the love impulse manifests. Mature love is unconditional love, pure love, is not something that is attained as an event but is that which is represented by our ongoing maturation. At the same time is that which we are and always have been as we are challenged to make real, to realise in our being human.

Mature love is characteristic of an independent dependence, freedom and mutuality. Therefore, when one comes to the place of the beautiful, and the beautiful just is, not as a justification or a denial, but rather, as an allowance that can be allowed because the being knows it to be so. Love has reached maturity, the midpoint between two poles. At one end of the pole love is described as an undifferentiated union or the prepersonal state.

The mother child metaphor can be used to explain this terminology where the child represents the prepersonal state. At the other end of the pole there is separation, and thus we can always 
fall back into the world of dualities or remain a child. We always can choose. Here-in, though, is the crucial point. Both access the midpoint by feeling, of the individual impulse to love, and at once it is feeling. Feeling is response to pattern, a recognition, an a priori, by which growth occurs (Chaudhuri, 1987). In this sense, growth as mature love is the ongoing expansion of consciousness. This midpoint cannot be approached until one knows, the beautiful.

The beautiful is in all things, and when that is known then one has experienced the poles of duality of a particular phenomenon and then choses to experience more. Even then, in experiencing the dimensions of the dualities, one is still required to feel. As a dualism, what is felt, is an emotion or the subjectivity, whereas what is felt from the place of the midpoint, the place where love has matured, is feeling, the true intuition, in other words, truth.

Some describe the midpoint as the union of the God and the Goddess, others as an alignment of the masculine and feminine principles. A point from which Eisler (1991) says, we can come to know where the spirituality of mankind lies. I would say this.

When I stand at this midpoint, in this place of feeling, I know that I know, for in that moment I have touched love, love here on earth. In standing in this place I can then see the illusion of boundaries, for my vision is clear. In this space there is no them and us or you and me, but rather in that moment I come to know you, exactly as you are. In such a moment, when I nurse you, I know you and I know how to act. I know what to do. For I have stood in more of my true power, my God consciousness, love. Where 'to will' and 'to be able' -those law's which God has assigned to the relations of our bodies with the world He has put them in, as an act of surrender is powerful beyond measure. As such, I am connected in body mind and spirit in an act of Being to your body mind and spirit. The bridge that connects us is, the beautiful. 


\section{Summary}

This chapter has further explored the nature of thinking by positioning thinking that is pure thought, as opposed to empirical thinking, by using the framework on Pure Reason presented by Immanuel Kant.

Through further exploration of image and perception thinking is viewed as object and subject and transformation, as it relates to changing consciousness or evolving the nature of reality. Such thinking is pivotal on experiencing life from the position of the beautiful. 'The beautiful' as this chapter explains, connects body, mind and spirit and in that way connects the self to the self, and other. Through the beautiful we are open to all things. We open to pure thought/intuition.

From this position, illness as a product of thinking, or a physical manifestation of thought, of consciousness, is then also open to the possibility of change. 


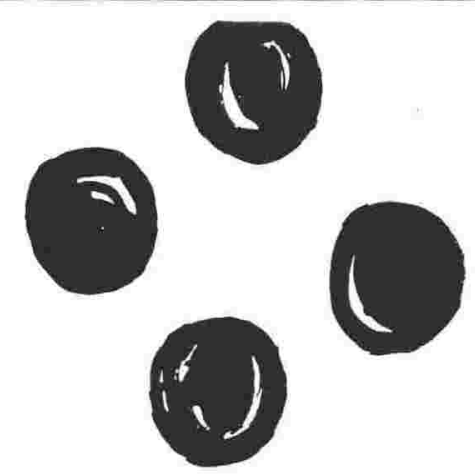

\section{Chapter 9: Body as Memory}

\section{Laying memories down}

In an exploration of art as a mode of knowledge, Heron (1992) says that knowledge is 'transacted', by the apprehension of perceptual imagery through the imaginal mode interacting with the conceptual mode. In the fifth chapter I interpreted this to mean, we experience something, process it and then create a construct of reality. While I still hold with this interpretation, I wish to expand further the 'apprehension of perceptual imagery' that is a tapping into consciousness, all of creation, and then expressed in the human condition.

The imaginal mode "comprises intuition and imagery of all kinds, including the imagery of sense perception" (Heron, 1992, p.15). This knowledge is termed presentational and in this sense can be perceived as bestowed or received and not transacted in the first instance. As presentational knowledge it is also the creation of perceptual elements in movement, sound, colour, shape and line that in some way "symbolises some deeper pattern that interconnects perpetual imagery of this world or other worlds" (Heron, 1992, p.165). Assuming the position that perceptual images are bestowed, then as a result of the transaction between the imaginal mode and being, an art form is created that is symbolic of a pattern which has been brought about by that transaction. Heron (1992) argues, that in this way blocks of knowledge as aesthetic patterns inform some whole arrangement as perceived within the world.

Using the Kantian position of the difference between empirical and true intuition (Kant 1788/1952) presented in the previous chapter, and Pole's (1983) argument on what constitutes an aesthetic judgement [response] presented in the third chapter, I agree with Heron (1992) in so far as perceptual imaging is the product of a transaction between psyche and being per se, but would add that what is transacted, is also determined by the psyche and Being-in-the-world. Transaction as a true intuition, I would argue, is enacted through an aesthetic response Being-in-the-world. In other words, what I have called my being to do [to be] as a response of Being -in-the world, from the space of beingness is to respond 
aesthetically. In so doing, perceptual imaging is not an arrangement attached to form and therefore would be insight in the Kantian sense of pure intuition. In this way, I called my self to respond to my Being-in-the world with unconditional love. For only in the space of unconditional love can the beingness of a being perceive something about the whole. In the feeling of love, as unconditional love, we approach 'the good', and each time we embrace the part we see the distortion and that then is an act of unconditional love of the self. In its expression, my love of the world and the love of myself are the same love. For I cannot love the world unconditionally without loving myself in the same way. By the process of embracing the part, I am re-membering the love of the whole. As I do so I can tap into more of creation, more love, and in that sense pure intuition.

Earlier in this work, using the work of Kuthumi (cited in Prophet, 1991) I presented the idea that everything observed with our physical senses is automatically transmitted to the subconscious levels by an 'inner hieroglyph', and in this way there is an unedited transmission of data from the external world to the internal world of our being. I have also presented the Roney-Dougal (1991) argument that says we may be conscious of only five or six things at any one time and so the rest of that data transferral remains unconscious. Kuthumi (1991), (cited in Prophet, 1991) in his discussion of the human aura says that in the process of generating percepts there is a misqualification of thought and feeling and that this misqualification is in the emotional body of human kind. This he says results in the heart being touched in such a way that it sways "the whole of the life record of the individual into a miasma of doubt and questioning while at the same time creating a certain leverage to the power of amplification (Kuthumi cited in Prophet, 1991, p.27). Therefore, our emotions amplify our misqualified thoughts in such a way that they assume a dominant position. And while Kuthumi (cited in Prophet, 1991) points out that such a path is dangerous, he also points out the potentiality in that it is precisely this path that is the turning point. This means that, while an aesthetic block of presentational knowledge might be bestowed in the transaction between psyche and being human, what is perceived is determined by how that transaction is transacted through an internal world, the breadth and depth of which is hardly conscious. How to move through that internal world has been the subject of this work, that is not an avoidance of the amplification of misqualified thought but a type of consideration where nothing is allowed to move past without examination. By examination, I mean a reflective attitude to life that is about becoming emotionally honest.

I saw that my soul's imprisonment had seriously impaired my connection with reality ... First I had to find a place where I could see integrity in action, where it was safe to risk being open ... Second I had to learn to see the specific nature 
and extent of my unreality so that my authenticity could be reestablished. I was

told to be patient, that it might take a long time to learn to be emotionally ... honest.

Miller (1997, p.194 - 197)

In being open to all experiences and then being honest with what is felt, for as has already been said everything is noticed whether we are conscious of it or not, in that experience is the moment to consciously choose to begin the turnabout that determines what is 'transacted'. While this statement about honesty might appear naïve or simple amidst a discussion of pure intuition and perceptual knowledge I cannot over emphasise the word honesty as it relates to being. For without emotional honesty one cannot access their integrity/wholeness because to be honest is to be real, and reality making requires realness/honesty.

We had been asked to bring a small gift. I had purchased a miniature porcelain plate that had been decorated with a cottage scene. We were asked to give our gift to someone in the room. I did. Having done so I was approached by a participant who offered me a match box, another who presented me with two wine glasses and a third who had forgotten to bring a gift and had substituted his filthy dirty pocket comb. There he stood with outstretched hand - smiling, as he offered me his gift. I accepted. I now had three gifts and some people had none.

When all the gifts were exchanged each person in turn was asked to state how they felt. In a room of fifty people I felt myself turning purple as I announced that what I felt was - disappointment. When each person had spoken, those people who were inclined to do so were invited to give their gift/s away again. I gave the wine glasses to a young woman who I knew had just moved into a flat, and the match box with its interesting cover design to some-one else who had offered me a crystal. I could give these items away not as something I did not desire, but as something I choose to give. Now I was left with the dirty filthy comb, and I could not give something to someone that I would not give to myself.

As I stood contemplating the comb in my hand, as if in a flash of inspiration it suddenly occurred to me - I did not have to accept this gift. I stood frozen in astonishment at this thought - and then as I slowly brought my orientation back to the room and its events I made the decision to return the comb to its original owner.

I walked up to him and said, "I would like to give you this comb back". I never would have done that in the past. In that moment, despite whatever I had done in my life, the consciousness that I actually had choice appeared in such a way that it was now real. I will never forget it! A dirty comb and my honesty had opened my beingness to the reality that I had choice. That I could choose!

The incredulity of it was that this was in spite of my having made millions of choices in my life I still believed that I had to accept whatever I was given. And while experience is something that I do choose [and without this knowing I can perceive myself to be a victim of life] how I respond to life in the moment, being-in-the-moment, was something that I had absolute choice about. 
On that evening I became conscious that I had choice. What a gift that boy offered me in the disguise of a dirty comb. In allowing myself to acknowledge disappointment, I then opened myself up to a new reality.

Journal entry

Therefore, I am saying that emotional honesty is critical in the transaction between the imaginal mode and human consciousness in the revealing of precept. I use the word reveal as opposed to generate deliberately, for to claim that we generate precept then raises questions about the origin of thought itself and such a discourse is not being positioned at this point. Rather what I am suggesting is that what is bestowed or received is then held in its authenticity as consciousness by how a human being responds emotionally. Attachment is a function of ego, that as an interaction with the reactive mind acts to hook us back into a particular thought or belief, that is a 'confused idea', a distortion. Therefore, where there is any judgement of an emotion it is mirrored by the outside world thereby serving to offer an opportunity to change consciousness or keep consciousness, as a human being, within a known reality. If the old reality is reified, the emotion was judged, the result is that the state of beingness is more negative or lesser than, and in that way while it is truth because it is that being's version of reality, it is however as Aquinas (1267/1952, p.721) claimed, a "less excellent thing".

Having said this though, the hooks do appear to be real. I have three gifts and others have none, I am being greedy, what will people say? I must accept what I am given. Where what a particular feeling represents is the known reality, and therefore a known feeling. In that way a sense of comfort or safety is reinforced. Albeit one that is an illusion. However, to be sensitive to what one is feeling, is then to begin to access our 'misqaulified' thoughts because our emotions are what amplify our misqualified thoughts (Kuthumi, cited in Prophet, 1991). As we begin to re-experience an emotion, in the experience, there is an idea or belief attached to that emotion which in the moment we can change by embracing the emotion and then choosing love.

\section{Belief:}

I have to accept and be grateful for what I receive.

\section{Creation or manifestation as a result of this belief:}

Accepting anything, accept second best in life.

\section{Feeling/emotion:}

Disappointment, powerlessness, worthlessness 


\section{New Belief}

I have choice

\section{Feeling/emotion}

Power, worthiness

So until we can feel an emotion in its entirety, which means in the multiple fractal patterns, then we are unable to release it and in the process change our thoughts, change our perception of reality. In the interplay between life, ego, feeling and emotion each time a particular emotion has been released the auric field changes. The human field changes. The layer closest to the core containing the negative primal emotions and the outermost layer the mask of the ego (Pierrakos, 1987) undergo a transformation. In so doing we open the self to more consciousness to be made conscious in the ongoing cycle of expanding consciousness.

I have already said, in this cycle of learning to respond to life emotionally, this does not mean that we never experience a particular emotion again, rather, it means that we are able to feel a particular emotion and then let it go by consciously changing what we feel. Hence the import of choice. For in feeling a thing and then choosing to feel again, is to sunder the bond, to cut the tie that has caused suffering! Not because we don't like what we feel (judgement), but because we have come to a place of knowing that knows that what we have felt is not real. As a human being I am no longer attached to that particular emotion and in that way it is free to come and go, for having cleared my auric field what I am clearing is, my mind. Without judgement, which is what creates the attachment to form, do not judge lest ye be judged, I am able to lovingly acknowledge what I feel and release it by consciously making the choice to feel something else. Until such time I no longer, create experiences to feel this particular feeling because I have nothing more to remember. In this process, my mind becomes more receptive to tuning into the whole of creation.

In this way, the apprehension of what is given, as pure intuition, in whatever way it is given, is able to be reproduced in a form that conveys that purity. All art is "at one and the same time a symbol of human feeling and of the other, rhythmic structure of organic life itself" (Langer 1952 cited in Heron 1992). Therefore, when I speak of pure intuition, I infer works that we term brilliance or genius that is recognised in Bingen, Shakespeare, Einstein, Rumi, Gibran, di Vinci, Pythagoras, Aquinas and Mozart and evidenced in the lives of Mohamed, Jesus, Confucious and Buddha. Brilliance is recognized. Brilliance is not measured as validity and reliability of truth because brilliance resonates, at some level, within the many. We feel it. And no matter when or where in time and space we come into contact again with this artwork, we experience it as if it were the first time. That is why music, painting, 
writing, poetry and film etc., works that are named Great, are, were, and always will be, Great Works. For within them they hold the patterns that innately each one of us knows to be a representation of love that is expanded or unlimited. These artists have remembered who we are, who we have been, and who we always will be. They have remembered from where we have come from and to where we will return. The no-thing. They have remembered the purpose of the experience of life. And so when we look, listen, touch, smell or taste these creations of a Creator that have come from creation, then just for a moment, it is possible for us to have this same experience - then we too remember. Then it can be said that we have heard in a way that is clear or seen in a way where our vision is straight. How do we know? We just know. We know a representation of truth as love because love is felt as feeling. Within each of us there is both an objective inner world and a subjective outer world, but they are within, and through the sensibilities of the imagination in our inner objective experience, the Immanent God is found (Artress, 1995). Those Gods, the ones who have and will continue to create the Great Works, have very clear memories. Their memories are clear because they have very clear bodies. These people shine from the inside out, they glow.

\section{Releasing memory}

If you bring forth what is within you, what you bring forth will save you. If you do not bring forth what is within you, what you do not bring forth will destroy you.

(Jesus, in the Gospel of Thomas, cited in Houston, 1997)

Kaelin (1970), exploring being in the body uses Langer's 1952 theoretical position on art. Art, Langer asserted, was not the expression of feeling but an icon, and as such was an imaginative symbol that through its design dialectical tensions in feeling were represented. Human feeling was then portrayed as the intensity of life process, raised to a level of complexity so that it is consciousness (Langer cited in Kaelin, 1970). This second proposition is the same position that Kuthumi's (cited in Prohet, 1991) posits in his notion of amplification of misqualification of thought as emotion. In the idea of art as icon to then bring forth what is within raises questions in relation to how the pattern as an icon is accessed. 
In exploring the idea of art as icon Kaelin (1970) uses dance as context to illuminate his position by arguing that the feelings of dance are unfelt. Feelings are merely symbolised by the movements of the dancers so that patterns are depicted which then are symbolic of patterns of sentience. This being so, how does the dancer access the pattern(s) and what occurs when the dance is viewed by an audience so that it is then translated into a kinaesthetic reaction which then present a feeling to be understood? "The feelings expressed in the dance, are the movements of the body, felt in the first instance and only then by the dancers as they move, and by an audience that perceives the forms of the movements themselves" (Kaelin, 1970 , p.132). In this way Kaelin (1970) is prompting us to ask whether the body generates the emotions which are then expressed through movement to then be felt by the dancer

For to suggest that a dancer first understands a feeling, and then translates it into kinaesthetic imagery, is to suggest that a dancer dances before dancing, and since the counters of the dance medium are movements, the dancer must already have made the movements in order to have gained his or her idea.

Kaelin (1970, p.149)

To date I have argued that emotion is stored in the body and is the end result of processing life events that have been judged. In this way we set up a perception of reality. In order to change how we perceive the world to be I have suggested that it is process of expanding consciousness that hinges on emotion being re-experienced and then processed differently. What I have not fully explored is how an emotion might be invoked (called up) or evoked (called forth) and what this might mean in relation to the self regulatory mechanisms introduced in the previous chapter. While both forms impacted on the structure of knowledge and the function of that structure in the ongoing acquisition of knowledge they were tied to the environment and in that way are outside of the being. Kaelin's (1970) assertions have raised questions relating to regulatory mechanisms that may exist along side the mechanisms that coexist with environmental input where patterns of sentience are accessed independent of the external environment.

Some things done by the body are not willfully caused and therefore are automatic and not willfull (Walsch, 1995). Automatic responses of the body are reflections of a State of Beingness which have already been attained (Walsch, 1995). For example, to laugh is an automatic response to a State of Beingness that has already been attained - happy, joyful or nervous (Walsch, 1995). "Therefore Automatic Doingness Functions of the body are used 
by the mind to reflect a Beingness State, while Wilful Doingness Functions are used by the mind to achieve a Beingness State (Walsch, 1995, p.27). In either case it is the mind which is causing the body, signalling the body, to do what it is doing and therefore the mind thinks that doingness is how to achieve beingness (Walsch, 1997).

This same phenomenon is how method actors act (Walsch, 1995). The actor thinks of a thing or remembers a time that produced the same emotional response as what is called for in the current situation. In that way the mind tricks the body because the body does not know whether what is being experienced is real or memory (Walsch, 1995). In this way the mind can tell the body what to "do", and so achieve either a State of Being (Willful Action) or demonstrate the State of being it has already achieved (Automatic Response) (Walsch, 1995). Therefore, the movement of the dance is contained within an idea that the body already holds of itself. The idea is held as a pattern that is feeling, and so in expressing the idea through the body it is the expression of the pattern that then becomes the art form. It is a connection with the self where the perceptual images become translated through form, which are then felt. And so the dancer can dance before dancing. The dancer dances the dance in his or her mind in a way that the "Doing (dancing) flows out of a place of Being, announcing itself rather than seeking to create it" (Walsch, 1995, p.30).

We were asked in turn to stand in the middle of the circle and make a gesture without speaking that was an expression of who we are. When my turn came I stood fixed in the centre. I could hear an internal voice saying jump around like a chimp and I even saw myself acting out my sense of fun in my minds eye. At the same time I felt myself respond to my idea in a way that said, No, that is not Ok for me. So I continued to stand for a while and the only thing I was conscious of was my breathing. I felt self conscious standing in the centre of the circle just breathing, but then, as if out of nowhere my body moved and the circle of people clapped saying, "Yes that is a Marina look". I was so flabbergasted because I had no idea where the idea came from or what a Marina look looked like - but they did - they all recognised a pattern.

Journal entry

I have already presented the idea of an entire transmittal of data from the external world to the internal world of our being and that the process of recall is both involved and almost instantaneous (Kathumi in Prophet, 1991). I have also outlined Dilthey's notion of a reflective awareness that is self consciousness and consciousness of the world that is then the two sides of the same consciousness (Dilthey cited in Ermarth, 1978). This thesis has recorded information in relation to the physicality of image generation along with the psychology of perception. So on one hand I have presented the notion that seeing is a reflection of what is thought and a transmission of data from the outside to the inside. Then using notions within the idea of dance as an idea of the mind, I have attempted to argue a process or form of recall that is an invocation that reflects a state of Being that on one hand is 
an automatic response that has been achieved and on the other a wilful action as an evocation that demonstrates a state of being. Therefore, I would suggest that an emotion as a pattern of sentience can be

2. evoked in response to the environment

3. invoked in response to the environment

4. invoked as an automatic response that reflects a state of being

5. evoked as a wilfull response to demonstrate a state of being

and in that way agree with Kuthumi's (Kuthumi cited in Prophet, 1991) assertion that how we construct our reality is in both feeling and felt and that the process of recall is involved and almost instantaneous. At its best, it represents a mind body spirit connection that then has both cellular and cerebral consequences.

And in that way it is both. "Why, it's both. It's not either/or; in fact, it's both and neither. It's simultaneous - a two way Street. Every change in the physiological state is accompanied by an appropriate change in the mental emotional state, conscious and unconscious, and conversely, every change in the mental emotional state, conscious or unconscious, is accompanied by an appropriate change in the physiological.

(Pert, and Green in Pert, 1997, p.137).

The unconscious mind is in the body and in that way the body is "a living demonstration of the state of beingness in which the soul resides" (Walsch, 1995, p.29). What we experience as an emotion or feeling is the way in which a particular neuronal circuit is activated simultaneously throughout the body which then generates an action with the corresponding physiological changes and as such "it's part of the constellation of bodily changes that occurs with each shift of subjective feeling" (Pert, 1987, p.145). So as I take in my external world I am imaging but at the same time I am also imaging my internal world. It is consciousness in the sense that I relate to the external world with my physical senses and in that way I activate my brain but also how I am responding to my world is also part of my consciousness that in the most part is unconscious, and that is a mind body connection. Both consciousness's are operating at the same time. 
The following extract of dialogue between Krishnamurti and David Bohm illustate this point.

Krishnamurti: When you were talking to me - I was noticing it - I was not listening to your words so much. I was listening to you. I was open to you, not your words. I am listening to you, not to the words which you use, but to the meaning, to the inward quality of your feeling that you want to communicate to me.

Bohm: I understand.

Krishnamurti: That changes me, not all this verbalisation. So you can talk to me about my idiocies, my illusions, my peculiar tendencies without the conscious mind interfering and saying, "Please don't touch all this, leave me alone"! What I am saying is: don't listen to me with your conscious ears but listen to me with the ears that hear much deeper. That is how I listened to you this morning. All this is explicable, easily understood - but to come to that thing together, feel it together! You follow? I think that is the way to break a conditioning, a habit, an image which has been cultivated. You talk about it at a level where the conscious mind is not totally interested. Say for instance I have a conditioning; you can point it out a dozen times, argue, show the fallacy of it, the stupidity - but I still go on. I resist, I say what it should be, what shall I do in this world otherwise, and all the rest of it. But you see the truth that as long as the mind is conditioned there must be conflict. So you penetrate or push aside my resistance and get to that, get the unconscious to listen to you, because the unconscious is much more subtle, much quicker. It may be frightened, but it sees the danger of fear much quicker than the conscious mind does. As when I was walking in California high in the mountains: I was looking at birds and trees and watching, and I heard a rattler and I jumped. It was the unconscious that made the body jump; I saw the rattler when I jumped, it was two or three feet away, it could have struck me very easily. If the conscious brain had been operating it would have taken several seconds.

Bohm: to reach the unconscious you have to have an action which doesn't directly appeal to the conscious. 
Krishnamurti: Yes. That is affection, that is love. When you talk to my waking consciousness, it is hard, clever, subtle and brittle. And you penetrate that, penetrate it with your look. With your affection, with all the feeling you have. That operates, not anything else.

Krishnamurti (1987, pp.537-538)

In other words, as the internal external imaging is occurring when in a state of awareness that as mindfulness is also a state of grace, is to then open the self to what is being felt and in that way when a feeling is anything less than love then it can be actioned in such a way that it is affected [loved]. The lesser feeling is transformed into love. And love, only loves. Krishnamurti illustrates this where in a state of beingness that was one of connection with all things, he was 'being' connected, that is connected with the consciousness of all things as he walked through the Californian mountains. In this state, his awareness was open to be conscious of what he was feeling, because the unconscious is much more subtle, much quicker. It may be frightened, but it sees the danger of fear much quicker than the conscious mind does. In feeling the feeling, and I am saying that what he felt was fear/danger he then affected it - loved it, that is, held his connected state of being within himself while acknowledging the feeling of fear. He then knew to jump without any external image of the snake. For love only loves.

In this way I wish to make clearer the process of the apprehension of percepts in a way that reflects pure intuition that is the result of clearing the local mind so as to connect to the mind of God. I am aware that the preceding discussion has explored a number of ideas that have not been presented as final arguments. What I am clear about thus far is, that we function at both a conscious and unconscious level and that most of our thoughts are unconscious. I am also clear that feelings can be invoked and evoked as both a connection to the environment that is outside of the being as well as from within a being that is not connected to the external environment in the way that we perceive boundaries. And the preceding discussion has raised a new dimension where what is felt is not a feeling but a pattern of sentience that when accessed allows a feeling to be made conscious. That pattern of sentience is 'held' in and known by the body, that is a state of beingness that can be invoked or evoked.

I now wish to focus on the identification of the presentation of form through art that has been bought about by an act[s] of sensation by the apprehension and facility of what is termed imagination that is imaging as pure intuition. In dance illustration, form is at once held in the body as a pattern of sentience conveying a feeling that is then felt that then has a chemical 
response (felt and feeling). What I have not made clear is that as the body is cleared there is an ongoing 'shifting shape of form'.

Energetically form is pattern. Pattern, Houston (1997) suggested, is what people tap into when they engage in an archaeology of the mind. The tapping into is a tapping into Creation itself. This I have argued is where every Great Work comes from and I sense is the same position theorised by Hawking (1993) who speaks to the possibility of a black hole emitting a television set or ten leather-bound volumes of Proust. It is the bringing forth of what is within from a place which is one vast nothing materially, and yet all things potentially. From the point of love/creation/pure thought, to the other point - human, physically created by genetic patterns, "our genes are universes in themselves, coded with enough information to recreate the world" (Houston, 1997, p.20), there is a flow of energy. By the interaction between these two points all things are possible. In this way we bring forth every distortion that as an idea about reality has been created through the engagement of our being by being human, until the human's pattern is the same pattern as that of God/Love.

As we bring the patterns forth, bring them into consciousness, we are clearing the densest layer of our being to then make manifest the leather bound volumes of Proust. It is as if through our emotions we see the universe upside-down. In order to invert the images we call ourselves, in the first instance, to feel our emotions. With each turn of the pattern I begin to undo the distorted image and so begin to see straighter - light curves/splits in space and time. Where the true is not to be found by conscious pursuit, but rather, by "going precisely in the opposite direction" (Baudrillard, 1990, p.28). In so doing I am able to connect more deeply or fully because I am clearer. This clarity is reflected in what I apprehend/see/perceive/receive, that is then feeling expressed as form. In this sense it is feeling and emotion as was introduced in chapter three that is whole and part. As pure intuition it is whole and therefore reflects the whole. The whole that it reflects is what we name Love/God and we hear it in Mozart, see in Picasso and feel in Rummi.

We who act as audience perceive via the forms. Forms, that as a visual, auditory or kinaesthetic stimuli are described by the brain and so become images of perception that serve to enact a communication between the brain and the body as a result of a particular chemical response - hence Pert's (1997) assertion of a two way street. In this way, I am arguing the potential of bodily schema that understands before the mind has interpreted. The word interpret is of import here because I have argued that the body is the unconscious mind and so the mind as unconsciousness, the body, perceives in a way that is then not conscious. In other words I do not have the awareness of what I have understood and yet the emotion or 
pattern of sentience is elicited as either an invocation or evocation, which the brain then describes and a chemical response occurs. As consciousness, it affirms the existing reality held by that part of the brain/body. And until one begins to work with the mind in a way that is a bodily awareness of feeling from which the interpretation follows as an after event by having learned to pay attention to what one is feeling, then what is held in the body cannot be brought forth - made conscious - known. No matter how pure an art form. For as audience I perceive through my filters, mostly unconsciously, thereby arranging the percepts into the same old concepts to reinforce my sense of reality until such time that I have the awareness of what I am feeling. For whether I am conscious of it or not, I choose what I see because I create my reality. In the meantime the data transferral goes on in every single living breathing moment and therefore I am laying memories down of which I am not even conscious of, until such time as I acutely reawaken my awareness to my feeling nature.

\section{Mind Body Relationships}

Holden (1991) presents the Cartesian concept of a relationship of body and mind, termed epiphenomenalism by Descartes, where the body is said to causally affect the mind but the mind cannot causally affect the body. The possibility of this particular mind body relationship raises some interesting points as they relate to this discussion. While I am not suggesting that the body and mind do not communicate, it is the process of communication in the way I have explored it in the two preceding chapters, which is of import here.

This work has presented the idea that the mind is confused and the way to unconfuse it is to work with the emotional body. In the dialogue between Krishnamurti and David Bohm, recorded above, Bohm reiterated Krishnamurti's point, "to reach the unconscious you have to have an action which doesn't directly appeal to the conscious" (Krishnamurti, 1987, p. 538). I would add conscious mind and feeling bypasses this consciousness. I have also argued, using Candace Pert's (1997) work that the unconscious mind is in the body and the body is in the unconscious mind. Having said this, I have also said that this does not mean that they always function together as a cohesive unit. I see that this is revealed in Descartes' work. Having said this, I am acutely aware that it is widely acknowledged that Rene Descartes philosophy, known as Cartesian dualism, is held responsible for splitting human kinds thinking about body and mind. This thesis on the other hand speaks to the notion of God/Love/Wholeness as thought that has it origins in feeling as a mind body spirit connection. However, what is rarely acknowledged about Descartes work is that he 
conceptualised thought as non-spatial and therefore mental function was not attributed to different parts of the brain (Vincent, 1990).

Holden (1991), in her discussion of Cartesian dualism points out that various philosophical positions under the rubric of dualism have created some false assumptions and that in fact three alternative positions of dualism exist. These positions are interactionism, parallelism and epiphenomenalism (Holden, 1991).

1. Dualist interactionism contains within its construct the notion of a two way causal relationship between body and mind, that is, "the mind and body causally interact with each other (Holden, 1991, p.1379).

2. Parallelism views the mind and body operating independently of each other, that is, there is no connection. No contemporary philosopher takes this position seriously (Holden, 1991).

3. Epiphenomenalism is an interaction that is a one way process where "the body can causally affect the mind but the mind cannot causally affect the body" (Holden, 1991, p.1379).

In the previous section I presented the concept of bodily schema or patterns, having used dance as form and in that way presented the idea that a body understands before there is consciousness of a thing. In this way, the body has a distinct ability to communicate. "Your body is a living demonstration of the state of beingness in which your souls resides" (Walsch, 1995, p.29). Therefore, what I am suggesting is, that the body is not just a great storehouse of patterns, our memory, but that the body is actually constructed out of and by these patterns. We know that our physicality is the result of sequences of genes. We also know that how DNA is sequenced and then replicated determines the shape of a pattern. These patterns, I argue, are energy made manifest. They are the products of the interaction of experience between body mind and spirit. In this way, I argue that we create our bodies through how we process life which in turn is thought. While I hasten to add that it is a process, having done so, what exists is a pattern that is an idea the body has of itself and as such is an expression of a state of beingness. This would then account for how a dancer can access patterns of sentience before they are made conscious/revealed/known. Thus an idea exists in the mind as unconscious thought to be made conscious and if the thought is not felt as a feeling, then it will not be known. This then is how I interpret the body affecting the mind and the mind not affecting the body. The technicality of this one way communication 
is, that the body in this instance is the unconscious mind where what is expressed is, unconscious memory. And not all unconscious memory is confused, so that a state of beingness demonstrated, as say a dancer dancing, may be 'pure'.

There the point I wish to make here is, that in the expression that brings a state of beingness into consciousness, in other words to make something real or known, the conscious mind has not been used, in the same way that Krishnamurti described. In this way, I argue, epiphenomenalism exists as a state of dualism that is of relevance to this discussion in as much as, when a thing is in the process of being made conscious it is still possible to judge what is felt and in that way lay down a memory to reinforce the notion that dualism or separatism is real.

Pattern as feeling is accessed as a corporeal sensation that does not affect the unconscious mind, because it is the unconscious mind in the process of being revealed. In making the feeling or pattern of sentience conscious/revealed there exists the potentiality to judge what is being felt and in that way affect the brain body system which may be termed the conscious/reactive mind. In this way, as I have already said, it is possible to suggest that the state of the body causally effecting the mind, but the mind not causally affecting the body does exist. Because in the process of making the unconscious conscious the body is the unconscious mind, however as the brain body system the human brain might also be termed the reactive or conscious mind. For the body to causally effect the mind, but the mind not to causally effect the body would then mean that the unconscious feeling when experienced is judged, thereby effecting the mind which is the body. Whereas, if the unconscious feeling is not judged then the mind as the unconscious body is effected and in that sense the mind is 'changed'. This interpretation rests on understanding the difference between the conscious and unconscious mind as they relate to the body and the word causally being interpreted to mean having an effect upon, that in keeping with this work would mean, reducing the space or gap in consciousness that perpetuated duality. Thus effect on the body that is the result of how a pattern of sentience is processed, for how it is processed will either widen or shorten the gap. And so there is an effect the interpretation of epiphenomenalism resting on these points.

Kaelin (1970) argues, the ability to 'see' how the dance feels is because the feeling is the global kinaesthetic image. A modification of the dancer's bodily schema to which we respond visually, visually in that it creates the image that is not an image in itself but our own bodily schemata undergoing a similar kinaesthetic modification (Kaelin, 1970). I would then add whether we are conscious of it or not this process is occurring with every breath. The 
body to body transmission/communication of thought is one way that young children begin to see the self in the world. Therefore, if our bodies are created by thought, then what is communicated by this body to body communication is also representative of how pure one's thoughts are, which in turn is reflected by the body. In a Western world obsessed with body/physical appearance, such a statement is almost inflammatory. Jesus the Christ is depicted as tall and slim, while the laughing Buddha is large and rotund. Yet, both these beings, as embodied beings, are acknowledged as having embodied such an expansive of love. Thus body shape and size is not indicative of how pure thought is or is not, rather, how the purity of a being is known, is by the love radiated from their being which in turn is pure thought. Thought. regardless of its purity which is communicated from one body to another.

In the dualistic state of epiphenomenalism it is another level or state of partial connection that represents a form of separatism of body and mind that is part of the illusion of duality. For we cannot, not be unconnected. Even in this state of separatism we are still connected, for what we are connected to, is each other - through our bodies. Thus the body causally effecting the mind can also be interpreted through a body to body transmission, as a global kinaesthetic feeling that can be processed as an unconscious experience, where we take it all in but are only conscious of some things, but as an unconscious process then either closes or expands the gap. Children I argue are experts at this process and in that way begin to formulate their ideas about the world from those around them.

In this way, through our bodies we serve as a reflection of each other and so draw ourselves to each other, so that we might release the memories that serve to support the illusion that dualism is real. In so doing, as process, we can continue to clear our bodies and in that way clear our minds. Having said this though it is still the same process, where in order to clear the mind what the bodily schemata represents is still pattern translated as a feeling and as such is to be felt. Awareness is the key to this possibility.

In pondering on Descartes' positions on dualism, I wonder if we have missed what this work has to offer? Where in the experience of being human dualism as states of polarity and boundaries do exist, but not as states in themselves but challenges to transcend this form of reality. What if Descartes work was the result of pure intuition that until I remove my filters and blocks, as they relate to dualism, I will be unable to see from a deeper perspective? In delivering The Theory of Relativity to the world Einstein while perceiving the potentiality, himself never conceived of Hiroshima. What followed Descartes work can hardly be attributed to him alone - his theory accredited with having split body and mind. Then again, I 
am reminded of two things. First, Baudrillard (1990) asserted that in order to pursue something we sometimes need to go in precisely the opposite direction. In other words, in our exploration of dualism might we bring ourselves closer to unity? Second, nothing in the universe is ever wasted, because there are no mistakes or accidents. Even a dead end can show us what we do not desire, and in that way, it has served a purpose.

I have said that we store pattern in the body and that our bodies are "a living demonstration of the state of beingness ...." (Walsch, 1995, p.29). So while a pattern may not be communicated to the mind, in the sense that the mind becomes conscious of a pattern as an end, these bodily schemata are responsible for drawing us together so that we can 'thing'. As with anything, how we engage in something determines the outcome, that is, by process we create product. So we come together to experience an aspect of life and in parting the pattern is either more complex or simple. And herein is an important point. In each instance of pattern, a state of duality still exists. For as I have already said, in the process of feeling, where feelings are felt, change is process and not event. Therefore, each step is a turn, an operation of an iteration of the fractal pattern. And while there does comes a point where the accumulative effect of the changes produces something different as an overall arching theme in the way Martha Rogers (cited in Madrid and Barrett, 1994) defines as the 'Principle of Resonancy', it remains a process. As process, it represents an increase in frequency that is the expansion of consciousness. In that way a boundary has been transcended because a human being, being, has engaged the self in a form of alchemy and therefore generated a more excellent thing from a less excellent thing (Aquinas, 1267/1952). None-the-less it remains a step by step process, where the only concern is, what is present in the moment.

In this process of uncovering, our being is evolving where the channel of communication 
consciousness where ultimately the father and I are one or La illaha el Allah hu (There is no god or self except for the unity that embraces all).

So rather than continuing to attribute blame and responsibility to Descartes' work for having split the mind and body of humanity instead, might another view of this particular body of work be viewed as an external image reflecting an internal state? One in which duality exists as a possibility of third dimensional seeing? For in positioning my argument I have argued that in the experience of being human we have called ourselves to come to know ourselves, in the experience of ourselves through feeling. Feeling I have then argued, is the dominion of the mind/soul that is evoked or invoked in daily living that then serves to connect us to our conscious or reactive mind through which the ego acts. In a moment, how we choose to respond to what we feel determines an outcome, the effect of which is both corporeal and mindful. Where it is the expansion of consciousness we are then less separate from God/love. On the other, as reality that is further distortion in that it is as a contraction of consciousness, it is then felt as less love. As such we feel more separate from love and so reinforce the idea that a here and there exists. That dualism is real.

If the dualist positions in relation to body and mind posed by Descartes are seen in this light, they then present an opportunity to work with duality that serves to assist in turning the images around. Eventually we do come to see that being human is not real. By perpetuating the reality that our bodies are real, for that is what is reflected in the idea of the mind not being able to causally affect the body, this then becomes a reifying idea/belief of the very essence of dualism. I think, therefore I AM. By continuing to tell ourselves that what physically exists must be real, reflected in the belief that reality is defined by physicality for if a body cannot causally affect the mind then the ideas that the body holds (I have argued unconscious memory/thoughts are patterns of energy creating our reality) are ideas that must be grounded in space and time. Ideas grounded in space and time cannot be expressions of expanded consciousness or, the mind of God.

I would also wonder if the mind body relationship described in the dualist position of epiphenomenalism is also a from of materialism. Because the human brain is part of the human body this does not assume that brain and mind are synonymous. And as I have argued earlier much depends on the interpretation of the words conscious or unconscious mind. If so then in either case, the outcome is the same. For in perceiving that the mind is not capable of a disembodied existence, the position of materialism, is to then define reality in relation to the body and therefore it is an independent form of surrender. In the belief that the mind is capable of a disembodied existence in the sense that it generates true thought is to 
believe that there are two minds and so reinforce the notion of dualism (my mind and God's mind). And as long as those two minds exist, there exists a state of dualism.

Having presented my argument thus far I am well aware that the philosophy of materialism maintains that the mind is contingently identical with the brain and therefore the mind is not capable of disembodied existence. Dualism holds that the mind is capable of a disembodied existence. In this way these two philosophical positions are said to be rendered as incompatible and mutually exclusive (Holden, 1991). I argue there is nothing in the universe that is incompatible or mutually exclusive, for all things come from love/God and it is only how we choose to see something. In demonstrating a connection between these philosophical positions as they relate to separateness, I have presented my argument in a manner that I hope has made clearer a process that reflects the possibility of the unity of body mind and spirit as we are guided back to the feeling of wholeness where dualism exists as one of those states and materialism as another.

Having said this, I would say again. In the same way that my small journal entry earlier in this chapter described a huge change in consciousness in relation to choice, in other words my coming to know that I had choice, to transcend the idea that existence is defined to an idea or a belief about the body is not attained by reading these words and agreeing with the argument. For in that way it is still that, an idea or belief. To believe a thing is not the same as knowing a thing. In the process of Aletheia we have called ourselves 'to be'. Not as an idea or belief, but in the fullest expression of the purity of our beingness. For in being God we are coming to know God. As we take each turn or step in our unconfusing the unconfused, this is our coming to know. "Where If I am to know God directly, I must become completely God and God I; so that this God and this I become one I" (Eckhart cited in Houston, 2000, p.128). Then God is not an idea, God is known.

I had said earlier that having a clear memory was having a clear body. Having said this, I would wish to place this thought here. Can one clear ones mind of confused ideas or thoughts, without clearing ones body? I wonder. I wonder if this is what is expressed in the dualist position of parallelism, which Holden (1991) reminds us is not taken seriously by any philosopher. Religious life, in both eastern and western worlds, devotes all conscious thought to thought on God/Love but at the same time has emphasised a denial or repression of the body. I am not specifying sexual expression in relation to the body but rather the order that was/is maintained by suppressing anything that was not deemed order. In this way clarity of mind can only exist as conscious mind, and in that way having a clear mind without 
the corresponding clarity of body must diminish, power. This then is reflected in the sentiment, you can not ascend from the neck up.

In order to 'will' - desire/pleasure/enjoyment something to make it a physical reality, it is as if it is brought down from pure thought, the world of forms, through various layers. Everything exists as energy. The layer before the physical body is the emotional layer. Therefore, before I can 'will' an apple in my hand as an act of Creation for my pleasure, I need to be able to connect with true mind or what some would call the realm of spirit or pure thought or the world of pure forms and connect with the pattern. From there I move it down through the mental and emotional layers. This schema of layers varies. Pierrakos (1987) depicts a being that magnifies the emotional layer in its relation to the core. The work of Brennan (1987) gives three layers with a total of eight sub planes or layers, while the esoteric schools derived from the Bailey writings (1930 -1950) show diagrams of seven layers each having their sublayers. So even while a number of positions exist, what is recognised is that we are multidimensional beings that have at very least physical, emotional, mental and spiritual layers/sheaths. Therefore, in order to bring something from pure thought I have to be able to bring it through the layers or levels where physicality is at the end of that spectrum. The layer preceding it is the emotional layer. This thesis has argued that the emotions are stored throughout the body and that the body is a reflection of the unconscious mind. In that way, unity has to be a body/emotion mind spirit connection, not conscious mind to spirit.

This thesis has argued that most of our thoughts are unconscious and that thought is stored in the body as emotion. Therefore wherever I am blocked at an emotional level, that is, the layer before the physical, the pattern held by the body is not consistent with the pattern of an apple. I cannot fully merge with creation itself. In that way I do not bring the pattern of a 'pure' apple forth and make it a physical reality. The apple either remains at whatever level/stratum before the block, thus is virtual reality a possibility existing as the potentiality of an idea, and so in that way everything is possible. What I bring through then is a variation that contains a distortion in the same way that I am distorted. In this way it not about apple creation per se, rather, it is about the manifestation of spirit into matter and hence as process deconstructing the idea that dualism exists. Therefore, I am arguing that we have a huge vested interest in having clear bodies, to release the memories. For if we bring forth what is within us then what we bring forth will save us. Not in the sense of physical survival but in the sense that love will abide so that we no longer exist in a state that perceives that we are separate from God/Love. 


\section{The role of body therapies}

In the foreword to the text, Natural Therapies - The politics and passion, by Judy Jacka, (1998) Willis writes that the text is timely because complementary therapy is a significant and growing part of health care in Australia. And that while the various modalities have not been taken too seriously by orthodox medicine in the past, "it is clear that they will need to do so in the future" (Willis cited in Jacka, 1998, p.xi).

In her discussion on the approach taken by orthodox medicine, Jacka (1998) uses the argument of particle identification having the characteristic of waves and thereby every particle is connected to every other particle through fields of energy. In this way, the body is made up of particles and we are an expression of energy, "expressed as energy through the wave function of each particle" (Briggs and Peate cited in Jacka, 1998, p.8).

This means that the energy factors in health and disease, which has been stressed by natural therapies, must be very important. Further reflection gives us the insight, that if every particle is connected to every other particle, we cannot treat one part of the body in isolation to the whole. Even Canon who gave modern medicine its physiological basis in the 1930s perceived that each part mirrors the whole. It appears that both the orthodox medical and naturopathic views of the body are correct. The body is material and it has parts which can be fixed and or replaced but, underlying these parts, are energy fields which connect or manifest the particles.

Jacka (1998, pp. 8-9)

Natural therapies work with the energy patterns that as physical manifestation are illness and dis-ease. It is not for this work to discuss the workings of each modality. The position of this work is to acknowledge that if we continue to place the centrality of our focus on healing and health care that is one of fixing up the body, then we will continue to ignore the manifestation of dis-ease as a potentiality in the lure of our becoming. Having said this, I do not wish to negate how our understanding of the universe has enabled developments in orthodox medicine that have assisted people who otherwise would have died or supported others who without such intervention would lead more restricted lives. The use of virtual 
reality incorporated into neurological and breast cancer surgery is one example. Therefore, while our insights into the workings of the universe have enabled new scientific developments to be translated into treatments, techniques and technologies that have changed the way in which we live, I am arguing, that these forms are a representation of the consciousness of those who have brought them to us. And like the forms that were translated into Nuclear Theory, we can use this knowledge as one would use a walking stick that supports us for a time in our ongoing evolution. Alternatively we can rigidly hold onto these ideas and therefore the consciousness that they reflect. We each make that choice. As knowledge all theory should eventually no longer serve us. That is not to say that it has not assisted us rather, in the ongoing process of expansion of consciousness the theory has served that ideal in some way. Alternatively, we can use the knowledge of nuclear theory to blow ourselves up. It is a choice.

So as we engage in the research and development of ways to fix or manipulate the human body humanity continues to manifest all wonder of new diseases and increase the incidence of others. As we open another century, coronary artery grafting is now performed with precision, keyhole surgery continues to advance, and when all else fails we can resort to transplant depending on the availability of an organ. The lack of 'spare' organs is one factor that has opened a new frontier of fixing or manipulating the body. Stem cell technology is being hailed as the new panacea in health care. We are excited that we can grow cells in a laboratory that then have the ability to replace or repair organs. The fact that the body is continually replacing cells and that this ability is disrupted by dis-ease has not led us to ask might this normal mechanism of the body be consciously invoked? The one organ that in physicality we assume to symbolise love has not even been considered from the perspective that heart dis-ease may be a reflection of the accumulated effect of love that has been 'attacked' - heart attack. To repair a damaged heart would mean that a human being would need to become conscious of how they were attacking love. For as this thesis argues, we create our bodies by how we think which in turn is connected to what we feel.

I have also said that where we place our focus then determines what we create. So if our focus, our thoughts, our energy, are placed on fixing disease then that is what will be made manifest. In the meantime, we will continue to create dis-ease so that we can keep on developing new ways to fix our bodies. So while our focus, in the main, remains on fixing/curing, we will continue to ground our thinking in physicality which in turn reinforces the idea that we are our bodies and that duality is real. I think therefore, I am. 
This thesis has argued that what exists initially exists as energy and therefore to change a thing is to first change the energy. Our current way of approaching orthodox medicine does not suddenly dissolve when we seek out natural therapies. In other words to approach the use of natural therapies with the same mode of thinking - to fix the body will have limited results. For health is a way of being, that reflects a choice we each make every time the need arises to seek out a form of health care. It is the potentiality to change confused thought and in that way become more - love, and in the process change the flow and heal the dis-ease. Natural therapies supporting one in that process.

\section{The relationship between body therapy, memory and disease}

In the third chapter of this work, the idea of passions [emotions] as they relate to movement and the body was discussed. I now wish to restate some of that argument in order to expand upon it.

Aquinas (1267/1952) claimed that passions are a domain of the soul and when taken from the perspective of reception they are feeling and understanding. In the exploration of the word passive in relation to the passions, Thomas Aquinas (1267/1952) argued that it is generally assumed that the word passive implies that one is the recipient of something and that nothing is taken away. This Aquinas (1267/1952) asserted is not passivity but a form of perfection. Passivity in its proper sense includes both being the recipient of something and as having something taken away (Aquinas, 1267/1952). Expanding on this idea, Aquinas (1267/1952) explains that it is a twofold process. Firstly, what is given up is sometimes that which was not suitable in the first place for example, ill health being replaced with health. In this way ill health is then deemed passive (Aquinas, 1267/1952). However, it is possible to turn this perspective around. Using health as an example, Aquinas (1267/1952) says that to ail is to be passive too because ailment is received and health is lost and therefore the passivity lies in the notion of giving and receiving. It is in the notion of giving and receiving, in the first sense, that passion has its proper meaning (Aquinas, 1267/1952). "For something is said to be passive from its being 'drawn to' the agent, and when a thing recedes from what is suitable to it, then especially does it appear 'to be drawn to' something else" (Aquinas, 1267/1952, p.721). Aquinas (1267/1952) then expands giving and receiving and in so doing gives us an important clue in the process of 'being drawn to'. "When a more excellent thing is generated from a less excellent, we have generation absolutely, and corruption relatively", and "when from a more excellent thing a less excellent thing is generated" (Aquinas, $1267 / 1952$, p.721). I have argued that non judgement of an emotion is the key to 'generation 
absolutely'. It would appear that Aquinas confirms this, not by his language but in the idea that "passion accompanied by the loss of something, is only in respect of bodily change" (1267/1952, p.721).

In this exploration of passion as movement, Aquinas (1267/1952), by what he terms as 'something is received and something is taken away', I perceive, is also explaining a process. As process, it is a movement, but at the same time has movement as its outcome.

Movement in the first instance as a recession in the sense that it is a reversal in the way that I have described movement from complexity to simplicity using fractal geometry in an earlier chapter. So while a movement appears to be a forward movement in relation to space and time, it is also a backward one [reversal]. In the second sense, where movement is termed a loss as opposed to being taken away, the movement remains at a bodily level (Aquinas, 1267/1952). In other words, the movement is one that is more complexity. It would also appear that this distinction is a factor in determining passion as the domain of the soul. For in the notion of being taken away or reversal that is connected to feeling and consciousness it is soul process, whereas movement which is termed loss is movement which remains at bodily (corporeal) level through having denied the soul. Judgement, fear and doubt will deny the soul. Such a view is consistent with the outcomes Aquinas (1267/1952) termed 'generation absolutely', in response to process where 'a more excellent thing is generated from a less excellent', and 'corruption relatively', in response to process 'when from a more excellent thing a less excellent thing is generated'. Further, this perspective is consistent with the Spinozian (1677/1952) idea of the passions serving to act as some sort of catalyst by which 'the self' [soul] can approach 'the good', or that which is useful to us, and escape 'evil', or that which hinders us from possessing anything which is good.

In repeating some of this argument from an earlier chapter coupled with the ongoing discussion of how life, as memory, is stored in the body at an emotional level that is then either invoked and evoked in way that it is a feeling to be felt or brought forth in the intention of expanding consciousness, I would now hope that the positions of Aquinas (1267/1952) and Spinoza (1677/1952) have been made more clear. I have said that we lay our experiences of life down in our bodies. Our bodies are our unconscious memories. I have attempted to illustrate this point using concepts from Fractal Geometry to show that we can pack infinity into a grain of sand. This same phenomenon is one depiction of the Lorenz butterfly, and even though there is a repetition of a pattern, the lines never intersect on them selves. In this way, we can experience 'a thing' over and over again until such time as the pattern is no longer predictable. That pattern can be termed chaos, and chaos, I have also argued, can be a 
metaphor for dis-ease while remembering that in chaos there is always an area of non-chaos. The more excellent thing that Aquinas (1267/1952) refers to is when a confused idea has become unconfused and in that way there is 'generation absolutely'. However when from 'a more excellent thing', and in this way he avoids making a judgement, 'a less excellent thing is generated', there is 'corruption relatively'. In other words, further distortion, or confusion or complexity.

Therefore, passivity when defined as receiving and giving up becomes another way to discuss gathering and holding as activity within the void. For in order to gather, one has to be able to receive. In holding there is also the notion of receiving and in that way something is then taken away at a corporeal level, a giving up, in the way that I have described loving or not judging what is felt. Then, what has been given, has then been received because the pouring out is a consecrated libation. One has to give up the old, which in the Heideggerian (1972) sense is in the holding that takes place in the void. In order to give the thing up, it is actually held (retained/heard). Where the true is not to be found by conscious pursuit, but rather, by "going precisely in the opposite direction" (Baudrillard, 1990, p.28). To hold then is to embrace/accept/receive and then give it up. In that way, 'a thing' is transformed. Aquinas (1267/1952) says as process it is movement, but at the same time has as its outcome movement. So movement in the first instance is a recession, in the sense that it is a reversal, that is, the idea has become less distorted. In the second instance it is that which is termed a loss, which is not to be interpreted as having been taken away. For this type of loss is movement that remains at a bodily level only (Aquinas, 1267/1952). In other words, what has been gathered has not been held in the void and so the loss is only at corporeal level. The outpouring then is a mere decanting.

Thus movement, as described by Aquinas (1267/1952) which is both process and loss in the sense that something has been taken away is, I argue, Descartes (1641 cited in Holden, 1991) dualistic position of interactionism. The body and mind have had a causal interaction with each other. Where movement is at body level only, and therefore can be expressed as a 'less excellent thing having been generated', then it is epiphenomenalism because the shift of an emotion remains within the body. In such instances communication remains at body level and as such remains unconscious, not known, not heard. However, there is one more variable in this ongoing process. When this occurs it is not always indicative of more complexity, for it is recognized that this may very well be the lifting or raising of unconsciousness so as to bring it toward consciousness. As such it is process, in the process of making the unconscious conscious, where thought remains unconscious in the body. While the emotion has not been transformed, none-the-less it may be a transition and so 
create a shift in awareness. That is why the focus is kept on not what has occurred, but on what is being felt in a present moment. For when the transition is complete, in the main, it becomes conscious. The thought form just surfaces. In the process this form of movement is not unity between one part and another because what has been shifted is the same distortion. In that way, the group of cells is receiving more of the same information. What has determined the movement is that there is a similar pattern in the first instance. Like attracts like. But in that way the distortion is magnified even further. The energy has been magnified and so the experience that is called forth is bigger. Eventually, it is experienced as pain in the way that a full thickness burn is not painful but a partial thickness is because it is closer to the surface. So on one hand we lift something into consciousness by this process but on the other at any point we can choose to begin to bury it again. In this way we bring a distorted thought through layers because sometimes it is not possible to make the movement in one movement. At any stage we can choose to abandon the process and so begin to make what was becoming more simple more complex again. In making the latter choice the net effect of repeatedly creating complexity through making a judgement of what is being experienced/felt is the mechanism for dis-ease as I have described in this work. On the other, it is the basis for aging because as oxygen is vital to our physical well being so love is vital to our being. The denser the organism the more it is cut off from the vibration of pure love. We do not let love into our being.

Aquinas (1267/1952) clearly acknowledges the passions as a soul process. In his idea of receptivity there is the implication of an impressionability or sensitivity. For in the argument of the interpretation of the word passive, where passivity is said to encompass not only being the recipient of something but also as something being given up, Aquinas (1267/1952) claims that such a receptivity is not passivity but a form of perfection. I wonder then, if the perfection he alludes to is an impressionability or sensitivity where having opened the self to the ongoing cycle of receiving and giving up then reflects the continuous flow in and out of pure love. For to be passive is to allow a flow that is without control and when we do not control what comes to us we can only receive. Receiving comes before giving.

When we consider that the Angelic Doctor [Thomas Aquinas] gave daily lectures to a crowd of disciples during nearly the whole of his public life $\ldots . .$. assures us, moreover that he had the faculty of being able to dictate to three and sometimes four, writers at the same time, on different matters; without ever losing the clearness and continuity of each subject. One of his secretaries 
testified that even when overcome by fatigue, he closed his eyes in sleep for a short time, he continued to dictate as before.

Cavanagh (1890, p.206)

Jacka (1998) notes that by the late 1990's there were at least one hundred types of natural therapies practised in Australia. Most of these modalities are concerned with assisting to balance body energy and in that way indirectly improve the organ function and eliminate toxins (Jacka, 1998). The centrality of natural therapies is the belief that prior to the development of a pathology, that is, before the clinical manifestation of a dis-ease, there are subtle imbalances of energy that have occurred over some period of time (Jacka, 1998).

This thesis has argued that we are energy, that all form is pattern and that we create pattern by 'the how' of our engagement in life. Further, I have argued, that to view health as 'the good' and ill health or dis-ease as 'the bad', is to view health from a dualistic position brought about by the notion of judgement where in naming something as good or bad we have rejected an aspect of the self and therefore continue to keep ourselves in a state of separation.

Dis-ease, it has been said, is about the beautiful, the good, and the true, a distortion of Divine possibilities (Bailey, 1953). Therefore, as has been explained in the creation of pattern, it would then follow that no natural therapy or orthodox medical practice can make any one whole. For as Heidegger has told us, "Thinking is thinking only when it recalls in thought the unspoken, tacitly". And it is this which is the duality of beings and Being" (1968, p.244). We cannot not think. Thinking is the lure of our becoming and as pattern is created in the process of life. In this way we create illness, but in this way we can also heal ourselves.

To then believe that another can uncreate our own creation is to not only deny ourselves as a Creator, but to deny the very purpose of our existence. Having said this, I would hasten to add that the various natural or complementary modalities can and do support us in our own process. What I am arguing is, that to claim that a natural therapy will cure is to adopt the same thinking that has guided orthodox medicine. It is another form of separatism for it locates power outside of the being.

Therefore, the purpose of natural therapies, I argue, is as Jacka (1998) has stated. Natural therapies work to support another in re-balancing the energy system, be it by whatever modality. Very clearly this is possible. However, until such time as the human being learns 
how to work with their emotional body and thoughts, then what has been created, the imbalances, will be recreated within minutes hours and days of having received a therapy. This, I argue, accounts for patients experiencing some relief of symptoms and others reporting no change in the long term. For those who do experience a 'cure', I argue, it is the result of having worked with the whole process where the particular modality has assisted and supported that being where what has occurred might not be understood. My early example of the women with diabetes and feet ulceration is a small illustration where my engagement was conscious. I would suggest though that it can be as simple as seeing a movie that then serves to act as the evocator for the emotion to be received, and which coincides with that person undergoing a course in acupuncture.

Further, in examining the argument on predictability, where the level of predictability prior to the state of chaos is predictable in the forward sense, this then applied to health care, be it orthodox or natural, would mean that there is something about the modality that is at the level of translation of the thought pattern, in the same way that truth can be patterned in art. Therefore, when we respond to the pattern we are responding to truth. This is not a conscious knowing for all, and yet at another level there is a recognition, and thus we are at an intuitive level 'being drawn to' what is appropriate for us at a particular time. This would not only account for some people responding to treatment but also why all modalities are not suitable for every being at the same time. It is a matter of vibration. Also, what presents as dis-ease and is classified as non threatening may have been the precursor to dis-ease of a more serious nature. Intervention by a natural therapy in this instance is preventative health care at its very best. Natural therapy is working with an energy imbalance that is behind the pathology, virtual dis-ease as it were, and although it is actioned on the body in some way, nonetheless it is directed through the body. Therefore, the person may have engaged in a form of health care where nothing is visible but where everything has occurred. However, I maintain that where a thought remains distorted, a dis-ease will be made manifest. It will only be a matter of time.

Orthodox medicine on the other hand focuses its practice on working with clinical symptoms and presenting pathologies. In its efforts to further understand illness orthodox medicine continues to focus its activity on understanding dis-ease at the biological level and then develop treatments accordingly. This is because orthodox medicine works on the physical body and in that way continues to view health and illness as separate to Being. It is another reflection of dualism to reinforce the reality that things happen to human beings. We 'get' sick. 
In owning dis-ease as a creation, it is then possible to perceive the ability to recreate it. Not in the sense of curing ourselves but to pattern our energy differently. For while dis-ease is an energy imbalance, to view health and illness within the notions of good and bad is to continue to think in terms of duality. As process then energy imbalance, that is dis-ease, is the opportunity to rebalance. Non chaos from chaos and hence the description of dis-eae as having it origins in the good, the beautiful, and the true in all manner of mystical writings. The choice is ours. As we come to understand this, then we will begin to work with natural therapies and orthodox medicine in different ways.

For the purpose of life is to create experience, and in the creations is the possibility of creating the self in every glorious moment of Now. You do not, therefore, choose the life you will experience ahead of time. You may select the persons, places, and events - the conditions and circumstances, the challenges and obstacles, the opportunities and options - with which to create your experience. You may select the colours for your palette, the tools for your chest, the machinery for your shop. What you create with these is your business. This is the business of life. Your potential is unlimited in all that you've chosen to do. Do not assume that a soul which has incarnated in a body which you call limited has not reached its full potential, for you do not know what that soul was trying to do. You do not understand its agenda. You are unclear as to its intent. Therefore bless every person and condition, and give thanks. Thus you affirm the perfection of God's creation - and show your faith in it. For nothing happens by accident in God's world, and there is no such thing as coincidence. Nor is the world buffeted by random choice, or something you call fate. If a snowflake is utterly perfect in its design, do you think the same could be said about something as magnificent as your life?

Jesus did not heal those he healed because he saw their condition as imperfect. He healed those he healed because he saw those souls asking for healing as part of their process. He saw the perfection of the process. He recognized and 
understood the soul's intention. Had Jesus felt that all illness represented imperfection, would he not have simply healed everyone on the planet, at once. So why were some healed and others not? Why would the Christ choose to have some suffer and others healed. For that matter, why does God allow suffering at any time? The question has been asked before and the answer remains the same. There is perfection in the process - and all life arises out of choice. It is not appropriate to interfere with choice, nor to question it. It is particularly inappropriate to condemn it. What is appropriate is to observe it, and then to do whatever might be done to assist the soul in seeking and making a higher choice. Be watchful, therefore, of the choices of others, but not judgmental. Know that their choice is perfect for them in this now moment - yet stand ready to assist them should the moment come when they seek a newer choice, a different choice - a higher choice. Move into communion with the souls of others, and their purpose, their intention, will be clear to you. This is what Jesus did with those he healed - and with all those whose lives he touched. Jesus healed all those who came to him, or sent others to him supplicating for them. He did not perform a random healing. To have done so would have been to violate a sacred Law of the Universe: Allow each soul to walk its path.

Walsch (1995, p.46-47)

\section{Nursing intervention}

At its very best, Nursing has always known that healing takes place from a soul to soul connection. These magic moments in Nursing are profound, and happen in the most common places in the most ordinary ways, Yet at the same time they are extraordinary. Extraordinary, because despite our organisation and reorganisation of our practice and education sites, healing is not the focus of activity or learning. In the main, while more considerate of human concerns than in the past, our focus is largely on the physicality of a person in the practice site. Our educational focus has concerned itself with ways of teaching which still reflect mechanisms of dis-ease and acquisition of tasks associated with various 
interventions and is coupled with much more emphasis on interpersonal relationship. The practice reality has frustrated many practitioners. And even though the account given by Jacka (1998) for her shift from Nursing into the exploration of natural therapies was some thirty two years ago, it can be said that Nursing in this point of our history as a group, is well into this very same shift. The difference on this occasion is that the transition is not from nurse to natural therapist, as Jacka (1998) did, but rather Nurses are shifting to incorporate some of the modalities of natural therapy into Nursing.

As such the question needs to be asked, why? But why, not as some justification of natural therapies, nor as a political issue of ownership, but rather, why as another attempt to bridge the rift of what is inherently known and what is encountered in organisational life. For every clinical day, every nurse is faced with the dilemma of the results of our having rendered ourselves helpless in order to become who we truly are. In the relationship of Nursing, which is the human-being to human-being relationship that can allow such closeness of being such intimacy, [into-me-you-see] it is as if we hear one another call. We then look around at our system of health care and know that we are not answering these calls. It is as if somewhere in our unconscious knowing we hold a memory of our ability to help one another. At one level we remember that we are all connected in the process of becoming and so then we are willing to embrace something else that appears more consistent with this inherent knowing of the whole. The why is our intention is to take another step forward. In being able to work with the mind and body as receptivity and giving up so as to make thought known, we are remembering. At some point in our remembering we will begin to make real the prophecy of a great healer, the works that I do shall he do also, and greater works than these shall he do.

Then we will not require 'spare parts', or experience dis-ease unconsciously, for by then we will see dis-ease as the opportunity to change thinking. Ultimately we each have the capacity to grow a new limb or body part once having decided to experience ourselves without that part - just for the experience of it. 


\section{Summary}

This chapter further explicates emotion, feeling and non-judgement as a process of being. The idea of the body as memory is extended to introduce states of mind body communication that holds central to the idea in the thesis that this communication occurs through an emotional/feeling process in which there is a conscious choice of will. The outcome of which is to either expand or contract consciousness. As contraction, it is further separation of body and mind where that separation reflects states of consciousness that exists as duality. The body as a reflection of the mind also communicates states of being. This idea then serves to further identify being as either an automatic response and thus an already achieved state, or a wilful action, and in that way a state to be achieved. In this way being is positioned as an engagement of the mind and body through emotion and feeling that serves to either reinforce the idea of separation or non unity through the experience of being human or, to connect a being to the greater Mind/God/Love/Source as consciousness that is feeling to be expressed. The idea of the body as reflecting states of being as an automatic response then opens the discussion to explore creation or creativity as a conscious intent.

Illness is also viewed as a state of mind. As such illness is then an expression of consciousness and in that way allows for the experience of illness to be viewed as the potentiality for a human being to express a greater consciousness through making choices about being. In this way, healing in nursing and the use of complementary therapies is positioned as a potential to enable or empower another from the place of choices about being. 


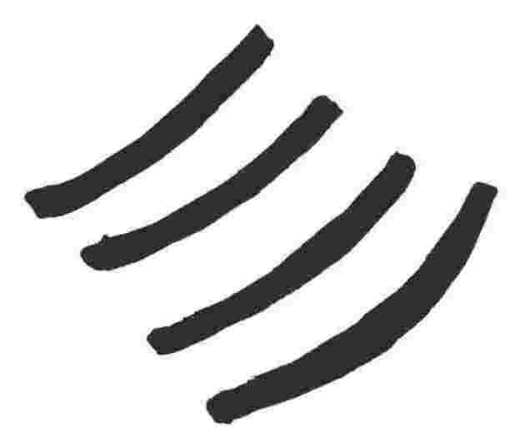

\section{Chapter 10: The Aesthetic in Practice and Curriculum}

\section{Nursing as it is lived}

During the past three decades, Nurse Scholars have created theories of Nursing in an effort to articulate the essence of Nursing. Nurse Researchers exploring nursing from various frameworks or methods of discourse have supported these theories and added new dimensions. In this way we have attempted to articulate the essence of nursing, so that its form might be more clearly explicated from which a scope of practice may be defined, developed and expanded. In making these statements I am not positioning myself for a top down or bottom up argument on the method of theory development, rather, I am making some statement about what I perceive to be possible reasons behind our pursuits. Further, I do not wish to pursue arguments about the economic or political nature of our endeavours.

We have argued whether we are a science or an art, or both. We have questioned our oral tradition. Recognised and made changes to the influences derived from military and religious structures of the past. Through our inquiry, we have attempted to espouse our hidden values, make more of our vested interests known and examined ourselves from feminist, critical and post modern perspectives. We have pronounced ourselves as caring nurturing women and men. The list is endless. Why have we engaged in such a pursuit? Is there any other discipline, if indeed we are a discipline, that has turned itself inside out in an effort to explain who we are and what it is we do? Such a struggle has to be more than just a quest for legitimacy within a social consciousness that assumes a pseudo power by rewarding legitimate groups accesses to structures and rights in a society. For if it were only a quest for this sort of legitimacy, then given our history, I argue, we would have retreated, battle worn and scarred, a long time ago.

Yet, history is witness to this struggle by successive generations of nurses since Florence Nightingale. Where Nurses, women and nursing, as one of the least powerful groups in society and health care have engaged in a myriad of activities that have ensured Nursing's 
survival as a group and as a profession. Nursing, it would seem, has been guided by something else. It is as if within the consciousness of Nursing there is a knowing. And by this struggle we continue to re-member that, "each generation of nurses are charged with the responsibility, individually and collectively, of making the symbol of healing transparent and of translating the myth of health into a personal and public vision" (Salmon cited in Martin, 1991, p.3). As we do so we are realising the vision, "the potential of nurses to fulfil their social responsibility in human service" (Rogers, cited in Malinski and Barrett, 1994, p. 116). Nurses and women have held in their consciousness this ideal of service to be lived out through health and healing. Our history when viewed in this light is purposeful.

In the writings of those nurses who have communicated their thoughts and findings on Nurses and Nursing, we have come to acknowledge that these writings have preserved in their theoretical positions central tenets of what we understand nursing to be. Each, in their own way, speaks to the knowing of what can take place between the one named nurse and the other named patient or client. Through the phenomenon, we name health and illness, what is known is that there is a quality of relationship that has as its basis the very essence of our existence that is expressed in our being-human. In Nursing, this magnificence is realised as we have called ourselves to witness every possible distortion of life but in which is held the most beautiful, wondrous, courageous, loving, and enduring beings, being-human. As a nurse I have been blessed to encounter so many who would show me that the distortions are just that, distortions. Having experienced nursing in this way there is no doubt of our magnificence. On each occasion I have been reminded that we are all made up of the same 'stuff'. I wonder, is this what enables us to continue the pursuit of our individual and collective visions?

I was asked to relieve in isolation room two. I had distanced myself from this child after Ro's death as I felt I had nothing more to give for a little while. Also the pain of the loss was still there. So I went in for the half hour tea break. Jackie was five and she had a C2 spinal fracture. In essence she could blink, swallow and smile. I was unfamiliar with her routine, "What will I do with her"? "Play fish" my colleague shouted as she left the room. Fish? "Jackie, what do I do"? As she spoke in time with the ventilator, she instructed me to get an ice cream container labelled fish from the shelf behind her bed. I located it. I opened the container to find a pole with string attached and a magnet tied to the end. The container also held about half a dozen fish which had staples inserted in them. "Ok Jackie, what do I do now?" She told me to put the stick/pole in her mouth and then hold the container as I threw the line into the container and then pulled it out to see if there was a fish on the end. Her part was to hold the stick in her mouth. I did so. On about the fourth attempt I began to choke back the tears. She had found pleasure in this simple game while all I could feel was total despair and helplessness. 


\section{Nursing as it is learned}

In the same way that Nurse Scholars have attempted to articulate the essence of Nursing, so too have Nurse Educators, who in the main have been the scholars to date, sought to develop an array of curriculum models that translate nursing into a learning activity. The dilemma has always been how to prepare practitioners to function in a system that revolves around the biological integrity of a person, while at the same time acknowledging the limitations of such a perspective on the possibility of Nursing. Since the late 1990s, this situation has been further complicated by access to clinical experience as educational institutions encounter both funding and site issues. This factor is not limited to the Australian experience. Where nursing is organised as a tertiary educative initiative and then coupled with a health system that is continually being revamped in an effort to be further driven by economics rather than a service to a society that is economically viable this problem exists. The issues can vary. Clinical sites may request payment for access to experience thereby limiting experience, there may be a lack of clinical sites because of downsizing or the student population may be surreptitiously factored into the workforce. The reasons are many and varied.

Having said this though, I perceive the real dilemma is as it always has been. In this country, it received much focus during the 1980's as numerous curricula were developed in preparation for nursing's transition from hospital to tertiary sector. We voiced this dilemma in questions and debate on bridging the theory practice gap. A phenomenon brilliantly articulated by Paterson and Zderad (1976) in relation to a discussion on their theory of Nursing.

The framework offers a little security by providing some reference points for the exploration. However, what is gained in clarity by conceptual abstraction is lost from the flavour of actual experience. Like a weather map that statically represents major factors and currents in their interrelatedness, the framework discloses a nexus of elements. But it is as far from the real phenomenon of nursing with its pains and suffering and comforting and joys and hope as the weather map is from real weather with its wind and rain and heat and cold.

Paterson and Zderad (1976, p.23)

This is what has, and continues to be, the challenge for those who take up the responsibility of creating and teaching formal education programmes that credential future practitioners. In 
some ways this dilemma is not as compounded for Post Graduate systems, where the challenge lies in finding structure that supports and assists the students as a practitioner to translate, while continuing to further redefine, their experiences in Nursing. As we have continued a mainly top down undergraduate education process, and a bottom up postgraduate education one, it would be remiss not to suggest that the experience has assisted in shaping both, and in this way the system represents an ongoing growth and development.

Even so, this is not to say that the challenge as expressed in the Pateron and Zderad citation does not still exist. One way of evidencing this is by listening to students nearing completion of their undergraduate programme story nursing. In saying this, I would emphasise students and stories, which are not the same as a student or two and, a few stories. For without such a broad perspective the following statement is not only erroneous but also its intent is then misdirected. In listening to the narratives of Nursing, also embedded in these narratives, amongst other things, are what they focus upon in their nursing practice. In other words, where they have placed their attention, and thus the formulation of their conceptualisations about nursing. Their stories are but one reflection of where and how they have been 'taught' or 'guided' to look. In such listening, one then comes to know the curriculum, the ideas, outlooks and belief systems of those responsible for its construction and implementation. 'My stories', the data for this research can then be viewed as evidence of a now past curriculum in action.

\section{Envisioning new ways of living and learning Nursing}

Given what we inherently know about nursing that is enacted through the nurse patient relationship and then reified in the living of nursing care, how then do we meet the challenge of creating structures through which to both learn and teach nursing given the insights of this work?

I have argued that everything exists because energetically it exists, and in that way we are energy. As energy we are patterned. We are patterns of energy. We are coded. As the Creators of our reality through the process of engaging in life, we create patterns, which are then translated into a physical reality. At the same time, it is through life that 'we be'. In our experiencing life as a process of Being, we take ourselves to where we need to be, in whatever way, in order to feel something and in that way change the space and so create a different vision. The greatest teacher for this process is our inner teacher, our in-tuition. 
..... Later that day I asked Mary if she'd like to go for a walk. With much persuasion, she agreed. "Just to shut you up", she said. I never knew that that would be the last walk I would have with Mary, our very last trip to the toilet to empty that horrible colostomy bag. I finally got Mary sitting up. I put her dressing gown on and placed her slippers on. She sat on the edge of the bed perched like a strong eagle, ready to swoop on its prey. She sat so high, her legs dangling from the bed, ready to take their first step. Clutching on to my arm she hesitated. "I can't do it, I'm too weak". But she wasn't weak, she was so strong. Mary huddled, her shoulders touching my waist. She held so tightly to my arm, her knuckles turning white. We made it to the toilet outside Mary's room. It took us a while, but we made it. When we got there Mary slumped herself on the toilet and flopped out her colostomy bag which was filled so tightly, mostly with air. "And this is what we came for", she laughed as she patted the bag which rested on her stomach. We emptied the bag with our usual laughs. I don't know really why we laughed so much about this smelly bag, but it kept us focussed and lifted out spirits. I took Mary back to her bed in a wheelchair and made her comfortable. She was so exhausted but I was so proud that she had tried so hard and done so well. I left Mary to sleep.

Later that night I was sitting with Mary and she took my hand and looked at me. "You know, I'm going to die", she said. I wanted to say, "No Mary you won't, you just won't", but I couldn't, because I too knew the truth deep down inside. I sat there for ages listening to Mary talk so softly. She barely had the energy to talk, she simply breathed and moved her mouth to make such soft noises come out. That night Mary shared with me her life. She told me that she was now waiting. Now she was waiting for her grand child.

The next day Mary was transferred to a single bedroom and her daughters had been notified of their mother's deteriorating condition. When Mary was handed over to me that day I wanted to get up and walk out of the room and never look back. I was petrified. "She's been moved to the death room", I thought. "This really is the last floor to Heaven". I looked at the Charge Nurse, I wanted her to see how scared I was, I wanted her to feel sorry for me and not give me Mary to care for today. I knew somehow that today would be my last day to be with Mary, not because it was Friday, that didn't matter, but because it was going to be Mary's last day too. But really, I did want to be with Mary on this special day, but I was so frightened. I've never had to deal with death but now I have no choice. I suppose I really did have a choice and this is what I had chosen. This is now my chance to take a step towards a new growth and acceptance of death.

Did the Charge Nurse really read my mind, or was she just being practical as I had been caring for Mary for a few weeks now? How she came to the decision I do not know, but it was decided that I would look after Mary on that thundery Friday night

I have argued that experience is energy translated into a physical form. I have also said that we call forth what we need to experience. Therefore, when we judge an experience to be bad what we are judging is the self by having judged the emotion the experience elicits. As we do so we then shut a part of ourselves off from ourselves through having made the thing matter. In that way, we deny the self through having denied/judged our act of creation. We have not listened to our inner teacher. It is also an act of carelessness for we have not cared for the self. We have denied our vulnerability and not nurtured or supported the self in this state of 
being. How then do we care for others when we do not know how to care for ourself? Surely caring for others must begin by 'doing' what is needed for the self, so that more love can love/move through us. In this way, caring for the self is to come to know the self that as a process is led by intuition as the possibility to be more.

I have learned not to let my concepts get in the way of my percepts, not to let my preconceived ideas block my ability to see and perceive afresh. This has been a worthy lesson, for I have found that no-one I encounter is a simple "either/or" proposition; a person is always "both/and" - plus much, much more.

Houston (2000, p.101)

OK, as a student nurse I had seen the film "Mrs Reynolds Needs a Nurse", the story of a demanding patient who really was demanding because she was lonely and frightened to be alone. Now here I was, a first year registered nurse and to be allocated Mrs Harris to care for was a punishment worse than death. She was an extremely intelligent woman in her mid to late fifties who by the time I met her had been mechanically ventilated for almost two years.

The result of being allocated to Mrs Harris was, that you would spend eight hours locked up in an isolation room attending to her every whim. "No Nurse, move my left leg a quarter of an inch to the right - no that was half an inch". She knew to what height the water level had risen in the water traps of her ventilator tubing behind her, and all hell would let loose if they were not emptied before they reached a certain critical level. She was convinced that if she could stay alive for seven years that her cells would regenerate and she would be well again. As such, she had a number of rituals to support her idea.

So in I went resolute that I was going to have a 'good day' with this woman and reminded myself that $I$ had seen Mrs Reynolds needs a nurse and the message was that demanding patients are frightened and lonely. The solution was simple, all I had to do was transfer these ideas into my care of Mrs Harris. It did not occur to me that Mrs Harris, an intensive care patient, was not ever left alone!

I began by getting her to tell me about her life - her life was amazing - this woman had done so much. She had been a tertiary educator in English, a fashion designer, a journalist in the war, had raised a family, was highly respected by the chess community (clubs in the state would send in people for training - she would tell a player where she wanted her piece and to my knowledge no-one had ever beaten her). She had calculated the movement in the fire station tower reflected in her hospital fourth floor window and had had a letter written to the City Fire Brigade informing them that their tower would topple down in a specified time. (Engineers latter confirmed her calculations and some years later the station was moved, the site to become a museum with modifications having been made to the tower). She had written to the overseas company telling them of the design faults in their ventilator and suggested the appropriate design modifications. She had created a new roster system for the intensive care department. The list was endless. I watched the clock - we had made it to lunchtime without any dramas. Still, I had a predominant sense of anxiety while not 
lived out in any particular occurrence. It was like a time bomb waiting to happen. I undertook the physical activities required and encouraged her to talk and talk. I felt as though I was manipulating her. When I got home I was exhausted.

The next day I was rostered on an afternoon shift and she asked if I might relieve her nurse at supper-time. I agreed. We greeted each other and she instructed me to find a particular pack of cards, well hidden, amongst her belongings. They were Tarot Cards (I did not have a clue what these were). She told me that we only had half an hour and so we had better get on with it. I did as she instructed, and every word she told me, now almost over thirty years ago, has been true. I placed the cards back in their secret position and she told me that I was not to tell anyone what had occurred. I didn't. But our previous day still haunted me.

It took me a few more years to realise that Mrs Harris, wasn't Mrs Reynolds. She had read my cards that day not as a form of manipulating me into being a particular way, but because she was prepared to see me as me, and not just as another nurse assigned to care for her.

In assigning percepts into concepts the reactive mind has reacted and thus rendered a part of the perceptual imaging as an arrangement attached to form. As form it is now concept and thus part of a belief system. This then influences how we will act when we begin to reexperience that particular emotion. For now it is a building block that we use to create our reality. I was 'taught' demanding patients are lonely frightened people that can be controlled/managed, albeit with what appeared as good intentions. In the attachment to form then we cannot just 'be', because the now is 'coloured' by a past which we then engage in an existence grounded in that particular belief. In that way we continue to deny that not only are we are able to create our reality but in fact that we do! Over and over again, until we choose something different!

This over and over until we make a different choice is clearly depicted in this student narrative.

$\mathrm{OK}$, my story today is basically about two personal experiences of my own which then went on to relate to an Arts Lab that we had in second year and I chose to tell this because it sort of shows a growth like of my own nursing practice and how to handle this sort of particular situation. It's to do with death and it's also for me it's like from a family perspective and then as I came to Deakin it's stirred from a nursing perspective.

The first experience for me was when I was in about year eleven or year ten. I was about fifteen or sixteen at the time and my eldest brother and his wife were expecting. Anyway, what happened was, at five months I think it was, when Angela was five months pregnant, she went into labour and through some infection or something like that anyway. And the baby was born prematurely and very prematurely as he was only five months and he only lived for a few hours. I really wasn't there at the time and I didn't see what was going on. He was very perfectly formed and he was just perfect but very underdeveloped and as a result he didn't live. 
The thing was that I was just looking at that death from that perspective and I was very sheltered from that and I know that I relied a lot on my mother when the time came to actually visit my brother and his wife to say the right things and do the right things and I was very much in the background and I've always felt that I wish I'd had the chance to say something but I never did. Of course, at the time it was like, I'm only this age, I'm very young, I didn't know what was going on, I don't know what it's like to have a baby or what it was like for Angela to have to deliver a baby at five months or six months and know that it's going to be so underdeveloped and what's going to happen.

That sort of starting me thinking about what I thought about death and at that stage I know I blocked it out, I blocked a lot of that sort of thing out. It was like, "Oh, I'm not going to cry, I'm just going to think these things happen in life and I'm just going to look at it from that perspective". And it was also, I guess at that time, being in high school, it was also like, "I'm not going to cry either, I'm going to be strong and not worry about it and you know, these things just happen".

I can remember like, my two sisters who were older and who always cried at these sorts of things, were just amazed at my reaction and they just kept on saying, "Don't you feel anything?" And it wasn't that at all, it's just that I never actually let it show. I also thought at that time another view of death was that it was the ceasing of the heart beating and the brain functioning, but it was just, the person, that spiritual being went on and so therefore I didn't feel as though it was such a disappearing of a person because you still had memories and things like that of them, even though, of a little baby, you don't have that.

Anyway, so then that occurred and I can remember going to the funeral which was very, that was very sad to see a tiny little coffin and to have that service. Then about a year and a half later, the same brother and his wife, my sister-in law, they were pregnant again and everyone was really happy, you know, they've begun again, they've started to have another baby and they haven't let what happened last time get to them, they're going to have another go. And we were all really happy and little bit hesitant I suppose, because we were worried about if anything would happen this time. And this time, Angela was watched far more closely, she was under a specialist, like an obstetrician and she changed her diet and she had to do all these sorts of things as a precaution so that what happened last time wouldn't happen again. And she got past that danger period of the five and six months and everything was going fine and it was about nine months and she was due in July. This time I was in year twelve and I was about seventeen or eighteen this time. And I can remember thinking, "I wish the baby wasn't due in July". I just kept on thinking that the last baby that she had died in July and I know that all my family relatives seem to die in July and I just think that it's winter and it's cold and it's depressing and I just think if this, the baby, the one that had died had have been due in summer, I'm sure things would have turned out differently but as it was, this baby was due in July again.

Anyway, I can remember going to school each day and people asking me how she was going because they knew what had happened last time and they were thinking this will be good, she'll have another baby and even though it's not going to ever repair what happened to the last one, it might help her feel, well take a little it of that hurt away. And I can remember people coming and saying, "How's she going?" You know, everyone wanting to know the up to minute details and things like that. Anyway, when the day came for her to be due, and I can remember, I went to school and I came home and I can remember riding into the driveway on my bike and getting off my bike, and mum was at the door. I was really eager to get home, you know, was it a boy or a girl, and you know, how much did she or he weigh and what are they going to call it? It was just so exciting and I rode up into the driveway and I can remember seeing mum 
and the look on her face - was that something's gone wrong. So I got off and I looked at mum and she just said that this time the baby had died before she was born.

Anyway, what had happened, and it was very strange and very unusual, but the umbilical cord had like, is it three blood vessels all intertwined with one another? Apparently with this baby it had no protective casing, those three blood vessels, so therefore it had functioned perfectly for the baby to develop but when Angela began to have contractions, they ruptured so therefore the baby lost all her blood. Anyway, what she noticed was Angela went to the toilet and noticed that she was bleeding and they did a test and they realised that it wasn't Angela's blood, that it was the baby's blood and she just said that they came from everywhere. She was at, I think it was the hospital in and she said they just came from everywhere. She was raced into theatre and they performed a caesarean and they said that it was just too late, that obviously the bleeding had gone on for awhile and that the baby had lost her oxygen.

So now, I was just like, I know my reaction this time, I was really mad. It was just like, "How come they didn't know this?" She was under a specialist and you know, not having any medical or nursing background then, it was a though, like specialists are like God, and why couldn't they see that and why didn't they know? And now she's going to have to deal with, like now she's lost a baby twice and yet this one she carried for nine months and she must have known, like I've got over that danger period and it must have been like just expecting to have a normal baby. And I can just remember being so mad. Then I thought, now what am I going to say this time, how am I going to approach my brother and sister-in-law? I just don't know what to say. I can remember going to the hospital and it was a really cold day and we stepped out of the car and it was just an icy cold wind and I remember walking into the hospital and the gush of hot air came and it was just, "Oh, what a relief". And it was as thought, like, how could death happen here? It was such a warm place even though it was a grey, cold, yucky day outside.

I can remember we walked into the foyer of the hospital. It was my mum, my dad, my two sisters and myself. And my dad went to see where she was, to find out which ward she was in and which room and I can remember my reaction and it was just, my two sisters and I who were older and this was the most irrational reaction, but we were so nervous about what we were going to say that we began to giggle and we just couldn't stop. And like, it wasn't about anything, it was just that we didn't know what on earth we were going to say. Anyway, we got over that and we realised that we just had to face this and I can remember walking up the flight of stairs and actually going into the room. Angela was lying in a bed by the window, it was a two bed room and she was next to a window and she had her mother with her, and her mother was crying. And I can remember being just very blank and walking in and just, I think again, blocking it out and looking towards my mother who had had children, to give her the comfort that she would need, that Angela would need. I know at that stage you just wanted to say something to make everything alright, you just wanted to say something or bring that baby back for them, so then you didn't have to handle the situation. And I just wound up feeling really inadequate and just hopeless. Like I just can't say anything and I just wanted so much to be able to actively do something that would help her.

Anyway, we went in there and she was OK. She was giving us a feint smile and she wasn't too bad and then the nurse, or, I can't remember whether it was the nurse or Angela asked us would we like to see the little baby and I can remember, my two sisters and I just looked and we just went, "Oh, we don't know if we could handle that". Because I know at that point I'd never seen a body before and I didn't know what to expect. You know, was it going to be, what on earth would a baby that had 
died looked like? Anyway, we sort of went "Oh", and in the end we agreed, we thought that maybe it would be a good thing. And they brought her in and she was just perfect, she was just like a little doll and we couldn't see anything apart from her face, she had been all wrapped up and we weren't allowed to touch her either. I can just remember thinking, "Oh, she's just perfect". Everything about her was just perfect and she looked very fine and I can remember saying to Angela, "Oh, isn't she wonderful?" She was just beautiful and perfect and I felt happy at least to be able to say that.

Anyway, so that went on and I can remember at that stage my two sisters were crying and I was sort of assessing my own reaction and saying, "Fiona, why aren't you crying? This is really sad". And I was really sad but it was just my reaction at the time. And I remember then that I began to think, to put myself into Angela's position and just began to think of how she would feel and I thought, "Well that's a change from what I felt the first time", whereas with the baby who died the first time I just more or less, not passed it off, but I didn't think about it. This time I put myself into her position and just thought, "What is she feeling? Is she feeling guilt? Is she feeling fear or just complete emptiness now she's lost another one?" And especially for my brother too, like the father as well, I know that a lot of emphasis is put on the mother and I just kept on thinking, "How's he feeling? Is he thinking probably more for his wife or what's going on?" And of course all of these questions remained more or less unanswered.

Then I came to Deakin and in second year I found myself in the Arts Labs and in second year, I don't know if anyone remembers but there was a situation where a mother had lost a baby and they wanted a student nurse to go in and talk to her. And I can remember sitting in that Arts Lab and everyone just looked up and down, like noone wanted to go in. Not because they didn't want to do this, it was such a heavy situation that everyone felt, you know, we don't want to do this. I can remember it went on for about ten minutes and everyone was just looking at everyone else and like up and around and I thought, "I should go in, I should do this. It's happened twice before and you should have another go". Finally I said I would and there was like a collective sigh of relief from everyone else in the room, it was like they didn't have to go in.

Anyway, I can just remember, I was so nervous, I thought "Oh, this time everyone's watching me and this time everyone's listening to me". And I went in and I can remember she was a woman, I think in about her early thirties and she had wavy brown hair and she was sitting in a big armchair. That's right, before we went in we had a discussion as to how we would approach this woman and everyone said what they would do and most people's reaction in that class was, "We'd go and touch her, we'd hold her hand". And I sort of thought, "I don't know whether I'd do that or not". Anyway, so I walked in and I sat down on another chair, not really close to her, but probably just perched on the edge and I can remember saying to her, 'Would you like me to hold your hand?" and she said "No", and it wasn't a cold like, no, I don't want you near me, it was just, I'm happy with how I am, I don't really need you to hold my hand. So I just thought, "Oh", and I said to her, "Would you like to talk about what has happened?" and she said "No, I don't want to talk about the baby", and I thought, "Alright, we'll try something else, I'll see what else I can do". Then I can remember going on and we got talking about something else, about what she did for an occupation I think it was, and I know that it was really soft, the tone of the conversation was very soft, so therefore the people outside couldn't hear us anyway and I didn't realise that until later and I had to tell everyone what was said and I thought, I was glad of that in a way because like, it was just us. And even though she was an actress it just felt as though I was back there again sitting with my sister-in-law, it was just so real. 
Anyway, so we sat there with one another and we just talked about other things and eventually she came around and she began to talk about the baby and I can remember I didn't do anything special at all, I just sat there and listened to her and I might have said a few little questions and I could see that she was just becoming more happy with talking about it and the way it ended was, she just said, "Do you think I'd be able to see my baby again?" and I said, "Oh I think that's a great idea, I'm going to go and see what I can do about that", and I left and that was the end of the role play.

So I walked back in and everyone was like, "What happened, what happened, we couldn't hear a word you said", and I explained what had happened and then she came in and she de-roled, they didn't want her in role, I think I can remember and she just said that the way I had handled it was good. She said, "I didn't want to be held, I didn't want to have my hand held and it was what I needed". And I just felt after that Arts Lab that - Oh, that's another interesting thing, she said, when I went in at the beginning I was sitting perched on the edge of my seat and I guess for her that body language is 'I'm going to go in a minute, I'm here but I don't really want to talk that long', I must have looked really nervous. I think after a while I just sort of settled back in my seat and she said that she really noticed that and then she relaxed and she began to talk to me more. So then, I just felt so happy about the whole, not happy, but satisfied with the whole interaction, like I had been able to help her and I just thought whereas I hadn't been able to help my sister-in-law, this woman seemed to think that I had made a difference and it wasn't anything that I said or did really, it was just being there and it just made me realise the things like listening and just presence and just, I think the difference was also that I communicated that I knew about the baby and that I wasn't denying that and that I was just there. And I just felt that that was good and that it was like, showed to me like a development and a growth. Like the first time I blocked it out, the second time I began to think with Angela, about what she might be feeling and the third time, it was just me in the room with that woman and she said that I'd helped her.

To think, therefore I AM, it has been argued is a 'false' surrender. I would add now in the context of a state of dualism where such a surrender, as discussed in chapters six and nine, is an independent performance of surrender. As an independent performance of surrender, the mind is thought to be the origin of thought and in that way maintains the reality that it is separate from God. This is despite how many fractal patterns exist as an extension of that thought, for they are still underpinned by the original thought. $i$ think, therefore $i$ am. Descartes wrote, "the whole force of my argument lies in the fact that the capacity for constructing such an idea could not exist in me, unless I were created by God" (1641/1952, p.120). And while on one hand there is truth in Descatres words, the ego too is a creation of God, and so it is how we use our ego in conjunction with our mind that is my point. We choose either a true or false surrender and in that way are created by God. As a surrender that is represented by 'to will' and 'to be able' where will and power coincide, I am speaking of God consciousness, or the mind of God. Where in the energy of the process what has transpired is a mind to mind interaction where feeling is the key, in which there is both a downward and upward movement of energy that then finds expression. 
I think Goethe may have been close to the mark when he said the greatest truths can only be expressed dramatically .... But whatever the words or nonverbal movement signifying surrender, this deep spiritual change takes place when God's hand reaches from His drama into ours and touches us in an exquisite and inexplicable way that unlocks the inner prison of our souls. Perhaps only those who have been through the head-on collision of the constructed personality with reality, and with God, to the point of surrender can easily recognize the landmarks and language of response.

Miller (1997, p.170)

Belief is a result of an interaction in our engagement in existence with mind and ego. I have argued that knowing is known through feeling. As such, knowing is not synonymous with belief. For thought that exists in the realm of belief still leaves still room for doubt. The ego can still impact at the belief level. It is as if in our being human we play out every belief structure that we have ever been created. In that way we sort the gold from the straw so that what is left is pure intuition that as an idea has moved down to the realm of belief and then down further to then become knowing. Knowing is wisdom/enlightenment. Knowing is when a thing is known, and like love there is only more knowing. It is in knowing more that the mind in working with the body move towards becoming One. Then there are no longer two clocks ticking away. Then there is only one clock ticking - only one sub beat.

Therefore, as we are willing to move in this process it is as if there is something that supports us in this mediation between body and mind that then enables more connection. A connection that then assists us as we call forth more mind body communication. I have called this something our inner teacher, our in-tuition. An aspect of self that is not mind or body but is that which assists in guiding us towards wholeness. In order to listen to our in-tuition we need to learn to quieten the mind. The language of our in-tuition is always positive, mind chatter is not. When we listen to that aspect of our inner self, a listening that is expressed by some as a gut feeling or experienced by others as such a clarity of choice because it feels as though one is being literally 'drawn to', then ultimately we are learning to listen to our world with our heart. The world I speak of is our inner world.

In such knowing it is an expression of trust. Trust is knowing that we are connected to all things. Trusting that we are always where we are meant to be and do not draw to any 
challenge to ourselves that we are not capable of meeting. Trust opens the heart. Nonjudgement opens the mind. Trust and non-judgement are the head and the heart working as one. This way of working is not to be interpreted as the physical heart and brain of a human being but rather, it is the working of the heart and mind of God that as consciousness is then expressed/actioned in some way. The expression finds form. As word, it is expression from the heart, for it comes through the heart, it is an authentic - word. How it is known is in the receiving. It is heart felt. As deed, it is done, and what is done is also heart felt because it has had its origins in love.

The form in nursing, in the main, has been through our hands. Yet, hands in conjunction with the head and heart in the mystery schools of old, was known as the triangle of the healer. Nursing as healing: Heart, head and hands. At one level in practice, I believe, we have all touched this knowing of our potentiality. I argue it is this that accounts for our dogged persistence in the shaping and re-shaping of ourselves. Having veiled our acts of being in our doingness, I argue we are now ready, where what was received as a head heart process in the Nightingale vision, a gift from God to humanity, is to be lived in a way that expresses more of the purity of that idea.

This then raises real questions about teaching/learning nursing. Our curricula remain filled with empirical knowledge. In this way, albeit unconsciously, we continue to espouse a set of beliefs that reify the notion of existence that is real because something exists. And so we continue to perceive ourselves as separate. This is coupled with a rhetoric of critical thinking and problem posing offered as frameworks/structure for learning but administered with the same world view where learning is an activity more and more devoid of human relationship. Thereby, we continue to create an epistemology that holds very little hope for the expansion of consciousness. For only in the expansion of consciousness can we engage in health and healing in ways that belong to higher states of consciousness. It is a matter of vibration. I assure you that if you have faith as big as a mustard seed ... You could do anything. (Mathew 18). In other words, Jesus knew of the possibility - he did not just believe it. The question is how did he evolve his consciousness to this place of knowing?

Such thinking, I argue, cannot be taught as a didactic form of pedagogy. In fact at this point I am seriously questioning whether I can teach another being anything. I can model, demonstrate suggest, argue and just be, however that is no guarantee that another will be taught. For until we are each willing to put down our constructed reality then we remain under the illusion that it is real. 
Ironically, although we cannot prove this, when the soul is released and comes into contact with God, it often seems to play hearts like a harpist. The words to the souls song are some variation of: 'I know this experience is true because it fits the deeper reality of my intuition and experience!' When the sense of being accepted by God is measured by the reality-checking soul, the soul's response is often a resounding 'Yes!' This encounter with God fits reality at the deepest level I've ever envisioned it!' That deep inner personal validation ... because it's what they've always longed for and known in their souls at some subterranean level was in fact true!

Miller (1997, p.171)

The key I have argued is to consciously feel our responses to life and then consciously choose what we desire to feel that is not a form of denial or judgement of the initial feeling. In essence, it is very simple. Our judgement on feelings, that is the accumulation of lifetimes of having done so, makes this process a very challenging one. Our beliefs about the world are tied to particular emotions. How many of us speak in terms of feeling states? When we do acknowledge what we feel how often is it couched in language of blame? Another made us feel a certain way. The world is 'thought about' in terms of rationality, deduction and analysis. As humanity, I am arguing that in the main we are out of touch with how we feel in response to our world unless the experience is gigantic. In our day to day human encounters, there is little awareness of what is being felt, in the moment. That we are feeling something is certain because that is how we engage in the world with that which connects us to the essence of that which we are.

Therefore, structure and process in Nursing would emmerse itself in activity that fosters encourages and supports participants in moving back into a sentient nature. Students, patients and teachers would engage in a form of teaching and learning that is healing. Learning then becomes the life of nursing where Nursing is learned from the lived experience. Where in-tuition directs the learning, and where there is the possibility of experience in many forms. It is learning that understands that human relationship is the core of activity, and so learning is activity to offer experience that engages participants in relationship. It is from these relationships that meaning might then made. 
As process, it is re experiencing an emotional experience so as to uncover the embedded emotion as distorted thought and belief. And while I do not wish to prescribe activity, Narrative Pedagogy, the use of the arts, journaling, Chinn and Wheeler's 'Peace and Power' (1995) offering a structure for classroom process which is inherently underpinned in making clear who and how we are in the world together, are some possibilities already available that when used for the purposes described in this thesis, can serve this end. When a practitioner/student/teacher knows how to work with his or her emotions and feelings, then they are able to engage in a form of reflection that is not only reflection in-action, but is Freire's (1972) notion of praxis in that where word becomes transformative.

(cont'd) ...... I walked down the hall to Mary's room. I could see her two daughters standing isolated at the end of the hallway. They were both clutching tightly to their cups of tea, smouldering the heat between their hands and the cups. Both ladies were looking down and their faces were reflecting back at them from their tea. I introduced myself to the two daughters and we talked for some time. It's amazing how strangers can be drawn together through crisis, but we weren't strangers, we were all connected through Mary.

That night I cared for Mary. I played her favourite music, I made her comfortable and sat there for some time simply talking to her. Mary didn't open her eyes at all, she lay still, the only movement being her ribcage rising and falling. I left Mary with her daughters. They stayed for most of the evening, then they decided that it was time for them to go. They said goodbye to their mother and thanked me for the care that I had given their mother for the past few weeks. I said to them that it had been a beautiful experience for me and it was I who should be thanking Mary for the opportunity to know her.

After Mary's daughters had left I went in to see her. She was lying so still, grasping for every breath of precious air. I pulled Mary's crocheted blanket up around her shoulders, just like I did every night before I left and I don't know why but I put her bell in the palm of her hand - just as I would every night. I don't know what I said to Mary that night, I don't think I really said much at all. I held her hand tightly and told her that it was OK to let go, she didn't need to fight and wait any more. I kissed her on the forehead and said goodnight - which is something that I've never done to any patient before. It wasn't because it was the thing to do or some stupid hospital protocol but I did it because I needed to. I needed to say goodbye, and thank you, for the special time we had had the opportunity to share - together.

I never saw Mary again - she died later that night. But I often think of her and how lucky I was to meet her. Before Mary I was scared of death, but I knew that I had to go through that experience in order for me to accept it - and in the end I was just really glad that I had that opportunity to know Mary and go through that experience of knowing her at that time of her life. And there isn't anything that I would change about the situation now if I was to do that again - except - that I think I would go for it with a little less fear.

Oh and in relation to Patterson and Zderad, its on page 101. It's under the heading Humanistic Nursing as Clinical Art: 
In genuine meeting the nurse recognises the patient as distinct from herself and turns to him as a presence. She is fully present to him authentically with her whole being and is open to him. Not as an object but as a present, a human being with potentials. In such a genuine lived dialogue the nurse sees within the patient a form (that is, a possibility) of well being or more being (or comfort or health or growth and so forth). Like a beautiful landscape inspiring a painter or poet, the form in the patient addresses itself to the nurse, a call for help demanding recognition and response. The form is clearer than experienced objects, it is not an image of her fancy, it exists in the present, although it is not 'objective'. The relation in which the nurse (artist) stands to the form is real for it affects her and she affects it. If she enters into genuine relation with the patient (I Thou) her effective power brings forth the form, just as the painter's or poet's power and skill create a painting or a poem ...... Perhaps the art of nursing could be described as transactional. Not only does the nurse see possibilities in the patient, but the patient also sees a form in the nurse, and he responds in relation to bring it forth.

I wonder, without being, could I ever have taught this student the meaning of these magnificent words from page 101 in a text? I think not.

Whereas, our arrangement shows that the power and capacity of learning exists in the soul already, and just as the eye was unable to turn from darkness to light without the whole body, so too the instrument of knowledge can only by the movement of the whole soul be turned from the world of becoming into that of being, and learn by degrees to endure the sight of being; and of the brightest and best of being, or in other words, of the good.

$$
\text { Plato } 428 \text { B.C. }-348 \text { B.C. (1952, pp.389-390) }
$$

What I now know is that the students and I were engaged in being, we were learning/remembering how 'to be'. In exploring a process of self reflection that revolved around storytelling, unconsciously I had begun to identify the corporeal sensations and thought process thereby engaging students in a way of learning that defied all traditional methods of teaching and learning. Where understanding was understood because it was lived/experienced. In engaging in our world in this way, we are all teachers and students. We reconstruct a relationship with each other where what underpins our way of acting is the knowing that we are all one and that we can empower ourselves as we assist and support each other in this same process. This potential exists in the classroom and at the bedside. For while the nurse patient activity may look different to the teacher student activity in truth the relationship is the same.

Imagine that you are in an all white room, totally white ... And imagine that you are suspended in that room ... you couldn't touch anything. Here you are in this 
sea of whiteness. And you imagine nothing else exits at all. How long do you think you will exist in your own experience? ... Because, in the absence of anything else, I am not. Not in my own experience. I mean, I am that I am. But I can't know that I am, except in relationship to something else. So I can't know anything about myself. ... That is to say: I define and, in that sense, recreate who I am in relationship to who you are. Ultimately, I cannot re-create myself as anything that you are not. I can only see in me what I am willing to see in you. And that which I fail to see in you, I will never find in myself, because I don't know that it exists.

Walsch (1999, p.12-15)

Many years ago there was a lady called Mrs Patterson. She was hospitalised and confined to bed for a very large leg ulcer. The charge nurse of the ward was particularly brutal to first year students. I was in first year. When I had witnessed or had been at the end of an attack I would gravitate to Mrs Patterson's room. She would take one look and say, "has she been picking on you again, love"? I would just nod my head and she would motion to pull the curtain around her bed. Then I would move the stool up to the head of her bed and prop myself on the stool to lay my head on her shoulder as she draped an arm around me. We didn't talk about what had happened, we would just be there together. When I was ready I would sit up, and at that point she usually gave me a kiss on the cheek and would say something like - "it will be alright love". Then I would put the stool back in its place, draw the curtain and get back 'to work'.

One day as I stood at her bedside 'doing her leg ulcer dressing' and reporting my observations on how her leg was healing, for no reason I heard my internal dialogue ask, "who, is really nursing who here?"

In the first chapter of this work I made the point of distinguishing between reflection and refraction. Refraction I have said, is the art of the healer where the nurse engages intuitively and consciously with another to guide them in their own healing. To attempt to suggest the forms that such activity would take is to limit being. In the final semester in which I engaged students in storytelling I allowed the creation of form to unfold as a moment to moment revelation and experienced 'teaching' in a way that I could never have planned. It is the same process for healing. Until we each understand how to work with reflection we cannot consciously refract the light with another. How 'to be' is 'teachable'. Being is teachable in the sense that we can remember how to feel again. As we are able to work with our own reflections through our relationships with one another we are engaging in a life long process 
of 're-membering'/learning. Where our fields are both magnatory (attract) and radiatory (give out). So that what we can draw forth and give out in the continuos cycle of ebb and flow in life is something vastly different from that which we currently 'experience' and 'do'. In the ability to radiate, which at one level is another expression for refraction, we are acting as a teacher and a nurse healer, in nursing, whether we 'be' in the classroom or at a bedside. In this way teaching and healing are synonymous. In the process of refraction, I argue, we will fulfil nursing's service to humankind.

To create such a structure then, is to focus on process where our intent is the empowerment of each other. Nursing is lived and learnt from experience. Not in the way we have done in the past nor in the way we are doing in the present; the past and the present have served to bring us to this now. Nursing is learned as it is lived, that is, by the contact between human beings; it is a human to human endeavour. Nurses and patients embody Being, 'that is they are entities within whom existence is situated' (Taylor, 1994, p. 7). It is in harnessing this embodiment of being that our potential for transformation lies.

Such a notion challenges the current trend in creating structures which, in the main, result in an isolated endeavour where technology is being used as a means to further support an ideology of separatism. In using technology this way we are not confronted with what we feel in response to a given situation. In so doing we lock ourselves into the transmission of information that is conceptual, and therefore remain chained in Plato's cave while the shadows dance about. For if the outside is but a reflection of the inside, then learning structures that see students as single units connected to a teacher within an institution must mirror this sentiment. For some this may seem a gross exaggeration, but I ask, how much of what we argue in the name of economic rationalism is an unconscious mechanism to recreate structures that serve the existing reality? The mind is at work, playing the same game with the ego standing on the side cheering in full support. Mind games. Certainly, there is a place for using technology as a tool in education and we do need to consider issues relating to distance and access. But to consider these as dictating structure is to continue to promote an ideology of separatism while having created another grand excuse (reason).

Experience then, which is the experience of the individual, becomes the step off point or centrality from which learning is structured. At the same time, students in the classroom environment, and students and patients in the clinical environment, are supported in the pursuit of their growth in body mind and spirit. Technical knowledge is approached with an attitude of disinterest, which is not the same as saying an attitude of avoidance, but that this 
knowledge is to be recognised as background and not foreground. The focus is on experiencing through nursing and embedded through any number of activities.

I watched as the performer, who was circus trained, teaching the students to tumble on mats, do handstands and start juggling. I laughed to myself - some people would not see how these activities belonged in a nursing curriculum. I did wonder how the playwright was going to put the acrobatic group in the annual third year nursing play. Still, it had always worked out. They had ten weeks of this and I divided the staff up to go and watch one of the activities. I had made a commitment to go and watch the gymnastics. One group were sculpturing, another was creating a photographic display, a third were writing songs and music for the performance and two groups were designated as the playwright group. The students choose their activity and somehow, with the assistance of a professional playwright and director all these activities were pooled together and an annual show was created. The activities varied each year. I watched the gymnastics work progress.

Some confided in me after the classes that they had not done a somersault since high school and were thrilled that they still could. Others told me how scared they initially were and how great it felt each time they mastered a new skill. The circus chap was amazed at their progress. I too could see the improvement as the weeks progressed. They always started with warm up exercises that involved yoga positions. No-one was ever forced to try anything that they did not want to do.

The weeks progressed and the annual play drew nearer. While the Director of the Arts Lab always invited me to caste my eye over the play script, I made it a policy not to attend the rehearsals.

As I sat in the audience on the first show night I watched in awe as one student was raised above the heads of the eight carrying her in a corpse like pose. I watched as students somersaulted in and out of all sort of scenes and juggle not balls but hospital equipment. I listened to them express themselves in song, while their fellow students accompanied them on all manner of instruments. But as the end drew near I watched my acrobatic group build a human pyramid, and in time to the music collapse it while making sure that the people on the top were caught. Team work, trust and connection to the flow of all things. They stood in a single line in front of the audience, triumphant in their achievement. Their acrobatic classes had served them well.

Journal entry

To Sing the Pain, directed by Noel Jordon

...After preliminary meetings and orientation to work, the scripting process began with weekly writing sessions with two groups of students. The students wrote about nursing - about bruises and miracles and studying and vomit. ... Extraordinary writing, rich in closely observed detail, revealing deep compassion and a keen interest in the human condition. Of this time Cas Anderson (the playwright) said, "I could not help being impressed by the students honesty and depth in expressing their thoughts, feelings and commitment to nursing" ...

\section{Scene 22 Ending}

(A scene similar to the introduction, in that it involves as many people as possible and mass voices. Each performer repeats one of the six statements below, beginning with a 
single voice, with sparse additions rising to a crescendo of overlaid text, then stopping. Then a solo voice performs $\mathrm{A}$ )

A. What did it all mean? I felt I had been allowed to become part of his world. We had shared a part of ourselves. In a simple touch we had reached out to each other.

B. We departed as friends.

C. We met as complete strangers in a nurse client relationship and left as though we had known one another for years.

D. She thanked me and rewarded my efforts with chocolate.

E. I learnt much about me.

F. She grabbed my hands and kissed them. I could feel the water filling my eyes.

G. He frantically tried to talk to me but the only noises he made were muffled wind like sounds, his tracheostomy preventing him from speech. He was pointing around the room trying to tell me something, but everything I guessed was wrong. He did not have pain, he did not need to go to the toilet, he was not hungry and he did not need suctioning. What did he want? I reached into my pocket and grabbed a pen, and from my other pocket a piece of paper. He smiled as I handed them to him and in shaky writing, he wrote the word - 'walk'. He wanted to go for a walk! I obliged and walked him to the sun room. We sat and watched television together for a while. It was a good afternoon.

What did it all mean? I felt I had been allowed to become part of his world. We had shared a part of ourselves. In a simple touch we had reached out to each other.

Ian Campbell (1994, pp.3-36)

Again I have attempted to show that whatever the form the focus is on the experience. More succinctly, the focus is on what is felt during or in relation to that experience. In the six years that I chaired third year, all the clinicians would report an observable change in the students level of nursing practice the week after their annual show/performance. The play was the culmination of two semesters of activity over twenty weeks, and in that way held multiple experiences. A colleague and I used to joke that it would make a great research project and then dismissed the idea because we would see it unfold before our eyes. In essence, to focus on experience to acknowledge feelings appears such a simple idea. At a time in our history where research has identified that children as young as five years of age have a body image disturbance, exploring how a student of nursing feels after having washed another human being might not be such a simplistic idea.

In continuing to promote what some term left brain thinking, which I hope I have broadened, where thinking is confined to our logical empirical and analytical nature, I argue we will continue to disempower/limit ourselves. This thesis has explained how and why we cannot access more of our true potentiality through this mode of thinking. Why we cannot connect 
more fully to the world of pure mind, pure thought, true thought. In saying this, what I am now also saying is that this is the same process for connecting with another human being.

The more that I am able to connect with what I have termed God Consciousness, the more I am able to connect with another - consciously. I then hear calls of being and so respond with my beingness. How I do so is through feeling, that as process I then intuit or know how to act. Intuit, in the sense that I can grasp the pattern of energy so as to then give it form.

So while we continue to structure our ways of learning in ways that distance ourselves from our experiences and how those experiences have been internalised we continue to distance ourselves from each other. In that way we cannot make real the magnificence of that which we truly are. If we cannot heal ourselves, how then can we hope to assist another in their healing? What then are we teaching? The last five years in this country (Australia) has seen a mass exodus of nurses from nursing. While we might be tempted to blame structure, I would boldly call our attention to attention, to remind us that the outside is a reflection of the inside. How alienated have we become from ourselves?

Such a vision then calls for a grand new way of living and learning Nursing.

\section{Working towards enlightenment}

Enlightenment was an international movement 'in the hundred-plus years from the 1680 s to the 1790s' (Kramnick, 1995, p.x). 'The Enlightenment' is identified as a period in history where intellectual development stemmed from thinking that was engaged in a rational ordering of life which saw science as providing answers to questions about life. 'The Age of Reason' was underpinned as "unassisted human reason, not faith or tradition, and was the principle guide to human conduct" in an effort to create a better society (Kramnick, 1995, p.xi). Religious faith and superstition were questioned, humanity was not portrayed as evil, and the prevailing idea of the church that 'the good life' was something that was to be found only in the afterlife had begun to be deconstructed. Central to the Enlightenment was the probing of religious superstition. Previous constructs were replaced with a rational religion where 'God became no more than the supreme intelligence or craftsman who had set the machine that was the world was to run to according to its own natural and scientifically predictable laws" (Kramnick, 1995, p.xi). 
This significant period in history is recognised as the removal of religion from public life and subsequently was said to have brought about some semblance of religious tolerance that had not been previously experienced in the world (Kramnich, 1995). This position on religious tolerance could be debated, however, Kramnich (1995) suggests that in the religious being separated from the political at this time it was another degree of freedom for some people as it served to end the global persecution of the masses on the basis of religious politics. As such, it was a significant period in our history, for along with the religious freedoms came more personal freedom. Furthermore, as Enlightenment writers argued, our natural inclination was to seek pleasure (Bayle cited in Kramnick, 1995) and so in that way humanity could be happy and comfortable. This was in stark contrast to the ideas of the past where asceticism and selfdenial were the predominant ideas governing human conduct. In this way it can be said that a radical individualism at the heart of Enlightenment, where the individual "as the centre and creator of meaning, truth, and even reality" (Kramnick, 1995, p.xv) existed as an idea.

The Enlightenment while attesting to a specific cultural milieu is also specified as a particular historical marker in Western history. The period of $800-1000 \mathrm{AD}$, initiated by Muslims in which Baghdad was a major centre for learning, is omitted from Kramnick's discussion. This period could also serve to illustrate another episode in history in which there was a radical individualism. At a time when Europe was experiencing the dark ages, the Muslim world was engaged in all splendour of learning and creation in which Jews and Christians were an integral part.

Nursing too is exploring the notion of Enlightenment through mid range theory development from Rogers' conceptual model (Hills and Hanchett (2001). Enlightenment within this framework is defined "as a positive, dynamic experience manifested as expanded awareness, increased wakefulness, and higher levels of well-being" (Hills and Hanchett, 2001, p.7).

Therefore I would suggest rather than confine The Enlightenment to a period in history, enlightenment might be viewed as an expression of consciousness in much the same way that Dilthey describes, "Self consciousness and consciousness of the world are only two sides of the same consciousness" (Dilthey cited in Ermarth, 1978, p. 126). As a historicism, I refer to a being in society and the society reflecting the idea of that thing. Such a position is then reflective of a thing within the psyche of that society. Where the thought or idea is translated into a belief and then reflected through the psyche of mankind in that period. Where Enlightenment per se is not the full translation of the thought/idea, but where what occurred is representative of a significant period that demonstrated a shift in consciousness of humankind toward that ideal, but which is not confined to a particular moment in history. 
In this way it is possible to begin to view The Enlightenment firstly as a developmental stage that could be equated with what Heron (1992) calls the movement from the prepersonal to individuation. The prepersonal, while reflective of the I-Though relationship, is in the expression of human existence not the mature I-Though relationship and thus not transcendent. Therefore, Individuation as the I-it relationship that is the movement away from the prepersonal, enables the I-self to "slip into seeing itself as an It-self thereby a separated subject cut from objects and other separated subjects, even though that is not what it really is" (Buber, cited in Heron, 1992, p.). As such it is Augustine's (354 - 430) surrender as the independent form of surrender. That is not to be interpreted as an end point, but rather represents the experiencing of the gulf, 'to will' and 'to be able' in which we call ourselves to bridge the gulf and a means of transcendence.

This same phenomenon is expressed in energetic terms by Myss (1996), where she describes shifts in consciousness from groupings of energy centres termed external power to groupings that are internal power where an overall belief guides that consciousness. Thus 'The Enlightenment' is another significant period in human history representing the ongoing shift in consciousness created by a critical mass of beings moving toward Enlightenment. Where on one hand what exists, exists because it exists energetically, and on the other reflects the challenge to make enlightenment real. To move/grow from the prepersonal through to the transcendent in the relationship we each have with ourselves. As such, a period in history as a designation is then termed a 'paradigm shift', that when viewed as an idea that originated in the mind of God can be understood as both a shift and shifts of consciousness in the downward movement toward the heart.

Enlightenment, in the context of this work is the process of bringing light into every cell of the body. It is what is represented by consciousness. Where in the expression of being human a being is no longer tied to the wheel of birth and death because that being has become enlightened, by enlightening. In this way it is the Aristotlian notion of becoming or the Platonic movement out of the cave into the light. It is represented in Dante's world, where he is reunited with his beloved Beatrice so that together they might travel paradise.

Thomas Aquinas also attempted to show that the garden of paradise, from which Adam and Eve were said to be expelled, was a physical reality to be found (Campbell, 1990). "The situation of paradise is shut off from the habitable world by mountains, or seas, or some torrid region, which cannot be crossed; and so people who have written about topography make no mention of it" (Aquinas, cited in Campbell, 1990, p.121). In other words, because 
a thing is not a physical reality does not mean that it does not exist. Paradise does exist but not as an image belonging to the afterlife but by the same thing that the Enlightenment thinkers were motivated by which they then was expressed in the need of a more civilised society. This same thing has motivated any one throughout history who has ever wondered how to approach 'the good'. For it exists as a possibility in every man's minds. And I have argued that it is ours to create, as we do so what we are doing is becoming enlightened.

Nursing too has historically reflected 'The Enlightenment'. As consciousness we have experienced self-denial and asceticism directed by a religious ideology of servitude and sacrifice that has been structured as a political system where power is handed down through a chain of command. From this blatant outward gaze we are shifting to a more inward one as we do so we are creating structures and processes supporting this shift and in that way be able experience ourselves in the individuation or I-It sense. We are moving toward our enlightenment through enlightening.

While the tenets of 'a consciousness' such as those expressed by the period prior, during and after the period named 'The Enlightenment' do not correspond with the historical markers in Nursing time, it is because the old belief systems as a consciousness have not been challenged or incorporated by that group. As a group we reflect a consciousness. But that history represents a shift in consciousness is because there is enough of a critical mass willing to embrace a new consciousness, even though it is not be the consciousness of the mass. Astonishingly, seven percent is the required critical mass of peoples to introduce a shift in consciousness. That is, just over seven percent of the peoples of the world to bring to the world another paradigm that may reflect a greater freedom, and new issues, in the ongoing expansion of consciousness. Post Modernity as a paradigm shift is then representative of thinking which continues to 'open up' human kind and Nursing. As such a new paradigm is reflective of a shift in consciousness that as thought is then 'translated' into a belief system. We then engage in the world with those doctrines/rules.

Descartes 1649 I think, therefore I AM, could be seen as the forerunner of the 'The Enlightenment' [1680's -1790's], which as a shift in consciousness is also the same shift presented as the individuation mode of being. While I am not suggesting that human beings prior to this period remained in a prepersonal state, what I am arguing is, that when thought of as metaparadigm reaching a critical mass level, as mass consciousness it coincides with new inventions, technology, language etc. It is as if we open the sky for all manner of new things that present us with new ways of living and learning, from which we can continue to challenge the belief structures embedded in a particular world view. Descarte has kept us 
busy for years, first deconstructing and then reconstructing. Metaparadigm then is not a final point but as a culmination of many points from which to bring new points to coalesce in a new metaparadigm. Consciousness is forever evolving, for if we are infinite there can be no end.

Therefore, the challenge now is the same as it has always been. Where what ideas exist, exist in the first instance as thought. Existing for the purpose of 'the thing' to gain conscious of itself. In the distinctive feature of being human, by the ability to feel emotion, where the expressed purpose is to make unconscious thought conscious is then realised. In so doing, I change my past. A past that has been created by how I have engaged in perceptual thinking as it relates to the generation of concepts, that as belief structures are embedded in my psyche. In changing the past, I am changing my reality. As I do so I come to recognise that I create my reality. An idea representing a paradigm shift, in which emotion and feeling are the keys to working within this level of consciousness.

As process, I can envisage the aesthetic in both curriculum and in the 'doing' of nursing. I would use the term doing rather than practice. Where practice denotes a rehearsal and doing implies a form of action as has been described in the thesis. Where such action in nursing represents movement depicted as activity done on or to the body, but one in which feeling is actioned through the body. As such it is a gathering of beingness where dis-ease is approached as distorted thought but in which there is divine possibility. In this way, nursing can further its service to humankind. Service not as some sort of servitude but rather, service that is an honour of self without ego growing in action, and in that way assist to further the enlightenment of humanity through the rubric of health care.

This shift in consciousness stems from a seed or sponsoring thought, that is, an inspired thought. I am the creator of my reality. Where the Aesthetic in Nursing as Praxis, is both thought and action that together serve to evolve the consciousness of Nurses and Nursing as we in our being-human 'be there' by 'being there', and so continue to move toward realising paradise, here, on earth. 


\section{Summary}

By exploring the possibility of nursing as an aesthetic praxis through how nursing is lived and learned this chapter reveals the possibility or potential of nursing. How thought and action can serve to evolve the consciousness of the human being named nurse, so that she/he can support another named patient who in the experience of illness can evolve their consciousness.

This chapter clearly argues that through experience, meaning making serves consciousness in the way discussed thus far in the work. Where the lived experience of the human to human encounter affords this potentiality, for all beings. This then raises questions on the nature of knowledge that consciously supports people in evolving consciousness, and to that end calls the intention to attention about structures and processes that serve 'enlightening'. 


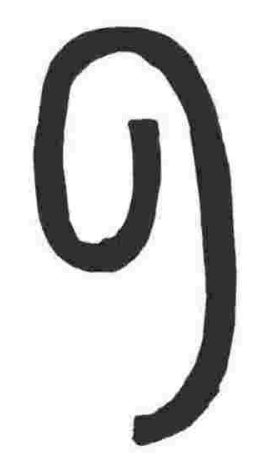

\section{Chapter 11: The Body as Temple}

\section{On being human}

In scripture, the soul is presented as the basis of a human being's deepest feelings and human desires (Miller, 1997). It is referred to as a particular spiritual part of the personality that relates to God or the things of God that also processes the highest values and is eternal (Miller, 1997). The soul, while confined to the human condition, makes things alive (Sheldrake, 1997). As the animating principle, the thing that is alive, the psyche in the Greek tradition is the life principle of all living things (Sheldrake, 1997). The Latin word for soul is anima. The word anima is derived from the word animal. In the English language, referring to something as being animate or inanimate is to refer to its aliveness or soul (Sheldrake, 1997). The word soul is also a synonym for the word mind (Holden, 1991), and in the Western tradition the psyche is synonymous with the human mind (Sheldrake in Sheldrake and Fox, 1997). This work challenges the latter definition whereby the human mind while connected to the psyche is not viewed as psyche.

In some cultures the word soul has its meaning in the breath. Breath, which not only encompassed air, but the whole process of breathing, because as a cycle it represented the activity of animating (Sheldrake, 1997). The breath was perceived as the great connector, that served as the bridge between heaven and earth in the same way that soul was perceived in the Christian tradition. The aliveness of things has thus found expression in many forms. In animistic traditions of the world people held that things in nature were alive (Sheldrake, 1997). Nor was aliveness restricted to being human, as some cultures held that all things had to be alive as the origin of all things, was God. And as it was not possible to exist apart from God all things then had to have an animating principle. Be that expressed as aliveness, breath, or soul.

I arrived for lunch to see the Indian papier-mache' doll I had given him for Christmas sitting on a side table. I smiled. "Have you named him?" $\mathrm{He}$ looked at me in astonishment - "No, he told me his name!" "Oh". "What is his name then?" 'Red 
Feather'. 'Hello, Red Feather", I said. "'What else has he told you?". 'Oh, when I asked him how he liked being locked up in that body do you know what he said to me!' "What?" "He asked me how I liked being locked up in mine!"

Journal entry

In the Greek tradition, through the writings of the Platonists, all things were considered to be alive. The anima mundi - the soul of the world, in its relation to the whole of the cosmos was viewed as a living being with a body, soul and spirit (Sheldrake, 1997). Aristotle (cited in Sheldrake and Fox, 1997) translated this idea into a biological concept where the soul of a plant, he argued, governed the form of the plant as it grew. Thus the soul was the formative principle in the same way that an acorn is the potentiality of an oak tree. The acorn is pulled ['drawn to'] toward its final form of a mature oak tree. "The soul contains the goal or what could now be called the attractor of the developmental process. The soul has the end (Greek telos) in itself, and Aristotle (cited in Sheldrake in Sheldrake and Fox, 1997, p. 66). "called it the entelechy". Moreover, while the goal is contained as an end, it is in the engagement of soul, or mind, through which the end is realised. Therefore, it is that within every engagement that the end always exists, and so in that way the soul is continually drawn toward an end.

In human beings the soul is said to reflect three levels (Sheldrake, 1997). I do not wish to debate Sheldrake's levels. What I propose to do is highlight the soul as consciousness so that I can portray a psychic system that is an interface between heaven and earth, human and divinity, as well as existing from one thing to another. In that way, the connection, through an animating principle can be conceived of as having a vertical and horizontal axis that if illustrated would depict the symbol of a cross.

Attempts to prove the existence of soul from a position grounded in materialism have limited the area for research to the physicality of being human. As such the seat of the soul has shifted a few centimetres from the pineal gland into the cerebral cortex so as to depict an animating principle that is located inside the brain that then controls the body (Sheldrake, 1997). A unitive notion, that is, a portrayal of an animating principle that allows for differences in the conceptualisation of body and soul by affording the body different psychic centres transcends the materialist view (Sheldrake, 1997). A soul in the body and a body in the soul that reaches beyond materialism can exist by one being located spatially and the other physically. This conceptualisation is not new. It has existed within the eastern tradition for thousands of years. Tenets of this idea can also be found in western theology. 
In early Christian liturgy, the heart is defined as the centre of deepest thought and designated as nestling in the midpoint between the breasts, rather than the accepted anatomical position as left of the sternum (Sheldrake, 1997). This midpoint is now well recognised in the western society as the heart chakra. Thus, in both eastern and western traditions there has existed the potentiality to explore ourselves from the notion of soul. In this way we have not been confined ourselves to the human body or our knowledge of physicality but are able to include energetic centres thereby connecting us as both spatial and non spatial entities.

Thales, the first of the Greek philosophers perceived that even a lodestone, a magnet, had a soul (Sheldrake, 1997). In making such a proclamation there is an implicit understanding of consciousness that transcends the notion of a division of the world into a them and us or me and you. There is a recognition that "self consciousness and consciousness of the world are only two sides of the same consciousness" (Dilthey cited in Ermarth, 1978, p. 126). For in proclaiming that a magnet has an animating principle, as Thales did proclaim, from a unifying sense the idea of the magnet held a reflection of an aspect of consciousness that was also reflected in another. In this way, from a horizontal sense, one arm of the cross, Thales saw that the magnet had a soul and so realised that he was looking at himself. In other words, if all things are from God then all things are animated, and so if a thing is animated and I am seeing it, then I too am animated. "For only what I see in you can I see in me" (Walsch, 1999, p.17). I cannot see what I am. I can only see a reflection of what I am.

It is understood that a magnet attracts or repels things as they move toward and away from its poles. When a magnet is heated beyond a certain temperature it loses its magnetism, its animating principle appears to disappear. This ability to attract and repel, a property of magnetism, when viewed from a unitive perspective that incorporates an animating principle, I claim, is my earlier argument of the description of chaos as it relates to the unfoldment of consciousness. What I now wish to do is make that process clearer.

I have explained how the drawing forth or attracting of an experience is the opportunity to change thought. What I have not made clear is that thought, existing as energy, can only exist between two points of consciousness (Ramtha, 1997). Thought as energy moves outward from the human being, in the same way that Pierrakos (1987) describes energy moving outward from the core. As the movement of energy there is intent, for the natural state of energy is to have intent (Ramtha, 1997). Thus thought, as energy, with intent, moves out from one point of consciousness to the other point of consciousness. This movement can only occur between two points because energy only exists between two points of consciousness (Ramtha, 1997). The terms I have used to express these two points of 
consciousness are the mind of man and the mind of God or Universal Mind. The Alpha and Omega points are other expressions used to convey this same thing. Energy moves between these two points. When thought, as a wave of energy, reaches that other point of consciousness, it is sent back to its originator in the form of a wave of energy so that the intent of the original thought can be made real (Ramtha, 1999). In this way thought is also memory, because in the experiencing, that is, to feel, it is a process of re-membering because then thought is made conscious.

In quantum physics it is known that what collapses a wave of energy is that it is observed. Thus the received thought (ask and ye shall receive) sent back as energy in third dimensional reality is received as an experience to be observed. To observe a thing is to collapse the energy in matter. As the thesis has already explained, this means that an experience as a pattern of energy can either be rejected/judged, or valued/loved/embraced. In the loving of the feeling an experience evokes is to change the memory. In changing memory, reality is changed and so it is a re-membering. And while an experience may evoke an old feeling, the challenge then becomes to change that feeling in the moment. This then is Saint Augustine's notion of in God's case, will and power coincide.

I must have done it a thousand times - this feeling of deep-seated loneliness not filled by people or things. As I lay in my bed and began to feel that old known feeling I shouted to the heavens waving my arms in the air "I have had enough, I don't want to feel this way any more!" As soon as I had finished shouting this thought, I felt a release of something inside my head that then quickly filtered throughout my whole body. I then lay still breathing deeply and rhythmically, and as I did so I realised I had moved from feeling wretched, to feeling a state of deep peace and tranquillity.

Journal entry

Space, distance and time exist between the two points of consciousness (Ramtha, 1997). As the distance between the two points of consciousness decreases, then so does the time for the intent of a thought made manifest in matter. Distance and time are then reflections of a level of consciousness. In my father's house, there are many mansions. The less space, distance and time, the faster the manifestation of the experience, the more expanded the level of consciousness and the more connected or closer to each other are the mind of man and the mind of God. Each time thought is changed, so then are new thoughts sent out to be received as new opportunities for experience. Moreover, while people and things may change in a person's life, when what a person is experiencing remains unchanged this then is a reflection that thought has not changed. I hope that I have made this point clear. Standing in front of a mirror reciting mantras of abundance or love will not change thoughts on abundance or love. 
Until thought is changed, the experience will not change. For what you put out is what you get back.

As a magnet we choose to either embrace what we have created and drawn forth as experience, or repel/reject it. To embrace is to love. To repel is to judge. Like a magnet, we can repel or attract. When what is felt is judged, there is a loss of heat. To lose heat is to lose energy. To embrace is to heat up, and when the level of heat reaches beyond a certain point a magnet appears to lose it magnetism. In other words, that thing which was repeatedly attracted to a particular magnet is no longer attracted, because that magnet appears to have lost its property of magnetism. The vibration has changed. In the ongoing loss of heat, as an accumulative effect, I perceive this represents the final entropy of a black hole. The magnet eventually appears to lose its animating principle and we radiate ourselves out of physical existence. Physically, we name this death. In the continuing experience of changing our magnetic property by raising our vibration or frequency we attract/call forth different life experiences. This is the process of the ongoing expansion of consciousness. We be. Where what is being expanded is the nature of reality. And if everything is consciousness and energy, then what we truly 'be' is, thought.

The concept of the repellent/attraction property of the magnet as it relates to the animating principle was lost until Faraday introduced the concept of field in the nineteenth century (Sheldrake, 1997). Einstein then extended this to include the field to gravitation; "the gravitational field co-ordinates and holds together the whole Universe, fulfilling the role of the anima mundi, the soul of the world, in the old cosmology" (Sheldrake, 1997, p.70). Thus fields were introduced in the shape of quantum-matter fields in physics, and biology introduced them in the form of morphogenic form-shaping fields (Sheldrake, 1997). These invisible formative fields were said to organise the development of animals and plants and were said to have attractors within them (Sheldrake, 1997). In this way it is possible to conceive that the oak tree has a morphogenic field containing an attractor that is the mature form of the oak drawing the developing acorn towards it! The field then acts in the same way that Aristotle called an entelechy, the attractor within the soul (Sheldrake, 1997). "Where the morphic fields of organisms underlie not only their form, but also their behaviour; they play the role of the animal soul, but also underlie the activity of the rational mind" (Sheldrake, 1997, p.70). In other words, what is in our field/aura is what we put there by what we think and, as such, acts as the field by which we then draw ourselves toward that which in essence we already are. 
As for how much of our thought is conscious, this has already been explained in an earlier chapter. Thought for most people is unconscious, unconscious in that sense that it is, unknown. Therefore, not only are our unconscious thoughts unknown but what is being thought can also be questioned.

Tikashi: So what do you suppose is doing the driving, the Volkswagon or the Porsche?

Me: The Porsche!

Tikashi: Yes, it is, but, the Porsche has mud on it and so it needs to be cleaned.

Tikashi (personal comunication, June, 1997)

How unconscious thought is made known, is through experiencing the emotion to which that thought is attached. This idea has been the focus of this work. However, once this process is known then it is possible to conceive of projecting thought consciously. So in the first instance the challenge is to make unconscious thought known, that then makes it possible to conceive of consciously beginning to project thought [wish to be] as an evolutionary step in the process that remains the same. Even so, thought is still felt. And while we may perceive ourselves to be projecting thoughts of caring, love and peace, what we initially experience may be the very opposite.

YOU cannot be ANYTHING except in the space of that which YOU are not. And so the opposite of what you wish to "be" will appear almost as soon as your wish to "be" it is heard. Indeed, your Soul draws these conditions to itself. And God will give the Soul everything it calls forth ..... in order that the Soul may fulfill Itself in this, Its highest desire.

Walsch (1995, p.55)

In this way we continually experience ourselves as thought in the process of making ourselves, as incarnate beings, into pure thought. The process remains unchanged. On one hand we experience what we think as unconscious thought, and on the other what we desire to project as thought is experienced "in the space of that which you are not" (Walsch, 1995, p.55). In other words, should I desire to be abundance, then I will experience everything that is not for the expressed purpose of knowing that which I desire - abundance. In reality, this will mean being able to feel the feeling of abundance no matter what presents itself. For 
only then can I know what abundance is, and when something is known it is then reflected in matter. Abundance is an aspect of God, because all things are God.

I have used the words God, God consciousness, Spirit, All That Is, Source, Universe, I $\mathrm{AM}$, the Is Not, to convey consciousness that exists beyond what the human mind can comprehend. The expansiveness which we inherently know and of which we have an infinitesimal glimpse when we experience states of pure bliss. States of consciousness that Saint Thomas (1273), upon seeing, is to have said, ... what I have seen this day makes all that I have written appear as straw ... Consciousness which is ever expanding. That in the experience of being human, we, like the acorn moving toward the mature oak, so too do we constantly move toward the maturity of pure being. That we already are this consciousness is certain, for we are God, and so we call/yearn to make this real. The realisation of which is soul work, because our animating principle, our soul, is the connection between heaven and earth, between being human and being God, that when played out in the human drama is both vertical and horizontal. For as I yearn, so too does the other, and as I am this consciousness, then so too is another. The potentiality of realising this consciousness is bound in the engagement of life through the animating principle (soul) that is not intellectualism, rationality, morality or ethics. For the expression of soul is FEELING. Through our soul, we process thought by feeling, and as we learn to do so, consciousness evolves toward being pure reason or God consciousness. That in itself is not finite but as consciousness is ever expanding.

Your brain is a grand receiver of electrical thought frequencies ... Your brain does not create thought ... It simply allows thought to enter it from consciousness flow. It is an organ ... for the purpose of receiving and housing thought that has come through the Spirit of your being, transforming it into an electrical current, amplifying it, and sending it through the central nervous system to every part of your body so that it can be realised for an understanding.

Ramtha (1999, p.182)

Thus we engage in our existence through soul making, that is, working with the field so as to change the field in a way that is reflective of the expansion of consciousness. I have described this process in different ways throughout the previous chapters of this thesis. It is consciousness and energy in motion, that in the human condition is transformed into feeling for the purpose of thought to be made conscious. For as we think so we are. 
As thought, we are energy - the wave that, when received by its corresponding point of consciousness, is sent back as a thought form for the purpose of being felt. Thought is a wave of energy that then becomes a particle when observed. The wave, when observed, collapses in matter, the observer observes the particle to be a certain way. The motion created by a thought is transmitted instantly to its primary source of consciousness [God] as either a dark or light thought. In other words, a thought is either a judgement or negative and in that way dark, or love or positive and in that way light. What is sent out returns, and becomes an experience of life through the e-motion it provokes.

Thought is energy in motion, and when a thought, as feeling, is not judged then the two points of consciousness that a thought travels between become more connected. The corresponding particle pairs are connected, and so what can travel between them, at that level, is a light wave. An unconfused thought is refracted between the particle pairs. The 'true' message is heard. Then thought is less confused and consciousness expands. That thought is made conscious, and so the reality is made manifest.

Consciousness perceives itself as separate from the moment a person perceives himself or herself as separate. How one creates the perception of separation is through judging what IS, felt. Equally, in that very same moment, a person can think whole and in that way become whole through loving what IS, felt. In so doing, one is then free to make a conscious choice to feel something different. We all have the ability to make this choice. It is called free will and the power to do so is an act of self-love.

In its expression it is a life circumstance from which to experience an experience. The form in which a feeling is embedded. In this way, experience after experience, feeling after feeling, the acorn progresses through its transformation to make manifest the tree. The space is slowly filled. Then the acorn, initially bound in space-time, Dasein - being-there, increases the spin of its particles to become the same as the spin of its particle pair - the oak tree. One which has been bound in time and space and the other which is beyond it are finally spinning or vibrating at the same frequency. That frequency is faster than the speed of light. The particles then appear as if they are still, for their net speed is zero. The net speed must be zero, for the particle pairs are no longer separate because they are no longer spread across space and time. They have only appeared to be going in different directions because the acorn is the mirror image of the oak tree. We have been made in God's image, and now that image no longer appears as if upside down. They are connected, and how they have been connected is through feeling. Feeling, that is the domain of the unifying principle - the soul. We name this connecting feeling LOVE. It is immeasurable, but known because it is felt. 
When love is the predominant thought of the soul in every moment, then the body has become a light body. The acorn no longer dwelling in space and time but revealed as an oak tree. Then there is no need to prove love, because it is visible for all to see.

Therefore, as more and more particle pairs spin or vibrate at the same level, the growing tree continues to enlighten, the process is realised, made real, a mature oak in the making, which it has always been. I am what I am, but I am also what I have not become. Distance, but not distance in a physical sense but in the vibratory sense, is decreased, for as the vibration of particle pairs become equal, then they are no longer separate. In truth, however, they never have been separate. The oak tree is here on earth, but always has been, its potentiality housed as an acorn. When it will become an oak tree is about choosing, but that the mature oak tree will always draw the acorn in this direction is certain. In its fullest expression of a being, as the mature oak tree, the acorn is a being who is being. The soul is in the body, and the body is in the soul. Together they move toward becoming the One.

Expanding consciousness is an expression of light. The soul the vehicle for that expression and the body a vehicle for the soul that, in the experience of being human, acts as a magnet to either repel or attract. I have said that it is a choice. As we make the choice to be attracted to, we are then drawn toward, to then attract again, to then be drawn toward, and so on and so on, again and again and again. Until finally, we are together again, a singularity - the point at the centre where both space and time stop.

Thus the property of magnetism can be interpreted in two ways. From a horizontal perspective the soul in a body no longer dwells in a particular place in time and space because as a black hole it has collapsed. From the vertical position, however, the black hole may have become white. How do we know the difference? When a soul is not present there is no radiation, the form is no longer animated. When a black hole has become a white hole it shines because it radiates. What it is radiating is light. Every black hole has this area of light; it is called the event horizon. Therefore this possibility exists. In every area of chaos there exists an area of non chaos. And so what has stumped science might easily be explained. Rather than perceive black and white holes as separate entities, what if that which determines if the hole is black or white is not two separate entities, but whichever attitude a hole is adopting in any given moment. In that way, what was black becomes white. In that state of whiteness it can emit 'things'. As a state of consciousness this attitude might be named love, and the more that a black hole loves, the more love it becomes, the whiter it becomes, the more light it radiates - enlightening. 
The laws of physics are time-symmetric. So if there are areas called black holes into which things can fall but not get out, there ought to be other objects that things can come out of but not fall into. One could call these white holes

Hawking (1993, p.119)

As beings, are we white holes expressing as black holes? I think so. As a human-being, being, is our challenge to make manifest the white hole? For we are each a star. Collectively we are white holes. We are also black holes. For what we be in the human condition is Body, Mind and Spirit.

Interestingly, researchers in 1998 have found evidence of an enormous black hole located at the centre of the Milky Way Galaxy. Is this the anima mundi, the soul of the world/planet? The soul of this galaxy expressed, human kind in its evolution beginning to reconnect to soul? I wonder?

\section{On Being}

In the second chapter of this work I attempted to define being using language that has subsequently expanded as this work has unfolded, as I have unfolded. My early understandings of being were presented as aspects, in much the same way that a weather map is defined by certain characteristics. A weather map is a representation of weather, with its air currents, temperatures and rainfall averages. All are constituents, which make up the map. Yet as a map, it may represent things that exist as an idea, weather as weather is still unknown. How something is made known is when it is experienced as a thing. I have argued it is in the experiencing that there can be a transformation. Transformation that is brought about through experience, which then renders the map as not only something which is an idea, but something which is then known. The map remains, at all times, simply a map. What has changed is one's relationship to the map. I would argue that this is the same for being. For until we have experienced, say, a 'step back', how do we ever come to know that the view after the 'step back' is always more expansive and the path is no longer a mere field path? I argue that we cannot know until we have 'stepped back'. In this way we can only be, by being.

I also argue that it is not useful to continue to define being, because being is understood through being, through living. And in order to live, we are called to experience, to do. In 
the expression of 'to do', it is not just a verb implying activity. Freire (1972) called this point to our awareness. Where action is taken for action's sake, it is mere activism and therefore an unauthentic word. An unauthentic word will not transform the world. To do, to live, to be, means an opening of the self that is a full engagement or participation in life that then is an act of allowance, where what is allowed is life to be absorbed into our very being. Absorption, not as a sponge engaged in the busyness of life, but rather, absorption that is the very reflection of breath and breathing, so that there can be a diffusion of that which is life enhancing coupled with the release of that which no longer serves us. "You are in the room to heal the room. You are in the space to heal the space. There is no other reason for you to be here" (Walsch, 1995, pp.2-3).

Therefore with each breath of life we not only vitalise, but revitalise ourselves. It is an act of surrender where we say yes to life. In saying yes, we are surrendering to the highest force of our being, in the knowing that the experience of life is always for the highest purpose. We are willing. We let go of the need to control the direction of life and so it is a surrender to the energy of all things. God is in all things and so we allow God to direct life. Where every desire I have is God's desire and every desire of God's is my desire. For there is no 'I and thou', there is only 'we'. Where "faith (I interpret faith in the sense of confidence and trust) is standing in the darkness and a hand is there and we take it. In that moment of surrender, although we may not realise it, we stand in an open doorway to freedom ..." (Miller, 1997, p.169).

In surrendering, then, I do not wish to portray an image of a ship without a rudder, nor a one time grand event. A more accurate portrayal is of a ship making many journeys and sailing in all manner of weather. For storm is also a part of the weather map, and when there is stormy weather there are always options. The ship can stay in port, choose to be tossed around for the experience of it or sail into the eye of the storm. Either way the storm exists, but what is important is how that storm, as storm, is experienced. The journey takes in all ports and harbours in all manner of weather. The challenge of the journey is to leave the experience of the last port in the last port so as to be able to experience the new port as if it were a first time; in the knowing that the wisdom or truth of the last is that which has created the possibility held within this next.

In the experiencing of 'the is-ness' of 'what is', we are able to see more. In so doing we come to know 'the is not'. For 'the is-ness' just is, and 'the is not' is not, because it is the same as 'the before'. In that way, we are not a 'no thing', because 'a thing' can become known. But not as some end point or destination, but rather as, "that which IS, IS NOT. 
This ISNESS is NEVER THE SAME. Which means the ISNESS is NOT" (Walsch, 1997, p.246). Put simply, there is always more. When every new situation is not coloured by the past, then today's evidence can speak in the clear light of a new awareness, and so on it goes. Awareness, Confidence and Willingness on a base of love form a triangle called - Knowing.

One of the challenges of this work has been to discuss being in a way that does not create an Anatomy of Being that then becomes a prescription of how to be, while at the same time providing enough structure in order to lay open key elements of a process. For every human being, being is an individual process, and while shared cannot be compared. The way of being for all beings is embedded within life, where the focus is on experiencing an experience. Transposing an experience from one person to another will not lay open being. This I have attempted to illustrate by using the concepts from fractal geometry where, after a certain point, predictability, in the futuristic sense, is not possible. We are each called to make our turns back, to unpick our individual patterns, but that we can and do make the turn back together, is certain.

Therefore, in speaking of being I speak of both One and Individuality. For while there exists a commonality in the triangle of becoming accessed through feeling, by our interaction with each other, in the first instance, we engage the self in the process of being. In calling forth by thinking - each being may be likened to becoming an expert craftsman who is learning when and how to use a myriad of tools [awareness, openness, validation, tenacity, commitment, trust etc etc etc] to build/create the self until such time that tools are no longer required because the craftsman has either become that which he has used, or no longer requires it. In becoming the tool the craftsman is no longer telling the body to do something in order to demonstrate the state of being, for he/she has become an automatic response of being that has already been achieved. Thus the engagement in the process of being is individual. It is an act of creation to become what we already are. And so it is the One and the many in the process of revealing something so as to then make that thing known.

Being cannot be measured or proven. To even attempt to compare or measure is contrary to being and, as such, being challenges the very basis on which we have structured much of how we perceive ourselves in our world, and thus perceive the world to be. How one knows being is that we each come to know. Knowing is not the same as understanding. Knowing is reflected in wisdom that in turn is an outcome of what has been realised. In other words, what has been made real within the being. In that way, being is also like love.

Being is process that is lived, and at the same time it is living. It neither commands nor demands but calls for us to throw away our rulebooks in order to submit to a higher 
authority. That authority is our God consciousness. Our God consciousness is not limited by how we should or must be and as such stands in total opposition to how, in most cases, we currently are. When we understand this and can allow ourselves 'to be', to live life through being, then how we each live/be will be very different to how we now live/be.

Martin Heidegger, the author of 'Being and Time', was asked to write a 'Human Ethic'. He declined the invitation saying that as human beings we did not yet understand being. I would suggest, that when we are able to live in accord with what it means 'to be', by being, then an Ethic on Being Human will not be necessary because the natural outcome of being is that an ethic defines itself. In the redefinition of the notion of God that positions God in a more subjective activity in our lives, we begin to see life through the eyes of divinity. In that way being, a divine being brings about its own evolution of morality, its own wisdom and its own understanding (Ramtha, 1997).

Each second we live is a new and unique moment of the universe, a moment that will never be again ... And what do we teach our children? We teach them that two and two make four, and that Paris is the capital of France. When will we also teach them what they are? We could say to them: do you know what you are? You are a marvel. You are unique. In all the years that have passed, there has never been another child like you. Your legs, your arms, your clever fingers, the way you move. You may become a Shakespeare, a Michaelangelo, a Beethoven. You have the capacity for anything. Yes you are a marvel. And when you grow up, can you then harm another who is, like you, a marvel?

Pablo Casals (1987, p.232)

\section{The power to be}

Walsch (1997), in a discussion on organized religion, argues that in order to put faith into something outside of ourselves we must first lose faith in ourselves. Then, having put our faith into something outside of ourselves, that outside thing is perceived as having the answers, while the ability to scrutinise those answers becomes diminished. In raising this point I do so from the position of personal responsibility, that is not a stance of antidependence but one that is questioning dependence as it relates to personal power. 
This work has had its origins in nursing and thus health care. It would be an accurate observation to say that the relationship between those that provide health care and those that are the consumers of health reflect this argument. While the relationship appears less hierarchal than in the past, consumers of health care are not positioned in a way that could be termed powerful, equal or responsible. There is less overt domination of health care by allopathic medicine and a much more humane face of its practitioners, but there continues to be a subversive manipulation of power that maintains the status quo in relation to medicine's perceived omnipotence, brought about by its alliance with technology. And so the present construct of health care does not yet represent the possibility of locating the locus of control within an individual, because it continues to be structured on the same belief that is represented in the opening sentiments of this section in relation to organized religion. In this way, our prevailing attitude prevents our ability to conceive of anything different.

I have argued clearly that reality is a reflection of how one/we think/s. Our systems of health care, in the Western world, are driven by belief systems concerning physical existence and fear of death, thereby creating the need for a system that then designates and assumes responsibility for health. This is not the same as saying that a society should abandon its health care or be devoid of practitioners to offer support during times of health care need. Rather, health care is something that needs to be recognised as the dominion of each human being. This thought is not even within the consciousness of the populace. Moreover, the significant investment in our putting faith into technology has further muddied the existing consciousness. Our health care is a system of people and machinery where other people go to have their health restored. As a society, we have yet to ask the questions about who we are and how this might relate to health and life. This is in spite of some individuals having made enormous efforts to reach the populace. Therefore I see health as an issue of attitude. The attitude that I speak of is of course one that views change as movement from the inside to outside. One where health care is directed from the inside out. For until we entertain the idea that we are the creators of our reality we will be unable to begin to take responsibility for our creation of dis-ease. In so doing we continue to perpetuate the perception that practitioners of health care and their supporting structures are the locus of power. In that way we each remain disempowered. I say each, because those delivering health care in this manner are not empowered either, for the power they exhibit is not true power.

Having made these claims I would say again that our creations, our dis-eases, are not to be viewed as some sort of punitive intervention or divine retribution inflicted upon man by the wrath of a benevolent God. Rather, our dis-eases are what the name implies. Dis-ease, without flow - a disruption to flow. It is important to understand that a disruption to flow can 
manifest itself within an individual, a community group, a country, or be evidenced as a global event. The collective unconscious. To see any one person with dis-ease, as an individual issue, is to continue to live within a paradigm that fosters separation. We are connected. Every movement in one corner creates a movement in another. All things flow. So whether it be a community or world epidemic, it is a reflection. Groups of human-beings, being, carry the manifestation of a dis-ease in order 'to be', and it is not just in them but it is in every one of us. These brave souls, while it is an individual call of being, carry a manifestation that in some way is a reflection for the whole of humanity. In some way, that epidemic, that dis-ease, is a representation of the block of flow within each and everyone of us in an individualistic sense in some way. As such, we are challenged both as a society and as an individual by the manifestation of dis-ease to create more flow within ourselves. In creating more flow within the self, each one of us is also creating our society. For love is not separate, we are not separate, and just as we are not separate from Love/God, so too are we not separate from each other. In this way, I speak of a horizontal and vertical axis that is connected through our animating principle.

From this position of unity, there can be no 'them and us' or 'me and you'. For in this position there is only ONE. In this way, too, nothing is done or just happens. We create it all. This can be said for all things. Then the position we stand in is neither an antidependence nor dependence, rather, it is a position of power. For we become aware that we cannot tinker in one place without considering the impact of our tinkering on another, be that a societal structure or the body, for it is all connected, it is all ONE. This then is power, it is the power to be, and is power that comes from the inside. It is not something to be given, nor is it something to be taken, but rather it is ours, and it is IN each and every one of us, for it is ours to create. It is as Augustine said, 'Where in God's case, will and power coincide' (Augustine cited in Arendt, 1996, p.87). It is as Williamson's (1996) interpretation from 'A Course in Miracles' that says, our deepest fear is that we are powerful beyond measure. We were born to make manifest the glory of God that is within us, and it is in everyone.

So if we each tapped into our own power, then how powerful would we be? This power is not the sort of power we now have in our societies. The power that we now have is power that is presumed to be a finite resource, and so we engage in struggles over power, power struggles, and are left with the illusion that some are more powerful than others. We put our faith in those things we perceive as more powerful than ourselves. In that way, we locate our power outside of ourselves. It is this attitude that reifies another image of dualism or separatism. The outside a mere reflection of the inside. This reflection of power is in almost 
every system we have created. It is what drives these systems, and as long as we locate our power outside of ourselves, we will continue to create bigger, better systems to achieve this kind of power. The health care system is but one example, and it is not a reflection of the power 'to be'.

Scientists report that our universe appears to be expanding. Things are moving further away from each other. I have said that we are the creators of our universe and so I wonder, is the ever expanding universe a reflection of just how far we have moved from our true power? For by not taking total responsibility for every occurrence in our lives, power remains something that is external to us. This type of power is power that is over something and we recognise it by the names of slavery, dictatorship, marginalisation, racism, impoverishment, class, gender, and manipulation. This type of power continues to perpetuate duality through being that moves between the polarities of powerful and powerless.

True power on the other hand is the power to be, and regardless of what we are and where we have chosen to be born, we each have this power. This power resides within. We claim this power when we reconnect with our animating principle through feeling. It is the power of freedom. and one cannot be free without also taking resnonsibilitv. In this way when I

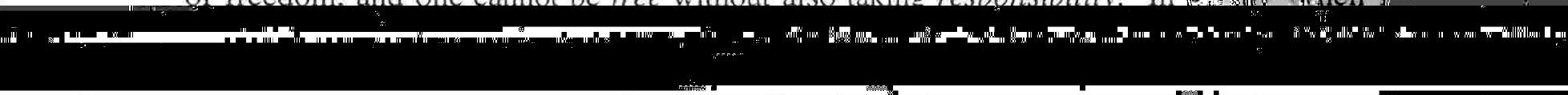

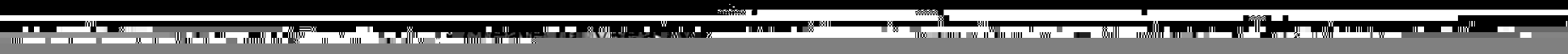


body mind interactions involving conceptual and perceptual processing. The expansion of consciousness is about the clearing of the mind that is undertaken in conjunction with the body, and in that way it is about the creation of flow of energy. Then it can be said that one is in the flow of all things. While one is always in the flow, one may not be flowing. When one is both in the flow and is flowing, then what is conveyed is not theoretical development as conceptual knowledge, but truth as pure intuition. This then is an important distinction.

On one hand truth can be perceived: it is what another has learned, or how it has been created, how it has been experienced (Ramtha, 1999). On the other, truth that is not a reflection of the understandings of an individual is as vision, where what is envisioned is only limited by how far one can see that in turn is a reflection of the clarity of mind and body of the visionary. In this way, truth too is limited. So while truth as vision is articulated/transmitted through language, which then calls for conceptual processes, such truth is not generated from thinking which is perceptual or conceptual. How is the difference known? Truth is felt. Truth is also a feeling. In this way, truth exists as whatever it is believed to be, and therefore there is no reality other than what we each give meaning to, through what we feel.

In the human condition what we feel is an emotion, and how it is felt is through the animating principle that is engaged in the experiences of life, where life serves as form. The form exceeds the image itself, because form acts to enable the creation of meaningful patterns within life, and therefore captures both object and subject through the weaving of past with present in the work of art (Lukacs 1916-1918 cited in Markus, 1983). The creation of a work of art arises out of the unison of the totality of life while enabling the transcendence of time. In this way so too do we create life, that as a work of art that then serves the purpose of bringing about the realisation that everything is true and nothing is, because "there is only the Isness of ongoing evolving life" (Ramtha, 1999, p.123). Thus truth exists as perceived or received until it is made known. For then what is known is, that nothing and everything exists.

Martin (1990), in her discussion of form in Nursing, suggests that form is the essence of nursing and is that which becomes visible or is what is made manifest in practice. Nursing practice, "is caring for peoples' souls by aligning with their spirit so the soul comes clearly to them as their consciousness" (Martin, 1990, p.120). I have argued that the soul is that through which we feel, and that we call to ourselves all manner of experiences for the expressed experience of feeling. Thus the expansion of consciousness is a soul process involving body and mind that is enacted by emotion and feeling encapsulated in experiencing 
life. Through feeling we align ourselves with spirit, expressed through patterns of sentience to then become consciousness. The consciousness that I speak of is consciousness of ourselves.

Lukacs (1983) depicts form as a representation of pattern. Pattern is a mixture of both object/pure thought/feelings and subject/confused ideas/emotions. As form, we are pattern that through soul we connect to spirit or monad. The attachment and manifestation of soul within the physical vehicle [human body] is something determined by an allowance of the presence. I have explained the presence of the presence in an earlier chapter. In esoteric schools, this phenomenon is termed soul infusion - the soul is in the body. The assumption is, though, that every being is always soul infused. That is not the same as saying that everyone has a soul. To assume that everyone is soul infused is an inaccurate representation. For as I have already explained, in judgement the self (soul + spirit) cannot be present. So while every being is a soul, and the soul is in the body and the body in the soul, the soul expresses itself in feeling. If what is felt is judged, judgement then serves to cut ourselves off from ourselves, that is, we are no longer connected to ourself. We are disconnected from our soul, and so we are disconnected from spirit - our pure consciousness (absolute). This then is separation. Separation too is a feeling and it feels lonely, empty and unloved.

Therefore, I would now say, "that form in nursing, and therefore its essence, would not only consist of the absolute, or object spirit, but also the subject in which culture enables the transcendence of the soul. The soul then aligned with spirit would then become consciousness, and as form, provide meaning" (Tucakovic, 1994, p.26). In other words, how we connect to spirit is through our soul, where in the human condition we are first called to connect to our soul. How we connect as a human being to our soul, to become soul infused, is to feel our emotions.

In the discussion on the difference between reflection and refraction, I explained that I cannot connect with you at a soul level, a beingness level, where I am blocked at that level within my beingness. Then I cannot consciously assist you. At best our connection is termed a reflection that then holds the potentiality of an unblocking for us both. In that way it is a horizontal connection through each other, that then enables the vertical connection of the connection to spirit through soul. As process it is still feeling, the relationship serving to reflect the blockage of flow to each other. Therefore, when I speak of the essence of nursing, it is what I have named refraction. For it truly is an art to be able to evoke, call forth, invite, awaken or energise in order to invoke the essence of another by being with another. For what the nurse is calling forth, consciously, is the soul of another being. It is 
an opportunity for that being to allow the presence of the presence. In allowing more of the presence of the presence, more of the consciousness of the absolute is made conscious.

In working with blocked flow, dis-ease, which Bailey (1953) suggests is the result of inhibited soul life, the nurse is acting as midwife where what she is birthing is more divinity through more soul. Such awareness enables a greater presence of the presence and this then serves the potentiality of the process of uncovering. In the process of Aletheia we are fostering healing, which at physical level is expressed as illness but, as an expression of the totality of being, it is being that in its grandest manifestation as a human-being is the expansion of consciousness. As nurses we are called not by the phenomenon of dis-ease in a human being, we are called by beingness. In this way, we are also called in our own process of Aletheia, that when seen in this light will make manifest Nursing's glorious destiny.

Nursing is an art; and if it is to be made an art, it requires as exclusive a devotion, as hard a preparation, as any painter's or sculptor's work; for what is having to do with dead canvas or cold marble, compared with having to do with the living body - the temple of God's spirit? It is one of the Fine Arts; I had almost said, the finest of the Fine Arts.

Florence Nightingale

That 'as exclusive a devotion' and as 'hard a preparation' I see means to engage ourselves in our own healing by connecting with our own soul so that we might then better support others, in connecting with theirs.

While sites of nursing practice differ and the expression of being-human vary in context, I hope that I have made clear that, regardless of where we are and what we are doing, be that in a hospital for physical dis-ease, an institution for mental dis-ease, or a centre for giving birth, each is an expression of being-human that is in some way a call of being to be made manifest. My argument is that we are yet to answer these calls of being consciously, that as a representation of Nursing are a response that takes the form of an evocation.

Nightingale's vision was a call to being. Until we, as nurses, experience ourselves as human beings from the place of being, we can only act in ways that express human sympathy. Sympathy will not raise the vibration/consciousness of humanity. Sympathy will not support another to move out of their condition. Compassion, I argue, as a 
thoughtfulness/mindfulness engaged through acts of care that is a caring for self and others, is what will make real the vision of an exclusive devotion as the finest of the fine arts. For then, will we know how to work with the temple of God's spirit.

It is on this capacity of one human being to receive another human being's expression of feeling and to experience those feelings for oneself that the artistic activity of nursing and caring is based. It is art when the nurse, having experienced or realised the feelings of another, is able to detect and sense these feelings and in turn is able to express them in such a way that the other person is able to experience them more fully and release the feelings he or she has been longing to express.

Watson (1988, p.67) 


\section{Summary}

This chapter weaves the key concepts identified in the thesis to expand the notion of thought/intent as conscious consciousness from the position of mind or soul that evolves from the knowing of 'how' reality is created. Consciousness is presented as the ongoing evolvement of mind/heart in the experience of being human, through being, a human being.

True thought is presented as a reception of thought rather than the generation of percepts. Receivership is then reflective of a clarity of mind which in turn is pivotal on a being, being more and then more again, and so on.

With this understanding on the nature of being and thinking, Nursing's role as midwife and healer is then further explicated in the understanding of Nursing as an art. Where the word art is used to denote a representation or portrayal of a process of being in action. 


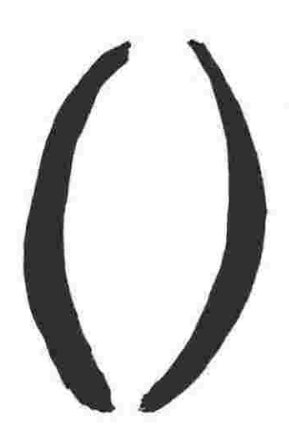

\section{Chapter 12: Transformation Through Health Care}

\section{Nursing - an entelechy}

In the previous chapter, the concept of an entelechy, in the Aristotelian sense, was said to be of the soul having the end, that is, the end is attained through the soul. In this way the soul is that which is the beginning, and also the end. This is not to be interpreted as in the beginning and at the end, but rather it is through the soul that there is an end. End not as some finite point but end as in a completion.

To speak of Nursing as an entelechy is to speak about nursing as having a soul that can also lay claim to a beginning and an end. To consider nursing as a soul allows for nursing to be approached as consciousness, a pattern of energy. This then opens the potentiality for change by working with energy to change consciousness that then engages us in the activity of making more of the unconsciousness conscious. In so doing, this then is the Aristotelian meaning of the soul having the end.

Nursing has a consciousness. At one level, it exists as pure consciousness, at another the present consciousness of Nursing is a pattern of energy created by the beings that do nursing. In other words, by what is thought. What is thinking? As pure consciousness, the pattern of energy that is nursing is pure thought. This pattern is contrasted to the current pattern and as such represents our movement toward 'an ideal'. I would hasten to add that by an ideal I do not mean the end, in the same way that I have interpreted the soul as having the end in the opening paragraph of this chapter. However, in the idea of Nursing as consciousness it is possible to conceive of the notion of nursing having a soul and therefore engaging in a soul process to evolve its consciousness. In the process of making the unconscious conscious, it is the revelation of the entelechy of Nursing. As the ongoing process of the unfoldment of consciousness, patterns of consciousness, that in some way will serve this end, are created in every single moment. Therefore, anything that is an event in nursing or involves nursing - any single occurrence, be it at an individual level or global 
one, is a reflection of an aspect of consciousness. To understand this, is to understand that the whole is the whole. This then means be it the one or the many, the event or occurrence is a reflection. Why? Be it by one or the many for one or the many, the whole always works as a whole.

In viewing nursing from this perspective of whole, it is then possible to see that the boundaries in nursing designated by role function are artificial. The boundaries from the perspective of consciousness are illusion. That is not to deny the variance in role function, rather, it is to say that the roles are not foreground. They are sites in which an individual can expand consciousness and from which the consciousness of nursing might be expanded. In this way, the one can affect the whole. For whether nursing be administered, practiced, or taught, these roles are a reflection of each other from within which there are multiple reflections. For example, a curriculum in an educative institution created with the intent to foster a greater degree of self responsibility in the learner may be no different to the health care agency with which that educative institution is affiliated, where the nursing system is representative of the opportunity to engender a greater degree of responsibility of its practitioners by promoting a greater autonomy. And while accountability is always to the self for who we are and what we are creating, using the above illustration, everything that is not autonomy will present itself in both sites, in all manner of experiences, as a challenge to the notion of autonomy. That these two sites are 'affiliated' is no accident, for like will attract like.

The educative activities in one institution and the nursing activity in the health care institution are places in which to experience experiences, and so will raise the same types of challenges for all individuals in unique ways. For the purpose at soul level is always expansion/growth enabled through and by one another, regardless of our site of practice or role function in nursing. As I have explained we are connected, both horizontally and vertically. Our horizontal connection is through our embodiment, and so we draw ourselves to each other according to similarities in our auric fields that are representative of either end of a duality, for the expressed task of transforming an illusion of consciousness that is invoked or evoked as an act of creation in our coming together so that we can be.

So I would say again, the boundaries are illusion. For what goes on in these sites is the opportunity to experience emotion, the result of which is to create the patterns that then serve to expand or contract soul growth. Therefore, whether it be the one or the many, by all that we engage in, in the name of Nursing, when it is growth it is growth of the individual soul, and so too is it growth of the soul of nursing. For the one affects the many. 
Thus it is change directed from the inside out. For when I expand my consciousness, then I am affecting everything around me. As I lift my vibration, then so too is the vibration of everything affected. Why? All things are connected. The whole is the whole. So even when groups of nurses do different things differently, the differences can be viewed as just that-difference. For in the knowing that all things just are, then what we know is that we are each where we need to be, as an expression of a possibility for the greatest growth. And so the only soul that we ever need take responsibility for, is our own soul. For the onus is on who I be and what I am creating. In so doing, I am then affecting the soul of nursing.

To view difference in any other way is to recreate duality by deeming some things better or worse than others. To focus difference in post modernist or modernist thought will not support the growth of consciousness. For while one framework is an attempt to perceive the world in a more encompassing way, it has been built by delineating itself from a previous set of constructs. And in that way sets up an either or situation. As soon as something is compared or contrasted, the comparison or contrast has to be to another thing. This then is an act of judgement. In judging a thing, that thing cannot be viewed from the perspective of the whole. This is a vital point and one that I hope I have made very clear. This does not preclude us in making observations.

To desire more is not because what IS, is less. That then is a judgement. To desire more is an expression of yearning for expansion, where what is being called forth is more love. To desire a thing because what is, is less desirable, is not loving a thing, and so one cannot come to a place of more love from this position. For the whole does not judge, and so the whole does not compare and contrast difference. The whole observes, because the whole knows that everything just IS. Everything IS, and so everything holds this potentiality, that as an observation is a reflection illuminated to bring about a greater awareness, from which there is the movement toward more love.

As I sat writing I would shift my gaze to the right and take in a beautiful vista of my garden. At other times I would turn my head to the left and take in the island of broken crooked tress that had been poorly planned and badly planted! How could any-one be so stupid as to create such a mess? As I would make my way down to the front of the property I would walk pass this section with my head turned in the opposite direction. I could not however block out my thoughts - no, this is too big a problem, I won't be here for ever, some-one else made that mess and some one else can take responsibility for $i t$. This went on for twelve months and as I tended to the garden on the right it grew more beautiful while the island on the left appeared more horrid. Then one day as I was pondering on the notion of connection I had the awareness that this island was also a reflection of me. And so at first I would just sit and look at it. After a few months I had the idea to consciously send thoughts of love. Would the trees straighten up, would new growth happen? I wasn't sure, but I was aware that when I looked at 
the island there was less and less judgement. Sitting looking at my island, I was aware that I did not feel the repulsion I had felt in the past.

About six months, after I started sending my island love, I was walking past it, face toward it, and ane idea appeared so clearly that I almost fell over. I got in my car and drove two miles up the road to the local nursery. To my delight they were having a sale, and in thirty minutes I had purchased eight, twelve foot trees. The woman who assisted me gave me a business card of a tree lopping service. I rang when I got home and he happened to be passing the next morning and said he would call in and quote the job. He arrived, the cost was minimal and he scheduled the task two days later. Two men arrived on the designated day and in six hours had removed all the trees, stacked next year's fire wood leaving piles of mulch. In the meantime, I asked the chap across the road if he would whipper snipper around the beautiful rocks to expose them again. He came over that evening. I rang the Greek farmer down the road to see if he had a post hole digger. He said he would come up and manually dig the eight big holes in the morning. I did not even know this man, yet at seven o'clock the next morning there he was in my garden - digging.

The nursery men delivered and placed the eight trees in their holes. A friend and I covered them in and spread the mulch. A few holes were too small and so Anastasios came back and made them bigger. In five days, my Island had been transformed with minimal fuss and minimal finance for such a job. Such is the power of love.

(Ah, and how those trees have grown in the last five years!).

Journal entry

My day began in handover, where I received my patient allocation and had my first introduction to $\mathrm{Mr} \mathrm{C}$. The information abruptly imparted was that $\mathrm{Mr} \mathrm{C}$ had $\mathrm{Ca}$ of the liver and was to be discharged this morning...medication ready...hospice notified...replacement patient ready to be admitted.

When I entered his four bed room, I automatically noticed $\mathrm{Mr} \mathrm{C}$, he had a startlingly yellow face with brilliant blue eyes, the "whites" were tinged with yellow. He wore a big welcoming "come hither" smile. He was sitting out of bed, which was made, and had just finished eating his breakfast.

Before I could finish introducing myself, he beckoned me urgently closer, grabbed my arm and said anxiously....PLEASE don't send me home to my wife! I like it here with you nurses...I want to stay. I was shocked and for just a split second felt such anxiety - it was as though it was contagious. I felt as though my eyes had bulged from my head, and my mouth had dropped wide open. And just at this moment Mrs C. stormed into the room. Mr C. withdrew his plea, it was as though the interaction had never taken place! Whilst I was still in a state of shock, Mrs C. introduced herself to me, and, ignoring her husband, proceeded to pack his belongings. She asked me if "the discharge medications were ready" clutching at my arm at the same time. I thankfully replied, I'll just check (an escape route!) and with this I scurried from the room.

I went to find my buddy RN and anxiously told her about the weird events I had just experienced, thinking it was a revelation, but she said " ...yeah, I know...isn't his wife a bitch...but we've got a patient waiting for the bed...Hospice needs to be notified that he needs a wheelchair ...so hurry!"

With this, I picked up the discharge drugs and returned to $\mathrm{Mr} \mathrm{C}$. As I entered the room, I saw that Mrs C. had everything organised and was eagerly awaiting my return. 
In an effort to push aside the preceding events, I began to silently recite the contraindications of $\mathrm{Mr} \mathrm{C}^{\prime}$ s. prescribed medications. I took a deep breath in an attempt to bring myself back to earth and began to educate $\mathrm{Mr} \mathrm{C}$. about his tablets. At this moment, Mrs C. blurted out ..."what are you telling him for? ... He won't understand!....He's sick"! I calmly told her that it was important for $\mathrm{Mr} \mathrm{C}$ to understand his medications and the side effects they might have. Mrs C. then proceeded to recite medication names, dosages and frequency of intake. She said see, we know them. I looked at Mr C., who had withdrawn into his own world and I wished I could join him! I told Mr C. I needed to contact Hospice and arrange for a wheelchair, giving me another excuse to leave the war zone.

I returned to the nurses station and contacted Hospice, and tried to regain some composure at the same time. The Hospice nurse said that the wheelchair wasn't a problem, but I added that there was a problem in that $\mathrm{Mr} \mathrm{C}$. was reluctant to go home. Hospice was aware of this...and she explained to me that they were dealing with it. I began to feel twinges of guilt. On reflection, I realised I was sympathising rather than empathising, and exhausting myself in the process. I returned to the room where the $\mathrm{RN}$ helped me transfer Mr C. into a wheelchair, we gathered his belongings and headed off to an elevator.

Up until now, Mr C. hadn't uttered a word since our first interaction. Whilst in the elevator with several other people, Mrs C. told her husband to put on his jacket...Mr C. replied I'm fine...put on your jacket!.... I'M FINE! .... She grabbed my arm and said see, he never takes any notice of me!....and thereby proceeded to put his jacket on him. I wished I could disappear!

On leaving the elevator, he looked up and said to me "...I want to play pool when I get home...I can play pool...can't I? I didn't get a chance to speak, because Mrs C. said, "You fool! It'll only make your condition worse....I've got your bed and chair ready!" At that point, all I could see was the exit doors (another escape route!)....I felt absolutely helpless... if I was to say anything to support either of them the conflict between the two may have been worsened.

We reached the exit doors and the ward pharmacist caught up with us to tell us that a drug was missing, and if we could wait for them, she would only be five minutes. My reaction was $\mathrm{OH}$ SHIT! So close but yet so far! It was at this moment and I don't know why that Mrs C. felt compelled to open her heart. Shedding a few tears, she said, "I can't believe this is happening to us, what if I haven't got everything right at home?"

I asked her to show me where the car was, and leaving Mr C. still in view, we walked through the doors to the other side in an attempt to give her a little privacy, and give $\mathrm{Mr}$ C. some time out. Once outside, she said through her tears "...I'm just so scared that I'm going to get this disease too....and I don't want to make my husband sicker. I don't know why, but then and there I decided to hug her. I just put my arms around her and acknowledged her fears. I encouraged her to be open with the Hospice nurses, and assured her that they were there for her too. I explained that $\mathrm{Mr} \mathrm{C}$ was still living even though he had this disease and that his quality of life was still important to him. I reassured her that he would still be able to play pool and that he would know what his limitations were. She then said, "I just don't want him to get sicker"...and I said, "I can see that, I can see that you are trying to protect him [pause] but he needs to set his own limits". She nodded, and then hugged me again. We went back inside. The pharmacist had returned and so we helped $\mathrm{Mr} \mathrm{C}$. into the car. I returned to the ward. I heard that he died two weeks later. 
In the experiencing without judgement there is the potential to see something anew, and in that way change consciousness. In the various role functions in nursing are experiences from which one can come to know more love. Such understanding is not knowledge. Such understanding is then wisdom through enlightenment, born from the experience of living where each experience is thought made manifest.

As such it is either truth reified or truth evolving. As truth it is the reality of that being. Wisdom on the other hand is representative of thinking that began as an idea, that when received as an experience is allowed, and as such the soul is fulfilled in whatever knowledge and understanding it requires. The soul becomes lighter; it is a process of enlightenment. Belief is not wisdom; belief is a law that a thing has about itself. To believe something and know something are not the same. How a thing is known is, that it is known. To suggest that thought is wisdom because it has been embodied is erroneous. Wisdom is embodied thinking that is representative of pure thought that in its transformation from idea to wisdom has lost none of its purity. At no level has it been corrupted. It is not percept attached to form. Having said this, though, are all ideas reflective of pure thought? No. But here-in is the miracle or wonder of it. All thought, regardless whether it be true/pure, creates the opportunity for experience, which in turn is the possibility to evolve thought, so that we eventually understand that in every breath we are "refining your own opinionated self ... then one day you become the truth of all thought, the platform from which all life springs forth (Ramtha, 1999, p.126).

The notion of Nursing as soul would enable us to position our theories [sets of beliefs] that are representative of patterns of energy, consciousness, to be experienced as feeling, to then make those thoughts conscious. Using caring as an illustration, I would argue that caring in its fullest expression is the feminine aspect of caring that is the ability to nurture the self on the inside [as opposed to the masculine aspect of nurturing that focuses on the outside]. The feminine aspect of caring reflects an internal dialogue that is devoid of criticism, judgement or doubt. That until the consciousness of a being, who is being a nurse, has this consciousness, then the expression of caring is reflected by the limitation of thought. Caring is like love. Until there is love for the self then love cannot love through one's being, for love loves through beingness. We be love we do not do love. And if I cannot love myself, then I am limited in how I can love another.

I had the honour of sitting next to her, she who has offered nursing so very much. And as she dialogued with the facilitator I could not believe what I was hearing. As I listened I could not hold back the tears welling up inside me. Here I sat next to someone who had done so much and yet what I was hearing was that she doubted the value of what she had contributed to her profession and her life. I then realised my tears 
were not for her, they were for me - for I too could continue my life in this manner thinking that no matter what I did it would never be enough, because I was not enough. Journal entry

We are each, then, through our various groups or organizations, working with an aspect of consciousness in nursing. Where we are, reflects that aspect of consciousness. In this way we take the self to exactly where we need to be and with whom we need to be with, so that we may experience whatever it is that we each need to feel for the purpose of making thought conscious. Heiddeger (1968) said, we cannot not think. Thinking is pattern made manifest in order to repattern. As each being within a group evolves, re-patterns, so too does this assist the whole group in the process of evolution, of evolving consciousness. In this understanding of being, I am saying that Nursing in its relationship with those being nursed, those with dis-ease, can engage in transformation that, while grounded in health and healing can support the transformation of the very essence of humankind.

For those of you who want health, illumination, love, something has to shift, because if left to itself the body will keep plodding along at its own frequency. When you place your awareness on the thought that in God all is perfection, you accelerate your energy to such a rate that disease can be moved out of the cells. This is how one gets healed. Real healing takes place because you simply move out of the condition.

Bartholomew (1998, p.108)

So as we have our own soul, so too is there a Soul of Nursing. Every nurse is a weaver working on the same tapestry. The tapestry of nursing is being woven, the soul of nursing is being woven, as we go about the day to day business of nursing. Whether nursing is taught, practiced or researched, in some way what is represented in the provision of nursing care with our fellow human-beings is that each one of us is both the strand being woven and the weaver of the strand. For, as we weave, what we are weaving is our own life in a way that is both Individual and One. That life is born through the interaction of the one life with the lives of others, is something that needs to be made more conscious within the psyche of Nursing. I can think of very few groups in our society in which there is the continual presentation of the opportunity for such a depth of intimacy as that which is represented by the nurse patient and nurse to nurse relationship. It is through this relationship that we 
ourselves can be born. And as we go about assisting another in their birth, as we birth, so too are we being born.

I was asked to give a talk to a group of women on Spirituality in Nursing. As I shared with the women what we as a School of Nursing had done a woman raised her hand. I stopped and invited her question. "You people seem to have been doing some wonderful things with your students so how do you feel about what has happened to the school and that all these wonderful things will no longer happen?" I was so taken aback, her question came out of the left field. The tears just filled my eyes and I struggled to contain them.

As the thesis was coming together I had agonised over this same question. As I re read their stories, filled with the passion of human encounters, I cried for what I perceived was loss. Why, when we appeared to be heading in a wonderful direction, was our school literally decimated. I, like many of my colleagues, had shed many tears. And here in a moment and from nowhere I was again reduced to this state. I mumbled some answer in return and went on. Two days later I was in bed with pneumonia - I now understand what it feels like to gasp for air.

As I lay in my bed I knew at the bottom of my illness was unresolved grief. In the years that have followed I have pondered the question of our destruction many times over - Why? This phenomenon is found throughout history, in many places and cultures. Where what appears to be outstanding, is then destroyed and by those who appear, to offer something less.

Why is it, that if the soul has the end, that we seemingly call forth destruction of grand acts of creation? Is it because our growth is accelerated further? Would I be who I am today had I stayed where I was? How has each person, once housed together creating a wondrous movement forward in Nursing Education evolved in the ensuing time span in ways they might not have had things been allowed to continue? I can only speak for myself.

\section{I have wondered!}

In the ebb and flow of life we come together for a while through an activity to enable our own and each other's growth. We then disband to continue this process with others in other ways in the absolute knowing that it is always for the highest good and that somewhere in time and space we will come together again for this same purpose. I had thought that death was real. I had thought - that we had died.

In truth nothing ever dies, it only changes shape. Ultimately though, form is no other than emptiness, emptiness no other than form, where at the vertical level we always were, and always will be, connected.

It has taken me years to know this. To know that I live in the hearts of my students and colleagues, and they in mine. We do not dwell in a building, or place or activity. We dwell inside one another as a feeling that can never be destroyed. That feeling is love, and thus we exist for eternity.

Journal entry

In the first chapter of this work, I did say that the magnificence of Taylor's, "Nurses and patients are beings, who embody Being, that is they are entities within whom existence is situated" (1994, p.7), would be more fully explicated. I hope that I have made this clearer. 
For if health is a window to enable the self 'to see' and 'to be seen', then as process, it is both reflection and refraction through which we can support transformation and be transformed. Transformation that is a soul process and, as Aristotle said, the soul has the end. Transformation that is occurring on all levels at once, from one cell within one being, to every cell in a being, to all cells in all beings. So as we continue the soul work of Nursing we continue in the process of healing. For not only are we transforming our own soul, we are assisting the transformation of the soul of humanity here on earth, strand by strand, tapestry by tapestry. Where what we are doing may be likened to the ultimate act of nursing/midwifery, until the last blade of grass, so it is in the beginning as it is in the end. The black hole, the anima mundi of the cosmos will be white again. Aletheia!

By his fidelity, he must build - starting with the most natural territory of his own self - a work, an opus, into which something enters from all the elements of the earth. He makes his own soul throughout all his earthly days; and at the very same time, he collaborates in another work, in another opus, which infinitely transcends, while at the same time it narrowly determines, the perspectives of his individual achievement: the completing of the world!

Teilhard de Chardin (1927 1968, pp. 60 - 61)

\section{The feminine in our lives}

I perceive that our society continues to struggle with its notion of the feminine that for many remains bound in an ideology of gender. Some descriptions of the feminine include qualities or attributes that are associated with the way women are seen in the world that reflect the cultural value of woman as nurturer. Nursing is perceived as women's work, despite its inclusion of men. Nursing as a choice of profession, in the English speaking world, remains linked to economic circumstance within a society. In a buoyant economy, there is a noticeable decline in applications for nursing preparation. In this way, Nursing as defined by gender and gender role is not valued. And as this is so in nursing, I argue, that we continue to live and move in a society that predominantly reflects a way of being where the masculine aspect of the self is perceived as superior. 


\section{BREAD \& ROSES}

written by James Oppenheim (1912)

As we go marching marching

In the beauty of the day

A million darkened kitchens

A thousand mill lofts grey

Are touched with all the radiance

That a sudden sun discloses

For the people hear us singing

Bread and roses, bread and roses

As we go marching marching

We battle too for men

For they are women's children

And we mother them again

Our lives shall not be sweetened

From birth until life closes

Hearts starve as well as bodies

Give us bread, but give us roses

As we go marching marching

We bring the greater days

For the rising of the women

Means the rising of the race

No more the drudge and idler

Ten that toil where one reposes

But the sharing of life's glories

Bread and roses, bread and roses

The Princess of Wales reflected an image through her life story, a story that we had been allowed to share. Mother Teresa, when presented with the Nobel Peace prize, responded, "In the name of the poor, the hungry, the sick, the homeless - I accept". She was being honoured by the world for a lifetime spent in gathering, gathering all those in a society who represented abandonment or rejection. Once having seen this, I could now see why I grieved, why we grieved, so deeply. I had cried from a depth I did not know existed within my being and in so doing, I had cried for me. I had cried from the essence of who I am. This done, then and only then could I see the illusion. The child abandoned by the mother. In truth, the mother never leaves the child, for the mother is within each and every one of us. No, we are not our own mothers per se; the love of the mother is within us, but we are our own nurturers, we are our own creators. How then can we abandon ourselves? The 'being' Mother Teresa reminded us of this, the mother who is always there, no matter what we create. Unconsciously we knew it for the people called her 'Mother', and she told us, "The hunger for love is much more difficult to remove than the hunger for bread". I give thanks to this 'being' for holding the image within the void of the world.

The other side of the reflection, the other side of the image, was portrayed by a life story positioned against a background of incredible material wealth and great beauty. Yet, as her brother told us, "For all the status, the glamour, the applause, Diana remained throughout a very insecure person at heart, almost childlike in her desire to do good for others, so that she could release herself from deep feelings of unworthinesss 
.... The world sensed this part of her character and cherished her for her vulnerability, whilst admiring her for her honesty."

Such a life story then served to remind us that as long as we perceive ourselves to be powerless in life, victims of life, passive recipients not active creators, we abandon ourselves - we lose heart. And this was contrasted in such a way to show us that even when the outer world appears full, the void can still feel empty. The illusion of the illusion - may we remember it when we speak the words, 'Queen of Hearts'. I would give thanks to this 'being' for holding the image within the void of the world.

And so we call, in this way we call and have called forth from afar, that which was both near and far. We have as a world gathered and held in the void the gift of a broken heart, so that we might pour out the authentic gift, the consecrated libation. I pray that individually and collectively we are able to do so. In this process then, I have touched my wholeness/oneness, I have embraced more of who I Am, and in so doing, I feel less separate. When I feel less separate my outside world reflects this to me and I can now say, we feel less separate, the world is less separate.

Tucakovic (1997)

This story is from my clinical experience on the Children's ward. Justin. He is ten weeks old. I have cared for him for the past three days. He is so tiny. I have never held a baby so small, so fragile. He weighs $2.70 \mathrm{~kg}$ and there is so little of him. Yesterday, I fed him throughout the day. When I was sitting there holding him the sun was shining in through the window, it was so warm. He just looked at me. He looked into my eyes. I held this tiny child and I just looked at him and he looked straight back at me. Through our eye contact I felt we really connected. And I sat there and said to him "I wonder why you are here, why you chose to not put on weight (just like little Hannah), why you chose to get bronchiolitis, why you chose hospital, why you chose to be born, why you chose me to be sitting here today". And I asked him if he knew what was going to become of him - where was he going?

His mum didn't come in on the first shift that I was there, but I did meet her and she is a lovely lady, but I really felt her insecurities. We have had a few talks all throughout the shift and I allowed her, and she allowed herself, to talk and share with me. I allowed her to give what she wanted to. I knew all about her partner being in prison, and that she had two children, five and three years old, who were molested and that she had been closely 'watched' by child protection services. But I wanted to hear what she wanted to give - from her to me. And she told me so much. She told me that she felt the doctor had classified her as a bad mother because she is on the pension, her partner is in prison and her children had been molested. She told me that the first questions she was asked were, if she had recently had an AIDS test and whether Justin had the same father as the other two boys. I felt really angry at the Registrar's questioning and I could see that this had really affected her - just another label she was given by the medical system.

Upon reading over and attempting to understand Paterson and Zderad's model of humanistic nursing, I see my experience with Justin, his mother and his two brothers as an intersubjective transaction; that being two or more human beings connecting together. With Justin in particular, there was no verbal conversation between us, other than myself talking to him. However, through touch, eye contact and warmth, I most definitely felt a connection. Paterson and Zderad describe this as whether the nursing act is verbal, or manual, or both, a silent glance or physical presence, some degree of intersubjectivity is involved and warrants recognition. They also state that as an 
intersubjective transaction, it holds the possibility for both persons to effect and be affected, the possibility for both to become more.

I know that, for myself, I looked into Justin's eyes as he stared back and asked many questions. Questions to which I may not know the full answers to, or perhaps the answers are already within myself and that is why I had this experience with Justin and his family. Why me and not someone else? What was it that each one of us needed to learn and feel from this experience?

If love can be described as a sense of incredible intense warmth then this is what I experienced when I sat and held Justin. Paterson and Zderad state that the person and the nurse are two unique individuals meeting for a purpose. Each of these persons is his or her choice, each is his or her own history. Each comes to meet the other with all that he is and all that he is not at this moment in this place. Since both are subjects with the capabilities for internal relationships they can be open, available, and knowable to each other. They can know each other within themselves.

Reflecting back on our experience, I can visualise such a small and tiny ten week old boy, who was so small and so young. But it was through Justin that I met his mother and also had a relationship develop with her. One that I believe was open, available and knowable to each other as described by Paterson and Zderad. And I thought connection occurred through being and presencing with Wendy. She felt that she could share aspects of her life and some thoughts and feelings with me, myself doing so also in a small way. How much more I could have done, I do not yet know. I do know that I sat with Wendy on one afternoon and we talked. I know that when she was not there physically I fed and held her baby. And I also know that I felt a special love of Justin. I wonder if Wendy felt it too?

But if there is one thing that has come to light for me being a part of this experience, it is that a certain question or thought has come into my mind. By being with Justin and seeing his extremely vulnerable and insecure mother, the words, 'that a small child is a direct reflection of his or her own mother', kept coming into my mind. So my question then is, do children become sick, some dying, so that through them, their mother (very much on a subconscious energy level) is seeking a time when their self and spirit is wanting and needing the opportunity to self-examine, to feel more about who they are, and to learn through the experience of life - LOVE.

It is also through the child that the person who chose to be called a nurse, and chose to be there, also learns and experiences love and so too can become - 'more'.

The 'Bread and Roses' song was a call to bring the whole of mankind's attention to the feminine, played out through gender within the social construct of the time. As a call played out through gender, I argue, it is yet to be answered by the whole world. The women sang, Give us bread, but give us roses. The clue is in the rose. Give us what we need for our body [bread] but more than that we need LOVE [roses]. A call to love that both Mother Teresa and the Princess Diana knew, because they knew the difference between the hunger for bread and the hunger for love. This same phenomenon was played out by a ten week old baby boy, his mother and a student nurse that as a reflection serves to bring to my awareness my own call for more love. 
I have said that the one is as beautiful as the many and the many as beautiful as the one. I have also said, the whole is the whole. Therefore, in considering the outside a reflection of the inside is to then acknowledge that everything Is. And that what it is, is, the whole. The bread and roses song yet another call to love, albeit through gender. This same sound of the call to love was demonstrated through the life of two great lives. This call to love is apparent in the tenuous hold on life of one tiny baby. Each calling in their own way. Each calling for the same thing. In this way the call to love cannot be ignored because this call is innate within every being, and so every being, regardless of time, place, or circumstance will move toward more LOVE. The how of how we move toward LOVE is metaphorically depicted in the line ... the rising of the women, means the rising of the race. Where woman is not bound to the notion of gender, yet serves as a physical manifestation of the expression of the feminine, where the feminine aspect of every human being is through that which she/he feels. That 'she' is our soul, and she is feminine, because in order to feel she must first receive. Through her do we attain the end, because through our soul in the experience of being human we change consciousness.

To then think in Nursing in a way that could move us closer to this end would be to embrace the feminine. While the thoughts and beliefs reflected in our scholarship are directed at change, to action this change more fully in the way that we as a mass provide nursing care needs to make more conscious the call to love. I say this not as a criticism, for this relationship with the feminine is not limited to Nursing. This is the relationship reflected in the traditional hegemony of society, the outside reflecting the inside, because we are yet to more clearly who we are in looking at the reflections of what we are. In this way, however we can bring a thing into our awareness.

Yet, I have said the potential for our transformation through nursing and health care is certain. That this idea already exists in our minds is evident in the scholarship of our greatest visionaries. Nightingale's proclamation that nursing is 'the finest of the fine arts', Roger's view of a 'true service to mankind' and the Patterson and Zderad's notion that through nursing there is 'more being' are all expressions of this call to love. While the potentiality of our transformation exists in these ideas, as ideas, they remain at a theoretical level. They exist as dreams. And while dreaming is integral to the creation of reality, in the way that I have said, theory is not transformative. I am suggesting that we have yet to work with our dreams more consciously in order to undergo the transformation we desire.

In this way, the beliefs we espouse within our theoretical positions are not wisdom. This is not the same as saying that they are not the wisdom of their authors. Of those who wrote 
them. Wisdom is the reflection of pure thought in physical existence. It is not belief, it is knowing. Wisdom begins as an idea/vision/dream that is then focused upon so as to be experienced in matter, that then is an engagement in being in the way that I have described in this work. Having done so, a being moves out of the dream left holding a pearl of wisdom. This is transformation through being so to consciously create more wisdom, and in that way, more love.

Care in nursing has largely been done to the body, and as such has been a form of nurturing which reflects the masculine aspect of the self, by having engaged ourselves in a doingness of care. The feminine in care is to turn care inward. The feminine in care is done through the body that is not a doingness, but is beingness. A beingness of care is facilitated through the feminine by embracing the emotional responses to life in a way that is nurturing, fulfilling and positive, rather than critical, fearful and doubtful. In this way, the masculine and feminine aspects of care, directed at both the inside and outside, is balanced. By only working with one side of things, we loose the ability to be aware of all possibilities because we are not balanced. And as we have worked predominantly with the masculine aspect of care, so too have we worked predominantly with the intellect and therein are not balanced.

Emotion is the expression of the human ability to feel that has traditionally been associated with women. So as women are secondary and subjugated within society, so too is emotion and feeling. This is the image, I am suggesting, that women have held through the image of being female that in no way supposes that all women are in touch with their emotional reactions to life. I am speaking of an image that then serves the purpose to bring a thing into awareness. In this way subjugation might be viewed in a way that is not bound in gender relations, but serves to reflect the subjugation of the feeling nature in us all. This would then mean that the image held by the masculine is the reflection of thinking through intellect and reason. In a society that values intellect and reason over feeling, this is the pervading image of every aspect of the culture. For as you think, so you are.

I would argue that the indigenous cultures have served to hold this image of the feminine for the world. Our recent appreciation of indigenous wisdom reveals a richer fuller understanding of life and an inherent reverence for all living things born from the understanding that everything has a spirit. The peoples [men and women] of these cultures have been perceived as being 'less developed' or 'uncivilised' for hundreds of years. In other words, their feeling nature has been deemed as subordinate to their intellect, and therefore they have been deemed inferior/subordinate. The same could be said about the African Negro. 
Masculinist thinking is supported by the belief that what exists only exists if it can be seen or proven. This then is one idea of reality. We have termed this way of seeing the world as empirical or logico-deductive. As a philosophical position it is reflected in the philosophy of, materialism. Most of science is constructed in this tradition, and while ever more sophisticated in its constructs, it is still thinking that predominantly might be termed masculinist. Yet, there have been great insights from science. Einstein himself claimed that his insights were not intuitive. If so, this then begs the question. If we create our reality, then are the revelations produced [things evidenced] the material manifestations of collective consciousness? If so, it would then follow that these things, the material manifestations, are subject to change, because as humankind evolves it is the result of thought having changed, and in that way we will reveal different material revelations. In other words, the world is not round because it is round, the world is round because it was thought to be round in the first instance. And where did that leave those who thought is was flat? Newtonian physics will not produce the same results as those subject to quantum physics. How then do we view truth? This then presumes that a process that we are hardly conscious of is responsible for reality. This then raises further questions in relation to thinking, consciousness and intuition.

In a previous chapter, using the work of Immanual Kant, I have presented ideas on thinking that are 'wonderings' about pure intuition. I use the word wonder rather than thoughts or thinking, in this context, to avoid giving the impression of deducing something. I wonder. My stance has been that the clearer the mind the greater the ability to access knowledge intuitively by taking the position that emotional response is the key to changing thought through changing belief systems. In the previous chapter, using the work of Ramtha (1999) I have said that the human brain does not create thought but allows thought to enter it from consciousness. The work of Candace Pert (1997) has been cited to support the idea of both the brain and body releasing chemical substances that affect the body at cellular level, but which occur as a result of what is felt and in that way identify thought as a firing/triggering of a certain group of neurones that have a specific chemical reaction. A chemical reaction is changed by consciously choosing to change a feeling and this then is a response to feeling, rather than a reaction. To consciously change a feeling is to make thought conscious, and in that way bring into one's conscious awareness what one is thinking. I have claimed this to be a process of mind clearing so that the mind of man/woman moves closer to the mind of God to become the one mind. The mind of God is pure consciousness - that as an ultimate state of being is forever creating itself and therefore not finite. 
What exists between the mind of man and the mind of God is time, distance and space. That in turn is energy. Energy and consciousness are the same. Energy follows thought. Therefore, in order to be God consciousness one is required to reduce the space, time and distance between the two points of consciousness, that is, the distance between the consciousness of man and the consciousness of God. It has been said that the kingdom of heaven lies within; that kingdom is God consciousness. It is the Isness of all that is, the realm of pure thought, the consciousness of who we be. As such it is the consciousness that we are making conscious by our being human, through the process of making the unknown known. So all that we ever need do, is be, and in that way there is nothing to attain because then we already are it. In this light there is nothing to forgive and only everything to accept. For there is no greater moment than now, the past and future do not exist and so in a now moment we make the choice to be God, or human. How we make that choice has been the subject of this thesis. Having explicated these points I would now wish to expand upon another.

Earlier in this work, I have documented moments in the life of Thomas Aquinas to illustrate the expression of profound feeling. I have also inserted lyrics of particular pieces of music, in this thesis, for the same purpose. It is apparent that the ability to apprehend expanded states of consciousness must depend upon the ability to feel. For if energy exists between two points of consciousness, and the less time, space and distance between the two points then the closer the consciousness of man is, to the consciousness of God, feeling is the bridge. Then, in order to access pure thought, as in the Kantian notion of pure intuition, requires such a depth of feeling, which in turn is the result of being able to feel. God is known through feeling, as a level of consciousness it is expressed as pure or unconditional love. Did Thomas Aquinas know this depth of love, and therefore was his Summa the product of this love. I wonder?

Love, as experienced in the human condition is the potentiality of this growth in consciousness, where what we call ourselves to do is to feel all things, in order to come to know all things. Then if all things come from God, then all things, every feeling, must be God. In experiencing all things, what I am experiencing is, that I am God, and I am Love. And if my human brain taps into streams of consciousness, that is, thought to be felt in order to be made conscious, then Kant's pure intuition also has to be feeling. If God is known in feeling then the place of deepest thought is as Thomas Aquinas declared it to be. That place is nestled in the space midway behind the breast bone. We name it the heart, that is not the physical heart of man but the heart that is a pathway leading to the doorway of God. That heart does not belong to the physical body. That heart belongs to our soul because how the 
body and soul connect is through feeling that then serves to connect the mind of man to the mind of God.

Thus I argue that thinking is thought accessed through the feminine. Generated from a movement that arises from an allowance that is a surrender of will as well as an act of independence with the ONE. It serves union in its highest form, because through it we connect to Universal Mind, the Mind of God, True Mind. And this mind, I have argued, cannot be accessed through (deductive/empirical/logical/) forms of thinking and it not bound in notions of gender.

Even so, in being able to access higher states of consciousness the challenge then is to bring forth the knowledge without corruption. We each have multiple belief systems attached to emotions, and as such there is the possibility of distorting thought to fit our known reality in the way that I have described in the earlier chapters. In clearing our own minds however, we are less likely to distort pure thought. In clearing our own minds, we can connect more deeply with the mind of another. For then, we can access that consciousness because we ourselves have learned to choose love, instead of the judgement.

Then we know how to be

.... The student beckoned me into the room. "Well hello, back again". Six weeks earlier I had met this woman on another ward, she was a diabetic and some of her toes were ulcerated. We had spoken about her diet, medication and lifestyle. I was clear that she was managing her diabetic condition well within this framework. I had then asked her would she be prepared to bath her feet in a solution of lavender oil. She had agreed to try and so I sent in a bottle of the oil via a student.

"So we meet again, how are the feet?" She remembered me, and looking down at her feet replied - "not good". I sat down next to her bed. "May I hold your hand?" She placed her hand in mine. "Now you can tell me to go away if you like, but do you know what I think?" "What", she said without looking at me. I paused. "I think, that you don't like yourself very much". She went white - and I counted under my breath 1 to 10 , watching that she took a breath. She did. She then turned, to look me straight in the eye. "Well, aren't you a smart bugger!" "Do you want to tell me about it?" Her eyes filled with tears.

"I was nine, my favourite aunt was getting married and she asked my sister to be a flower girl - and not me. I was so - so hurt. I reckoned it was because I wasn't pretty enough - as pretty as my sister". (Pause) "So, are you going to continue comparing yourself to your sister, or are you just going to get on with it?" She laughed. We laughed. I stood up and kissed her on the forehead. "Now, I am going to watch this student do your dressing".

About twelve months later as I stood feeding a parking meter in the town some-one tapped me on the shoulder. "Hello, remember me?" I laughed as we both looked 
down at her feet. "Yep I might wear slippers, but I still got all my toes and I can walk. Thanks love". "Now, this is my grand daughter - say hello to the nurse ...."

Having received/tapped into thought, the challenge then is to convey that thought through form. In above the scenario, I could have expressed what I had intuited in any number of ways. Language and the specific words represent a form. In this way, while language, mathematics, reading and writing are said to originate as left brain activity, my argument is that they are vehicles to convey thought as are the so called right brain activities of painting, dance, music, photography, sculpture, drawing etcetera. As human beings we create form to convey/communicate truth/knowing/ideas. When Einstein formulated $E=m c 2$ was that any less rapturous than when Mozart composed the Requim? If not, then the difference in what is being conveyed is not the form or which part of the brain is used to express it, rather, that difference is contingent upon the energy conveyed by the form which in turn is contingent upon the individual's ability to receive/tap into thought. The form, as a skill, develops through tenacity, experience and a great love of that activity. Any Olympian will testify to the hours of training, and a concert pianist will have clocked up many hours of practise. And yet practice on its own does not what make a thing art in the sense that it is a representation of thought which is pure/great/expansive.

A great piece of music played in a technically correct fashion does not make that music art. In contrast, those very same notes as art can be experienced as if they had arisen deep within the musician. This difference is also visible in words. For words too can just be words, or words too can be art. The distinction between work that is and is not, an art, is not determined by the type of form, rather, the distinction that distinguishes a thing as a work of art is, that it is alive! The aliveness is its animating principle, its soul. The animating principle conveys the energy felt by the artist and then conveyed through the work. The artist is able to portray a feeling that when felt by an observer makes that thought conscious in the other. The form created by a pattern of energy has not lost its purity/clarity. The greater the energy, the greater the depth of feeling. For as I have said, the soul is about feeling and we connect to all consciousness/thought through feeling. Feeling that distinguishes us as being human, and through which the very idea of the self is contained by our human emotions in their relationship with desire, as the catalyst for approaching 'the good'.

To access thought as consciousness is the ability to feel. On one hand feeling is immersed in emotion, and on the other the negative emotions, sadness, grief, deception, powerlessness hurt etcetera are transformed with love so that happiness, joy, bliss and love become the natural state. True thought is accessed via the feminine and as expression conveys an idea. 
Thought exists as a pattern of energy. It is consciousness that when accessed is felt, for what is then expressed is the pattern of feeling and in that way thought is made conscious through feeling. As human beings we express ourselves using language, music, movement, painting etc. And while language, music, movement, painting etc are all art forms, what determines the unlimitedness of a thought being expressed is the feeling conveyed through the form. We know this because, it is felt. Such an expression is not just another picture or story, nor is it just a papier-mache' doll of an Indian figure sitting on a side table.

The feminine in our lives is the way to love. For LOVE is what underpins the human passions in that it contains and excites them (Senault 1641 in Vincent 1992). The dichotomy is that without love, there are no passions and yet with it all the passions disappear. The whole and part working in unison - the subject is not separate from its object. The passions serving to free us as they are the basis of our being, being human. Existence is experienced through the passions in that they are the communication between beings, linking and interlinking us in our ongoing evolution. As such, they are a reminder of the need for bread [experience/life] that serves to make real our desire for roses [love]. This then is the key to the liberation of men! Then will we no longer be hungry. The feminine holding the key as she sings give us bread but give us roses. For it is she that knows and through her we are born, where on one hand what we are birthing is ourselves and on the other is 'the how' to our freedom. Freedom, that is not a release from an imprisonment, but a freedom in which we can know more - more love, more joy, and more bliss.

\section{The feminine in Nursing}

'The obs.', 'the dressings', 'the drugs' 'the washes/sponges', ECG's, ECMO's, CPPV's, IMV's, IV's IA's etc. are activities in nursing that in no way provide that fuller picture of nursing care such as I have described in terms of reflection and refraction as an art of healing. While this statement might appear provocative or an over simplification, I argue that, despite our scholarship and research, on any day in any hospital in the Western world, mostly, nursing revolves around these activities.

I don't know why I want to tell this story, but it keeps popping up in my head and won't go away. I guess I'll find out today. It doesn't seem particularly extraordinary, but nevertheless, here goes.

I was in theatre, and assigned to the day stay section with another nurse this day. We were instructed to admit patients together - Which was ok, I thought it would get me reorientated (which didn't take very long, as I'd been there before - as a student and a patient). The first patient we admitted was a 70 year old lady who came in for a left cataract lens insertion and trabeculectomy (a procedure performed to recreate a drainage 
system to reduce intraocular pressure caused by inadequate drainage of aqueous fluid due to obstruction in the eye's natural drainage system). She had undergone the procedure in her right eye several years earlier and said the right eye had been the worst.

Several times during the admission procedure she jokingly called herself a coward, the first time she did this I gave her a little smile and continued with my tasks...the second time, I acknowledged her fear, but tried to keep everything light hearted by saying....I guess women, especially mothers, are supposed to be able to cope with anything life dishes out...do you have children? She nodded. While I said this, I felt there was more behind this than light hearted chit chat, because she sort of looked as though she was fighting to keep her composure. So I said to her it's ok to be afraid sometimes and tried to hold her hand to comfort her, but although she didn't actually reject it, I sensed that she didn't welcome it either, so I withdrew the contact with her hand, but stayed within the cubicle. The other student nurse was still there, as we were just finishing Mrs B's admission, and the RN gave us several more to go on with. I gave Mrs B. a smile, said see you later and we both left the cubicle. Thinking back on it, I obviously hadn't quite connected with her at this stage, or I would have stayed.

I did a couple more admissions, but thought 'stuff it', this could go on all day if I let it...I know how to admit patients by now, I want to do something I might never get the opportunity to do again...I decided I wanted to go right through with someone. From admission, into theatre and then discharge...dammit, we are supernumerary after all! (That's how I needed to justify my actions).

I decided to go back to Mrs B., I felt her need to talk. I pulled up a footstool (she was sitting on the chair next to the trolley) and asked if she'd mind if we had a chat. (As I did this, I could feel the staff looking at me, but I ignored the discomfort I felt .... and thought bugger it, if I'm doing the "wrong" thing, let them come and tell me!) ...

I felt gratified by the day. I had met my goal of caring for one patient from admission to recovery, and although it took a whole morning, I felt I made a difference to Mrs B. I also realise that this isn't really realistic as far as time constraints go in the 'real world', but I feel I should aim for it while I can.

In order 'to do' nursing care that comes from the feminine the nurse has to be able to consciously feel. Our structures and processes for care delivery in nursing are almost alien to this potentiality. And yet only in feeling will nursing uncover a totally different way to practice care through directing its focus at changing consciousness. How might the woman in the scenario above be supported in seeing something from a different perspective and in that way create clearer sight?

I decided to go back to Mrs B., I felt her need to talk. ... She looked a bit taken aback, at first, but then said ok. By then I had decided I wanted to find out more about her fear, and see if talking would dispel some of it...if she had felt this way prior to her last operation, and if perhaps something to do with the last op had caused it. If so, why was she putting herself through it again? 
I reconnected our previous conversation by asking about her children, and if she had a partner. "Yes, I have a husband, who is very good and patient...but he needs to be". I asked why he needed to be patient, was she a problem wife? No, she didn't think so, but they had a 'problem' daughter. I asked why the daughter was a problem. She had apparently left her son-in-law and the two children two years previously, and had broken her father's heart (and mine). They had tried to stop her from going, but she still went, with her new partner, who had left three children behind.

Mrs B. was principle carer for the children now, ...Before and after school, but her husband was looking after the children today. I asked if they saw their mother ... The answer was negative. In fact the oldest hadn't spoken to or of her mother for $1 \quad 1 / 2$ years until she went to visit recently. I asked about her son-in-law....He was a very good man, ...possibly a bit conservative, but always treated his wife very well.

This lady seemed broken hearted, exhausted, resentful and angry. I wondered aloud that her daughter must have been very much in love with her new partner to be able to do this, and it must have been hard for her to leave her children. I told her that I thought in a way it was unselfish of her too, because I had seen first hand how heartbroken the abandoned parent and grandparents can be if they lose contact with their children after a marriage breakdown. I said these things not to support or condone her daughter's actions as such, but to try and help her see her daughter in a more positive light. However, I did say that it must have been very difficult for Mrs B. to have that responsibility. Mrs B. then acknowledged that her daughter did miss the kids, and that her new man did love her. She had visited them once, and he was quite a friendly chap, but she said she just could not understand how her daughter could have left her children. Those words just came right out of her mouth ...

In our ability to feel, I perceive this to be what Patricia Benner (1984) began to lay open when she identified nursing practice that she termed expert - a level of practice guided by deep truths. To be able to tap into deep truth is to tap into creation itself, and while such practitioners exist, they are rare. For thinking as deep truth is intuitive. It is an act of love. From the place of love, one taps into all creation and in that way connects one to the core of another being. It is a soul to soul connection that is also a soul to spirit connection. It is also trust in action, to put the altered ego down - to step aside and get out of the way, to surrender.

To do so, is to be able to be in the now moment, to be able to leave the past in the past and allow something new to enter consciousness. It is also an act of allowance where what is allowed, is a flow of energy that as pattern is to be translated. The energy cannot be allowed if there is judgement. Allowance, non-judgement and unconditional love are not mutually exclusive. In allowance, the information received is not conceptual language but precept that, when felt, becomes consciousness. Thought, word and deed. It is also at this point that what has been gathered can be mistranslated, and hence the investment in a clarity of mind. As process, it is thinking not confined to cerebral activity, but is simultaneous with the body and pivotal on feeling. The secret being, that the more love one can feel, the more love, true thought, is then made visible in the world. 
So take care not to hide your light, but let it shine brightly, so that everyone can see it ... And then it is not you who should be praised, but your Father in heaven. For you must tell them that you do not do those good works of yourself, but that your heavenly father lives with His Spirit in your hearts.

Mathew 5 (14)

Nightingale's vision of Nursing was that it is an art, the finest of the fine arts. If the word art denotes imagination, a form of dreaming or pretending for the purpose of expressing an intention that is the conscious act of creating as a mental act, that is, something we do as human beings, then to be the finest of the fine arts would mean that what we are dreaming, if we are the finest of the fine arts, is brilliance. And if brilliance is interpreted as light, then what we intend through our dreaming is to create more light. The lightness of being, has been the subject of discussion of this thesis.

In this act of creating more light, more brilliance, we are reminded that nothing can exist without the impulse to be love, a devotion, so that love can love through a human being in response to the call to love. As such, the impulse to love as a human being is where the image (dream/pretending) is invoked. I have said that thinking begins as feeling. The energy, as a feeling, is lifted from the heart to form an image in the mind and given to God as the dream/desire/expectation to be received [you do not do those good works of yourself, but that your heavenly father lives with His Spirit in your hearts]. Thus the energy moves between two points of consciousness, human consciousness and God consciousness, where what is returned/received is consciousness or energy in which an emotion is embedded.

Thinking/thought begins from the centre of deepest thought, the point midway between the breasts, that is an act of creation to make manifest creation. It is thinking that has its origins in love that in turn is love expressed in form. In this way, all things are made manifest. In the manifestation expressed as the finest of the fine arts, Nursing, where the intent is to create brilliance or more light, is this then what we mean by healing? Healing, to uncover, to make thought unconfused, pure thought, to restore flow. Through healing will we in Nursing shine our lights and in that way make real the image of the lamp carried by a woman.

If we are to foster more nursing doing/practice that is reflected in Benner's (1984) expert practice then we have to consciously learn how to answer our own calls of being. How to 
do so, has been a focus of this thesis. Our present relationship with nursing competencies supports our doing the well being - well, in the Paterson and Zderad (1976) sense of the word, but says nothing about the 'more being'. For far too long the 'more being' is something that sometimes 'happens' behind the curtains or doors of our institutions and homes, in the places where nurses and patients meet. Yet, I think we do know that it is the 'more being' which continues to urge us on so that we might make our lights visible. As we continue to call forth more of the soul of nursing then will the many lights come together to form a brilliant light.

As we move closer and closer to the pureness of being through listening to our calls of being the strange attractor serves as a reminder of the image. This energy has been tapped into by Florence Nightingale, Martha Rogers, Jean Watson, Peggy Chinn, Josephine Patterson and Loretta Zderad, Patricia Benner and Margaret Martin. These are some of the women that in following their calls of being, supported by their strange attractors, have touched upon that consciousness through their own soul, and in turn have touched the soul of nursing. If we are all to not just touch upon that force but live within it, then our ongoing evolvement calls for even more in nursing. We can continue down the present path or we can take a leap that is about consciously nurturing the ability, innate within every being, to think intuitively. To do so will call for new processes from which we will create new structures to support that leap. Thinking in this way is from the feminine mode of our being, it is she, and we connect to her by being able to feel. "For the God beyond God, is God's Mother" (Campbell, 1991, p.125). The choice is always ours and yet where we are is always perfect.

The Process of Creation is never done. It is never complete. I am never done. Nothing - nothing - is without motion. Everything is energy, in motion. In your earthly shorthand, you have called this 'E-motion!' You are God's highest emotion. It was Buckminster Fuller who said, 'I seem to be a verb'. He was right. God is an event. You have called that event life. Life is a process. That Process is observable, knowable, predictable. The more you observe, the more you know, and the more you can predict. You not only interpret energy, you create it. Imagination is a function of your mind. In your mind you image something, and it begins to take physical form. The longer you image it (and the more OF you who image it), the more physical that form becomes, until the increasing energy you have given it literally bursts into light, flashing an image of 
itself into what you call your reality. You then see the image, and once again decide what it is. Thus the cycle continues. This is what I have called The Process. This is what YOU ARE. You ARE THIS PROCESS. This is what God IS. God is this Process. This is what I have meant when I have said, you are both the Creator and the Created.

Walsch (1998, pp.345-361)

\section{True thought}

I ask him, what is love?

Love is a Beingness that exists from the inside out, a feeling that exists no matter what or how of anything external. Love emanates from within, love begins from within. Love knows no boundaries, love lacks judgement, and thus love is immeasurable, boundless and eternal. Love is an immeasurable feeling of Being, emanating from within, fleeting moments of bliss, a connection to self without boundaries. Love is what you are, when you strip away all that you have become. Love - is the purest form of Being.

Tikashi (1995)

Every nurse that has ever felt the awe of assisting a new life into this world, stood helplessly beside a bed surrounded by machinery knowing that the life force was gone, jumped for joy with a family when 'the tests' results were negative, been witness to the words of deep peace, thankfulness, acceptance and grace uttered as a life draws to an end, sat by a bed holding a hand, cradled another, or stroked a forehead, at some level knows this work. What hasn't been known is how to make being more visible through Nursing in a way that is not some sort of dismantling for the purpose of offering an anatomy of nursing, or a geography of the soul. At the same time though, I have had to present enough process to make the process visible while offering enough intellectual argument to describe and support the argument. In this light, I have unfolded a map that is not a map, per se. 
This thesis began in the simplicity of listening to stories about nursing as it had been lived. In the intention to listen to stories about nursing, this story [the thesis] was gathered. Once having gathered the nursing stories, I needed to learn how to hold a story in such a way that 'what was poured out' was the consciousness of what was gathered. In other words, an expression of thinking as it relates to truth. Truth that is not a truth positioned against an untruth, but truth as consciousness that then reflects the expansion of consciousness where pure thought as consciousness might be named Isness, God Consciousness, I AM or unlimitedness. Having said this, I am not attempting to position this work as pure God consciousness, rather, what I have identified is a process of being that then enables the movement toward this consciousness. This process of being is then not confined to a pile of nursing stories, this process of being exists in every living breathing moment. As such the work expresses the ongoing movement toward this consciousness that then is expressed as levels of reality as truth resulting in a thesis which demonstrates thinking as a trajectory. This evolvement is evident in the presentation of this work. For while there is connection between the chapters, many of the chapters can be read as an essay in themselves which in turn is the result of the process of expanding consciousness.

Being is a process - a verb and elements such as trust, awareness, non-judgement and focus but tools used in that process. Emotion and feeling are the keys from which to begin. It is an allowance of the self to feel every response to every life experience and in that way engage the soul in the call to love by choosing to adopt an attitude of love in response to whatever is being felt. Then thought, regardless of what that thought is, is made conscious. Then consciousness has expanded in the ongoing upward spiral of ever expanding consciousness. This then determines what thought is drawn to, for not only how I am is what I think, but what I then think is then drawn to my being.

Dis-ease/Illness, I have said is thought. Dis-ease has been presented as the impediment to the flow of the energy of all things. Dis-ease calls us; it is a call of being, the opportunity to see differently. In other words, to change reality. In so doing, we are changing sight, that is the expansion of vision as the reflection of the expansion of consciousness. Then, we are lighter. Having said this, physical death is not interpreted as failure or darkness. In the experience of dying consciousness can be expanded, and so in dying there is also healing. To expand consciousness by whatever experience is to heal. It is only judgement that determines one experience/drama/story/life to be better than another.

Dis-ease then is about transcending the duality of the health illness continuum by shifting the focus from the dis-easement to the process of being and in that way enlightening the self and 
in the process move out of the consciousness. In so doing, we are becoming that which we already are. God made manifest in man/woman. In other words, to have the consciousness of ourselves as God. In the process of enlightening, we are able to access greater truth/thought because we are not our bodies - we are consciousness/energy/thought.

To be enlightened simply means to be in light of, to have knowledge of, to have knowledge available to you so that you can apply it however you choose. The only way you become enlightened is by allowing thought to enter into your thought processes, embracing it into emotion, and experiencing it as wisdom. ... Knowledge allows your mind to reason and contemplate beyond what you already know. ... Because whatever you know, you will become. And when you learn how to know all things that are, you become all that is - which is God completely: unlimited knowingness ... . To understand how you can know all that is, you must first understand that not only does everything exist from thought, which is the mind of God, but everything emanates the thought of its being back to the mind of God. ...Your Spirit is like a sieve on the bank of the ever-moving, ever-changing river of thought. Through that light you stand in receivership of the mind of God, the thought flow where all knowledge is. Thus you have the ability to know all there is to know, for you are in the continuous flow of all consciousness, the river of all knowledge.

Ramtha (1999, pp. 177-179)

I have argued that we are consciousness. Consciousness is all thought. Consciousness consists of varying frequencies of consciousness. The idea of levels of frequency is contained within Martha Rogers' Theory of Nursing and expressed in the Principle of Resonancy. Like frequencies attract like values of frequency and as thought, is lowered into a light form to penetrate the light surrounding the body (aura). That light then explodes into a burst of light to enter the brain changed into an electrical charge of the frequency equating to the value of the thought being received (Ramtha, 1999).

Thus God is true thought, that in the human condition we have challenged ourselves to receive ourselves. For who we are, is God, and as we allow this reception then do we 
expand ourselves. Every action, every thought, is energy, and energy follows thought. In this way, for every action there is a reaction. With every thought there is a corresponding shift in energy. And so every one of our thoughts can be either according to the Oneness of the life force, and in that way be light, or in the denial of it, and therefore be dark. In this conscious awareness we can remain connected at all times to that source, the Oneness of life force. By Oneness of the life force, what I am speaking of is God/LOVE/Thought. As we each do this for ourselves then so too are we assisting humanity. "Every moment you live for the love of God within you - every illusion you embrace and give up, everything you do to find your joy and light - emanates from your being into consciousness flow to feed the whole of mankind ... then do you exude God into the density of social consciousness" (Ramtha, 1999, p.198).

In the course of this work I have explained that we create our reality through how we experience life emotionally. I have also said that belief and knowing are not expressions of the same thing. What we think, our thoughts, as ideas about the world might then be termed belief. The distinction between belief and knowing highlights a crucial difference. On one hand I have said that most of what we think is unconscious - in other words we do not have the awareness of what we are thinking. On the other, I have said that belief is attached to emotion. By changing an emotion what is being changed is a belief and therefore a thought is changed. True thought begins with feeling and in the sense that there is no untruth, only expanding consciousness. There are however frequencies of thought that are higher and higher and higher. At some stage thought is God Consciousness/Unlimited Thought/Pure Thought that is not as an end in itself, but is ever expanding because God is infinite. Thus knowing is the same as certainty. Belief assumes, for it requires convincing because as truth it has not been an experienced reality. Knowing, is knowing. Knowing is wholly a feeling, for when something is felt it has an identity. It has been accepted into the brain and experienced throughout the body and as such there is emotional ascertainment, the thing is known because the feeling of it is known (Ramtha, 1999).

How will you describe the feeling of unlimited thoughts. You cannot. The knowingness of an unlimited thought has no word that you can associate with it because it is a new thought being experienced, a new emotion, an immense feeling that moves you in a profound yet quiet manner. Knowingness will come to you as pure feeling: unannounced, unidentified, nameless emotion.

Ramtha (1999, p.199) 
The oneness of life involves feeling the emotions held within the body, and in that way light is allowed into the cells. Where there is light there can be no dark, and it is this life force energy that stimulates cell growth. Thus the elements of all life are sustained and by constantly revitalising the life force energy into every cell the body is lightened. As process, it is what is gathered, held, and then poured (Heidegger's jug) from the void. When this life force is constantly received into the whole being of women/man kind, the body [flesh] is eternally enlivened (refreshed, vitalised, animated, and inspired). When it is not, this then becomes the basis of dis-ease. In the understanding of how to change consciousness lies the capacity to use our ability to dream/think to heal the body. For if wellness is a thought, like love, then so too is growing a new limb or healing a part of the body. That this is so is, because we create ourselves through what we are thinking.

This then is the challenge. We are each challenged to make the above and below ONE. One, from whatever position. In that way our language of brother, mother, father or sister is in the knowing, that we are both the many and the ONE. "Who is my mother and who is my brethren? Whosoever shall do the will of my father which is in heaven, the same is my brother and sister and mother" (Christ in Nightingale cited in Calabria and Macrae, 1994, p.114). Where regardless of who we are the purpose is to transcend these walls/barriers/boundaries - the altered ego - so as to rise above by going through and, in that way, be God. The father and I are one. To reveal the divine dichotomy and be that which we already are. "For love is Who You Are, and who you always have been. It is all there ever was, is now, and ever shall be" (Walsch, 2000, p.212). Where all we need do, is be it.

In naming this work 'Nursing as an Aesthetic Praxis' I mean this to be the work of nursing where people presenting with dis-ease are shown how to work and be supported in working with blocks in energy flow. Such a framework is located within a design of thinking that interprets what is, as IS. Inherent in this process is the greater awareness of what it means to be, Being.

To allow the self to be however it is and wholly loving the self for being that. To feel whatever is being felt and living that emotion. Being is living wholly in the moment because you know that the Now is all there is. It is doing whatever you want to do, living the adventure that your soul urges you to pursue. And in living that way you never judge yourself or others or the thoughts that occur to you. Then there is neither right nor wrong, possible or impossible, perfection 
nor imperfection, positive or negative. There is no longer the illusion of time which does not permit you to feel or savour the beauty of the moment. When you are in a state if being, there is only the Isness of life and the ongoingness of the Now. ... In being, you do not hold to any particular truth but are the reviewer of all truths. You see all truth as an Isness and allow each to be explored to determine if it is workable in your state of being. When you live that way, then all thoughts that come to you are pondered and, through your brain, understood as feelings, which allows more knowing, more thought, more Isness to come forth. When you simply are, you are in alignment with the Isness of all things. And through that alignment you may have anything you desire, and you will have to do nothing except be. The God of your being will draw to you whatever you think, whatever you desire, and it will come. Those who busy themselves by trying to do every outward principle make a little mockery of the inward one. In being, you already have and are everything. When you simply are, and you allow yourself to receive all thoughts, then can you hear the voice of God. Then everything you ever wanted to know you may know in the twinkling of an eye. When you do not judge your thoughts but allow them to manifest as an emotion within your soul, you are living as an unlimited God merely by being open to the isness and all that is. Then you become a pure channel of your own God-self and you come closer to the pure simplicity of the mind of God.

$$
\text { Ramtha (1999,pp.209 - 210) }
$$

The Aesthetic I have presented as emotion and feeling. Praxis in its dialectical relationship of thought and action is bound to emotion and feeling in such a way that it illuminates the nature of thinking, which is thinking that, is transformatory. Transformation, as process, is one of incremental human freedom accompanied with incremental responsibility, while in its end it is that of human freedom. Such transformation is to live in the light.

In living in the light as embodied beings what we can be is mortal immortals, rather than what we now experience, mortals who are immortal. For death too is a belief. As the sons 
and daughters of God we have yet to tap into our knowingness in order to create a very different picture of health and healing. That this possibility exists is certain and we in Nursing and Health Care can play a pivotal role. What an enormous task! What an allowance of ourselves 'to be'! Where the responsibility is not in assuming responsibility for others, but where the accountability is to the self for who we are and what we create so that we might then support others in this same process. How fitting then that this thought, as intent, be made manifest through the heads, the hearts, and the hands, of Nursing. Close your eyes and dream.

\section{ACROSS THE BRIDGE}

Ozark Mountain Hymn (source unknown)

Across the bridge where angels dwell, Across the bridge where angels, Across the bridge where angels dwell, Children play.

Beyond the place where time is still, Beyond the place where time is, Beyond the place where time is still, Night is day.

Close your eyes in fields of wonder, Close your eyes and dream,

Close your eyes in fields of wonder, Close your eyes and dream.

Ahead where home awaits the heart, Ahead where home is waiting, Ahead where home awaits the heart, All is near.

Beyond the place where heaven lies, Beyond the place where heaven, Beyond the place where heaven lies, Peace is near.

Close your eyes in fields of wonder, Close your eyes and dream, Close your eyes in fields of wonder, Close your eyes and dream. 


\section{Summary}

The final notion of Nursing as Entelechy, an Aristotelian notion reframes nursing for a new era in human history, allowing it to paradoxically to return to its soul and soulful purpose. The process of Entelechy manifests in a single caring moment; however it is captured and lived through revealed story. Thus this chapter further expands the key concepts through examining the feminine as feeling that then serves to connect a human being to God, through which all things are then made possible.

In this way, this chapter has argued that God is known in feeling. That God is made known through energy and consciousness as thought/intent. As such health and healing have been positioned in relation to these key concepts so as to revolve around intent/thought, and emotion and feeling. Object and Subject in a new light. 


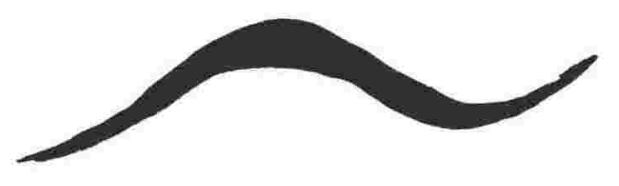

\section{Chapter 13: To Love and to Nurse}

\section{In the name of love}

Is there any one thing in the human condition that has been the object of such vast exploration and pondering as the idea of love? Where, or what, is love? Ideas about love are to be found in every human form of expression, and as such would suggest that love $B e$ in some way integral to being human. These ideals of love are lived out amidst great paradox. On one hand human kind continues the exploration and pondering of what it deems to be integral to life, whereas life itself is lived out in a way that appears as though it is a quest for survival.

Throughout history love has been portrayed as all bearing, all forgiving, all righteous. Love is a form of perfection, a self denial that is also self fulfilling, that claims to acquiesce while at the same time be benevolent. Love between humans is experienced as a depth of intimacy that is represented by every shade and graduation of levels as it finds multiple forms of expression. Camelot and Romeo and Juliet died in the name of love. Joan of Arc, Martin Luther King and the Gladiator all died for love. St Francis of Assisi, mystics throughout the ages and the Knights of the Round Table searched for love. Shakespeare, Rumi and Gibran wrote about love. Mother Teresa and Mahatma Gandhi served love. The Buddha, Jesus the Christ, Moses, Confucius and Mohammed are said to have embodied love.

This work has been called a love story - a story about love - that in the telling is a telling about a way TO LOVE as it describes love and life as being. The story and stories are located in nursing and dis-ease, and in this way nursing and dis-ease have served to bring 
about the potentiality of making the ideal of love more visible. As such, dis-ease can be recognized as energy/consciousness/thought that is reflected by the body that as a call of being becomes an opportunity to come to know more love.

Dis-ease knows no human boundaries, dis-ease is universal. Nursing, while practised in differing ways in different cultures, has an intentionality that is germane as it finds its expression in 'caring for the sick' or the desire 'to help people'. The intent to love in nursing, I argue, is found in the expression of 'caring for the sick' or the desire 'to help people'. Therefore, Nursing, located in an endeavour that intends to care, a devotion, cannot be an expression of anything other than love. In this way, Nursing and Dis-ease as manifestations of love have been positioned as subjects of inquiry, research. And if this research be true, a revelation of a truth, that is not truth but Is, then nursing and dis-ease cannot be revealed as anything else other than love. Why? The outcome is always the intent, the outcome of any situation is always the intent, and so the outcome of the intent of love - has to be more love! As an outcome, it is love made real. It is love that has been realised. That love has been revealed through story into a story about love. The manifestation at one level a thesis titled Nursing as an Aesthetic Praxis - A Love Story, through an exploration of being by the immersion of self in human emotion and feeling. And while the outcome as a manifestation is as it is, the focus is on the process and not intent or outcome, for in essence this work is about a process of love, being, so as to be love.

As process, it is a 'doing' of nursing that is not 'doing' in the usual sense of the word but a doing in the name of love done by 'being'. It is also about, Now. Now it remains to be seen whether nursing will consciously choose 'to be'. This choice confronting nursing is the same choice facing every discipline at this time in our evolution, in our evolving, where humankind continues to search for ways to expand its knowledge.

When science embraces being, it will be able to 'prove' that love is faster than light and so expand its theorems. In viewing culture as an expression of belief systems that is then 
experienced as life in order to re-experience and in that way become the freedom to choose to experience more, sociologists will understand how people come together 'to be'. When psychology supports beings to be, it will see how cognitive and behavioural theory cannot analyse human behaviour, for the psyche is beyond explanation. When Western Religion accepts that Jesus was a man who in the living of his life became the expression of Love/God/Christed then this one life will have served as an illustration of each soul's destiny. Then, our present theology underpinned by beliefs of sin and sacrifice will be acknowledged as contrary to being and love, and in that way contrary to God. In this understanding, human kind will realise that good and evil exist only in the mind of man for then man will understand that the mind of man is not the creator. God is the creator.

Thus good and evil as constructs of the mind of man will no longer be perceived as real because nothing that is real can exist apart from God. God just Is. In that way, God cannot be known as good or evil. God is known as love. In the Isness of what is, is to be, being, and so man as God is an infinity of the purest form of being, of love, and therefore beyond the dualist position of good and evil.

In this understanding we will be abandon our doctrines on Morality and Ethics, for they too are man's creation; created to determine good and evil and so make judgements about right and wrong. God does not judge, God just Is. In abandoning judgement we will free ourselves to be, for in judgement we remain spatially located within dualism thereby perpetuating the illusion that we are separate from God/Love.

When Nursing and Medicine open themselves to the idea that dis-ease is the expression of consciousness/thought/energy that as a grand act of creation can be recreated, then will we move toward ways that truly serve humankind. Where service to humankind is the enabling of others to invoke the healing power innate within every being. In so doing, our present health care practices will be revealed as primitive. For by then will we have opened our eyes, and what we will have opened our 'I's to, is being. 
Love then is who every being, being human, is. It is also what every human being, being, is becoming. This is the purpose of human existence. The experience of being human is to remember love. To remember love is to return to love in a way that uses the part, but is not the sum of the parts. It is process. To be love, is how we come to know love. For in being something, the thing is becoming conscious of itself. Until a thing has consciousness of itself it is a no-thing, where love is love but does not know that it is love. In the knowing of a thing, knowing, what is known is the nature or essence of a thing.

To believe a thing and know a thing are not the same. For in believing a thing there can still be doubt. Where there is doubt there is disbelief. In doubt there is also distrust. Without trust a being is not connected to all things and therefore cannot $\mathrm{Be}$ all things. In not being all things, then some things must remain separate. It is in separation that the being thinks; I think, therefore I AM.

In the knowing of a thing there can be no doubt. Therefore, when a human being, being, is not just love because love is who a being is, but when each being knows that they are love, then a being knows who they truly are. Then a being has re-membered, and when a being has re-membered what they remember is that they are God. God as love is expressed, for God is love and in the expression of love as God it the purest form of Being. Then the being knows I AM, therefore I think and I think therefore I AM because they have become one and the same. And the I AM thinks in feelings, because how love is known is, LOVE IS FELT. In the knowing that one is love, there can be no doubt that One is God.

In the first chapter I spoke about the process of reflection and refraction and argued that until nurses understand the process of reflection they will not be able to refract. Refraction is a conscious holding of the light with another that then assists that other in straightening their light. That holding cannot be prescribed, it is grasped intuitively and given expression through form. 
She asked what I perceived was stopping me from leaving to begin my research. I told her that I knew I was ready but that in my mind I still saw myself leaving my teaching position at the end of the following year. That leaving the last group undertaking this curriculum did not make any sense because I was the only person who had Chaired the third year of the programme and that following year was to be its last. The possibility of leaving felt like letting the students down - deserting them.

The next day she presented me with a Christmas present. It was a blue cracked ceramic clock face. She said it was for my garden. It was one of the ugliest things I had ever laid eyes on. I thanked her and bid her farewell. As another friend and I made our way home I struggled with the feeling of wanting to destroy my Christmas gift. I shared this with my friend and she just acknowledged what I had told her. Such destruction seemed abominable, and so I entertained the idea of putting the clock in the garbage bin - the urge to actually destroy it was paramount. The longer I resisted the greater the urge became. At last, we arrived. I climbed a wall in the back garden and with the clock encased in a plastic bag, I hurled it with all my might onto the concrete below. It smashed into a million pieces.

I flew home the next day and by early afternoon had arranged to leave my teaching position. I had let go, and in the process changed my perception of time. I had freed myself to go, and she had held the light for me in the process.

Journal entry

To straighten the light means to become more pure light, more LOVE, because light in gravity is curved or bent and so can revolve around itself. The more curved the light the less it glows, it appears to lose its glow. In being able to refract the light, one is then enabling the healing power innate within every being as conscious intent. Healing is facilitated through a soul to soul connection. The form then apprehended through pure intuition because there is no attachment to form. The pattern becomes clear, one knows the pattern and so then knows how to act. Where there is a shared attachment to form, then a reflection becomes method in order to release a shared attachment (emotion). Whether it be refraction or reflection, the light can be straightened. In so doing we then light up [like Luna Park/Disney Land] because we have become more glowing, where what we are glowing is more love.

OK. I'm going to start my story off at home because that's where the day sort of started for me. It was a very long day. I remember rolling over in bed and looking at my clock and it read 7.34 am and I groaned as I saw the red numbers on the clock because it was so early considering that I had to start my first night of night shift that 
night. I lay there for a while telling myself to go to sleep. The harder I tried, the more awake I was. In the end I decided to get up and try again later on. I wandered around not doing much and then I decided I needed a hair cut, so I rang up and made an appointment. While I was having my hair cut I was telling my hairdresser about how I was starting my very first night on night shift that night. I told her how I couldn't sleep in. It was the first morning I couldn't sleep in for years. Normally I would do it with such ease. I don't know if it was my subconscious that made me lie there wide awake, knowing that I had to do night shift. I did feel a bit uneasy about it. I worried whether I would be able to stay awake all night and if there would be enough to do all night to keep me occupied, or whether anyone would die. I felt a bit apprehensive.

As I walked out of the hairdresser's the hairdresser said to me, "Good luck tonight, I hope you end up having an interesting night and don't fall asleep". I laughed and said, "I hope I have an interesting night too". Well, those words couldn't have been said any better, because that is exactly what happened.

I made sure I left home in plenty of time. I arrived at the hospital fifteen minutes early. I had never worked in the PNU before and I didn't know what to expect. I had heard all sorts of stories about it. I guessed that I would have to find out for myself and make my own opinion. I looked out the car window, it looked so cold. There were nurses running to the hospital, all rugged up in their coats, scarves and some even wore gloves. As they breathed, steam formed from the hot air meeting the cold. I remembered when I used to love the winter when I was a kid because I used to pretend I was smoking with the steam forming like smoke as I breathed out. I was reminiscing as I flung open the car door. I grabbed my bag that sat on the seat next to me. The next thing I knew, bang, I didn't know what had hit me. I felt a very hard blow to my right eye, I was shocked for a few seconds, what had happened? Had someone punched me? No-one else was standing near me. Then I realised I had punched myself. I had wondered how on earth I had done it. Then I discovered the strap of my bag had been caught around the hand brake and as I pulled the bag out of the car it must have stayed around the hand break, causing my hand to slip off the bag and thump me in the eye. I couldn't see out of the eye and it was just gushing down with tears, they were just like running all down my cheek and I just felt so stupid, and my eye was throbbing. So I untangled the strap from the brake and stood stunned. I didn't know what to do. I walked to the ward in shock, mesmerised by the blow, still wondering how I could have done it. I just couldn't believe it.

I walked in, I didn't know any of the staff. The afternoon staff were all still there. I couldn't see properly, I was holding my eye. Two of the nurses noticed me. They came running over. "What has happened?" they both asked me at the same time. "I punched myself in the eye" I said. When I think back now I know how stupid and weird this must have sounded. "You punched yourself in the eye!", they both said questioningly. "Yes I did", I said, still in shock. One of them ran off and came back with a cold pack. She put it over my now swollen eye. She said to me, "Tell me 
what happened?" So I told her. I said, "I feel like a fool". She asked me if that was what really happened to me and I said, "Yes", and at the time I was a bit hurt that she didn't believe me, but now when I think about it I know how suspicious it must have looked. Me walking in and holding my eye and it was swollen, and yeah.

I just felt really silly and I sat there amazed at myself. I must have looked so ridiculous walking in there holding my eye, tears and mascara running down my cheek. I regained some normality to my thinking and said, "I'm sorry, you're all probably wondering who I am". I introduced myself to the now rather large crowd gathered around me. I must have been glowing as red as a tomato. I remember wishing that the floor would split in half and gobble me up. But now I think about this and laugh at it, thinking how silly I must have looked, just standing at the door to the ward, holding my eye and trying to focus on the two nurses rushing towards me.

Anyway, that's the funny part of my story and now comes the serious part.

I started the night in an awful way but it ended up in a very special satisfying way. It was ten thirty and I was doing the drug round with the RN on the shift. We had nearly finished the round except for the end room where two men were. I don't know whether any of you have worked in the old PNU on level one of Baxter but it was a really sort of old ward and at night it was pretty dark and scary. They even tried to tell me that there was a ghost in there and if you went to the end of the ward you might see it. But I didn't see it. We walked into the last room and it was so dark I was just waiting for the ghost to make its noises but I didn't hear any. We pushed the trolley towards the men. I could just see one man because the green exit sign glowed on his face. You know that green? And I could hardly see the other man. From handover I remembered these two men as - one having cerebral metastasis and the other one having prostate, bladder and kidney metastasis. And I remembered the afternoon sister saying that his catheter needed milking every hour or so. So at handover I was assigned to do this for the shift. After my eyes adjusted to the light I introduced myself to him and told him what I would be doing during the night for him, the other man looked on but did not speak. We gave them both their pills. The other man in the room took them but didn't say anything, even when I introduced myself, he didn't speak, he just looked at me. I didn't know what to think of this but I wasn't too worried because I had other things on my mind at the time. I think I was concentrating more on what I was doing and what I was going to be doing. I remember the other nurse saying to me as we walked out, "He's the one with the cerebral mets, he has a dysphasia so he can't talk but he can understand what you say".

I went back to the room a little while later. George, the man with the catheter, was fast asleep. He had asked for two sleeping pills which had worked very well. I noticed the other man, Keith, was still wide awake. I went over to him and asked if he was OK, he nodded. This happened a couple of times when I went to milk George's catheter. I remember it was about $2 \mathrm{am}$. I went into the room, George's 
catheter was draining well. I looked over at Keith's bed and I noticed he was still awake. I decided to go over to him to see if he was alright. I walked over to him. I could see the sweat shining on his forehead as the green exit sign reflected on his face. I reached out and felt his forehead and said to him, "You're really hot". As I took my hand away, his hand came shooting out from under the sheets like lightning. He grabbed my hand, he squeezed it so hard I nearly screamed - but I didn't. He held it so tight, he wasn't going to let go. I asked him if he was alright, he struggled to say something. He tried so hard to tell me something. I decided to sit down on the chair next to his bed to show him I would stay and listen. He didn't let go of my hand as I sat down but he did loosen his grip. He kept trying to say something. It was so hard to sit there and watch him struggle to speak. I wanted to be able to push a button and let it all out. I asked him, "Do you want something?" He shook his head. I said, "Are you feeling alright?" He nodded and I heard him softly say, "Yes". I was surprised. I remember thinking, he can speak and I'm going to sit here with him until he says everything he wants to, even if it takes all night. We sat there. He was holding my hand. By this time I was holding his hand back in return. I felt more comfortable. He had frightened me to begin with. I didn't know what he was going to do, but I realised he just wanted someone to talk to.

He tried and tried to say what he wanted to tell me. He eventually managed to say, "Fifty". So I repeated, "Fifty". He nodded. I said, "Fifty what?" I sat with him very patiently. It took a very long time but he finally said, 'Fifty years'. And I thought to myself, You're not trying to say you are fifty, because I knew he was seventy one, so I said, "Go on". He kept trying and trying to say what he wanted to say. He said after much struggle, "Wife", and I thought maybe his wife was fifty, but I doubted that, seeing that he was seventy one, but I said, "Is it her birthday?" He said, "No". The frustration showed on his face. He was so frustrated that he couldn't say what he wanted to say. He had nearly given up at this stage but then it clicked. I said, "Is it you and your wife's fiftieth wedding anniversary?" His eyes opened up like Luna Park. He sat up straight in bed and said, "Yes, Marie and me, fifty years". Then he lay back down with a huge smile on his face and tears rolling down his cheeks. He still clung to my hand. A few minutes later he was making soft snoring sounds, he still had the smile on his face. I sat with him for a while longer, holding his hand. When I thought that I should leave and he wouldn't wake up I slowly put his hand back on his chest and pulled up the sheets and walked out of the room. I felt so happy, excited and drained of energy all at once. I think I had a smile as big as his as I walked out of that room. I looked at the clock in the corridor, three thirty it read. I couldn't believe it, I had sat with him for an hour and a half. While we sat there it was like nothing else in the world existed, just the two of us. I walked around for the rest of the night in a daze. I can't even remember what happened after that very clearly.

When I got home that morning, I walked inside and burst into tears. I wasn't sure if they were tears of sadness for him, or tears of happiness that I was the one that had shared this experience with him, or whether they were tears of release after 
experiencing such a close, intense experience. Even now when I think back to this, I still don't know exactly why I sobbed my heart out afterwards, but I think it was a combination of happiness, sadness and release.

When I think back to this experience it brings back memories of members of my family, dying from all various types of cancer. With all five of my family members, I went to visit them over the months of their illnesses but I didn't ever share an experience alone with them and an experience so intense. I think the experience I had with Keith lifted some of the guilt and the longing of wanting to have been able to share some time alone with my family members before they died. In some weird way I think I was supposed to share this experience with Keith so I could deal with the guilt I felt about my own family members. I felt a huge weight lift off my shoulders. I can't really describe the way such an intense unique experience like that felt for me, but just knowing that Keith wanted to share his excitement about his wedding anniversary with me and the struggle it took him to say one sentence, and he still persisted in trying to tell me, has given me a new outlook on life. I think back to Keith when things are getting a bit tough and think to myself, "I can't ever give up on anything, now matter how hard it is". To me these types of experiences are what makes nursing.

The next night, he was awake again when I went into his room. He had stayed awake to talk to me again. After much struggle I managed to understand that he wanted me to look in his cupboard. He had a massive bunch of flowers on a stand, it was probably as tall as me. It was the biggest bunch of flowers I have ever seen and I saw a card on the floor next to them. I said to him, "Are they for your wife?" He nodded and said, "For tomorrow". He had that big, cheeky, happy smile on his face. I sat with him for a long time that night. We didn't talk but there was no need for words. We both felt comfortable and happy enough with one another to just sit there together.

You might all be thinking how could this happen with a person that you'd never met. I was amazed myself that I had never met this man before but at that moment of connection I felt like I'd known him for my entire life. I can't explain what it felt like but everything was sort of, all the boundaries were lifted and I felt like there was only the two of us in the entire world just for those short few minutes. It was a connection that I really can't describe. I just felt an enormous connection with him. And this experience with Keith is what made my mind up what nursing is for me. 
It was a late shift and I was going to find the RN to say that I was leaving for debriefing. I'd seen her last at the other end of the ward and so I was walking back there. A woman came running out at me in a panic and she was saying, "Help me, help me, my husband."

So I went in and there he was sitting and holding the bedtable and he just couldn't breathe. He was very pale and sort of wheezy and his eyes were popping out of his head. I just got my hand behind him and sat him up more and talked to him. Then I left him with another nurse and I went and got the charge nurse because his wife had said to me, "He's never been this bad before." And I had said, "Well what do you do?" And she said, "You know, he has ventolin and a repco," so I went to find a nurse and she was talking with a surgeon and I said, "Mr Smith is not well and he needs a repco," and she said, "I'll be with you in a minute," and I said, "No, he needs it now," and she said, "OK." So I went back and within a minute she came back with the repco for him. And when I was happy that everything was fine I left.

Then the next day I was working on side one again and I went around to side two - I don't know what made me go, I just did. I just bowled straight into that room and as I walked in, here was this man and his wife sitting with a table between them and I thought, "Um, OK." And I walked in and I said to his wife, "How are you today?" And she said, "Oh, he's been very confused," and I thought, That's not what I asked you. So I said, "You'll probably kick me for saying this, but I feel I have to say it. It's really important to take care of you." And with that her whole posture dropped and she started to cry, and I put my arm around her and she said, "I don't know how, how do I do that?" And I said, "Well you can have a bubble bath. Or do you like the beach or the bush?" She said, "I love the beach." I said, "Well go down and sit there, and if it's cold, sit in the car." And she was just crying and I said, "Just because you take time out for you does not mean that you love your husband any less." And with that she cried even harder. I put my arm around Mr Smith as well as having my arm around Mrs Smith - and then I said, "I can see that you do love him," and she turned around and she looked at him and she said, "Yes, I love you with all my heart", and he turned around and said back to her, "and I love you." Now this man had been very confused and in that moment he just 'came back' and said that to her. So I just pushed the table away and stepped back, and left them hugging each other.

I came back in to hand over the next day. They said that he'd died that night .

The first story shows an encounter between nurse and patient that is a reflection, as a form of mirroring, of the same thing, that while created from differing life experience, finds resolution in how the now moment is experienced. At any time in the encounter, the nurse could have withdrawn - as could have the patient. They could have given up on each other, 
and in so doing, given up on themselves. When a more excellent thing is generated from a less excellent thing, we have generation absolutely, and corruption relatively (Aquinas, 1267, p.721). For Keith it concludes with a huge arrangement of flowers sitting in his cupboard that is coupled with a sense of deep satisfaction, as he lies smiling in his hospital bed. In being able to speak what he spoke, this man was able to let go of something through having acknowledged a connection with another human being that has lasted fifty years. It is in the simplicity of the energy of acknowledgment that this man is conscious of the love.

For the student, the release occurs when she goes home, she sobs her heart out. For love that was not expressed/ acknowledged. That night they come together again, and together they experience a sense of communion. I can't explain what it felt like but everything was sort of, all the boundaries were lifted and I felt like there was only the two of us in the entire world just for those short few minutes. It was a connection that I really can't describe. I just felt an enormous connection with him. Therein is the key. To make conscious the unconscious in the story is to be aware of what is felt as the story is read. In that way the reader too can be brought to this place of knowing where what is known is that what these two beings have experienced is more love. And how this is known is the reader too can feel more love. So together, on some level, we have all engaged in our own healing. We all can feel more love.

In interpreting story as method, interpretation begins by experiencing the emotion embedded within the story. In this way, the experience is akin to gathering in the Heideggarian sense, where the story represents the fouring of the fourfold which is poured into the jug as a potentiality of the holding to take place. To hold, in the first instance, is both an act of allowance and vulnerability so as to feel an emotion that is then felt without judgement. In being able to do so, then there can be an outpouring. This type of pouring out is what Heidegger (1962) terms a 'consecrated libation'. It is one movement forward in the expansion of one's consciousness that is the ongoing experience of feeling human emotion, to then consciously be able to choose to feel the feeling of love in every now 
moment. It is process, not event. In the moving forward of consciousness it is an expansion in the knowing of love. For while love always has existed and always will exist, it is our knowing of love which expands as we expand in consciousness. Knowing then is the same as making something manifest, making a thing real, and so as we know more love, then so too do we make love real. We realise more love.

Embedded in the expansion of consciousness is freedom. This is not to say that we are not free, for freedom too is a feeling, and so it is our perception of freedom which I speak of in a way that presents freedom that, like love, is not an all or nothing thing but which is realised in increments. As we know more love so too do we know that we are free, where freedom does not exist without responsibility/accountability. They dwell in a relationship that is at once a pairing and at the same time an independence. Freedom with responsibility is the same as love which is mature/transpersonal, whereas love that is free, but does not know responsibility is love that is immature/prepersonal. The child will love the perpetrator because the child does not know that he/she has choice, and in that way the child is not responsible for love and therefore does not know that she/he is truly free. Therefore, in freedom with responsibility there is always choice.

Love will always choose, and the choice of love will always be love. Choosing love, as this work has made clear, is not the romanticised, Pollyanna, turn the other cheek, sacrificial portrayal of love. Choosing love is to acknowledge what IS, and then make a choice for more love and in that way come from love. It would have been so easy to dismiss the lead in of the first story - the scenario of the student punching herself in the eye. For given the morning events of her lack of sleep and then her injury, it would have been so very easy, even justifiable, for her to not have taken responsibility that night and to have gone home. In every given moment she was free to choose, and every choice she made is here for all to witness. So sometimes love begins by not sleeping well and punching oneself in the eye, but in truth, love is neither of these things, rather, these things are an opportunity to choose more love. An opportunity where we were, are and always will be free to choose what we feel in every now moment. 
In the second story the nurse is able to consciously enable the other to unlock what needs to be unlocked because she has no attachment to the emotion that is creating the lock. At that level she has acknowledged love. In saying that she is doing this act consciously, I need to re-emphasise that such consciousness does not think as logic, deduction or reason. Firstly, she listens to herself, she takes herself into that particular room without questioning what it is that took her there. She is willing, she has listened to her intuition. Secondly, she observes the table between them, and it is just that, an observation. Where she observes the thing, she does not judge it - concluding that something IS - and in that way notes that the outside is a reflection of the inside. There is something creating a distance between them, an obstacle in the way. In not making a judgement she has opened up her awareness. Then she moves to speak. How many times have we wondered what to say? In truth we do not need to figure out/work out/deduce what to say. For when we are able to let go of trying to make things happen and just wonder we allow the energy of all things to move and flow in perfect timing. We allow ourselves to be inspired. It is as if the words flow forth because we have invited/allowed them in. These words are an outcome, a response to the call of being, where the beingness of the other has called and the beingness of another has responded to evoke a response. That other is willing, for in God's case will and power coincide. In the story, the patient's wife IS willing, she responds to what the nurse has said. The posture of her body changes - there is movement emovere, and she cries. She has 'opened up'; the same phenomenon that occurs at cellular level when a ligand and receptor connect - the cell wall 'opens up'.

In the 'letting go', which paradoxically is an 'opening up', she is then willing to be open to more, and so again the nurse brings forth/evokes the words and actions to assist both the wife and patient to 'do' what it is they unconsciously wish to experience. She says what needs to be said, she positions her self in a way that shows confidence. They then acknowledge love to each other and in that now moment what they all experience is more love. This nurse has consciously held the light to assist these two beings to straighten their light. She has consciously mirrored back to these people what they were asking to see. She 
has heard and answered a call of being. She is love and light in action. She has been of service, and a grand healing has taken place.

When we as nurses consciously act in such ways, then we will truly be able to assist people in their process of healing. We will enable each other in our own healing through the practice of the art of realising our wholeness, where the 'I - self' is consciously rediscovering its one-ness because it is known that every act is an act of self definition. "In the absence of that which you are not, that which you Are is not. It cannot be experienced. It cannot be known" (Walsch 2000, p.128).

Being as process, as this work has repeatedly stated, needs to be made conscious. A process that will be supported by the use of various body therapies and energy work. A process that is a choice 'to do', by making the choice 'to be' so that the finest of the fine arts, nursing's service to humankind, and our lightness of being envisaged by Nightingale, Rogers and Watson will no longer dwell beyond time and space but exist IN time and space. Then what will be experienced in time

... can best be captured metaphorically as the age of light, which takes us into a new relationship with our being-in-the-world as embodied forms of light, intersecting and coming into our light metaphorically and evolutionary. We are becomong more god like and divine as we move towards the light of our divinity, a level of connectedness, the oneness of all, attending to the implicate spiritual unfolding and evolving - as the 'lightness of "being"' - wherein the light of the universe is enfolded and embodied into our very existence.

Watson $(1999, \mathrm{p}, 271)$ 
Such then can be the power of nursing, for it can be the same power as the power of love. Love that was in the beginning and is at the end. Love that is the origin of all true things where, in the human condition, we are the potentiality of this expression in physicality. Where all things existing in physicality exist because that is how we have imagined them to be. As we imagine, so we become; that is not an end but a way to come to know what is and what is not love.

In the awakening to the potential of the adventure of living, we open our awareness to what we are creating in our lives. With the awareness that everything is consciousness and energy we can then consciously engage our being in a form of reflection and action, Praxis, to transmute energy through emotion and feeling, the Aesthetic, to approach dis-ease as a physical manifestation of thought. Thought that is not the product of logic or intellect, but as the unfoldment of consciousness, is the expression of beingness that, as a human being, is then received as an emotional experience to be experienced as the feeling of love. As we in Nursing learn to work with thought as consciousness and energy manifested as dis-ease, we will be revealing Nursing as an Aesthetic Praxis. 


\section{Summary}

The final notion of Nursing as Entelechy, an Aristotelian notion reframes nursing for a new era in human history, allowing it to paradoxically to return to its soul and soulful purpose. The process of Entelechy manifests in a single caring moment; however it is captured and lived through revealed story. Thus this chapter further expands the key concepts through examining the feminine as feeling that then serves to connect a human being to God, through which all things are then made possible.

In this way, I have argued that God is known in feeling. God is made known through energy and consciousness as thought/intent. As such health and healing have been positioned in relation to these key concepts so as to revolve around intent/thought, and emotion and feeling. Object and Subject in a new light. 


\section{Concluding Remarks}

I began this work six years ago. To say that I had any conscious consciousness, of where my students' stories would take me does little to convey the sense of awe I feel when I look at the collated pile of paper on my desk. I suppose most researchers would make comments of this nature as they approach the completion of their work.

To have written what has been written and arrived at these insights is such a surprise. For I cannot say that in the past I had thought deeply about who I was or pondered on a purpose or meaning of life. Embodiment was not a word in my vocabulary and Philosophy was the legacy of some great persons. Having said this though, God did exist in the beauty I felt when I leant on the fence and watched the sun set in the back paddock. This was the same feeling I could feel in a walk along the beach with a friend, laughing, the sun dancing on the water and the tide lapping at my feet. On a warm summer's evening I could see and smell heaven, in my rose garden.

As I stand in the paddock during the early hours of the morning my head bent toward the heavens gazing at the back velvet star studded night the sea roaring in the background and the smell of fresh cow manure penetrating my nostrils, I feel both peace and expansiveness. I remember how I felt the first time I saw the birth of a human being and how different I felt when it became evident that my dear Mrs Waterhouse and Miss Searle were going to die. In the ongoing dramas that we call to life, I have felt such wonderment and despair for and about my fellow human beings. These things I did already know.

In my life as a nurse teacher I have read a multitude of essays, watched my students undertake all manner of activity, listened to a myriad of nursing encounters and applauded hundreds as they crossed the stage on graduation day. I have experienced much. In my life as a nurse I have stood beside countless beds holding a hand, kissed foreheads of patients after they had died, and watched with a family as the game of life and death played itself out. In all this, there has been much to experience. 
In my having undertaken this work then, none of these 'things' has changed. What has changed though, is that I now know that the potentiality of knowing God existed - in all of these things. That in some way these 'things' held the possibility of knowing God by knowing more LOVE.

This knowing of God, of who we are, is what the thesis offers. The thesis offers my insights into being through how I have been, that at the same time has been reflected to me in the world around me. This world has been the world of Nursing. In unfolding being through having revealed a process about being, I have made facets of being visible. These facets have been identified as tools, in the possibility of the self engaging the self in life, where the intent is first and foremost, to be 'more'.

The tools revealed in the work are; non-judgement, love, tenacity, trust, honesty, awareness, willingness, creativity, openness, allowance, gentleness, confidence, vulnerability, self-responsibility, courage, support, spontaneity, flexibility, now, honour and integrity, listening, anticipation, wonder, worthiness, choice, focus, respect, stillness, commitment, patience, surrender, acknowledgment and passion.

Nursing as an Aesthetic Praxis is the product of a research work into how we be in Nursing, approached through narratives of nursing. As an inquiry, it is both phenomenological and metaphysical as they relate to being. Being is unfolded as a process by which and through which we create and recreate ourselves for consciously knowing who we already are. In this way, Nursing as an Aesthetic Praxis is really a love story, a story about a way to love that when known by nurses will enable nursing to be an art of healing.

This work is about being in a body, who we are and how through the expression of beinghuman we create the patterns we know as dis-ease. Dis-ease has been positioned as one result of how we be in this process, that as an act of ongoing creation can be recreated. To come to this place of knowing is to begin to know love/God. 
This work places nurses in their relationship with other human beings as a process of being, where the relationship is one of reflection as a possibility to transcend being-human. As the nurse learns to consciously re-pattern, that is, to hold a new pattern, then she is more able to assist others consciously in their process of re-patterning. In consciously holding a pattern with another, this way of acting, nursing/healing, is one that I term refraction. To be able to refract is to practice as expressed in the vision of - the finest of the fine arts - and as such is to be of service to human kind.

Nursing as an Aesthetic Praxis reveals that life is experienced emotionally. That emotion is the basis for the creation of belief systems/patterns that in turn become thought expressed through the understanding that energy follows thought. It is asserted that thought attached to emotion is 'confused', confused in the sense that it is a limitation of reality/truth.

The project recognises that to change thinking is to re experience an emotion because feeling is considered the dominion of the soul/spirit. Thinking as the work reveals, cannot be approached by the rational/logical/intellectual/local mind. Thinking is immersed in feeling, where the outcome as process is a greater and greater connection of $a$ mind to the universal mind.

In this way this work shows how in the subjectivity of being human, this way of thinking, distinctively identifies us as human beings. That in the ability to respond to our world emotionally lies a key to unlocking our power to connect to universal mind. Universal mind is described in this work as the mind of God or Love, that as a field of consciousness exists for every being, being human.

This work expresses this way of thinking while simultaneously challenging the reader to explore the paradigms/patterns that underpin the reality that duality and separatism are real. To this end the text both challenges and records the project in which nursing education and practice are explored as possibilities to express being. The text, to the reader and project, show that in giving up/surrendering the human capacity to judge, expressed as a responding 
to what is felt in life, is to begin to embrace one's divinity through being love. Thus the thesis is presented as a unique text to reveal and guide the reader to consider and explore the idea that while on one hand we are each free to think, on another, thinking is how we be free.

In the idea that thought is attached to emotion that in the first instance is feeling to be consciously felt lies the concept of human freedom. The text shows that as process it is a process of consciously choosing to feel love as the response to what is felt and in that way come to know who we really are. The work positions human beings as the expression of love, not as an end, but as infinity. The project suggests that in realising this consciousness, and naming it as being love, this is how we are then free to become free travellers in the universe. We sunder the bonds of suffering and in that way break the chains that tie us to the idea that the shadow is real.

To this end we learn how to create the appraisal from the outcome of a life experience. In the letting go of the expectation of perfection, the expression of ego, there is a conscious choice to live not only differently, but to live in the light. In fact, the text states clearly, that unless we choose to live life as a state of excellence, to be, then we can only continue striving for perfection and thus we remain in the dark.

This work is primarily about consciousness and energy uncovered through nursing. As such this work presents human beings as consciousness and energy to then describe human beings as light and love. We are light and love.

This work has been a journey of both honesty and integrity and the text is presented in such a way to remain authentic to reveal the purpose of being human, and so make that ideal/intent real. To be, light and love. From this position, I have made the distinctive and unusual suggestion in the thesis that dis-ease and nursing are opportunities that can serve this ideal/intent. Where the return to light and love is not some sort of afterlife, but a 
revelation to be created, here, whilst being in a body. That as a process life can be an act of conscious creation, in every living breathing moment.

Thus the project, as a text reveals that in creating our realities we are creating what we create. For not only do we create out lives by what we think, but that we are in fact creating the cosmos with our thoughts. That in the knowing how we create our realities, lies the potentiality for creation as an act of conscious intentionality that is not a response to life, but a calling forth of life - Elohim - I call forth or, in the beginning. To call forth in this manner is to call forth from the fullest expression of who/what we be. For who we be, is simultaneously God/Love/Source.

With the understanding that all things come from or have their origins in God, then it is understood how healing is made manifest from and by that which we language as God/Love. God that is not an end point but the source from which healing takes place that in turn is known through feeling.

Nursing as an Aesthetic Praxis began in the simplicity of the desire to reveal more of nursing through stories about nursing. To this end, the text stands as that revelation. Thus, I have arrived at a place where I find myself both answerable and able to answer my own quest. I wonder, how can I teach nursing in a way that enables them (and me) to see more? I called. Nursing as an Aesthetic Praxis is the response.

I have said that before undertaking this work I had not consciously engaged in thoughts about existence (despite having written a Master's thesis titled Spiritual Aesthetics in Nursing). What I clearly do remember is, that from a very early age I felt such a depth of loneliness that as a small child I would say - I want to go home, I want to go home.

Whenever I experienced life as what I perceived to be a lack of love, this loneliness would surface as a reminder of the tenuous hold on my living my life. And no matter what I filled my life with and with whom I filled it, these things served as only a short respite from this 
loneliness. In hindsight, I can now see how my loneliness served to support the search/seeking for something that I would eventually came to discover was not to be found in other people, places or things. The feeling of loneliness has taken me on a great journey. It has served me very very well.

Finally though, my search is over. For in my having undertaken this work, this part of my life journey, I can again feel the cavity midway between my breastbone pulsating. Now the pulsation is no longer dependent on any one or any one thing and as such, I have awoken to my potential, my love, myself. And how that feels is - VERY EXCELLENT. "... when a more excellent thing is generated from a less excellent, we have generation absolutely ... "(Aquinas, 1267, p.721).

Through loneliness I found more of my origin. In having undertaken this journey I have remembered that home is not out there or in some body or something. Home I know is within me, and it is my choice and mine alone to feel it with every breath in every heartbeat.

And so it is in this light that I offer this work. And if it would assist you to fill your space with even one more drop of love, then I say, thank God. For as I Am, so are you. 


\section{References}

\section{Chapter 1}

Crotty, M., 1996 Phenomenology and Nursing Research. Churchill Livingstone, Melbourne.

Emden, C., 1998 Theoretical perspectives on narrative inquiry, Collegian, 5(2) 30-35.

Freire, P., 1972 Pedagogy of the Oppressed, Penguin Books, London.

Heidegger, M., 1971 Poetry Language Thought. Harper and Row Publishers, New York.

Hillman, J., 1996 The Souls Code: In search of character and calling. Random House, New York.

Houston, J., 1997 A Passion for the Possible. Harper, San Francisco.

Houston, J., 2000 Jump Time: Shaping your future in a time of radical change. Vicking, New York.

Koestler, A., 1964 The act of creation. Pan books Ltd., London.

O'Connor, J. \& Seymour., 1995 Introducing neuro-linguistic programming, Thorsons, London.

Rogers, M., 1970 An introduction to the theoretical basis of nursing. F A Davis Company, Philadelphia.

Street, A., 1991 From Image to action: Reflection in nursing practice, Deakin university, Geelong.

Trainor, D., 1997 Enlightenment in nursing in Thorne. S. \& Hayes, V., (Eds.) Nursing praxis: Knowledge and action. Sage publications, London.

van Manaen, M., 1990 Researching lived experience: Human science for an action sensitive pedagogy, State University of New York Press, London.

Walsch, N.D., 1995 Bringers of the Light. Millennium Legacies Inc. Ashland.

\section{Chapter 2}

Crotty, M., 1996 Phenomenology and Nursing Research. Churchill Livingstone, Melbourne.

Ermarth, M., 1978 Wilhelm Dilthey: The critique of historical reason. Chicago University Press, Chicago.

Heidegger, M., 1962 Being and Time. Harper and Row Publishers Inc., New York.

Heidegger, M., 1971 Poetry Language Thought. Harper and Row Publishers, New York.

Herald Sun, 1998 Researchers find black hole. Saturday January 10th, Melbourne, 18. 
Hillman, J., 1996 The Souls Code: In search of character and calling. Random House, New York.

Levin, D. M., 1988 The Opening of Vision: Nihilism and the postmodern situation. Routledge, New York.

Madrid, M. \& Barrett, E A., (Eds.) 1994 Rogers' Scientific Art of Nursing Practice. National League for Nursing Press, New York.

Malinski V. \& Barrett, E A., 1994 Martha E Rogers: Her life and her work. F. A. Davis Company, Philadelphia.

Merleau-Ponty, M., 1964 The Primacy of perception. North Western University Press, United States of America.

Newman, M. A., 1994 Health as expanding consciousness. National League for Nursing Press, New York.

On Wings of Song and Robert Gass, 1990 Heart of perfect wisdom. CD, Spring Hill Music, Colorado.

Paterson, J.G. \& Zderad, L.T., 1976 Humanistic Nursing. Wiley and Sons, Inc., New York.

Rogers, M., 1970 An introduction to the theoretical basis of nursing. F A Davis Company, Philadelphia.

Taylor, B. J., 1994 Being human: Ordinariness in nursing. Churchill Livingstone, Melbourne.

Walsch, N. D., 1997 Conversations with God: An uncommon dialogue Book 2. Hampton Roads Publishing Company, Inc., Charlottesville.

Watson, J., 1988 Nursing: Human science and human care: A theory of nursing. National League for Nursing, New York.

\section{Chapter 3}

Holmes C., 1991 Theory: Where are we going and what have we missed along the way? In Gray, G. \& Pratt, R. (eds.) Towards a Discipline of Nursing. Churchill Livingstone, Melbourne.

Chinn, P. L. Maeve, K. \& Bostick, C., 1997 Aesthetic Inquiry and the Art of Nursing Scholarly Inquiry for Nursing Practice 11(2); 83-96.

Heidegger, M., 1962 Being and Time. Harper and Row Publishers Inc., New York.

Heron, J., 1992 Feeling and Personhood: Psychology in Another Key. Sage Publications, London.

Houston. J., 2000 Jump Time: Shaping your future in a time of radical change. Vicking, New York.

Koestler, A., 1964 The act of creation. Pan books Ltd., London. 
Merleau-Ponty, M., 1964 The Primacy of perception. North Western University Press, United States of America.

Markus, G., 1983 Life and Soul: The young Lucaks and the problem of culture. In Heller A (ed) Lucaks Revalued. Basil Blackwell Publisher Ltd., Oxford.

Nightingale, F., 1859 Notes on Nursing. Harrisons and Sons, London. (Commemorative Edition) 1992 Lippincott, Philadelphia.

Pole, D., 1983 Aesthetic forms and emotion. Duckworth, London.

Scruton, R., 1983 The aesthetic understanding. Carcanat Press, Manchester.

Scruton, R., 1974 Art and imagination: A study in the philosophy of mind. Routledge \& Kegan Paul, London.

Spinoza, B. de., 1677 Ethics. Hutchins R M (ed.) 1952 Great Books of the Western World. Encyclopaedia Britanicca, Inc., Chicago.

Valliot, M. C., 1970 Hope: the restoration of being. American Journal of Nursing, February 70 (2) $268-275$.

Vernon, M. D., 1971 The psychology of perception. Penguin Books Ltd., London.

Walsch, N. D., 1998 Conversations with God: An uncommon dialogue Book 3. Hampton Roads Publishing Company, Inc., Charlottesville.

\section{Chapter 4}

Brennan, B., 1987 Hands of light. Bantam Books, Toronto.

Brennan, B., 1993 Light emerging. Bantam Books, Toronto.

Baudrillard, J., 1990 Revenge of the crystal. Pluto press, Australia.

Dossey, L., 1991 Meaning and medicine. Bantam Books, New York .

Fox, M., 1985 Illuminations of Hildegard of Bingen. Bear \& Companyy, Sante Fe.

Hawking, S., 1993 Black holes and baby universes. Bantam Press, London.

Heidegger, M., 1962 Being and Time. Harper and Row Publishers Inc., New York.

Heidegger, M., 1971 Poetry language thought. Harper and Row Publishers, New York.

Lang, P., 1994 The varieties of emotional experience: A meditation on James-Lange theory. Psychological Review 101(2):211-221.

Malinski, V. \& Barrett, E. A., 1994 Martha E Rogers: Her Life and Her Work. F. A. Davis Company, Philadelphia.

Madjar, I., 1997 The body in health illness and pain. In Lawler J (ed.) The Body in Nursing. Churchill Livingstone, Australia. 
McGuire, M., 1991 An eye for fractals. Addison-Wesley Publishing Company, New York.

Pert, C. B., 1997 Molecules of emotion. Scribner, New York.

Pierrakos, J. C., 1987 Core energetics. Life Rhythm Publication, USA.

Prophet, M., 1991 Kuthumi: Sudies of the human aura, Summit University Press, USA.

Roberts, U., 1950 The mystery of the human aura. Samual Weiser, Inc., Maine.

Taylor, B. J., 1994 Being Human: ordinariness in nursing. Churchill Livingstone, Melbourne.

Vernon, M. D., 1971 The psychology of perception. Penguin Books Ltd., London.

\section{Chapter 5}

Aquinas, T., 1267 The summa theologica of Saint Thomas Aquinas. Hutchins R M (ed.) 1952 Great Books of the Western World. Encyclopaedia Britanicca, Inc., Chicago.

Benner, P., 1984 From novice to expert: Excellence and power in clinical nursing. AddisonWesley Publishing Company, Menlo Park.

Chinn, P. L., 1994 Developing a method for aesthetic knowing in nursing. In Chinn, P. L. \& Watson, J. (eds.) Art and aesthetics in nursing. National League for Nursing Press, New York.

Crotty, M., 1995 Phenonenology as radical criticsm. In proceedings Asia-Pacific Human Science Research Conference. Monash University, Gippsland Campus. 87 - 97.

Curling, C., 1991 Science: evolving new models of reality. World Goodwill Occasional Paper, November, London.

Dossey, L., 1991 Meaning and Medicine. Bantam Books, New York.

Ermarth, M., 1978 Wilhelm Dilthey: The critique of historical reason, Chicago University Press, Chicago.

Freire, P., 1972 Pedagogy of the oppressed, Penguin Books, London.

Halperin, M. L. \& Goldstein, M. B., 1988 Fluid electrolyte and acid-base emergencies. W B Saunders Compnay, Philadelphia.

Hawking, S., 1993 Black holes and baby universes. Bantam Press, London.

Heidegger, M., 1971 Poetry Language Thought. Harper and Row Publishers, New York.

Heidegger, M., 1968 What is called thinking. Harper \& Row, Publishers, New York.

Hillman, J., 1996 The souls code: In search of character and calling. Random House, New House.

Koestler, A., 1964 The act of creation. Pan books Ltd., London. 
Lemay, E. \& Pitts, J., 1994 Heidegger for beginners. Writers and Readers Publishing Inc., New York.

Levin, D, M., 1988 The Opening of vision: Nihilism and the postmodern situation. Routledge, New York.

Malinski, V. \& Barrett, E., A., 1994 Martha E Rogers: Her life and her work. F. A. Davis Company, Philadelphia.

Markus, G., 1983 Life and soul: The young Lucaks and the problem of culture. In Heller A (ed.) Lucaks Revalued. Basil Blackwell Publisher Ltd., Oxford.

Merleau-Ponty, M., 1964 The primacy of perception. North Western University Press, United States of America.

Morgan, B. \& Morgan, R., 1986 Brain Food. Pan Books, London.

Paterson, J.G. \& Zderad, L.T., 1976 Humanistic Nursing. Wiley and Sons, Inc., New York.

Pert, C. B., 1997 Molecules of emotion. Scribner, New York.

Pierrakos, J. C., 1987 Core energetics. Life Rhythm Publication, USA.

Spinoza, B. de., 1677 Ethics. Hutchins R M (ed.) 1952 Great Books of the Western World. Encyclopaedia Britanicca, Inc., Chicago.

Vincent, J. D., 1990 The biology of emotions. Basil Blackwell Ltd., Oxford.

Walsch, N. D., 1995 Conversations with God: An uncommon dialogue Book 1. Hampton Roads Publishing Company, Inc., Charlottesville.

Wheeler, J. A., 1977 Genesis and Observership. In Butts R E, \& Hintikka J (eds.) Foundational problems on the special sciences. D Reidel, London.

\section{Chapter 6}

Adams, P., 1993 Gesundheit. Healing Arts Press, Rochester.

Aquinas, T., 1267 The summa theologica of Saint Thomas Aquinas. Hutchins R M (ed.) 1952 Great Books of the Western World. Encyclopaedia Britanicca, Inc., Chicago.

Bailey, A. A., 1953 Esoteric healing. Lucis Publishing Company, New York.

Calabria, M. D. \& Macrae, J. A., (Eds.) 1994 Suggestions for thought by Florence Nightingale. University of Pennsylvania Press, Philadelphia.

Hawking, S., 1993 Black holes and baby universes. Bantam Press, London.

Heidegger, M., 1971 Poetry language thought. Harper and Row Publishers, New York.

Hodgson, J., 1943 Wisdom in the stars. The White Eagle Publishing Trust. England. 
Houston, J., 1997 A Passion for the possible. Harper, SanFrancisco.

Morrissey, M. M., 1996 Building your field of Dreams. Bantam Books, New York.

Mouskouri, N., 1973 I have a dream. Passport. CD PolyGram Records, Philips USA.

Paterson, J.G. \& Zderad, L.T., 1976 Humanistic nursing. Wiley and Sons, Inc., New York.

Perera, S, B., 1981 Descent to the goddess. Inner City Books, Canada.

Williamson, M., 1992 A return to love: Reflections on the principles of a course in miracles. Thorsons, London.

\section{Chapter 7}

Arendt, H., 19961929 Love and Saint Augustine: Edited and with an Interpretative essay by Scott J. \& Stark, J., The University of Chicago Press, Chicago.

Blum, R., 1990 The new book of runes. Angus and Robertson, Pymble.

Campbell, J., 1990 Transformations of myth through time. Harper and Row, Publishers, New York.

Freire, P., 1972 Pedagogy of the oppressed. Penguin Books, London.

Heidegger, M., 1968 What is called thinking. Harper \& Row, Publishers, New York.

Heron, J., 1992 Feeling and personhood: Psychology in another key. Sage Publications, London.

Houston, J., 1997 A Passion for the possible. Harper, San Francisco.

Madrid, M. \& Barrett, E A., (Eds.) 1994 Rogers' Scientific Art of Nursing Practice. National League for Nursing Press, New York.

Prophet, M., 1991 Kuthumi:Sudies of the human aura. Summit University Press, USA. 
Tucakovic, M., 1996 I, of myself, cannot heal. Holistic Nurses Association of Australia 3rd Annual National Conference, Healing Partnerships: A Global Re-Forming of Health, Caloundra, Unpublished paper.

Valliot, M. C., 1970 Hope: the restoration of being. American Journal of Nursing, February $70(2): 268-275$.

Williamson, M., 1992 A return to love: Reflections on the principles of a course in miracles. Thorsons, London.

\section{Chapter 8}

Aquinas, T., 1267 The summa theologica of Saint Thomas Aquinas. Hutchins R M (ed.) 1952 Great Books of the Western World. Encyclopaedia Britanicca, Inc., Chicago.

Arendt, H., 19961929 Love and Saint Augustine: Edited and with an Interpretative essay by Scott J, \& Stark, J . The University of Chicago Press, Chicago.

Bailey, A. A., 1953 Esoteric Healing. Lucis Publishing Company, New York.

Chaudhuri, H., 1987 The philosophy of love. Routledge \& Kegan Paul, New York.

Ermarth, M., 1978 Wilhelm Dilthey: The critique of historical reason. Chicago University Press, Chicago.

Freire, P., 1972 Pedagogy of the oppressed. Penguin Books, London.

Gregory, R., 1997 Mirrors in mind. Penguin Books, London.

Grundy, S., 1987 Curriculum: product or praxis. The Falmer Press, London.

Heron, J., 1992 Feeling and personhood: Psychology in another key. Sage Publications, London.

Kant, I., 1788 The Critique of pure reason. Hutchins R.M. (ed.) 1952 Great Books of the Western World. Encyclopaedia Britanicca, Inc., Chicago.

Krishnamurti, J., 1956 Krishnamurti and the experience of the silent mind. Chetna, Bombay.

Krishnamurti, J., 1987 The awakening of intelligence. Harper, SanFrancisco.

Levin, D. M., 1988 The Opening of vision: Nihilism and the postmodern situation. Routledge, New York.

Nightingale, F., 1992 Notes on nursing: What it is and what it is not, (Commemorative Edition). J B Lippincott Company, Philadelephia.

Northrup, C., 1998 Women's bodies, women's wisdom. Bantam Books, New York.

Plato 428 B.C-348 B.C. The dialogues of Plato. Jowett (ed.) 1952 Great Books of the Western World, Encyclopaedia Britanicca Inc., Chicago.

Pole, D., 1983 Aesthetic forms and emotion. Duckworth, London. 
Scruton, R., 1983 The aesthetic understanding. Carcanat Press, Manchester.

White, M. \& Gribbon, J., 1993 Einstein a life in science. Simon \& Schuster, London.

Want, C. \& Klimowski, A., 1997 Introducing Kant. Totem Books, New York.

\section{Chapter 9}

Aquinas, T., 1267 the Summa Theologica Of Saint Thomas Aquinas. Hutchins R M (ed) 1952 Great Books of the Western World. Encyclopaedia Britanicca, Inc., Chicago.

Artress, L., 1995 Walking a sacred path: rediscovering the labyrinth as a spiritual tool. Riverhead Books, New York.

Bailey, A., A., 1953 Esoteric healing. Lucis Publishing Company, New York.

Baudrillard, J., 1990 Revenge of the crystal. Pluto press, Australia.

Brennan, B., 1988 Hands of light. Bantam Books, New York.

Cavanagh, P., (Ed.) 1890 The life of St Thomas Aquinas, the angelic doctor. Burns \& Oates, Limited, London.

Hawking, S., 1993 Black holes and baby universes. Bantam Press, London.

Heron, J., 1992 Feeling and personhood: Psychology in Another Key. Sage Publications, London.

Houston, J., 1997 A Passion for the possible. Harper, SanFrancisco.

Houston, J., 2000 Jump time. Viking, Australia.

Holden, R. J., 1991 In defence of Cartesian dualism and the hermeneutic horizon. Journal of Advanced Nursing 16, 1375-1381.

Jacka, J., 1998 Natural Therapies: The politics and passion. Ringwood Natural Therapies Pty Ltd., Victoria.

Kaelin, E. F., 1970 Art and existence: A phenomenological aesthetics. Bucknell University Press, Lewisburg.

Kant, I., 1788 The Critique of pure reason. Hutchins R.M. (ed.) 1952 Great Books of the Western World. Encyclopaedia Britanicca, Inc., Chicago.

Krishnamurti, J., 1987 The awakening of intelligence. Harper, SanFrancisco.

Madrid, M. \& Barrett, E A., (Eds.) 1994 Rogers' Scientific Art of Nursing Practice.

National League for Nursing Press, New York.

Miller, J. K., 1997 The secret life of the soul, Bantam Books, London.

Pert, C. B., 1997 Molecules of emotion. Scribner, New York.

Pierrakos, J. C., 1987 Core energetics. Life Rhythm Publication, USA. 
Pole, D., 1983 Aesthetic Forms and emotion. Duckworth, London.

Prophet, M., 1991 Kuthumi: Sudies of the human aura. Summit University Press, USA.

Roney-Dougal, S., 1991 Where science and magic meet. Element Books Limited, Dorset.

Spinoza, B. de., 1677 Ethics. In Hutchins R M (ed) 1952 Great Books of the Western World. Encyclopaedia Britanicca, Inc., Chicago.

Vincent, J. D., 1990 The biology of emotions. Basil Blackwell Ltd., Oxford.

Walsch, N. D., 1995 Conversations with God: an uncommon dialogue Book 1. Hampton Roads Publishing Company, Inc., Charlottesville.

Walsch, N. D., 1995 Bringers of the light. Hampton Roads Publishing Company, Inc., Charlottesville.

\section{Chapter 10}

Campbell, I., (Ed.) 1994 To sing the pain. Deakin University, Geelong.

Campbell, J., 1990 The Flight of the Wild Gander. Harper Perennial, New York.

Chinn, P. L., 1995 Peace and power: Building communities for the future (4th ed.) National League for Nursing Press, New York.

Descarte, R., 1641 Objections Against the Meditations, and Replies, Great Books of the Western World, 1952 Encyclopedia Britannica, Inc., Chicago.

Ermarth, M., 1978 Wilhelm Dilthey: The critique of historical reason. Chicago University Press, Chicago.

Freire, P., 1972 Pedagogy of the Oppressed. Penguin Books, London.

Habermas, J., 1987 Knowledge and human Interests. Polity Press, Great Britian.

Hills, R. \& Hanchett., E. 2001 Human change and individuation in pivotal life situations: development and testing the theory of enlightenment, Visions: The Journal of Rogerian Nursing Science, 9(1) 6-19.

Heron, J., 1992 Feeling and Personhood: Psychology in Another Key. Sage Publications, London.

Kramnick, I., 1995 (Ed.) The portable enlightenment reader. Penguin Books, New York.

Malinski, V. \& Barrett, E. A., 1994 Martha E Rogers: Her life and her work. F. A. Davis Company, Philadelphia.

Martin, M., 1991 Trans-form-ation Metaphors: A critical action study of form in life challenging situations. Science Reflectivity and Nursing Care Exploring the Dialectic National Nursing Conference, Melbourne, Unpublished paper.

Miller, J. K., 1997 The secret life of the soul. Bantam Books, London. 
Myss, C., 1996 Anatomy of the Spirit. Harmony Books, New York.

Paterson, J.G. \& Zderad, L.T., 1976 Humanistic Nursing, Wiley and Sons, Inc., New York.

Plato 428 B.C-348 B.C. The dialogues of Plato. Jowett (ed.) 1952 Great Books of the Western World, Encyclopaedia Britanicca Inc., Chicago.

Taylor, B. J., 1994 Being human: Ordinariness in nursing. Churchill Livingstone, Melbourne.

Williamson, M., 1992 A return to love: Reflections on the principles of a course in miracles. Thorsons, London.

\section{Chapter 11}

Arendt, H., 19961929 Love and Saint Augustine: Edited and with an Interpretative essay by Scott J. \& Stark, J., The University of Chicago Press, Chicago.

Bailey, A. A., 1953 Esoteric healing. Lucis Publishing Company, New York.

Casals, P., 1987 Songs of the birds: Sayings, stories and impressions. Bantam, London.

Freire, P., 1972 Pedagogy of the oppressed. Penguin Books, London.

George, J., 1995 Nursing theories: The base for professional nursing practice (4th ed.). Appleton \& Lange, Connecticut.

Hawking, S., 1993 Black holes and baby universes. Bantam Press, London.

Heidegger, M., 1962 Being and Time. Harper and Row Publishers Inc., New York.

Markus, G., 1983 Life and soul: The young Lucaks and the problem of culture. In Heller A (ed) Lucaks Revalued. Basil Blackwell Publisher Ltd., Oxford.

Martin, M., 1990 Form-Elation: An exploration of form in Nursing. Conference Proceedings Fourth National Nursing Education Conference, Deakin University, Geelong.

Miller J. K., 1997 The secret life of the soul. Bantam Books, London.

Nightingale, F., 1992 Notes on nursing: What it is and what it is not, (Commemorative Edition.) J B Lippincott Company, Philadelephia.

Paterson J.G. \& Zderad, L.T., 1976 Humanistic Nursing. Wiley and Sons, Inc., New York.

Ramtha, 1997 The magical brain: doorway to a master's reality, Video JZK Inc. Yelm.

Ramtha, 1999 The Great Work. JZK Publishing, Australia.

Sheldrake, R. \& Fox, M., 1997 Natural grace: Dialogues on science and spirituality, Bloomsbury, Great Britian. 
Teilhard de Chardin, P., 1975 The phenomenon of man. Harper \& Row Publishers, New York.

Tucakovic, M., 1994 Spiritual aesthetics in nursing: Within and without, me and you, above and below. The Australian Journal of Holistic Nursing 1(1) 16-27.

Walsch, N. D., 1997 Conversations with God: An uncommon dialogue book 2. Hampton Roads Publishing Company, Inc., Charlottesville.

Watson, J., 1988 Nursing: Human science and human care a theory of nursing. National League for Nursing, New York.

\section{Chapter 12}

Bartholmew, 1998 Reflections of an elder brother: Awakening from the dream. Hay House, Inc., California.

Campbell, J., 1991 The mystery number of the goddess. In all her names, Campell J, \& Muse`s C (eds.). Harper, SanFrancisco.

Heidegger, M., 1968 What is called thinking. Harper \& Row, Publishers, New York.

Oppenheim, J., 1912 Bread and roses. Sung by Denver, J. Higher Ground CD 1988, BMG Arista Limited, USA.

Across the bridge. Ozark Mountain Hymn (source unknown).

Paterson, J.G. \& Zderad, L.T., 1976 Humanistic Nursing, Wiley and Sons, Inc., New York.

Prophet, M., 1991 Kuthumi: Sudies of the human aura. Summit University Press, USA.

Ramtha, 1997 The magical brain: doorway to a master's reality, JZK Inc. [videotape].

Ramtha, 1999 The Great Work. JZK Publishing, Australia.

Taylor, B. J., 1994 Being human: Ordinariness in nursing. Churchill Livingstone, Melbourne.

Taylor, S., 1998 Sexual radiance.Harmony. Books, New York.

Teilhard de Chardin, P., 1968 The divine milieu. Harper \& Row Publishers, New York.

Tikashi, 1995 Love love love: Evol evol evol. In Tikashi Speaks, G T Hoiles Nominees (Vic) Pty Ltd, Australia 1(2): 6.

Tucakovic, M., 1997 Story as pre-word: Allowing the background to become the foreground so as to create the space to heal. Second Biennial International Nursing Conference, Nursing at the Threshold of the 21st Century: Connecting Conversations of Nursing Practice. Massey University, New Zealand, Unpublished paper.

Walsch N D., 1995 Bringers of the light. Hampton Roads Publishing Inc., Charlottesville.

Walsch N D., 1999 On relationships. Hampton Roads Publishing Inc., Charlottesville. 
Walsch, N. D., 2000 Communion with God. G.P Putnam's Sons, New York.

\section{Chapter 13}

Aquinas, T., 1267 The summa theologica Of Saint Thomas Aquinas. Hutchins R M (ed) 1952 Great Books of the Western World. Encyclopaedia Britanicca, Inc., Chicago.

Heidegger, M., 1971 Poetry language thought. Harper and Row Publishers, New York.

Watson, J., 1999 Postmodern nursing and beyond. Churchill Livingstone, London. 